Exzerpieren - Kompilieren - Tradieren 


\section{Millennium-Studien}

zu Kultur und Geschichte

des ersten Jahrtausends $\mathbf{n}$. Chr.

\section{Millennium Studies}

in the culture and history

of the first millennium C.E.

Herausgegeben von / Edited by

Wolfram Brandes, Alexander Demandt, Helmut Krasser, Hartmut Leppin,

Peter von Möllendorff, Karla Pollmann

\section{Volume 64}




\section{Exzerpieren - Kompilieren - Tradieren}

Transformationen des Wissens

zwischen Spätantike und Frühmittelalter

Herausgegeben von

Stephan Dusil, Gerald Schwedler und Raphael Schwitter 
Diese Publikation wurde im Rahmen des an der Bayerischen Staatsbibliothek durchgeführten und durch das Bundesministerium für Bildung und Forschung geförderten Vorhabens 16TOA021 Reihentransformation für die Altertumswissenschaften („Millennium Studien“) mit Mitteln des DFG-geförderten Projekts Fachinformationsdienst Altertumswissenschaften - Propylaeum im Open Access bereitgestellt.

\section{(c) BY-NC-ND}

Dieses Werk ist lizenziert unter der Creative Commons Attribution-NonCommercial-NoDerivatives 4.0 International Lizenz. Weitere Informationen finden Sie unter http://creativecommons.org/licenses/by-nc-nd/4.0/.

Die Bedingungen der Creative-Commons-Lizenz gelten nur für Originalmaterial. Die Wiederverwendung von Material aus anderen Quellen (gekennzeichnet mit Quellenangabe) wie z.B. Schaubilder, Abbildungen, Fotos und Textauszüge erfordert ggf. weitere Nutzungsgenehmigungen durch den jeweiligen Rechteinhaber.

ISBN 978-3-11-050126-1

e-ISBN (PDF) 978-3-11-051634-0

e-ISBN (EPUB) 978-3-11-051508-4

ISSN 1862-1139

\section{Library of Congress Cataloging-in-Publication Data}

A CIP catalog record for this book has been applied for at the Library of Congress.

\section{Bibliografische Information der Deutschen Nationalbibliothek}

Die Deutsche Nationalbibliothek verzeichnet diese Publikation in der Deutschen Nationalbibliografie; detaillierte bibliografische Daten sind im Internet über http://dnb.dnb.de abrufbar.

(C) 2017 Walter de Gruyter GmbH, Berlin/Boston

Druck und Bindung: $\mathrm{CPI}$ books $\mathrm{GmbH}$, Leck

@ Gedruckt auf säurefreiem Papier

Printed in Germany

www.degruyter.com 


\section{Vorwort}

Der vorliegende Band ist dem Phänomen der Transformation und Tradition von Wissen zwischen Spätantike und Frühmittelalter gewidmet. Aus der Perspektive unterschiedlicher Disziplinen wird der Umgang mit überlieferten Wissensbeständen aus der Antike untersucht und das schriftliche Erbe analysiert, das durch Exzerpieren, Kompilieren und selektives Tradieren einen grundlegenden Transformationsprozess durchlief. Das heutige Bild von der Spätantike ist wie auch die Bewertung des Frühmittelalters immer noch stark von Narrativen des Niedergangs und des Verlusts geprägt. Es ist daher ein Ziel dieses Bandes, neue Zugänge zur Bewertung des spätantiken und frühmittelalterlichen Umgangs mit antikem Wissen zu weisen, um die durchaus innovativen und kreativen Praktiken offenzulegen, mit denen in der untersuchten Periode vergangene Wissensbestände fruchtbar gemacht wurden. Dazu sollen unterschiedliche Perspektiven und Zugangsweisen einzelner Disziplinen verknüpft und bekannte Methoden weiterentwickelt werden. Die sich daraus ergebenden Konzepte verstehen sich als Beitrag zur historischen Erforschung des Wandels, der Neuformierung und Umkodierung von kulturellem Wissen.

Der Band ist das Ergebnis der Tagung „Verdichtung oder Vernichtung? Entwicklungen und Strategien im Umgang mit der Komplexität von Wissen in Spätantike und Frühmittelalter“, die vom 19. - 21. September 2013 an der Universität Zürich abgehalten wurde.

Wir bedanken uns bei den Herausgebern der „Millennium Studien / Millennium Studies“ für die Aufnahme des Bandes in ihre Reihe. Bei der Durchführung der Tagung erhielten wir Unterstützung durch Hanno Menges; bei der Vorbereitung des Manuskriptes von Cato van Paddenburgh und Katrin Vanheule. Ihnen sei dafür herzlich gedankt. Zu Dank verpflichtet sind wir auch dem Graduate Campus der Universität Zürich und dem VAUZ, deren großzügige finanzielle Unterstützung die Tagung erst ermöglichte.

Zürich / Leuven, im Mai 2016

Stephan Dusil, Gerald Schwedler, Raphael Schwitter 
Wir haben uns also vorgenommen, denen, die gerne lesen, Anregung zu verschaffen, denen, die

ihrem Gedächtnis etwas einprägen möchten, leichtere Übersicht zu geben, allen aber, die das Buch in die Hand nehmen, Gewinn zu bringen. Und wir merken wohl, dass es uns nicht eben leicht werden wird, uns der Mühe dieser Kürzung zu unterziehen; denn es gehört viel Arbeit und großer Fleiß dazu, wie es auch ohne Arbeit nicht zugeht, wenn man eine Mahlzeit bereiten und den Gästen etwas zugute tun will.

Dennoch wollen wir diese Mühe gern auf uns nehmen, um vielen damit zu dienen, dabei allerdings die genaue Erforschung des Einzelnen dem Geschichtsschreiber überlassen, uns selbst aber darum bemühen, die Vorlagen für unsere Zusammenfassung durchzugehen. Denn wie ein Baumeister, der ein neues Haus baut, sich um den gesamten Bau zu kümmern hat, der aber, der es übernimmt, das Haus auszumalen, nichts weiter zu bedenken hat, als was man zur Ausschmückung braucht, so, meine ich, steht es auch bei uns.

In die Dinge einzudringen und sie zu durchforschen und sich mit den Einzelheiten genau $z u$ beschäftigen, das kommt dem Geschichtsschreiber zu; wer aber nur nacherzählen will, der darf sich kürzer fassen und sich von der eingehenden Darstellung der Geschichte freimachen.

Und nun wollen wir mit der Erzählung beginnen, nachdem wir so viel dem Vorausgeschickten hinzugefügt haben; es wäre ja töricht, wenn die Vorrede länger würde als die ganze Erzählung.

(2 Makk 2, 26-33) 


\section{Inhalt}

Vorwort - V

Stephan Dusil, Gerald Schwedler, Raphael Schwitter

Transformationen des Wissens zwischen Spätantike und Frühmittelalter. Zur

Einführung - 1

\section{Exzerpieren}

Marietta Horster

Livius-Epitome: ein spätantiker Blick auf die (kurzgefasste) römische

Republik - 25

Christian Rohr

Von Plinius zu Isidor und Beda Venerabilis. Zur Übernahme antiken Wissens über Witterungsphänomene im Mittelalter — 49

\section{Kompilieren}

Inge Kroppenberg

Codex Theodosianus revisited - Plädoyer für eine Geschichte der juridischen

Form - 71

Carmen Cardelle de Hartmann

Wissensorganisation und Wissensvermittlung im ersten Teil von Isidors Etymologiae (Bücher I-X) -85

Hans-Georg Hermann

Verformung, Verdrängung und Verlust von Rechtswissen in den Leges — 105

Mayke de Jong

The Resources of the Past: Paschasius Radbertus and his Epitaphium Arsenii — 131

Annina Seiler

Untangling the strands: The spelling of the Épinal glossary — 153 


\section{Tradieren}

Julian Führer

Verbrannte Steuerliste oder zerstörte Verwaltung? Zum Umgang mit

Verwaltungswissen im merowingischen Frankenreich — 177

Ian Wood

The Problem of Late Merovingian Culture - 199

Karl Ubl

Eine Verdichtung der Lex Salica. Die Septinas septem der Handschrift Paris, BN, lat. $4411-223$

Peter Stotz

Hohe Weltgeschichte für langobardische Krieger. Verdichtung und Vereinfachung von Texten in der Handschrift Bamberg Hist. 3-245

Andreas Thier

Aus Altem ein Neues - Versuch eines Schlusswortes - 249 


\title{
Transformationen des Wissens zwischen Spätantike und Frühmittelalter
}

\author{
Zur Einführung
}

Omnia orta occidunt et aucta senescunt.

(Sall. Iug. 2,3)

Mundus iam seniscit.

(Fredeg. 4 prol.)

Der römische Historiker Sallust im 1. Jahrhundert v. Chr. und der Redaktor der FredegarChronik des 7. Jahrhunderts n. Chr. verwenden beide das Motiv der Vergreisung der Welt, mit dem sie - freilich auf unterschiedlichen Stil- und Sprachniveaus - ihr eigenes Tun, nämlich das Abfassen von Geschichtswerken, in einen metahistorischen, geschichtsphilosophischen Rahmen stellen. Geschichtsschreibung bot sich als Ort an, um über Entstehen und Altern, aber auch über das Bewahren und Verlieren von kulturellen Errungenschaften zu reflektieren. Der von einem Autor konstatierte Schwund von vormals kollektiv verbindlichen Werten und Wissensbeständen sollte nicht nur dazu anregen, über die Relevanz alter Normen in neuen sozialen Kontexten nachzudenken, sondern sollte diese, wenn möglich, auch wiederbeleben. Der jeweilige Verlust wurde daher in einen negativen Kontext gerückt und, falls vorhanden, mit einem kontemporären Dekadenzbewusstsein verknüpft. Auch die zeitgenössische geisteswissenschaftliche Forschung kann sich, wenn sie historisch arbeitet, diesem Mechanismus nicht ganz entziehen. Dem in die Vergangenheit geworfenen Blick, der frühere Kulturen und Gesellschaften analysiert und in Bezug zueinander setzt, fällt es häufig schwer, sich der Zuschreibung von ,Höhepunkten' und ,Niedergängen' zu enthalten. Da solche Bewertungen stets mit der Evaluation der kulturellen Leistungen einer Zivilisation einhergehen, sind Bruchstellen zwischen Epochen besonders interessant, lassen sie doch die charakteristische Errungenschaften einer Gesellschaft paradoxerweise gerade im Prozess ihrer Auflösung hervortreten.

Das Ende des weströmischen Reiches und die Entwicklung Mitteleuropas in der Zeit vom späten 5. bis zum frühen 8. Jahrhundert n. Chr. fungierte seit der Renaissance als das historische Paradebeispiel für einen kulturellen Niedergang. Meist wurde dessen Bewertung von moralischen Kategorien überlagert, die den Bezug zur eigenen Gegenwart ermöglichten: Die vermeintliche Dekadenz der spätrömischen Gesellschaft bildete die Kontrastfolie vor der man die eigene Zeit abhob. Neben politischen und sozialen Faktoren war es insbesondere der kulturelle Rückschritt, der die Vorstellung eines Niedergangs nach dem Ende Westroms begründete. Die Annahme, Europa durchlitt Dark Ages, basiert auf der Vorstellung, dass nach militärischen Verlusten nun auch die über Jahrhunderte angesammelten klassischen Wissensbestände durch begrenzte Aufnahmefähigkeit sowie begrenzten Aufnahmewillen in der postimperialen 
Ära verloren gingen. Die Metapher der dunklen Jahrhunderte fusst auf der Annahme, angehäuftes Wissen stehe für Licht; die Frage nach der Notwendigkeit oder den Mechanismen der Substituierung wird dabei jedoch ausgeblendet.

Obwohl die Forschung der letzten Jahrzehnte zahlreiche neue Erkenntnisse über die Verhältnisse des 6. und 7. Jahrhunderts n.Chr. zutage gefördert hat, steht eine umfassende und differenzierte Ursachenbewertung dieses komplexen Phänomens, das eng mit sozialen, politischen und religiösen Prozessen verknüpft ist, noch aus. Der vorliegende Band versteht sich als Beitrag zur Erhellung der dahinterstehenden Abläufe, wobei der Fokus insbesondere auf den Formen und Wegen der Wissensorganisation und Wissenstradierung zwischen Spätantike und Frühmittelalter im lateinischen Westen liegt. ${ }^{1}$ Das Ziel ist die exemplarische Erschliessung der durchaus kreativdynamischen Prozesse im Umgang mit tradierten Wissensbeständen, die man exzerpierte, kompilierte und dadurch zwangsläufig auch transformierte. Durch die Analyse der unterschiedlichen Auswahltechniken treten Schwerpunktverschiebungen und funktionale Neukonfigurierungen hervor, die den Blick auf die Umstände und Intentionen jener Transmissionsmechanismen legen, die für die Formierung des Wissenskanons im Frühmittelalter verantwortlich waren. Dabei stellt sich für die Bereiche des literarischen Schaffens, des Rechts- und Wirtschaftslebens wie auch für Religion und Wissenschaften in gleicher Weise die Frage, ob und in welchem Umfang eine Komplexitätsreduktion oder -verlagerung stattfand und inwiefern diese intentional gesteuert war.

Die folgenden Überlegungen versuchen in drei Schritten den Zeitraum vom frühen 4. bis zum späten 8. Jahrhundert unter der Perspektive der Neuformierung von Wissensbeständen $\mathrm{zu}$ analysieren. In einem ersten Schritt geht es darum, bisherige Sichtweisen auf den Übergang von Spätantike ins Mittelalter, allem voran das Narrativ des Verfalls im Hinblick auf den gesellschaftlichen Umgang mit Wissen zu reflektieren. In einem zweiten Schritt soll nach neuen Wissensordnungen für neue gesellschaftliche Kontexte gefragt und dabei Phänomene wie Wissensverengung und Komplexitätsreduktion als kulturelle Transformationsprozesse in der spätantiken und frühmittelalterlichen Wissenskultur definiert werden. Dazu werden in drei Bereichen der kulturellen Textproduktion, nämlich in der Poesie, in der Geschichtsschreibung und in Rechtstexten konkrete Einzelphänomene aufgezeigt. Schliesslich werden in einem dritten Schritt unterschiedliche, in allen Bereichen wiederkehrende Vorgehensweisen und Methoden zusammengeführt. In diese summarischen Überlegungen ist die Zusammenfassung der einzelnen Beiträge dieses Bandes integriert.

1 Vgl. dazu mit Fokus auf den literarischen Bereich Paulo F. Alberto, David Paniagua (Hrsg.), Ways of Approaching Knowledge in Late Antiquity and the Early Middle Ages. Schools and Scholarship, Nordhausen 2012 (Studia Classica Medievalia, Bd. 8). 


\section{Wege der Forschung: Vom Narrativ des Verfalls zur „autre antiquitē“}

Phantomschmerzen. Schon lange vor der Renaissance des 15. Jahrhunderts zählt das Narrativ des Niedergangs und des Verfalls der Antike zum Argumentarium derer, die durch Rom- und Klassikbezüge Reform und Erneuerung von Wissen und Bildung der eigenen Zeit vorantreiben wollten. ${ }^{2}$ Als Meistererzählung, in welcher der Untergang des römischen Weltreichs als notwendige Folge der eigenen Unzulänglichkeit und Dekadenz verstanden wurde, blieb diese Vorstellung Teil aufklärerischen Bildungsgutes. ${ }^{3}$ Edward Gibbons zwischen 1776 - 1788 erschienene History of Decline and Fall of the Roman Empire monumentalisierte dabei nur eine längst etablierte Lese- und Deutungsform. ${ }^{4}$ Zuvor hatte bereits Charles de Montesquieu anhand der Grösse und des Niedergangs des römischen Imperiums modellhafte Betrachtungen über den Gewinn und Verlust von politischer Macht aufgestellt. ${ }^{5}$ Auch spätere Geschichtsforscher hatten diese Denkfigur verinnerlicht und mit Blick auf die Spätantike die Dekadenzvorstellung übernommen. Von Jacob Burckhardts Die Zeit Constantins des Grossen (1852) über Theodor Mommsen $\left(1893^{6}\right)$ und Otto Seecks Geschichte des Untergangs der antiken Welt (1895-1920) bis zu Ferdinand Lot $\left(1927^{7}\right)$ und Joseph Vogts Der Niedergang Roms. Metamorphose der antiken Kultur von 200-500 (1965) erstreckt sich eine Traditionslinie, in welcher der Fokus der historiographischen Betrachtung

2 Vgl. Theo Kölzer, Kulturbruch oder Kulturkontinuität? Europa zwischen Antike und Mittelalter - Die Pirenne-These nach 60 Jahren, in: Das Mittelmeer. Die Wiege der europäischen Kultur, hrsg. von Klaus Rosen, Bonn 1998, 208 -227; Reinhold Kaiser, Das Problem der Periodenbildung, Kontinuitäten und Brüche, Konzeptionen und Befunde, in: Von der Spätantike zum frühen Mittelalter, hrsg. von Theo Kölzer und Rudolf Schieffer, Ostfildern 2009, 319-338.

3 Zur Deutungsgeschichte der Spätantike vgl. ausführlich Alexander Demandt, Der Fall Roms. Die Auflösung des Römischen Reiches im Urteil der Nachwelt, erweiterte und aktualisierte Neuauflage, München 2014; ferner Richard Klein, Die Auflösung des weströmischen Reiches. Zeitliche Entwicklung - Selbstverständnis - Deutung, in: Richard Klein, Roma versa per aevum. Ausgewählte Schriften zur heidnischen und christlichen Spätantike, hrsg. von Raban von Haehling und Klaus Scherberich, Hildesheim/Zürich/New York 1999, 91 - 127. Mit Fokus auf die Moderne: Stefan Rebenich, Late Antiquity in Modern Eyes, in: A Companion to Late Antiquity, hrsg. von Philip Rousseau, London 2009, 77 - 92. 4 Edward Gibbon, The History of the Decline and Fall of the Roman Empire, hrsg. von Betty Radice und Felipe Fernández-Armesto, London 1983-1990. Vgl. dazu Lynn White, The Transformation of the Roman World. Gibbon's Problem after two Centuries, Berkeley 1973; C. Ando, Narrating Decline and Fall, in: A Companion to Late Antiquity, hrsg. von Philip Rousseau, London 2009, 59-76; Jeroen Wijnendaele, Apocalypse, Transformation or Much Ado About Nothing? Western Scholarship and the 'Fall' of Rome (1776 - 2008), in: Iris. Journal of the Classical Association of Victoria 24 (2011) 41-52. 5 Montesquieu, Considérations sur les causes de la grandeur des Romains et de leur décadence. Betrachtungen über die Ursache von Grösse und Niedergang der Römer, herausgegeben und übersetzt von Lothar Schuckert; mit den Randbemerkungen Friedrichs des Grossen, Bremen 1962.

6 u. a. in: Abriss des römischen Staatsrechts, Berlin 1893, 289.

7 Ferdinand Lot, La Fin du monde antique et le début du Moyen Âge, Paris 1927. 
auf die Krise und den Verfall Roms im 4./5. Jahrhundert n.Chr. gerückt wurde. Detailliert wurde dabei auf Dekadenzphänomene wie den Niedergang des antiken Städteund Bildungswesen sowie des Handels und der Wirtschaft aufmerksam gemacht. Oswald Spengler (1918/1921) und Arnold Toynbee (1934) erhoben die zyklische Kulturentwicklung von Aufstieg und Verfall zum geschichtsphilosophischen Prinzip. ${ }^{8}$ Über den Zeitpunkt, die tieferen Ursachen und die Folgen des Niedergangs der antiken Welt wurde jedoch kein wissenschaftlicher Konsens erzielt. Neben innenpolitischen, sozialökonomischen und naturwissenschaftlichen Erklärungsansätzen wurden insbesondere das Christentum und der Einfluss germanischer Stämme angeführt, wobei letzterer Ansatz einer heftigen, meist ideologisch vorbelasteten Debatte unterzogen wurde. ${ }^{9}$

Legitimation erhielt das wissenschaftliche Narrativ des Niedergangs durch das gut bezeugte, zeitgenössische Krisenbewusstsein jener Epoche. ${ }^{10}$ Von dort stammt auch die Metaphorik, derer man sich in den späteren Jahrhunderten bediente. ${ }^{11}$ Die tatsächliche Relevanz dieser zeitkritischen Zeugnisse für die moderne Beurteilung dieser Epoche ist jedoch umstritten. Zwar dürften die politischen Katastrophen, unter anderem die Eroberung Roms im Jahr 410 n.Chr., ${ }^{12}$ durchaus zu pessimistischen Pro-

8 Oswald Spengler, Der Untergang des Abendlandes. Umrisse einer Morphologie der Weltgeschichte, ungekürzte Sonderausgabe in einem Band, München 1990; Arnold Toynbee, A Study of History, 2. Auflage, London 1972.

9 Vgl. dazu umfassend Demandt, Fall Roms (Anm. 3), 170 - 492. Aufschlussreich ist der Sammelband, in dem Karl Christ massgebliche Aufsätze bekannter Vertreter zusammengestellt hat: Karl Christ (Hrsg.), Der Untergang des römischen Reiches, Darmstadt 1970.

10 Exemplarisch ist Walther Rehm, Der Untergang Roms im abendländischen Denken. Ein Beitrag zur Geschichtsschreibung und zum Dekadenzproblem, Leipzig 1930. Zum historischen Selbstverständnis und Krisenbewusstsein der Spätantike vgl. u. a. Friedrich Vittinghoff, Zum geschichtlichen Selbstverständnis der Spätantike, in: Historische Zeitschrift 198 (1964), 529-574; Ferdinand Heinzberger, Heidnische und christliche Reaktionen auf die Krisen des weströmischen Reiches in den Jahren 395 410, Bonn 1976; Klaus Rosen, Über heidnisches und christliches Geschichtsdenken in der Spätantike, München 1982; Demandt, Fall Roms (Anm. 3), 44-70.

11 Vgl. dazu Alexander Demandt, Das Ende des Altertums in metaphorischer Deutung, in: Gymnasium 87 (1980), $178-204$.

12 Das Jahr 2010 hat anlässlich des 1600jährigen „Jubiläums“ der Eroberung Roms den Anstoss zu mehreren Publikationen und Konferenzen gegeben, die sich mit dem Thema des Falls beschäftigt haben, vgl. Mischa Meier, Steffen Patzold (Hrsg.), August 410. Ein Kampf um Rom, Stuttgart 2010: Angelo di Berardino, Gianluca Pilara, Lucrezia Spera (Hrsg.), Roma e il sacco del 410. Realtà, interpretazione, mito, Rom 2012; Henriette Harich-Schwarzbauer, Karla Pollmann (Hrsg.), Der Fall Roms und seine Wiederauferstehung in Antike und Mittelalter, Berlin 2013; Johannes Lipps, Carlos Machado, Philipp von Rummel (Hrsg.), The Sack of Rome in 410 AD. The Event, its Context and its Impact, Wiesbaden 2013. Der Tenor dieser Publikationen verlautet relativ einstimmig, dass in Tat und Wahrheit „not much happened“, vgl. Peter van Nuffelen, in: Journal of Roman Studies 105 (2015), 322 -329. 
gnosen geführt haben, die tatsächliche Auflösung des Reiches und der Gesellschaft scheint jedoch nicht zum vollen Bewusstsein gekommen zu sein. ${ }^{13}$

Das spätantike Krisen- und Dekadenzbewusstsein war darüber hinaus kein neues Phänomen. Es zehrte aus uralten kosmologischen Weltuntergangsspekulationen, die mit der naturgesetzlichen Vorstellung vom Altern der Welt verbunden waren. Das von christlichen wie heidnischen Autoren bemühte Narrativ des Verfalls, das bisweilen hyperbolische Züge annahm, war zudem untrennbar mit zeitgenössischen politischideologischen Diskursen verknüpft, unter anderem mit der Frage nach der richtigen oder falschen Religion. ${ }^{14}$

Mit Beginn des 20. Jahrhunderts begann die historische Forschung parallel zur Darstellung des Niedergangs auch zunehmend die Kontinuitäten ins Auge zu fassen, die den ,Abgrund' zwischen der antiken Welt und dem europäischen Mittelalter überbrückt haben sollen. ${ }^{15}$ Diese Ansätze beeinflussten wiederum die heftig diskutierte Periodisierungsproblematik. In provokativer Distanz zu 476, dem seit Barthold Georg Niebuhr etablierten Datum für die Epochengrenze, ${ }^{16}$ rückte Henri Pirenne die Zeitenwende zwischen Antike und Abendland in die Zeit der arabischen Eroberungen. ${ }^{17}$

Darstellungen von Niedergang und Fall der antiken Welt verloren seit den 1960er Jahren zunehmend an Konjunktur. ${ }^{18}$ Die Forschung richtete ihr Augenmerk nun auf die Kontinuitätselemente und die damit verbundenen Transformationsprozesse, welche die mediterran-antike Welt zum europäischen Mittelalter führten. In dieser Perspektive wurde die Spätantike zur exemplarischen „period of transition“ erklärt, was nur

$13 \mathrm{Zu}$ diesem Ergebnis kommt Franz Georg Maier, Niedergang als Erfahrung und Begriff. Die Zeitgenossen und die Krise Westroms 370-470, in: Niedergang. Studien zu einem geschichtlichen Thema, hrsg. von Reinhard Koselleck und Paul Widmer, Stuttgart 1980, 59-78, hier 71.

14 Vgl. etwa Ralph W. Mathisen, The Theme of Literary Decline in Late Roman Gaule, in: Classical Philology 83 (1988), 45 -52; spezifisch zur Funktion des Verfallsnarrativs bei Sidonius Apollinaris: Raphael Schwitter, Umbrosa lux. Obscuritas in der lateinischen Epistolographie der Spätantike, Stuttgart 2015, 228-236.

15 Etwa durch Alfons Dopsch, Wirtschaftliche und soziale Grundlagen der europäischen Kulturentwicklung von Caesar bis Karl dem Grossen, Wien 1918-1920; Christopher Dawson, The Making of Europe. An Introduction to the History of European Unity, 6. Auflage, London 1939.

16 Barthold G. Niebuhr, Vorträge über alte Geschichte, an der Universität zu Bonn gehalten, III (1829/ 48), 346-347, vgl. Demand, Der Fall Roms (Anm. 3), 221-222.

17 In mehreren Publikationen: Henri Pirenne, Mahomed et Charlemagne, in: Revue belge de philologie et d'histoire 1 (1922), 77 - 86; Henri Pirenne, Un contraste économique: Mérovingiens et Carolingiens, in: Revue belge de philologie et d'histoire 2 (1923), 223-235; Henri Pirenne, Mahomet et Charlemagne, Paris 1937 (postum erschienen).

18 Darstellungen des ,Falls’ von Rom scheinen jedoch auch in neuester Zeit ihren Reiz nicht verloren zu haben, vgl. Christine Delaplace, La fin de l'Empire romain d'Occident. Rome et les Wisigoths de 382 à 551, Rennes 2015. Auf eine historiographische Methodenreflexion zielt der Band von Mirella Romero Recio (Hrsg.), La caída del Imperio Romano, Cuestiones historiográficas, Stuttgart 2015 (Potsdamer Altertumswissenschaftliche Beiträge, 53). 
teilweise zur Aufwertung der Epoche beitrug. ${ }^{19}$ Im Zuge dieser Entwicklung wurden angesichts der umfassenden sozialen, kulturellen, politischen, administrativen und ökonomischen Transformationen Begriffe wie ,Verfall', ,Niedergang’ oder ,Dekadenz' zugunsten einer wertfreieren Terminologie aufgegeben. ${ }^{20}$

Erst vor wenigen Jahrzehnten ist die Vorstellung von der Spätantike als einer Epoche des Nieder- oder Übergangs einer radikalen Neubewertung unterzogen worden, nicht zuletzt durch die überzeugenden Arbeiten von Peter Brown. ${ }^{21}$ Dieses Umdenken betraf nicht nur die kulturelle und religiöse Sphäre, für deren positivere Bewertung Henri-Irénée Marrou bereits 1948 das Wort erhoben hatte, ${ }^{22}$ sondern auch den politischen Bereich. ${ }^{23}$

Neben der Geschichtswissenschaft hat auch in den anderen Disziplinen, die sich mit dieser Epoche beschäftigen, wie der Klassischen Philologie, der Kunstgeschichte, der Theologie und Philosophie sowie in der Rechtsgeschichte ein Umdenken stattgefunden. Während die literarischen, künstlerischen und rechtlichen Erzeugnisse der Spätantike noch bis in die 1990er Jahre in den Altertumswissenschaften eher marginale Berücksichtigung fanden, so sind die fachspezifischen Untersuchungen zu dieser Epoche mittlerweile kaum noch zu überblicken. Dabei wird nicht nur die durchaus distinktive Sprache und Stilistik, die lange Zeit als typisches Verfallssymptom gedeutet wurde, ${ }^{24}$ in neuem Licht gesehen, auch im Bereich der bildenden Künste, etwa in Baukunst oder Buchmalerei, stellen moderne Studien die Einzigartigkeit der Epoche positiv hervor. ${ }^{25}$

Dieses Umdenken zeigt sich etwa auch in der rechtsgeschichtlichen Beurteilung des ,Vulgarrechts‘. Mit dem Begriff des Vulgarrechts werden Entwicklungen in der Rechtswissenschaft seit dem 3. Jahrhundert n.Chr. bezeichnet, die sich gegenüber der ,klassischen` Periode der Rechtswissenschaft durch begriffliche Ungenauigkeiten und

19 Reiche Ergebnisse finden sich in den 14 Bänden des Forschungsprojekts „Transformation of the Roman World“ (1997-2004), das den vielfältigen Wandel vom 4. bis zum 8. Jh. n.Chr. in interdisziplinärer Zugriffsweise untersucht.

20 So vertritt etwa P. S. Barnwell, Emperor, Prefects and Kings. The Roman West 395 - 565, London 1992, die Ansicht, dass das Westreich nicht untergegangen sei, sondern sich lediglich transformiert habe. Jedoch impliziert bereits der - mangels Alternativen - gemeinhin verwendete Begriff „Spätantike“, der auf Alois Riegl, Spätrömische Kunstindustrie, Wien 1901 zurückgeht, eine zur Neige gehende, alternde Welt, die ihre Hochphase bereits hinter sich hat.

21 u. a. Peter Brown, The Making of Late Antiquity, Cambridge Mass. / London 1978; Peter Brown, The World of Late Antiquity Revisited, in: Symbolae Osloenses 72 (1997), 5 - 30.

22 Henri-Irénée Marrou, Histoire de l'éducation dans l'antiquité, Paris 1948.

23 Vgl. etwa Glenn W. Bowersock, Peter Brown, Oleg Grabar (Hrsg.), Late Antiquity. A Guide to the Postclassical World, Cambridge M.A. 1999, ix: „The reformed Roman empire of Diocletian and Constantine was the most formidably governed state ever created in the ancient world.“

24 Einen guten Überblick bietet Marie-France David-De Palacio, Antiquité latine et décadence, Paris 2000.

25 Vgl. Paul Veyne, Die Kunst der Spätantike. Geschichte eines Stilwandels, Stuttgart 2009. 
systematische Vereinfachungen auszeichnen. ${ }^{26}$ Besitz und Eigentum (possessio und dominium) wurden gleichgesetzt, ebenso eigentumsartige Rechte mit Eigentum; schliesslich wurde gefordert, dass nur schriftliche Verträge wirksam waren, so dass die ältere Trennung von Recht (eben dem mündlichen oder schriftlichen Kaufvertrag) und Beweisbarkeit des Rechts (mit Hilfe eines geschriebenen Dokuments) verschwammen. ${ }^{27}$ Darüber hinaus - und teilweise in Gegensetzung zu diesen dogmatischen Veränderungen - wurden gerade die Stilveränderungen als kennzeichnend für das Vulgarrecht beschrieben. ${ }^{28}$ Die ältere Literatur interpretierte diese Strömungen als „Niveauabfall“ und „Verflachung“, als „Eindringen der Denk- und Ausdrucksformen juristischer Laien“, wodurch älteres Material einer „entstellenden und simplifizierenden Überarbeitung “ unterworfen wurde. ${ }^{29}$ Insgesamt, so konstatierte Max Kaser noch 1975, zeichneten sich die spätantiken Bearbeiter durch die Unfähigkeit aus, „dem hohen Geistesflug der klassischen Juristen zu folgen““. ${ }^{30}$ Kurzum, das Recht ,vulgarisierte‘. Dieses Narrativ ist inzwischen einer differenzierteren Sicht gewichen, ohne dass die prinzipielle Andersartigkeit des spätantiken Rechts gegenüber dem klassischen Recht in Frage gestellt wird. ${ }^{31}$ So erschienen die populären Rechtsanschauungen teils sogar als „echte[r] sachliche[r] Fortschritt gegenüber dem klassischen Recht“, da letzteres den praktischen Erfordernissen des täglichen Rechtslebens nicht mehr genügt hätte. ${ }^{32}$

26 Martin Schermaier, Art. Römisches Vulgarrecht, in: Reallexikon der Germanischen Altertumskunde 25 (2003), 175-177; Max Kaser, Das Römische Privatrecht, Band 2: Die nachklassischen Entwicklungen, 2. Auflage, München 1975 (Handbuch der Altertumswissenschaft 10.3.3.2), 5 spricht von einer „Abkehr vom zunftgerechten Denk- und Ausdrucksstil der klassischen Jurisprudenz und den Übergang zu einer im ,Volk', d.h. in juristischen Laienkreisen verbreiteten Betrachtungsweise“. Der Begriff selbst ist durch Ernst Levvy, West Roman Vulgar Law. The Law of Property, Philadelphia 1951 und Ernst Levy, Weströmisches Vulgarrecht. Das Obligationenrecht, Weimar 1956 bekannt gemacht worden; ferner die grundlegende Studie von Franz Wieacker, Vulgarismus und Klassizismus im Recht der Spätantike, Heidelberg 1955 (Sitzungsberichte der Heidelberger Akademie der Wissenschaften, phil.-hist. Klasse, 3. Abhandlung).

27 Beispiele bei Wolfgang Waldstein, Michael Rainer, Römische Rechtsgeschichte, 11. Auflage, München 2014, 263-264 sowie Kaser, Das Römische Privatrecht (Band 2) (Anm. 26), 23-24.

28 Einen vielschichtigen Einstieg bietet Theodor Mayer-Maly, Art. Römisches Vulgarrecht, in: Handwörterbuch zur Deutschen Rechtsgeschichte, hrsg. von Adalbert Erler / Ekkehard Kaufmann, Band 4 (1990), $1132-1137$.

29 Die ersten beiden Beurteilungen bei Hans Schlosser, Grundzüge der Neueren Privatrechtsgeschichte, 8. Auflage, Heidelberg 1996, 5; die letzteren bei Kaser, Das Römische Privatrecht (Band 2) (Anm. 26), 18, 20.

30 Kaser, Das Römische Privatrecht (Band 2) (Anm. 26), 21.

31 Zur Kritik an dem Begriff und Konzept ,Vulgarrecht' siehe die Nachweise bei Mayer-Maly, Art. Römisches Vulgarrecht (Anm. 28), 1132 - 1137; Franz Wieacker, Römische Rechtsgeschichte, 2. Abschnitt: Die Jurisprudenz vom frühen Prinzipat bis zum Ausgang der Antike. Ein Fragment. Aus dem Nachlass von Franz Wieacker hrsg. von Joseph Georg Wolf, München 2006, 211 - 218 sowie Kaser, Das Römische Privatrecht (Band 2) (Anm. 26), 28.

32 Waldstein/Rainer, Römische Rechtsgeschichte (Anm. 27), 264. 
Insgesamt gesehen lassen sich in den Bereichen Kunst, Sprache, Geschichtsschreibung und Recht keineswegs Entwicklungen beobachten, die eine eindeutige Bewertung im Sinne eines Niedergangs oder einer kulturellen Dekadenz rechtfertigen. Gerade in diesen Bereichen konnte zwar im Vergleich zu vorangehenden Epochen, insbesondere gegenüber der Klassik, relativ leicht auf offensichtliche Niveauverluste hingewiesen werden. ${ }^{33}$ Denn aus einer positivistischen Perspektive heraus ist es methodisch einfach, ein „mehr“ oder „weniger“ an Textvolumen, rhetorischen Figuren oder literarischen Anspielungen zu belegen als qualitative Aussagen zu treffen oder über Funktionalitäten zu urteilen. Doch wird eine idealisierte klassische Norm, durch deren Linse die wissenschaftliche Betrachtung auf die Spätantike lange Zeit erfolgte, heute in der Regel nicht mehr als verbindlich erachtet. Spätantike und der Übergang zum Mittelalter wird zu Recht als eine „,andere Antike“34 aufgefasst, in der sich im Prozess der Auseinandersetzung und Abgrenzung von der Klassik eigene ästhetische Paradigmen und politische Rahmenbedingungen entwickelt haben. ${ }^{35}$

Aufbauend auf dieser Deutung, dieser Übergangsphase Eigenständigkeit und kreative Lösungsansätze zuzugestehen, sollen die kulturellen Techniken des Exzerpierens, Kompilierens und Tradierens als wesentlicher Teil der Transformationsprozesse in der Spätantike herausgestellt werden. Angesichts der Tatsache, dass sich ein konsolidierter Wissensbegriff im interdisziplinären Diskurs bisher nicht herausgebildet hat, erscheint es weder möglich noch nötig, eine abschliessende Definition vorzuschlagen. ${ }^{36}$ Vielmehr ist der Wissensbegriff dabei bewusst offen gelassen, um unterschiedlichen heuristisch-hermeneutischen Untersuchungskonzepten Raum zu bieten. Im Vordergrund stehen jedenfalls die Fragen, wie ,Wissen' generiert, verändert und modifiziert, aber auch vernichtet wurde. Das Beispiel der ,klassischen` Texte des römischen Rechts, die in dem Corpus iuris civilis exzerpiert, in den Aufzeichnungen

33 So etwa noch Demandt, Der Fall Roms (Anm. 3), 207 - 208.

34 Der Gedanke geht zurück auf Henri-Irénée Marrou, Décadence romaine ou Antiquité tardive? $\mathrm{III}^{\mathrm{e}}-\mathrm{V}^{\mathrm{e}}$ siècle, Paris 1977, 13.

35 Vgl. aus literaturwissenschaftlicher Perspektive Marco Formisano, Towards an Aesthetic Paradigm of Late Antiquity, in: Antiquité Tardive 15 (2007), 277-284; Jésus Hernandez Lobato, Vel Apolline muto. Estetica vel poetica de la Antiguedad tardia, Bern 2012; Marco Formisano, Reading Décadence Reception and the Subaltern Late Antiquity, in: Décadence. „Decline and Fall“ or „Other Antiquity“, hrsg. von Marco Formisano, Therese Fuhrer, Heidelberg 2014, 7-16, bes. $7-8$.

36 Ein Überblick über ,Wissen` im (intra- oder interdisziplinären) Diskurs fehlt. Die Relativität von Wissen betont zum Beispiel Achim Landwehr, Das Sichtbare sichtbar machen. Annäherungen an ,Wissen' als Kategorie historischer Forschung, in: Geschichte(n) der Wirklichkeit. Beiträge zur Sozialund Kulturgeschichte des Wissens, hrsg. v. Achim Landwehr, Augsburg 2002 (Documenta Augustana 11), 61 - 89; zum Thema der,Wissensgesellschaft‘ ist instruktiv Nico Stehr, Art. Wissensgesellschaften, in: Handbuch der Kulturwissenschaften, Band 3: Themen und Tendenzen, hrsg. von Friedrich Jaeger, Jörn Rüsen, Stuttgart / Weimar 2004, 34 - 49. In der frühmittelalterlichen Mediävistik wird der Begriff ,Wissen' u. a. benutzt von Steffen Patzold, Episcopus. Wissen über Bischöfe im Frankenreich des späten 8. bis frühen 10. Jahrhunderts, Ostfildern 2008 (Mittelalter-Forschungen 25). 
des römischen ,Vulgar'rechts modifiziert und im übrigen dem Vergessen anheimfielen, verdeutlicht diese Transformationsprozesse. ${ }^{37}$

\section{Neue Ordnungen für eine neue Welt? Wissensverengung und Komplexitätsreduktion als kulturelle Prozesse in der spätantiken und frühmittelalterlichen Wissenskultur}

Die Spätantike wird heute verstärkt als Epoche prosperierender kultureller Innovationen, künstlerischer Vitalität und hoher intellektueller Eigenleistungen verstanden. Gleichwohl scheint es in gewissen Bereichen aber methodisch sinnvoll zu sein, weiterhin von Rückgang oder gar Verfall zu sprechen, etwa in der Verwaltung oder der Ökonomie. ${ }^{38}$ Auch innerhalb des kulturellen Wissens verlief die Transformation von der hochkomplexen spätrömischen Welt zum christlichen Mittelalter ganz offensichtlich nicht ohne qualitative und quantitative Verluste. Aber gerade kulturelles Wissen kann nicht nur angehäuft werden, sondern erhält seinen Wert erst durch erneute und bisweilen kreative Ver- und Anwendung. Hier sind spätestens im 5. und 6. Jahrhundert n. Chr. eindeutige Tendenzen erkennbar, die zumindest in quantitativer Hinsicht auf einen Wissensrückgang schließen lassen, wenngleich auf der Basis der im Original überlieferten Handschriften der Merowingerzeit dafür argumentiert werden kann, dass das aus karolingischer Sicht propagierte Verfallsnarrativ für Gallien nicht unbedingt zutreffen muss. ${ }^{39}$ Dieser Prozess ist nur mittelbar an den zeitgleichen Rückgang des Schul- und Bildungswesens gekoppelt, seine Ursprünge gehen weiter zurück. Bereits im 4. Jahrhundert n. Chr. zeigt sich im Formalen eine Entwicklung zur Verkürzung und Verdichtung von Wissen. Obwohl etwa im Bereich der Historiographie und der Fachschriftstellerei Grossformen weiterhin gepflegt wurden, treten sekundäre Literaturformen wie Exzerpt und Epitome zunehmend ins Zentrum. Schriftsteller wie Aurelius Victor, Eutropius, Festus und in späterer Zeit Prosper Tiro oder Jordanes stehen für eine Tradition der Wissensverdichtung und -verengung, die sich bis ins frühe 8. Jahrhundert nachvollziehen lässt.

Angesichts dieses Befundes steht die Problematik einer wertfreien Beurteilung dieses Phänomens im Raum, insbesondere die Frage, ob sich daraus Rückschlüsse auf generelle Tendenzen einer Komplexitätsreduktion beziehungsweise - negativ gesprochen - auf einen Prozess der „Simplifizierung“ in Spätantike und Frühmittelalter

37 Siehe zum römischen Recht weiter unten 18-21.

$38 \mathrm{Vgl}$. dazu die Arbeiten von Bryan Ward-Perkins, The Fall of Rome and the End of Civilization, Oxford 2005 und John H.W.G. Liebeschuetz, Decline and Change in Late Antiquity. Religion, Barbarians and their Historiography, Aldershot 2006.

39 Vgl. den Beitrag von Ian Wood unten 199-222. 
ziehen lassen, ${ }^{40}$ die möglicherweise in Zusammenhang zu sehen sind mit sich wandelnden Rahmenbedingungen etwa infolge der Christianisierung und der germanischen Reichsgründungen auf dem Boden des ehemaligen Imperiums. Eine diesbezügliche Interpretation muss sich also hüten, wieder in das alte Narrativ des Niedergangs zu fallen, doch darf sie die teils ambivalenten Befunde gleichwohl nicht aus den Augen zu verlieren. Die gewichtigen Argumente der älteren Forschung müssen zu Wort kommen dürfen, ohne dass dabei die Einzigartigkeit dieser Epoche in Zweifel gezogen wird. ${ }^{41}$

Aus literaturwissenschaftlicher Perspektive zeigen sich in der lateinischen Spätantike Entwicklungen, die als Mechanismen einer Variierung und Verdichtung, als Prozesse des Verlierens und Vergessens von Wissen bezeichnet werden können, welche das Mittelalter entscheidend prägten. Im Bereich der Literatur muss die Verdichtung von Wissen jedoch keinesfalls zwangsläufig als Symptom eines kulturellen Rückgangs verstanden werden. Es handelt sich vielmehr um ein ubiquitäres Phänomen literarischen Schreibens in der Antike, das sich entlang stilistischer und formaler Konventionen, Gattungstraditionen und Vorbildern bewegte und damit Wissensbestände berücksichtigen musste, die zwangsläufig nur in verdichteter Form miteinbezogen werden konnten. ${ }^{42}$

Im lateinischen Westen erlebte das literarische Leben im 4. Jahrhundert eine eigentliche Blüte, die sich bis ins 5. und 6. Jahrhundert halten sollte. Eine Grundlage dafür war die von den Tetrarchen und den nachfolgenden Kaiserdynastien angetriebene Restauration der Bildungsinstitutionen in Rom und in der Peripherie, die zu einem Aufschwung des kulturellen und literarischen Lebens führte. Gesellschaftlicher Träger und Profiteur dieses kulturellen Aufschwungs war in erster Linie die Oberschicht, welche Bildung und kulturelle Aktivitäten traditionell als festen Bestandteil aristokratischer Lebensform verstanden. Zumindest für diese privilegierte Gruppe garantierte die Schule durch Aufrechterhaltung einer überkommenen Sprachnorm den kulturellen und ideologischen Rückbezug an eine historische definierte Romanitas. ${ }^{43}$

In diesem Prozess des bewussten Bewahrens von kulturellem Wissen kam der Schule entscheidende Bedeutung zu, die wegweisende Konsequenzen haben sollte. Zum einen hatte die traditionalistische Ausrichtung der Schule auf die Literatur der römischen Klassik eine bemerkenswerte kulturelle Homogenität der Bildungsschicht zur Folge. Vergangenheitsbild und Sprachstil der Gebildeten sind Ergebnis derselben

40 Von einer Simplifizierung wurde besonders im Bereich des Rechts gesprochen, vgl. etwa Fritz Schulz, Geschichte der römischen Rechtswissenschaft, Weimar 1961, 368-371.

41 Die Einzigartigkeit der Spätantike vertritt in einem eindringlichen Statement Scott F. Johnson, Preface: On the Uniqueness of Late Antiquity, in: The Oxford Handbook of Late Antiquity, hrsg. von Scott F. Johnson, Oxford 2012, xi-xxix.

42 Vgl. dazu etwa Marietta Horster, Christiane Reitz (Hrsg.), Condensing texts, condensed texts, Stuttgart 2010.

43 Vgl. u.a. Ulrich Eigler, Lectiones vetustatis. Römische Literatur und Geschichte in der lateinischen Literatur der Spätantike, München 2003. 
intensiven Beschäftigung mit einer Reihe klassischer Normautoren, die als allein gültige Instanz und Orientierungspunkt einer spezifisch römischen Kultur angesehen wurden. Zum anderen zementierte die Schule für die nachfolgenden Jahrhunderte den massgeblichen literarischen Kanon. Was nicht dazugehörte, verfiel früher oder später dem Vergessen oder lebte gleichsam virtuell in Form von Zitaten weiter. Es sind somit zwei durchaus gegenläufige Prozesse erkennbar: Für die als normativ anerkannten Texte und Autoren bemühte man sich um möglichst reichhaltige Dokumentierung und Wissenskumulierung. Das zugehörige Wissen wurde in Kommentaren und Glossen gesammelt, aufgearbeitet und weiter vermittelt. Alle anderen Texte blieben, falls sich noch irgendwo Abschriften fanden, bestenfalls Liebhaber-Objekt oder verschwanden, da ihnen der institutionelle Rahmen fehlte, allmählich aus dem kulturellen und historischen Bewusstsein.

Die enge Bindung an einen starren Literaturkanon determinierte in hohem Masse die Produktion neuer literarischer Werke. Themen, Gattungen und besonders Stil und Sprache waren an den vorbildhaften Schulautoren wie Cicero und Vergil orientiert. Literarisches Schreiben war nur möglich in direkter Auseinandersetzung mit diesen Bildungsautoren, deren Stil und Inhalte man entweder bewusst ablehnen oder aber imitieren musste.

Diese spezifische literarhistorische Konstellation beförderte in besonderem Masse das Wechselspiel von imitatio und aemulatio. Für spätantike Autoren wie den Historiker Ammianus Marcellinus (um 330-392 n.Chr.) oder die Dichter Claudius Claudianus (um 375-404 n.Chr.) und Prudentius (um 348/49-405 n.Chr.) gehörte das subtile Überbieten ihrer jeweiligen klassischen Vorlagen $\mathrm{zu}$ den entscheidenden literarischen Wirkungsabsichten ihrer Werke. Und noch im Übergang zum Frühmittelalter knüpfte ein Autor wie Venantius Fortunatus (um 530-610 n.Chr.) bewusst an dieser Tradition an. Dieser kompetitive Kontext generierte wichtige Impulse für die hier verhandelten Leitfrage nach den Entwicklungen und Strategien im Umgang mit Wissen in Spätantike und Frühmittelalter. Zwei Beispiele sollen dies verdeutlichen:

Eine beliebte Technik zur Überbietung einer literarischen Vorlage war die inhaltliche beziehungsweise formal-stilistische Verdichtung. Verschiedene Motive, Metaphern oder Ausdrücke wurden auf kunstvolle Weise verkürzt oder miteinander verquickt. So entstand zwar etwas Neues, das aber immer noch mit dem Alten verbunden und dadurch auch legitimiert war. Die klassische Vorlage bot die normative Folie, vor der der spätantike Autor aktiv werden konnte. Ein Beispiel dafür stellt eine Stelle aus einem Gedicht des gallischen Schriftstellers Sidonius Apollinaris (um 430/ 31-486 n.Chr.) dar. Darin hat Sidonius einen Ausdruck aus Vergils Eklogen in auffälliger Weise verdichtet: Während Vergil den mythischen Sänger Orpheus als Thracius Orpheus (Verg. ecl. 4,55) titulierte, beschränkt sich Sidonius auf die Nennung des Epithetons, das er zusätzlich noch verfremdet: Thrax (Sidon. carm. 15,163). Diese Kondensierung hat zwangsläufig eine inhaltliche Verdunkelung zur Folge. ${ }^{44}$ Der Re-

44 Dieser Effekt gehörte zu den Wirkungsinteressen des Textes. Zu den ostentativen Verdunklungs- 
zipient muss hinter dem konzentrierten Ausdruck Thrax die vergilische Vorlage erkennen, um Sidonius' Gedicht vollständig verstehen zu können. Dies setzt beim Rezipienten ein gewisses Hintergrundwissen voraus, das prinzipiell jederzeit aktualisiert werden musste. Vergil bleibt also als virtueller Hintergrundtext erhalten, dasselbe gilt für seine literarischen Vorlagen Ennius oder Homer. ${ }^{45}$

Eine andere Methode des kompetitiven Umgangs mit dem Bildungskanon war die bewusste Zerstückelung oder Fragmentierung der normativen Vorlage. Eine bekannte Variante stellte hier die Cento-Literatur dar, die wie weitere Miniatur-Genres einer spätantiken Vorliebe für das Kleine und Preziöse entsprach. So gestaltete zum Beispiel der Dichter und Rhetor Ausonius (um 310 - 393/394 n. Chr.) aus Versatzstücken Vergils ein kunstvolles Kleingedicht, das in jedem Vers einen oder mehrere verschiedene Kontexte aus den Gedichten dieses Schulautors aufrief und den Text in ironischparodistischer oder auf andere Weise färbte. Das Erkennen und die jeweilige Aktualisierung des entsprechenden vergilischen Subtextes hat Ausonius ganz den Rezipienten überlassen. Verfügte dieser nicht über die notwendige Bildung, blieb - wie im Beispiel des Sidonius - das im Gedicht implizierte Wissen letztlich unentdeckt.

Diese zwei Formen literarischer Verdichtung und Kondensierung von Wissensbeständen, die hier nur im Ansatz behandelt werden konnten, haben für die hier behandelte Fragestellung dahingehend Relevanz, dass sie eine Verfahrensweise darstellen, in der tradiertes Wissen zwar aktiv verwendet, jedoch nicht explizit benannt wird. Sobald die dazugehörigen Kenntnisse der Entschlüsselung fehlen, entfallen auch die Bezüge auf die implizierte Vorlage. Dieses Szenario ist vom Autor nicht beabsichtigt. Es handelt sich also, wenn man so will, um eine nicht-intendierte Form der Wissensvernichtung. Das jeweilige Potential bleibt gleichwohl im Text erhalten. Das implizite Wissen ist nicht eigentlich vernichtet, sondern kann jederzeit wieder aktualisiert werden, so etwa, wenn im Zuge einer Neustrukturierung - wie während der karolingischen Bildungsreform - der alte Schulkanon und seine Begleittexte wieder entdeckt werden.

Etwas anders sieht die Situation aus, wenn es um Verfahrensweisen geht, die sich im Umgang mit dem überkommenen historischen und kulturellen Wissen ergeben, das in literarischen Werken gespeichert war. Hier gibt es Formen und Mechanismen von literarischer Verdichtung und Verkürzung, die einen bewussten oder zumindest wissentlich in Kauf genommenen Verzicht bestimmter Wissensbereiche zur Folge hatten. Ein schönes Beispiel einer derartigen literarischen Wissenskondensierung sind etwa die Periochae des Livius oder die sogenannten Argumenta Vergiliana, Kurzzusammenfassungen einzelner Bücher, die der Memorierung dienten und im Grammatik- und Rhetorikunterricht Einsatz fanden. Die in Verse gefassten Argumenta

tendenzen spätantiker Autoren mit Fokus auf die Epistolographie vgl. Schwitter, Umbrosa lux (Anm. 14).

45 In der antiken und spätantiken Vergilkritik wird regelmässig auf die literarischen Vorlagen des Dichters hingewiesen.Vgl. z. B. Servius in Vergilii Aeneidos praefatio 83 - 84, Editio Harvardiana, Bd. 2, 1946, 4. 
entwickelten sich in der Spätantike zu einer eigenen literarischen Kleinform, die im Kontext der Katalogdichtung zu verorten ist. ${ }^{46}$ In dieser Form konnten sie ihre Vorlage auch ersetzen, wie es auch im Bereich der Historiographie etwa bei Livius geschehen ist. Ein weiteres Beispiel ist die Epitome oder - in frühmittelalterlicher Terminologie gesprochen - das Breviarium. ${ }^{47}$ Die Epitome gehörte zweifellos zu den beliebtesten und gängigsten Reduktionsformen der Spätantike und des Frühmittelalters. Dabei handelt es sich um eine pragmatische Verkürzung vorwiegend historiographischer Werke. Diese wurden nach bestimmten Auswahlprinzipien exzerpiert oder paraphrasiert. So gibt es zu einzelnen Werken verschiedene Epitome-Fassungen mit unterschiedlicher Schwerpunktsetzung.

Trotz ihrer Beliebtheit in der Spätantike handelt es sich bei den genannten literarischen Verfahrensweisen um überzeitliche Phänomene. Die Tradition des Exzerpierens kann bis zu den alexandrinischen Gelehrten zurückverfolgt werden; eindeutige Spuren finden sich bei Cicero, Livius, Plutarch oder Cassius Dio. ${ }^{48}$ Auch der römische Gelehrte und Polyhistor M. Terentius Varro hat Epitome seiner eigenen Werke hergestellt, wohl weil deren Umfang und begrenzte Verfügbarkeit einer breiteren Rezeption im Weg standen. Erst durch die materiellen Verluste der Originalwerke im Zusammenhang mit den militärischen und politischen Veränderungen im 5. und 6. Jahrhundert kam den Epitome-Fassungen ein besonderes Gewicht zu. Vielfach blieben sie die einzigen Überlieferungsstränge antiken Wissens. Sie lassen damit einerseits Rückschlüsse auf die Ausmaße des Verlusts zu, aber auch auf die beliebte alltägliche Praxis der Annäherung an komplexe Wissenssammlungen.

Für die spätantike Geschichtsschreibung und die damalige zeitgenössische Wahrnehmung der Welt kam in besonderer Weise die Ambiguität von Ablehnung und Imitation der römisch-heidnischen Antike zum Tragen. ${ }^{49}$ Die Zahl der ,Wissenshorte' nahm zwar nachweisbar ab, aber nach wie vor waren Kenntnisse der römischen Ämterhierarchie für bestimmte Posten notwendig. In gewisser Weise verhalf dies der Breviarliteratur historischen Inhalts im 4. Jahrhundert $\mathrm{zu}$ einem gewissen Aufschwung, solange es Karrierechancen in Zivil- und Militäradministration verbessern konnte. $^{50}$

\footnotetext{
46 Vgl. dazu Anne Friedrich, Das Symposium der XII sapientes. Kommentar und Verfasserfrage, Berlin 2002, 185-191; Massimo Gioseffi, ,Introducing' Virgil. Forme di presentatione dell' Eneide in età tardoantica, in: Ways of approaching knowledge in Late Antiquity and the Early Middle Ages. Schools and Scholarship, hrsg. von Paulo F. Alberto, David Paniagua, Nordhausen 2012 (Studia Classica Medievalia, Bd. 8), $122-143$.

47 Marco Galdi, L'epitome nella letteratura Latina, Neapel 1922; Ilona Opelt, Art. Epitome, in: RAC 5 (1962), $944-973$.

48 Vgl. Jens E. Skydsgaard, Varro the Scholar. Studies in the first book of Varros' de re rustica, Kopenhagen 1968, 101-116.

49 Vgl. die systematischen Überlegungen in Anton Scharer, Georg Scheibelreiter (Hrsg.), Historiographie im frühen Mittelalter, Wien 1994.

50 Sextus Aurelius Victor, Die römischen Kaiser / Liber de Caesaribus, hrsg. und übersetzt von Kirsten Groß-Albenhausen und Manfred Fuhrmann, 2. Auflage, Darmstadt 2002, 156.
} 
Relativ unberührt von kulturellen und politischen Umstürzen scheint die Annalistik die stabilste Textsorte der Geschichtsschreibung geblieben zu sein. Sie wurde eigenständig an zahlreichen Orten auch noch lange nach dem Zusammenbruch des weströmischen Imperiums weitergepflegt. ${ }^{51}$ Doch das Verfassen von Annalen durchlief im Übergang zum christlichen Frühmittelalter formale Veränderungen. ${ }^{52}$ Die Texte wurden bewusst in einfacher und verständlicher Sprache abgefasst, selbst hochstehende Literaten wie der Bischof Gregor von Tours (um 538- gest. um 594) rühmten sich ihres stilus rusticus. Ein konkretes Beispiel für die „Christianisierung“ römischer Formen bei Tradierung historischen Wissens waren die Konsularsfasten. Statt wie in der hohen Kaiserzeit Amtslisten von Konsuln und Statthaltern zu führen, setzte es sich seit dem 4. Jahrhundert durch, dass in den christlichen Gemeinden die eigenen Bischöfe und Metropoliten in Listen, in Form von Dyptichen oder konkreten Amtslisten eingetragen wurden. Damit übernahm man einerseits die aus der Zivilverwaltung bekannte Auflistung der Amtsinhaber und konnte damit ein zeitliches Verhältnis zur weltlichen Geschichte bestimmen. Andererseits wurde die Liste der Bischöfe in einen liturgischen, ja heilsgeschichtlichen Kontext gestellt. ${ }^{53}$ Später waren diese Listen Ausgangspunkt für die Entwicklung des Genres des liber pontificalis bzw. der gesta episcoporum. ${ }^{54}$

Auf anderen Ebenen brach man stärker mit den traditionellen konservativen und vor allem auf Sammeln ausgerichteten Mechanismen der Wissensordnung. ${ }^{55}$ Das in der Antike weit verbreitete Umgestalten von Texten, ja das „Verfälschen des Originals“ gewann durch die politischen und vor allem kulturellen Umbrüche eine neue Dynamik. ${ }^{56}$ Christianisierung und Provinzialisierung in der postimperialen Zeit führten zu mehrfacher Brechung und kontinuierlicher Umgestaltung der überlieferten Traditionen und Textsorten, die das Wissen der römisch-antiken Vergangenheit bereitstellten. Die hochstehende Chronistik, die sich in der Antike durch elaborierte Quellenkritik und hohes Maß an Methodenbewusstsein auszeichnete, wich neueren Formen zur

51 Z. B. Marius von Avenches / Marius d'Avenches, La Chronique de Marius d'Avenches (455-581). Texte, traduction et commentaire, hrsg. und übersetzt von Justin Favrod, Lausanne 1991.

52 Beat Näf, Antike Geschichtsschreibung. Form - Leistung - Wirkung, Stuttgart 2010.

53 Robert Lee Williams, Bishop lists. Formation of apostolic succession of bishops in ecclesiastical crises, Piscataway, New Jork 2005; Robert B. Eno, The Significance of the List of Roman Bishops in the Anti-Donastist Polemic, in: Vigiliae Christianae 47 (1993), 158 - 169; Kim Bowes, Ivory Lists. Consular Diptychs, Christian Appropriation and Polemics of Time in Late Antiquity, in: Art History 24 (2001), $338-357$.

54 Herman Geertman, Documenti, redattori e la formazione del testo del Liber Pontificalis, in: Herman Geertman (Hrsg.), Il Liber Pontificalis e la storia material, Assen 2003 (Mededelingen van het Nederlands Instituut te Rom 60-61), 267 -284; Herman Geertman, La genesi del Liber pontificalis romano. Un processo di organizzazione della memoria, in: Liber, Gesta, histoire. Écrire l'histoire des évêques et des papes, de l'Antiquité au XXIe siècle, hrsg. von François Bougard / Michel Sot, Turnhout 2009, 37-108.

55 Matthias Gerth, Bildungsvorstellungen im 5. Jahrhundert, Berlin 2013, 224.

56 Markus Mülke, Der Autor und sein Text. Die Verfälschung des Originals im Urteil antiker Autoren, Berlin 2008. 
Präsentation historischen Wissens. Das Neusortieren erfolgte anhand von dezidierten und bisweilen radikalen Überzeugungen. Das Vergangenheitsbild wurde überwiegend durch die eindeutig heilsgeschichtlich konturierten Genres der Kirchengeschichte und Heilsgeschichtsschreibung geprägt. Zu den großangelegten Werken zählten hier die Kirchengeschichtsschreibung, etwa eines Eusebius von Caesarea (260/64 - um 339) mit seiner Historia ecclesiastica oder dessen Fortsetzer Rufinus von Aquileia oder Sozomenos und Theodoret. ${ }^{57}$ Hinzu kam eine enorme Zahl hagiographischer Texte. Zwar bewahrten viele christliche Autoren durch die interpretatio christiana heidnische Wissensbestände vor dem Verlust, indem ihnen ein wertvoller Bezug zum Christentum zugeschrieben wurde. ${ }^{58}$ Für die neuen bischöflichen Eliten galt es aber, sich dem karitativen und administrativen Aufgaben des Bischofsamtes zu widmen, statt sich mit heidnischer Literatur zu beschäftigen. In einem Regelwerk, das die Rechte und Pflichten der christlichen Gemeindevorsteher ordnen wollte, den Statuta ecclesiae antiqua, die um 475 entstanden sind, heißt es im 5. Kanon, dass Bischöfe keinesfalls heidnische Literatur lesen sollten, häretisches Schrifttum nur, soweit es notwendig und zeitlich möglich wäre. Noch Papst Gregor I. tadelte bekanntlich Bischof Desiderius von Vienne im Jahre 601 für dessen Grammatikunterricht, in dem er pagane Autoren verwendete. Gemäß Gregor könne man nicht das Lob Christi und zugleich das Lob Jupiters im selben Mund formulieren. ${ }^{59}$

Der Kreis der Personen, die als Geschichtsschreiber tätig waren, engte sich stark ein. Nicht nur die Produktionsbedingungen auch eine potentielle Leserschaft mit Interesse an antiken Themen und Literaturformen gingen erheblich zurück. ${ }^{60}$ Es kann durchaus als symptomatisch bezeichnet werden, dass zwischen Gregor von Tours (gest. um 594) und Einhard (um 770 - 840) - und das sind immerhin fast 250 Jahre kein Geschichtsschreiber mit Namen überliefert ist. Und schon Gregor verstand sich nicht in erster Linie als Historiker, sondern als Bischof und Hagiograph, mag auch sein historisches Werk heute weitaus mehr rezipiert werden. Zwischen 400 und 800 entstanden vergleichsweise kaum chronikalische Werke, umso überwältigender ist aber die Menge der neu verfassten hagiographischen Werke, der Heiligengeschichtsschreibung. Hagiographie entwickelte sich als neue Form der Geschichtsschreibung,

57 Eusebius, Historia ecclesiastica, übersetzt von Philipp Haeuser, 2. Auflage, München 1981. Vgl. Näf, Antike Geschichtsschreibung (Anm. 52), 58 - 59.

58 Explizit formulierte dies etwa Augustinus in seiner Lehrschrift De doctrina christiana: „Alles was die sogenannte Geschichtswissenschaft Geschichtsschreibung von der Ordnung der vergangenen Zeiten angibt, ist ein sehr wirksames Hilfsmittel zum Verständnis der Heiligen Schriften, selbst wenn es außerhalb der Kirche im Schulunterricht gelehrt wird.“ (Aug. doctr. christ. 2,28,42).

59 Statuta ecclesiae antiqua, can. 5, in: Concilia Galliae a 314-506, hg. von Charles Munier, 1963 (CCSL 148 A), 166-167; Gregor I., Reg. XI, 34 (CCSL 140 A), 922.

60 Rosamond McKitterick, The audience for latin historiography in the early middle ages. Text transmission and manuscript dissemination in: Historiographie im frühen Mittelalter, hrsg. von Anton Scharer und Georg Scheibelreiter, Wien 1994, 96-114. 
die allgemeine Heilsgeschichte und individuelle memoria verband. ${ }^{61}$ Ein Beispiel mag hier die große Beliebtheit des Genres aufzeigen. Gregor von Tours verfasste nicht nur die heute so hoch geschätzte Sammlung der Zehn Bücher Geschichte (Decem libri historiarum), sondern auch eine Anzahl an Heiligenviten. Mit den Lebensbeschreibungen des Hl. Martin, des Hl. Julian und weiteren Sammlungen an Texten über Heilige kam er auf acht Bücher hagiographischen Charakters (Octo libri miraculorum). Während sein historiographisches Werk heute in etwa 50 Handschriften und Fragmenten erhalten ist, ${ }^{62}$ sind vom hagiographischen Werk weit mehr als 90 Handschriften und Fragmente bekannt. ${ }^{63}$ An Gregors Werk und dessen Rezeption erkennt man exemplarisch eine Schwerpunktverschiebung von der Darstellung historischen Stoffs hin zu hagiographischen Texten, bei denen unterschiedliche Funktionsweisen und Gebrauchskontexte im Hintergrund stehen. Geschichtsschreibung im Gewand der Hagiographie war dezidiert parteiisch und methodisch explizit an einem heilsgeschichtlichen Entwicklungsparadigma ausgerichtet. Hagiographische Texte, die ja Vergangenes mit heilsgeschichtlicher Zukunftsperspektive verbanden, überflügelten andere historische Genres dabei nicht nur in der Zahl der Neuentstehungen, sondern auch in der Zahl der Abschriften. ${ }^{64}$

Dennoch kam es nie zu einem gänzlichen Verlust einer politischen Herrschaftsgeschichtsschreibung. Das im Folgenden ausgeführte Beispiel der Reduktion von Gregors historiographischem Werk durch spätere Redaktoren zeigt, dass Selektionsprozesse durch Kürzungen und Verdichtungen nicht objektiv erfolgten, sondern immer jeweilige Tendenzen und Deutungsrichtungen wiedergaben. Ein geschickter Epitomator oder Kompilator konnte ohne große eigene Formulierungen das bearbeitete Werk ins Gegenteil verkehren. Schon Herwig Wolfram war auf ähnliche Fälle aufmerksam geworden. Er konkludiert, basierend auf einem Zitat von Thomas von Aquin („Es ist erlaubt, in kluger Weise die Wahrheit zu verschleiern.“ S.Th, 2,II q.110a 3,4), dass in der Historiographie trotz des postulierten Wahrhaftigkeitsanspruchs ein

61 Martin Heinzelmann, Bischofsherrschaft in Gallien. Zur Kontinuität römischer Führungsschichten vom 4. bis zum 7. Jahrhundert. Soziale, prosopographische und bildungsgeschichtliche Aspekte, München 1976.

62 Vgl. Gregorii Episcopi Turonensis, Libri historiarum X, hrsg. von Bruno Krusch, Hannover 1951 (MGH SS rer merov. 1,1), XXI-XXXV.

63 Vgl. Gregorii Episcopi Turonensis, Miracula et opera minora, hrsg. von Bruno Krusch, Hannover 1969 (MGH SS rer merov. 1,2), $12-25$.

64 Martin Heinzelmann, Manuscrits hagiographiques et travail des hagiographes. Études, Sigmaringen 1992 (Beihefte der Francia 24); Martin Heinzelmann, L'hagiographie du haut Moyen Âge en Gaule du Nord. Manuscrits, textes et centres de production, Stuttgart 2001 (Beihefte der Francia 52); Marc van Uytfanghe, Die Vita im Spannungsfeld von Legende, Biographik und Geschichte. Mit Anwendung auf einen Abschnitt aus der Vita Amandi prima, in: Historiographie im frühen Mittelalter, hrsg. von Anton Scharer und Georg Scheibelreiter, Wien 1994, 194- 221. 
„Lügen mit der Wahrheit“ durchaus regelmäßig vorkam. ${ }^{65}$ Das Beispiel der Verdichtung der Historiographie Gregors mag verdeutlichen, wie die historischen Ereignisse mehrfach höchst selektiv auf die eigene teleologische Perspektive hin selektiert und sortiert wurden. Im Geschichtswerk Gregor von Tours wurde ein Grossteil der politischen Geschichte des antiken Roms bewusst übergangen. Im Gegenzug wurden Einzelheiten im Hinblick auf das Leben Christi beziehungsweise das Leben des Märtyrers Martin in Tours neu sortiert und integriert. Allem voran stellte er stets die Bischöfe als Triebkräfte der Geschichte Galliens heraus. Doch diese Hervorhebung im Geschichtswerk Gregors reduzierten spätere Redaktoren in verschiedenen anonymen Überarbeitungen und entkleideten so Gregors Geschichte ihres bischöflich-heilsgeschichtlichen Gewands. Sowohl in der Überarbeitung des sogenannten B-Redaktors als auch in der Fassung des sogenannten Fredegar-Kompendiums wurde durch Auswahl und gezielte punktuelle Ergänzungen das Hauptnarrativ wieder in Richtung einer politischen Geschichte gerückt. ${ }^{66}$ Von den 10 Büchern Geschichte blieben zwei Generationen später nur noch $10 \%$ des Inhalts übrig. ${ }^{67}$ Dies resultierte aus einer neuen Schwerpunktsetzung sowie aus dem Versuch, den jüngsten zeitgeschichtlichen Ereignissen mehr Raum zuzugestehen. Die Beliebtheit des „Fredegar-Textes“ zeigt sich nicht nur in den zahlreichen Abschriften, sondern auch in den mehrfachen Fortsetzungen, die bis in die frühe Karolingerzeit reichten. ${ }^{68} \mathrm{Ab}$ dem 8 . Jahrhundert kam indes das Genre der Annalen wieder als geläufiges Medium der Geschichtsschreibung auf, kombiniert mit dem Aufkommen von Geschichtsdichtungen und der auf Sueton referierenden Vita Caroli Einhards, mit welcher dieser den Weg in eine neue Kultur der Geschichtsschreibung öffnete. ${ }^{69}$

Insgesamt zeigt sich auch in Bezug auf historisches Wissen die Diversität der Formen des Umgangs mit überkommenen Wissensordnungen, wie sie gerade im frühen Mittelalter mit besonderer Stärke hervortreten. $\mathrm{Zu}$ berücksichtigen bleibt, dass sich historisches Wissen differenziert nicht nur in den Bereichen der Schriftstellerei

65 Herwig Wolfram, Einleitung oder Lügen mit der Wahrheit. Ein historiographisches Dilemma, in: Historiographie im frühen Mittelalter, hrsg. von Anton Scharer und Georg Scheibelreiter, Wien 1994, $11-25$.

66 Ausführlich hierzu: Helmut Reimitz, History, Frankish Identity and the Framing of Western Ethnicity 550-850, Cambridge 2015.

67 Die Vollversion Gregors zu den Büchern II-IV belegt auf Basis der MGH Edition 230 Seiten, das dritte Buch Fredegars lediglich 29, also etwas mehr als ein Zehntel. Gregor, Buch II, von 43 Kapiteln fehlen 10; Buch III, alle 37 Kapitel vorhanden; Buch IV, von 51 Kapiteln fehlen 15; Buch V, von 50 Kapiteln fehlen 16; Buch VI, von 46 Kapiteln fehlen 33. In Gregors vollem Text der Bücher II-VI zählt man 5,778 Zeilen. Für die B-Redaktion seien die Zahlen von der Handschrift B5 verwendet. Dort umfassen die Bücher II-VI insgesamt 4498 Zeilen. Vgl. dazu ausführlich Gerald Schwedler, Lethe and „delete“. Discarding the past in the early Middle Ages; the case of Fredegar, in: Collectors' knowledge, hrsg. von Anja-Silvia Göing, Antony Grafton und Paul Michel, Leiden 2013, 71 - 96.

68 Andreas Fischer, Reflecting Romanness in the Fredegar Chronicle, in: Early medieval Europe 22 (2014), 433-445.

69 Steffen Patzold, Ich und Karl der Große. Das Leben des Höflings Einhard, Stuttgart 2014. 
und der Geschichtsschreibung, sondern im Sinne einer neuen Erinnerungskultur durch Liturgie, Totenmemoria, Denkmäler- und Liedkultur sowie auch den Narrationes der Urkunden im öffentlichen Raum medial präsent war. ${ }^{70}$

Im römischen Recht lässt sich ab dem dritten Jahrhundert n.Chr. eine Vereinfachung der Rechtssprache beobachten, die mit einer Aufweichung der begrifflichen Schärfe und mit der Verbreitung dogmatischer Ungenauigkeiten einherging. Wie man diese Entwicklungen einzuordnen hat und ob insbesondere der Begriff des Vulgarrechts passend ist, unterliegt heute vielleicht noch stärker als vor einigen Jahrzehnten der Diskussion..$^{71}$ Vom Gesichtspunkt des Verdichtens, Variierens und Neugestaltens lassen sich einige Beobachtungen für die Zeit zwischen dem 3. und dem 8. Jahrhundert n. Chr. zusammentragen.

Die Frühphase dieser Epoche zeichnete sich durch die Zusammenfassung bereits bestehender Juristenschriften aus. Eine solche komprimierende Tätigkeit von Rechtsgelehrten lässt sich zum Beispiel an den Sententiae Pauli ablesen, die gegen Ende des 3. Jahrhunderts entstanden sind und echte Schriften des Juristen Paulus verdichteten. Diese Sentenzen waren hochgeachtet und als gesetzesgleich geschätzt. ${ }^{72}$ Zeitgleich entstanden Zusammenstellungen von Kaisergesetzen wie der Codex Gregorianus (291 n.Chr.) und der Codex Hermogenianus (295 n.Chr.). Der Codex Gregorianus bestand aus Reskripten, die aus der Zeit zwischen Hadrian (reg. 117-138 n. Chr.) und Diokletian (reg. 284-305 n.Chr.; Reskripte bis 291 n.Chr.)) stammen; der Codex Hermogenianus aus diokletianischen Reskripten der Jahre 293 und 294 n. Chr. Es steht $\mathrm{zu}$ vermuten, dass die Verfasser beider Schriften das kaiserliche Archiv benutzen konnten und dort auswählten, was ihnen wichtig, hilfreich oder nützlich erschien. ${ }^{73}$ Eine vergleichbare auswählende Tätigkeit liegt einer offiziellen Publikation von Kaiserkonstitutionen zugrunde, dem Codex Theodosianus, der auf den beiden genannten Codices aufbaute, diese jedoch verbreiterte. Kaiser Theodosius II. (408-450 n. Chr.) liess für den Bereich des Staats- und Verwaltungsrechts wichtige Konstitutionen zusammentragen und im Jahr 438 n. Chr. für das Oströmische Reich publizieren; Kaiser Valentinian III. (425-455 n.Chr.) übernahm den Codex im Jahr 439 n. Chr. für das

70 Georg Scheibelreiter, Vom Mythos zur Geschichte. Überlegungen zu den Formen der Bewahrung von Vergangenheit im Frühmittelalter, in: Historiographie im frühen Mittelalter, hrsg. von Anton Scharer und Georg Scheibelreiter, Wien 1994, 26-40.

71 Siehe oben 6-7.

72 Detlef Liebs, Römische Jurisprudenz in Africa. Mit Studien zu den pseudopaulinischen Sentenzen, 2. Auflage, Berlin 2005, 41 - 128; Kaser, Das Römische Privatrecht (Band 2) (Anm. 26), 42; Wieacker, Römische Rechtsgeschichte (2. Abschnitt) (Anm. 31), 171-172.

73 Detlef Liebs, Recht und Rechtsliteratur, in: Restauration und Erneuerung. Die lateinische Literatur von 284 bis 374 n.Chr., hrsg. von Reinhart Herzog, München 1989 (Handbuch der lateinischen Literatur der Antike 5), § 504 - 505 (60 - 64); Detlef Liebs, Jurisprudenz im spätantiken Italien (260 - 640 n.Chr.), Berlin 1987, 30-52, 134-143; Wieacker, Römische Rechtsgeschichte (2. Abschnitt) (Anm. 31), 171-172; Detlef Liebs, Hermogenians iuris epitomae, Göttingen 1964, insbes. 23 - 24. 
weströmische Reich. ${ }^{74}$ Dieser Codex markiert das Ende der Legislationsbemühungen für beide Teilreiche; ob und inwiefern er als „gescheiterter Codex“ zu gelten hat, bleibt zu diskutieren. ${ }^{75}$

Bemerkenswert ist jedenfalls bei der Berücksichtigung der spätantiken Entwicklungstendenzen im weströmischen Reich, dass die germanischen Herrscher die auswählende und komprimierende Tätigkeit von privaten wie von offiziellen Stellen übernahmen. In den im Westen neugegründeten Reichen führte die Überlagerung und Verbindung von germanischer Herrschaft mit römischer Rechtskultur zur Entstehung von Gesetzesbüchern für die romanische Bevölkerung, den leges romanae. Das wohl bekannteste Beispiel für diese Variation ist die Lex Romana Visigothorum, die Alarich II. 505/506 n. Chr für die Romanen im Einflussbereich der Westgoten im heutigen Südfrankreich erliess. ${ }^{76}$ Sie baute vor allem auf dem Codex Theodosianus und späteren Novellen auf, exzerpierte die Codices Gregorianus und Hermogenianus und nahm Auszüge aus den Paulussentenzen auf. Darüber hinaus entstand - wohl in Südgallien des 5. Jahrhunderts - eine Erörterung und Auslegung der Paulussentenzen, die Interpretatio Pauli Sententiarum, die ebenfalls einen Teil der Lex Romana Visigothorum ausmachte. ${ }^{77}$ Anfang des 6. Jahrhunderts entstand damit eine bunte ,Best of ${ }^{6}$-Kollektion nachklassischer Rechtsschriften, die sowohl den Bedürfnissen Alarichs II. wie denjenigen der romanischen Adressaten genügen sollte. Dass in einer solchen auswählenden, zusammenfassenden Tätigkeit nicht nur, Verlust‘ steckt, lässt sich schon daran ermessen, dass die Lex Romana Visigothorum alleiniger Transmissionsriemen für die Interpretatio Pauli Sententiarum ist. Zudem enthält diese Kompilationen viel kreatives Potential, entwickelte sich die Lex Romana Visigothorum doch zum „rechtlichen Credo der Germanen“78 im Frankenreich und wurde bis in das 10. Jahrhundert

74 Zum Codex Theodosianus siehe Adriaan J. B. Sirks, The Theodosian Code. A Study, Friedrichdorf 2007; Tony Honoré, The Making of the Theodosian Code, in: Zeitschrift für Rechtsgeschichte, Romanistische Abteilung 103 (1986) 133-222 sowie Wieacker, Römische Rechtsgeschichte (2. Abschnitt) (Anm. 31), 196-200.

75 Inge Kroppenberg, Der gescheiterte Codex. Überlegungen zur Kodifikationsgeschichte des Codex Theodosianus, in: Rechtsgeschichte 10 (2007) 112 - 126. Vgl. dazu aber ihren Beitrag in diesem Band, $71-84$.

76 Detlef Liebs, Römische Jurisprudenz in Gallien (2. bis 8. Jahrhundert), Berlin 2002 (Freiburger Rechtsgeschichtliche Abhandlungen N.F. 38), 166 - 176; Detlef Liebs, Art. Lex Romana Visigothorum, in: Reallexikon der Germanischen Altertumskunde 18 (2001), 323-25 sowie Detlef Liebs, Art. Lex Romana Visigothorum, in: Handwörterbuch zur Deutschen Rechtsgeschichte, hrsg. von Albrecht Cordes und Heiner Lück, 2. Auflage, Band 3, 20. Lieferung (2014), 918-924. Einen ersten Überblick vermittelt auch Laurent Waelkens, Amne adverso. Roman Legal Heritage in European Culture, Leuven 2015, $81-86$.

77 Zur Interpretatio Pauli Sententiarum siehe Hartwig Schellenberg, Die Interpretationen zu den Paulussentenzen, Göttingen 1965 (Abhandlungen der Akademie der Wisssenschaften in Göttingen, phil.-hist. Klasse, Folge 3, Nr. 64). Zu den im westgotischen Gallien entstandenen Interpretationen zu den Codices Gregorianus und Hermogenianus vgl. Nicole Kreuter, Römisches Privatrecht im 5. Jahrhundert n.Chr. Die Interpretatio zum westgotischen Gregorianus und Hermogenianus, Berlin 1993. 78 So die Beurteilung von Liebs, Art. Lex Romana Visigothorum (Anm. 76), 325. 
abgeschrieben, epitomisiert und mit Germanenrechten ergänzt. ${ }^{79}$ Die Auflistung der Beispiele für solche Transformationsprozesse des zumeist nachklassischen Rechts in Rechtsaufzeichnungen der germanischen Teilreiche ließe sich mit der zur Lex Romana Visigothorum ungefähr zeitgleichen Lex Romana Burgundionum oder der späteren, auf der Lex Romana Visigothorum aufbauenden Lex Romana Curiensis und weiteren Schriften verlängern. ${ }^{80}$

Im Vergleich zur klassischen Epoche der Rechtswissenschaft ging in diesen Transformationsprozessen ,Rechtswissen' unweigerlich verloren, doch bleibt zu diskutieren, wieviel bewahrt, wieviel verloren und wieviel Neues gewonnen wurde. Letztlich stellen diese Transformationen wohl notwendige Adaptionsprozesse an eine sich ändernde Umwelt dar.

Im Gegensatz zur Entwicklung im weströmischen Reich, in dem sich Sprache und dogmatische Aufbereitung des römischen Rechts prinzipiell wandelten sowie sich, nicht zuletzt, mit germanischen Elementen unauflösbar verbanden, versuchte Kaiser Justinian im Osten, den Prozess der Transformation des Rechts aufzuhalten und an die klassische Periode anzuknüpfen. Er ließ im Jahr 529 n. Chr. die noch anwendbaren Kaiserentscheidungen zusammentragen (Codex Iustinianus, revidiert 534 n.Chr.), überarbeitete das Institutionenlehrbuch des Gaius (Iustiniani Institutiones, 533 n. Chr.) und promulgierte im selben Jahr die unter Tribonius zusammengestellten Digesten bzw. Pandectae, in denen er Exzerpte aus klassischen Juristenschriften nach Themen strukturiert zusammenstellen ließ.$^{81}$ Gerade in dem Prozess der Erstellung der Digesten werden zwei gegenläufige Tendenzen sichtbar: Auf der einen Seite versuchte Justinian den Weg der Komplexitätsreduktion, den der Westen eingeschlagen hatte, umzudrehen, indem er auf die klassischen Juristentexte rekurrierte, diese erneut publik machte und damit an die Klassik anzuknüpfen versuchte. Auf der anderen Seite bediente er sich dafür gerade der Technik der Reduktion von Wissen: Nicht mehr als 5 $10 \%$ der klassischen Juristentexte passierten die sortierende Hand des Tribonius; was die Kommissionsmitglieder nicht schätzten, fiel, bis auf wenige Ausnahmen, dem Vergessen anheim. Das Corpus iuris civilis, wie diese Zusammenstellung von Codex, Digesten, Institutionen und Novellen, also späteren Kaisergesetzen, genannt wurde, erhielt in der sanctio pragmatica pro petitione Vigilii im Jahr 554 n.Chr. zwar auch

$79 \mathrm{Zu}$ den Epitomisierungen siehe Liebs, Römische Jurisprudenz in Gallien (Anm. 76), 184-190; zur Beurteilung Herman Nehlsen, Alarich II. als Gesetzgeber. Zur Geschichte der Lex Romana Visigothorum, in: Götz Landwehr (Hrsg.), Studien zu den germanischen Volksrechten. Gedächtnisschrift für Wilhelm Ebel, Frankfurt a. M. 1982, $143-203$, insbes. 178-180.

80 Detlef Liebs, Art. Lex Romana Burgundionum (Anm. 76), 322-323; Elisabeth Meyer-Marthaler und Hans-Jürgen Becker, Art. Lex Romana Curiensis, in: Handwörterbuch zur Deutschen Rechtsgeschichte, hrsg. von Albrecht Cordes und Heiner Lück, 2. Auflage, Band 3 (2014), 913 - 918; allgemein: Martin Schermaier, Art. Leges Romanae, in: Reallexikon der Germanischen Altertumskunde 18 (2001), $213-214$.

81 Ulrich Manthe, Corpus Iuris Civilis, in: Handwörterbuch zur Deutschen Rechtsgeschichte, hrsg.von Albrecht Cordes und Heiner Lück, Band 1 (2008), 901 - 907; Wieacker, Römische Rechtsgeschichte (2. Abschnitt) (Anm. 72), 287 -336; Kaser, Das Römische Privatrecht (Band 2) (Anm. 26), 32-40. 
Geltungskraft in Italien; Kristallisationspunkt einer neuen, europaweiten Beschäftigung mit dem klassischen römischen Recht sollte diese verdichtete Darstellung jedoch erst Jahrhunderte später werden, nämlich im 12. Jahrhundert.

\section{Zum Inhalt des Bandes: Mechanismen und Techniken im Umgang mit Wissen}

Der kulturelle und politische Kontext generierte wichtige Impulse für die Leitfrage nach den Entwicklungen und Strategien im Umgang mit Wissen in Spätantike und Frühmittelalter. Mit den drei Kategorien Exzerpieren, Kompilieren und Tradieren, die als Titel für diesen Band gewählt wurden, sollen wesentliche Techniken identifiziert werden. Dabei ist weder eine abschliessende Aufzählung angestrebt noch eine überschneidungsfreie Abgrenzung. Vielmehr ist die Beschreibung der jeweiligen Techniken idealtypisch gedacht. Dabei wurde ganz bewusst in Kauf genommen, dass Selektionsprozesse immer auch alle drei Phänomene beinhalten können, wenn auch mit unterschiedlichen Schwerpunkten.

\section{Exzerpieren}

Als eine erste Technik des Umgangs mit antikem Wissen lässt sich das Exzerpieren beschreiben, womit eine bewusste Verkürzung eines Textes im Sinne einer Adaptation für ein anderes Publikum gemeint ist. Eine solche Wissenskondensierung lässt sich auf vielen Gebieten beobachten: In der Literatur entstanden die Periochae des Livius oder die sogenannten Argumenta Vergiliana, im Bereich des Rechts fassten die Sentenzen des Paulus Klassikerschriften zusammen. Die beiden hier versammelten Beiträge zeigen diese Techniken auf ihre je eigene Weise: Mariette Horster verdeutlicht das literarische Potential einer solchen Exzerpierung anhand der Livius-Epitome; Christian Rohr stellt Übernahmevorgänge aus den naturkundlichen Schriften des Plinius bei Isidor und Beda Venerabilis vor.

\section{Kompilieren}

Ist gerade dem Exzerpieren ein Verlust inhärent, kann eine Zusammenstellung von Exzerpten auch wieder neues Wissen schaffen. Ein solcher Gewinn an Wissen zeigt sich insbesondere bei der Technik des Kompilierens. Hier sind vor allem die Zusammenstellungen im Bereich des Rechts zu nennen, insbesondere die in kaiserlichem Auftrag erstellen Sammlungen des Codex Theodosianus und des Codex Iustinianus. Inge Kroppenberg setzt sich mit den Funktionen dieser Rechtskompilationen mit Blick auf den Codex Theodosianus auseinander. Die Bedeutung der Sprache bei der Über- 
führung antiken Wissens in das Frühmittelalter untersucht Carmen Cardelle de Hartmann am Beispiel des Isidors von Sevilla. Transformationsprozesse zwischen Schriftlichkeit und Mündlichkeit beobachtet Hans-Georg Hermann bei den germanischen Leges, während Mayke de Jong die persuasive Funktion antiker Wissenselemente im Epitaphium Arsenii des Radbert von Corbie beleuchtet. Annina Seiler gibt schliesslich mit der Entwicklung von Glossen ein treffendes Beispiel für die Vor- und Nachteile einer Systematisierung von Wissen.

\section{Tradieren}

Das weitaus größte Problem der Überlieferung von Wissen ist oftmals der sehr dünne Faden ihrer materiellen Übertragung. Katastrophen wie Brände und Wasserschäden oder ganz allgemein der Niedergang der Trägerinstitutionen beeinflusste essentiell den Fortbestand des antiken Schrifttums. Ein äusserer Grund, der zu Wissensverlust führen konnte, ist der Mangel an Schreibmaterial, was eine Palimpsestierung und damit die Vernichtung älterer Texte mit sich brachte. Auf inhaltlicher Ebene sorgten Fehler im Abschreibevorgang, Emendationen und Ergänzungen von Texten durch ,intelligente Schreiber für Veränderung und Modifikationen von überlieferten Wissensbeständen. Im Kern geht es um Traditionsfragen, die die hier versammelten Beiträge beleuchten: Julian Führer spricht einen abrupten Abbruch der Überlieferung von Steuerlisten an; Ian Wood beleuchtet die Erwartungen der merowingischen Elite, die zur Neustrukturierung von hagiographischen, kirchenhistorischen und historiographischen Schriften führte. Karl Ubl stellt die legitimierende Kraft der Leges anhand der Überlieferung der Lex Salica vor, während Peter Stotz an einem Beispiel aufzeigt, wie die Erwartungen eines bestimmten Publikums die Präsentation und Tradierung älterer Texte mitgestalten konnte.

Insgesamt zeigt sich, dass es keine singuläre Perspektive gibt, aus der heraus die Prozesse zwischen Wissensverdichtung und -vernichtung zu erklären sind. Wissensverluste durch Kürzungen oder Epitomisierungen sind teilweise nur bei spezifischen Autoren oder Textsorten anzutreffen; teilweise beeinflussen gänzlich externe Faktoren den Verlust an Wissen. Kulturelle Veränderungen führten zur Etablierung neuer Wertesysteme und Wissensordnung, die das Sortieren und Skartieren, aber auch das Transformieren und Bewahren bestimmten. Zur Dynamisierung von Wissen, der Fruchtbarmachung für Gegenwart und Zukunft waren zwangsläufig Anpassungen notwendig, um nicht nur der Nützlichkeitsfrage, sondern auch der Attraktivitätsfrage begegnen zu können. Nicht zuletzt bleibt zu berücksichtigen, dass Wissen zu keiner Zeit einem reinen Selbstzweck diente. Treffend bemerkte daher Johann Wolfgang von Goethe: „Alter Held schützt alte Bücher, / Doch das Wetter zieht vorüber. / Unsre holden jungen Krieger / Schützen hübsche Mädchen lieber.“ (J. W. von Goethe, Weimarer Ausgabe I,4,135). 


\section{Exzerpieren}





\title{
Livius-Epitome: ein spätantiker Blick auf die (kurzgefasste) römische Republik
}

\begin{abstract}
This paper places the Periochae of Livy's History within the practice of literary condensation in Late Antiquity and investigates the techniques, aims and circumstances of their production. Based on a close reading and thorough analysis of two specific examples, it is shown that the unknown author created a new and coherent text rather than summarizing Livy's account of Roman history.
\end{abstract}

\section{Vom (verkürzenden) Umgang mit Texten in der Antike}

Verdichtung oder Vernichtung - diese Frage könnte man nicht nur für Texte ab der Spätantike stellen, sondern auch schon für die seit dem 4. Jh. v. Chr. entstandenen und unterschiedlich genutzten Zusammenfassungen und Exzerpte umfangreicherer Texte. ${ }^{1}$ Die Einstellung zum Umgang mit Texten und Autoren in Antike und Spätantike ist ein anderer als heutzutage. ,Plagiat' oder auch der von Antonie Wlosok in die Debatte geworfene Begriff des ,Epigonentums‘ sind für die Antike keine angemessenen Kategorien, um den Umgang mit Texten zu beschreiben und das Verhältnis der Autoren zueinander $\mathrm{zu}$ analysieren. ${ }^{2}$ Sie passen nicht in eine literarische Kultur und jahrhundertealte Tradition, in der der Verweis, die Adaptation, das wörtliche Zitat oder Halbzitat, der spielerische und raffinierte Umgang mit anderen Texten als Kunstform praktiziert wurden. Verschiedene Arten und Grade der Nachahmung von Inhalt, Aufbau und Form oder auch der selbstständigen Gestaltung des gleichen oder ähnlichen Stoffes werden in der antiken wie modernen Textanalyse und Interpretation voneinander unterschieden, wobei die lateinische Sprache die Begriffe und Kategorien der mimesis, aemulatio, imitatio und interpretatio unterscheidet. ${ }^{3}$ Solch ein Umgang,

1 Vgl. hierzu grundlegend Marietta Horster, Christiane Reitz, Introduction, in: Condensing Texts Condensed Texts, hrsg. von Marietta Horster und Christiane Reitz, Stuttgart 2010 (Palingenesia 98), 3-14 mit Hinweisen auf weitere Literatur.

2 Gemäß Antonie Wlosok, Originalität, Kreativität und Epigonentum in der spätantiken Literatur, in: Actes du VIIe congrès de la FIEC Budapest 1979, hrsg. von Janós Harmatta, Bd. 2, Budapest 1984, 251 265 ist der Begriff des Epigonentums als Gegensatz zum Begriff der Originalität eine Erfindung der Goethezeit. Erst dann habe das Nicht-Originale eine negative Konnotation erhalten.

3 Hierzu Arno Reiff, Interpretatio, imitatio, aemulatio. Begriff und Vorstellung literarischer Abhängigkeit bei den Römern, Diss. Köln 1959; Gordon Williams, Roman Poets as Literary Historians. Some Aspects of Imitation, in: Illinois Classical Studies 8 (1983), 211 - 237; Wlosok, Originalität (Anm. 2) und knapp Christopher L. H. Barnes, Images and Insults. Ancient Historiography and the Outbreak of the Tarentine War, Stuttgart 2005 (Historia Einzelschriften 187), 15-19. Mit dem Schwerpunkt auf 
verkürzend oder nicht, ist per se eine Hommage an die literarische Tradition, er schreibt den älteren Text in die jüngere Textproduktion ein. Das schließt jedoch nicht aus, dass der jüngere den älteren Text verdrängt oder zumindest das ,Original ' im Verhältnis zum späteren Text in den Hintergrund gedrängt wird, was unter Umständen durch Mangel an Abschriften des beispielsweise früheren und umfangreicheren Textes dann sogar zu dessen zunehmender physischer Absenz in den Bibliotheken führt. ${ }^{4}$

Vor dem Hintergrund der literarischen Autoritätskonstruktion, die darauf basiert, dass beim jüngeren Text die Vorbilder bekannt und für den Kenner identifizierbar sind - wovon schließlich auch der Wert der Neuproduktion abhängt -, ist davon auszugehen, dass das Überleben des Vorbildtextes schlechterdings notwendig ist und in der Intention des jüngeren Autors liegt. Eine Ausnahme bilden Gebrauchstexte zur vereinfachten, verkürzten Lektüre, ${ }^{5}$ wenn auch nicht die, die unter diesem Deckmantel (Exzerpte und Kurzfassungen als Gebrauchstexte für den Bildungshungrigen) ein umfangreiches neues Oeuvre schaffen. So sind beispielsweise auch die zitatreichen Noctes Atticae des Aulus Gellius nur so lange wertvoll, wie zumindest der größere Teil der zitierten Autoren auch weiterhin als Autoritäten gelten und Vorbildcharakter haben. ${ }^{6}$

Dass neue Texte Form und Inhalt früherer Texte variieren und verdichten, ist, wie schon anfangs betont, allerdings kein Phänomen, das in der Antike besonders durch

Ciceros Dialogen, aber mit Hinweisen auf die neuere Literatur und die breitere Diskussion zum Thema des Umgangs mit Texten in der antiken Tradition, Lothar Spahlinger, Tulliana Simplicitas. Zu Form und Funktion des Zitats in den philosophischen Dialogen Ciceros, Göttingen 2005 (Hypomnemata 159). 4 Dies ist z. B. der Fall beim Werk des Pompeius Trogus. Er schrieb in augusteischer Zeit die Historiae Philippicae in 44 Büchern, die neben wenigen Zitaten späterer Autoren vor allem durch Justin (2. Hälfte 2. Jh./frühes 3. Jh.) bekannt ist. Justin hat allerdings in seinem zumeist als Epitoma Historiarum Philippicarum Pompeii Trogi bezeichneten Werk durch seine literarische und rhetorische Gestaltung mehr als ,nur' eine Kurzfassung von Pompeius' Werk verfasst, vgl. John Yardley, Justin and Pompeius Trogus. A study of the language of Justin's Epitome of Trogus, Toronto 2003 (Phoenix Supplementary Volume 41); John Yardley, What is Justin Doing with Trogus?, in: Condensing Texts - Condensed Texts, hrsg. von Marietta Horster und Christiane Reitz, Stuttgart 2010 (Palingenesia 98), 469-490.

5 Solche Exzerpte werden beispielsweise im Briefwechsel von Mark Aurel und Fronto erwähnt, wobei suggeriert wird, dass für den vielbeschäftigten Kaiser die Auswahl abwechslungsreicher und leichter handhabbar ist als die vollständigen Texte, M. Cornelius Fronto, Epistulae, hrsg. von Michael P. J. van den Hout, Leipzig 1988, Ep. ad Anton. Imp., 105, 13 -17: etiam si qua Lucretii et Enni excerpta habes. Vgl. Marietta Horster, Was bleibt von Vergils Georgica? Zur Rezeption von Lehrdichtung im 2. und 3. Jh. n. Chr., in: Wissensvermittlung in dichterischer Gestalt, hrsg. von Marietta Horster und Christiane Reitz, Stuttgart 2005 (Palingenesia 85), 265 - 294, hier 272 - 277 zu Fronto. Dabei könnte es sich ebenso um eine Auswahl wichtiger Sentenzen und Zitate handeln wie es denkbar ist, dass es sich dabei um Zusammenfassungen von beispielsweise Lukrez' Philosophie oder auch Ennius‘ Tragödien oder seiner Annales (einer epischen Geschichtsschreibung in 18 Büchern) handelte.

6 Leofranc Holford-Strevens, Aulus Gellius. An Antonine Scholar and his Achievement, 2. Auflage, Oxford 2005, 27 - 47 fasst die Diskussion um Anlage und Zweck des Textes zusammen; Wytse Keulen, Gellius the Stilist. Roman Cultural Authority in Attic Nights, Leiden 2009 (Mnemosyne Supplementum 297), 17 -94 (,Part One') diskutiert die Frage der Autoritätskonstruktion unter Aspekten von Textauswahl und Textkomposition. 
das Anfertigen von Kompendien, Enzyklopädien, Kurzfassungen und Exzerpten provoziert wird, sondern ist der Art der antiken literarischen Produktion inhärent, auch der spätantiken. Bei dieser Art der Kompetition von schreibenden Autoren mit den schon bestehenden früheren Texten und deren Autoren gibt es bestimmte Muster, wie durch die Adaptation oder das Zitat aus einem älteren Text Autorität ,usurpiert“ wird. Lediglich beim Umgang mit den kanonisierten und über die Jahrhunderte als hochrangig anerkannten Autoren und ihren Texten gibt es Ausnahmen, die abgesehen von Homer nur für den jeweiligen Sprachraum gelten: für den griechischen neben Homer auch Euripides, für den lateinischen auch Vergil und Cicero. Wenige andere Autoren gehören zeitweilig und kontextabhängig zum Kanon, zum Beispiel durch Konjunkturen in Rhetorikpräferenzen oder durch Phasen der literarischen Rückbesinnung auf historisch große Zeiten - insbesondere das klassische Athen und die frühe römische Republik. ${ }^{7}$ Diese zentralen Autoren waren zusammen mit anderen, darunter einige attische Redner sowie Terenz und Sallust, die wichtigen Schulautoren. Allerdings wurden die Texte dieser Autoren, anders als von vielen gedacht, keineswegs in vollem Umfang rezipiert und unterrichtet, sondern es wurden - und das zeigen die sogenannten Schulpapyri aus Ägypten (von der hellenistischen Zeit bis ins frühe 4. Jh. n. Chr.) ganz klar - von diesen ,Heroen der Literatur' nur ausgewählte Bücher gelesen, abgeschrieben und zur Wortschulung und Bildung besprochen. ${ }^{8}$

7 Für den lateinischen spätantiken Westen dominiert wie schon in der Kaiserzeit Vergil, vor allem seine Aeneis, als Referenz nicht nur explizit, sondern, wie z. B. Horster, Vergils Georgica (Anm. 5), 272 - 278, 286 - 290 für die kaiserzeitliche Lehrdichtung und besonders Ulrich Eigler, Lectiones vetustatis. Römische Literatur und Geschichte in der lateinischen Literatur der Spätantike, München 2003 (Zetemata 115) für die spätantike Literatur deutlich gemacht haben, unabhängig von den ,Gattungen` der später entstandenen Texte. Selbst die Origo gentis Romanorum aus der Mitte des 4. Jhs. n.Chr. wird von Markus Sehlmeyer, Geschichtsbilder für Pagane und Christen. Res Romanae in den spätantiken Breviarien, Berlin / New York 2009 (Beiträge zur Altertumskunde 272), 128 - 133 als eine Art Vergilkommentar für lehrende Grammatiker oder Rhetoren interpretiert; dieser solle den Zugang zur römischen Frühgeschichte und Republik weniger durch Historiographie als vielmehr über Vergil vermitteln. Zur Cicerorezeption in der Spätantike siehe Sabine MacCormack, Cicero in Late Antiquity, in: The Cambridge Companion to Cicero, hrsg. von Catherine Steel, Cambridge 2013, 251 - 305 mit einem guten Überblick. Zu Cicero als Quelle für exempla siehe Frank Bücher, Verargumentierte Geschichte. Exempla Romana im politischen Diskurs der späten Römischen Republik, Stuttgart 2006 (Hermes Einzelschriften 96).

8 Mit einer vorzüglichen Diskussion um Identifizierung und Funktion der sogenannten Schulpapyri vgl. Rafaella Cribiore, Writing, Teachers, and Students in Graeco-Roman Egypt, Atlanta 1996 (American studies in papyrology 36) und Rafaella Cribiore, Gymnastics of the Mind. Greek Education and Roman Egypt, Princeton 2001. Zum spätantiken Grammatik- und Rhetorikunterricht, der öfter in Mischformen als in einer klaren Zweiteilung des Unterrichts existiert, siehe Rafaella Cribiore, The School of Libanios in Late Antique Antioch, Princeton 2007 und Rafaella Cribiore, Higher Education in Early Byzantine Egypt, in: Egypt in the Byzantine World 300-700, hrsg. von Roger Bagnall, Cambridge 2007, 47 -66. 


\section{Spätantike ,Verdichtungen' und verkürzende ,Variationen'}

Verlieren und Vergessen, Verweigern und Vernichten, Variieren und Verdichten sind die drei Möglichkeiten, die von den Organisatoren dieser Tagung als Konsequenz des intentionalen wie nicht-intentionalen Umgangs mit Texten in Spätantike und Frühmittelalter formuliert worden sind. Für die antike und spätantike literarische Produktion, die sich den antiken real existierenden und verfügbaren Texten wie einer zum Teil nur noch durch Zitate und Verweise evozierten virtuellen (antiken) Bibliothek verpflichtet fühlt, bedeutet dies aber keineswegs, dass der Verweis auf biblische Texte, Homilien und hagiographische Erbauungsliteratur deswegen ausgeschlossen ist. Anders als bei einer ausschließlich auf einen christlichen Referenzrahmen verpflichteten Schriftstellerei, ist daher bei den meisten Autoren, die auf der Basis antiker Texte eine Kurzfassung oder andere ,verkürzende“ Textgattungen produzieren, das Verweigern und Vernichten der Vorlagen und Bezugstexte keine Option, das Verlieren und Vergessen zumindest nicht beabsichtigt. In den Kontext der ausgewählten Lektüre gebildeter (nicht nur) christlicher Schichten, in diesen literarisch konstruierten Referenzrahmen aus mythischen, historischen und literarisch-virtuellen Lebenswelten, passt auch eine Reihe der Kurzfassungen und Exzerptensammlungen mit historischem Gehalt hinein, die im 4. und frühen 5. Jh. n. Chr. produziert wurden. ${ }^{9}$

Die von den Herausgebern angesprochene Komplexitätsreduktion, die in Verbindung steht mit der Frage nach den spezifischen historischen Rahmenbedingungen der Spätantike und der Frage, inwiefern für diese spezifische, nicht nur verkürzende Art des Umgangs mit Texten die politischen, religiösen wie auch soziokulturellen spätantiken Konditionen förderlich waren, ist in der Forschung schon länger diskutiert. Dabei wurde vor allem das vielbeschworene „Age of Anxiety“10 angeführt, da-

9 Einen Überblick über die spätantiken Epitomai, allerdings mit unterschiedlichen Ausschluss- und Auswahlkriterien, bieten Ilona Opelt, Art. Epitoma, in: Reallexikon für Antike und Christentum 5 (1962), 944-973, hier 949-50, 964 (Geschichte), 953, 966 (Grammatik und Rhetorik), 954 Geographie, 955, 965 (Medizin und Recht), 956 (Militär) und Sehlmeyer, Geschichtsbilder (Anm. 7), 284304. Zum Text und zur Arbeitsweise der im 4. Jh. kompilierenden Autoren Aurelius Victor, Eutrop und Festus vgl. Willem den Boer, Some Minor Roman Historians, Leiden 1972.

10 So der Titel von Eric R. Dodds, Pagans and Christians in an Age of Anxiety. Some Aspects of Religious Experience from Marcus Aurelius to Constantine, Cambridge 1965 (the Wiles Lectures 1963) (mit Nachdrucken). Peter Brown, The Making of Late Antiquity, Cambridge Mass. / London 1978 (The Carl Newell Jackson Lectures 1976) (mit Nachdrucken), 2 - 3 weist darauf hin, dass die Wahrnehmung eines ,malaise of life' -Gefühls als Erklärung nicht überstrapaziert werden solle und geht S. 5 explizit auf die seines Erachtens unpassende Charakterisierung des Lebensgefühls im 3. Jh. durch Dodds ein, denn nach Brown hätten Angst und Hass bei Weitem keine so wichtige Rolle gespielt. Zwar sei ,anxiety eines der „pervasive and distinguishing features“ nicht nur des 3. Jhs. (S. 5), sondern auch der späteren Zeit, doch warnt Brown, Late Antiquity (Anm. 10), 9-11 vor einer Überemotionalisierung der Epoche und weist Terminologie und Forschungsrichtung, die dem mentalen Zustand der spätantiken Gesellschaft des 4. und 5. Jhs. auf die Spur kommen will, modernen, der eigenen Zeit verpflichteten Forschungs- 
neben auch die Umbruchphase in der Religion, die Abwendung vom Polytheismus und die Hinwendung zum philosophisch-theosophischen Neuplatonismus und Christentum, die ein derartig starkes Orientierungsbedürfnis beförderten, das bei gleichzeitiger Absenkung bzw. Veränderung des Bildungsstandards der Eliten, ${ }^{11}$ dann zum Anstieg des Bedarfs einer Vielzahl von verkürzten Texten führten, von denen die historiographischen Abrisse nur eine Gruppe sind. Diese grundsätzliche Frage wird in diesem Beitrag zurückgestellt, wird sie doch in der Einleitung der Herausgeber wie in einer Vielzahl von Beiträgen im vorliegenden Band immer wieder und unter verschiedenen Blickwinkeln erörtert.

\section{Die Periochae}

Der als Periochae oder auch als Epitome bezeichnete Text ist eine auf der Basis von Livius‘ monumentalem historiographischen Werk wahrscheinlich im 4. Jh. n. Chr. entstandene kurzgefasste Darstellung. ${ }^{12} \mathrm{Zu}$ den Kurzversionen, die schon seit dem 1.

trends der Nachkriegszeit zu. Was nach Brown im Verlauf des 3. Jhs. und den folgenden Jahrhunderten gewechselt hat, ist vor allem die Wahrnehmung des Göttlichen und der 'übernatürlichen' Dinge und Mächte. Dies werde in modernen Untersuchungen missverstanden als eine im Verhältnis zur paganen Antike abgenommenen Rationalität in Wahrnehmung und Welterklärung, die Hand in Hand gehe mit einer gewachsenen Leichtgläubigkeit bzw. dem Glauben an die Macht des Übernatürlichen, sowie gesteigerter Furcht vor Strafen Gottes und aller weiterer Mächte (ebd. 11 - 26). Vgl. auch Peter Brown, The World of Late Antiquity Revisited, in: Symbolae Osloenses 72 (1997), 5 - 30 mit einer Diskussion Peter Brown, Reply to Comments, in: Symbolae Osloenses 72 (1997), $70-80$.

11 Vgl. zum ,Bildungsstandard‘ im lateinischen Westen etwa Sehlmeyer, Geschichtsbilder (Anm. 7), 168-169, der behauptet, dass schon seit Constantius II. der „Bedarf an kurzen historischen Darstellungen zur Schließung von ,Bildungslücken“ bestehen blieb“; ebd., S. 171 zum geringen Bildungsstand einzelner Amtsträger. Vgl. wesentlich differenzierter Ralph W. Mathisen, The Theme of Literary Decline in Late Roman Gaule, in: Classical Philology 83 (1988), 45 - 52 und Beat Näf, Senatorisches Standesbewusstsein in spätrömischer Zeit. Freiburg i.Ü. 1995 (Paradosis 40), passim (e.g. S. 56-57 zu Ammian; 196 - 203 zu Ennodius); Mathisen, Theme (Anm. 11), 47 deutet die erst seit dem späten 5 Jh. (e.g. bei Avitus, Sidonius, Gregor von Tours) expliziten illiteratissimae litterae und vergleichbare Formulierungen nicht als Beschreibung realer Zustände, sondern als eine der Techniken, um unter anderem (Mathisen nennt weitere Gründe) mit dem Gestus der Bescheidenheit zugleich die Kunstfertigkeit der eigenen Schriften und Verse besonders hervorzuheben.

$12 \mathrm{Zu}$ den unterschiedlichen Manuskriptüberschriften (Periochae, Epitoma, Breviarium) vgl. Paul Jal, Histoire romaine. Abrégés des livres de l'histoire romaine de Tite-Live, Bd. 34,1 „Periochae“ transmises par les manuscrits (Periochae 1-69), Paris 1984, IX-XI. Die wesentlichen Argumente zur Datierung sind ausgetauscht. In den letzten Jahrzehnten hat es hierzu keine neuen externen Hinweise gegeben. Insofern folge ich den auf der Basis interner (sprach- und literaturhistorischer) Kriterien gewonnenen Datierungen durch die Kenner des Textes wie Marco Galdi, Gli epitomatori di Livio, in: Studi Liviani, Rom 1934, 237 -272, hier 253, Cynthia M. Begbie, The Epitome of Livy, in: Classical Quarterly 17 (1967), 332-338, hier 337, William J. Bingham, A Study of the Livian Periochae and their Relation to Livy's Ab urbe condita, Diss. Univ. of Illinois 1978, 475 - 478 und Jal, Abrégés, Bd. 1 (Anm. 12), XXIV (mit Fußnote 7: eher 2. Hälfte des 4. Jhs.), die sich alle für eine wahrscheinliche Datierung ins 4. Jh. aussprechen. Vgl. jedoch Luigi Bessone, Le 'Periochae' di Livio, in: Atene e Roma n.s. 29 (1984), 42 - 
Jh. n. Chr. auf der Basis von Livius entstanden, sind seit den 1970er Jahren vor allem die Arbeiten von Luigi Bessone, William J. Bingham und Paul Jal hervorzuheben. Diese drei (und auch frühere Autoren) haben durchaus unterschiedliche Auffassungen über die Originalität der verkürzten Livius-Versionen und über die literarischen Ambitionen des anonymen Autors der Periochae. Ob nun indirekt über Orosius und die Periochae, direkt über Livius oder vermittelt durch den Livius' Werk nutzenden Hieronymus Livius und die von ihm und seiner Erzählung der Anfänge Roms und der republikanischen Geschichte abhängenden Texte prägten die mittelalterliche Darstellung und Vorstellung der römischen vorkaiserzeitlichen Geschichte. ${ }^{13}$ Insofern steht ein Beitrag zu Livius und den in über 80 Manuskripten überlieferten Kurzversionen am Anfang dieses Bandes, der einen Schwerpunkt in den verschiedenen Verkürzungstraditionen und unterschiedlichen Kontexten der Nutzung seit der Spätantike hat.

Livius schrieb und publizierte sein umfangreiches, mindestens 142 Bücher starkes römisches Geschichtswerk $A b$ urbe condita in augusteischer Zeit und in den ersten Jahren des Tiberius. Neben Polybius, Cicero und einigen anderen Autoren ist Livius eine wichtige Quelle für die römische Republik, für das Selbstverständnis republikanischer Eliten, für die Geistesgeschichte der augusteischen Zeit - die Liste der Nutzungsmöglichkeiten der erhaltenen Bücher des livianischen Werkes ist fast unerschöpflich. Auch wenn in den meisten Fällen heutzutage die Kurzversionen als eine Art Lückenbüßer genommen werden, als Texte, die verdeutlichen, was mit den vielen verlorenen Livius-Büchern der Moderne entgangen ist oder sein könnte, so sind selbst für eine solche Untersuchung auch quellenkritische Kenntnisse der Arbeitsweise des Autors notwendig, um abschätzen zu können, wie der Epitomator mit seiner Textvorlage umgegangen ist.

Entsprechend gibt es Untersuchungen des Verhältnisses der Livius-Kurzformen zu Livius, deren Erträge dann u.a. Zusammenstellungen und Aufzählungen sind, wie beispielsweise

- Listen mit Worten und Halbsätzen, mit gleichartigen Reihenfolgen von Namen, Orten Ereignissen, die bei den erhaltenen Livius-Büchern und der jeweiligen Epitome identisch sind, ${ }^{14}$

55, hier 45 und sehr zurückhaltend Jane Chaplin, The Livian Periochae and the Last Republican Writer, in: Condensing Texts - Condensed Texts, hrsg. von Horster und Reitz (Anm. 4), 451 - 467, hier 452 mit Anm. 1. Die Frage der Vorlagen jedoch ist nicht nur für die Datierung von Belang, sondern vor allem auch für das Verständnis der Arbeitstechnik des anonymen Autors und seiner möglichen Zielsetzung. Weitere durch die inhaltliche Gestaltung naheliegende Datierungen ins 4. Jh., die bisher allerdings kaum beachtet wurden bzw. als ,period coulour' bewertet wurden, werden in Anm. 48 aufgeführt. 13 Eigler, Lectiones (Anm. 7), 203-204 mit Literaturhinweisen.

14 Bingham, Study (Anm. 12), 88-89 (Methode des Vergleichs), 389-405 (Ergebnis), Jal, Abrégés, Bd. 1 (Anm. 12), LVI-LX (insg. 30 wörtliche Übereinstimmungen, bei denen lediglich einige Varianten wie Wortinversion oder Ähnliches zu finden sind) sowie Paul Jal, Histoire romaine. Abrégés des livres de l'histoire romaine de Tite-Live, Bd. 34,2: „Periochae“ transmises par les manuscrits (Periochae 70 142) et par les papyrus d'Oxyrhynchos, Paris 1984, 167-174 mit einem tableau de concordance. 
- Analysen der Proportion von Haupttext zu verkürztem Text (e.g. bei der Periochae in Buch 1 - etwa 20\%, in Buch 2 - etwa $18 \%),{ }^{15}$

- Listen mit Besonderheiten, z.B. mit der Auswahl und Menge göttlicher Zeichen oder auch zu Umfang und Art der Darstellung römischer Siege und Niederlagen usw. $^{16}$

Diese Art des formalen wie inhaltlichen Vergleichs ist von wesentlicher Bedeutung, um die Abhängigkeiten der Texte voneinander zu klären und die Art und Technik des Umgangs mit der Vorlage zu identifizieren, ebenso aber auch um zu bestimmen, ob und wenn ja welche weiteren Vorlagen in den Text eingeflossen sind, wo Umstrukturierungen, wo Auslassungen, wo Missverständnisse und wo Neudefinitionen bei der Livius-Periochae wie auch beispielsweise den im vorliegenden Band von Karl Ubl behandelten Leges Romanorum und Leges Barbarorum zu finden sind. Diese Untersuchungen sind zusammen mit vielen anderen Ansätzen, sprachlichen, formalen und inhaltlichen, notwendiger Bestandteil dessen, was Philologen wie Historiker als Quellenkritik bezeichnen. ${ }^{17}$

Die Autoren solch kurzer Texte sind heutzutage oft nicht identifizierbar, wenn sie nicht in den praefationes genannt werden. In der Regel kann davon ausgegangen werden, dass es sich um einen gebildeten Mann, allerdings nicht immer um einen aus der (senatorischen) Oberschicht handelte. Damit steht hinter der Frage nach dem Autor und seiner Intention auch die Frage nach der raison d'être der Kurztexte und der möglichen Leserschaft. Diese Frage sollte aber nicht nur epochenspezifisch für die Spätantike oder das frühe Mittelalter im engeren Sinn beantwortet werden, würde es sich doch dann gleich auf die besonderen gesellschaftlichen und politischen Rahmenbedingungen der Lektüre und Bildung in der jeweiligen Zeit reduzieren und dabei aus den Augen verlieren, dass Kurzversionen und Exzerpte schon eine lange Tradition in der antiken Literaturgeschichte haben. Hier sei nur noch einmal an Aulus Gellius als Beispiel aus dem 2. Jh. n.Chr. erinnert: ${ }^{18}$ Gellius spricht in seiner Vorrede der Noctes Atticae, einer Sammlung von in seinen Augen wissenswerten Dingen, Zitaten und Anekdoten, nach eigener Aussage vor allem die an, die wenig Zeit haben zur Lektüre,

15 Jal, Abrégés, Bd. 1 (Anm. 12), XIII-XVI, zu unterschiedlichen Vorlieben der von Livius abhängigen Autoren siehe Luigi Bessone, La tradizione epitomatoria liviana in età imperiale, in: Aufstieg und Niedergang der Römischen Welt, hrsg. von Hildegard Temporini, Reihe II: Prinzipat, Bd. 30.2: Sprache und Literatur, Berlin / New York 1982, 1230-1263.

16 E.g. Bingham, Study (Anm. 12), 409-414.

17 Vgl. zur Quellenkritik und den verschiedenen Arbeitsweisen und Abhängigkeiten spätantiker Texte Bruno Bleckmann, Überlegungen zur Enmannschen Kaisergeschichte und zur Formung historischer Traditionen in tetrarchischer und konstantinischer Zeit, in: Historiae Augustae Colloquium Bonnense, hrsg. von Giorgio Bonamente und Klaus Rosen, Bari 1997, 11-37 sowie speziell zu den von Livius abhängigen Texten Peter L. Schmidt, Livius-Rezeption und kaiserzeitliche Historiographie, in: Livius. Aspekte seines Werkes, hrsg. von Wolfgang Schuller, Konstanz 1993 (Xenia 31), 189- 201 (= Peter L. Schmidt, Traditio Latinitatis, Studien zur Rezeption und Überlieferung, Stuttgart 2000, 181-190). 18 Siehe oben 26-27 mit Anm. 6. 
weil sie verantwortungsvolle, zeitintensive Aufgaben für die Gemeinschaft übernommen haben. ${ }^{19}$ Dieses Argument, dann allerdings ungeachtet der schon zuvor existierenden Topik, ist wenig überzeugend mit Bezug auf die sogenannten neuen Schichten der sozialen Aufsteiger in der Spätantike in modernen Darstellungen wiederzufinden. ${ }^{20}$ Explizit wird die Topik des vielbeschäftigten Verantwortungsträgers in der Tradition eines Kaisers wie Mark Aurel (und nicht der sozialen Aufsteiger) auch in der Praefatio von Eutrops Brevarium ab urbe condita benannt. Hier ist es der Kaiser Valens (364-378), der vor lauter Arbeit und Verantwortung kaum Zeit zum Lesen gehabt haben soll und daher nach den Worten Eutrops den Vorbildern der hervorragenden römischen Männer bei seiner Arbeit gefolgt sei, ohne von ihnen zuvor etwas gehört zu haben:

Res Romanas ex uoluntate mansuetudinis tuae ab urbe condita ad nostram memoriam, quae in negotiis uel bellicis uel ciuilibus eminebant, per ordinem temporum breui narratione collegi strictim, additis etiam his, quae in principum uita egregia extiterunt, ut tranquilitatis tuae possit mens diuina laetari prius se inlustrium uirorum facta in administrando imperio secutam, quam cognosceret lectione. ${ }^{21}$

Denkbar sind zwar auch Leserschichten, die nicht nur aus realem oder auch literarisch-konstruiertem Zeitmangel, sondern aus geringem Interesse oder weniger soliden Lesekenntnissen sich an die umfang- und anspielungsreiche Lektüre nicht heranwagen. Für sie kann die Kurzversion eine einfache Art des Bildungserwerbs sein oder auch als eine Art Kompaktversion für die weniger Gebildeten, ein Handbuch oder Sachbuch für den Unterricht dienen. Auch wenn dies eine in den modernen Überblicksdarstellungen zu findende Ansicht ist, so ist sie nicht nachweisbar und selbstredend ist eine solche Einschätzung und Bewertung dieser Texte in den praefationes der antiken und spätantiken Autoren nicht zu finden. Dies hätte nicht nur den Text selbst, sondern auch dessen Autor, vor allem aber auch die Leser des Textes als minderwertig bzw. ungebildet stigmatisiert.

Für die beiden direkten Verkürzungen des Livius, die längeren Periochae und die sehr kurzen Oxyrhynchos-Epitome, ${ }^{22}$ dürften die Antworten auf die Fragen nach Autor, Leserschaft und raison d'être unterschiedlich ausfallen. Beim längeren Text der Periochae werden literarische Ambitionen des Autors deutlich (siehe unten). Der Autor dürfte entsprechend auch einen literarisch versierten und gebildeten Leser vorausgesetzt und erhofft haben. Die sehr knappe, in der Regel nur wenige Zeilen für ein

19 Aulus Gellius, Noctes Atticae, hrsg. von Peter K. Marshall, Oxford 1968, praef. 11-12.

20 So bspw. Sehlmeyer, Geschichtsbilder (Anm. 7), 3-4 und 168-169.

21 Eutrop, Breviarium ab urbe condita, hrsg. von Joseph Hellegourc'h, Paris 1999, 1, praef. Zu Mark Aurel siehe oben, 26 mit Anm. 5.

22 P. Oxy. IV 668 (Epitome of Livy, XXXVII-XL and XLVIII-LV), in: The Oxyrhynchus Papyri. Bd. 4, hrsg. von Bernard P. Grenfell und Arthur S. Hunt, London 1904, 90 - 116. Der Papyrus enthält die jeweils nur wenige Zeilen, aber unterschiedlich langen Inhaltsangaben der Bücher $37-40$ und 48 - 55, die jeweils mit der Datierung nach den Konsuln beginnen. 
Livius-Buch umfassende Epitome aus Oxyrhynchos war dagegen wohl Gebrauchstext und könnte ein Repetitorium wichtiger Daten, Namen und Fakten der römischen Republik gewesen sein. Als solches wäre sie beispielsweise geeignet zum Studium der lateinischen Sprache mittels eines Gerüsts der römischen Geschichte in lateinischer Sprache, insbesondere für die griechisch-sprachige Mittel- oder Oberschicht im Osten des Reiches, genauer gesagt im griechisch-sprachigen Ägypten, wo der Papyrus gefunden wurde.

Wie schon auf den letzten Seiten wird sich auch die folgende Darstellung ausschließlich mit der literarisch ambitionierten längeren Periochae beschäftigen. Die Textüberlieferung spielt für den hier behandelten Aspekt der Frage nach Gestaltungswillen und Textgestalt weniger eine Rolle und auch auf die Diskussion der Abhängigkeitsidentifizierung soll hier nicht näher eingegangen werden. ${ }^{23}$ Vielmehr wird im Folgenden zunächst kurz auf einige wichtige Arbeitstechniken in den Periochae im Verhältnis zu ihrer Hauptvorlage generell hingewiesen, bevor dann einige wenige Textteile auf ihre mögliche Wirkung und ihre im Verhältnis zu Livius anders, ja neu geartete Dynamik und Fokussierung hin untersucht werden.

23 Die Diskussion um die Abhängigkeiten der verschiedenen - mehr oder weniger - auf Livius beruhenden späteren Texte wird seit dem späten 19. Jh. geführt. Dabei spielen genaue Textvergleiche (Wortwahl bis hin zur wörtlichen Übereinstimmung, aber auch Satzstruktur und Grammatik) die entscheidende Rolle. Vgl. hierzu etwa Friedrich Drescher, Beiträge zur Liviusepitome, Diss. Erlangen 1900; Bingham, Study (Anm. 12), 314-400; Jal, Abrégés, Bd. 1 (Anm. 12); Jal, Abrégés, Bd. 2 (Anm. 14), zu Florus insbesondere Paul Jal, Nature et signification politique de l'ouvrage de Florus, in: Revue des études latines 43 (1965), 358-383; Luigi Bessone, La storia epitomata. Introduzione a Floro, Rom 1996 (Problemi e ricerche di storia antica 19). Dabei wird deutlich, dass es zwar wohl kaum eine frühere Livius-Epitome gab, von der dann statt von Livius direkt alle späteren Texte abhingen. Dennoch könnte aber ein solcher, nicht erhaltener Text, die ein oder andere Gemeinsamkeit der nachlivianischen Texte erklären, vgl. e.g. Bessone, tradizione (Anm. 15) und Bessone, Periochae (Anm. 12). Eine Livius-Epitome aus dem 1. Jh. n. Chr. mag existiert haben (Mart. 14.190, Stat. Silv. IV 7.53 - 56), sie muss aber nicht dieses Bindeglied gewesen sein. Es gibt weitere Theorien der Nutzung einer zweiten Quelle, um die Verbindungen zwischen in unterschiedlichem Maß auf Livius zurückgehenden Autoren wie Florus im 2. Jh. oder Orosius im späten 4. / frühen 5. Jh. zu erklären. So stellt z. B. das Schema von Schmidt, Livius-Rezeption (Anm. 17) Hyginus‘ De viris illustribus als wichtige Quelle für Exempla in den Mittelpunkt, die dann auch bei Florus und Orosius Eingang gefunden habe. Den Periochae-Text sieht Schmidt dagegen als einzig und allein von Livius abhängig. Für die im vorliegenden Beitrag angestrebte Konzentration auf die spezifische und eigenständige Literarizität und die im spätantiken Kontext des 4. Jhs. präfigurierte Gestaltung des Textes ist die komplexe Frage der Abhängigkeit von mehr als nur dem Livius-Text irrelevant, da diese zwar für andere Livius-Verkürzungen eine wichtige Rolle zum Verständnis der Organisation der Texte spielt, im vorliegenden, hier untersuchten Fall (Periochae und 2. Punischer Krieg) die direkte Abhängigkeit so evident ist, dass ein möglicher weiterer vom Epitomator direkt rezipierter Text auf die oben geführte Argumentation keinen Einfluss hätte. 


\section{Methoden und Techniken zwischen Kompilierung und Neuschöpfung}

Es gibt weder Standardbücher bei Livius noch Standardlängen der Kapitel der Kurzfassung. Bedeutsam ist daher die Beobachtung, dass es keine nachvollziehbare und beobachtbare Korrelation des Umfangs der Kapitel der Kurzfassung zu den unterschiedlichen Längen und der Detailfreudigkeit der Livius-Bücher gibt. Damit ist aber die Entscheidung über Inhalt und Länge der Darstellung in der Kurzfassung nicht durch Livius, sondern ausschließlich durch den Autor der Kurzfassung gesteuert, selbst wenn es weniger aktive Entscheidungen waren als möglicherweise reaktive, die auf die wechselnden Schwerpunkte von Livius' Darstellung reagieren. ${ }^{24}$ Intentional wäre beispielsweise auch ein Desinteresse am Prinzipat, was dann die besondere Kürze der letzten Bücher erklären könnte, wie Chaplin betont. ${ }^{25}$ Es wäre dann der Periochae-Autor, der ein nur geringes Interesse an der augusteischen Zeit im Verhältnis zur Republik hatte, und nicht etwa Livius, der hier an seiner Zeitgeschichte wenig Interesse gezeigt hat. Ronald Syme und Karl Zangemeister haben zur Erklärung der wechselnden Längen und der (in ihren Augen nicht vorhandenen oder jedenfalls häufig nicht nachvollziehbaren) Auswahlkriterien dagegen die menschliche Unzulänglichkeit des Autors ins Spiel gebracht: Zeitdruck, aufkommende Langeweile, zunehmender Lustverlust an der sich lang hinziehenden Aufgabe der Epitomisierung. ${ }^{26}$ Allerdings hat Otto Rossbach schon in seiner Edition der Periochae aus dem Jahr 1910 den Vorschlag gemacht, dass der Aufbau und die Auswahl im Detail vor allem vom Ziel und Zweck des Textes determiniert seien, der Rhetorikausbildung zu dienen, insbesondere für den Einsatz bei Deklamationen. ${ }^{27}$ Dementsprechend seien besonders lange Textpassagen zu den Mythen, den Taten der Helden in Kriegen, der Tapferkeit als Tugend usw. zu erklären, die in besonderem Maße zu den spätantiken Lese- und ge-

24 Evtl. könnten Inhalt wie Art der Präsentation und Fokussierung der Livius-Bücher die Wahl der unterschiedlichen Ausführlichkeit des Epitomators beeinflusst haben. Vgl. hierzu das gleich näher vorgestellte Beispiel der Darstellung des 2. Punischen Krieges.

25 Andererseits gibt es keine Hinweise darauf, dass der Periochae-Autor kein Interesse an bestimmten Phasen der römischen Republik hatte. Deutlich werden aber bestimmte Interessen des Autors, beispielsweise in der Darstellung der Zeit von 191 bis 186 v.Chr., den Büchern 36 - 39 bei Livius (und der Periochae). Der Autor gibt Livius‘ Buch 36 mit gerade einmal 8 Zeilen wieder, dagegen dann Buch 39 mit 50 Zeilen. Ausführlich (im Verhältnis zu den sonst üblichen knappen Formulierungen) wird hier der Bacchanalien-Skandal, das senatus consultum zu den Festen und Priestern des Bacchus dargestellt. 26 Hinweis und Nachweise bei Jal, Abrégés, Bd. 1 (Anm. 12), XV Anm. 5 und 6, Ronald Syme, Livy and Augustus, in: Harvard Studies in Classical Philology 64 (1959), 27 - 87, hier 29; Karl Zangemeister, Die Periochae des Livius, Freiburg i. B. / Tübingen 1882 (Festschrift der in Karlsruhe tagenden 36. Philologen-Versammlung) 1882, 100.

27 Otto Rossbach, T. Livi Periochae omnium librorum, Fragmenta Oxyrhynchi reperta, Iulii Obsequentis Prodigiorum liber, Leipzig 1910, XXIV. Gebrauch im Rhetorikunterricht wird auch von Bessone, Periochae (Anm. 12), 46 angenommen. 
lehrten Gesprächsvorlieben passen und die Dominanz der Rhetorik im 4. Jh. widerspiegeln würden. ${ }^{28}$

Über die Präferenzen hinaus gab es eine gewisse Erfolgssteuerung der Rezeption eines Textes, nicht nur der verkürzenden Texte, sondern auch der durch Kompilation und Exzerpt neu komponierten (oft längeren) Texte. Der Verweis auf den Kanon und das Einschreiben in den Kanon scheinen ein entscheidendes Kriterium für die Wahrnehmung solcher Texte gewesen zu sein. Dass dies nicht nur in Bezug auf die Auswahl der Autorenvorlagen galt, sondern ebenso auch für die konkrete Auswahl der exempla und historischen Beispiele, hat am Beispiel der Darstellung der Römischen Republik in der spätantiken Literatur Ulrich Eigler 2003 gezeigt. In seinen Beispielen ist es die in der Spätantike alles überragende Prägung und Präfiguration durch Vergils Aeneis, die durchaus zum Überleben der Texte entscheidend beigetragen haben, wovon deren Vorhandensein in mittelalterlichen Manuskripten zeugt. ${ }^{29}$ Unabhängig davon sei nochmals betont, dass Kurzversionen schon länger angefertigt wurden und die ersten des Livius offensichtlich schon im 1. Jh. n. Chr. im Umlauf waren. ${ }^{30}$ Diese Textgattung ist per se keineswegs ein Zeichen des Bildungsverfalls, obwohl dies eine immer wieder postulierte Behauptung ist. Entsprechend wurde auch die literarische Qualität der Periochae wie auch der historische Inhalt von der Forschung sehr unterschiedlich bewertet. Marco Galdi spricht 1922 von einem chronologisch konfusen Buch mit Hang zur Anekdote und ohne jeden literarischen Wert. Sein Urteil hat er dann 1934 nur leicht abgemildert. ${ }^{31}$ William J. Bingham spricht im Jahr 1978 zwar von einem gebildeten Autor, der ein Handbuch der Römischen Geschichte entlang des Inhalts der Livius-Geschichte geschrieben habe, betont aber andererseits, dass nichts in der Periochae sei, was nicht auch in Livius stehe. ${ }^{32}$ Paul Jal spricht ebenfalls von einem recht gebildeten Autor, ${ }^{33}$ geht aber über Bingham hinaus, indem er auch literarische Ambitionen in der Textgestaltung erkennen will. ${ }^{34}$ Vor allem aber geht Jal wie schon vor

28 Dagegen geht Bessone, Periochae (Anm. 12), 46 (ohne Nachweise) beispielsweise davon aus, dass Livius ebenso wie die Exempla-Auswahl eines Valerius Maximus im Rhetorenunterricht verwandt wurde.

29 Wie u. a. Sehlmeyer, Geschichtsbilder (Anm. 7), gezeigt hat, gibt es in der spätantiken Literatur ein archaisierendes Interesse und dabei eine inhaltliche Kanonbildung wichtiger Ereignisse und Mythen (exempla) mit einem deutlichen Schwerpunkt auf der römischen Republik und ihren Helden. Andererseits ist dieser inhaltliche Schwerpunkt allerdings auch nicht neu, denn nicht nur Cicero wird so schon in spätrepublikanisch / frühkaiserzeitlicher Literatur für republikanische exempla benutzt (Bücher, Verargumentierte Geschichte (Anm. 7)). Einen vergleichbaren Trend zur Archaisierung und zur Republik als Referenzsystem gab es schon seit dem frühen 2. Jh. n. Chr. in der lateinischen Sprache und Literatur der zweiten Sophistik, z. B. in Suetons Grammatikerbiographien oder Aulus Gellius' Noctes Atticae.

30 Siehe oben Anm. 23.

31 Marco Galdi, L'epitome nella letterature latina, Neapel 1922, 91 - 92, Galdi, epitomatori (Anm. 12), $253-254$.

32 Bingham, Study (Anm. 12), e.g. 476.

33 Jal, Abrégés, Bd. 1 (Anm. 12), LIV.

34 Jal, Abrégés, Bd. 1 (Anm. 12), LXXXIIIf. 
ihm Otto Rossbach 1910 von einem Autor des 4. Jhs. n. Chr. aus, der von der literarischen Mode seiner Zeit, insbesondere dem Hang zur Rhetorik und zu bestimmten Themen, beeinflusst war. ${ }^{35}$ Zuletzt hat Jane Chaplin 2010 den Autor der Epitome charakterisiert als einen von den Präferenzen und Interessen des Livius unabhängig gestaltenden Autor und hat dies insbesondere für die Haltung gegenüber Augustus herausgearbeitet.

Die Unterschiede zwischen Livius und der Epitome sind - abgesehen von der Länge - vielfältig. Abgesehen einmal von Fehlern, die in der Manuskripttradition begründet sind (wie e.g. falsch geschriebene Namen), sind es verschiedenste Nachlässigkeiten und/oder 'Fehler' des Epitomators, wichtiger aber die gestaltend eingreifenden Veränderungen wie phrases de transition, das Umarrangieren der (inhaltlichen) Erzähl- oder Wortfolge, aber auch Abweichungen vom Inhalt des Livius, was keineswegs zwangsläufig einen anderen oder zweiten Basistext nahelegt, sondern durch die Belesenheit und Vorstellungen des Autors begründet sein mag, ohne dass ihm hierfür ein konkreter Text vor Augen war. Aus diesen und anderen Unterschieden zwischen beiden Texten lässt sich der Umgang des Epitomators mit der Vorlage erkennen. Das Hinzufügen, die eigene inhaltliche Interpretation und Schwerpunktsetzung, das systematische Auslassen bestimmter Themen, die Neuanordnung der Informationen und das Zusammenfassen von Inhalten sind keine Seltenheit. Diese Arbeitsweise erlaubt es dem anonymen Autor nicht nur einen kompakten, kurzen Text herzustellen, sondern auch eine in sich geschlossene Erzählung bzw. eine Vielzahl solcher Erzählungen. Vor allem die Anekdoten, ${ }^{36}$ die im Fall der Periochae im Verhältnis zu historisch knappen Informationen überproportional repräsentiert sind, lockern mit ihren Adjektiven, Partizipien, Attributen usw. den Text auf und lassen ihn trotz der Kürze nicht zu einer langweiligen Inhaltsangabe und Orientierungshilfe für das längere Werk, sondern zu einer recht kurzweiligen, eigenständigen Lektüre werden. Selbst wenn man den Autor der Periochae z. B. verglichen mit Florus und dessen literarischen Qualitäten als eher mittelmäßig bezeichnen würde, so war sein Text offenbar erfolgreich, wurde viel gelesen und benutzt, wovon die zahlreichen Abschriften zeugen.

\section{Entzeitlichung und Enthistorisierung}

Im folgenden Abschnitt werden zwei Merkmale des Periochae-Textes angesprochen, die für das Thema dieses Sammelbandes von besonderem Interesse sind und überraschenderweise kaum beachtet wurden. Es sind dies die Entzeitlichung und Enthistorisierung der römischen Geschichte. Eine der Textingredienzien, die einen his-

35 Dies erkläre nach Jal, Abrégés, Bd. 1 (Anm. 12), LV Anm. 2 bspw. auch den Namenswechsel von Astapa (Liv. 28.22.2) zu Gisia (Periochae, hrsg. von Paul Jal, Paris 1984, 28.7).

36 Jal, Abrégés, Bd. 1 (Anm. 12), LXXXV mit Anm. 5-14 klassifiziert Anekdoten nach ihrem Unterhaltungswert. 
toriographischen Text als solchen markieren, sind klare Indikatoren für die Chronologie. Livius wie auch die Oxyrhynchos-Kurzversion oder auch Julius Obsequens, der u. a. die Omina aus Livius exzerpierte, nutzen hierfür die in der römischen Tradition üblichen Konsulatsangaben. Dagegen lässt der Autor der Periochae das livianischmonotone $A$ et $B$ consulibus ganz weg. ${ }^{37}$ Das Auslassen dieser Art der chronologischen Einordnung, die bei Livius den Anfang der Bücher charakterisiert und im Folgenden dann das gliedernde Grundgerüst bildet, gibt dem kurzen Text der Periochae wesentlich mehr Freiheiten, würde doch ein immer wiederkehrendes $A$ et $B$ consulibus den einzelnen Kapiteln wie dem Gesamttext einen trockeneren und stereotypen Anstrich verleihen. Inhaltsangaben wie die Oxyrhynchos-Epitome oder Exzerpte wie die des Obsequens scheint das aber nicht zu stören, waren diese chronologischen Angaben doch für die Funktion beider Texte von ganz anderem Wert. Für sie war eine andere Art der Nutzung durch die Leser vorgesehen als für die hier im Zentrum stehenden Periochae. Deren Autor verlässt sich vielmehr auf die Kraft der Gliederung durch die Durchnummerierung der Bücher bzw. Kapitel. Der mit den Ereignissen der römischen Republik und der Einordnung wichtiger innenpolitischer Ereignisse und der Dauer der großen Kriege und Eroberungen nicht vertraute Leser dürfte die Orientierung verlieren und war, wenn er denn Interesse an der Chronologie im Groben wie im Detail hatte, auf die Vorlage Livius oder ein anderes Werk angewiesen.

Die Periochae ziehen sich damit aus der historiographischen Tradition heraus, ganz unabhängig von der Kürze oder Länge des Textes. Ein solcher Text schafft eine neue Form der Geschichtserzählung. Was in der ebenfalls nicht an korrekter Chronologie interessierten antiken biographischen Tradition schon lange existiert, wird hier nun an einer Epoche durchexerziert. Ein definitiv anderer Fokus und ein anderes Selbstverständnis als das des Livius und der kaiserzeitlichen Geschichtsschreiber wird hierdurch deutlich: Die Geschichte wird durch das mangelnde chronologische Gerüst ahistorisch, entspricht also mehr den epischen historischen Darstellungen in Versform und den überhistorischen Exempla-Sammlungen und Biographien, die den Vorbildcharakter der Handlung von Einzelnen wie von Gruppen unabhängig von ihrem gesellschaftlichen und politischen Entstehungskontext herausstellen. ${ }^{38}$

Ein weiterer Aspekt vertieft diesen Eindruck des durch wenige gestalterische Eingriffe entstanden enthistorisierten Werkes: Die Benennung der ersten Dinge, zumeist mit primum oder Ähnlichem eingeführt, der, wie Bingham sie nennt, „first-time

37 Diese Beobachtung machte bereits Jal, Abrégés, Bd. 1 (Anm. 12), LXXXVIII. Zum annalistischen Schema und der Erzählzeit bei Livius vgl. Dennis Pausch, Livius und der Leser. Narrative Strukturen in ab urbe condita. München 2011 (Zetemata 140), 75-102.

38 So Eigler, Lectiones (Anm. 7), passim in Bezug auf die Funktion der exempla-Auswahl, die nicht durch die Historiker, sondern in der Kaiserzeit und vor allem der Spätantike durch den stilbildenden Vergil gesteuert wurde. Vgl. oben Anm. 7 zur Rolle Vergils für die Origo gentis Romanorum bei Sehlmeyer, Geschichtsbilder (Anm. 7). 
notices““. ${ }^{39}$ Dabei handelt es sich um ebenso im luftleer-unhistorischen Raum hängende Hinweise wie, dass Servius Tullius als erster den Census durchgeführt hat (Per.1B, 50), die ersten Konsuln ihr Amt antraten (Per.1B, 40), das erste Ackergesetz auf den Weg gebracht wurde (Per. 2, 24), die ersten Zensoren eingesetzt wurden (tunc primum creati sunt: Per. 4, 4), zum ersten Mal den Soldaten ein Stipendium ausgezahlt wurde (Per. 4, 14), zum ersten Mal Zelte für die Soldaten zum Einsatz kamen (Per. 5, 2), zum ersten Mal ludi scaenici in Rom stattfanden (Per. 7, 3), das erste Gesetz gegen Giftmord verabschiedet wurde (Per. 8, 10), und dass der erste, der als Prokonsul einen Triumph erhielt, Q. Publilius war (Per. 8, 13).

Wenige erste Male sind negativ konnotiert: Vor Sulla hat es niemals einen so grausamen Menschen gegeben ${ }^{40}$ und P. Licinius Crassus war (im Jahr 131 v.Chr.) der erste pontifex maximus, der außerhalb Italiens kämpfte und dann auch noch im Kampf fiel. ${ }^{41}$ Andere Nachrichten dieser Art sind ambivalent, aber wohl insgesamt eher negativ als neutral bis positiv zu werten, z. B. dass Pompeius der erste war, der als Ritter einen Triumph erhielt, ${ }^{42}$ dass Pompeius als er zum dritten Mal Konsul wurde, dieses Amt sine collega innehatte, was vorher noch nie vorgekommen war. ${ }^{43}$ In derselben Kategorie, jedoch zeitlich wesentlich früher, wäre auch das Ereignis anzusiedeln, dass römische Soldaten mit Söldnern gemeinsam zum ersten Mal in einem Lager untergebracht waren. ${ }^{44}$

Trotz einiger Rückschläge und unangemessener Übergriffe und Fehltritte einzelner Weniger (Vestalinnen usw.) wird die Entwicklung insgesamt offenbar bis in die Zeit der Gracchen positiv konnotiert. Neuerungen sind in der Regel ein Schritt nach vorne. Danach etabliert sich das Gute, was in der Folge zur Regel wird. In der Zeit danach gibt es jedoch sowohl positive wie auch ambivalente und sogar negative erste Male - auch die Art dies auszudrücken verändert sich, das primum der Bücher bis zu den Gracchen verliert sich. Stattdessen werden die ,Neuerungen' nun negativ ausgedrückt wie z.B. numquam antea; nullo hominum; quod nulli. ${ }^{45}$

Die ,first-time notices' ordnen die Ereignisse nicht historisch-chronologisch ein, sondern geben Signale an den Leser, die zugleich auch eine Dynamik der Ereignisse suggerieren, Geschwindigkeit simulieren und die Idee einer Entwicklung und des Fortschritts zumindest bis zu den Gracchen in die Erzählung einschreiben, eine Tendenz, die man bei Livius so nicht findet. Die Selbstständigkeit des Textes und die Art der enthistorisierten, aber dennoch sehr dynamischen Darstellung wird nicht nur hieran deutlich, sondern auch durch die Fokussierung auf bestimmte Helden oder

39 Begriff von Bingham, Study (Anm. 12), 407 - 409 (lediglich knappe Aufzählung); Chaplin, Periochae (Anm. 12), 457.

40 Per. 88, 1: ...crudelitatem quanta in nullo hominum fuit ...

41 Per. 59, 4: ... quod numquam antea factum erat...

42 Per. 89, 7: ... adhuc eques R., quod nulli contigerat, ex Africa triumphavit.

43 Per. 107, 3: ... et a senatu cos. tertio factus est absens et solus, quod nulli alii umquam accidit.

44 Per. 24 mit Bezug auf die Zeit 215/13 v. Chr. könnte als feine Zeitkritik zu verstehen sein.

45 Siehe den Text in den Anm. 40-4. 
Charaktere. Anders als beim kategorischen älteren Cato, dem Namen nur Ausweis von Eitelkeit sind und der meint, die römische Geschichte 'namenlos' erzählen zu können, ${ }^{46}$ haben die bei Livius überlieferten zahllosen Namen in seinem Werk nicht nur die Funktion der möglichst genauen Darstellung, sondern auch der Weitergabe einer bestimmten Sicht auf die res publica: ${ }^{47}$ Jeder einzelne Römer ist wichtig und trägt zum Gelingen des ,Projekts“ Weiterbestand der Republik und Verbesserung des Systems wie der Lebensbedingungen der Gesamtheit und des Einzelnen bei. Dass dabei in der Menge die großen senatorischen Familien dominieren, macht die Grundaussage nicht zur Unwahrheit, sondern unterstreicht die besondere Verantwortung der Elite, die entsprechend mit der Führung des Staates Pflicht wie Lohn erhält.

Durch die Reduktion der zahlreichen Namen, die aber oft dann im Falle ihrer Nennung gleich mit einer Anekdote verbunden werden, stehen die einzelnen Personen viel stärker im Mittelpunkt als bei Livius. Sie scheinen deutlich das Zentrum des Werkes und damit auch die Träger der Geschichte zu sein, wesentlich mehr als die die Republik tragenden Strukturen, Ämter und Institutionen oder auch die die Macht Einzelner begrenzenden systemischen Vorgaben. Dies mag im Verhältnis zu Livius unausgewogen wirken, aber das soll es wohl auch. Die Periochae haben offenbar eine andere Zielsetzung als Livius. ${ }^{48}$

46 Cornelius Nepos, Vitae, hrsg. v. E. O. Winstedt, Oxford 1904 repr. 1956, Cato 3, 3-4.

47 Oft wird die Namenstradierung durch Livius in Untersuchungen senatorischer Familien und die durch sie und ihre Erzähltraditionen dominierten Geschichtstradition eingebunden. Zu Livius 'Bild der Republik in seiner Darstellung des 2. Punischen Krieges und den in diesem Kontext charakterisierten Individuen und Familien, vgl. Patrick G. Walsh, Livy and the Aims of 'historia'. An Analysis of the Third Decade, in: Aufstieg und Niedergang der Römischen Welt, hrsg. von Hildegard Temporini, Reihe II: Prinzipat, Bd. 30.2: Sprache und Literatur (Literatur der augusteischen Zeit: Allgemeines: Einzelne Autoren), Berlin / New York 1982, 1058-1074. Zu Auswahl und narrativer Funktionalisierung des Personals in den Periochae vgl. Chaplin, Periochae (Anm. 12), 460-463.

48 Damit wird aber auch verständlich, wieso der Name des Priesters am Altar der Tres Galliae in Lyon / Lugdunum, C. Iulius Vercondaridubnus, eines Adeligen der Haeduer (Per. 139, 2) wiedergegeben wird oder auch die Namen der Nervii, die mit den beiden in die römischen Einheiten eingegliederten Militärtribunen, Chumstinctus und Avectius, Drusus unterstützten. Sie kämpften gemeinsam gegen die Stämme auf dem gegenüberliegenden rechten Rheinufer (Per. 141, 2). Ein besonders gesteigertes Interesse an der Geschichte der keltischen oder germanischen Stämme der augusteischen Zeit ist hieran nicht zu erkennen, dagegen aber ein Interesse an besonderen Regionen, die wahrscheinlich zum Zeitpunkt des Entstehens der Periochae ein dauerndes Kampfgebiet waren. Ebenso zeithistorisch dürfte das Thema der Integration von Germanen in die römische Armee sein, wie auch die Ansiedlung rechtsrheinischer Gruppen auf dem linken Rheinufer. Denkbar wäre, ähnlich wie oben Anm. 44, auch hier eine versteckte Zeitkritik zu entdecken; ebenso kann es sich hier wie bei dem Hinweis auf die Armee um Zeitkolorit handeln. Dass der Epitomator die Loyalität zu Rom und Kaiser durch die beiden Stämme Haeduer und Nervier derart unterstreicht, gibt m.E. keinen Hinweis auf die mögliche Herkunft des Epitomators aus der Region (vgl. Jal, Abrégés, Bd. 1 (Anm.12), XXV mit Hinweisen auf die ältere Literatur), sondern verweist auf die Offenheit und Integrationskraft des römischen Reiches. Dagegen dürfte die Wahl der lateinischen Sprache deutlich auf eine Herkunft aus dem Westen deuten und der entsprechend stärkere Fokus auf Ereignisse im Westen verständlich sein, zumal in einer Zeit, in der es zwar noch das eine Reich, aber doch zunehmend getrennte Karrieren, Strukturen, Traditionen usw. gibt. 
Ein erstes Beispiel hierfür ist ein Passus aus dem 13. Buch der Periochae: In Kapitel 13 werden in den insgesamt 11 Sätzen sieben verschiedene Individuen mit Namen genannt. Und der Fortgang der Geschichte wird mit dem Einschub vorbereitet, dass ein vierter Vertrag mit den Karthagern ausgehandelt wurde, die allerdings zuvor nie genannt worden waren. ${ }^{49}$ Den Auftakt zur gemeinsamen Geschichte von Karthagern und Römern macht Per. 7, 11 mit einem simplen: Amicitia cum Carthaginiensibus iuncta est (zum Jahr 362-344 v.Chr.). Die Verträge vorher sind im Detail nicht wichtig: Es gibt eine lange Tradition der amicitia, die auch noch im Kontext des Kampfes gegen Pyrrhos existiert und vertraglich gesichert ist, bevor dann bald darauf der große Krieg zwischen Karthago und Rom auf Sizilien ausbricht - die Römer sind für das Ende dieser etwa 100 Jahre dauernden Verbindung nicht verantwortlich. Das zweite Beispiel ist ebenfalls namens- und anekdotenlastig, es dient aber auch darüber hinaus der Verdeutlichung der Möglichkeiten und Spielräume dieses allerdings nicht für alle Bücher gleichermaßen strukturiert arbeitenden Autors.

\section{Römer gegen Karthager - der 2. Punische Krieg, ein spannungsreiches Drama in wenigen Akten}

Das zweite Beispiel ist die verkürzte Version von Livius' 21 . Buch. Sie besteht aus nur 8 Sätzen, die aber rund 50 Seiten Livius entsprechen, die dieser in vergleichbarer Schrift in den gängigen Teubner-, Oxford- und Budé-Editionen einnimmt. Trotz dieser Kürze enthält der Text viele Ortsangaben: Die Flüsse Ebro, Ticinus und Trebbia, die Gebirge Pyrenäen, Appenin und Alpen, die Stadt Sagunt und den geographisch-politischen Raum Italien. Außerdem werden das römische Volk, gallische Stämme und die Volsker genannt, denen die karthagischen Truppen während ihres Zuges begegnen. Auch Eigennamen fallen in diesen wenigen Zeilen: Hannibal und Mago auf der Seite der Karthager, P. Cornelius Scipio mit seinem Sohn, der nur mit seinem zukünftigen Namen Africanus genannt wird, und Cn. Cornelius Scipio auf der Seite der Römer.

Belli Punici secundi ortum narrat et Hannibalis, ducis Poenorum, contra foedus per Hiberum flumen transitum (Per. 21, 1). Das Kapitel in der Periochae setzt mit einer Art Überschrift ein, wie ein Paukenschlag: Auf die Ankündigung des Punischen Krieges folgen unmittelbar dessen Ursachen. Ein vergleichbarer Beginn findet sich in keinem der Bücher oder Kapitel des Livius. Die Ursachen des Krieges werden dann im Falle der

\footnotetext{
Dagegen sind die unterlegenen Parther weniger interessant: Nicht einmal der Name des parthischen Königs wird überliefert, der den Friedensvertrag mit Augustus unterzeichnete und die signa der Legionen zurückgibt, die Crassus bei der Niederlage von Carrhae verloren hatte (Per. 141, 4).

49 Per. 13: Valerius Laeuinus cos. parum prospere aduersus Pyrrhum pugnauit, elephantorum maxime inusitata facie territis militibus. .... C. Fabricius missus ad eum a senatu, ut de redimendis captiuis ageret, .... Cineas legatus a Pyrrho ad senatum missus petiit ... Appius Claudius ... uenit in curiam et sententia sua tenuit ut id Pyrrho negaretur. $\underline{\text { Cn. Domitius }}$ censor primus ex plebe lustrum condidit. .... Cum $\underline{\text { C. Fabricio }}$ consuli is qui ad eum a Pyrrho transfugerat,....
} 
Periochae in Satz 1 abgehandelt, ein Thema, das die ersten 18 Kapitel von Livius‘ 21. Buch behandeln. In der Periochae heißt es, dass Hannibal gegen den bestehenden Vertrag den Fluss Ebro überquerte und die Karthager Sagunt belagerten, eine mit den Römern verbündete Stadt. An Liv. 21, 5-14 wird zwar eindeutig angeknüpft, doch bei Livius belagert Hannibal erst Sagunt und überquert erst danach den Ebro.

Die Periochae setzt damit fort, dass, da die römische Gesandtschaft $\mathrm{zu}$ den Karthagern keinen Erfolg gehabt habe, der Krieg habe erklärt werden müssen. Hannibal überquert die Pyrenäen und erreicht die Alpen. Nach einem schwierigen und gefährlichen Übergang erreicht Hannibal Italien. Der Autor verschenkt in den Augen der modernen von der technischen Leistung und dem Mut faszinierten Leser eine Möglichkeit hier den spektakulären Alpenübergang mit Elephanten und großen Verlusten zu schildern..$^{50}$ Dies macht deutlich, wie anders die antike Hannibal-Lektüre und Leseerwartung im Vergleich zur modernen gewesen sein dürfte.

Der Autor verweist dann auf zwei Niederlagen der Römer, von denen er aber einzig die bekannten Namen der Schlachten nennt (Ticinum flumen; ad flumen Trebiam). Hier wird nun eine Anekdote über einen Scipio eingefügt, ${ }^{51}$ die bei Livius (21.46.7-9) dagegen in einem anderen, früheren Kontext, dem der ersten Treffen der Karthager und Römer steht. Dagegen werden die in den Periochae auf zwei Ortsnamen reduzierten Niederlagen (Ticinus, Trebia) unmittelbar verknüpft mit einer Anekdote über den zukünftigen Africanus, Sohn des P. Cornelius Scipio. Gefolgt wird dieser knappe Hinweis mit einer weiteren personalisierten Erzählung, C. Cornelius Scipio, der den römischen Sieg in Spanien über die Karthager erringt. ${ }^{52}$

Bei Livius werden in diesen ersten Sätzen eine Vielzahl von Orten, Personen und Namen eingeführt, zahlreiche Anekdoten erzählt, größere Kontexte hergestellt. Der Periochae-Autor beginnt die Erzählung über den Krieg mit römischen Niederlagen, die aber schon Signale für ein gutes Ende bieten. Der Verweis auf die Lichtgestalt des zukünftigen römischen Siegers Scipio und den durch seinen Namen angedeuteten Schauplatz Afrika transportiert Hoffnung. Diese Reduktion bindet den für die Römer schlechten Kriegsbeginn in eine Art Heilsgeschichte und Zukunftsperspektive ein.

Bei Livius (21.46.7-9) ist die Hanno/Mago-Scipio-Anekdote zwar vorhanden, aber nur kurz ausgeführt. Sie geht in der Gesamtdarstellung des Kriegsbeginns und vor allem den vielen anderen Anekdoten, die mit individuellen Namen von Römern verbunden sind, fast gänzlich unter. Sie ist weder durch ihre Stellung im Text noch durch Wortwahl und Gestaltung besonders hervorgehoben und wird dadurch auch nicht wie in der Periochae zum Vorboten des zukünftigen Sieges. Die beiden letzten der acht

50 Per. 21, 5: Hannibal superato Pyrenaeo saltu per Gallias, fusis Volcis, qui obsistere conati erant ei, ad Alpes uenit et laborioso per eas transitu, cum montanos quoque Gallos obuios aliquot proeliis reppulisset, descendit in Italiam et ad Ticinum flumen Romanos equestri proelio fudit.

51 Per. 21, 6: In quo uulneratum P. Cornelium Scipionem protexit filius, qui Africani postea nomen accepit.

52 Siehe den Text in Anm. 53. 
Sätze der Periochae 21 weisen dann auf Probleme der Karthager hin..$^{53}$ Auch dies ist für den in den Augen der Römer katastrophalen Anfang des Krieges proportional viel und zeigt ebenfalls, dass es machbar ist, sie zu besiegen. Es ist ein Verweis auf die folgenden Kapitel, da trotz dieses Einstiegskapitels in den Punischen Krieg dieser dann keineswegs gleich wieder beendet werden kann, sondern sich noch in Realität wie in Erzählung hinziehen wird. Im vorletzten Satz (Per. 21, 7) werden die äußeren Umstände, Topographie und Wetter, benannt, mit denen Hannibal und seine Soldaten zu kämpfen haben. Implizit macht dieser Fokus auf die externen Faktoren deutlich, dass es zu diesem Zeitpunkt nicht die römische Armee und ihre Führung in Italien sind, die den Karthagern im Weg stehen und daher im Moment den Kriegsausgang auch noch nicht beeinflussen können. ${ }^{54}$ Der das Kapitel abschließende Satz in der Periochae ist dann wieder kurz und weist ebenfalls schon auf das Potential eines Sieges der Römer unter Führung der Scipionen hin: Scipio siegt zwar, aber eben nicht in Italien, sondern fern der Heimat. Und er ist in der Lage, einen der karthagischen Heerführer, hier ist die Rede fälschlicherweise von Mago und nicht von Hanno, gefangen zu nehmen.

Trotz der Kürze des 21. Kapitels der Periochae wird hier eine kohärente Geschichte konstruiert, die nicht der von Livius entspricht, weder in der Proportion der Schwerpunkte von Ursachen und Kriegsverlauf sowie hinsichtlich der Beachtung der Heerführer der Römer und Karthager noch in der Art Spannungsbögen zu konstruieren: Die Livius-Lektüre bereitet den Leser auf einen schwer über- und durchschaubaren Krieg vor, der auch durch die römische Führungsschwäche in die Länge gezogen werden wird, während die Periochae das Potential der Scipionen betont, das durch die Leistungsfähigkeit Hannibals als Kriegsführer aufs Äußerste herausgefordert werden wird.

Auch im Detail werden die Unterschiede in der Gesamtanlage unabhängig vom Umfang deutlich: Livius geht auch auf die Stämme in Norditalien ein. Für den Autor der Periochae sind aber nur die Stämme in Gallien erwähnenswert. Livius baut einige Digressionen ein, in denen er die Vorgänge in der Stadt Rom in den Mittelpunkt stellt, die Diskussionen im Senat, das Verhalten des Volkes, insbesondere deren Reaktionen auf die verlustreichen Niederlagen. Diese Art der Betrachtung ist kein Thema der Periochae.

Insgesamt bietet das Periochae-Kapitel eine wesentlich kohärentere Darstellung als Livius, was deutlich macht, dass hier wirklich ein neuer Text und nicht eine zusammenfassende Livius-Darstellung entstanden ist.

Zusammengefasst lautet die Geschichte in Periochae 21:

1) Hannibals Verhalten in Spanien zwingt die Römer zur Kriegserklärung $(21,1)$.

2) Tapfere gallische Stämme können Hannibal nicht daran hindern bis nach Italien vorzudringen $(21,4)$.

53 Per. 21, 7-8: Iterumque exercitu Romano ad flumen Trebiam fuso Hannibal Apenninum quoque permagna uexatione militum propter uim tempestatium transiit. Cn. Cornelius Scipio in Hispania contra Poenos prospere pugnauit duce hostium Magone capto.

54 Per. 21, 7 in der vorigen Fußnote. Siehe dagegen Liv. 21.58 - 59: Hannibal ist gezwungen wegen des schlechten Wetters umzukehren. 
3) Hannibal kann in Italien mehrere Siege über die Römer davontragen (21, 6-7).

4) $\mathrm{Zu}$ diesem Zeitpunkt sind Land und Wetter das Einzige, was Hannibal ernsthaft Schwierigkeiten macht $(21,7)$.

5) Trotzdem zeigen sich schon Zeichen der Hoffnung für das römische Volk: Der Sohn des P. Cornelius Scipio, der seinen Vater aus der Gefahr rettet, und dann Cn. Cornelius Scipio, der in Spanien siegt und einen karthagischen General gefangen nehmen kann.

Periochae 22 ist mit 16 Sätzen doppelt so lang wie das vorherige Kapitel, obwohl Livius“ 22. Buch den gleichen Umfang hat wie Buch 21. Das Kapitel der Periochae beginnt mit den Schwierigkeiten, die Hannibal in Italien hat und die nicht auf militärischen Widerstand der Römer zurückzuführen sind, sondern auf die Widrigkeiten des Landes, Widrigkeiten, die ihn sogar ein Auge kosten. ${ }^{55}$ Dann wird Gaius Flaminius eingeführt (bei Livius 22.3.4-14). Anders als die schon in Per. 21 genannten Scipionen, Hannibal und Mago wird hier erstmals nicht der sozial verortete Römer (oft Amtsinhaber), sondern ein homo ,Mann“ charakterisiert - wie die weitere Lektüre und der Kontext des Wortgebrauchs zeigt, mit einer negativen ,a-sozialen ${ }^{6}$ Konnotation. ${ }^{56}$ Dieser homo temerarius, dieser Mann, der unbesonnen und unüberlegt handelt, der die offensichtlichen Zeichen (der Götter) übersieht, von denen drei explizit erwähnt werden, führt eine römische Armee am Trasimenischen See in den Untergang. Daraufhin wird auch Hannibal näher charakterisiert. Bisher hat der Leser oder Hörer ihn nur durch seine Taten, seine Stärke, seinen Willen und seine Siege kennengelernt, doch nun wird auch ein Charakterzug, die perfidia, explizit gemacht. ${ }^{57}$ Hannibals Verschlagenheit wird einer anrührenden Anekdote gegenübergestellt: Vor dem Hintergrund der Tausenden von toten und gefangenen römischen Soldaten sterben zwei römische Mütter durch einen Herzinfarkt, da sie die Freude über die unverhoffte Rückkehr ihrer Söhne nicht ertragen können. ${ }^{58}$ Diese Inhalte finden sich ebenfalls bei Livius, die auspicia und omina, die der Konsul Flaminius nicht beachtet (22.3.4-14), die ausführliche Schilderung von Hannibals Hinterhalt, der ihn am Trasimenischen See siegen lässt (22.4.1-6.7), das Schicksal der kriegsgefangenen Soldaten, die Geschichte der römischen Mütter - aber bei Livius wirken zumindest einige der Geschichten durch die Länge und die vielen Namen, die dort einfließen, weniger eindringlich. Trotz der für die Römer dramatischen Situation fügen sich die Erzählstränge nicht zu einem Höhe-

55 Per. 22, 1: Hannibal per continuas uigilias in paludibus oculo amisso in Etruriam uenit ...

56 Per. 22, 2: C. Flaminius cos., homo temarius, contra auspicia profectus signis militaribus effossis, quae tolli non poterant, et ab equo, quem conscenderat per caput deuolutus, insidiis ab Hannibale circumuentus ad Thrasymennum lacum cum exercitu caesus est.

57 Per. 22, 2: insidiis ab Hannibale ...; 22, 3: 6000 Männer (Römer und Verbündete) werden entgegen der Zusage gefangen genommen wegen der perfidia Hannibalis; nicht einmal am Ende der Schlacht ist einem solchen Sieger $\mathrm{zu}$ trauen.

58 Per. 22, 3-4: Sex milia, quae eruperant, ..., perfidia Hannibalis uincta sunt. Cum ad nuntium cladis Romae luctus esset, duae matres ex insperato receptis filiis gaudio mortuae sunt. 
punkt. Die Länge und der Rhythmus der livianischen Erzählung produzieren andere Gegensätze und andere Kulminationspunkte bei der Darstellung des Themas des ersten Frühjahrs der Karthager in Italien. ${ }^{59}$

Die Unterschiede zwischen Livius und den Periochae, nicht in Details (,it's all in Livy'), sondern in der Botschaft, sind im 22. Buch mindestens ebenso deutlich. Auch hier sind der häufige Wechsel der innen- und außenpolitischen Ereignisse sowie vor allem die Verschränkung der Kriegsereignisse und verschiedenen Schauplätze bei Livius ein deutlicher Hinweis auf die enorme Komplexität der Lage. Mit seiner Art der Präsentation scheint Livius nahezulegen, dass die deutliche Schwäche der römischen Führung in den ersten Kriegsjahren nicht nur an Persönlichkeiten hängt, sondern auch durch die große Zahl der Akteure (Karthager, Hannibal und seine Armee, zahlreiche Bundesgenossen der Römer, die unterschiedlich reagieren und handeln, die Römer in der Stadt, die Römer im Feld, die einzelnen Amtsträger und Offiziere) und der Orte der Handlung (Rom, Italien, Sizilien, Spanien, Mittelmeer) in dieser für Rom so existentiellen Situation verstärkt wird.

Anders die Periochae: Hannibal eröffnet das Kapitel - ein rastloser vom Siegeswillen getriebener Feldherr; Varro beendet das Kapitel - das römische Volk ist ihm zu großem Dank verpflichtet, denn er gibt allen Hoffnung. Ansonsten gibt es nur den Schauplatz Italien (Etrurien, Cannae und immer wieder ,Italia‘ werden genannt), Spanien gehört ein Satz: res in Hispania meliore euentu gestas continet (Per. 22, 14), die Stadt Rom wird nur im vorletzten Satz insinuiert.

Nachdem der erste Satz mit dem aktiven und unaufhaltsamen Hannibal eingeführt wird, folgt der sich anschließende lange Satz (Per. 22, 2) nicht dem weiteren Darstellungsverlauf bei Livius, sondern kombiniert insgesamt neun, nur zum Teil aufeinander folgende Livius-Kapitel (Liv. 22, 10 -12 und Liv. 22, 25-29) und fasst sie zusammen. Durch Struktur und Länge unterstreicht der Satz den Inhalt: Die Diskussion der römischen Führung über die richtige Strategie. Ist es in der Sache nur ein Halbsatz, der dies zum Inhalt hat, entscheidet sich der Epitomator dennoch, das Zögern und Debattieren durch eine verlangsamte Erzählgeschwindigkeit zu unterstreichen. Dabei wird mit wenigen Worten Marcus Minucius desavouiert und dem Q. Fabius Maximus, der sich als weise und zurückhaltend erweist, gegenübergestellt. Für Minucius wählt der Epitomator dasselbe Wort wie für Caius Flaminius, temerarius, und auf diese Weise wird ein eindeutiges Signal gesetzt, das auf eine zukünftige Niederlage durch persönliches Verschulden hinweist. Darüber hinaus ist er schlimmer als Flaminius, denn er hintergeht das römische Volk. Aber am Ende des Satzes wird trotz dieses unheilschwangeren Adjektivs dann alles zum Guten gewendet: Der gute Fabius Maximus rettet mit seinen Leuten den unfähigen Minucius und dessen Heer. Trotz der Missetaten des Minucius, der sogar Maximus persönlich beleidigte und hinterging, hat Maximus,

$59 \mathrm{Zu}$ Darstellungsart und Narrativitätsmustern vgl. David S. Levene, Livy on the Hannibalic War, Oxford 2010, 34-81 und Pausch, Livius (Anm. 37). 
ein echter Römer, die Größe, die Staatsraison in den Mittelpunkt zu stellen und außerdem die römischen Soldaten zu retten.

Jetzt allerdings ist wirklich der Autor gefordert, muss er doch nach diesen Vorgaben dem Leser verständlich machen, wieso ein so fähiger Mann wie Fabius Maximus nicht in der Lage ist, den Krieg zu beenden. Hier wird nun Hannibal in seiner ganzen Gemeinheit vorgeführt, denn er schafft es mit seiner Verschlagenheit und seinen Intrigen, dass das, so muss man ergänzen, gute, aber eben auch gutgläubige, etwas naive, aber anständige römische Volk die Loyalität und Fähigkeiten des Fabius Maximus in Frage stellt. ${ }^{60}$ Erst diese Intrigen, die einzig der Hinterlist Hannibals zuzuschreiben sind und deren Aufdeckung durch den Autor jede Mitschuld der Römer hinwegfegen, führen dann zur brutalen und blutigen Schlacht von Cannae. Die Niederlage wird in ihrer Dramatik durch die nackten Zahlen verdeutlicht, die große Zahl der gefallenen Römer, unter denen sich auch einer der beiden Konsuln befindet. ${ }^{61}$ Nicht nur in Kapitel 21, in dem der Sohn des Scipio seinen Vater rettet, sondern auch in Kapitel 22 wird dieser Cornelius Scipio, der spätere Africanus eingebunden: Obwohl nur einer der Tribunen, ist Scipio doch derjenige, der sich nach der Schlacht von Cannae als Modell, als exemplum für einen römischen Heerführer erweist. Mit großem Respekt und tiefer Ergebenheit ist er dem römischen Volk und seinem Schicksal verpflichtet und verbunden: Weil einige junge nobiles verzagen, müssen nun alle anwesenden Soldaten und Offiziere nach der Schlacht einen Eid auf die ewige Treue zum römischen Volk schwören und dass sie Italia nie aufgeben werden. ${ }^{62}$

Abgesehen vom Hinweis auf die Kämpfe in Spanien, die anders als bei Livius (22, 19-22) nach Cannae platziert sind, geht es im Folgenden um die Römer, die mit sich selbst beschäftigt sind: Mit dem Streit unter den Heerführern, der unglücklichen Wahl des Konsuls Aemilius Paulus, den ängstlichen jungen nobiles, der moralischen Stärke und harten Disziplin des Africanus, der Bewaffnung der Sklaven, der Weigerung der römischen Führung, Lösegeld für die gefangenen römischen Soldaten zu zahlen. Dennoch steht, wie schon gesagt, am Ende des Kapitels 22, wie schon beim 21. Kapitel, die gute Nachricht, ein Muster, das sich auch auf der Mikroebene der Sätze immer wieder findet.

So wird die Verwüstung Kampaniens durch die Klugheit eines Fabius Maximus in ein und demselben Satz kompensiert (Per. 22, 8), wie auch die römische Niederlage Cannae (Per. 22,10) trotz der hohen Verlustzahlen mit positiven Signalen ausgeglichen

60 Per. 22, 9: Idemque [Hannibal] Q. Fabi Maximi dictatoris, cum circumposita ureret, agro pepercit, ut illum tamquam proditorem suspectum faceret.

61 Per. 22, 10: Aemilio deinde Paulo et Terentio Varrone coss. et ducibus cum magna clade aduersus Hannibalem ad Cannas pugnatum est, caesaque eo proelio Romanorum XLV (milia) cum Paulo cos. et senatoribus XC et consularibus aut praetoriis aut aediliciis XXX.

62 Per. 22, 11: Post quae cum a nobilibus adulescentibus propter desperationem consilium de relinquenda Italia iniretur, P. Cornelius Scipio tribunus militum, qui Africanus postea vocatus est, stricto supra capita deliberantium ferro iurauit pro hoste se habiturum eum, qui in uerba sua non iurasset, effecitque ut omnes non relictum iri a se Italiam iureiurando adstringerentur. 
wird. Direkt im Anschluss (Per. 22, 11) ist es der Hinweis auf P. Cornelius Scipio, der mit Tatkraft, Klarheit und römischer Disziplin, seine Vorgesetzten wie Untergebenen auf den Staat einschwört und dann weiter unten (Per. 22,16) Terentius Varro, der als Konsul und trotz der Niederlage bei Cannae nach vorne schaut. Er ist damit derjenige, der in der sozialen wie politischen Hierarchie ganz vorne steht, die Verantwortung trägt, der neben dem jugendlichen Scipio den Hoffnungsschimmer auf der Ebene des Staates bedeutet.

Auch am Ende des Kapitels wird noch einmal ein negatives Vorzeichen mit einem Hoffnungsschimmer verknüpft. Dies wird eingeläutet durch die radikale Verkürzung eines gravierenden Sakrilegs, das durch diese knappe Darstellung lediglich als negativer Zwischenfall in Rom erscheint: ${ }^{63}$ Es ist der Inzest von zwei vestalischen Jungfrauen, von den Priesterinnen also, die doch eigentlich die Sicherheit des heiligen Herdes und damit der Heimat und auf diese Weise den Schutz der Götter garantieren sollten. Mit ihren Handlungen setzen sie dies aufs Spiel, gefährden leichtfertig das Wohl des ganzen Staates. Und dennoch - der gute Konsul Varro, der durch sein Verhalten und seine Einstellung deutlich macht, dass er dem römischen Volk mit Rat und Tat in jeder Situation zur Seite steht, zeigt den Weg aus der Krise, wird die Gefahr, die von den unverantwortlichen Vestalinnen, von einem unverantwortlichen Marcus Minucius ausgeht, mit seiner Stärke und seinem Vertrauen in die Kraft des römischen Volkes ausgleichen, ja bannen (Per. 22, 16): Varroni obuiam itum et gratiae actae, quod de re $p$. non desperasset.

Diese letzten Worte des Kapitels quod de re publica non desperasset sind ein wahrhaft starker Schlusssatz, der erstens ein Individuum als Akteur hervorhebt und zweitens zwar auf die noch unsichere Situation, aber auch auf die moralische Stärke des römischen Volkes hinweist, das dem Konsul dankt und sich bewusst ist, wie wichtig diese mental-moralische Stärke für den Kriegsausgang sein wird, um sich von der perfidia eines Hannibal nicht demoralisieren zu lassen.

\section{Spannung mit Fortsetzung}

Man kann zwar mit Bingham sagen: „Es ist doch alles in Livius“, aber das wird dem Werk nicht gerecht, auch wenn es sehr kurz und in der Grundstruktur simplifizierend ist. Einfache, simple Botschaften werden vermittelt, klare Helden und Antihelden werden geschaffen. Doch vom Aufbau bis zur Abfolge der Ereignisse im Detail und zur Auswahl von Anekdoten, die das magere Gerüst zusammenhalten, ist das eben alles nicht Livius.

Der Spannungsbogen, den die Periochae 21-22 konstruieren, ist der folgende:

In Per. 21 beginnt der Krieg. Hannibal ist stark, sehr stark und eigentlich können ihn nur Wind und Wetter, nicht aber die Menschen aufhalten, doch es gibt Hoffnung,

63 Per. 22, 15: Opimia et Florentia, uirgines Vestales, incesti damnatae sunt. 
denn es gibt den noch sehr jungen Scipio. So ist schon klar, dass der Krieg länger dauern wird, denn Scipio muss ja erst die richtige Reife, das richtige Alter haben.

Es folgt Per. 22: Zur Hinterlist von Hannibal, die wie ein Gift wirkt und die Römer entzweit, kommen zwei Erzählstränge hinzu: Die interne Schwäche der Führung der Römer und ihre Zerstrittenheit (die aber eigentlich erst durch Hannibals Verschlagenheit und Bosheit wirklich zum Problem wird) einerseits und andererseits die zusätzliche Schwächung der Römer durch äußere Umstände, die jeden Mann und jede Frau betreffen oder betreffen können. Die guten Beispiele eines Africanus oder Varro zeigen aber, dass trotz dieser Entwicklung begründete Hoffnung auf einen guten Ausgang besteht und auch bestehen sollte. All das wird nicht trotz, sondern gerade durch die Kürze klar transportiert.

Mit mehr Platz und Geduld der Leser könnte diese an zwei Kapiteln der Periochae exemplarische Darstellungsweise auch für die Periochae 23-30 und damit für den ganzen Punischen Krieg weitergeführt werden, der einerseits den Spannungsbogen hält, andererseits aber die Geschichte als eine Aneinanderreihung individueller Einzelentscheidungen und Handlungen beschreibt.

Die wesentlich differenziertere und komplexere Erzählung des Livius kann zwangsläufig kaum zu einer solch klaren Botschaft kommen, würde doch bei diesen Massen von Papyrusrollen mit Kriegsdarstellung das Interesse langsam erlahmen. Gerade die moralischen Aussagen gehen in den ineinander verzahnten und immer wieder die Schauplätze ändernden Geschichten bei Livius eher verloren. ${ }^{64}$ Durch den Haupterzählstrang mit wenigen Ereignissen, die insgesamt dichte und kohärente Geschichte eines Krieges, und durch das Hervorheben weniger Charaktere können die Periochae dagegen solche starken Botschaften leicht transportieren. Ganz simpel und simplifizierend sind sie dabei aber nicht, da Verbindungen und Verweise auf frühere und vor allem spätere Ereignisse eingeflochten oder zumindest angedeutet werden. Der Text hat damit die Qualität eines guten Fortsetzungsromans, nicht nur weil es am Ende vieler Kapitel nach Katastrophen auch einen kleinen Hoffnungsschimmer gibt, sondern auch weil es ähnlich wie in solchen Romanen ständig neues Personal gibt, das eingeführt wird und das für eine kurze Zeit eine Nebenerzählung zur Haupterzählung werden lässt, vor allem aber auch durch diese Permanenz der Digression - wenn es denn so etwas geben kann - die Qualität und Kurzweiligkeit der Lektüre garantieren soll.

Die entzeitlichte Geschichte des römischen Volkes ist im Ergebnis wesentlich dichter in der Periochae als in den elaborierten Exempla-Sammlungen eines Valerius Maximus des frühen 1. Jhs. n.Chr. und der von ihm abhängigen späteren Exzerptliteratur. Sie ist eine Geschichte von Individuen, die mit dem Gemeinwesen oder dem römischen Ganzen eins sind. Versagt einer, versagen alle und alles geht unter; siegt einer, bleibt redlich und stark, so wird dies auch für alle Folgen haben. Der Aspekt der

$64 \mathrm{Zu}$ den durchaus vorhandenen Techniken der Erzeugung von Spannung in Livius Ab urbe condita, siehe Pausch, Livius (Anm. 37), 191-250. 
negativen exempla und Handlungen wie auch der impliziten Kritik ${ }^{65}$ ist sicher ebenfalls ein hierfür wichtiges Feld, das bisher im Verhältnis zu den positiven Beispielen vernachlässigt wurde, das aber gerade vor dem möglichen Hintergrund spätantiker Kontingenzerfahrung von besonderer Bedeutung sein dürfte - aber dieses spannende Thema könnte die Basis für einen nächsten Aufsatz sein (um im Stil der Periochae am Ende den Spannungsbogen zu halten).

65 Siehe oben zum Beispiel die negativen ,first-time notices‘ ab den Gracchen (S. 38 mit Anm. 40 - 43) oder auch die Bemerkungen zum integrativen Potential der römischen Armee (Anm. 44). 


\title{
Von Plinius zu Isidor und Beda Venerabilis
}

\section{Zur Übernahme antiken Wissens über Witterungsphänomene im Mittelalter}

\begin{abstract}
This paper contributes to the study of the literary reception of Pliny's monumental Naturalis historia by analysing in how far later authors, like Isidore of Seville or the Venerable Bede, incorporated meteorological phenomena described in book II of the Naturalis historia into their own works. The paper concludes with an outlook on the encyclopaedists of the $12^{\text {th }}$ and $13^{\text {th }}$ century.
\end{abstract}

\section{Einleitung}

Die Naturalis historia des C. Plinius Caecilius Secundus maior (23/24-79 n.Chr.) ist eines der wenigen monumentalen Werke aus der römischen Antike, das durch die Jahrhunderte vollständig in insgesamt 37 Büchern überliefert ist. Diese umfangreichste erhaltene Enzyklopädie antiken Wissens lässt somit einen detaillierten Einblick in das Wissen der Römerzeit zu, der alle Bereiche der damaligen Wissenschaft umfasst: von der Kosmologie und Astronomie über die Meteorologie und Geologie zur Geographie und Ethnologie der Erde, von der Anthropologie und Physiologie über die Zoologie und Botanik bis hin zur Landwirtschaft, Pharmakologie, Metallurgie und Mineralogie. Mehr als 200 mittelalterliche Handschriften zeugen bis heute davon, dass das von Plinius zusammengetragene Wissen auch nach der Spätantike vielerorts zugänglich war. ${ }^{1}$

Die Nachwirkung des Werkes war enorm: Schon Zeitgenossen wie der Satiriker Martial zitierten daraus und auch christliche Autoren hatten keinerlei Scheu, sich immer wieder auf Plinius zu beziehen, von Minucius Felix über Augustinus bis hin zur Martianus Capella. ${ }^{2}$ Aufgrund des enormen Umfangs wurden aber schon in der Spätantike Exzerpte und Kompilationen verfasst, die sich Teilaspekten widmeten. Besonders wichtig wurden dabei die Collectanea rerum memorabilium des C. Iulius Solinus aus dem 3./4. Jahrhundert, eine Sammlung von aussergewöhnlichen Merk-

\footnotetext{
1 Vgl. Leighton D. Reynolds, The Elder Pliny, in: Texts and Transmission. A survey of Latin Classics, hrsg. von Leighton D. Reynolds, Oxford 1983, 307-316; Francesca Romana Berno, Plinius d. Ä. (Gaius Plinius Caecilius Secundus maior). Naturalis Historia, in: Die Rezeption der antiken Literatur. Kulturhistorisches Werklexikon (Der Neue Pauly), Supplemente 7, hrsg. von Christine Walde, Stuttgart Weimar 2010, 697-726, hier 699.
}

2 Vgl. dazu im Detail Berno, Plinius d. Ä. (Anm. 1), 700-702. 
würdigkeiten, insbesondere aus den Büchern über die Geographie ${ }^{3}$, Anthropologie ${ }^{4}$, Zoologie $^{5}$, Botanik ${ }^{6}$ und Mineralogie ${ }^{7}$. Daneben fasste die anonym überlieferte Kompilation der Medicina Plinii aus dem 4. Jahrhundert ${ }^{8}$ vornehmlich die medizinischen und pharmakologischen Bücher ${ }^{9}$ zusammen. Besonders Solinus war auch im Mittelalter weit verbreitet, sodass heute nicht immer klar erkennbar ist, ob die Rezeption über das Gesamtwerk des Plinius oder über die Collectanea erfolgte. ${ }^{10}$

Es liegt daher nahe, anhand der Rezeption der Naturalis historia des älteren Plinius danach zu fragen, wie das bei ihm überlieferte Wissen im Laufe der Spätantike und im Mittelalter variiert und verdichtet wurde, in welcher Form es behalten und umgestaltet wurde, wie es durch andere Wissensstränge ergänzt wurde und wie explizit oder rein sprachlich auf Plinius als unumstössliche Autorität Bezug genommen wurde.

Die Forschung zur Plinius-Rezeption konzentrierte sich erstens darauf, die wichtigsten Entwicklungslinien aufzuzeigen, blieb dabei aber oft auf einer allgemeinen Ebene. Hervorzuheben sind die ausführlichen Darstellungen von Marjorie Chibnall, Arno Borst sowie zuletzt Aude Doody und Francesca Romana Berno, die jeweils auch den Forschungsstand ausführlich wiedergeben. ${ }^{11}$ Auch Handbücher zur Wissensgeschichte des Mittelalters gehen in der Regel wenig in die Tiefe, was das genaue Ausmass und die Form der Rezeption betrifft. ${ }^{12}$ Zweitens existieren zahlreiche Studien zu Einzelaspekten, in denen vor allem gefragt wurde, woher das Wissen eines mittelalterlichen Autors zu einem bestimmten Thema stammte; häufig führte dabei der Weg zurück zum älteren Plinius, was dann entsprechend auch mit Textvergleichen zu belegen versucht wurde. ${ }^{13}$ Drittens wurde auch die Überlieferungsgeschichte im Sinne der Verbreitung der Handschriften sowohl zur Naturalis historia selbst als auch zu den

3 C. Plinius Secundus Maior, Naturalis historia, 6 Bände, hrsg. von Karl Mayhoff, Leipzig 1906 (ND Stuttgart 1967), 3-6.

4 Plinius, Naturalis historia (Anm. 3), 7.

5 Plinius, Naturalis historia (Anm. 3), 8-11.

6 Plinius, Naturalis historia (Anm. 3), $12-13$.

7 Plinius, Naturalis historia (Anm. 3), 37.

8 Vgl. dazu besonders Aude Doody, Pliny’s Encyclopedia. The Reception of the Natural History, Cambridge 2010, 135 - 152.

9 Plinius, Naturalis historia (Anm. 3), 20-32.

10 Berno, Plinius d. Ä. (Anm. 1), 700-701.

11 Marjorie Chibnall, Pliny's Natural History and the Middle Ages, in: Empire and Aftermath. Silver Latin II (Greek and Latin Studies. Classical literature and its Influence), hrsg. von Thomas A. Dorey, London / Boston 1975, 57 - 78; Arno Borst, Das Buch der Naturgeschichte. Plinius und seine Leser im Zeitalter des Pergaments, Heidelberg 1994 (Abhandlungen der Heidelberger Akademie der Wissenschaften, Philosophisch-historische Klasse 1994, 2); Doody, Pliny's Encyclopedia (Anm. 8); Berno, Plinius d. Ä. (Anm. 1).

12 So etwa bei Otto Mazal, Geschichte der abendländischen Wissenschaft des Mittelalters, 2 Bände, Graz 2006, Bd. 1, 50 und Bd. 2, 208 und 223.

13 Vgl. dazu die ausführliche Bibliographie bei Berno, Plinius d. Ä. (Anm. 1), $722-726$ mit zahlreichen Beispielen bis hin zum Wissen über den Gesang des Kuckucks oder über Smaragde. 
Kompilationen genau aufgearbeitet. ${ }^{14}$ Der Aspekt der Verdichtung und Variierung plinianischen Wissens wurde jedoch nur ansatzweise behandelt, ja im neuesten, umfangreichen Sammelband „Condensing Texts - Condensed Texts“ zur Verdichtung antiker Texte wird auf Plinius gerade zweimal kurz und nichtssagend Bezug genommen. ${ }^{15}$

Im Folgenden soll daher der Versuch unternommen werden, insbesondere auf die Aspekte der Wissensverdichtung und Wissensvariierung einzugehen, indem anhand des Wissens über Witterungsphänomene überprüft wird, wie mit den Erkenntnissen aus Plinius umgegangen wird. Dieser Themenkomplex wird in Buch 2 der Naturalis historia ausführlich erwähnt, also einem Buch, das von Solinus nur am Rande exzerpiert wurde, sodass davon auszugehen ist, dass das jeweilige Wissen jeweils direkt aus Plinius oder von den auf Plinius aufbauenden mittelalterlichen Vorbildern stammt. Am Beginn der Kapitel wird zunächst kurz summarisch angegeben, welche Witterungsphänomene insgesamt in den einzelnen Werken Beachtung finden und wie konkret die Themen Hagel und Donner abgehandelt werden. Der Bogen spannt sich dabei über die Enzyklopädie Etymologiae (Origines) des Isidor von Sevilla sowie dessen Schrift De natura rerum bis zum gleichnamigen De natura rerum des Beda Venerabilis. Ein kursorischer Ausblick wird schliesslich bis zu den Enzyklopädisten des 12. und 13. Jahrhunderts sowie zum Buch der Natur Konrads von Megenberg, der ersten umfangreichen Naturkunde in deutscher Sprache, gerichtet.

\section{Witterungsphänomene in der Naturalis historia des älteren Plinius}

Plinius widmet der Kosmologie sowie der Erklärung von Witterungsphänomenen das gesamte zweite Buch, wobei er sich in einem ersten ausführlichen Teil mit dem Wesen der Welt und ihrer Gestalt, der Natur und Bewegung der Planeten, mit Sonnen- und Mondfinsternissen, Kometen und anderen Himmelserscheinungen bis hin zu musikalischen und geometrischen Betrachtungen über die Welt auseinandersetzt. ${ }^{16} \mathrm{Nach}$ einem Abschnitt über die Witterung, ${ }^{17}$ auf den unten detaillierter eingegangen wird, folgt eine allgemeine Abhandlung zur Beschaffenheit der Erde, ${ }^{18}$ etwa über den

14 Vgl. etwa Reynolds, The Elder Pliny (Anm. 1); Birger Munk Olsen, C. Plinius Secundus, in: L'étude des auteurs classiques latins aux XI en XII siècles, 3 Bände, hrsg. von Birger Munk Olsen, Paris 1982, 1985, 1989, hier Band 2, 243 - 273. Zur handschriftlichen Verbreitung der Collectanea des Solinus vgl. Mary E. Milham, A Handlist of the Manuscripts of C. Julius Solinus, in: Scriptorium 37 (1983), 126129.

15 Marietta Horster, Christiane Reitz (Hrsg.), Condensing Texts - Condensed Texts, Stuttgart 2010 (Palingenesia 98), 489 und 520.

16 Plinius, Naturalis historia (Anm. 3), 2,1-101.

17 Plinius, Naturalis historia (Anm. 3), 2,102-153.

18 Plinius, Naturalis historia (Anm. 3), 2,154-179. 
Wasserkreislauf, über die bewohnten und unbewohnten Gebiete, die Klimazonen ${ }^{19}$ oder die Länge von Tag und Nacht zu den verschiedenen Jahreszeiten und in den einzelnen Weltregionen. Das Buch endet mit Ausführungen zu Erdbeben, zur Entstehung neuer Inseln, zu den Gezeiten und einer Auflistung seltsamer Naturerscheinungen. ${ }^{20}$

Da die Kapitel zu den Witterungserscheinungen den Ausgangspunkt für die meisten mittelalterlichen Abhandlungen des Themas bildeten, soll im Folgenden eine genaue Übersicht geboten werden, bevor konkret auf die Fallbeispiele Hagel und Donner eingegangen wird.

2,102-104 De aëre

2,105-110 De statis tempestatibus

2,107 De caniculae ortu

2,108-110 Vis temporum anni stata

2,111

2,112-113

2,114-130

2,131-132

2,133-134

2,135-146

2, 135-136

2,137

2,138-145

2,140-141

2,142-145

2,146

2,147

2,148

2,149-150
De incertis tempestatibus. De imbribus et quare lapidibus pluat

\section{De tonitribus et fulgetris}

Qua ratione echo reddatur. Vento rum genera, naturae, observationes

\section{Ecnephias, typhon}

Turbines, presteres, vertices, alia prodigiosa genera tempestatum De fulminibus

Quibus in terris non cadant et quare

Genera fulgurum et miracula Etrusca observatio in iis et Romana

De fulminibus evocandis

Catholica fulgurum

Quae numquam feriantur

Lacte pluisse, sanguine, carne, ferro, lana, lateribus coctis $<$ Armorum crepitum, et tubae sonitum de caelo auditum>

De lapidibus caelo cadentibus. Anaxagorea de his
Von der Luft

Von den bestimmten Ursachen der Witterung

Vom Aufgang des Hundssterns

Vom Einfluss der Jahreszeiten

Von den zu unbestimmten Zeiten auftretenden Gewittern. Vom Regen und warum es Steine regnet

Vom Donner und Blitz

Wie das Echo entsteht. Die Winde, ihre Arten, ihre Natur, Bemerkungen über sie

Eknephias (der Orkan), Typhon

Wirbelwinde, feurige Wirbelwinde, Wirbelstürme und andere merkwürdige Arten von Stürmen Von den Blitzen

In welchen Ländern man keine bemerkt und weshalb

Arten der Blitze und wunderbare Erscheinungen

Etruskische und römische Beobachtungen über

Blitze

Vom Herbeirufen der Blitze

Allgemeines über Blitze

Welche Gegenstände nie vom Blitz getroffen werden

Regen aus Milch, Blut, Fleisch, Eisen, Wolle und Ziegelsteinen

$<$ Waffengeklirr und Trompetengeschmetter vom Himmel gehört>

Steine, die vom Himmel fallen. Was Anaxagoras darüber sagt 


$\begin{array}{ll}2,151 & \text { Arcus caelestis } \\ 2,152 & \text { Natura grandinis, nivis, pruinae, } \\ & \text { nebulae, roris. Nubium imagines } \\ 2,153 & \text { Proprietates caeli in locis }\end{array}$

2,151

2,153
Der Regenbogen

Beschaffenheit des Hagels, des Schnees, des

Reifs, des Nebels, des Taus. Wolkenbilder

Eigentümlichkeiten des Himmels an verschiedenen Orten

Widmen wir uns nun konkret und exemplarisch den Ausführungen zum Donner sowie zum Hagel. Es geht dabei nicht so sehr um eine inhaltliche Beurteilung aus heutiger, fachwissenschaftlicher Sicht, ${ }^{21}$ sondern um die Frage, wie die Nachrichten bei Plinius in der Folge verdichtet oder variiert wurden. Über die Entstehung von Donner (und Blitz) vermerkt Plinius:

Igitur non eam infitias posse in has et ignes sup- Nicht will ich also in Abrede stellen, dass auf diese erne stellarum decidere, quales sereno saepe Wolken von oben auch das Feuer der Sterne herabcernimus; quorum ictu concuti aëra verum est, fallen kann, wie wir es oft bei heiterem Himmel sequando et tela vibrata stridunt; cum vero in nubem hen; dass durch dessen Aufschlag die Luft erschütperveniunt, vaporem dissonum gigni, ut candente tert wird, trifft zu, da ja auch abgeschossene Pfeile ferro in aquam demerso, et fumidum verticem schwirren; wenn aber das Feuer in eine Wolke gevolvi. hinc nasci procellas et, si in nube luctetur langt ist, entsteht offenbar unter Zischen Dampf, wie flatus aut vapor, tonitrua edi; si erumpat ardens, wenn man glühendes Eisen in Wasser taucht, und es fulmina; si longiore tractu nitatur, fulgetras. his bildet sich wirbelnder Qualm. Auf diese Weise entfindi nubem, illis perrumpi, et esse tonitrua in- steht Gewittersturm. Staut sich in einer Wolke Wind pactorum ignium plagas, ideoque protinus co- oder Dunst, so gibt es den Donner; bricht der glüruscare igneas nubium rimas.

hende Dunst hervor, so entstehen die Blitze; wenn er eine längere Strecke dahinfährt, das Wetterleuchten. Durch dieses werden die Wolken gespalten, durch jene zerrissen. Die Donnerschläge sind Schläge von herabprallendem Feuer, und deshalb zeigen auch sogleich die aufgerissenen Wolken einen feurigen Schein.

posse et repulsu siderum depressum qui a terra Auch die von der Erde emporgestiegene Luft kann, meaverit spiritum nube cohibitum tonare, natura durch den Gegendruck der Gestirne zurückgedrängt, strangulante sonitum, dum rixetur, edito fragore in einer Wolke eingeschlossen, zum Donner führen. cum erumpat, ut in membrana spiritu intenta. Solange die Luft im Kampfe liegt, erstickt die Natur posse et attritu, dum praeceps feratur, illum, jeden Laut, bricht sie aber hervor, so entsteht ein quisquis est, spiritum accendi. posse et conflictu Knall wie beim Zerplatzen einer mit Atem gefüllten nubium elidi, ut duorum lapidum, scintillantibus Blase. Auch durch Reibung kann sich die Luft, wie fulgetris. sed haec omnia esse fortuita; hinc bruta immer sie beschaffen sein mag, während des fulmina et vana, ut quae nullam habeant rationem schnellen Herabstürzens entzünden. Ebenso kann

21 Vgl. zu dieser Frage ausführlich Gabriele Loose, Das 2. Buch der Naturalis Historia von Plinius dem Älteren. Eine kritische Analyse im Lichte moderner geowissenschaftlicher Erkenntnisse (InauguralDissertation Universität Köln), Köln 1995, 91 - 100 (zu Blitz und Donner) sowie 119-120 (zu Hagel, Schnee, Regen und Reif).

22 Plinius, Naturalis historia (Anm. 3), 2,112-113.

23 Übersetzung nach C. Plinius Secundus d. Ä., Naturkunde. Lateinisch - deutsch, Buch II: Kosmologie, hrsg. und übersetzt von Roderich König, München 1974, 95 - 97. Die Orthographie wurde bei allen hier zitierten Übersetzungen an die neue Rechtschreibung (Schweiz) angepasst. 
naturae; his percuti montes, his maria, omnesque sie beim Zusammenprall von Wolken herausgestosalios inritos iactus. Ilia vero fatidica ex alto sta- sen werden, ähnlich wie bei zwei Steinen mit zutisque de causis et ex suis venire sideribus. ${ }^{22}$ ckenden Blitzen. Dies alles jedoch, heisst es, ist zufällig; hieraus entstehen die stumpfen und nichtssagenden Blitze, die aus keinem Naturgesetz hervorgehen; die einen treffen Berge, die anderen Meere und alle anderen fahren wirkungslos herab. Jene Schicksal verkündenden Blitze jedoch kämen aus höheren Bereichen, aus bestimmten Ursachen und aus ihren eigenen Gestirnen. ${ }^{23}$

Inhaltlich fällt auf, dass die Entstehung des Donners in den Wolken angesiedelt und zunächst nicht mit dem Einschlag des Blitzes in Verbindung gesetzt wird. Dies erfolgt dann erst einige Kapitel später, wenn Plinius nochmals ausführlich auf die Blitze und damit - weniger prominent - auch auf den Donner zu sprechen kommt; die Gleichzeitigkeit von Blitz und Donner wird aber auch hier nicht auf den Einschlag des Blitzes, sondern auf die Entstehung beider Phänomene in den Wolken bezogen:

Fulgetrum prius cerni quam tonitrua audiri, cum Gewiss ist, dass man den Blitz früher sieht als man simul fiant, certum est, - nec mirum, quoniam den Donner hört, obgleich beide gleichzeitig entlux sonitu velocior; ictum autem et sonitum stehen - und dies ist nicht verwunderlich, da das congruere ita modulante natura, sed sonitum Licht sich schneller fortpflanzt als der Schall; geprofecti esse fulminis, non inlati, etiamnum wiss ist aber auch, dass Schlag und Schall zusamspiritum ociorem fulmine, ideo quati prius omne menfallen, nachdem die Natur es so einrichtet, dass et adflari quam percuti, nec quemquam tangi qui dann aber der Schall die Wirkung des ausfahrenden prior viderit fulmen aut tonitrum audierit. ${ }^{24} \quad$ Blitzes ist, nicht des einschlagenden und dass auch dann die Luftbewegung schneller ist als der Blitz; daher werde alles eher erschüttert und vom Wehen erreicht als vom Strahl getroffen; und es werde niemand erschlagen, der den Blitz bereits gesehen oder den Donner gehört hat. ${ }^{25}$

Etwas zutreffender nach heutigen wissenschaftlichen Kriterien wird die Herkunft des Hagels und anderer alltäglicher Witterungserscheinungen abgehandelt:

Cetera eiusdem naturae non multis dubia esse Die übrigen Naturereignisse dieser Art sind, wie ich video: grandinem conglaciato imbre gigni et ni- sehe, nur weniger zweifelhaft: dass Hagel aus gevem eodem umore mollius coacto, pruinam autem frorenem Regen, der Schnee aus der gleichen, nur ex rore gelido; per hiemem nives cadere, non weniger fest gewordenen Feuchtigkeit entsteht, der grandines, ipsasque grandines interdiu saepius Reif aber aus gefrorenem Tau; dass im Winter

24 Plinius, Naturalis historia (Anm. 3), 2,141.

25 Übersetzung nach C. Plinius Secundus d. Ä., Naturkunde, hrsg. und übersetzt von König (Anm. 23), 121.

26 Plinius, Naturalis historia (Anm. 3), 2,152.

27 Übersetzung nach C. Plinius Secundus d. Ä., Naturkunde, hrsg. und übers. von König (Anm. 23), $129-131$. 
quam noctu, et multo celerius resolvi quam nives; Schnee fällt, aber kein Hagel, der Hagel selbst nebulas nec aestate nec maximo frigore exsistere, häufiger bei Tage als in der Nacht und dass er viel rores neque gelu neque ardoribus neque ventis schneller schmilzt als der Schnee; dass Nebel wenec nisi serena nocte: gelando liquorem minui, der im Sommer noch bei sehr grosser Kälte noch bei resoluta glacie non eundem inveniri modum; va- windigem Wetter, sondern nur in heiteren Nächten, rietates colorum figurarumque in nubibus cerni, dass beim Gefrieren das Wasser weniger wird und prout admixtus ignis superet aut vincatur. ${ }^{26}$ dass, wenn das Eis aufgetaut ist, sich nicht die gleiche Menge findet; dass man in den Wolken verschiedene Farben und Gestalten wahrnimmt, je nachdem das beigemischte Feuer vorherrscht oder zurücktritt. ${ }^{27}$

Die Berichte über Donner, Blitz, Hagel oder Schnee waren viel zu wenig aussergewöhnlich, um das Interesse des C. Iulius Solinus zu erwecken. Dementsprechend vernachlässigbar sind daher auch die zwei Bezugnahmen auf die meteorologischen Kapitel von Buch 2 der Naturalis historia in den Collectanea rerum memorabilium. ${ }^{28}$ Somit wird aber auch deutlich, dass die Übernahme des meteorologischen Wissens eben nicht über Solinus, sondern direkt über Plinius ins Mittelalter gelangt sein muss.

\section{Die Rezeption der Naturalis historia bei Isidor von Sevilla}

Noch weiter verbreitet als die Naturalis historia des Plinius war im Mittelalter das enzyklopädische Kompendium des gelehrten Bischofs Isidor von Sevilla (560 - 636), die Originum seu etymologiarum libri $X X$, an denen Isidor offenbar bis zu seinem Lebensende arbeitete, sodass das Werk erst von seinem Schüler Braulio geordnet und veröffentlicht wurde. Im Zentrum steht allerdings weniger der Versuch, das gesamte Wissen der Zeit enzyklopädisch festzuhalten, sondern das Werk war vornehmlich auf die höhere Schulbildung, das Trivium und Quadrivium, ausgerichtet. Die ersten Bücher sind daher der Grammatik, Rhetorik und Dialektik gewidmet, ${ }^{29}$ ein weiteres der Mathematik. ${ }^{30}$ In unserem Zusammenhang ist vor allem Buch 13 der Etymologiae von Bedeutung, in dem Isidor auf Witterungsphänomene zu sprechen kommt. Wie in Buch 2 der Naturalis historia beginnt Isidor mit kosmologischen Kapiteln über die Welt, die

28 Die einzigen Bezugspunkte bilden C. Iulius Solinus, Collectanea Rerum Memorabilium, hrsg. von Theodor Mommsen, 2. Aufl., Berlin 1895 (ND Zürich / Hildesheim 1999), 5,8 (zu Plinius, Naturalis historia (Anm. 3), 2,153, dass in Syrakus an jedem Tag des Jahres zumindest zeitweise die Sonne scheine) sowie Solinus, Collectanea (Anm. 28), 32,37 (loser Anklang an Plinius, Naturalis historia (Anm. 3), 2,107 über die Auswirkungen des Hundssterns auf die Witterung).

29 Isidor von Sevilla, Etymologiarum sive originum libri XX, 2 Bände, hrsg. von Wallace M. Lindsay, Oxford 1911 (ND Oxford 1962) (ebenso zugänglich: Isidoro di Siviglia, Etimologie, Libro XIII: De mundo et partibus, hrsg. Giovanni Gasparotto, Paris 2004), $1-2$.

30 Isidor, Etymologiae (Anm. 29), 3. 
Atome, die Elemente und den Himmel mit seinen Teilen, ${ }^{31}$ um in der Folge auf die Luft und die Wolken, Donner und Blitz, auf Regen, den Regenbogen, Tau sowie die Winde einzugehen. ${ }^{32}$ Der Rest des Buches ist schliesslich dem Wasser und den unterschiedlichen Gewässern gewidmet. ${ }^{33}$ Über den Donner schreibt Isidor:

De tonitruo. Tonitruum dictum quod sonus eius Vom Donner. Der Donner soll so genannt worden terreat; nam tonus sonus. Qui ideo interdum tam sein, weil sein Klang erschreckt (terrere). Denn sonus graviter concutit omnia ita ut caelum discississe (Ton, Klang) ist tonus (Ton, Klang, Donner). Dieser videatur quia, cum procella vehementissimi venti erschüttert deswegen manchmal alles so schwer, nubibus se repente inmiserit, turbine invalescente dass der Himmel zu zerreissen scheint, weil ein exitumque quaerente, nubem, quam excavavit, Sturm eines sehr heftigen Windes sich plötzlich mit impetu magno perscindit, ac sic cum horrendo Wolken vermischt [und], nachdem ein Wirbel erfragore defertur ad aures. wachsen ist, der sich einen Ausweg sucht, die Wolke, welche er angetrieben hat, durch einen massiven Anstoss zertrennt und mit einem gewaltigen Krachen in die Lüfte hinabgetragen wird.

Quod mirari quis non debeat, cum vesicula Darüber muss man sich nicht wundern, wo doch quamvis parva magnum tamen sonitum displosa noch so kleine Bläschen dennoch einen lauten emittit. Cum tonitruo autem simul et fulgura ex- Knall von sich geben, wenn sie aufspringen. Mit primi: sed illud celerius videtur, quia clarum est; dem Donner wird aber gleichzeitig ein Blitz herhoc autem ad aures tardius pervenire. Lux autem ausgedrückt. Jener aber kommt schneller, weil er quae apparet ante tonitruum fulgetra vocatur. leuchtend ist. Dieser aber kommt langsamer zu den Quae, ut diximus, ideo ante videtur quia clarum Ohren. Das Licht aber, welches vor dem Donner est lumen; tonitruum autem ad aures tardius erscheint, wird fulgetra (Wetterleuchten) genannt. pervenit. $^{34}$

Dieses wird, wie wir gesagt haben, vorher gesehen, weil es ein leuchtendes Licht ist. Der Donner aber gelangt langsamer zu den Ohren..$^{35}$

Der Abschnitt beginnt, dem Charakter der Etymologiae gemäss, mit einer Herleitung des Begriffs, die wie viele andere aus heutiger etymologischer Sicht nicht haltbar ist. Nach einem Mittelteil, der inhaltlich von Plinius nicht allzu sehr abweicht, allerdings auch keine sprachlichen Parallelen aufweist, folgt am Schluss die bei Plinius ebenfalls abgehandelte Verbindung, dass man zuerst den Blitz sehen und dann erst den Donner hören könne.

Ein Vergleich der Passagen zum Donner und Blitz macht deutlich, dass Isidor die Naturalis historia zwar eindeutig kannte, sie aber in den seltensten Fällen wörtlich übernahm - im Gesamtwerk wird Plinius gerade sechsmal explizit zitiert ${ }^{36}$-, während

31 Isidor, Etymologiae (Anm. 29), 13,1-6.

32 Isidor, Etymologiae (Anm. 29), 13,7-11.

33 Isidor, Etymologiae (Anm. 29), 13,12-22.

34 Isidor, Etymologiae (Anm. 29), 13,8,1-2.

35 Übersetzung nach Isidor von Sevilla, Enzyklopädie, übersetzt von Lenelotte Müller, Wiesbaden 2008, 496.

36 Vgl. im Detail José Oroz Reta, Présence de Pline dans les Etymologies de saint Isidore de Seville, in: Pline l'Acien témoin de son temps. Conventus Pliniani internationalis, Namneti 22 - 26 Oct. 1985 habiti acta, hrsg. von Jackie Pigeaud und José Oroz Reta, Salamanca / Nantes 1987 (Bibliotheca Salmaticensis 
andere Autoritäten wie Vergil ständig wörtlich herangezogen werden. Da aber Buch 2 der Naturalis historia weder von Solinus noch anderen - erhaltenen - Kompilatoren der Spätantike exzerpiert wurde, ist davon auszugehen, dass sich Isidor direkt an Plinius hielt, aber die Inhalte sehr frei und mit eigenen Worten verarbeitete. Auch zeigt die Zusammenstellung der entsprechenden Textstellen, dass die Abhandlung der ausgewählten Themen bei Isidor deutlich kürzer geworden ist, obschon auch die Etymologiae insgesamt ein monumentales Werk sind.

Grando appellata quod forma eius granorum simi- Hagel (grando) wird genannt, was durch seine Form litudinem habeat. Haec autem ventorum rigore Ähnlichkeit mit Körnern hat. Dieser aber wird durch durantur in nube, ac solidantur in nivem, ruptoque die Kälte des Windes in der Wolke gehärtet und zu aere solvuntur. Nix a nube, unde venit; et glacies a Schnee gefestigt und durch das Reissen der Luft gelu et aqua, quasi gelaquies, id est gelata aqua. aufgelöst. Schnee (nix) ist nach nubes (Wolke) beGelus autem quod eo stringatur tellus; yñ quippe nannt, woher er auch kommt, und glacies (Eis) nach terra dicitur.Tunc autem maiori gelu stringitur terra, Frost (gelu) und Wasser (aqua) wie gelaquies ${ }^{37}$ cum fuerit nox serena. Pruina est matutini temporis (kaltes Wasser), das ist gefrorenes Wasser. Gelu frigus, quae inde pruina nomen accepit quia sicut (Frost) aber [heisst so], weil durch dieses die Erde

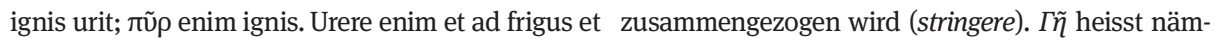
ad solem pertinet; nam uno sermone duo diversa lich Erde. Die Erde wird aber dann von heftigerem significantur, pro eo quod unum effectum habent. Frost zusammengezogen, wenn die Nacht klar war. Similis enim vis est et caloris et frigoris, unde et Reif (pruina) ist die frühmorgendliche Kälte, welche utraque saxa rumpunt. [...]

daher ihren Namen erhalten hat, dass sie wie das Feuer brennt. Пũ $\rho$ heisst nämlich Feuer. Urere (brennen) bezieht sich sowohl auf die Kälte als auch auf die Sonne. Denn mit einem Begriff werden zwei unterschiedliche Dinge bezeichnet, weil sie eine einzige Wirkung haben. Ähnlich ist nämlich die Kraft der Wärme und der Kälte, woher auch jedes von beiden Felsen zerspringen lässt. [...]

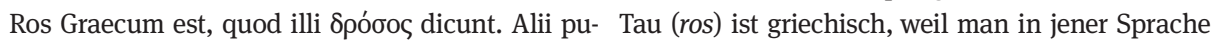
tant ros dictum quia rarus est, et non spissus ut $\delta \rho o ́ \sigma o \varsigma$ (Tautropfen, Tau, Feuchtigkeit, Wasser) sagt. pluvia. Nebula inde dicta, unde et nubila, ab ob- Andere glauben, ros sei so benannt, weil er rarus nubendo scilicet, hoc est operiendo, terram, sive (selten, dünn) ist und nicht dicht wie Reif. Nebel quod nubes volans faciat. Exhalant enim valles (nebula) ist wie auch nubilia (trübes Wetter) natürhumidae nebulas et fiunt nubes; inde nubilum, inde lich von obnubere (verhüllen) benannt, d.h. von nives. Nebulae autem ima petunt cum serenitas est; operire (bedecken), [nämlich] die Erde, oder weil er summa, cum nubilum. ${ }^{38}$

die Wolken (nubes) zum Fliegen (volare) bringt. Es atmen nämlich die feuchten Täler Nebel aus, und es entstehen Wolken. Daher nubilium (trübes Wetter), daher nives (Schnee). Nebel aber streben nach den

Estudios 87), 611-622, der aber auch ausführlich belegt, dass neben den sechs expliziten Zitaten mehr als 270 sprachlich eindeutige Anlehnungen an Plinius in den Etymologiae zu finden sind, etwa zu mineralogischen und metallurgischen Fragen (Plinius, Naturalis historia (Anm. 3), 36 - 37 bzw. Isidor, Etymologiae (Anm. 29), 16).

37 Eine Wortschöpfung Isidors. Vgl. Müller (Anm. 35), 497.

38 Isidor, Etymologiae (Anm. 29), 13,10,5-11.

39 Übersetzung nach Isidor von Sevilla, Enzyklopädie, übers. von Müller (Anm. 35), 497-498. 
untersten Stellen, wenn es klar ist, und nach den obersten, wenn das Wetter trüb ist. ${ }^{39}$

An der Passage zu Hagel, Schnee, Eis und Reif wird noch deutlicher, dass Isidors Intention eine ganz andere war als die des Plinius in der Naturalis historia. In den Etymologiae steht die Herleitung der Begriffe im Vordergrund, wenn auch zum Teil auf der Basis völlig unkorrekter Volksetymologien, ${ }^{40}$ und nicht die meteorologische Beschreibung des Phänomens. Gewiss, auch hier ist noch zu erkennen, dass bei der Auswahl der behandelten Themen Plinius Pate stand, aber das Ziel und das Ergebnis gehen in eine völlig andere Richtung.

Viel enger ist die strukturelle Anlehnung an Buch 2 der Naturalis historia hingegen in Isidors Werk De natura rerum, das er zwischen 612 und 621 verfasste und dem Westgotenkönig Sisebut widmete. Nach einem einleitenden Teil über die Zeit - Tag, Nacht, Wochen, Monate, Jahre, Tag- und Nachtgleiche, Winter- und Sommersonnenwende sowie die Jahreszeiten ${ }^{41}$ - kommt er auf die „plinianischen“ Themen der Kosmologie zu sprechen: Er erwähnt unter Berufung auf klassisch-antike Autoritäten die fünf Erd- bzw. Klimazonen, die Teile des Himmels sowie die Planeten, Sonne, Mond und Sterne. ${ }^{42}$ Aber auch ein meteorologischer Teil ist enthalten, ${ }^{43}$ der im Aufbau an Plinius angelehnt ist, aber seine Vorlage deutlich strafft:

$\begin{array}{ll}29 & \text { De tonitruo } \\ 30 & \text { De fulminibus } \\ 31 & \text { De arcu } \\ 32 & \text { De nubibus } \\ 33 & \text { De pluviis } \\ 34 & \text { De nive } \\ 35 & \text { De grandine } \\ 36 & \text { De natura ventorum } \\ 37 & \text { De nominibus ventorum } \\ 38 & \text { De signis tempestatum }\end{array}$

Vom Donner
Vom Blitz
Vom Regenbogen
Von den Wolken
Vom Regen
Vom Schnee
Vom Hagel
Vom Wesen der Winde
Von den Namen der Winde
Von den Vorzeichen für Unwetter

Schliesslich folgt ein Kapitel über Seuchen, weitere über die Meere und Flüsse und zuletzt über Erdbeben und Vulkanismus. ${ }^{44}$

Das Kapitel zum Donner macht aber offenkundig, dass sich Isidor inhaltlich von Plinius löst und unter deutlicher Bezugnahme auf das Exameron des Ambrosius ${ }^{45}$ eine „christliche“ Erörterung des Donners gegenüberstellt:

40 Vgl. zu den Etymologien in der zitierten Stelle Müller (Anm. 35), 497 Anm. 2 - 4 und 498 Anm. 1 - 2. 41 Isidor von Sevilla, De natura rerum liber, hrsg. von Gustav Becker, Berlin 1857 (ND Amsterdam 1967), $1-8$.

42 Isidor, De natura rerum liber (Anm. 41), 9-28.

43 Isidor, De natura rerum liber (Anm. 41), $29-38$.

44 Isidor, De natura rerum liber (Anm. 41), 39-48.

45 Ambrosius, Exameron, hrsg. von Carl Schenkl, Prag / Wien / Leipzig 1897 (CSEL 32,1), 2,4,16 zum Donner. 


\section{DE TONITRUO}

Tonitrua autem ex fragore nubium generantur. Concepti enim intra sinum nubium ventorum spiritus versantur ibidem, cumque vehementer sese erupturos eliserint et virtutis suae mobilitate in quamlibet partem eruperint, magno concrepant murmure et in morem exilientium de stabulis quadrigarum sonus fragoris eius ad aures nostras emittitur.

Alias autem tonitruum vocis divinae superna est increpatio sive clara praedicatio sanctorum, quae clamore forti per totum orbem terrarum in auribus fidelium perstrepit, per quod possit culpam suam admonitus agnoscere mundus. ${ }^{46}$

\section{DE GRANDINE}

Simili quoque ratione grandinum coagulatio fit. Aquae enim nubium rigore ventorum stringuntur in glaciem adque [!] durescunt, de hinc glacies ipsa partim fragore ventorum comminuta in fragmina partim solis vapore soluta frustatim ad terras delabitur. Quod autem rotunda videtur, hoc solis calor facit et mora refrenantis aeris, dum per longum spatium a nubibus usque ad terras decurrit.

Figuraliter namque grando perfidiae duritia es torpore malitiae frigida; nix autem homines increduli sunt frigidissimi et pigri et in infima torpore mentis depressi. ltem alio intellectu nives sunt homines dilectione frigentes, qui etiam etsi existant candidi puritate baptismatis, non fervent spiritu caritatis. ${ }^{47}$

\section{Vom Donner}

Der Donner rührt von einem Krachen in den Wolken her. Denn die im Wolkenbausch eingeschlossenen Windstösse wenden sich ebendort, und wenn sie danach drängen, aus der Wolke auszubrechen bzw. durch ihre Schnelligkeit und Kraft in einen beliebigen Teil der Wolke ausbrechen, ertönen sie mit lautem Grollen und, wie wenn ein Viergespann seine Garage verlässt, wird das Getöse zu unseren Ohren getragen.

In einem anderen Sinne aber ist der Donner auch mit dem himmlischen Erschallen der Stimme Gottes bzw. der herrlichen Verkündigung der Heiligen gleichbedeutend, die mit lautem Klang über den ganzen Erdenkreis zu den Ohren der Gläubigen dringt, wodurch die Welt ermahnt werden kann, ihre Schuld zu bekennen.

\section{Vom Hagel}

Auf ähnliche Weise aber [wie beim Schnee] kommt es auch zur Bildung des Hagels: Das Wasser in den Wolken wird nämlich durch die Kraft der Winde steif und gefriert zu Eis; danach wird das Eis selbst teils durch den tosenden Wind in Stücke zerkleinert, teils durch die Sonnenhitze aufgelöst und fällt körnchenweise zur Erde. Die runde Erscheinungsform kommt von der Sonnenwärme und vom Widerstand der sie abbremsenden Luft, weil der Hagel ja über eine weite Strecke von den Wolken bis zur Erde fällt.

Bildlich gesprochen freilich steht der Hagel für Härte der Treulosigkeit, die kalt durch die Trägheit der Schlechtigkeit ist; der Schnee aber entspricht den ungläubigen Menschen, die überaus kalt, untätig und von tiefster Trägheit im Geist bedrückt sind. Ebenso entspricht nach anderer Interpretation der Schnee den Menschen, die in der Liebe erkältet sind, die zudem, wenn sie auch weiss durch die Reinheit der Taufe bleiben, nicht vom Geist der Nächstenliebe brennen.

Es zeigt sich somit, dass die Rezeption des Plinius vor allem struktureller Natur ist, dass sich aber Isidor inhaltlich ganz offensichtlich scheut, sich direkt auf Plinius zu beziehen. Lieber zitiert er Autoritäten wie Lukrez und sprachlich erfolgt eine Anlehnung an Ambrosius. Der zweite Teil der Kapitel zum Donner und zum Hagel ist jeweils

46 Isidor, De natura rerum liber (Anm. 41), 29.

47 Isidor, De natura rerum liber (Anm. 41), 35. 
bildlich-exegetisch ausgerichtet und setzt sich somit deutlich von Plinius ab, ja das Werk macht den Eindruck einer „pastoralen Gegenwehr“48 gegenüber Plinius.

\section{Die Rezeption der Naturalis historia bei Beda Venerabilis}

Der angelsächsische Gelehrte Beda Venerabilis fand im nordenglischen Doppelkloster Wearmouth und Jarrow wohl eine der besten Bibliotheken seiner Zeit vor. Dennoch ist davon auszugehen, dass er nur einen Teil der Naturalis historia im Volltext zur Verfügung hatte, darunter aber sicher Buch 2, das er ausgiebig für seine eigene naturkundliche Schrift De natura rerum exzerpierte. ${ }^{49}$ Nach einem ersten kosmologischen Teil zu Himmel, Erde, Planeten, Kometen und verwandten Themen ${ }^{50}$ folgen Ausführungen zu den Witterungserscheinungen ${ }^{51}$; beschlossen wird das Buch von Kapiteln zu Seuchen, Gewässern, Erdbeben und Vulkanismus. ${ }^{52}$ Der Aufbau der meteorologischen Teile der Schrift lehnt sich inhaltlich lose sowohl an Plinius als auch an Isidors De natura rerum an:

$\begin{array}{ll}25 & \text { De aere } \\ 26 & \text { De ventis } \\ 27 & \text { Ordo ventorum } \\ 28 & \text { De tonitruo } \\ 29 & \text { De fulminibus } \\ 30 & \text { Ubi non sint et quare } \\ 31 & \text { De arcu } \\ 32 & \text { De nubibus } \\ 33 & \text { De imbribus } \\ 34 & \text { De grandine } \\ 35 & \text { De nive } \\ 36 & \text { Signa tempestatum vel serenitatis }\end{array}$

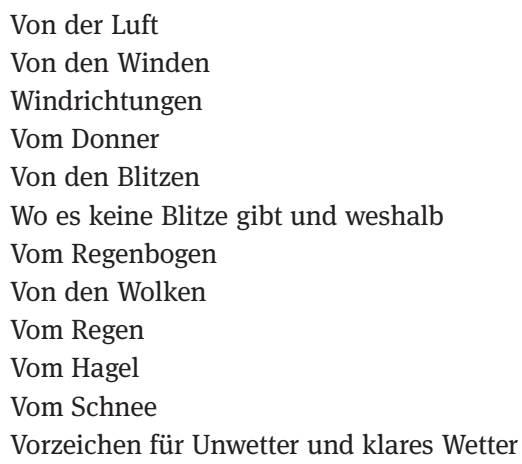

Schon an der Aufstellung der einzelnen Kapitel wird deutlich, dass sich Beda sowohl direkt auf Plinius als auch auf Isidor stützen konnte. Während die Kapitel 25 und 26 weitgehend an Isidor angelehnt sind, bauen insbesondere die Kapitel 29-32 und 34-

48 Borst, Das Buch der Naturgeschichte (Anm. 11), 90.

49 Berno, Plinius d. Ä. (Anm. 1), 703 sowie im Detail zu den Stellen, die Beda direkt aus Plinius zitierte, Karl Welzhofer, Beda's Citate aus der Naturalis historia des Plinius, in: Abhandlungen aus dem Gebiet der klassischen Altertums-Wissenschaft. Wilhelm von Christ zum 60. Geburtstag dargebracht von seinen Schülern, München 1891, 25 - 41.

50 Beda Venerabilis, De natura rerum, hrsg. von Charles W. Jones, Turnhout 1975 (CCSL 123 A), 189-234, ebenfalls zugänglich: hrsg. von Elisa Tinelli, Bari 2013 (Biblioteca della Tradizione Classica 6), $1-24$.

51 Beda Venerabilis, De natura rerum (Anm. 50), 25-36.

52 Beda Venerabilis, De natura rerum (Anm. 50), 37 - 51. 
36 ausschliesslich oder vornehmlich auf Plinius auf. Kapitel 28 über den Donner bedient sich kaum bei Plinius, aber dafür fast wörtlich bei Isidors De natura rerum: ${ }^{53}$

De tonitruo

Tonitrua dicunt ex fragore nubium generari, cum et spiritus ventorum earum sinu concepti, sese ibidem versando pererrantes et virtutis suae mobilitate in quamlibet partem violenter erumpentes, magno concrepant murmure instar exilentium de stabulis quadrigarum, vel vesicae quae licet parva, magnum tamen sonitum displosa emittit. ${ }^{54}$
Vom Donner

Man sagt, dass der Donner von einem Krachen in den Wolken herrührt. Wenn sich die im Wolkenbausch eingeschlossenen Windstösse ebendort hin- und herwenden und durch ihre Schnelligkeit und Kraft in einen beliebigen Teil der Wolke ausbrechen, ertönen sie mit lautem Grollen, wie wenn ein Viergespann seine Garage verlässt, oder wie ein Bläschen, das, wenn auch noch so klein, dennoch einen lauten Knall bei der Explosion von sich gibt.

Zur Ursache des Donners heisst es bei Isidor tonitrua autem ex fragore nubium generantur, was Beda nur unwesentlich $\mathrm{zu}$ tonitrua dicunt ex fragore nubium generari variiert. Ebenso sind die Formulierungen zum spiritus ventorum und concepti intra sinum (Isidor)/sinu concepti (Beda) eindeutig aufeinander bezogen. Auch der bildliche Vergleich magno concrepant murmure et in morem exilentium de stabulis quadrigarum sonus ... emittitur (Isidor) bleibt mit magno concrepant murmure instar exilentium de stabulis quadrigarum ... sonitum ... emittit (Beda Venerabilis) inhaltlich und sprachlich praktisch unverändert. Jedoch wird der zweite Abschnitt des Kapitels bei Isidor mit den religiösen Deutungen von Beda zur Gänze ausgespart.

Anders verhält sich die Frage nach der sprachlichen und inhaltlichen Abhängigkeit bei Bedas Hagel-Kapitel:

De grandine

Grandinis lapilli ex stillis pluviae, frigoris et venti rigore conglaciati in aere coagulantur. Sed citius nive solvuntur, et interdiu saepius quam noctu decidunt. ${ }^{55}$
Vom Hagel

Hagelkörner entstehen aus Regentropfen; sie vereisen durch die Kraft der Kälte und des Windes und bilden sich somit in der Luft. Freilich schmelzen sie schneller als der Schnee und sie fallen auch häufiger am Tag als in der Nacht.

Es wird deutlich, dass sich Beda auf die rein naturkundlichen Erläuterungen des Plinius bezieht und die religiöse Deutung bei Isidor erneut ganz bewusst weglässt. Um die genauen sprachlichen Abhängigkeiten der Texte voneinander zu verdeutlichen, seien im Folgenden die entsprechenden Ausführungen zum Hagel nochmals gegenübergestellt.

53 Beda Venerabilis, De natura rerum (Anm. 50), 28.

54 Beda Venerabilis, De natura rerum (Anm. 50), 28.

55 Beda Venerabilis, De natura rerum (Anm. 50), 34. 
Plinius, Naturalis historia 2,152
grandinem conglaciato imbre gigni et nivem eodem umore mollius coacto, pruinam autem nut ex rore gelido; per hiemem nives gun cadere, non grandines, ipsasque grandines interdiu saepius quam noctu, et multo celerius resolvi quam nives.
Isidor, De natura rerum 35

Simili quoque ratione grandinum coagulatio fit. Aquae enim nubium rigore ventorum stringuntur in glaciem adque [!] durescunt, de hinc glacies ipsa partim fragore ventorum comminuta in fragmina partim solis vapore soluta frustatim ad terras delabitur. Quod autem rotunda videtur, hoc solis calor facit et mora refrenantis aeris, dum per longum spatium a nubibus usque ad terras decurrit.
Beda, De natura rerum 34 Grandinis lapilli ex stillis pluviae, frigoris et venti rigore conglaciati in aere coagulantur. Sed citius nive solvuntur, et interdiu saepius quam noctu decidunt.

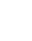


als Quelle kam, sollen gleichsam als Ausblick einige wichtige Stationen der Rezeptionsgeschichte im 12. bis 14. Jahrhundert hier aufgezeigt werden. ${ }^{57}$

Im frühen 12. Jahrhundert verfasste der Benediktiner Honorius von Autun ein ausführliches naturkundliches Kompendium mit dem Titel De imagine mundi (1110 1139). Ein Blick auf seine Beschreibung des Hagels zeigt, dass er sich sprachlich vor allem auf Bedas Plinius-Rezeption stützt; ${ }^{58}$ ob er die Naturalis historia des Plinius direkt kannte, kann auch aus anderen Stellen des Werkes nicht restlos erschlossen werden, seine Bezüge auf Plinius sind wohl Übernahmen aus dem Werk des Iren Johannes Scottus Eriugena aus dem 9. Jahrhundert. ${ }^{59}$

Das 13. Jahrhundert kann allgemein als eine Zeit der Hochblüte für das Entstehen von Naturenzyklopädien bezeichnet werden. Dabei spielte es eine massgebliche Rolle, dass mit der Scholastik neu auch das Wissen auf der Basis der naturkundlichen Schriften des Aristoteles Verbreitung in den gebildeten Kreisen fand. Thomas von Cantimpré vollendete um 1241 sein Hauptwerk De natura rerum; es ist eine der vier wichtigsten Naturenzyklopädien der Zeit - neben De proprietatibus rerum des Bartholomaeus Anglicus (um 1240), dem Speculum naturale des Vinzenz von Beauvais (um 1256/59) und der Historia naturalis des Juan Gil de Zamora (um 1275/1295). ${ }^{60}$ Thomas von Cantimpré ist für zwei Fassungen seiner Naturenzyklopädie verantwortlich, eine etwas kürzere (Thomas I) und eine erweiterte (Thomas II), wobei für die längere Fassung zusätzliche Details sowie ein neues Kapitel über die Bewegung der Sterne eingefügt wurden. Als wichtigste Quellen nennt Thomas in seinem Prolog insbesondere Aristoteles, Plinius, Solinus und Isidor. ${ }^{61}$ Dass diese Enzyklopädie im Mittelalter weit verbreitet war und auch entsprechende Nachwirkung hatte, beweisen nicht nur die über 100 Handschriften zu den Versionen Thomas I und Thomas II, sondern auch der Umstand, dass selbst sein Lehrer Albertus Magnus fünf Bücher von

57 Zur Weitergabe des Wissens über Hagel von Honorius von Autun bis Konrad von Megenberg vgl. Christian Rohr, Extreme Naturereignisse im Ostalpenraum. Naturerfahrung im Spätmittelalter und am Beginn der Neuzeit, Köln / Weimar / Wien 2007 (Umwelthistorische Forschungen 4), 424.

58 Honorius von Autun, De imagine mundi, hrsg. von Valerie I. J. Flint, in: Archives d'histoire doctrinale et littérature du moyen âge 57 (1982), 1,60: Quid grando sit. Stillae pluviae ventis et frigore congelatae in aere coagulantur, et in lapillos grandinis mutantur. Auch der kurze Abschnitt zu Donner und Blitz (De imagine mundi 1,57) folgt inhaltlich vor allem Beda als Autorität.

59 Vgl. dazu im Detail Borst, Das Buch der Naturgeschichte (Anm. 11), 232-235.

60 Traude-Marie Nischik, Das volkssprachliche Naturbuch im späten Mittelalter. Sachkunde und Dinginterpretation bei Jacob von Maerlant und Konrad von Megenberg, Tübingen 1986 (Hermaea, N.F. 48), 26; Benedikt Konrad Vollmann, Thomas von Cantimpré und Konrad von Megenberg, in: Konrad von Megenberg (1309 - 1374): ein spätmittelalterlicher, Enzyklopädist' im europäischen Kontext, hrsg. von Edith Feistner, Wiesbaden 2011 (Jahrbuch der Oswald von Wolkenstein-Gesellschaft 18), 13 - 20, hier 13.

61 Thomas von Cantimpré, Liber de natura rerum, hsrsg. von Hermann Boese, Berlin / New York 1973, prologus. Daneben werden auch noch Ambrosius, Basilius, Jakob von Vitry (1180-1240), der Physiologus, Palladius sowie die Mediziner Galen und Matthaeus de Platea (gest. 1161) genannt. 
De animalibus ${ }^{62}$ auf der Basis von Thomas von Cantimpré verfasste und zudem Vinzenz von Beauvais die Thomas'sche Enzyklopädie exzerpierte. Ausserdem wurde das Werk um 1250, also noch zu Lebzeiten von Thomas von Cantimpré, durch einen namentlich unbekannten Autor überarbeitet und in vielen Teilen gestrafft, an manchen Stellen aber auch erweitert. Diese Version Thomas III machte vom Umfang her etwa 45 Prozent von Thomas I/II aus; sie wurde später zu einer der Hauptvorlagen für Konrad von Megenbergs Buch der Natur. ${ }^{63}$

Ausführlich geht Thomas auf Witterungsphänomene wie den Hagel ein, wobei dieser in ein System von sieben Regionen oder Feuchtigkeitszuständen der Luft (septem regiones sive septem humores aeris) eingegliedert wird. Als Quelle für diese Kategorisierung werden die Meteora des Aristoteles angegeben, dem Thomas aus Gründen der Kürze allerdings compendiosius folgt. ${ }^{64}$ Trotz dieser selbst verordneten Kürze verfasste Thomas ein ausführliches Kapitel zum Hagel, das zwar auf der Definition des philosophus (Aristoteles) aufbaut, dann aber sprachlich wieder erstaunlich nahe an Plinius und Beda ausgestaltet ist. Gänzlich neu ist hingegen der Bezug zu aktuellen Ereignissen: Chroniken würden immer wieder von schweren Hagelgewittern und riesigen Hagelkörnern berichten, die nicht nur Vögel und kleinere Landtiere, sondern auch Grossvieh und Menschen erschlagen hätten. ${ }^{65}$

62 Albertus Magnus, De animalibus libri XXVI, 2 Bände, hrsg. von Hermann Stadler, Münster 19161920 (Beiträge zur Geschichte der Philosophie des Mittelalter 15-16), Bd. 2, 22-26.

63 Vollmann, Thomas von Cantimpré und Konrad von Megenberg (Anm. 60), 13-14. Allgemein zum Wesen der Naturenzyklopädie von Thomas von Cantimpré vgl. Benedikt Konrad Vollmann, Enzyklopädie im Wandel: Thomas von Cantimpré, De natura rerum, in: Die Enzyklopädie im Wandel vom Hochmittelalter bis zur frühen Neuzeit, hrsg. von Christel Meier, München 2002 (Akten des Kolloquiums des Projekts D im Sonderforschungsbereich 231, 29.11-1.12.1996), 169-180.

64 Thomas von Cantimpré, Liber de natura rerum (Anm. 61), 16,1: De quibusdam istorum humorum in libro Metheororum Aristotiles diffusius et habundantius scripsit, que quidem brevitatis causa compendiosius exequemur.

65 Thomas von Cantimpré, Liber de natura rerum (Anm. 61), 16,4: De grandine. Grandinis regio tertia est. Grandinem quidem Philosophus ita diffinit: Stille, inquit, pluvie ventis et frigore superioris aeris conglaciate in aere coagulantur et in lapillos grandinis permutantur, qui utique corpus spericum habere probantur propter circumactionem volubilitatis, qua de aere violentius impelluntur. Grando aliquando pisarum vel fabarum aut etiam nucis avellane magnitudinem prefert. Que, si de superiori regione dilabitur et eius materiam, stillas pluvie, condensatim aer fuderit, conglobate multe gutte in unicas grandines, tunc grando excedit solitam quantitatem et fit pestis valida frugum et volucrum. Narrant annales et cronica temporum multotiens grandines tante magnitudinis cecidisse, ut non solum volucres et minora animalia, sed etiam bestias et homines extra tecta positos conquassarent. Grando turbida magis est quam in terra glacies congelata; et hec ratio, quia de minima gutta primitus coagulata paulative adicitur descendenti fitque de multis partibus, quod utique non sic de glacie, que ex continua aque materia concrescit per gelu. Grando multum infrigidat aerem, unde quandocumque in vere et autumpno de celo grando ceciderit, tunc periculum imminet pestis in frugibus dire gelideque pruine. Et hoc raro fallitur, nisi immediate post grandinem sol calidior aerem terramque lustraverit. Grando si media estate circa solstitium estivale ceciderit, signum est, in superiori aeris regione frigus esse permaximum et, nisi pars inferior aeris solis radiis calefacta grandinem liquefaceret descendentem, in immensam quantitatem moles faceret monstruosas. At quoniam tunc simul et semel sunt opposita frigoris et caloris, morbos generari tunc facillime 
Umfangreich ist auch das Kapitel zu Donner und Blitz: Als Autoritäten werden dabei nicht nur die philosophi (also u. a. Aristoteles) angegeben, sondern insbesondere auch Plinius, der allein in diesem Kapitel dreifach genannt ist. Ebenso wird aber auch aus dem entsprechenden Kapitel bei Isidor zitiert und dieser explizit als Autor genannt. Was nach der Ankündigung des Zitats folgt, ist in unserem rezeptionsgeschichtlichen Zusammenhang bemerkenswert: Thomas zitiert nicht wörtlich, sondern gibt eine Paraphrasierung mit zum Teil eigenen Worten, die auf Inhalten sowohl aus Isidors De natura rerum als auch aus den Etymologiae aufbaut - und ein Satz ist fast wortwörtlich aus Bedas De natura rerum übernommen! ${ }^{66}$

Vom Umfang her beginnt mit den Naturenzyklopädien des 13. Jahrhunderts ein Gegentrend zur Verdichtung, gleichsam eine amplificatio, indem sowohl die Aristoteles- als auch die Plinius-Tradition referiert werden und mit zeitgenössischen Bezügen verbunden werden.

Den Endpunkt dieses Ausblicks bildet schliesslich Konrad von Megenberg mit seinem weit verbreiteten Buch der Natur (1349), der oft als „erste Naturgeschichte in deutscher Sprache“ titulierten Adaption scholastisch orientierter Enzyklopädien. Mit seiner fast volkstümlichen Sprache und durch viele Beispiele gelang es ihm, aristotelisch und plinianisch geprägtes Wissen einer breiteren Öffentlichkeit zu vermitteln, was sich auch in einer sehr grossen Zahl an Handschriften sowie Übersetzungen niederschlug. ${ }^{67}$ Inhaltlich orientierte sich Konrad von Megenberg in erster Linie an Albertus Magnus ${ }^{68}$ und Thomas von Cantimpré (in der Kurzversion Thomas III ${ }^{69}$, verkürzte aber deren Darstellungen wieder, um die Lesbarkeit zu erleichtern. Sein Kapitel über den Hagel ist daher nicht einmal halb so lang wie das bei Thomas von Cantimpré - und Albertus Magnus widmet in seinen Meteora dem Thema Hagel gar

comprobantur. Remedium autem tunc precipuum est includi tectis et domibus et hominem tueri calidis mutationemque fieri aeris circa se et focum accendi.

66 Thomas von Cantimpré, Liber de natura rerum (Anm. 61), 18,2: De tonitruo quidem Ysidorus dicit: Tonitrus interdum graviter concutit omnia, quia, cum procella vehementissimi venti nubibus se repente miscuerit, turbine invalescente exitumque querente, nubem quam excavabat impetu magno rescindit ac sic cum horrendo fragore defertur ad aures. Quod mirari quis non debet, cum vesica quamvis parva magnum tamen sonitum displosa emittit. Der letzte Satz entspricht fast wörtlich Beda Venerabilis, De natura rerum (Anm. 50), 34: ... vel vesicae quae licet parva, magnum tamen sonitum displosa emittit. 67 Zur handschriftlichen Verbreitung des Buchs der Natur vgl. ausführlich Gerold Hayer, Konrad von Megenberg, „Das Buch der Natur“. Untersuchungen zu seiner Text- und Überlieferungsgeschichte, Tübingen 1998 (Münchener Texte und Untersuchungen zur deutschen Literatur des Mittelalters 110), sowie für einen ersten Überblick Claudia Märtl, Gisela Drossbach und Martin Kintzinger (Hrsg.), Konrad von Megenberg (1309-1374) und sein Werk. Das Wissen der Zeit, München 2006 (Zeitschrift für bayerische Landesgeschichte, Beiheft 31), XXIV-XXX.

$68 \mathrm{Zu}$ Konrads Albertus Magnus-Rezeption in Bezug auf das aristotelische Konzept der Luftregionen und zur Meteorologie allgemein vgl. ausführlich Dagmar Gottschall, Konrad von Megenbergs Buch von den natürlichen Dingen. Ein Dokument deutschprachiger Albertus-Magnus-Rezeption im 14. Jahrhundert, Leiden / Boston 2004 (Studien und Texte zur Geistesgeschichte des Mittelalters 83), 292 - 339. 69 Zur Abhängigkeit Konrads von Megenberg von der gekürzten Fassung Thomas III vgl. im Detail Vollmann, Thomas von Cantimpré und Konrad von Megenberg (Anm. 60), 14-19. 
fünf Kapitel ${ }^{70}$. Konrad meint zum Ursprung des Hagels, dass es sich dabei um Regentropfen handle, die durch eine kalte Luftschicht dringen und dann gefrieren. Sie hätten daher oft, wie der Schnee im Winter, die Form von Kristallen. ${ }^{71}$ Auf ähnliche Weise baut auch das Kapitel Konrads über Donner und Blitz auf Albertus Magnus und Thomas von Cantimpré auf, verkürzt diese Autoritäten aber ebenso radikal. ${ }^{72}$

\section{Fazit}

Die Untersuchung von Berichten zu ausgewählten Witterungserscheinungen (Donner und Hagel) hat gezeigt, dass die Rezeption der Naturalis historia des Plinius durchaus komplex verlief und nicht rein unter dem Aspekt der Verdichtung betrachtet werden kann. Da sich C. Iulius Solinus, so wie auch andere Kompilatoren der Spätantike, jeweils nur auf bestimmte Aspekte konzentrierte - in diesem Fall auf merkwürdige oder wunderbare Begebenheiten und Erscheinungen -, fanden so profane Inhalte wie Erklärungen zu Witterungsphänomenen dort keine Aufnahme. Somit müssen sowohl Isidor als auch Beda Venerabilis direkt Kenntnis von Buch 2 der Naturalis historia gehabt haben.

Die Abschnitte in Isidors Etymologiae haben ein völlig anderes Erkenntnisinteresse als die naturkundlichen Werke vor und nach ihm, doch ist trotz einer auffallend distanzierten Bezugnahme zu erkennen, dass sich Isidor vom Aufbau und teilweise auch vom Inhalt her doch an Plinius orientierte. Näher ist der inhaltliche Bezug in Isidors De natura rerum, doch auch hier werden zu nahe sprachliche Anklänge aus „pastoraler Gegenwehr“ offenbar bewusst vermieden. Ein zusätzlich exegetisch-moralisierender Teil der einzelnen Kapitel zu Donner und Hagel steht in der Tradition des Exameron des Ambrosius.

70 Albertus Magnus, Meteora, hrsg. von Paul Hossfeld, Münster 2003 (Alberti Magni Opera Omina 6,1), 2,1,24-28: De loco, ubi generatur grando / De tempore generationis grandinis, ex quo etiam scitur, quare saepius fit in locis calidis quam frigidis / Et est digressio docens materiam grandinis / Et est digressio declarans de causa efficiente grandinis / De figura grandinis.

71 Konrad von Megenberg, Buch der Natur, hrsg. von Robert Luff und Georg Steer, Bd. 2: Kritischer Text nach den Handschriften, Tübingen 2003 (Texte und Textgeschichte 54), 2, 20: Von dem schawr: Der schaur haizzt in anderr dåutsch der hagel, vnd chümt da von, daz der wazzrig dunst dez ersten sich entsliuzt in regentropfen ain ainer niht vibrig chalter stat in dem luft, da der regen wirt, und die tropfen darnach vallent durch ain gar chalt stat, da die hitz in dem sumer die chelten ze samen hat getriben, wan die selb vibrig chelten verchert die tropfen in eys, reht als sie daz wazzer tüt hie in den winter zeiten. Dar umb sint des schaurn chörner gestalt sam die christallen vnd sint sinbel darvmb, daz sie sich sleifent durch den luft her $a b$ zů allen enden.

72 Konrad von Megenberg, Buch der Natur (Anm. 71), 2,25 (Von dem doner vnd von dem plitzen) nach Albertus Magnus, Meteora (Anm. 70), 3,3,4 (De causa tonitrui et fulguris secundum sententiam Aristotelis et de diversitate sonorum tonitrui) sowie 3,3,19-23 bzw. Thomas von Cantimpré, De natura rerum (Anm. 61), 18,2 (De tonitruo). 
Beda bedient sich in seinem Werk De natura rerum sowohl bei Plinius selbst als auch bei Isidors De natura rerum, wobei die Bezugnahme in die eine oder andere Richtung je nach Kapitel variiert. Die moralisierenden Teile Isidors werden aber konsequent weggelassen. Vom Umfang her ist Beda um Kürze bemüht und verdichtet somit seine Vorlagen.

Auch für die Blütezeit naturkundlicher Enzyklopädien und Kompendien blieben Plinius, Isidor und Beda Autoritäten, auf die explizit oder sprachlich Bezug genommen wurde, obwohl mit der Scholastik die Werke des Aristoteles im Westen wiederentdeckt wurden. Autoren wie Honorius von Autun oder Thomas von Cantimpré hatten mit Sicherheit direkten Zugriff auf alle drei Autoren, ja Letzterer führte sie prominent in seinem Prolog zu De rerum natura als Hauptquellen neben Aristoteles an. Durch die Heranziehung sowohl der Aristoteles- als auch der Plinius-Tradition wurde die allmähliche Verdichtung der Inhalte, wie dies noch bei Beda zu konstatieren war, in eine gegenteilige Richtung geführt: die Naturkundebücher des Spätmittelalters, ob Thomas von Cantimpré oder das mittelhochdeutsche Buch der Natur Konrads von Megenberg, übertreffen die spätantiken und frühmittelalterlichen Werke deutlich an Umfang. Die Naturalis historia selbst blieb aber auch als Gesamtwerk im Mittelalter in zahlreichen Abschriften erhalten, sodass im Gegensatz zum immer noch weit verbreiteten Klischee, das antike Wissen sei im Mittelalter verloren gegangen, zumindest auf Plinius bezogen, das Gegenteil der Fall ist. ${ }^{73}$

73 Zum Mythos des Verlusts naturkundlichen Wissens vgl. zuletzt am Beispiel der Kenntnis von der Kugelgestalt der Erde Christian Rohr, Die Welt als Scheibe oder Kugel? Zum Wissen von der Kugelgestalt der Erde im Mittelalter, in: Welterfahrung und Welterschließung in Mittelalter und Früher Neuzeit, hrsg. von Anna Kathrin Bleuler, Heidelberg 2016 (Interdisziplinäre Beiträge zu Mittelalter und Früher Neuzeit 5), 9-24. 

Kompilieren 



\title{
Codex Theodosianus revisited - Plädoyer für eine Geschichte der juridischen Form
}

\begin{abstract}
This paper discusses a critical approach established in legal studies and presents a new perspective. Focussing on the Codex Theodosianus and her previous treatment of it as a „failed Codex“, the author argues that late classical legal texts should not be viewed as inferior versions of classical law. Instead, they can be understood as stabilisers in post-imperial legal practice.
\end{abstract}

\section{Einleitung}

\section{Eine Deutung des Codex Theodosianus}

Die Frage nach den Mechanismen von Verdichtung und Vernichtung gibt mir Gelegenheit, auf einen der Signaturtexte des komplexen Phänomens zurückzukommen, das gemeinhin als römisches Vulgarrecht bezeichnet wird: den Codex Theodosianus. In meinem Beitrag „Der gescheiterte Codex“, der vor einigen Jahren in der Zeitschrift „Rechtsgeschichte“ des Max-Planck-Instituts für europäische Rechtsgeschichte erschienen ist, befasste ich mich mit dessen Kodifikationsgeschichte. ${ }^{1}$ Damals zeichnete ich das Bild eines zumindest in Teilen misslungenen Codex - als Gesetzbuch äußerst erfolgreich, als Gesetzeswerk hingegen unzulänglich. Für diesen zwiespältigen Befund habe ich seinerzeit zwei Gründe angeboten. Zunächst habe ich mich auf die politisch instabile Situation im Westteil des Reiches bezogen. Sie beschränkte die Gestaltungsmöglichkeiten des Kaisers Valentinian III. so sehr, dass die Verstetigung des oströmischen Codex im Jahr 438 n.Chr. in Westrom letztlich nicht gelang. ${ }^{2}$

Für das Thema der Wissensorganisation in der Spätantike bedeutsamer ist eine zweite Überlegung, die ich damals angestellt habe. Als Ursache für den angeblichen Misserfolg des Codex hatte ich vor allem die mangelnde kompilatorische Leistung der ersten Expertenkommission um Kaiser Theodosius II. ausgemacht. Dem ersten Gesetzgebungsauftrag folgend stellte sie zwei Codices zusammen, einen mit den praktisch bedeutsamen Rechtsregeln und einen weiteren, der scholasticae intentioni gewidmet war. Er sollte deshalb auch Recht dokumentieren, das „dem Schweigen

Die Vortragsform des Beitrags wurde überwiegend beibehalten. Der Text nimmt auf das Oberthema der Zürcher Tagung Bezug. Er lautete: „Verdichtung oder Vernichtung? Entwicklungen und Strategien im Umgang mit der Komplexität von Wissen in Spätantike und Frühmittelalter“.

1 Inge Kroppenberg, Der gescheiterte Codex. Überlegungen zur Kodifikationsgeschichte des Codex Theodosianus, in: Rechtsgeschichte. Zeitschrift des Max-Planck-Instituts für europäische Rechtsgeschichte 10 (2007), $112-126$.

2 Kroppenberg, Codex (Anm. 1), 121-124. 
übergeben, in Nichtgebrauch gefallen und lediglich für praktische Zwecke zu ihrer Zeit gültig gewesen war. “3 Ich habe damals argumentiert, die gesetzgeberische Strategie Theodosius' II. im Umgang mit Rechtswissen sei problematisch gewesen, weil das Nebeneinander von Wissenschaft und Praxis, Kontemplation und Applikation den Geltungsanspruch seines Gesetzbuchs schwächten. ${ }^{4}$

Auch der zweite Anlauf, den der oströmische Kaiser mit seinem Gesetzbuch nahm, war nach meiner damaligen Einschätzung letztlich zum Scheitern verurteilt, obwohl er die Kommission verstärkt zu kompilatorischer Stringenz anhielt. ${ }^{5}$ Meine Begründung: die so genannten Zitiergesetze, deren Absicht es war, die Äußerungen einer kleinen Zahl klassischer Juristen in eine Autoritätshierarchie herrschender Meinungen einzubringen, wurden neben dem Codex angewendet und schmälerten seine Verbindlichkeit. ${ }^{6}$ In meinen damaligen Ausführungen kam ich zu dem Schluss, das knapp 100 Jahre jüngere Gesetzeswerk Justinians sei dem theodosianischen in der Organisation des enthaltenen Wissens überlegen gewesen. Auch habe Justinian die antiquitates der historischen Überlieferung viel konsequenter abgeschnitten und ausschließlich das neu kompilierte Textarrangement mit dem in der kaiserlichen auctoritas wurzelnden Geltungsbefehl verbunden. ${ }^{7}$

\section{2 ... und ihre Kritik}

Heute würde ich den Codex Theodosianus keineswegs als gescheitertes Gesetzgebungswerk ansehen. Zum Nach- und Überdenken meiner Auffassung haben mich neben dem zeitlichen Abstand namentlich die Stellungnahmen zweier Kollegen inspiriert, ein Jurist und Rechtshistoriker sowie ein Ägyptologe. Bedenkenswert ist der Hinweis von Peter Kreutz in seiner Dissertation „Rombild und Rechtsbild in der Spätantike“ aus dem Jahre 2008, ${ }^{8}$ der auf die Gefahr von Anachronismen hinweist, die sich aus dem Gebrauch moderner juristischer Terminologie für historische Sachverhalte ergibt. Dieser Gedanke soll im Folgenden über die reine Semantik hinaus entfaltet werden. ${ }^{9}$

3 Codex Theodosianus XV, 1.1.

4 Kroppenberg, Codex (Anm. 1), 119-120, et passim.

5 CodTh XVI, 1.1.

6 Kroppenberg, Codex (Anm. 1), 120.

7 Kroppenberg, Codex (Anm. 1), 120-121.

8 Peter Kreutz, Romidee und Rechtsbild in der Spätantike. Untersuchungen zur Ideen- und Mentalitätsgeschichte, Münster 2008, 151 Fn. 52.

9 Weitere Nachweise bei Reinhard Zimmermann, Codification. The Civilian Experience Reconsidered on the Eve of a Common European Sales Law, in: Codification in International Perspective, hrsg. von Wen-Yeu Wang, Cham / Heidelberg u.a. 2014, 11-43, 12 Fn. 6. Zustimmend aber Nils Jansen, The Making of Legal Authority. Non-legislative Codifications in Historical und Comparative Perspective, Oxford 2010, 109 Fn. 84: „Cf., with regard to the failure of the Codex Theodosianus, Kroppenberg, Der gescheiterte Codex, $118 \mathrm{ff}$. Kroppenberg argues, convincingly, that this legislation's failure resulted 
Dabei kommen zunächst diejenigen Beschränkungen zur Sprache, die in der überkommenen rechtshistorischen Anschauung eine Annäherung an die spätantike und frühmittelalterliche Rechtslandschaft erschweren. ${ }^{10}$ Zum Nachdenken über diese hat mich eine Stellungnahme des Münsteraner Ägyptologen Christian Bayer angeregt, der in einer Diskussion der Abschlusstagung des DFG-Nachwuchsnetzwerks ,Norm

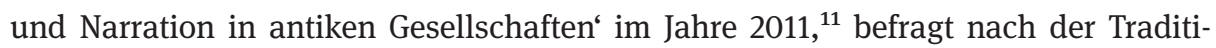
onspraxis und Kompilationsstrategie antiker Normgeber, pointiert bemerkte: „Die werfen nichts weg. “12

Die These der folgenden Ausführungen ist, dass eine Verengung des Rechtsbegriffs auf die Wissenskategorie, ein (zu) eng am Geist angelegtes Verständnis, wie er traditionell besonders im deutschen Sprachraum anzutreffen ist, Gefahr läuft, Recht und Rechtswissenschaft für identisch zu halten. Der Begriff Römisches Vulgarrecht ist ein besonders anschauliches Beispiel dieser kognitiven Selbstbeschränkung. Im Anschluss sollen daher einige alternative Überlegungen zur gängigen spätantiken Rechtsgeschichte vorgestellt werden. ${ }^{13}$ Dabei soll auf die immer noch gängige Rationalitätsfixierung der rechtshistorischen Forschung aufmerksam gemacht und dafür plädiert werden, neben der geistig-stofflichen auch andere Dimensionen des Rechts in den Blick zu nehmen. Der Stoffgeschichte sollte, so der Vorschlag, eine Geschichte der juridischen Form an die Seite gestellt und damit gewissermaßen der Blick für die Sozialdimension des spätantiken Rechts geschärft werden. In dieser Perspektive ist Recht weder eine rein geistige Schöpfung noch ausschließlich das Ergebnis einer Entscheidung. Es entsteht vielmehr in den Vorstellungen einer konkreten historischen Gemeinschaft. Seine Formen und Regeln sind daher immer zugleich auch Aussagen über ein Wir in Abgrenzung zu den Anderen. ${ }^{14}$

from the fact that it did not meet the formal requirements of a codification: a comprehensive, clear, and well-structured text that unifies the law by including everything that is valid and excluding former, dead norms."

10 Unter II, siehe $74-80$.

11 Anke Blöbaum, Therese Hansberger, Christian Reitzenstein-Ronning (Hrsg.), Norm und Narration in antiken Gesellschaften, Berlin 2014.

12 Christian Bayer, Echnaton - Sonnenhymnen, Stuttgart 2007. Siehe auch Mario Bretone, Geschichte des Römischen Rechts. Von den Anfängen bis zu Justinian, München 1998, 247: „Man stellt sich im Inhalt des Codex gleichzeitig das Nebeneinander von Gültigem und Ungültigem vor, und dies lässt eine juristische Mentalität erkennen, die die Vergangenheit selbst dann bewahrt, wenn sie keinerlei Wirkung mehr hat. [...] So erscheint die Gesetzgebung insgesamt als etwas Zusammenfassendes und Dauerhaftes, in dem auch das Überwundene niemals vollständig verloren gegangen ist. Diese Mentalität hat bekanntlich sehr weit zurückliegende Wurzeln.“

13 Unter III, siehe 80 - 83.

14 Unter IV, siehe 84. Grundlegend zu diesem Ansatz für die (moderne) Kodifikationsgeschichte jetzt Inge Kroppenberg, Nikolaus Linder, in: Coding the nation. Codification History from a (Post-)Global Perspective, Entanglements in Legal History: Conceptual Approaches, hrsg. von Thomas Duve, Frankfurt a. M. 2014 (Global Perspectives on Legal History 1), 67-99. 


\section{II „A reductionist concept of law ${ }^{615}-$ Selbstbeschränkungen spätantiker Rezeptionsforschung}

\section{Rezeptionsgeschichtliche (Zerr-)Bilder eines antiken Gesetzgebers}

Rechtshistorisches Forschungsinteresse richtet sich nicht selten auf das, was Max Weber die formelle und materielle Rationalisierung des Rechts genannt hat, ${ }^{16}$ im Hinblick auf das Oberthema der Tagung also auf das rationale Verdichten von Stoff und das Vernichten des nicht oder minder Rationalen durch juristische Experten in Rechtsstäben. Rationalisierung, so die Überzeugung, legt den wahren Rechtsstoff frei, in den Worten Savignys ,das eigentlich technische, wovon der wahre Werth abhieng“ ${ }^{17}$ Verdichtetes Recht ist daher, zumindest nach Meinung vieler Juristen, stets auch das qualitativ bessere Recht.

Im Kontext der neuzeitlichen Rezeptionsgeschichte des Codex Theodosianus und seines Schöpfers kann diese Anschauung an eine lange Tradition anknüpfen. „Théodose étoit fort pieux, mais peu éclairé“, schreibt der Enzyklopädist d'Alembert $1753^{18}$, und 35 Jahre später legt Edward Gibbon wenig schmeichelhaft nach: „Schlimmster Aberglaube knechtete und erniedrigte seinen durch die Fürstenerziehung entkräfteten Geist; er fastete, er sang Psalmen, er glaubte blind die Wunder und Doktrinen, womit man sein Gemüt beständig nährte. "19 Über die Geistesschwäche und Frömmelei hinaus wird Theodosius als weicher, verspielter und weibischer Herrscher dargestellt, der die Regierungsarbeit seiner Schwester Pulcheria überließ. ${ }^{20}$

15 Thomas Duve, European Legal History - Concepts, Methods, Challenges, in: Duve, Entanglements in Legal History (Anm. 14), 29-66, 51.

16 Zum prägenden Einfluss des Weberschen Rationalitätskonzepts auf die moderne Rechtsgeschichtsschreibung namentlich Franz Wieackers sind zuletzt mehrere Arbeiten erschienen: Viktor Winkler, Der Kampf gegen die Rechtswissenschaft. Franz Wieackers „Privatrechtsgeschichte der Neuzeit" und die deutsche Rechtswissenschaft des 20. Jahrhunderts, Hamburg 2014; Duve, European Legal History (Anm. 15), 44-48; Kroppenberg/Linder, Coding the nation, (Anm. 14), 70 - 74; Gerhard Dilcher, Franz Wieacker als „Germanist“. Mit einigen Bemerkungen zu seiner Beziehung zu Marx, Nietzsche und Max Weber, in: Franz Wieacker - Historiker des modernen Privatrechts, hrsg. von Okko Behrends, Eva Schumann, Göttingen 2010, 223-252.

17 Friedrich Carl von Savigny, Vom Beruf unserer Zeit für Gesetzgebung und Rechtswissenschaft, Heidelberg 1814, 59.

18 Jean Baptiste Le Rond d'Alembert, Art. Code, in: Encyclopédie, hrsg. von Jean Baptiste Le Rond d'Alembert und Denis Diderot, Neufchastel 1753 (tom. 3: Cha - Consécration), 584.

19 Edward Gibbon, Verfall und Untergang des römischen Imperiums. Bis zum Ende des Reiches im Westen, Bd. 4, München 2003, 404.

20 Gibbon, Verfall und Untergang (Anm. 19), 403-404: „[D]er Sohn des Arcadius war dazu verurteilt, seine lebenslange Kindheit ausschließlich im Kreis eines unterwürfigen Gefolges von Frauen und 
Auch in der neueren und neuesten rechtshistorischen Forschung fällt das Urteil über sein Gesetzgebungswerk überwiegend negativ aus. Meist wird es nicht für sich allein behandelt, sondern als weniger gut gelungener Vorläufer zum Werk Justinians. Aussagen wie etwa diejenige Seecks - „erbärmliches Flickwerk“21 - oder Wielings „Programm, das Justinian später durchführen wird“22 - sind eher die Regel als die Ausnahme. In jüngerer Zeit sind sie zwar relativiert worden. Jedoch auch diese neueren rechtshistorischen Arbeiten bewegen sich oft immer noch im herkömmlichen Paradigma der Stoffgeschichte von Textorganisation und -systematisierung. ${ }^{23}$

Die erwähnte qualifizierende Wertung von schlechterem und besserem Recht ist in der rechtshistorischen Forschung auch sonst geläufig. Sie kommt etwa in der Periodenbildung von vor- und hochklassischem, spätklassischem und nachklassischem Recht zum Ausdruck, die im Zuge von Historisierung und Ästhetisierung des römischen Rechts durch die Romanisten des frühen 20. Jahrhunderts aufkam und immer auch ein wertendes Element enthält. ${ }^{24}$ Auch gelten die bereits erwähnten Zitiergesetze des Jahres 426 nicht selten als Ausbund vulgärer Vernichtung einer höher stehenden

Eunuchen zu verbringen. Die reichen Mußestunden, die er durch die Vernachlässigung der wichtigsten Pflichten seines hohen Amtes gewann, füllten sinnlose Zeitvertreibe und unnütze Studien. Die Jagd war die einzige aktive Beschäftigung, die ihn aus den Grenzen seines Palastes herauslocken konnte; indes übte er eifrig und manchmal bis spät in die Nacht das Kunsthandwerk des Malens und Schnitzens, und die Zierlichkeit seiner Abschriften religiöser Bücher bescherte dem römischen Kaiser den außergewöhnlichen Beinamen „der Kalligraph“ oder Schönschreiber. Abgesondert von der Welt durch einen undurchdringlichen Schleier, schenkte Theodosius sein Vertrauen den Menschen, die er liebte; und er liebte diejenigen, die ihm in seiner Untätigkeit Abwechslung verschafften und schmeichelten, und da er die ihm zur Unterzeichnung vorgelegten Papiere nie durchlas, wurden in seinem Namen häufig Ungerechtigkeiten begangen, die er im Grunde seines Herzens verabscheute.“

21 Otto Seeck, Geschichte des Untergangs der antiken Welt, Darmstadt 2000 (Neudruck der Ausgabe von 1921), 176. Zur negativen Rezeption Theodosius' in Seecks Werk vgl. Hartmut Leppin, Theodosius der Große, Darmstadt 2003, 231 - 232; Boudewijn Sirks, The Theodosian Code: A Study, Friedrichsdorf 2007, 109-115; kritisch dazu Detlef Liebs, Besprechung von Adriaan J. Boudewijn Sirks, The Theodosian Code: A Study, Friedrichsdorf 2007, in: Zeitschrift der Savigny-Stiftung für Rechtsgeschichte, Romanistische Abteilung 127 (2010), 516-539, 530-532.

22 Hans-Josef Wieling, Die Einführung des Codex Theodosianus im Westreich, in: Iurisprudentia universalis, Festschrift für Theo Mayer-Maly zum 70. Geburtstag, hrsg. von Martin Josef Schermaier, Michael Rainer und Laurens Winkel, Köln / Weimar / Wien 2002, 865-876, spricht von einem „Programm, das Iustinian später durchführen wird“.

23 Gian Gualberto Archi, Giustiniano legislatore, Bologna 1970, in: Zeitschrift der Savigny-Stiftung für Rechtsgeschichte, Romanistische Abteilung 92 (1975), 386 - 398; ders., Studi sulle fonti del Diritto nel tardo Impero Romano. Teodosio II et Giustiniano, Cagliari 1987; ders., Le codificazioni postclassiche, in: La certezza del diritto nell'esperienza giuridica Romana. Atti del Convegno Pavia 26-27 aprile 1985, hrsg. von Manlio Sargenti und Giorgio Luraschi, Padua 1987, 149-168; John F. Matthews (Hrsg.), Laying down the law. A study of the Theodosian Code, New Haven London 2003, und Sirks (Anm. 21).

24 Im romanistischen Schrifttum lässt sich der Begriff „nachklassisch“ am frühesten nachweisen, pointiert etwa bei Gerhard von Beseler, Beiträge zur Kritik der römischen Rechtsquellen, 3 Bde., Tübingen 1910. 
Rechtskultur. ${ }^{25}$ Spätantike Rechtsbücher und auch etwa die Gesetzbücher der germanischen Stämme, die zeitgleich mit den Kaisercodices entstanden und sich am Vorbild des theodosianischen Codex orientierten, vermochten das Interesse der romanistischen Forschung, von wenigen Ausnahmen abgesehen, ${ }^{26}$ nicht nachhaltig zu wecken. ${ }^{27}$

Auf einer besonderen Stufe dieser Tradition, wenn auch - wie gesehen - nicht an ihrem Anfang, steht Friedrich Carl von Savigny. In seiner berühmten Programmschrift „Vom Beruf unserer Zeit für Gesetzgebung und Rechtswissenschaft“ aus dem Jahr 1814 spricht er von den „beiden Seiten des Rechts“, der „technischen“ und der „politischen“, denen er jeweils weitere Begriffe zuordnet. ${ }^{28}$ Die technische Seite befasst sich mit dem „Stoff“ des (Römischen) Rechts - ein Begriff, den Savigny oft verwendet ${ }^{29}$-, der von professionellen Juristen gestaltet und beherrscht wird. Auf der politischen Seite kommen der Gesetzgeber, die Nation und das Volksrecht mit seinen urwüchsigen Formen zu liegen.

Obwohl Savigny beide Seiten behandelt, neigt sich sein Interesse doch merklich der technischen Seite zu, als deren Inbegriff der von allem Materialen gereinigte, historisch erforschte und schließlich zum System geronnene Stoff erscheint. Am Ende stehen wir vor dem Entwurf einer juristischen Geisteswissenschaft, die nicht nur Recht und Unrecht, sondern auch nach wissenschaftlichen Maßgaben das richtige Recht vom falschen zu trennen vermag. Diese Sichtweise hatte bekanntlich ungeheuren Erfolg, auch außerhalb Deutschlands. Nicht nur die moderne Romanistik hat sich ihr angeschlossen. Auch die historische Kodifikationsforschung, wie sie namentlich von Franz Wieacker in den 1950er Jahren begründet wurde, ist ihr verpflichtet. ${ }^{30}$ Die nationalen Gesetzbücher werden hier gewissermaßen in Ranglisten eingeteilt. ${ }^{31}$

Einer merklich anderen Tradition folgt die französische Rezeptionsgeschichte des Codex Theodosianus. Das Politische des Gesetzbuchs, seine symbolische Dimension,

25 Paradigmatisch Max Kaser, Das Römische Privatrecht, Zweiter Abschnitt: Die nachklassischen Entwicklungen, 2. Aufl., München 1975, 55: „Ohne nach den alten Geltungsgrundlagen zu fragen, entnimmt man dem überkommenen Quellenmaterial mit den Vereinfachungen, die dem vulgären Rechtsdenken eigentümlich sind, die Einrichtungen und Rechtssätze, die für die Praxis und Lehre dieser Zeit noch brauchbar erscheinen." Detlef Liebs, Römisches Recht, 6. Auflage, Göttingen 2004, 90, spricht von den Zitiergesetzen als einem „traurigen Dokument geistiger Selbstlosigkeit.“

26 Detlef Liebs, Römische Jurisprudenz in Gallien (2. bis 8. Jahrhundert), Berlin 2002.

27 So etwa der Befund bei Leopold Wenger, Die Quellen des Römischen Rechts, Wien 1953, 543: „Wenige Sterne leuchten noch durch den Nebel und auch diese nur mit schwachem Glanz. Was wir über die Jurisprudenz in diesen dunklen Zeiten, von denen - was nicht zu vergessen! - wir auch sonst kein klares Bild haben, noch zu ergründen ist, ist in moderner gelehrter Arbeit zusammengesucht worden. Der Jurist ist bei der Gesetzgebung, in richterlicher und anwaltlicher Tätigkeit beschäftigt.“

28 Savigny, Beruf (Anm. 17), 4, 12 et passim.

29 Ebd. 21 et passim.

30 Nachweise Anm. 16.

31 Erst „[d]ie modernen Gesetzbücher gehören zum köstlichen Besitztum der Völker des neueren Europa“: Franz Wieacker, Aufstieg, Blüte und Krisis der Kodifikationsidee, in: Festschrift für Gustav Boehmer. Dem Siebziger von Freunden und Kollegen dargebracht, Bonn 1954, 34-50, 48. 
ist hier seit jeher ein zentrales Thema. Schon Montesquieu war der Meinung, es sei wichtig, dass die „Worte der Gesetze bei allen Menschen die gleichen Ideen wecken“ sollten. ${ }^{32}$ In der Besprechung des Codex Theodosianus bemängelt Jean Gaudemet denn auch weniger die Stofforganisation, sondern zeichnet das Bild eines politisch und sozial konstitutiven Gesetzbuchs, dessen Einheitsform das spätantike Imperium noch einmal konsolidiert habe: „Après un siècle de partage législatif, le $C$. Th. rétablissait l'unité du droit officiel (en face de la variété d'usages locaux) pour ce qui restait de l'orbis romanus. “33 Hier ist der Sinn für die Form des Gesetzbuchs und deren Eigenwert mit Händen zu greifen, wie es in der Nation der Cinq Codes kaum anders zu erwarten ist. Demgegenüber hat das kategorische Verständnis von Recht als einer machtgestützten Ordnung des Geistigen seinen Ort in der deutschen Rechtswissenschaft des 19. Jahrhunderts. Ihren vielleicht deutlichsten Ausdruck gefunden hat sie in der Rechtssoziologie des studierten Juristen Max Weber. ${ }^{34}$

\section{2 „Fesseln“35 einer rechtshistorischen Stoffgeschichte}

\section{a Einseitige Konzentration auf die stoffliche Innenseite juridischer Formen}

Mit Blick auf die Spätantike sind an der soeben geschilderten Sichtweise drei Punkte kritikwürdig. Der erste betrifft das Verhältnis von Verdichten und Vernichten, der zweite das Universalisierungspathos und den Fortschrittsglauben in der Rechtswissenschaft. Beim dritten Punkt geht es um Inklusion, ein Thema, das in der Rechtsgeschichte oft unter dem Stichwort der Adressatenfrage abgehandelt wird. Sie betrachtet, wie Verbindlichkeit und Geltung konkret erzeugt werden und für wen ein bestimmtes Recht gilt.

Zum ersten Aspekt: In den Einleitungskonstitutionen der großen spätantiken Gesetzgebungswerke finden wir den Topos Verdichten / Vernichten oft im Begriffspaar Kürze / Weitschweifigkeit, das von den Gegenbegriffen Licht / Schatten und Reinheit / Unreinheit metaphorisch flankiert ist. So heißt es in der ersten Novelle des Codex Theodosianus:

32 Charles-Louis de Secondat, Baron de La Brède et de Montesquieu, De l'esprit des loix, ... Seconde partie, Genève 1749 (Liv. 29) c. 16: Choses à observer dans la composition des lois, 253: „Il est essentiel que les paroles des lois réveillent chez tous les hommes les mêmes idées.“

33 Jean Gaudemet, Art. Théodosien (Code), in: Dictionnaire de droit canonique, Bd. 7, Paris 1965, 1215 - 1246, 1217 - 1218. Im Ergebnis gleich Jill Harries, Law and Empire in Late Antiquity, Cambridge 1999, 60-61.

34 Dies die pointierte Meinung von Harold Berman, Some False Premises of Max Weber's Sociology of Law, in: Washington University Law Quarterly 65 (1987), Nr. 4, 758-770, 770.

35 Terminus im Anschluss an Joachim Rückert, „Große“ Erzählungen, Theorien und Fesseln in der Rechtsgeschichte, in: Das Recht und seine historischen Grundlagen. Festschrift für Elmar Wadle zum 70. Geburtstag, hrsg. von Tiziana J. Chiusi, Thomas Gergen und Heike Jung, Berlin 2008, 963-986. 
Damit [das Recht] nicht mehr weiter in geschäftiger Zweideutigkeit verhandelt werde, wie das bei dieser Unmenge von Büchern und Klageformeln, der Verworrenheit von Rechtsfällen und der schieren Masse kaiserlicher Konstitutionen der Fall ist, die ihren Inhalt vor der menschlichen Erkenntnis verschließen wie mit einer Mauer, wie wenn sie mit einer dicken Wolke der Finsternis umgeben wären, haben wir die Herausforderung unserer Zeit schlechthin angenommen: wir haben die Dunkelheit vertrieben und dem Recht das Licht der Kürze gebracht, eine verdichtete (conpendiosa) Fassung aller Kaiserkonstitutionen seit dem vergöttlichten Konstantin [...] Wir haben die Erlasse früherer Kaiser von Interpretationen gereinigt und veröffentlicht, damit die Rechtsgelehrten ihre Unkenntnis nicht mehr, wie bisher, mit übertriebener Härte kompensieren müssen. ${ }^{36}$

Schon hier ist zu sehen, wie sich rechtliche, politische und religiöse Programmatik gegenseitig durchdringen. Auch wenn juridisches Wissen im Mittelpunkt steht, so wird doch mehr verhandelt als dessen Reorganisation. Dabei sind Verdichten und Vernichten nicht etwa Gegensätze, sondern die zwei Seiten derselben Form. „Where there is dirt there is system“, so die Formel der Kulturwissenschaftlerin Mary Douglas: „Dirt is the by-product of a systematic ordering and classification of matter, in so far as ordering involves rejecting inappropriate elements. “37

Dem Blick, der sich nur auf die verdichtete Innenseite der Form richtet, entgeht das Vernichtete, das die Form erst konstituiert, die Perspektive öffnet auf die stark religiös geprägten Topoi von Reinheit / Unreinheit und Erleuchtung / Finsternis und damit auf die Eigenarten der Regierungspraxis der spätantiken Kaiser, auf die zurückzukommen sein wird. Durch die methodische Verengung auf den Stoff, die in der professionellen Identität von Juristen begründete fachdisziplinäre Selbstbezüglichkeit, werden diese Bezüge ausgeblendet. ${ }^{38}$

\section{b Der Stoff als Medium universalen Fortschrittsglaubens}

Die Konzentration auf den Stoff hat in der Rechtsgeschichte noch weiter gehende Auswirkungen. Wenn es möglich ist, das „wahrere“ (und deshalb „bessere“) Recht durch geistige Verdichtung zu erschließen, liegt es nahe, dieses Recht auch in weiterem Umfang für verbindlich und letztlich für universal $\mathrm{zu}$ halten, zumal dieses Programm einer lex generalis, die im gesamten orbis terrarum gelten solle, historisch eine wichtige Neuerung des spätantiken Rechts selbst darstellt. ${ }^{39}$ Unmittelbar mit den

36 Nov. I [= brev. I] De Theodosiani Codicis Auctoritate, in: Theodosiani libri XVI cum constitutionibus Sirmondianis et leges novellae ad Theodosianum pertinentes. Consilio et auctoritate Academiae litterarum regiae Borussicae, hrsg. von Theodor Mommsen und Paul M. Meyer, volumen II, Berolini 1905, 3 [Übersetzung der Verfasserin]. Dazu Harries, Law and Empire (Anm. 33), 59-60.

37 Mary Douglas, Purity and Danger. An Analysis of Concept of Pollution and Taboo, London 2002, 44. 38 Pekka Niemelä, Law and Universalism. From Antiquity to the Middle Ages, in: Finnish Yearbook of International Law 18 (2007), $307-342$.

39 Cornelia Vismann, Akten. Medientechnik und Recht, Frankfurt a. M. 2000, 100-101. S. auch Harries, Law and Empire (Anm. 33), 37 - 38. 
Vorstellungen von Verbesserung und Universalisierung verbunden ist die des zivilisatorischen Fortschritts, die den Stoff unablässig rationalisierender Reformanstrengung unterwirft. „[T]hat reform is the appropriate end of scholarship“, gehört zum Grundprogramm der Rechtswissenschaft; diese Überzeugung lässt sie mitunter aber auch die Distanz zu ihrem eigenen Untersuchungsgegenstand verlieren. „The legal scholar“, so Paul Kahn, „,comes to the study of law already understanding herself as a citizen in law's republic. She is committed to 'making law work', to improving the legal system of which she is a part“. ${ }^{40}$ Diese reformatorische Grundhaltung kann möglicherweise den Blick auf das Besondere am Recht konkreter historischer Gemeinschaften verstellen.

\section{c Das Inklusionsproblem der Stoffgeschichte}

Der Rechtsbegriff des reinen Stoffs hat ein Adressatenproblem. Er kann nicht erklären, dass und weshalb Recht jenseits seiner geistigen Vermittlung unter Experten verbindlich sein soll. Das Kartell der Stoffkundigen exkludiert diejenigen, die den Stoff zwar nicht zu fassen vermögen, von seinen realen Auswirkungen aber betroffen sind. Dieses Argument mag im Gespräch unter Rechtsexperten außen vor bleiben. Eine rechtshistorische Betrachtung, die sich ihm verschließt, läuft freilich Gefahr, sich in juristischen Tautologien zu verlieren und die gesellschaftliche Bedeutung ihres Gegenstands zu verkennen.

Resümiert man diese drei Kritikpunkte, kommt man zu einer Diagnose, wie sie Hermann Kantorowicz schon vor über hundert Jahren gestellt hat. Er spricht vom

Parallelismus [...] zwischen dogmatischer Jurisprudenz und orthodoxer Theologie. [...] Dort Gott, hier ,der Gesetzgeber’, beides für die Erfahrung unzugängliche Wesen. Ihre Intentionen sind der profanen Masse verborgen oder nur undeutlich bekannt; eine privilegierte Kaste von TheologenJuristen vermittelt ihre Offenbarungen. [...] Der Jurist muss jede Handlung als Recht oder Unrecht, der Theologe jede als Gott wohlgefällig oder verhasst nachweisen können. ${ }^{41}$

Die von Kantorowicz kritisierte dogmatische Innensicht erschwert eine adäquate Behandlung (nicht nur) rechtshistorischer Fragestellungen. Dies gilt ganz besonders für die Epoche der Spätantike, gerade weil die erwähnten Vorstellungen von Recht, Gesetz und Autorität zu guten Teilen in dieser Zeit entstanden sind: „[T]he constructions that have been in long use are often ones that go back to the late antique period itself “42, wie der Althistoriker James O’Donnell bemerkt. Pointiert lässt sich sagen, dass eine Rechtswissenschaft, die als säkulare Theologie betrieben wird, die (im Weber'schen

40 Paul W. Kahn, The Cultural Study of Law: Reconstructing Legal Scholarship, Chicago 1999, 7. 41 Gnæus Flavius [Hermann Ulrich Kantorowicz], Der Kampf um die Rechtswissenschaft, Berlin 1906, 35.

42 James J. O’Donnell, Late Antiquity. Before and After, in: Transactions of the American Philological Association 134 (2004), Nr. 2, $203-213,204$. 
Sinne) „irrationalen“, aber deshalb historisch nicht minder wirksamen und bedeutsamen Dimensionen von Recht zu verkennen droht. Es geht ihr wie der Religionswissenschaft am Ende des 19. Jahrhunderts. Auch sie musste erst den Glauben an ihren Gegenstand suspendieren, um dessen kulturgeschichtliche Grundlagen verstehen zu können. ${ }^{43}$

\section{Elemente einer juridischen Formgeschichte am Beispiel des Codex Theodosianus}

\section{Medialität}

Im letzten Teil meines Vortrags möchte ich gerne eine Alternative skizzieren. In Abgrenzung zur Stoffgeschichte des antiken Rechts kann man sie als Formgeschichte bezeichnen. Ihr Gegenstand sind die juridischen Formen, deren Eigenwert sie anerkennt. Zu ihren Vorteilen gehört es u. a. auch, die juristische Romanistik wieder stärker an die Altertumswissenschaften und an die neuere Kulturgeschichte heranzuführen.

Ausgangspunkt ist der Codex des kaiserlichen Gesetzesrechts in seiner medialen Materialität. Vor aller intellektuellen Textbeherrschung, juristischer Organisationsund Systematisierungsleistung verkörpert das Gesetzbuch, dessen Pionier Theodosius' II. ist, Abgeschlossenheit und Totalität des Texts. Es schafft, in Anlehnung an Walter Ong, ,a sense of closure, a sense that what is found in a text has been finalized, has reached a state of completion“. ${ }^{44}$ Damit ermöglicht es die kontextfreie, generelle Wiederholbarkeit von Texten und sichert so deren beliebigen - abstrakten - Wiedergebrauch. Auch macht es Textstellen leicht auffindbar. Das Buch, so Cornelia Vismann, übt mithin „in den Bestand des kodifizierten Rechts ein. Stereotyp repetierbare ,Merkregeln', kanones, veranschaulichen [...] den Normbestand, sodass sich sagen lässt: Eine ,Codification“ ist die völlige, sinnlich sich darstellende Kanonisation“. ${ }^{45}$ Theodosius kann sich bei seinem Werk bereits auf die Erfahrung mit der Kanonisierung religiöser Texte stützen, insbesondere auf die lateinischen Bibelübersetzungen seit dem Ende des 4. Jahrhunderts (Vetus Latina, Vulgata).

43 Kahn, Cultural Study (Anm. 40), 2. Ähnlich Ulrich Haltern, Recht und soziale Imagination, in: Rechtsanalyse als Kulturforschung, hrsg. von Werner Gephart, Frankfurt a. M. 2012, 89-102, 92 - 93. 44 Walter J. Ong, Orality and Literacy. The Technologizing of the Word, London 2004, 129 (in Bezug auf das Druckmedium).

45 Dazu Vismann, Akten (Anm. 39), 106 mit Zitat aus Theodor von Zahn, Geschichte des neutestamentlichen Kanons, Bd. 1: Das Neue Testament vor Origenes, Leipzig 1888, 60. 


\section{Diffusion}

Neben der Medialität sind es zweitens Prozesse der Vermischung und Diffusion rechtlich-religiöser Konzepte, die es zu beachten gilt. In die eben erwähnten biblischen Texte haben im Zuge ihrer Kanonisierung Ideen und Begriffe des Römischen Rechts, etwa zur guten Regierungspraxis, Eingang gefunden. Walter Ullmann spricht von der „infusion of Roman law and jurisprudence into the bible“ und von einem „soaking of biblical text with Roman terminology and ideas“. ${ }^{46}$ Spiegelbildlich zur „Profanisierung“ (oder Politisierung) der biblischen lässt sich nun auch die Sakralisierung der kanonischen Rechtstexte beobachten. In ihnen formiert sich das Pastorat als spätantike (und für die Zukunft höchst bedeutsame) Regierungsform, die „Herrschaft der Seelen“, deren Inhaber die Herde der gehorsamen Untertanen führt und lenkt und jeden einzelnen - omnes et singulatim - unablässig im Blick hat. ${ }^{47}$ In der Sprache des Codex findet diese Programmatik ihren vollkommenen Ausdruck. Jill Harries hat das so beschrieben: „Through the rhetoric of legislation a moral universe was created, headed by a caring emperor, responsive to problems, but stern with evildoers, in particular his own servants. But imperial laws were far more than an exercise in marketing the emperor; they were also a form of communication, through which the autocrat conferred beneficia on the governed.“ ${ }^{48}$

\section{Performanz}

Die sakrale Dimension des Gesetzes zeigt sich auch in den Berichten zu seiner Verkündung kurz vor der Inkraftsetzung zum 1. Januar 439. Sie trägt die Züge einer veritablen Verkündigung. Die Lesung aus dem ersten Buch des Gesetzes im Hause des Faustus in Rom war von stürmischen Akklamationen des senatorischen Auditoriums begleitet. Die Rezitation der Worte des Kaisers ließen diesen nach zeitgenössischen Schilderungen gleichsam selbst im Raum erscheinen. ${ }^{49}$ Die Kombination von textueller und ritueller Kohärenz, die Performierung des kodifizierten Texts im Ritual, erweist sich vor diesem Hintergrund als wesentliches Element zum Verständnis der großen zeitgenössischen Bedeutung und Ausstrahlung des Codex Theodosianus ins mediterrane Mittelalter.

Es handelt sich bei alledem ganz offensichtlich um eine „Politik der Form“, die in der Inszenierung zur Wirkung gebracht wird. Mit der vis formae hat Pierre Bourdieu einen Begriff eingeführt, der diese eigentümliche Kraft zu erfassen sucht. Im An-

\footnotetext{
46 Walter Ullmann, Law and Politics in the Middle Ages. An Introduction to the Sources of Medieval Political Ideas, London 1975, 42. Im Anschluss daran Niemelä, Law and Universalism (Anm. 38), 323. 47 Nach Michel Foucault, Omnes et Singulatim: Towards a Criticism of „Political Reason“, in: The Tanner Lectures on Human Values 2, hrsg. von Sterling N. McMurrin, Salt Lake City 1981, 223 - 254. 48 Harries, Law and Empire (Anm. 33), 58.

49 Harries, Law and Empire (Anm. 33), 65-66.
} 
schluss an Max Weber erklärt auch er freilich ihre Wirkung vor allem mit der gelungenen Demonstration überlegener Organisation und vollständiger intellektueller Durchdringung des Stoffs. ${ }^{50}$ Wissen, Kürze, Klarheit und das Versprechen allgemeiner Geltung des Gesetzes waren in der Tat zentrale programmatische Anliegen von Theodosius' Werk. Doch sie weisen über die Stoffebene wesentlich hinaus, auf der die Veränderungen ja gerade nicht zu finden waren: „the vast corpus of juristic writings remained untouched. “51 Die Veränderungen lagen vielmehr in der Form und ihrer performativen „Inkraftsetzung“. 52

Die Macht der Form lässt sich mithin erst begreifen, wenn man den Codex Theodosianus nicht in erster Linie als das Produkt misslungener formaler Rationalisierung, sondern von Glauben und Gemeinschaft versteht. Vom Codex adressiert zu werden, war danach weniger eine Frage juristischer ratio als der confessio. Der consensus universorum, ein Statusvertrag zwischen Kaiser und Untertanen, verschaffte dem Gesetzeswerk zwar Legitimität. Geltung aber erhielt es durch die Akklamation, die den Bund, dessen Symbol der Codex war, auf eine religiös konnotierte Ebene erhob. ${ }^{53}$

\section{Hybridisierung}

Bei der Betrachtung der politischen Ausstrahlung der Codex-Form sollte man freilich nicht den Fehler machen, die programmatischen Selbstbeschreibungen der historischen Akteure unbesehen zum Nennwert zu nehmen. Denn diese fanden in einer zunehmend unübersichtlichen und verwirrenden Umgebung konkurrierender Weltdeutungen statt, die sich höchst unterschiedlicher Narrative bedienten. ${ }^{54}$ Das galt auch für die widerstreitenden Richtungen der christlichen Glaubensgemeinschaften: So schreibt James O’Donnell: „There was plenty of competition in the narrative business in those days. Christians of every stripe had found story-telling the way to make their new age, high-tech (because text-based) religion prevail. They created a canon of texts out of the most improbable mix of materials, perhaps only completing that exercise in the fourth century. “55

Die unterschiedlichen Narrative, seien sie christlicher oder heidnischer, römischer oder barbarischer Provenienz, einte der Gebrauch der neuen Technik des Buchs und

50 Pierre Bourdieu, La force du droit, in: Actes de la recherche en sciences sociales 64 (1986), 1-19, $17-18$.

51 Harries, Law and Empire (Anm. 33), 61.

52 Das englische Wort „enactment“ bringt die beiden Bedeutungsfelder „Inkraftsetzung“ und „Inszenierung“ zusammen.

53 Harries, Law and Empire (Anm. 33), 68.

54 Dazu grundlegend Marie Theres Fögen, Die Enteignung der Wahrsager. Studien zum kaiserlichen Wissensmonopol in der Spätantike, Frankfurt a. M. 1997, 183-221.

55 O’Donnell, Late Antiquity (Anm. 42), 205. 
der kulturelle Bezug auf Rom. ${ }^{56}$ Diese Gemengelage schuf die Voraussetzungen für zahllose Hybridisierungsprozesse entlang dieser Unterscheidungslinien, wobei sich der Schwerpunkt im Verlauf der Spätantike allmählich von der Differenz römischbarbarisch auf christlich- heidnisch verschob. ${ }^{57}$ Die begriffliche Engführung von Recht und Konfession verweist dabei deutlich ins Mittelalter: „Paien unt tort e crestiens unt dreit“, wird es dann bekanntlich im Rolandslied heißen. ${ }^{58}$

Damit wird das weite und kontroverse Feld spätantiker Identitätspolitik betreten, auf dem die Rechtsgeschichte aus den dargelegten Gründen bislang nicht so präsent war, wie sie es eigentlich sein sollte. Denn wenn man spätantikes Recht nicht nur als eine Technik der Produktion, Kommunikation und der Domination begreift, sondern (auch) als eine „Technik des Selbst [...], mit denen sich die Subjekte transformieren, modifizieren, einen bestimmten Perfektionsgrad erreichen, einen Glückszustand, einen Stand der Reinheit und der übernatürlichen Macht",59 eröffnet sich der spätantiken Codex-Forschung eine andere Perspektive: Verdichten und vernichten, kanonisieren und kodifizieren von Texten in sakralisierten Formen ist dann nicht Ausdruck von Vulgarisierung und Verfall, sondern die Verfertigung eines neuen politischen Körpers mit einer Herrschaftsform, in deren Zentrum lex, iurisdictio und gubernatio stehen. ${ }^{60}$ Zugleich werden die Anfänge des dualen, ständischen Musters erkennbar, in dem Recht in Europa fortan gedacht wird, nämlich als Gesetz, das von einer ,allmächtigen Autorität“ erlassen wird, die, so der englische Rechtshistoriker Carleton K. Allen, „hoch über der Gesellschaft steht und ihre Befehle von dort erschallen lässt.“ Oder als Volksrecht, als „spontanes Gewächs“, das „unabhängig von einem beherrschenden Willen [...] emporwächst.“61

\section{Ergebnisse in Thesen}

Zum Schluss sollen die Merkmale der hier vorgeschlagenen Sicht auf den Codex Theodosianus noch einmal thesenartig rekapituliert werden. Spätantikes Recht wird in der Rechtsgeschichte nicht selten als autoritär und paternalistisch beschrieben. ${ }^{62}$

56 O’Donnell, Late Antiquity (Anm. 42), 209.

57 Niemelä, Law and Universalism (Anm. 38), 322.

58 Das altfranzösische Rolandslied, zweisprachige Ausgabe, übersetzt und eingeleitet von Wolfgang Steinsieck, Stuttgart 1999, Str. 79 v. 1015, 80-81.

59 Michel Foucault, Richard Sennett, Sexuality and Solitude, in: London Review of Books 3 (1981), Nr. 9, 3-7, 4. Im Anschluss daran Thomas Lemke, Eine unverdauliche Mahlzeit? Staatlichkeit, Wissen und die Analytik der Regierung, in: Michel Foucaults „Geschichte der Gouvernementalität“ in den Sozialwissenschaften. Internationale Beiträge, hrsg. von Susanne Krasmann und Michael Volkmer, Bielefeld 2007, 47-74, 54.

60 Ullmann, Law and Politics (Anm. 46), 33 - 34 et passim.

61 Carleton Kemp Allen, Law in the Making, 7. Aufl., Oxford 1964, $1-2$.

62 Liebs, Römisches Recht (Anm. 25), 83: „autoritäre und das heißt auch: sozialfürsorgerische Züge“. Bretone (Anm. 12), 238, spricht von einer „legalistischen Mentalität.“ 
Diese Kritik am „spätantike[n] Absolutismus“63 erinnert bisweilen an die Urteile, die die historische Schule über die vernunftrechtlichen Kodifikationen, insbesondere den französischen Code und das preußische Allgemeine Landrecht, gesprochen hat. ${ }^{64}$ Es wäre demgegenüber wohl an der Zeit, der Spätantike auch in der Rechtsgeschichte mehr Gerechtigkeit widerfahren zu lassen, und sie nicht zu etwas zu machen, das sie nicht war und auch nicht sein wollte. Der Codex Theodosianus wäre hiernach keine Schwundstufe des Früheren; er wäre schlicht anders konstituiert. „[A] cultural form,“ gibt uns Paul Kahn in dieser Hinsicht zu bedenken, „,is never a failed form of something other than itself. “65

Die hier vorgeschlagene Anschauung anerkennt die Eigenart und den Eigenwert des Rechts zwischen 380 und 565 im Sinne einer besonderen „Sattelzeit“. ${ }^{66}$ Weder stipuliert sie Rangordnungen noch vergleicht sie „Textstufen“, sondern enthält sich wertender Stellungnahmen und verzichtet namentlich auf das Narrativ des klassischen Zeitalters, dessen spätantike Ursprünge sie vielmehr kritisch reflektiert. ${ }^{67}$ Sie bemüht sich, die Okzidentalismen der gängigen Stoffgeschichte zu vermeiden. Mit der Einbeziehung von Aspekten der Reflexivität und des kollektiven Selbst situiert sie schließlich das spätantike Kaiserrecht im Kontext der epochalen Umwälzungen der Zeit. Am Ende des Plädoyers für eine Rechtsgeschichte der juridischen Formen steht zwar nicht unbedingt der Wunsch nach weniger Text, wohl aber der nach mehr Kontext in der juristischen Romanistik und einer Rechtswissenschaft, die mehr Sinn für die „dichte Beschreibung“ (thick description) ${ }^{68}$ entwickelt, ohne die sich die stoffliche Verdichtung, wie gezeigt, kaum adäquat verstehen lässt.

63 Liebs, Römisches Recht (Anm. 25), 76.

64 Savigny, Beruf (Anm. 17), 2 et passim (zum Code civil); ebd., 81 et passim (zum Allgemeinen Preußischen Landrecht).

65 Kahn, Cultural Study (Anm. 40), 92.

66 In Anlehnung an Reinhart Koselleck, Einleitung, in: Geschichtliche Grundbegriffe, hrsg. von Otto Brunner, Werner Conze und Reinhart Koselleck, Bd. 1, Stuttgart 1979, VII-XXVII, XV.

67 O’Donnell, Late Antiquity (Anm. 42), 210-211.

68 Clifford Geertz, Thick Description. Toward and Interpretive Theory of Culture, in: The Interpretation of Cultures. Selected Essays, hrsg. von Clifford Geertz, New York 1973, 3 - 32; deutsch: Clifford Geertz, Dichte Beschreibung. Bemerkungen zu einer deutenden Theorie von Kultur, in: Dichte Beschreibung. Beiträge zum Verstehen kultureller Systeme, hrsg. von Clifford Geertz, Frankfurt a. M. 1987, $7-43$. 


\title{
Wissensorganisation und Wissensvermittlung im ersten Teil von Isidors Etymologiae (Bücher I-X)
}

\begin{abstract}
Isidore of Seville's encyclopaedia played a key role in the transmission of antique knowledge in the Middle Ages. Its first part (books i-x) discusses the artes liberales, law, medicine and the organization of human society at large. Historical and philological evidence suggests that it circulated separately in a number of versions. This paper argues that Isidore wrote this first part for king Sisebut, who was intent on acquiring Latin erudition. A close reading shows that Isidore had assembled basic information, which could be of help for more advanced studies, and that he considered some fields of knowledge to have become obsolete. He selected his material according to his understanding of the language as an epistemological tool, whose origin faithfully reflected the structure of the world.
\end{abstract}

Wer die Etymologiae Isidors von Sevilla konsultiert, ${ }^{1}$ etwa um die Bedeutung eines seltenen Wortes zu klären oder bestimmte Aspekte der antiken Kultur besser zu verstehen, trifft häufig auf kommentarlos aneinandergereihte Klassifizierungen oder Definitionen, die voneinander abweichen oder sich gar widersprechen, und wird in keiner Einleitung und keinem Schlusswort darüber orientiert, welche Ziele Isidor bei seiner Kompilationsarbeit verfolgte. Man mag deshalb in dem Werk eine gedankenlose Anhäufung alten Materials sehen - und eine solche Auffassung war im 19. Jahrhundert weit verbreitet,$-^{2}$ oder aber den Eindruck von Objektivität, von neutraler Darlegung von mitunter abweichenden Lehrmeinungen gewinnen. Zu beiden Ansichten kann allerdings nur ein Leser kommen, der die Enzyklopädie Isidors punktuell betrachtet. Wer die Etymologiae zusammenhängend liest, bemerkt, dass Isidor sein Material nach bestimmten Kriterien ausgewählt und geordnet hat, und kann sogar die grundlegende Einstellung des Autors entdecken. Dies wurde von Jacques Fontaine, der den Bereich

1 Die Etymologiae werden nach der kritischen Edition zitiert, sofern das jeweilige Buch darin erschienen ist. Die Bücher, die noch nicht in der kritischen Edition erschienen sind, werden nach folgender Edition zitiert: Isidori Hispalensis episcopi Etymologiarum sive Originum libri 20, hrsg. von Wallace M. Lindsay, Oxford 1911 (Nachdrucke 1971 und 1989). Zur größeren Klarheit wird in den Fußnoten die jeweils verwendete Edition angegeben.

2 Vgl. die Zusammenstellung bei Arno Borst, Das Bild der Geschichte in der Enzyklopädie Isidors von Sevilla, in: Deutsches Archiv 22 (1966), 1-62, hier 3-6. 
der Artes und der Philosophie untersuchte, ${ }^{3}$ und von Arno Borst, der Isidors Bild der Geschichte in einer sorgfältigen Lektüre freilegte, eindrücklich vorgeführt. ${ }^{4}$ In diesem Aufsatz soll - von der Lektüre des Werkes ausgehend - der Frage nachgegangen werden, welches Verständnis von Wissen und Wissensvermittlung in den Etymologiae erkennbar ist. Dazu wird der erste Teil der Etymologiae (Bücher I-X) herangezogen, der sich in Ansatz und Konzept vom zweiten Teil (Bücher XI-XX) unterscheidet: Der erste stellt nämlich ein Wissenskompendium dar, während der zweite eine Beschreibung der Welt, vom Himmel bis zu den Werken des Menschen, enthält. Es besteht die begründete Vermutung, dass der erste Teil vor dem zweiten entstand und wohl auch alleine zirkulierte, was in einem einleitenden Abschnitt dargelegt wird. Daraufhin werden die thematischen Schwerpunkte besprochen, die Isidor für seine Enzyklopädie setzte. Es folgt eine Diskussion darüber, wie Isidor seine Quellen verwendete und was sich aus der Strukturierung des Materials lernen lässt, wobei einige Aussagen aus der Enzyklopädie herangezogen und im Kontext dieser Fragestellung interpretiert werden. Zum Schluss werden die Ergebnisse im Hinblick auf die historische Situation Isidors und die zeitgenössischen Leser gedeutet.

\section{Die Entstehung der Etymologiae}

Über die Entstehung der Etymologiae lassen sich einige Informationen aus einem kleinen Briefcorpus gewinnen, das in einzelnen Handschriften dem Werk vorangestellt wurde: ${ }^{5}$ sieben Briefe, die zwischen Isidor und seinem jüngeren Freund Braulio von Zaragoza ausgetauscht wurden, und ein Widmungsbrief, der den anderen zeitlich vorangeht. Dieser letzte Text ist sehr knapp gehalten und an Sisebut (König der Westgoten zwischen 612 und 621) gerichtet. In ihm bezieht sich Isidor auf ein Werk „über den Ursprung einiger Sachen“, das er dem König versprochen hatte:

3 Jacques Fontaine, Isidore de Séville et la culture classique dans l'Espagne wisigothique, Paris 1959 und Jacques Fontaine, Isidore de Séville et la culture classique dans l'Espagne wisigothique, Bd. 3, Notes complémentaires et supplément bibliographique, Paris 1983.

4 Borst, Bild (Anm. 2).

5 Die Briefe von und an Braulio werden nach folgender Edition zitiert: José Madoz, Epistolario de San Braulio de Zaragoza. Edición crítica según el códice 22 del Archivo Capitular de León con una introducción histórica y comentario, Madrid 1941, ep. I-VIII, 71-88. Die Nummerierung in etym. Ed. Lindsay, die von derjenigen von Madoz abweicht, wird ergänzend in Klammern angegeben. In der Ed. Lindsay (die unpaginiert ist) finden sich die Briefe vor dem Haupttext als ep. A, B und I-VI. Der Widmungsbrief an Sisebut wird nach etym. Ed. Lindsay zitiert, weil er im Codex von León nicht überliefert ist und deshalb von Madoz aus der Ed. Lindsay übernommen wurde. Es gibt eine weitere Edition der Briefsammlung Braulios: Luis Riesco Terrero, Epistolario de San Braulio, Sevilla 1975, 62 76 (die Zählung der Briefe stimmt in dieser Edition mit derjenigen in der Ed. Madoz überein). Der Text der drei Editionen wurde verglichen, die Varianten in den zitierten Texten verändern den Inhalt nicht und wurden deshalb außer Acht gelassen. 


\section{Domino et filio Sisebuto Isidorus.}

En tibi, sicut pollicitus sum, misi opus de origine quarundam rerum ex ueteris lectionis recordatione collectum atque ita in quibusdam locis adnotatum, sicut extat conscriptum stilo maiorum. ${ }^{6}$

Diese knappe Beschreibung passt gut zu den Etymologiae, wie wir sie kennen: Der Fokus liegt auf dem Ursprung der besprochenen Begriffe, Gegenstände und Sachverhalte und das Werk setzt sich mehrheitlich aus Paraphrasen und genaueren Zitaten aus älteren Texten zusammen. Es hat also vorerst den Anschein, als habe Isidor die Etymologiae für den gelehrten König Sisebut geschrieben. Dies scheint plausibel, wenn man die Beziehung zwischen König und Bischof und ihren erkennbaren Einfluss auf das Schaffen Isidors berücksichtigt. Sisebut bat ihn ausdrücklich um die Abfassung von De rerum natura und mag allgemein hinter der Erweiterung seines Themenspektrums stehen, die sich während der Regierungszeit Sisebuts erkennen lässt. ${ }^{7}$ Der Bischof, der bis dahin vor allem als Exeget tätig gewesen war, verfasste nun eine Reihe von Werken, die den Interessen und sogar der Politik Sisebuts entsprachen: den Traktat De fide adversus Iudaeos, ${ }^{8}$ zwei historische Werke (die Chronica und De origine Gothorum, Wandalorum, Suevorum, das auch als Historiae bekannt ist) und die Sententiae, in denen eine Ethik für alle sozialen Gruppen - auch für die Regierenden entworfen wird. ${ }^{9}$ Besonders die historiographischen Werke reflektieren die Politik der Integration von germanischer und hispano-römischer Bevölkerung auf der Halbinsel, welche die Könige seit Leowigild (569-586) vorangetrieben hatten. ${ }^{10}$ Sisebut selbst

6 Ep.VI in etym. Ed. Lindsay, ep.VII Ed. Madoz (dort Text aus der Ed. Lindsay). In vielen Handschriften der Etymologiae wird Braulio als Widmungsempfänger genannt, was eine spätere Anpassung sein dürfte, die sogar auf den Autor zurückgehen kann, dazu José Carlos Martín, La Renotatio librorum Domini Isidori de Braulio de Zaragoza (+ 651). Introducción, edición crítica y traducción, Logroño 2002, 90-92; auch in Scripta de vita Isidori Hispalensis episcopi, hrsg. von José Carlos Martín, Turnhout 2006, in: CC SL 113B, 78-79. Die Ed. Riesco, 76, nimmt die Widmung an Braulio in den Text auf. 7 Zur Beziehung zwischen Sisebut und Isidor siehe José Carlos Martín, Sisebuto, in: La Hispania visigótica y mozárabe. Dos épocas en su literatura, hrsg. von Carmen Codoñer, Salamanca 2010, 191 196 und Yitzak Hen, Roman Barbarians. The Royal Court and Culture in the Early Medieval West, New York 2007, 149-151.

8 Der Traktat ist zwar Isidors Schwester Florentina gewidmet, behandelt allerdings ein Thema, das Sisebut besonders am Herzen lag. Der König beschloss gegen den Rat Isidors, die Juden zur Bekehrung zu zwingen, was weitreichende Folgen haben sollte. Dazu Alexander P. Bronisch, Die Judengesetzgebung im katholischen Westgotenreich von Toledo, Hannover 2005.

9 Die Sententiae finden sich unter den Quellen von Sisebuts Vita Desiderii, dazu José Carlos Martín, Une nouvelle édition critique de la Vita Desiderii de Sisebut, accompagnée de quelques réflexions concernant la date des Sententiae et du De uiris illustribus d'Isidore de Séville, in: Hagiographica 7 (2000), $127-163$, hier 134-142.

10 Zur Darstellung der Westgoten in den Chronica maiora siehe Jamie Wood, Religiones and gentes in Isidore of Seville's Chronica maiora, in: Post-Roman Transitions. Christian and Barbarian Identities in the Early Medieval West, hrsg. von Walter Pohl und Gerda Heydemann, Turnhout 2013, 125 - 168. Zur Politik der westgotischen Könige ab Leowigild siehe die neueren Übersichten bei Roger Collins, Visigothic Spain. 409-711, Malden u.a. 2004, 50-91 und Gerd Kampers, Geschichte der Westgoten, 
hat eigene literarische Werke hinterlassen (eine Vita Desiderii, ein Isidor gewidmetes Carmen de luna und mehrere Briefe), die von einer beeindruckenden Beherrschung der lateinischen Literatursprache zeugen. ${ }^{11}$

Doch geht aus den Briefen eine längere und kompliziertere Entstehungsgeschichte hervor. In einem Brief, den Braulio ungefähr zwischen 625 und 627 (vier Jahre nach Sisebuts Tod $)^{12}$ an Isidor richtete, bittet er um die Zusendung des Etymologiae-Buches, das Isidor auf seine Bitten hin verfasst habe:

Suggero sane et omnimoda supplicatione deposco, ut librum Etymologiarum, quem iam fauente Domino audiuimus consummatum, promissionis uestrae memores seruo uestro dirigere iubeatis, quia, ut mihi conscius sum, magna ibi ex parte serui tui postulatione sudasti. ${ }^{13}$

Sieben Jahre später (632) ${ }^{14}$ hatte Braulio den Text noch nicht bekommen, worüber er in einem weiteren Brief klagt:

Septimum, ni fallor, annum tempora gyrant, ex quo memini me libros a te conditos Originum postulasse, et uario diuersoque modo et praesentem me frustratum esse, et absenti nihil in inde uos rescripsisse, sed subtili dilatione modo necdum esse perfectos, modo necdum esse scriptos, modo meas litteras intercidisse, aliaque multa oppontes ad hanc usque diem peruenimus et sine petitionis effectu manemus. ${ }^{15}$

Besonders verärgert ist Braulio darüber, dass bereits einige Exemplare des Werkes im Umlauf seien, die er als „unvollständig und mit einem fehlerhaften Text“ charakterisiert, weshalb er das Werk erneut mit Nachdruck von Isidor verlangt, und zwar in einer korrekten, vollständigen, überprüften und wohlgeordneten Abschrift:

Ergo et hoc notesco, libros Etymologiarum, quos a te, domino meo, posco, etsi detruncatos conrososque iam a multis haberi. Inde rogo ut eos mihi transcriptos, integros, emendatos et bene coaptatos dignemini mittere, ne raptus auiditate in peruersum, cogar uitia pro uirtutibus ab aliis sumere. ${ }^{16}$

Paderborn u. a. 2008, 177 - 196, zur Widerspiegelung dieser Politik in den Gesetzen siehe Collins, ebd., 223 - 246, zu deren gesellschaftlichen Auswirkungen Kampers, ebd., 272-280.

11 Zum literarischen Werk Sisebuts siehe Martín, Sisebuto (Anm. 7), mit Auflistung der Editionen und weiterführender Literatur. Zur Rolle des Königs in der Kultur seiner Zeit siehe Hen, Roman Barbarians (Anm. 7), 124-152.

12 Ep. III Ed. Madoz, 74-77 (ep. II in etym. Ed. Lindsay). Dieser Brief wird in Bezug zu ep. V (IV in etym. Ed. Lindsay) gesetzt, wo Braulio sagt, sieben Jahre seien vergangen, seitdem er seine Bitte geäußert habe.

13 Ep. III Ed. Madoz, Z. 20-24, 76-77 (ep. II in etym. Ed. Lindsay).

14 Im Brief erwähnt Braulio, dass der Bischofssitz von Tarracona vakant sei. Bischof Eusebius verstarb 632, sein Nachfolger Audax unterschrieb im Dezember 633 die Akten des IV. Toledanischen Konzils. Zu dieser Datierung siehe Carlos H. Lynch und Pascual Galindo, San Braulio obispo de Zaragoza (631651). Su vida y sus obras, Madrid 1950, 54-55.

15 Ep. V Ed. Madoz, Z. 16-22, 80 - 81 (ep. IV in etym. Ed. Lindsay).

16 Ep.V Ed. Madoz, Z. 92-96, $83-84$ (ep. IV in etym. Ed. Lindsay). 
Isidor antwortet (wohl kurz darauf) ${ }^{17}$ mit einem Brief aus Toledo, wo er sich befand, weil König Sisenand ein Konzil einberufen hatte und seine Entscheidung, dieses zu vertagen, Isidor erst erreichte, als er bereits Toledo näher als Sevilla war. Da er sich sehr krank fühle und nicht wisse, ob er am geplanten Konzil werde teilnehmen können, wenn es denn stattfinde, habe er Braulio bereits den Codex der Etymologiae gesendet, den er ihm eigentlich persönlich hätte übergeben wollen:

Codicem Etymologiarum cum aliis codicibus de itinere transmisi, et, licet inemendatum prae ualetudine, tamen tibi modo ad emendandum studueram offerre, si ad destinatum concilii locum peruenissem. ${ }^{18}$

Es gibt noch einen Nachtrag zum Inhalt dieses Briefcorpus. Nach Isidors Tod stellte Braulio einen Katalog von dessen Werken zusammen, in dem er als letztes die Etymologiae aufführt. Isidor habe sie auf Braulios Bitte geschrieben, sie nach tituli geordnet und unvollständig hinterlassen. Braulio habe sie dann nach Isidors Tod in zwanzig Bücher gegliedert:

Etymologiarum codicem nimiae magnitudinis distinctum ab eo titulis, non libris, quem quia rogatu meo fecit, quamuis imperfectum ipse reliquerit, ego in uiginti libros diuisi. ${ }^{19}$

Diese Texte legen nahe, dass es mindestens zwei Fassungen des Werkes gegeben hat, nämlich eine, die Isidor König Sisebut widmete, und eine, die er für Braulio schrieb. Da Braulio seine eigene Anregung als Anstoß für das Werk ansieht, dürfte der Unterschied zwischen beiden wesentlich gewesen sein. ${ }^{20}$

17 Auch Isidor erwähnt den vakanten Stuhl von Tarracona (siehe oben Anm. 14). Dieses abberufene Konzil, von dem es keine weiteren Zeugnisse gibt, dürfte zum Ende des Jahres 632 oder Beginn des Jahres 633 einberufen worden sein, siehe dazu Madoz, Epistolario (Anm. 5), 41 und Lynch/Galindo, San Braulio (Anm. 14), 56-57. König Sisenand hatte sich ohnehin sehr lange Zeit gelassen, um das erste Konzil seiner Regierungszeit einzuberufen; die Gründe dafür sind unbekannt, siehe dazu José Orlandis und Domingo Ramos Lissón, Die Synoden auf der Iberischen Halbinsel bis zum Einbruch des Islam (711), Paderborn u. a. 1981, 145 - 146. Isidor entsprach wohl schnell der Bitte, die Braulio in ep. $\mathrm{V}$ so vehement ausgedrückt hatte, denn es blieb ihm nicht mehr viel Zeit, um sie zu erfüllen. Isidor verstarb nämlich am 4. April 636.

18 Ep. VI Ed. Madoz, Z. $12-15$, 87. (ep. V in etym. Ed. Lindsay)

19 Martín, La Renotatio (Anm. 6), 262, Z. 34-36.

20 Dieser Widerspruch ist auch anders interpretiert worden. Díaz vermutet, dass das Werk vom Anfang an auf Anregung von Braulio entstand, der König sich aber dafür interessierte und es ihm deshalb von Isidor gewidmet wurde (Manuel C. Díaz y Díaz, Introducción general, in: Isidoro de Sevilla. Etimologías, hrsg. von José Oroz Reta und Manuel A. Marcos Casquero, Madrid 1982 (Neudruck Madrid 2004), 7 257, hier 172 - 174). Dagegen wendet Martín ein, dass Braulio wohl zu jung und (als einfacher Diakon von Zaragoza) zu unbedeutend war, um sich einige Jahre vor 621 vom Bischof von Sevilla ein Werk dieses Umfangs zu wünschen. Martín selbst vermutet, dass Braulio sich lediglich auf eine Abschrift der Etymologiae bezieht, doch scheint mir das mit dem Wortlaut der Nachrichten nicht vereinbar (Martín, La Renotatio (Anm. 6), 89 - 94, sowie Scripta (Anm. 6), 76 - 89; zur Biographie von Braulio ebd., 15 46, sowie Scripta (Anm. 6), 15- 48. 
Die Untersuchung der Überlieferung mit dem Ziel, stemmatische Beziehungen zu bestimmen und somit die Grundlage für eine sichere Edition zu liefern, hat auch Licht in die Entstehungsgeschichte gebracht. Die Untersuchungen von Porzig und von Reydellet haben gezeigt, dass es zwei große Redaktionen des Werkes gibt, von denen eine - die kürzere - als ältere bestimmt werden kann. ${ }^{21}$ In einzelnen Handschriften dieser Redaktion finden sich Spuren einer früheren Gliederung des ersten Teils in drei Bücher: ein liber primus umfasste die jetzigen Bücher I-III; zum liber secundus gehörten die Bücher V und VI, der liber tertius enthielt die Bücher VII bis X. Buch IV (über die Medizin) dürfte später dazugekommen sein, denn es wird in der Überlieferung unterschiedlich eingereiht. In anderen Handschriften der kürzeren Redaktion gibt es eine Gliederung des ersten Teils in zehn Bücher, die von der üblichen Aufteilung abweicht. Dieser Befund legt nahe, dass es eine frühere Redaktion des ersten Teils mit oder ohne Medizin und mit einer Gliederung in drei Büchern gab. Die Handschriften, die noch Hinweise darauf enthalten, sind wohl auf Exemplare zurückzuführen, die nach dem Vorbild von Braulios Rezension aktualisiert wurden. Die Aktualisierung bestand in der Neugliederung des ersten Teils in zehn Bücher, die meistens getreu nach Braulios Einteilung, aber vereinzelt auch nach eigenem Gutdünken der Schreiber durchgeführt wurde, und vermutlich in der Ergänzung durch den zweiten Teil, in dem sich keine Hinweise auf eine frühere Textstufe finden und der wohl nach dem ersten entstand. ${ }^{22}$

Diese Erklärung des Befundes impliziert mehrere Textzustände: einer umfasst den ersten Teil mit der Gliederung in drei Bücher, ein zweiter die kürzere Redaktion des vollständigen Textes und der dritte die längere Redaktion, ebenfalls den vollständigen Text enthaltend. Es ist sehr viel spekuliert worden, wie der Befund aus der Überlieferung mit den Angaben im Briefkorpus und in der Renotatio in Einklang gebracht werden kann. Die Diskussion wurde kürzlich von Carmen Codoñer kritisch zusammengefasst, ${ }^{23}$ hier interessiert uns vor allem die Frage, ob eine dieser Textstufen mit

21 Ich gebe hier nur eine sehr geraffte Zusammenfassung der Diskussion und eine vereinfachte Darstellung der stemmatischen Untersuchung. Für die Frage der Redaktionen sind vor allem relevant Walter Porzig, Die Rezensionen der Etymologiae des Isidorus von Sevilla, in: Hermes 72 (1937), 129170; Marc Reydellet, La diffusion des Origines d'Isidore de Séville au Haut Moyen Âge, in: Mélanges de l’École Française de Rome 78 (1966), 383 - 437. Der letzte Stand der Forschung zur Textüberlieferung der Etymologiae findet sich in Carmen Codoñer, Isidorus Hispalensis ep. Etymologiae, in: La trasmissione dei testi latini del Medioevo. Medieval Latin Texts and their Transmission. Bd. 2, hrsg. von Paolo Chiesa und Lucia Castaldi, Firenze 2005 (Strumenti e studi n.s. 10), 274-299.

22 Die Annahme, der zweite Teil sei nach dem ersten entstanden, lässt sich nicht nur text- und überlieferungskritisch, sondern auch inhaltlich abstützen. So konnte Fontaine in seinem Vergleich zwischen einem Buch aus dem ersten Teil (Buch III) und einem aus dem zweiten Teil (Buch XIII), die zum Teil dieselben Themen behandeln, feststellen, dass Buch III vor Buch XIII entstanden sein muss; dazu Fontaine, Isidore (Anm. 3), 583-585.

23 Die Schwierigkeiten, den Befund in den Handschriften mit den Angaben in den Schriften von Isidor und Braulio zu vereinbaren, werden prägnant auf den Punkt gebracht von Carmen Codoñer, Problemas de transmisión en la primera parte de las Etimologías: algunas reflexiones, in: L'édition critique des œuvres d'Isidore de Séville. Les récensions multiples. Actes du colloque organisé à la Casa de Velázquez et à l’Université Rey Juan Carlos de Madrid (14-15 janvier 2002), hrsg. von María Adelaida Andrés 
der Sisebut-Fassung identifiziert werden kann. Die Länge des Werkes muss zwischen beiden Fassungen stark zugenommen haben, da Isidor an der zweiten, der BraulioFassung, für die er bereits auf die erste als Vorlage zurückgreifen konnte, länger als elf Jahre arbeitete, vielleicht sogar wesentlich länger, denn Braulio erwartete 625 bereits ein vollendetes Werk. Es wäre möglich, dass der erste Teil mit der Gliederung in drei Bücher mindestens im Konzept der Sisebut-Fassung entspricht, dass er einzeln zirkulierte (wovon Spuren geblieben sind) und dass Braulio dessen Abschriften für unvollständige Exemplare des von ihm gewünschten Werkes hielt. ${ }^{24}$ Allerdings ist auch denkbar, dass nur einzelne Bücher aus dem ersten Teil zur Sisebut-Fassung gehörten. Die Frage ist nicht abschließend zu beantworten, es ist aber wichtig festzuhalten, dass der erste Teil sehr wahrscheinlich separat konzipiert wurde und auch separat zirkulierte, und dass Isidor am Beginn seiner Arbeit die Interessen eines Laienpublikums, nämlich des Königs und dessen Entourage, vor Augen hatte.

\section{Die thematischen Schwerpunkte}

Die Präsenz der weltlichen Wissenschaften ist im ersten Teil der Etymologiae augenfällig, sogar tonangebend. Isidor beginnt mit einer Darlegung der sieben Artes liberales (Bücher I-III), zu denen zwei weitere Wissensgebiete, die gelegentlich zu den Artes gezählt wurden, hinzukommen: Medizin (Buch IV) und Recht (Va und VIa). Erst nach Buch V kommt religiöses Wissen überhaupt vor: Die Darlegung des weltlichen Rechtes (Va) wird von einer Einführung in die Heiligen Schriften (das göttliche Gesetz) in VIa ergänzt. Der Bereich der Zeitrechnung, der für die Kirche eine entscheidende Bedeutung hat (VIb), vervollständigt wiederum eine Übersicht der Zeitrechnung in der menschlichen Gesellschaft - auch vor und außerhalb der Kirche (Vb). Die letzten Bücher sind unter anderem anhand von Dichotomien strukturiert: die erste ist die von Himmelreich (VII) und menschlicher Gesellschaft (VIII und IX). Die Gesellschaft wiederum teilt sich in einen religiösen (VIII) und einen außerreligiösen Bereich (IX), der religiöse Bereich gliedert sich in Kirche und Judentum einerseits (VIIIa) und Heidentum andererseits (VIIIb). Buch X, eine wörterbuchartige Vokabelliste, lässt sich schlecht in diese Struktur einpassen; Carmen Codoñer vermutet deshalb, es sei als Ergänzung zu den früheren Büchern konzipiert worden. ${ }^{25}$

Das Interesse für das weltliche Wissen an sich zeigt sich auch darin, dass Isidor die Behandlung der Artes anders als Augustinus oder Cassiodor nicht mit ihrem Nutzen für

Sanz, Jacques Elfassi und José Carlos Martín (Collections des Études Augustiniennes. Série Moyen Âge et Temps Modernes 44), Paris 2008, $195-198$.

24 Bereits Porzig, Die Rezensionen (Anm. 21), nahm an, dass der erste Teil mit seiner Gliederung in drei Bücher der Sisebut-Fassung entsprach. Lynch vermutet hingegen, dass Isidor dem König nur Teile aus einem Werk, das er von Anfang an auf Anregung Braulios verfasste, gewidmet habe (in Lynch/ Galindo, San Braulio (Anm. 14), 50-51).

25 Codoñer, Isidorus (Anm. 21), 297. 
die Bibelexegese begründet. Ganz im Gegenteil betont er am Beginn von Buch I und von Buch II den Wert von Rhetorik und Dialektik für die öffentlichen Angelegenheiten:

Disciplinae liberalium artium septem sunt. Prima grammatica, id est loquendi peritia. Secunda rhetorica, quae propter nitorem et copiam eloquentiae suae maxime in ciuilibus quaestionibus necessaria existimatur. ${ }^{26}$

Rhetorica est bene dicendi scientia in ciuilibus quaestionibus, eloquentia copia ad persuadendum iusta et bona. ${ }^{27}$

Isidor verwendet sogar christliche Quellen, um daraus Informationen über das antike Wissen zu gewinnen. Fontaine hat in seiner grundlegenden Untersuchung zur Präsenz der antiken Kultur im Werk Isidors zeigen können, dass viele Zitate antiker Autoren und viele Informationen $\mathrm{zu}$ den weltlichen Wissenschaften patristischen Quellen entnommen wurden. Dies geht so weit, dass Isidor mit großer Wahrscheinlichkeit sein Vorbild Varro, dem er im Verständnis der Etymologie und im Aufbau der Enzyklopädie folgt, lediglich indirekt, vor allem aus Zitaten in patristischen Schriften kannte. ${ }^{28}$

Isidor streut zwar einige ablehnende Sätze über das Heidentum ein, entwickelt aber nie eine Polemik gegen das heidnische Wissen, das er aufnimmt. In diesem Kontext ist die Lektüre des langen Abschnittes über die heidnischen Götter aufschlussreich. An wenigen Stellen äußert Isidor eine entschiedene Ablehnung des Heidentums, so sagt er etwa, dass der Prozess der Vergöttlichung besonderer Menschen von Künstlern und Dichtern bewusst zur Täuschung betrieben wurde: In quorum etiam laudibus accesserunt et poetae, et conpositis carminibus in caelum eos sustulerunt. ${ }^{29}$ Eine Schuld treffe auch die Bildhauer, die Statuen dieser Menschen schufen. Die Teufel profitierten von der Vorarbeit der menschlichen Künstler und bemächtigten sich dieser Statuen, um die Menschen zu täuschen und sie zu ihrer Anbetung und Verehrung $\mathrm{zu}$ bewegen. ${ }^{30}$ Cupido soll gar ein Teufel sein: Cupidinem vocatum ferunt propter amorem. Est enim daemon fornicationis. ${ }^{31}$ Die langen Listen von euhemeristischen Erklärungen, in die diese Aussagen integriert sind, können als Unterstützung dieser polemischen Einstellung interpretiert werden. Anders verhält es sich mit der Erklärung von Mythen als erzählerischer, allgemein zugänglicher Darstellung von Naturphänomenen. Zuerst distanziert sich Isidor davon und behauptet, dass die

26 Etym. I, 2, 1, Ed. Lindsay.

27 Etym. II, 1, 1, zitiert nach Isidorus Hispalensis. Etymologiae II. Isidore of Seville. Etymologies. Book II. Rhetoric, hrsg. von Peter K. Marshall, Paris 1983, 23.

28 Siehe die zusammenfassende Bewertung in Fontaine, Isidore (Anm. 3), 784-806; zu Isidors Kenntnis von Varro siehe ebd., 749, sowie die punktuellen Präzisierungen und Aktualisierungen in Fontaine, Notes (Anm. 3), 1153-1158, zu Varro 1147-1148.

29 Etym. VIII, 11, 2, Ed. Lindsay.

30 Simulacrorum usus exortus est, cum ex desiderio mortuorum constituerentur imagines uel effigies, tamquam in caelum receptis, pro quibus se in terris daemones colendi supposuerunt, et sibi sacrificari a deceptis et perditis persuaserunt. Etym. VIII, 11, 5, Ed. Lindsay.

31 Etym. VIII, 11, 80, Ed. Lindsay. 
vermeintliche Aufdeckung philosophischer Wahrheiten in den Mythen nur ein Versuch der Heiden sei, diese Lügengeschichten zu rechtfertigen.

Quaedam autem nomina deorum suorum gentiles per uanas fabulas ad rationes physicas conantur traducere, eaque in causis elementorum conposita esse interpretantur. Sed hoc a poetis totum fictum est, ut deos suos ornarent aliquibus figuris, quos perditos ac dedecoris infamia plenos fuisse historiae confitentur. ${ }^{32}$

Im Kontrast - man möchte fast sagen: im Widerspruch - dazu stehen die physikalischen Mythenerklärungen, die Isidor zahlreich und kommentarlos aufführt. Für diesen Abschnitt über die Götter sind wir in der glücklichen Situation, die genauen Quellen zu kennen und zur Verfügung zu haben. Wie Katherine McFarlane in einer detaillierten Untersuchung nachgewiesen hat, stammen Isidors Informationen zum größten Teil aus Augustinus’ De ciuitate Dei. ${ }^{33}$ Dort sind sie in eine polemische Auseinandersetzung mit dem Heidentum eingebettet, als Beispiele für die Gefährlichkeit des heidnischen Glaubens, der vom Teufel gesteuert wird und auf Täuschung basiert. Diese Polemik ist in den Etymologiae auf wenige Sätze reduziert, während die naturphilosophischen Erklärungen selbst die zentrale Stelle einnehmen. ${ }^{34}$

In der Makrostruktur des Textes zeigt sich die Tendenz zu binären Verteilungen, in denen das Heidentum vom Judentum und Christentum geschieden wird, in der Mikrostruktur werden hingegen die drei Religionen nebeneinander aufgeführt, wenn das vom definierten Wortschatz her angebracht ist. Ein Beispiel dafür findet sich etwa in etym.VI, 19 De officiis, wo liturgische Fragen besprochen werden. Isidor definiert zuerst die liturgischen Feiern, geht dann zu den liturgischen Gebeten und ihrer musikalischen Aufführung über, erklärt anschließend hebräische Wörter, die in der Liturgie vorkommen, und daraufhin die Termini, die für die Eucharistiefeier verwendet werden: offertorium, munus (im Unterschied zu donum), sacrificium. Die Definition, die Isidor für dieses letzte Wort gibt, trifft sowohl für die christliche Eucharistie als auch

32 Etym. VIII, 11, 29, Ed. Lindsay.

33 Katherine N. MacFarlane, Isidore of Seville and the pagan gods (Origines VIII.11), in: Transactions of the American Philosophical Society n.s. 70 (1980), 3-40.

34 Im Vergleich zu früheren Autoren fällt Isidors Polemik insgesamt milde aus, dazu Petra Korte, Die antike Unterwelt im christlichen Mittelalter. Kommentierung - Dichtung - philosophischer Diskurs, Frankfurt am Main u. a. 2012 (Tradition - Reform - Innovation 16), 77 - 94 und Carmen Cardelle de Hartmann, Bücher, Götter und Leser: Theodulfs Carmen 45, in: Karolingische Klöster. Wissenstransfer und kulturelle Innovation, hrsg. von Julia Becker, Tino Licht und Stefan Weinfurter, Berlin 2014 (Materiale Textkulturen 4), 39-51, hier 45 - 47. Jacques Fontaine, Le „sacré“ antique vu par un homme du VII siècle: le livre VIII des Etymologies d'Isidore de Séville, in: Bulletin de l'Association Guillaume Budé 48 (1989), 394-405, hier 339-400, sieht darin vor allem eine Desakralisierung antiker Mythologie im Gefolge von Varro und von Dichtern wie Ovid und Horaz, die Isidor auch zitiert. Zur kritischen Einschätzung der naturphilosophischen Allegorese durch christliche Autoren vor Isidor siehe Paule Demats, Fabula. Trois études de mythographie antique et médiévale, Genève 1973, 37 - 54, und Jean Pépin, Mythe et allégorie: les origines grecques et les contestations judéo-chrétiennes, Paris 1976, $315-322,365-392,431-442$. 
für heidnische Opfer zu, ohne dass dies offen thematisiert wird. Anders verhält es sich bei den anschließenden Begriffen immolatio, hostia, uictima, holocaustum, in denen die alte und die neue Bedeutung aneinandergereiht werden, oder aber nur die alte Bedeutung erläutert wird. Ich zitiere diesen Abschnitt auszugsweise:

Sacrificium autem est uictima et quaecumque in ara cremantur seu ponuntur ... Immolatio ab antiquis dicta eo quod in mole altaris posita uictima cederetur ... Nunc autem immolatio panis et calicis conuenit, libatio autem tantummodo calicis oblatio est ... Libare ergo proprie fundere est, sumptumque nomen ex Libero quodam, qui in Graecia usum repperit uitis. Hostiae apud ueteres dicebantur sacrificia quae post uictoriam, deuictis hostibus, immolabant ... Olocaustum illud est, ubi totum igne consumitur quod offertur. Antiqui enim cum maxima sacrificia administrarent, solebant totas hostias in sacrorum consumere flamma, et ipsa erant olocaustomata. ${ }^{35}$

Wie man an diesen Sätzen sehen kann, stellt Isidor zwei Epochen - die der Alten (antiqui, veteres) einerseits, seine Gegenwart (nunc) andererseits - gegenüber. Der Text zeigt, dass unter den Alten zwei Gruppen zu verstehen sind: sowohl die Juden (die erklärten Wörter kommen auch in der lateinischen Bibel vor) als auch die heidnischen Römer, wie die Verwendung eines Götternamens mit einer euhemeristischen Erklärung (Liber) erkennen lässt. Diese Gegenüberstellung und die selbstverständliche Bezugnahme auf das Heidentum in einer liturgischen Erklärung zeigen, dass der religiöse Unterschied vor allem als epochaler Bruch und nicht als gegenwärtiges Problem thematisiert wird.

In diesem Wissenskompendium gibt es aber einen Bereich, der in auffälliger Weise nur kurz behandelt wird, nämlich die Philosophie. Ihre nachrangige Stellung ist deshalb bemerkenswert, weil Isidor ausdrücklich sagt, es gebe zwei Wissenschaften, die in ihrer Betrachtung des Menschen umfassend seien, die Medizin und die Philosophie: Hinc est quod Medicina secunda Philosophia dicitur. Vtraque enim disciplina totum hominem sibi vindicat. Nam sicut per illam anima, ita per hanc corpus curatur. ${ }^{36}$ Die Medizin findet eine separate Behandlung, während die Philosophie nur kurz, in der Aufzählung und kurzen Charakterisierung der philosophischen Schulen (etym. VIII, 6), diskutiert wird. Wie Carmen Codoñer beobachtet hat, ist die spekulative Philosophie sogar in der Einteilung der Philosophie etym. II, 24, 3 abwesend und der Anteil der Artes am spekulativen Denken bleibt unberücksichtigt. ${ }^{37}$ Der Bereich des Metaphysischen wird in den Etymologiae durch die christliche Offenbarung und nur durch sie abgedeckt. Dies kommt an einer Stelle zum Ausdruck, in der die Artes als Grundlage für ein Denken, das die irdische Realität transzendiert, charakterisiert werden. Am Ende von Buch III heißt es, die Artes seien in dieser Reihenfolge, mit der

35 Etym. VI, 19, 30 - 35, zitiert nach Isidorus Hispalensis. Etymologiae VI. Isidoro de Sevilla. Etimologías. Libro VI. De las sagradas escrituras, hrsg. von César Chaparro Gómez, Paris 2012, 133 - 135. 36 Etym. IV, 13, 5, Ed. Lindsay.

37 Carmen Codoñer, Influence isidorienne sur l'évolution des artes liberales, in: L'Europe héritière de l'Espagne wisigothique. Colloque international du CNRS tenu à la Fondation Singer-Polignac (Paris, 14-16 Mai 1990), hrsg. von Jacques Fontaine und Christine Pellistrandi, Madrid 1991, 231-241. 
Astronomie am Ende, diskutiert worden, damit diejenigen, die in der weltlichen Wissenschaft unterrichtet wurden, ihren Geist auf das Himmlische richteten:

Ordo autem iste septem saecularium disciplinarum ideo a philosophis usque ad astra perductus est scilicet ut animos saeculari sapientia implicatos a terrenis rebus abducerent et in superna contemplatione conlocarent. ${ }^{38}$

\section{Die Auswahl aus den Quellen}

Im vorherigen Abschnitt wurde bereits ein leitendes Interesse bei der Auswahl der Quellen erwähnt, und zwar die Gewinnung von antikem Wissen. Ein weiteres lässt sich erkennen, nämlich die Bevorzugung von Grundwissen. Es sei vorausgeschickt, dass die Frage nach den Quellen nicht abschließend geklärt werden kann, denn Isidor hat offenbar auch etliches Material, das für uns verloren ist, zur Verfügung gehabt. Dem bereits zitierten Jacques Fontaine ist eine grundlegende Untersuchung des ersten Teils (insbesondere der Bücher über die Artes und des Abschnitts über die Philosophen) zu verdanken, die wichtige Quellen identifizierte und $\mathrm{zu}$ begründeten Annahmen über weitere Vorlagen führte. ${ }^{39}$ Fontaine stellte fest, dass Isidor in seiner Behandlung der Artes liberales von zwei wenig früher entstandenen Übersichten ausging: Cassiodors Institutiones und den Nuptiae Philologiae et Mercurii des Martianus Capella. Dieser Kernbereich wurde durch vielfältiges Material aus Schriften ergänzt, die sich an ein breites Publikum oder auch an Lernende richteten. So konnte Fontaine einige Informationen über Astronomie auf patristische Homilien zurückführen. ${ }^{40}$ Die Informationen zur Philosophie dürften wegen ihres allgemeinen Charakters und ihres Eklektizismus vornehmlich isagogischen Schriften entnommen worden sein. ${ }^{41}$ Manche Ergebnisse antiker Philosophie erscheinen als knapp formuliertes, nun allgemein akzeptiertes Wissen, ohne Angaben darüber, welche Schule oder Schulen in welchem Kontext zu diesem Ergebnis gekommen waren. Ein Beispiel dafür liefert Isidors Definition von etymologia, die zu Beginn die Naturgegebenheit von Sprache voraussetzt, dann jedoch als eine Lehre der Benennungsgründe erscheint. ${ }^{42}$

38 Etym. III, 70, 41, zitiert nach Isidorus Hispalensis. Etymologiae III. Isidore de Séville. Livre III. De mathematica, hrsg. von Giovanni Gasparotto und Jean-Yves Guillaumin, Paris 2009, 151.

39 Fontaine, Isidore (Anm. 3) und Fontaine, Notes (Anm. 3).

40 Fontaine, Isidore (Anm. 3), 581-583.

41 Fontaine, Isidore (Anm. 3), 707 - 732 sowie Fontaine, Isidore. Notes (Anm. 3), 1138-1142.

$42 \mathrm{Zu}$ diesem Abschnitt siehe Wolfgang Schweickard, „Etymologia est origo vocabulorum ...“: Zum Verständnis der Etymologiedefinition Isidors von Sevilla, in: Historiographia linguistica 12 (1985), 1 25, und Mark Amsler, Etymology and Grammatical Discourse in Late Antiquity and the Early Middle Ages, Amsterdam 1989, 136-147. Zum antiken Verständnis der Etymologie siehe Clemens-Peter Herbermann, Antike Etymologie, in: Sprachtheorien der abendländischen Antike, hrsg. von Peter Schmitter, 2., verbesserte Auflage, Tübingen 1996 (Geschichte der Sprachtheorie 2), 353-376, dort 358 die Definition „Lehre von den Benennungsgründen“. 
Etymologia est origo uocabulorum, cum uis uerbi uel nominis per interpretationem colligitur. Hanc Aristoteles sumbolon, Cicero adnotationem nominauit, quia nomina et uerba rerum nota facit exemplo posito; utputa „flumen“, quia fluendo creuit, a fluendo dictum. Cuius cognitio saepe usum necessarium habet in interpretatione sua. Nam dum uideris unde ortum est nomen, citius uim eius intellegis. Omnis enim rei inspectio etymologia cognita planior est. Non autem omnia nomina a ueteribus secundum naturam inposita sunt, sed quaedam et secundum placitum, sicut et nos seruis et possessionibus interdum secundum quod placet nostrae uoluntati nomina damus. Hinc est quod omnium nominum etymologiae non reperiuntur, quia quaedam non secundum qualitatem, qua genita sunt, sed iuxta arbitrium humanae uoluntatis uocabula acceperunt. Sunt autem etymologiae nominum aut ex causa datae, ut "reges" a [regendo et] recte agendo, aut ex origine, ut „homo", quia sit ex humo, aut ex contrariis ut a lauando „lutum“, dum lutum non sit mundum, et „lucus“, quia umbra opacus parum luceat. Quaedam etiam facta sunt ex nominum deriuatione, ut a prudentia „prudens"; quaedam etiam ex uocibus, ut a garrulitate „garrulus"; quaedam ex Graeca etymologia orta et declinata sunt in Latinum, ut „silua“, „domus“. Alia quoque ex nominibus locorum, urbium, [uel] fluminum traxerunt uocabula. Multa etiam ex diuersarum gentium sermone uocantur. Vnde et origo eorum uix cernitur. Sunt enim pleraque barbara nomina et incognita Latinis et Graecis. ${ }^{43}$

Fontaine machte ferner eine interessante Beobachtung zu den Zitaten aus antiken Dichtern. Sie werden in der Regel als Belege für eine Wortbedeutung oder einen Sachverhalt herangezogen, was eine Verwendung von Scholien nahelegt, in denen der Dichtertext zum Ausgangspunkt für breitere Erläuterungen über verschiedene Wissensgebiete genommen wurde (eine Vorgehensweise, die in den erhaltenen spätantiken Kommentaren zu beobachten ist). Isidor hat das Verhältnis der Texte verkehrt, indem er die Scholie in seinen Haupttext aufnahm und den kommentierten Vers in einen Beleg umwandelte. ${ }^{44}$ Wir können feststellen, dass sich in der Quellenauswahl ein Verständnis von Enzyklopädie als geordnete Vermittlung von Grundlagenwissen und nicht als Ansammlung von verfügbarem Wissen zeigt.

\section{Die Strukturierung des Materials}

Wir haben bereits die thematische Ordnung des Materials diskutiert, nun soll ein auffälliges Merkmal des Werkes besprochen werden, das ihm seinen Titel gegeben hat: die Strukturierung innerhalb jedes Themenbereiches.

Die Etymologiae sind nämlich um die Auslegung von Wörtern geordnet. Jedes Thema wird durch die Aneinanderreihung von Begriffen dargelegt, die durch die Methoden der Grammatik erklärt werden: die gloss a oder definitio, also die Erläuterung durch geläufigere Wörter, die differentia oder Abgrenzung zu anderen Begriffen und die etymologia. Letztere sucht nach dem Ursprung eines Wortes und erfordert auch eine Überlegung über dessen eigentliche Bedeutung, seine vis. Diese Vorgehensweise verknüpft die Kenntnis der Sprache eng mit der Kenntnis der Welt: ${ }^{45}$ Wenn man ein

43 Etym. I, 29, 1-4, Ed. Lindsay.

44 Fontaine, Isidore (Anm. 3), 742-743 und 750-751.

45 Dazu Amsler, Etymology (Anm. 42), 133-172. 
Wort nach seiner Herkunft, nach seiner Abgrenzung zu synonymen Ausdrücken durchleuchtet und versucht, es möglichst präzise zu definieren, eruiert man auch, was das Wesentliche am von ihm bezeichneten Gegenstand ist, dann unterscheidet man sekundäre von primären Eigenschaften.

Die Fokussierung auf den Ursprung, um die genaue Bedeutung und damit die Natur des Genannten zu erfassen, erklärt das Interesse für den historischen Beginn menschlicher Tätigkeit und für die ursprünglichen Erfinder sowie die Orientierung am antiken Wissen. Dies sagt Isidor ausdrücklich in etym. IX, 1, im Kapitel über die Sprachen, einem Text, der auf ihn selbst zurückgehen dürfte. ${ }^{46}$ Dort wird zuerst die Entstehung der Sprachenvielfalt geschildert, anschließend finden sich Informationen zu den drei linguae sacrae Hebräisch, Griechisch und Latein und eine Erwähnung der orientalischen Sprachen Syrisch und Chaldäisch. Zum Schluss diskutiert Isidor das Erlernen der Sprache. Fürs Lateinische definiert er vier Sprachepochen. Die älteste Sprachstufe (lingua prisca) findet sich etwa im Carmen saliare. Die lateinische Sprache (lingua Latina) wurde zur Zeit der Könige gesprochen, ein Beispiel dafür bietet das Zwölftafelgesetz. Die römische Sprache (lingua Romana) ist nach dem Fall der Könige anzusetzen. Im Römischen Reich wurde das Latein zur Mischsprache (lingua mixta), da die neuen Sprecher Wörter und Konstruktionen aus ihren Sprachen hineinnahmen und so die ursprüngliche lateinische Sprache korrumpierten.

Latinas autem linguas quattuor esse quidam dixerunt, id est priscam, latinam, romanam, mixtam. Prisca est quam vetustissimi Italiae sub Iano et Saturno sunt usi, incondita ut se habent carmina Saliorum. Latina quam sub Latino et regibus Tusci et ceteri in Latio sunt locuti, ex qua fuerunt duodecim tabulae scriptae. Romana quae post reges exactos a populo Romano coepta est, qua Neuius, Plautus, Ennius, Virgilius poetae, et ex oratoribus Gracchus et Cato et Cicero vel ceteri effuderunt. Mixta quae post imperium latius promotum simul cum moribus et hominibus in Romanam ciuitatem inrupit, integritatem uerbi per soloecismos et barbarismos corrumpens. ${ }^{47}$

Diese Epochen sind, wie Borst beobachtet hat, durch politischen und nicht durch sprachlichen Wandel definiert. ${ }^{48}$ Zwischen der lingua mixta des Kaiserreichs und der Sprache seiner eigenen Zeit zieht Isidor keine Trennungslinie. Isidor, der die Literatursprache so gut beherrschte und sich mit der Grammatik so intensiv auseinandergesetzt hatte, hat die Unterschiede zwischen der gelehrten und der Alltagssprache genau beobachtet, wie Michel Banniard anhand von Aussagen in verschiedenen

46 Bisher konnten keine Quellen gefunden werden. Borst, Bild (Anm. 2), 41, vermutet, dass Isidor selbst diese Gliederung in vier Epochen definiert, denn darin sind einige grundlegende historische Ansichten des Autors zu erkennen, etwa die Verknüpfung der Ursprungszeit einer Gesellschaft mit der Religion sowie des sich formierenden Königtums mit dem Recht.

47 Etym. IX, 1, 6-7, zitiert nach Isidorus Hispalensis. Etymologiae IX. Isidore de Séville. Etymologies. Livre IX. Les langues et les groupes sociaux, hrsg. von Marc Reydellet, Paris 1984, 35 - 37.

48 Borst, Bild (Anm. 2), 41. 
Werken gezeigt hat. ${ }^{49}$ Für diese Schere zwischen gesprochener und geschriebener Sprache macht er hier den Einfluss fremder Völker verantwortlich. ${ }^{50}$ Die Sprache ist das Unterscheidungsmerkmal zwischen Mensch und Tier, die schlechte Beherrschung der Muttersprache bedeutet deshalb einen Verlust an Humanität, ja ein Herabsinken in die Bestialität:

Omnem autem linguam unusquisque hominum siue Grecam, siue Latinam, siue ceterarum gentium aut audiendo potest tenere, aut legendo ex praeceptore accipere. Cum autem omnium linguarum scientia difficilis sit cuiquam, nemo tamen tam desidiosus est ut in sua gente positus suae gentis linguam nesciat. Nam quid aliud putandus est nisi animalium brutorum deterior? Illa enim propriae vocis clamorem exprimunt, iste deterior qui propriae linguae caret notitiam. ${ }^{51}$

Die Veränderungen in der Sprache, die Isidor wahrnimmt, werden als Korruption dieser Muttersprache wahrgenommen, die in seinem Verständnis immer noch Latein ist. So wie dieses Latein in der Literatursprache anzutreffen ist, enthält es noch Hinweise auf die ursprüngliche Gestalt der Wörter, die unmittelbar auf das Wesen der Sachen hinwies. Dies gilt umso mehr für den Sprachzustand, den Isidor als lingua Romana bezeichnet und der sich im Werk der antiken Autoren findet. Isidor versucht, Hinweise auf diesen Zustand zu gewinnen und ihn für seine Zeitgenossen $\mathrm{zu}$ erschließen. Hier soll allerdings betont werden, dass es ihm nicht darum geht, eine überkommene Sprachstufe zu neuem Leben zu erwecken oder Veränderungen wie etwa die Erweiterungen im Wortschatz rückgängig zu machen. In seiner Behandlung der Rhetorik unterstreicht Isidor sogar, dass es notwendig sei, die zeitgenössische Sprache zu sprechen. ${ }^{52}$ Sein Anliegen ist vielmehr die Erhaltung einer Sprachform, der gelehrten Sprache, die den epistemischen Zugang zur Welt ermöglicht. ${ }^{53}$

\section{Der anvisierte Leser}

Wie in der Auswahl aus den Quellen zeigt sich in der Strukturierung des Materials der Charakter der Etymologiae als Sammlung von grundlegendem Wissen. Nun schreibt kein mittelalterlicher Autor für sich allein, sondern hat immer ein Zielpublikum, einen bestimmten Lesertypus vor Augen. Es stellt sich deshalb die Frage, ob sich durch den

49 Michel Banniard, Viva voce. Communication écrite et communication orale du IV $\mathrm{Iu}^{\mathrm{e}} \mathrm{IX}^{\mathrm{e}}$ siècle en Occident latin, Paris 1992, zu Isidor allgemein 181-253, zu diesem Abschnitt 240-245.

50 Die Rückführung der Sprachverderbnis auf den Einfluss von Anderssprachigen hat eine lange Tradition; dazu Banniard, Viva voce (Anm. 49), 242 - 243.

51 Etym. IX, 1, 10, Ed. Reydellet, 39.

52 Latine autem loquitur, qui uerba rerum uera et naturalia persequitur, nec a sermone atque cultu praesentis temporis discrepat, etym. II, 16, 2, Ed. Marshall (Anm. 27), 65.

53 Die grundsätzliche Hinwendung Isidors zur eigenen Zeit betont Borst, Bild (Anm. 2), 56-62, der den Charakter der Etymologiae als „Lebenshilfe“ und nicht als „Wissenschaftskunde“ unterstreicht (ebd., 56). 
Text selbst, nämlich durch die beobachteten Themen und Schwerpunkte, ein solches Zielpublikum erkennen lässt.

Sisebut als erster Widmungsträger war nicht der einzige Leser, den Isidor bei der Kompilation der Etymologiae vor Augen hatte. Dies zeigt sich bei einem Gegenstand, den Isidor sowohl in seiner Enzyklopädie als auch in einem auf Anregung Sisebuts entstandenen Werk, De natura rerum, behandelt, nämlich bei der Astronomie. Im Vergleich zwischen beiden Werken konnte Fontaine eine größere Aufnahmebereitschaft für heidnisches Wissensgut in den Etymologiae feststellen. ${ }^{54}$ Die Astrologie wird darin ausdrücklich, ja sogar vehement abgelehnt, anschließend wird aber der mythische Ursprung der Namen von Sternen und Konstellationen ausführlich vorgetragen. Dazu wird zwar eine euhemeristische Erklärung gegeben, die aber nicht polemisch entwickelt wird. In De natura rerum werden hingegen astrologische Inhalte konsequent vermieden. Für die Diskrepanz zwischen beiden Werken erwägt Fontaine als mögliche Erklärungen den größeren Wert des praktischen Nutzens in den Etymologiae sowie die Heranziehung von Autoren wie Laktanz und Texten wie dem spätantiken christlichen Roman Recognitiones, die eine relative Offenheit für heidnisches Wissen zeigen. Meines Erachtens muss man auch die Veranlassung und das anvisierte Publikum beider Schriften in Betracht ziehen. Sisebut wünschte die Abfassung von De natura rerum, weil eine Mondfinsternis Ängste in Teilen der Bevölkerung ausgelöst hatte. Es ist anzunehmen, dass diese Schrift König und Bischöfe in die Lage versetzen sollte, diesem Aberglauben zu begegnen. Isidor musste daher einen sekundären Adressaten berücksichtigen. Hier war es wichtig, die christliche Position $\mathrm{zu}$ betonen, und das Wissen, das sich mit dem Christentum vereinbaren ließ, von Elementen des heidnischen Glaubens zu unterscheiden. Die relative Unbekümmertheit in den Etymologiae weist hingegen auf einen Leserkreis hin, der eine solide christliche Bildung bekam oder bereits bekommen hatte.

Ein weiterer Hinweis auf das Publikum findet sich in dem besprochenen Abschnitt über die Götter. Wie wir gesehen haben, erscheint das antike Heidentum als eine überwundene, vergangene Epoche. ${ }^{55}$ Es stellt sich deshalb die Frage, ob das Wissen darüber für die zeitgenössischen Benützer der Enzyklopädie einen Wert hatte. Wir haben zwar nur wenige direkte Hinweise auf eine Zirkulation von Werken aus der heidnischen Antike im westgotischen Spanien, etwa in der Form von erhaltenen

54 Fontaine, Isidore (Anm. 3), 532-539.

55 Das zeitgenössische Heidentum interessiert ihn hingegen nicht, obwohl noch das dritte Konzil von Toledo 589 es als weit verbreitetes Problem im Westgotenreich erwähnt. Über die genauen Inhalte dieses Heidentums sind wir nur für die Callaecia, wo es sich offensichtlich um ein vorrömisches Heidentum handelte, durch das Werk Martins von Bracara unterrichtet. Die Gesetzbücher des Westgotenreiches erwähnen vor allem Magie und Zauberei als heidnische Praktiken. Dazu siehe Stephen McKenna, Paganism and Pagan Survivals in Spain up to Fall of the Visigothic Kingdom, Washington 1938 (http://libro.uca.edu/mckenna/paganism.htm, 16.07.2014) und Jocelyn N. Hillgarth, Popular religion in Visigothic Spain, in: Visigothic Spain. New Approaches, hrsg. von Eduard James, Oxford 1980, 3-60. 
Handschriften oder von direkten Nennungen, aber deren Lektüre lässt sich für Autoren der Zeit nachweisen. ${ }^{56}$ Als Beispiel dafür eignet sich König Sisebut selbst, dessen an Isidor adressiertes Carmen de luna die Kenntnis von Vergil, Ovid, Lukrez und Claudian, vielleicht auch von Silius Italicus und Statius verrät ${ }^{57}$, und der sogar in seinem hagiographischen Werk, der Vita Desiderii, an einer Stelle Vergil zitiert. ${ }^{58}$ Die Lektüre der heidnischen Autoren wurde durch Isidors Informationen erleichtert, sie ermöglichten sogar die Übernahme mythischer Anspielungen in die Literaturproduktion. Als Beispiel darf wieder das Carmen de luna gelten, in dem Sonne und Mond mit großer Selbstverständlichkeit Phoebus und Phoebe genannt werden. Für den Abschnitt über die Götter scheint Isidor also eine kleine, sehr gebildete Elite vor Augen zu haben. Aber die Kenntnis der Götter war nicht nur im Rahmen der Beschäftigung mit Literatur nützlich, sondern auch für das bessere Sprachverständnis und für die Klärung des Ursprungs manch kultureller Erscheinung.

Dieser letzte Aspekt führt uns zu der Strukturierung des Werkes nach Worterklärungen. Auch in der Behandlung der Wissenschaften ist Isidors Ziel die Definition der Begriffe, nicht die Erstellung eines Handbuchs oder gar einer umfassenden Abhandlung..$^{59}$ Dies ist genauso nützlich für die Leser, die bereits über Kenntnisse verfügen, wie auch für die Schüler, die sich diesem Gebiet zum ersten Mal nähern. Jedenfalls scheint Isidor die bestehenden (Schul)traktate nicht ersetzen, sondern ergänzen zu wollen. ${ }^{60}$

Insgesamt lässt sich erkennen, dass Isidor in den Etymologiae die Interessen einer gebildeten Elite berücksichtigte, aber nicht allein diesen kleinen Benutzerkreis anvisierte. Der Rezipientenkreis, der im Text vorausgesetzt wird, besteht demnach aus all denjenigen, die Zugang zur Bildung hatten, was in dieser Zeit sowohl eine rein sprachliche als auch eine religiöse Bildung bedeutet: die Zöglinge der Kathedral-

56 Dazu siehe Manuel C. Díaz y Díaz, La transmisión de los textos antiguos en la Península Ibérica en los siglos VII-XI, in: La cultura antica nell'Occidente latino dal VII all'XI secolo (Spoleto, 18 - 24 aprile 1974), Bd. 1, Spoleto 1975 (Settimane di Studio del Centro Italiano di Studi sull'Alto Medioevo, 22), $133-175$.

57 Edition in Isidore de Séville. Traité de la nature, hrsg. von Jacques Fontaine, Bordeaux 1960, 328 335, zum Stil und Einfluss antiker Dichter ebd., 155-157, sowie Giovanni Gaparotto, La epistula di Sisebut a Isidoro di Siviglia nel contesto culturale del mondo visigotico di Spagna, in: De Tertullien aux Mozarabes, Bd. 2: Antiquité tardive et Christianisme ancien (VI ${ }^{\mathrm{e}}$-IX ${ }^{\mathrm{e}}$ siècles), hrsg. von Louis Holtz und Jean-Claude Fredouille, Paris 1992, 57 -67, bes. 64-66.

$58 \mathrm{Zu}$ den Quellen siehe Martín, Une nouvelle édition (Anm. 9), 134-142, Nachweis des Vergil-Zitats 177.

59 Dies zeigt Fontaine, Isidore (Anm. 3), 202 - 207, für das Buch I, dessen Beziehungen zu früheren Grammatiklehren er ausführlich beleuchtet, und es gilt auch für die weiteren Büchern zu den Artes, zum Recht und zur Medizin in diesem ersten Teil.

60 Die Bücher über die Artes sind im Mittelalter (zumal im Frühmittelalter) wohl als Grundlage für den Unterricht verwendet worden, wurden aber zu diesem Zweck mit zusätzlichem Material angereichert; dazu Carmen Cardelle de Hartmann, Uso y recepción de las Etymologiae de Isidoro, in: Wisigothica. After Manuel C. Díaz y Díaz, hrsg. von Carmen Codoñer und Paulo Alberto, Firenze 2014, 381 - 399 , hier $385-387$ und $393-394$. 
schulen, Isidors Mitbrüder im Bischofsamt, die Mönche oder die Adligen. ${ }^{61}$ Dass auch die Interessen der Laien mitberücksichtigt werden sollen, wird dann klar formuliert, wenn der Nutzen der Artes für das gesellschaftliche Leben genannt wird. ${ }^{62}$

Diese Publikumswahl und die Konzentration auf die Sprache hatten eine politische Seite. Seit Leowigild trieben die westgotischen Könige die Einheit der von ihnen regierten Völker - Westgoten, Suewen, Hispano-Römer - und Regionen voran. ${ }^{63}$ Der Bezug zwischen Sprache und Volksgruppen wird von Isidor selbst im Kapitel über die Sprache thematisiert, und zwar an zwei exponierten Stellen, am Anfang und am Ende. Der Anfang des Kapitels weist nämlich darauf hin, dass es nach Babel mehr Völker als Sprachen gibt, das Ende, dass aus den Sprachen Völker entstehen und nicht umgekehrt:

Initio autem quot gentes tot linguae fuerunt, deinde plures gentes quam linguae, quia ex una lingua multae sunt gentes exortae. ${ }^{64}$

Ideo autem prius de linguis ac deinde de gentibus posuimus, quia ex linguis gentes, non ex gentibus linguae exortae sunt. ${ }^{65}$

Die Folgerung ist klar: Auch zwei unterschiedliche Völker können sich derselben Sprache bedienen. Dass diese ein Bindeglied sein kann, lässt sich aus der Geschichte des Römischen Reiches, wie im Abschnitt über die lingua Romana kurz angedeutet wird, lernen. Die Westgoten sprachen schon längst die Sprache der hispano-römischen Bevölkerung, ${ }^{66}$ nun mussten sie auch die Literatursprache erobern, ein Bestreben, das bei Sisebut wie bei anderen Adligen zu beobachten ist. ${ }^{67}$ Für dieses Interesse dürfte es

61 Fontaine, Isidore (Anm. 3), 334-335, weist darauf hin, dass Isidor in seinen Sententiae die Anwendung der Rhetorik in all diesen Bevölkerungsgruppen voraussetzt. Die wenigen Hinweise auf die Formen schulischer Bildung werden kritisch ausgewertet bei Díaz, Introducción (Anm. 20), 70 - 84. Zur lateinischen Kultur der westgotischen Zeit siehe die grundlegenden Arbeiten von Manuel C. Díaz y Díaz, La cultura de la España visigótica del siglo VII, in: Ders., De Isidoro al siglo XI. Ocho estudios sobre la vida literaria peninsular, Barcelona 1976, $21-56$ (zuerst erschienen in: Caratteri del secolo VII in Occidente, Spoleto 1958, 813-844), und La cultura literaria en la España visigótica, ebd., 57-86 (zuerst erschienen in: Anales Toledanos 3 (1970), 35 - 58), sowie die Übersichten in Díaz, Introducción (Anm. 20), 71-94, und Collins, Visigothic Spain (Anm. 10), 147-173.

62 Siehe oben 92.

63 Siehe oben Anm. 10.

64 Etym., IX, 1, 1, Ed. Reydellet.

65 Etym. IX, 1, 14, Ed. Reydellet.

66 Das lässt Isidor bei seiner Definition des Barbarismus anklingen: Barbarismus a barbaris gentibus, dum latinae orationis integritatem nescirent (etym. I, 32, 1). Isidor lässt auch den Beitrag der Westgoten zur Korruption der lingua mixta unerwähnt. Banniard, Viva voce (Anm. 49), 242 - 243, vermutet, dass nicht nur Rücksichtnahme im Spiel ist, sondern dass die soziolinguistische Differenz eine größere Rolle spielt: Die Westgoten bedienten sich derselben Umgangssprache, die Isidor als die Sprache des einfachen Volkes ansieht.

67 Dazu Manuel C. Díaz y Díaz, La obra literaria de los obispos visigóticos toledanos: supuestos y circunstancias, in: Ders., De Isidoro (Anm. 61), 87 - 116, bes. 100 - 101. Es lassen sich eine Generation früher Graf Bulgaranus und Johannes von Biclarum nennen, der in Konstantinopel studiert hatte 
eine weitere politische Veranlassung geben. Seit Leowigild hatten die Könige die byzantinische Provinz in Südspanien erfolgreich angegriffen, was 625-626 zur kompletten Rückeroberung durch Suinthila führte. Dabei traten sie den byzantinischen Herrschern selbstbewusst entgegen. Die Übernahme von imperialen Insignien und Ritualen aus Byzanz, die länger bestand, intensivierte sich unter Leowigild und wurde von seinen Nachfolgern weitergeführt. ${ }^{68} \mathrm{Ihr}$ angenommenes Römertum unterstrich ihre Legitimität und sollte auch in ihrer Teilnahme an der traditionellen römischen Kultur seinen Ausdruck finden.

Die Etymologiae haben dazu beigetragen, die antike Literatursprache als Norm und Maßstab zu erhalten, nicht nur indem sie ihre vertiefte Kenntnis ermöglichten, sondern weil Isidor durch seine Heranziehung antiker Autoren deren Lektüre im Kontext des Sprach- und Wissenserwerbs sanktionierte.

\section{Schlusswort}

In den Etymologiae wird verschiedentlich auf Stufen in der menschlichen Geschichte und Kultur hingewiesen, die bald zum Besseren führen (in der Heilsgeschichte), bald zu einer Verschlechterung (wie in den Epochen des Lateins). In diesen Brüchen können einige Wissensgebiete ganz oder zum Teil obsolet werden: Die spekulative Philosophie scheint im Werk weitgehend von der christlichen Lehre abgelöst worden oder vielmehr darin aufgehoben zu sein. Auch Judentum und Heidentum werden in dieser Perspektive gesehen, als überwundene Stufen und nicht als die gegenwärtigen Herausforderungen, die sie waren. Es sind das alte Judentum und das alte Heidentum, die Isidor interessieren. Von einer Ansammlung von totem Buchwissen zu reden, würde allerdings dem Wissensverständnis des Werkes nicht entsprechen. Die Etymologiae vermitteln eine Wissensgrundlage, die von der Sprache gebildet wird. Da für Isidor die Kenntnis der Sprache zur Kenntnis der Welt führt, ist es unverzichtbar, auf das Wissen

(einführend zu diesen beiden Autoren siehe die Überblicksartikel von Salvador Iranzo, Bulgarano, in: Hispania visigótica (wie Anm. 7), 100 - 102, und José Carlos Martín, Juan de Biclaro, ebd., 56 - 60). Die Annahme der lateinischen Literatursprache durch den letzteren könnte mit seinem Katholizismus in einer Zeit, in der die Goten Arianer waren, zusammenhängen. Isidor betont aber seine Zugehörigkeit zum Volk der Westgoten, es scheint ihm vor allem wichtig, darauf hinzuweisen, dass auch ein Westgote sich der lateinischen Literatursprache bedienen kann (Isidor, De uiris illustribus 31, in: El De viris illustribus de Isidoro de Sevilla, hrsg. von Carmen Codoñer Merino, Salamanca 1964, 151-152). Nach Isidors Ableben und noch im 7. Jh. verfassten zwei westgotische Könige, Chindaswinth und Wamba, sowie vielleicht ein dritter, Suinthila, lateinische Verse (dazu die drei Beiträge von Salvador Iranzo, Hispania visigótica (Anm. 7): Chindasvinto, 105-106, Wamba, 225-227 und Chintila, 106-107. 68 Dazu die ausführliche Diskussion bei María del Rosario Valverde Castro, Ideología, simbolismo y ejercicio del poder real en la monarquía visigoda, Salamanca 2000, 179-254; zur politischen und militärischen Geschichte der Beziehungen zwischen dem Westgotenreich und Byzanz siehe Margarita Vallejo Girvés, España y Bizancio: una relación desconocida, Madrid 2012 (232-233 zu den symbolischen Übernahmen). 
älterer Epochen zurückzugreifen, in denen das Latein noch nicht durch die Beimischung fremder Elemente verfälscht worden war. Isidors Suche nach antikem Wissen ist von dem Interesse geleitet, die ursprüngliche Bedeutung und die richtige Verwendung von Wörtern und Begriffen zu bestimmen, was zu einer größeren Aufnahmebereitschaft gegenüber antikem Wissen als bei anderen christlichen Autoren führt. $\mathrm{Zu}$ dieser Offenheit dürfte auch beigetragen haben, dass er ein breites Publikum, das auch adlige Laien einschloss, ansprechen wollte. Deren Aneignung der lateinischen Sprache und Kultur war Teil eines politischen Programms. Mit ihrer weiten Perspektive haben die Etymologiae in späterer Zeit insgesamt die Suche nach weiterem Wissen, sogar die Beschäftigung mit antiker Literatur legitimiert und vorbereitet, andererseits haben sie auch der Bildungselite vorgegeben, welches Wissen erstrebenswert war und somit Grenzen für das Wissensstreben gesetzt. 



\title{
Verformung, Verdrängung und Verlust von Rechtswissen in den Leges*
}

\begin{abstract}
This paper establishes a new perspective on the relationship of legal knowledge and its material manifestations in the early Middle Ages. The complex nature of leges collections derives from the intentional arrangement of its material. In a case study of the Fragmenta Gaudenziana 15, the author demonstrates that several redactors had created quite elaborate compilations for contemporary needs without indicating the complexity of different legal sources behind their text passages. Legal sources of different authority, ranging from imperial issues to local commentaries, were combined into a new form of legal knowledge.
\end{abstract}

\section{Rechtsüberlieferung und Rechtsanwendung}

Was heute vom Rechtswissen in den Leges des Frühmittelalters bekannt ist, steht in Handschriften, die Texte vermitteln, ${ }^{1}$ und zwar teils solchen, die normativen Geltungsanspruch haben (oder wenigstens zu vermitteln scheinen), teils solchen, denen ein narrativer Charakter innewohnt. ${ }^{2}$ Urkundenförmig erhaltene Leges gibt es nicht. ${ }^{3}$

\footnotetext{
* Gewidmet ist der vorliegende Beitrag meinem verehrten Lehrer Hermann Nehlsen zu seinem 80. Geburtstag.

1 Ganz selten findet es sich auch in bildlichen Darstellungen angedeutet oder lassen sich Artefakte rechtsarchäologisch in diesem Sinne deuten. Ein berühmtes Beispiel für das eine findet sich in der Hs.

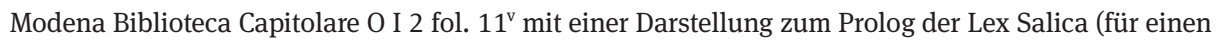
Druck vgl. Hubert Mordek, Leges und Kapitularien, in: Die Franken, hrsg. von Alfried Wieszorek, Mainz 1996, 490; allgemein: Hubert Mordek, Frühmittelalterliche Gesetzgeber und Iustitia in Miniaturen weltlicher Rechtshandschriften, in: La Giustizia nell'Altomedioevo [s. V-VIII], Settimane di studio XLII, Spoleto 1995, 997 -1052), für das andere mit der Agilulf-Platte im Florentiner Museo Bargello, vgl. Gerhard Dilcher, Exkurs: Die Agilulf-Platte als Zeugnis des langobardischen Gairethinx, in: Leges Gentes - Regna. Zur Rolle von germanischen Rechtsgewohnheiten und lateinischer Schrifttradition bei der Ausbildung frühmittelalterlicher Rechtskultur, hrsg. von Gerhard Dilcher und Eva-Marie Distler, Berlin 2006, 449-458.

2 So etwa dem Rechtsaufzeichnungsbericht in den Lorscher Annalen zum Jahr 802, vgl. Annales Laureshamenses, hrsg. von Georg Heinrich Pertz (MGH SS 1), Hannover 1826, 39: Sed et ipse imperator, interim quod ipsum synodum factum est, congregavit duces, comites et reliquo christiano populo cum legislatoribus, et fecit omnes leges in regno suo legi, et tradi unicuique homini legem suam, et emendare ubicumque necesse fuit, et emendatum legem scribere, et ut iudices per scriptum iudicassent, et munera non accepissent; sed omnes homines, pauperes et divites, in regno suo iustitiam habuissent. Für eine Interpretation dieser Ereignisse vgl. Reinhold Kaiser, Die Capitula Remedii: Veranlassung, Autorschaft und Geltungsgrund, Verbreitung und Wirkung, in: Schrift, Schriftgebrauch und Textsorten im frühmittelalterlichen Churrätien. Vorträge des internationalen Kolloquiums vom 18. bis 20. Mai 2006 im
} 
Für das Beispiel einer Rechtshandschrift, die nicht nur kraft der Aussagen ihrer einzelnen Texte, sondern schon kodikologisch „Rechtswissen“ repräsentierend kumuliert, steht etwa die Handschrift St. Paul im Lavanttal Cod. 4/1. Es handelt sich um eine Sammelhandschrift u.a. verschiedenster frühmittelalterlicher Leges. ${ }^{4}$ Die inhaltliche Spannbreite des Cod. 4/1, der in wesentlichen Teilen bald nach 800 geschrieben worden zu sein scheint, reicht von den Epitome Aegidii (also Literatur zum alaricianischen Breviar), zahlreichen Kapitularien, den fränkischen Rechten der Lex Ribuaria und Lex Salica, den beiden oberdeutschen Rechten der Lex Baiuvariorum und Lex Alamannorum, zu den beiden burgundischen Gesetzen Lex Burgundionum und Lex Romana Burgundionum - diese aber nur mit ihrem Titel 17 aufscheinend - , bis hin schließlich zu einem Auszug aus der Collectio Herovalliana, einer kirchenrechtlichen Sammlung. ${ }^{5}$ Solche Sammelhandschriften signalisieren nach verbreiteter Meinung den Bedarf nach umfassendem Zugriff auf verschriftlichte Leges vielerlei Provenienz; tatsächlich mag man sich ihren Bedarf für gerichtliche Tätigkeit vor allem dort vorstellen, wo das Personalitätsprinzip über das anzuwendende Recht entschieden haben mag $^{6}$ und in Tätigkeit aufscheint, von der - in karolingischer Zeit - Hinkmar von Reims $^{7}$ in seiner Ordnung des Hofpalatinats spricht. Ihr Kapitel 21 steht als Beispiel für einen, obwohl deskriptiv angelegten, doch wohl durchaus normativ mindestens gemeinten Text. In c. 21 geht es darum, daß der Pfalzgraf als Hofrichter agiert, der aber den König einschaltet, wenn es Probleme mit den Rechtsgrundlagen gibt, nach denen der Prozeß zu entscheiden sei:

Rätischen Museum in Chur, hrsg. von Heidi Eisenhut, Karin Fuchs, Martin Graf und Hannes Steiner, Basel 2008, 146-181, 162.

3 Unbeschadet der denkbar großen Bedeutung, die diesen - auch in Form von Formelsammlungen für Aufschlüsse über die frühmittelalterliche Rechtspraxis zukommt, geht es vorliegend lediglich um die Leges (barbarorum) als Rechtsquellenbegiff (hierzu vgl. Ruth Schmidt-Wiegand, Art. „Leges“, in: Reallexikon der Germanischen Altertumskunde [RGA], 2. Aufl., Bd.18 (2001), 195-201 [196]. Für weitere Hinw. vgl. aber Hans-Georg Hermann, Jörg Müller, Art. „Urkunden“, in: RGA, 2. Aufl., Bd. 31 (2006), 545 - 549. Einen singulären, zudem typologisch nicht unzweifelhaften Ausnahmefall bildet lediglich eine vandalische lex in Urkundenform, die Victor Vitoriensis überliefert, vgl. Historia persecvtionis Africanae provinciae sub Geiserico et Hvnirico regibvs Wandalorvm (MGH Auctores antiquissimi Bd. 3), hrsg. von Karl Halm, Berlin 1878, 40 - 43 (43 Z. 21 - 23 Hanc ergo legem fonte iustitiae profluentem cunctis praecipimus innotescere, quatenus nullus sibi ignotum esse, quod praeceptum est possit obtendere. Optamus vos bene valere. Data sub die VI. Kal. Mart. Carthagine); hierzu: Lothar Saupe, Die Unterfertigung der lateinischen Urkunden in den Nachfolgestaaten des weströmischen Reichs, Kallmünz 1983 (Münchener Historische Studien, Abt. Geschichtl. Hilfswissenschaften; 20), 125.

4 Für weiterführende Hinweise vgl. die Übersicht in der Projektdatenbank „Bibliotheca legum regni Francorum manuscripta“ unter http://www.leges.uni-koeln.de/mss/handschrift/st-paul-abs-4-1/ [zuletzt 13.12.14].

5 Hierzu Peter Landau, Kanonessammlungen in der Lombardei im frühen und hohen Mittelalter, in: Peter Landau, Kanones und Dekretalen, Goldbach 1996 (Bibliotheca eruditorum: 2), 437 - 466, 455. 6 Für einen differenzierenden Überblick insb. zur vorkarolingischen Zeit vgl. Fritz Sturm, Art. „Personalitätsprinzip“, in: HRG 1. Aufl., Bd. 3, 1587 - 1597 („Sicher ist, daß das P. im Reich der Karolinger galt“ [1588]).

7 Vgl. Jörg W. Busch, Art. „Hincmar von Reims“, in: HRG 2. Aufl., Bd. 2, 1033-1035. 
„Der Pfalzgraf aber war neben schier unzähligen sonstigen Dingen hauptsächlich damit beschäftigt, alle Rechtsstreitigkeiten, die, anderwärts entstanden, wegen eines gerechten Urteils an den Hof gebracht wurden, recht und sinnvoll zu entscheiden oder ungerechte Urteile auf den Pfad der Gerechtigkeit zurückzuführen, damit er sowohl vor Gott wegen seiner Gerechtigkeit wie auch vor den Menschen wegen der Beachtung der Gesetze allseits Wohlgefallen finde.

Handelte es sich aber um einen Fall, den die weltlichen Gesetze in ihren Bestimmungen nicht geregelt hatten oder den sie nach heidnischer Gewohnheit grausamer handhabten, als es die Richtschnur des Christentums und die heilige Lehre mit Recht billigen konnten, so sollte dies dem König zur Milderung vorgetragen werden, damit dieser gemeinsam mit jenen, die beiderlei Recht kennen und Gott mehr fürchten als menschliche Satzungen, so urteile und so entscheide, daß beides eingehalten werde, wo dies geschehen könne, sonst aber das weltliche Gesetz gebührend zurückgedrängt und Gottes Gerechtigkeit gewahrt werde."8

Drei Beobachtungen lassen sich für das gegebene Thema an diese Rechtsüberlieferungs- und Rechtsanwendungsperspektiven knüpfen:

1. So stark hier frühmittelalterliches Recht manifest wird, so wenig tut es das antike Recht: paradigmatisch zeigt der Kodex St.Paul im Lavanttal Cod. 4/1 das Grundphänomen der Überlieferungssituation für antikes Recht: es ist textlich oft gar nicht unmittelbar greifbar. In diesem Kodex ist es das nur in ausgedünnter Form der Epitome Aegidii. Dennoch erscheint das römische Recht im frühen Mittelalter als nicht nur gegenwärtig relevante Größe - mindestens für die romanische Bevölkerung oder die Kirche ${ }^{9}-$, sondern auch (theoretisch jederzeit?) nachlesbar und in entsprechenden Texten verfügbar vorgestellt und vorausgesetzt, so zumindest, wenn ein missus auf seine Anfrage von Karl dem Großen die Antwort bekommt: Lege Romanam legem, und was er dort finde, so solle er es machen. ${ }^{10}$

8 Hinkmar von Reims, De ordine palatii, hrsg. u. übersetzt von Thomas Gross und Rudolf Schieffer [MGH fontes iur.; i.u.s.] Hannover 1980, 70-73): Cap. 21. Comitis autem palatii inter cetera paene innumerabilia in hoc maxime sollicitudo erat, ut omnes contentiones legales, quae alibi ortae propter aequitatis iudicium palatium aggrediebantur, iuste ac rationabiliter determinaret seu perverse iudicata ad aequitatis tramitem reduceret, ut et coram Deo propter iustitiam et coram hominibus propter legum oberservationem cunctis placeret. Si quid vero tale esset, quod leges mundanae hoc in suis diffinitionibus statutum non haberent aut secundum gentilium consuetudinem crudelius sancitum esset, quam christianitatis rectitudo vel sancta auctoritas merito non consentiret, hoc ad regis moderationem perduceretur, ut ipse cum his, qui utramque legem nossent et Dei magis quam humanarum legume statuta metuerent, ita decerneret, ita statueret, ut, ubi utrumque servari posset, utrumque servaretur, sin autem, lex saeculi merito comprimeretur et iustitia Dei conservaretur.

9 Vgl. C. G. Fürst, Ecclesia vivit lege Romana?, in: ZRG KA 61 (1975), 17 -36; Andreas Thier, Art. „Ecclesia vivit lege Romana“, in: HRG Bd. 1, 2. Aufl., 1176.

10 Es ging um eine Gebührenfrage; sollte die Lex Salica einschlägig und dort hierzu nichts zu finden sein, müsse er die Frage beim placitum generale vorlegen: De secundo unde me interrogasti, si comes de notitia solidum unum accipere deberet et scabinii sive cancellarius. Lege Romanam legem, et sicut ibi inveneris exinde facias; si autem ad Salicam pertinet legem et ibi minime repereris quid exinde facere debeas, ad placitum nostrum generale exinde interrogare facias. (Responsa misso cuidam data, MGH 
2. Die Verfügbarkeit von Rechts-,,Wissen“ hängt entscheidend davon ab, ob ein Medium existiert, das es verfügbar macht und verfügbar hält. Verläßlich und auf Dauer kann das nur in verschriftlichter Form sein; mithin mündliche Rechtstradition leistet das zwar unter Umständen auch, aber unter ganz anderen Bedingungen, Leistungsgrenzen und - bei aller Leistungsfähigkeit mittelalterlicher Mnemotechnik - mit evident größerer Unschärfe, größeren Reproduzierbarkeitsschwankungen und zudem einem faktischen Konsenszwang unter den eine Norm (angeblich) erinnernden maßgeblichen Personen. ${ }^{11}$

3. Doch selbst verschriftlichtes Recht ist gefährdet durch Verluste seiner physischen Textträger und darüberhinaus ist es auch nicht unabweisbar bindend oder unabänderlich, sondern unterliegt intentionalen Eingriffen, beispielsweise wenn es Wertungswidersprüche zu produzieren oder zu provozieren droht. Das zeigt obiger Text paradigmatisch: Hinkmar lässt keine Zweifel aufkommen, daß das Richteramt des Königs (und in der delegierten Form beim Pfalzgrafen) nicht nur Kompetenz, sondern sogar Verpflichtung zum Eingriff hat, wenn höherrangig gedachtem Recht als vorrangigem Recht zum Durchbruch verholfen werden soll. Die Disposition über konfligierendes Recht ist dabei keineswegs erst eine Erscheinung der Karolingerzeit, sondern überkommenes Recht ist gesetzgeberische Verfügungsmasse ${ }^{12}$ etwa ausweislich des „Gesetzgebungsberichts“ im Prolog der Lex Baiuvariorum. Die dort genannten merowingischen Könige beseitigten beherzt solches Recht, das mit christlichen Prärogativen nicht in Übereinstimmung gestanden haben soll. ${ }^{13}$ Der Gesetzgebung kommt eine Schlüsselstellung zu, soweit

Capitularia I, hrsg. von Alfred Boretius, Hannover 1883, c.2, 145). Für grundsätzliche Beobachtungen und Interpretationsansätze vgl. Harald Siems, Zum Weiterwirken römischen Rechts in der kulturellen Vielfalt des Frühmittelalters, in: Leges - Gentes - Regna. Zur Rolle von germanischen Rechtsgewohnheiten und lateinischer Schrifttradition bei der Ausbildung frühmittelalterlicher Rechtskultur, hrsg. von Gerhard Dilcher und Eva-Marie Distler, Berlin 2006, 231 - 255, hier 247 zu genannter Stelle. 11 Weiterführend zum Problemfeld vgl. nur Bernd Kannowski, Art. „Aufzeichnung des Rechts“, in: HRG Bd.2, 2. Aufl., 347-355; zentral für das frühe Mittelalter: Wolfgang Sellert, Aufzeichnung des Rechts und Gesetz, in: Das Gesetz in Spätantike und frühem Mittelalter, hrsg. von Wolfgang Sellert, Göttingen 1992 (Abh. d. Akad. d. Wiss. in Göttingen, Phil.-Hist. Kl., F. 3, Nr. 196), 67 - 102.

12 Zum „guten alten Recht“ als „Volksmythos der oralen Kultur“ vgl. Johannes Liebrecht, Art. „Gutes altes Recht“, in: HRG Bd.2, 2. Aufl., 624-626, sowie Johannes Liebrecht, Das gute alte Recht, in: Funktion und Form. Quellen- und Methodenprobleme der mittelalterlichen Rechtsgeschichte, hrsg. von Karl Kroeschell und Albrecht Cordes, Berlin 1996 (Schriften zur europäischen Rechts- und Verfassungsgeschichte; 18), 185 - 204.

13 Lex Baiwariorum, hrsg. von Ernst von Schwind (MGH LL nat. Germ. 5,2), Hannover 1926, $201-$ 203: Theuderichus rex Francorum, cum esset Catalaunis, elegit viros sapientes, qui in regno suo legibus antiquis eruditi erant. Ipso autem dictante iussit conscribere legem Francorum et Alamannorum et Baioariorum unicuique genti quae in eius potestate erat, secundum consuetudinem suam, addidit quae addenda erant et inprovisa et inconposita resecavit. Et quae erant secundum consuetudinem paganorum mutavit secundum legem Christianorum. Et quicquid Theuderichus rex propter vetustissimam paganorum consuetudinem emendare non potuit, post haec Hildibertus rex inchoavit, sed Chlotarius rex perfecit. Haec omnia Dagobertus rex gloriosissimus per viros inlustros Claudio Chadoindo, Magno et Agilulfo renovavit et 
es um intentionale Veränderung von Recht geht (also dem „Verdrängen“ und „Verformen“), das damit „neues“ Rechtswissen wird und altes obsolet macht oder nur modifiziert aufrechterhält.

Karolingerzeitlich ist die Erschließbarkeit solcher Eingriffsabsicht mit dem Stichwort der Kapitularien besonders manifest. Soweit sie die leges ergänzen ${ }^{14}$ oder „bessern“, hat man unlängst sogar eine „Gesetzgebungskompetenz“ der missi für möglich gehalten ${ }^{15}$, als gleichsam delegierungweise Gesetzgeber „zweiter Ordnung“. Das wäre dem antiken römischen Amtsrecht ähnlich, was gelegentlich in so einem technischen Sinn auch bei einem so unspezifischen Terminus wie „edictum“ mitanklingen mag, wie beispielsweise vielleicht beim „Edictum Theoderici“16.

omnia vetera legum in melius transtulit et unicuique genti scriptam tradidit, quae usque hodie perseverant. In der Übersetzung von Konrad Beyerle, Lex Baiuvariorum, München 1926, 8: „Theoderich, ein König der Franken, da er zu Chalons weilte, erwählte weise Männer aus, die in seinem Reiche in den alten Gesetzen bewandert waren; diesen aber befahl er, nach seiner Anweisung das Recht der Franken und Alamannen und Bayern aufzuzeichnen, für ein jedes Volk, das unter seiner Herrschaft stand, nach seiner Gewohnheit, er fügte hinzu, was anzufügen und unvorhergesehen war und beschnitt das Unschickliche. Und was darin nach der Gewohnheit der Heiden war, das ließ er nach dem Gesetz der Christen abändern. Was aber Theoderich wegen alteingewurzelter heidnischer Bräuche nicht zu bessern vermochte, das hat nachmals König Childebert von neuem begonnen, König Chlotar aber vollendet. Dies alles hat Dagobert, der ruhmreiche König, durch die erlauchten Männer Claudius, Chadoindus, Magnus und Agilolfus erneuert und alle alten Gesetze verbessert und jedem Stamm schriftlich gegeben, die bis auf den heutigen Tag noch in Geltung sind.“

14 Eingehend Steffen Patzold, Die Veränderung frühmittelalterlichen Rechts im Spiegel der „Leges“Reformen Karls des Großen und Ludwigs des Frommen, in: Rechtsveränderung im politischen und sozialen Kontext mittelalterlicher Rechtsvielfalt, hrsg. von Stefan Esders und Christine Reinle, Münster 2005 (Neue Aspekte der europäischen Mittelalterforschung; 5), 63-99.

15 So Reinhold Kaiser, Die Capitula Remedii (wie Anm. 2), bes. 169. Dagegen mit starken Gründen: Harald Siems, Recht in Rätien zur Zeit Karls des Großen. Ein Beitrag zu den Capitula Remedii, in: Wandel und Konstanz zwischen Bodensee und Lombardei zur Zeit Karls des Grossen. Kloster St. Johann in Müstair und Churrätien. Tagung 13.-16. Juni 2012 in Müstair, hrsg. von Hans Rudolf Sennhauser, unter Mitarbeit v. Katrin Roth-Rubi und Eckart Kühne, Zürich 2013 (Veröffentlichungen der Stiftung für Forschung in Spätantike und Mittelalter), 199-238, hier 213.

16 In diesem Sinn, wenn man das Edictum Theoderici [im folgenden: EdTheod] etwa in der Forschung teilweise dem praefectus praetorio Galliarum zuweist, der es für seinen Amtsbereich geschaffen haben soll; ediktale Aktivität weist aber begrifflich Isidor ebenfalls auch dem rex zu, vgl. Anm. 21. Doch recht forsch indikativisch mit der Zuweisung überhaupt ins Westgotenreich und nicht nach Italien: Wolfgang Kunkel, Martin Schermaier, Römische Rechtsgeschichte, 14. Auflage, Köln 2006, 205 (unter dem praefectus praetorio Galliarum Magnus v. Narbo [458-459], nicht von seinem König Theoderich II. [453 - 466]). Spätestens seit Hermann Nehlsen, Rez. zu Giulio Vismara, Edictum Theoderici. Ius Romanum Medii Aevi I, 2 b aa a, Milano 1967, in: ZRG GA 86 (1969), 246-260 wird man das so apodiktisch nicht mehr sagen können, entsprechend entschiedene Zuweisung an den Ostgotenkönig Theoderich d. Gr. bei Detlef Liebs, Art. „Edictum Theoderici“, in: HRG Bd. 1. 2. Aufl., 1184; in der Tendenz wohl auch Harald Siems, Handel und Wucher im Spiegel frühmittelalterlicher Rechtsquellen, Hannover 1992 (MGH Schriften; 35), 277-284. Für eine komprimierte Übersicht zur Breite der Zuweisungskontroverse vgl. Clausdieter Schott, Der Stand der Leges-Forschung, in: Frühmittelalter- 


\section{Intentionale Disposition über Rechtswissen in den Leges: Beobachtungen auf Makroebene}

\section{Aspekte: Aufzeichnung - Gesetzgebung - Rechtsanwendungsrecht}

Bekanntlich ist für das Frühmittelalter das moderne Verständnis von „Gesetzgebung“ nicht angebracht: Sicherlich handelte es sich im Frühmittelalter ebenso wenig ausschließlich um königliche Attitüden herrscherlicher Selbstdarstellung in Form von applizierten Attributen römischer Herrschermacht wie sie andererseits nicht ein Lenkungsinstrumentarium modernen, gar noch freiheitlich-rechtsstaatlichen Gesetzesverständnisses darstellte. Rechtspolitische Intentionen verband man allerdings glaubt man den Prologen und Epilogen der leges - durchaus selbstverständlich damit, wenigstens faßbar ist der Glaube an das Potential von Gesetzen oder Gesetzgebung zur Befriedungswirkung oder die Notwendigkeit, mit ihrer Hilfe die Christianisierung voranzutreiben.

Über die Bewertung von Funktion und Wirksamkeit von Gesetzgebung in den sog. germanischen Nachfolgereichen herrscht ansonsten in der Forschung keine Einigkeit. ${ }^{17}$ Tatsächlich läßt sich überhaupt nur unter klarer regionaler Differenzierung ein Nachweis nennenswerten Effektivität der lex scripta in der Rechtspraxis führen. ${ }^{18}$ Außerdem trifft vermutlich die Annahme einer singulären Zwecksetzung von Gesetzgebungsakten nicht die Vielfalt möglicher intendierter, keineswegs nur rechts-, sondern auch herrschaftspolitischer Vorstellungen über den Sinn solcher legislatorischer Aktivitäten. Häufig ist darüberhinaus hinter den überlieferten Rechtstexten kein individualisierter Gesetzgeber identifizierbar, auch wenn sich ein Rechtstext nicht lediglich als Aufzeichnung von rechtlichen Gewohnheiten darstellt - und selbst in

Studien 13 (1979), 29 - 55, hier 34. Letztlich keine Zweifel nach eingehender Analyse läßt Sean D. W. Lafferty, The Edictum Theoderici: A Study of a Roman Legal Document from Ostrogothic Italy, Diss. Phil. Toronto 2010 [erreichbar unter https://tspace.library.utoronto.ca/bitstream/1807/26363/6/Lafferty_ Sean_D_201011_PhD_thesis.pdf; 13.12.14], 18-45 (,in light of all this evidence, Pithou's original attribution of the ET to Theoderic the Great seems more than justified“ (44); dort auch Näheres zur Editio princeps von Pithou [18-19]); s.a. die Dissertation in überarbeiteter Form: Sean D. W. Lafferty, Law and Society in the Age of Theoderic the Great. A Study of the Edictum Theoderici, Cambridge/New York 2013; parallel dazu erschienen nun auch: Orazio Licandro, Edictum Theoderici. Un misterioso caso librario del Cinquecento, Rom 2013 (Fra Oriente e Occidente; 3), sowie Orazio Licandro, Edictum Theoderici. Traduzione con testo a fronte, Turin 2008 (mit Bespr. von Marcella Raiola in Rivista di Diritto Romano XI 2011, http://www.ledonline.it/rivistadirittoromano [30.12.14]).

17 Vgl. Bernd Mertens, Art. „Gesetzgebung“, in: HRG Bd. 2, 2. Aufl., 302 - 315 [303]; Hans-Georg Hermann, Jörg Müller, Art. „Rechtssatzung“, in: RGA, 2. Aufl., Bd. 24 (2004), 262 - 268; im Kontext des Verschriftlichungsprozesse der Leges: Siems, Zum Weiterwirken römischen Rechts (wie Anm. 10), 244. 18 Vgl. eingehend hierzu Hermann Nehlsen, Zur Aktualität und Effektivität germanischer Rechtsaufzeichnungen, in: Recht und Schrift im Mittelalter, Sigmaringen 1977 (VuF 23), 450-502. 
diesem Fall kann die Aufzeichnung herrscherlich initiiert und wird dann motivgeleitet gewesen sein.

$\mathrm{Zu}$ fragen ist auch nach Instrumenten für den Umgang mit Komplexität in den leges. Hier wird es darauf ankommen, wodurch die Komplexität überhaupt generiert wurde und wann sie also solche erkannt und sich Bedarf einstellte, auf Komplexität zu reagieren. Hierfür sei zunächst unterschieden zwischen Recht, das bereits verschriftlicht erscheint und (noch) nicht verschriftlichtem Recht.

\section{Verschriftlichtes Rechtswissen: Das westgotische Beispiel}

Glaubt man den Pauli Sententiae, und zwar so, wie sie sich im alaricianischen Breviar (Lex Romana Visigothorum [LRV]) finden, hat ein westgotischer König womöglich eigentlich keine (genuine) Gesetzgebungsgewalt, denn: die Gesetze macht der Imperator,

Sententia: Testamentum, in quo imperator heres scriptus est, inofficiosum argui potest: eum enim, qui leges facit, pari maiestate legibus obtemperare convenit.

Interpretatione non eget. ${ }^{19}$

So wörtlich ist das allerdings nicht zu nehmen, sagt die Stelle doch nur, daß ein Kaiser als derjenige, der Gesetze macht, sich auch daran halten soll - übrigens ein Satz, von dem die interpretatio behauptet, er bedürfe keiner Erläuterung. ${ }^{20}$ Als Aussage ausschließlich kaiserlicher Gesetzgebungsgewalt ist das Fragment also nicht zu deuten, und schon gar nicht eine solche Interpretation zu postulieren, im Gegenteil: die Westgoten sind die

19 Pauli Sententiae 4,5,3, hrsg. von Gustav Friedrich Hänel, Lex Romana Visigothorum, Berlin 1849 (ND 1962), 402.

20 Eine eingehend systematische Untersuchung, wann und wie diese apodiktische Feststellung angewandt wurde, könnte von Interesse sein, ist indessen vorliegend nicht zu leisten. Es ist aber offensichtlich, daß eine solche Behauptung simplifiziert. Ihre rhetorische Hocheffektivität findet sachargumentativ gerade keine explizierte vergleichbare Validität, denn der eigentlich erläuternd zu behandelnde Text sei nicht zu erläutern. Die vorauszusetzende Begründung hierfür kann nur meinen, eine Interpretation sei unnötig, weil der Text selbsterklärend sei. Dabei fehlt für eine solche Evidenz- und Notorietätsbehauptung jede Transparenz der Maßstäbe, auf denen sie beruht. Vielleicht ist Interpretatione non eget / non indiget auch nur ein arbeitsökonomischer Ansatz unter Wahrung einer Vorgabe grundsätzlich durchgängiger Kommentierung der Konstitutionen, vielleicht ist er reduzierter juristischer Fachkompetenz geschuldet, die einen juristischen Text nur unterkomplex verstehen kann, jedenfalls ist es kein weiterführender Ansatz, und im Grunde sogar eine punktuelle Informationes- und Diskursverweigerung, aus welchen Gründen auch immer. Für beliebige Beispiele vgl. etwa Hänel, LRV (wie Anm. 19), 238, 244 (Ista Lex tam evidens est, ut expositione non indigeat; mit dieser Formulierung auch 194), 250, 252; für die hochkontroverse Diskussion um die Interpretationes überhaupt vgl. nur Hermann Nehlsen, Alarich II. als Gesetzgeber. Zur Geschichte der Lex Romana Visigothorum, in: Studien zu den germanischen Volksrechten. Gedächtnisschrift für Wilhelm Ebel, Frankfurt a.M. 1982, 143 - 203 (bes. 144 ff., 181), oder Michael Memmer, Die Konstitutioneninterpretation in der Lex Romana Visigothorum, in: Gedächtnisschrift Herbert Hofmeister, hrsg. von Werner Ogris und Walter H. Rechberger, Wien 1996, 443-459. 
eifrigsten Gesetzgeber in den germanischen Nachfolgereichen, das Königtum ist vitaler Promotor des Rechtsetzungsgedankens: entsprechend ganz selbstverständlich steht etwa bei Isidor von Sevilla der (westgot.) König neben dem Imperator als Normgeber (Etym. 2,10 Lex est constitutio populi, quam maiores natu cum plebibus sancierunt. Nam quod Rex vel Imperator edicit, constitutio vel edictum vocatur ${ }^{21}$ ).

Isidor ist es auch, der vor allem Eurich im 5. Jahrhundert und - unter Übergehung Alarichs II. - Leovigild in dieser Funktion benennt. ${ }^{22}$ Von vorliegend besonderer Relevanz ist allerdings das Einführungsgesetz gerade Alarichs II. zur LRV, das sich als Rechtsanwendungsrecht zeigt: Vorhandenes Recht ist operable Masse und autoritativen Eingriffen ausgesetzt, wenn es (weil iniquum oder wegen seiner obscuritas) nicht funktionsfähig genug erscheint. Es wird „korrigiert“ - und damit fällt alles das weg, was sich nach Auffassung der vom König am Werk Beteiligten als korrekturbedürftig erwiesen hat:

Utilitates populi nostri propitia Divinitate tractantes, hoc quoque quod in legibus videbatur iniquum meliori deliberatione corrigimus, ut omnis legum romanarum et antiqui juris obscuritas, adhibitis sacerdotibus ac nobilibus viris, in lucem intelligentiae melioris deducta resplendeat, et nihil habeatur ambiguum unde se diuturna aut diversa jurgantium impugnet objectio. Quibus omnibus enucleatis, atque in unum librum prudentium electione collectis, haec quae excerpta sunt vel clariori interpretatione composita venerabilium episcoporum vel electorum provincialium nostrorum roboravit assensus. $^{23}$

Der Text transportiert also nicht nur Informationen zum Redaktionsgang, sondern auch intentionale Aussagen. Technisch erfolgt im Commonitorium Alarichs II. Komplexitätsreduktion und Reduktion von empfundenen Mißverständnispotentialen, mag man das effektiv auch nur als topische Kanzleirhetorik werten. ${ }^{24}$ Allerdings erging es der LRV selbst schließlich auch nicht besser, als sie im Jahr 654 von Recceswinth mit Erlaß des Liber iudiciorum abgeschafft wurde. Der Umstand, daß ihre wichtigste heute

21 Isidor von Sevilla, Etymologiarum sive originum libri XX, ed. Wallace Lindsay, Oxford 1911 [ohne Paginierung]; zum Problem edictum / lex für das westgotische Recht vgl. Hansgünther Schmidt, Zum Geltungsumfang der älteren westgotischen Gesetzgebung, in: Gesammelte Aufsätze zur Kulturgeschichte Spaniens, Bd. 29, hrsg. von Odilo Engels, Münster 1978, 1-84, hier 53-56.

22 Isidor v. Sevilla, Historia Gothorum (MGH Auct. ant. 11), hrsg. von Theodor Mommsen, Berlin 1894, 281, 288, c. 35 zu Eurich: Sub hoc rege Gothi legum instituta scriptis habere coeperunt. Nam antea tantum moribus et consuetudine tenebantur, und c.51 zu Leovigild: In legibus quoque ea quae ab Eurico incondite constituta videbantur correxit, plurimas leges praetermissas adiciens, plerasque superfluas auferens.

23 Hrsg. von Hänel, LRV (wie Anm. 19), 2.

24 Zur Eingriffsintensität gegenüber den Textmassen von Leges und Ius vgl. Nehlsen, Alarich II. (Anm. 20), 177 f., sowie Detlef Liebs, Art. „Lex Romana Visigothorum“, in: HRG Bd. 3, 2. Aufl., 918 924, hier 920. 
erhaltene westgotische Überlieferung im Codex Legionensis nur palimpsestiert ${ }^{25}$ er- $^{-}$ halten ist, erscheint dabei sogar als manifestes Beispiel für eine Beseitigung der LRV im Westgotenreich. ${ }^{26}$

Deutlich umrissen wurde von Recceswinth, was im Westgotenreich ab jetzt als Recht gewusst werden und was als solches gelten sollte, erstaunlicherweise ohne dabei unbedingt kongruierend:

Aliene gentis legibus ad exercitiam hutilitatis [sic!] inbui et permittimus et optamus; ad negotiorum vero discussionem et resultamus et proibemus. Quamvis enim eloquiis polleant, tamen difficultatibus herent. Adeo, cum sufficiat ad iustitie plenitudinem et prescrutatio rationum et conpetentium ordo verborum, que codicis huius series agnoscitur continere, nolumus sive Romanis legibus seu alienis institutionibus amodo amplius convexari. ${ }^{27}$

Hier zeigt sich eine bemerkenswerte Ambivalenz: Fremdes Recht wird als anwendbares Recht verboten, wiederum ist Vereinfachung das Mittel der Stunde: Abschaffung der LRV im Westgotenreich, damit sich niemand mehr mit dem römischen Recht plagen muß: nolumus ... convexari. Andererseits gilt die Kenntnis der „Gesetze des / eines anderen / fremden Volkes“ - worunter ohne weiteres offensichtlich auch und besonders das römische Recht verstanden wurde - als Gegenstand im Ausbildungsbetrieb (ad exercitiam hutilitatis) nicht nur als erlaubt, sondern sogar wünschenswert, weil nützlich. Das bedeutet, daß Rechtswissen hier über das bloße Wissen um das geltende Recht durchaus hinausgehen können sollte. Die Westgotengesetze bieten damit nicht nur Anschauung dafür, wie sehr das Königtum Recht und das Wissen um Recht und das Wissen vom Recht als Verfügungsmasse für ganz unterschiedliche Zwecke behandelte (vorstehend durch die Zweigleisigkeit von geltendem Recht in der Prozeßpraxis und ausbildungshalber erlerntem Recht), sondern auch Beispiel für ein das Frühmittelalter dominierendes Prinzip, nämlich das der Personalität des Rechts - und seine Behandlung (so streitig das im einzelnen auch sein mag) ${ }^{28}$. Territorialer Geltungsanspruch eines einheitlichen und für

25 Vgl. Regia historiae Academiae Hispana. Fragmenta ex Codice palimpsesto Sanctae Legionensis Ecclesiae, hrsg. von A. Fernández Guerra y Orbe u.a., Madrid 1896 (Faksimile der 1887 entdeckten zweitältesten Hs).

26 Nehlsen, Aktualität (wie Anm. 18), 489; s.a. Ian Wood, The Code in Merovingian Gaul, in: The Theodosian Code, hrsg. von Jill Harries und Ian Wood, Ithaca N.Y. 1993, 161-177, hier 165. Aber Palimpsestierung ist nicht zwingend eine intentional harte Vergessensmaßnahme. So plakativ einleuchtend Abschabung als solche Maßnahme erscheinen mag - mit dem Pariser Palimpsest des Codex Euricianus hätte man ein weiteres ganz prominentes Beispiel aus dem Gesetzesbereich - so wenig zwingend ist es: wenn in einer Bibliothek Pergament zweitverwertet wird, dann kann es auch Ressourceneinsatz sein, ohne auf Wissen zu verzichten: Textdubletten beseitigt auch heute noch jede Bibliothek, wenn es - meist in Hinblick auf die begrenzte Ressource Raum - sinnvoll erscheint.

27 Liber iudiciorum II, 1,10, hrsg. von Zeumer, LVis (wie Anm. 38), 58.

28 Vgl. einerseits Schmidt, Geltungsumfang (wie Anm. 21), andererseits Paul David King, The alleged territoriality of Visigothic Law, in: Authority and Power. Studies on Medieval Law and Government presented to Walter Ullman on his $70^{\text {th }}$ birthday, hrsg. von Brian Tierney und Peter Linehan, Cambridge 1980, 1-11; unter intensivem Aufschluß der Kontroverse insgesamt: Manuel Jesús Garcia Garrido, 
alle Reichsangehörigen geltenden Rechts bedeutet jedenfalls einen kardinalen Einschnitt nicht nur in seiner Wertigkeit und Aufwertung für den herrschaftspolitischen Geltungsanspruch des Gesetzgebers, sondern bedeutet ganz praktisch auch eine Vereinfachung, wenn man die gentile Perspektive verläßt und komplette „Rechtsmassen“ eliminiert, wie es Recceswinth unternommen hat. Eliminiert man sie, verlieren sie auch den Anspruch, befolgt zu werden. Ob die Rechtspflege damit besser oder schlechter funktionierte, mag hier dahinstehen.

\title{
3 Vorverschriftlichtes Rechtswissen: Das langobardische Modell und ein burgundisches Beispiel
}

Die Überführung einer oralen Rechtskultur in die Verschriftlichung ihrer Normen beschreibt Rothari im Epilog des Edictum, c.386. Dieser hochinteressante Vorgang ist seinerseits entsprechend häufig beschrieben und untersucht worden. ${ }^{29}$

\begin{abstract}
Das gegenwärtige von Uns verordnete Edikt - Wir haben, unter Gottes Huld, eifrigst und höchst sorgsam mit Himmels Gunst die alten Rechtssatzungen Unserer Väter, die [noch] ungeschrieben waren, [darin] gesammelt, und haben uns mit gemeinem Rat und Vollbort Unsrer Richterfürsten sowie Unseres ganzen heilgewohnten Heeres sie vermehrt und [neu] verordnet - [dieses Edikt also] haben wir in dies Pergament[buch] schreiben lassen. Jedoch wohl eingedenk Uns in diesem Stück [ausdrücklich] vorbehaltend, daß Wir auch fortan, was Wir mit Gottes Gnade durch gewissenhafte Nachfrage an alten Satzungen der Langobarden noch ermitteln können, sowohl von Uns aus wie mit Hilfe alter Leute, diesem Edikt anhängen mögen. Und setzen noch hinzu, ja, festigen es nach dem Brauche Unseres Langobardenvolks mit Geergeding: daß dies Gesetzbuch fest und stetig sein soll, auf daß man es sowohl zu Zeiten Unserer glücklichen [Herrschaft] wie auch in Zukunft fest und unverbrüchlich seitens aller Unserer Untertanen halte. ${ }^{30}$
\end{abstract}

Aufmerksamkeit provoziert vorliegend hier insbesondere eine spezielle Art einer gesetzgeberischen „Öffnungs- oder Nachtragsklausel“. Sie soll dem Verlust von

\footnotetext{
Nazionalismo e Romanismo nel diritto die Visigoti. I principi della personalitá e della territorialitá del diritto nel Regno Visigoto, in: Territorialitá e personaliltá. Compresenza di diversi piani normativi, hrsg. von Gisella Bassanelli Sommarviva und Simona Tarozzi, Milano 2013, 1-10.

29 Vgl. Gerhard Dilcher, Art. „Langobardisches Recht“, in: HRG 2. Aufl., Bd.3, 624-637, hier 627. 30 Edictus Rothari c. 386 (Die Gesetze der Langobarden, übers. u. bearb. v. Franz Beyerle, Weimar 1947, 156): Praesentem uero dispositionis nostrae edictum, - quem deo propitio cum summo studio et summis uigiliis a celestem faborem praestitis, inquirentes et rememorantes antiquas legis patrum nostrorum quae scriptae non erant, concedimus, et, quod pro commune omnium gentis nostrae utilitatibus expediunt, pari consilio parique consensum cum primatos iudices, cunctosque felicissimum exercitum nostrum augentes constituimus - in hoc membranum scribere iussimus; pertractantes et sub hoc tamen capitulo reseruantes, ut quod adhuc, annuentem diuinam clementiam, per subtilem inquisitionem de antiquas legis langobardorum, tam per nosmetispos quam per antiquos homines memorare potuerimus, in hoc edictum subiungere debeamus; addentes, quin etiam et per gairethinx secundum ritus gentis nostrae confirmantes, ut sit haec lex firma et stabelis, quatinus nostris felicissimis et futuris temporibus firmiter et inuiolabiliter ab omnibus nostris subiectis costodiatur.
} 
Rechtswissen gegensteuern, denn was nicht verzeichnet ist, das scheint verloren. Solche Ergänzungen von „Gewohnheitsrecht“ sind offenbar erst einmal unterblieben; hatte es weiteres gegeben, so ist es tatsächlich verloren. Verschriftlichung schafft Klarheit, scheidet als gültig Angenommenes von Sonstigem. Klarstellungs- und Bewahrungsabsicht bestimmen die konzeptionell dem Text ablesbare Handlungsstrategie. Jedoch man griff diese Technik punktuell doch wieder auf und zwar trotz einer höchst agilen nachrotharischen Novellengesetzgebung, die manchmal diesen Namen jedoch eigentlich gerade gar nicht verdient, dann nämlich, wenn sie gar nicht „novelliert“. Einen solchen Fall nicht novellierender, sondern in den Bahnen des Rotharischen Epilogs nur attestierender „Gesetzgebung“ bietet die Novelle 77 Liutprands. Punktuell scheint hier bisher nicht verschriftlichtes Recht auf, das nun auch noch Verschriftlichung erfährt:

Sind zwei Brüder oder Vater und Sohn [durch] Gedinge [voneinander abgeteilt] und stirbt einer von ihnen, ohne Söhne oder Töchter [zu hinterlassen], so folgt der Könighof ihm [ins Erbe]. Das aber schreiben wir deshalb, weil - obzwar im Satzungsbuch es nicht ausdrücklich steht - doch alle Unsere Richter und Getreuen sich dahin erklärten, daß es bisher schon so altes Herkommen sei. ${ }^{31}$

Vorliegend wichtiger als der Umstand, daß die Langobarden mit dem Begriff cawerfeda für „altes Herkommen“ sogar ein eigenes Rechtswort für diese - anscheinend aus Gerichtsgebrauch entstandenen ${ }^{32}$ - Gewohnheiten hatten, ist folgendes: Nach erbrechtlicher Abschichtung wird das Verwandtenerbrecht unterbrochen und ein Abgeschichteter, der ohne Nachkommen verstirbt, gilt als erbenlos, so daß der Nachlaß an den Königshof fällt. Liutprand behauptet nun, gestützt auf die Aussagen aller seiner Richter und Getreuen, ein gewohnheitsmäßiges Erbrecht des Fiskus - und gerade das mag und muß als legitimatorisches Vehikel und entsprechende Akzeptanzwerbung dienen. Offenbar tut das auch not, denn die Verwandten der anderen Linie leben ja schließlich noch. In diesem prekären Fall ist es gerade besonders fraglich, ob wirklich schon ein Erbrecht des Fiscus bestanden haben mag: Genau hierfür bemüht man sogar den langobardischen Terminus technicus cawerfeda. Offenbar war das Fiskalerbrecht bei diesem speziellen Sachverhalt so allgemein jedenfalls nicht bekannt oder selbstverständliches Allgemeingut, so daß es womöglich - wenigstens den Verwandten der anderen Linie - doch neu erscheinen konnte, weshalb eine Etikettierung als „alte Cawarfeda“ dann Legitimitätsprobleme reduzierte.

31 Übers. nach Beyerle, Gesetze der Langobarden [wie Anm. 30], 240, Liutprand Nov. 77: Si duo frates, aut si pater et filius thingati fuerunt, si unus ex ipsis sine filiis, filiabus mortuos fuerit, curtis regia ei succedat. Ideo autem hoc scripsimus, quia etsi adfictum in edictum propriae non fuit, tamen omnes iudices et fidelis nostri sic dixerunt, quod cauuerfeda antique usque nunc sic fuisset.

32 In diesem Sinn: Daniela Fruscione, Eine philologische Schlußbemerkung, in: Leges - Gentes Regna (wie Anm. 1), 525-535, bes. 530-535; s.a. S.a. Claudio Azzara, ,...quod cawerfeda antiqua usque nunc sic fuisset“. Consuetudine e codificazione nell'Italia longobarda, in: Alto medioevo mediterraneo, hrsg. von Stefano Gasparri, Florenz 2005 [Reti Medievali. E-book, Reading, 3], 251-257. 
Wie stark sich solche Gewohnheit durchaus ausnehmen konnte, daß noch nicht einmal der König sie dann ändern konnte, zeigt die berühmte Novelle 118 Liutprands über das Scheitern der Abschaffung des gerichtlichen Zweikampfes:

[...] Wiewohl wir uns unsicher sind über das Gottesurteil und wir viele gehört haben, daß durch den Zweikampf die eigene Rechtssache ohne Gerechtigkeit verlorengegangen ist, können wir das Gesetz selbst nicht verbieten wegen der Gewohnheit bei unserem Volk der Langobarden. ${ }^{33}$

In der Nov. 118 behinderte den König der Charakter als consuetudo, bei Nov. 77 kam ihm die Qualifizierbarkeit einer Rechtspraxis als cawerfeda entgegen. Obwohl der Begriff „Novelle“ auf neues Recht zu zielen scheint, darf man offenbar nicht zu viel typologisches Gewicht allein darauf legen, sondern sie kann in sich Rechtsgewohnheit aufnehmen und dabei nicht nur dokumentieren, sondern ihr nun eigentlich auch den Stempel der Anerkennung kraft königlicher Autorität verleihen, mag diese Anerkennung wie in Nov. 118 auch nur nolens volens erfolgen.

So nebulös und verloren damit das (noch) nicht aufgezeichnete Recht weithin erscheinen muß, manchmal hebt sich doch der Schleier ${ }^{34}$. Punktuell erkennbar wird solches „vorverschriftliche“ Recht etwa bei den Burgunden, so in Tit.18,1 der Lex Burgundionum: ${ }^{35}$

33 Übers. nach Beyerle, Gesetze der Langobarden [wie Anm. 30], 280-283: 118. [...] Quia incerti sumus de iudicio Dei, et multos audivimus per pugnam sine iustitia causam suam perdere; sed propter consuitudinem gentis nostrae Langobardorum legem ipsam vetare non possumus.

34 Auf gewisse Unschärfen ist jedenfalls auch dann noch hinzuweisen: Das aufgezeichnete langobardische Recht etwa behandelt nicht die Adoption - was dem entspricht, daß die Forschung annimmt, die germanischen Rechte hätten keine Adoption im engeren Sinn gekannt, wohl aber Institute „von adoptionsähnlichem Charakter ...; die sog. Ehrenadoptionen durch Waffengabe oder Haar- bzw. Bartschur“ (W. D. Wackernagel, Art. „Adoption“, in: HRG Bd.1, 1. Aufl., 56-57 [57]; ebenso E. Koch in der 2. Aufl., a.a.O., 78 -81; s.a. zum folgenden R. Schmidt-Wiegand, Art. „Haar, Haarscheren“, in: HRG Bd.2 2.Aufl., 635-641 [638]). Paulus Diaconus - also eine narrative Quelle - berichtet von einer solchen „Ehrenadoption“, wie im Jahr 737 Liutprand durch Haarschur „Vater“ des zu ihm geschickten Pippin wurde: Carolus princeps Francorum Pipinum suum filium ad Liutprandum direxit, ut eius iuxta morem capillum susciperet. Qui eius caesariem incidens, ei pater effectus est multisque cum ditatum regiis muneribus genitori remisit (Historia Langobardorum, hrsg. von L. Bethmann et G. Waitz, Hannover 1878 [MGH SS rer. Lang.], VI, 53, 183; zum Kontext vgl. Jörg Jarnut, Die Adoption Pippins durch König Liutprand und die Italienpolitik Karl Martells, in: Karl Martell in seiner Zeit, hrsg. von Jörg Jarnut, Sigmaringen 1994 [Beihefte der Francia 37], 217 -226.). Bei aller terminologischen Unschärfe ist es vielleicht kein Zufall, daß für diese rechtlich aber anscheinend auch kaum völlig irrelevante Zeremonie davon die Rede ist, sie sei iuxta morem von statten gegangen - jedenfalls hat Liutprand, obwohl er selbst die Haarschur vornahm und Pippin damit ,adoptierte“, nicht veranlaßt, dieses Institut in seinen Novellen zu verschriftlichen.

35 MGH LL. sect. I Bd. II,1 hrsg. von Salis, Hannover 1892, 56; übers. Franz Beyerle, Gesetze der Burgunden, Weimar 1936 (Germanenrechte; 10), 34: Tit. XVIII. De his, quae casu contigerint. 1. Si quodcumque animal quolibet casu aut morsus canis homini mortem intulerit, iubemus etiam inter Burgundiones antiquam exinde calumniam removeri, quia quod casus operatur non debet ad damnum aut inquietudinem hominis pertinere. Ita ut si de animalibus subito caballus caballum occiderit aut bos bovem 


\begin{abstract}
Von dem, was so von ungefähr geschieht.
Wenn irgendein Tier durch ein Verhängnis - sei es auch eines Hundes Biß - eines Menschen Tod bewirkt, soll man künftig die alte Sitte, Schuld darum zu geben, lassen und zwar auch zwischen Burgunden. Denn was der Zufall bewirkt, soll nicht dem Menschen Schaden oder Unfrieden bringen. Doch so: wenn unter Tieren unversehens ein Pferd das andere zu Tode schlägt oder ein Rind das andere verletzt oder ein Hund, wen oder was er anfällt, zum Krüppel beißt, soll man das schädigende Tier - insonderheit auch den Hund - demjenigen ausliefern, den der Schaden traf.
\end{abstract}

Es handelt sich um burgundisches Stammesrecht novellierende Königsgesetzgebung (iubemus), das den alten Rechtszustand abschafft und in Anlehnung an das römische Recht offenbar nun etiam inter Burgundiones eine Art Noxalhaftung anstelle vorher verschuldensunabhängigen Wergeldes statuiert. Die Kenntnis der alten Rechtslage wäre ohne seine klarstellende Erwähnung verloren.

Verschriftlichung bedeutet also keineswegs durchwegs nur einen Medienwechsel als jetzt bloß literale Abbildung von Vorhandenem und Vorgefundenem, sondern ggf. Eingriff, Abschichtung, Verformung, Verdrängung, Verlust bisherigen Rechts, seiner Kenntnis und Valenz. Bleibt damit schon für das vorverschriftlichte „Gewohnheitsrecht“ eine nicht einmal grob abschätzbare Dunkelziffer, so ist die Behauptung von Gesetzgebern seiner bloßen Aufzeichnung (so wie etwa hinsichtlich des Erbrechts des Fiskus bei Liutprand) wohl gelegentlich durchaus mehr Absichtserklärung als eine belastbare Aussage.

\title{
III Intentionale Disposition über Rechtswissen in den Leges: Beobachtungen auf Mikroebene
}

1. Nach diesen „Makrobeobachtungen“, die schwerlich Unbekanntes, sondern (wenngleich im Einzelnen auch durchaus sehr umstritten) Wohlbekanntes kursorisch zusammengetragen haben, sollen jetzt Perspektive und Zugriff wechseln und es bei einem Detailproblem um Rechtswissen als operable Masse gehen. Dieses rechtliche Detailproblem liegt zudem mutmaßlich auf einer Schnittstelle von germanischem und römischem Recht. Es geht um die Voraussetzungen der Schenkung von Immobilien, ${ }^{36}$ wie sie eine kleine, wohl aus Südfrankreich und aus wohl dem 6. Jahrhundert - nach Wieacker „am wahrscheinlichsten zwischen 507 und 526“ - stammende Sammlung gefasst hat. Es handelt sich um die in der Forschung nach Augusto Gaudenzi als ihrem Entdecker benannten Fragmenta Gaudenziana, heute London Brit. Mus. Add.

percusserit aut canis momorderit, ut debilitetur, ipsum animal aut canem per quem damnum videtur admissum, tradatur illi, qui damnum pertulit.

Zur Sache: Hermann Nehlsen, Art. „Lex Burgundionum“, in: HRG Bd.2, 1. Aufl., 1901-1915 [1910]. 36 Allg. zu Grundstücksübertragungen: H.-R. Hagemann, Art. Grundeigentum § 1 - 2 in: RGA 2.Aufl., Bd. 13, 103 - 110 [108]; Ernst Levy, West Roman vulgar Law - The Law of Property, Philadelphia 1951, $128-168$. 
Mss. $46676,{ }^{37}$ ediert von Zeumer in den Leges Visigothorum, ${ }^{38}$ von diesem allerdings auch deutlich später datiert, nämlich, „nicht vor Ende des VI. Jahrhunderts““. ${ }^{39}$ Sie bestehen aus 14 Kapiteln als Einsprengsel in der pars prima (dort Kapitel 7 bis 20) einer größeren Handschrift, nämlich der sog. Collectio Gaudenziana, die ihrerseits überwiegend dem beginnenden 10. Jh. zugewiesen wird. Die Immobilienschenkung behandelt Kapitel 15 dieser Fragmenta Gaudenziana [FG] folgendermaßen: ${ }^{40}$

Wenn jemand Haus oder Hof einem anderen schenkt, bekräftige er das, was er schenkt, mit einer Schenkungsurkunde; und zwar so, daß bei dieser Schenkung der Schenker selbst mit eigener Hand unterschreibe, und die Schenkung selbst mit nicht weniger als drei Zeugen bestärkt werde.

Wenn aber der Schenker selbst und die Zeugen schreibunkundig sind, mache ein jeder einzelne ein Zeichen mit eigener Hand.

Und die Schenkung selbst werde vor die Kurialen gebracht.

Wenn in derselbigen civitas keine Kurialen gefunden werden können, soll (die Schenkung [surkunde]) in eine andere civitas gebracht werden, wo [welche] gefunden werden.

Benötigt wird hiernach für eine wirksame Immobilienschenkung eine cartula, in ihr die eigenhändige Unterschrift des Schenkers sowie mindestens 3 Zeugen, die die Schenkung bekräftigen. Wenn sowohl der Schenker wie die Zeugen Analphabeten sind, soll jeder ein Handzeichen (bzw. ein „Zeichen mit eigener Hand“) machen. Die

37 Franz Wieacker, Römische Rechtsgeschichte, 2. Abschn / a.d. Nachlaß hrsg. von Joseph Georg Wolf, München 2006, § 73 V, 255; Max Conrat (Cohn), Geschichte der Quellen und Literatur des römischen Rechts im frühen Mittelalter, Leipzig 1891 (ND 1963), 277-284 [279-281]; Rudolf Buchner, Die Rechtsquellen. Beiheft zu: Wattenbach-Levison, Deutschlands Geschichtsquellen im Mittelalter, Weimar 1953, 8; Guilio Vismara, Fragmenta Gaudenziana, Mailand 1968 (IRMAE I 2b bb $\beta$ ); umfassend für die ältere Lit. vgl. H. Benna, Art. „Gaudenzische Fragmente“, in: HRG Bd.1, 1. Auflage, 1403-1404; siehe a. Hans-Georg Hermann, Art. „Gaudenzische Fragmente“, in: HRG Bd.1, 2. Aufl. (2008), 1945; Detlef Liebs, Römische Jurisprudenz in Gallien (2. bis 8. Jahrhundert), Berlin 2002 (Freiburger Rechtsgeschichtliche Abhandlungen, n.F. 38), 179-181; Wolfgang Kaiser, Epitome Iuliani. Beiträge zum römischen Recht im frühen Mittelalter und zum byzantinischen Rechtsunterricht, Frankfurt a. Main 2004 (Studien zur Europäischen Rechtsgeschichte 175), 655, bes. 670, 729, 737, 819-824. Nach Hermann Nehlsen, Art. „Lex Visigothorum“, in: HRG Bd.2, 1. Auflage, 1966 - 1979 [1968] ist die Zuordnungsfrage bis heute nicht befriedigend geklärt - in diesem Sinn auch schon ders., Sklavenrecht zwischen Antike und Mittelalter, Bd.1, Göttingen 1972 (Göttinger Studien zur Rechtswissenschaft; 7), 153 Fn.3 und 156 Fn.22. Das ist wohl immer noch so.

38 Leges Visigothorum, hrsg. von Karl Zeumer (MGH LL nat. Germ. 1), Hannover / Leipzig 1902, 469 472 unter Rubrizierung als „Collectionis Iuris Romano-Visigothici capita VII-XX (Fragmenta Gaudenziana)“.

39 Karl Zeumer, Eine neuentdeckte westgothische Rechtsquelle, NA 12 (1887), 387 - 400 [Zitat 397], sowie Karl Zeumer, NA 23 (1898), 419-516 [466 „... vermute ich, daß die Abfassung unter Leovigild fällt"].

40 Ed. Zeumer, LVis (wie Anm. 38), 471: c. 15 Si quis domum aut villam alio donaverit, hoc, quod donavit, per donationis cartulam firmet; ita ut in ea donatione ipse donator propria manu subscribat, et ipsa donatio non minus tribus testibus roboretur. Si autem ipse donator et testes litteras nesciunt, unusquisque signum propria manu faciat. Et donatio ipsa ante curiales deferatur. Quod si in civitate eadem curiales non possunt inveniri, ad aliam civitatem, ubi inveniantur, deferatur. 
Schenkung selbst ist sodann vor die „curiales“ der civitas zu bringen - das deutet in Richtung gesta municipali $a^{41}$-, wo diese Urkunde zu allegieren sein würde. ${ }^{42}$ Zugleich deutet der Passus auch darauf hin, daß die Belegenheit der Immobilie zunächst die Zuständigkeit der civitas bestimmt, in deren Bereich sich das Schenkungsobjekt befindet. Doch die Norm reflektiert auch den Fall, daß sich in der civitas keine Kurialen finden lassen (was wohl nur heißen kann: daß es keine [mehr] gibt) - in diesem Fall spielt die an sich gegebene örtliche Zuständigkeit keine Rolle mehr, sondern man kann sich dorthin wenden, wo man überhaupt (noch) Kurialen findet.

Das ist einerseits eine Lockerung, die womöglich der Not der faktischen Verhältnisse gehorcht, andererseits aber auch ein Festhalten an tradierten Strukturen (Allegierungspflicht, Mitwirkung von Kurialen). Entscheidend bleibt, daß die Schenkung in acta municipalia auftaucht. Wo sich diese finden, ist letztlich nicht entscheidend, weil eine flächendeckend anzutreffende Präsenz einer voll funktionsfähigen Civitas-Verwaltung nicht (mehr) existiert. Offenbar als unproblematisch vorausgesetzt wird, daß sich aber jemand finden läßt, der die cartula aufsetzen kann. Nicht nur keinerlei Hinweise gibt c. 15 darauf, ob zur Formwahrung vielleicht sogar die bloße sog. „Handfestung“, also das bloße Handauflegen auf die Urkunde ausreichen könnte, ${ }^{43}$ sondern im Gegenteil: wenn von jedem Beteiligtem (Aussteller wie Zeuge) wenigstens gefordert wird, er solle ein Zeichen mit eigener Hand machen (signum propria manu faciat), sind unzweideutig skripturale Formvoraussetzungen expliziert und dabei - auch für die Ersatzform - immer noch relativ höher angesetzt als für eine Handfestung. Wenn hier auch ein bloßes Zeichen - üblicherweise ein einfaches Kreuz

41 Als uneingeschränkt verläßlicher Beweis für eine fortwährende Praxis der Gesta municipalia in Südostfrankreich gilt umgekehrt genau c. 15 FG für Rudolf Buchner, Die Provence in merowingischer Zeit, Stuttgart 1933 (Arbeiten zur deutschen Rechts- und Verfassungsgeschichte 9), 25, der zudem (wie schon Zeumer, LVis [wie Anm. 38], 472 Fn.1) auch c. 19 FG als Modifizierung einer Vorschrift ebenfalls des EdTheod (c. 80) sieht: „Die beiden Stellen der Holkhamer Kapitel [sc. Fragmenta Gaudenziana] lassen also erkennen, daß ihr Verfasser die Vorschrift [!] des Edictum Theoderici den Verhältnissen der Provence anpaßte, ...“ [26]. Grundlegend zu den gesta: Bruno Hirschfeld, Die gesta municipalia in römischer und frühgermanischer Zeit, Marburg 1904; für weitere Hinweise vgl. Peter Johanek, Art. „Gesta municipalia“, in: Lexikon der Mittelalters Bd.4 (1989), 1408; für eine eingehende Analyse der Solemnitäten, auch in überregionalem Zusammenspiel der Behörden (allerdings in Italien), vgl. Leo Santifaller, Die Urkunde des Königs Odovakar vom Jahre 489, in: MiÖG 60 (1952), 1-30; zu dieser Schenkung s.a. (mit Übersetzung) Olof Tjäder, Die nichtliterarischen Lateinischen Papyri Italiens aus der Zeit 445-700, Uppsala 1955 [ND 1982] (Acta Instituti Romani Regni Sueciae, series in 4ㅇ; 19, 1), 279-293.

42 Enger aber Karl Zeumer, Zum westgotischen Urkundenwesen, NA 24 (1899), 15 - 38, hier 22, der erwägt, die Kurialen seien nötig, um nur die Übereinstimmung der bloßen Handzeichen / Signa mit der sie leistenden Personen zu beglaubigen; nach dieser Interpretation hätte c. 15 FG überhaupt keinen Bezug zu der Frage, ob die Schenkung insinuiert werden muß - das ist indessen wenig wahrscheinlich, weil in einer civitas, in der keine Kurialen gefunden werden können, wohl auch keine gesta municipalia geführt sein werden. Damit bliebe die wohl zentralere Frage der Eintragung in öffentliche Bücher mit entsprechendem Informationspotential für die Eigentumsverhältnisse bei lokalen Grundstücken hier ungeregelt.

43 Vgl. hierzu Saupe, Unterfertigung (wie Anm. 3), 43, 83. 
- genügen soll, zeigt das ein Beharren auf einem Skripturakt, auch wenn dieser nicht mehr notwendig selbst indivualisierte Züge aufweist und zeigt Abnahme der Schreibfertigkeit auch nur wenigstens des eigenen Namens, den man nicht selbst geschrieben fordert. Das liegt noch einmal unterhalb dessen, daß die Subscriptio normalerweise ohnehin nicht nur die Unterfertigung mit dem eigenhändig ausgeführten Namenszug meinte. ${ }^{44}$

2. Schon Zeumer wies auf die Nähe von FG c. 15 zu evtl. Vorlagen hin, in Betracht zog er den Codex Euricianus, in dessen c. 307 es allerdings um Schenkungen allgemein und nicht nur von Grundstücken geht, dafür aber nur unter Ehegatten:

cap. CCCVII Maritus si uxori suae aliquid donaverit, de hoc, quod voluerit, scriptura sua manu signo sive subscriptione confirmet, ita ut duo aut tres testes ingenui subscriptores accedant; et sic voluntas ipsius habeat firmitatem. ... ${ }^{45}$

Wenn ein Ehemann seiner Ehefrau etwas geschenkt hat, bestärke der das, was er [sie?] will, mit einem Schriftstück mit einem Zeichen durch seine Hand oder Unterschrift, so, daß zwei oder drei freigeborene Zeugen als Unterschreibende hinzukommen; und so habe sein Wille Geltungskraft. ${ }^{46}$

Was sich hier so unzweideutig gibt, beruht auf allerdings schwankendem editorischen Boden und dürfte angesichts der Pariser Palimpsestüberlieferung schlechterdings nicht verbindlich $\mathrm{zu}$ entscheiden sein. ${ }^{47}$ Mit gewissen Modifzierungen hat diese Regelung dann Eingang auch in die Antiqua gefunden. Hiernach können auch die Zeugen mit lediglich ihrem signum unterzeichnen:

LVis V,2,7 Antiqua

Maritus si uxori sue aliquid donaverit, de hoc, quod ipsa sibi habere voluerit, scriptura [m] manus sue suscriptione vel signo confirmet, ita, ut duo aut tres testes ingenui suscriptores vel signa facientes accedant; et sic volumtas ipsius habeat firmitatem.

Hat eine Mann seiner Frau etwas geschenkt, was diese für sich haben soll, so soll er die Urkunde durch seine Unterschrift oder sein Handzeichen bekräftigen und zwei oder drei freie Zeugen sollen mit ihren Unterschriften oder Handzeichen dazu treten; und so habe sein Wille Rechtsbestand. ${ }^{48}$

44 Vgl. Saupe, Unterfertigung (wie Anm. 3), 42.

45 ed. Zeumer, LVis (wie Anm. 38), 12 (mit Emendationen); ohne insoweit nennenswert abweichende Lesart auch bei Alvaro d'Ors, El Código de Eurico. Estudios visigóticos II, Rom-Madrid 1960 (Cuadernos del Instituto Juridico Español; 12), 33.

46 Leicht anders Eugen Wohlhaupter, Gesetze der Westgoten, Weimar 1936 (Germanenrechte; 11), 19: „Wenn der Mann seiner Frau etwas geschenkt hat, von dem was er will, so bekräftige er die Urkunde mit eigener Hand durch ein Handzeichen oder Unterschrift, wobei zwei oder drei freie Zeugen mit unterschreiben sollen; und so habe sein Wille Rechtsbestand ...“.

47 Vgl. unten Anm. 60.

48 Zeumer, LVis (Anm. 38), 215 - 216 bzw. Wohlhaupter, Westgotische Gesetze (Anm. 46), 116-117; Zeumer, Urkundenwesen (Anm. 42), 21 hielt es aus Platzgründen für ausgeschlossen, daß die entsprechende Erweiterung vel signa facientes für die Zeugen in c. 307 CodEur gestanden haben könne. 
Nachdem in den Fragmenta Gaudenziana eine geltungsmäßige Engführung nur auf Germanen / Goten nicht erkennbar ist, sind jedenfalls auch römischrechtliche Parallelstellen mit in den Blick zu nehmen. Mit den näheren Voraussetzungen einer Schenkung befaßt sich nämlich auch das Breviar, eingehend hierzu vor allem die zweite Hälfte der Interpretatio zu LRV 8,5,1:49

[...] In conscribendis autem donationibus hic ordo servandus est, ut donatio nomen prius contineat donatoris vel illius, cui donatur; deinde res, quae donatur, sive in agris sive in mancipiis sive in quibuslibet rebus atque corporibus, nominatim in donatione conscribendae sunt, non occulte, sed publice, non privatim vel secrete, sed aut in tabulis aut in chartis aut ubicunque legatur facta donatio. Quam tamen donationem, si literas novit, donator ipse subscribat: si vero ignorat, praesentibus plurimis eligat, qui pro ipso subscribat: et hanc ipsam donationem gestorum solennitas et corporalis traditio subsequantur, ita ut, si mobilia donantur, praesentibus plurimis tradantur: si vero ager vel domus donatur, quod moveri non potest, ut inde donator abscedat et novo domino pateat res donata, si tamen sibi de his rebus usumfructum donator non reservaverit. Gesta vero donationum aut apud iudicem aut apud curiam alleganda sunt..$^{50}$

Angesichts der Unklarheit, die über den Entstehungskontext der FG herrscht, wobei aber allgemein als Referenzrahmen gotisches Recht angenommen wird, ${ }^{51}$ erscheint die Einbeziehung auch des ostgotischen ${ }^{52}$ EdTheod als Vergleichstext kaum fernliegend. Auch wäre die ausdrückliche Bezugnahme auf ein „edictum“ in FG c.7, 10 und 11 theoretisch als Bezugnahme auf das EdTheod denkbar, sie wird aber zumeist als Bezugnahme auf den Codex Euricianus interpretiert, der zeitgenössisch als „Edictum“ bezeichnet gewesen sein soll..$^{53}$ Jedenfalls schon Zeumer nahm „haud dubie“ eine

49 Hänel, LRV (Anm. 19), 156.

50 Übers. Max Conrat (Cohn), Breviarium Alaricianum. Römisches Recht im fränkischen Reich in systematischer Darstellung, Leipzig 1903, 206 - 207: „Bei Abfassung der Schenkungen ist vielmehr die folgende Ordnung in Acht zu nehmen, dass die Schenkung den Namen zuerst des Schenkers, bez. desjenigen, welchem geschenkt wird, enthält, hierauf die Sachen, welche geschenkt werden, sei es an Grundstücken, sei es an Sklaven, sei es an irgendwelchen Sachen und Gegenständen, namentlich in der Schenkung zu verzeichnen sind, nicht im Verborgenen, sondern öffentlich, nicht privatim bez. heimlich, sondern entweder auf Tafeln oder auf Chartae oder, worin immer die Schenkung abgefasst zu lesen ist. Die Schenkung soll sodann der Schenker, der die Schrift kennt, selbst unterzeichnen; kennt er sie aber nicht, so soll er in Gegenwart zahlreicher Personen Jemanden auswählen, der an seiner Statt unterzeichnet. An diese Schenkung soll sich die Solennität der Gesta und die körperliche Übergabe anschliessen, derart, dass, wenn bewegliche Sachen geschenkt werden, sie in Gegenwart zahlreicher Personen übergeben werden sollen, wenn dagegen ein Grundstück oder ein Haus geschenkt wird, was sich nicht bewegen lässt, der Schenker sich von dort entferne und die geschenkte Sache dem neuen Eigentümer zur Verfügung stehe [außer der Schenker hätte sich die Nutznießung vorbehalten; fehlt bei Conrat]. Die Gesta über die Schenkungen sind entweder bei dem Iudex oder bei der Kurie zu allegieren.“ 51 Das stützt sich vor allem auf den Begriffs sajo in c.12 FG und seiner west- wie ostgotischen Belegverbreitung, vgl. Vismara, Fragmenta Gaudenziana (Anm. 37), 10, sowie Jan F. Niemeyer, Co van de Kieft, Mediae Latinitatis Lexicon minus, Leiden 1976, s.v. „,sagio, sago, sajo, sayo, sajus“, 929.

52 Vgl. oben Anm. 16.

53 Gegen diese Zuschreibung Schmidt, Geltungsumfang (Anm. 21), 54. 
Konzeption von c. 15 FG nach c. 51 und c. 52 des EdTheod an. ${ }^{54}$ Die einschlägigen Vorschriften lauten: ${ }^{55}$

c. 52: Si vero praedium rusticum aut urbanum quisquam libero arbitrio conferre voluerit, scriptura munificentiae etiam testium subscriptionibus roborata gestis municipalibus allegetur; ita ut confectioni gestorum praesentes adhibeantur tres curiales et magistratus, aut pro magistratu defensor civitatis cum tribus curialibus, aut duumviri quinquennales: qui si defuerint, in alia civitate quae haec habuerit, allegationis firmitas impleatur, aut apud iudicem eiusdem provinciae, quod donatum fuerit, allegetur.

c. 53: De traditione vero quam semper in locis secundum leges fieri necesse est, si magistratus, defensor, aut duumviri quinquennales forte defuerint, ad conficienda introductum gesta tres sufficient curiales: dummodo vicinis scientibus impleatur corporalis introductionis effectus. ${ }^{56}$

Wenn die Nennung von urbanem und ländlichem Gut als gleich zu Beginn positionierter Regelungsgegenstand der Norm zur Klarstellung des einschlägigen (immobilen) Verfügungsobjektes in c. 15 FG eine Parallele findet, weil dort unter domus aut villa ebenfalls das eine wie das andere begriffen ist, ${ }^{57}$ dann läge hier eine erste klare Strukturparallele, die in der Interpretatio zu LRV 8,5,1 zwar mit ager vel domus auch aufscheint, jedoch weitaus weniger augenfällig und nur als Erläuterung der Immobilienschenkung.

Am augenfälligsten erschließen sich das Auftreten, die Modifizierung und das Fehlen einzelner Tatbestandsmerkmale obiger Quellenstellen durch eine graphische Gegenüberstellung:

54 Zeumer, LVis (Anm. 38), 471 Anm.2.

55 MGH LL V,1 hrsg. von Friedrich Bluhme, 1875, 157 (mit abw. Kapitelzählung).

56 In der Übersetzung von Lafferty, Edictum Theoderici (Anm. 16), 273-274: „52) If anyone bequeaths a rural or urban estate. But if anyone wishes to willingly make a gift of rural or urban estates, a record of the generosity, confirmed by the signatures of witnesses, shall be registered in the municipal records; provided that three curials or municipal magistrates, and a defensor civitatis on behalf of the municipal magistrate together with three decurions or duumviri or quinquennales are present as witnesses for the drawing up of the records [of the gift]; but if these are not available, the registering of the transaction shall be fulfilled in another municipality which has these officials; or let a report of what was given be forwarded to the governor of that province. 53) On transferring ownership (traditio). Concerning traditio, it is necessary for it to be conducted according to the laws in the district: if a municipal magistrate, defensor, duumviri and quinquennales are not available, three decurions shall be sufficient for executing the records of transfers, provided that the performance of the material conveyance is carried out before knowledgeable men in the neighborhood."

Durchaus grundsätzlich Aufmerksamkeit verdienen dabei auch noch die Kommentierungen von Felix Dahn, Die Edicte der Könige Theoderich und Athalarich. Das gothische Recht im gothischen Reich, München 1866, die über die von Lafferty hinausgehen, hier $67 \mathrm{f}$. (im speziell vorliegenden Zusammenhang aber ohne weiteren Belang).

57 Es dürfte jedenfalls mit den angegebenen Belegen (nämlich LVis 9,1,21 und c.15 FG) kaum ausreichen, domus und villa in Spanien und Gallien einfach für synonym zu erklären, wie es Jean Durliat, Les finances publiques de Dioclétien aux Carolingiens (284-889), Sigmaringen 1990 (Beihefte der Francia 21), 153 tut. 
Vergleichsaspekte ausdrücklich benannter Voraussetzungen einer Immobiliarschenkung

\begin{tabular}{|c|c|c|c|c|c|}
\hline & CodEur & LVis & LRV (interpr.) & Fragm.Gaud c.15 & EdTheod \\
\hline Parteien & Ehegatten & $\begin{array}{l}\text { wie } \\
\text { CodEur }\end{array}$ & $\begin{array}{l}\text { donator / [ali]quis, } \\
\text { cui donatur }\end{array}$ & [ali]quis[quam] & quisquam \\
\hline $\begin{array}{l}\text { Schenkungs- } \\
\text { gegenstand }\end{array}$ & aliquid & aliquid & $\begin{array}{l}\text { res [ager, mancipia] } \\
\text { atque corpora [ager } \\
\text { vel domus] }\end{array}$ & domus aut villa & $\begin{array}{l}\text { praedium rusticum } \\
\text { aut urbanum } \\
\text { (Schenkung?) }\end{array}$ \\
\hline $\begin{array}{l}\text { Fertigung } \\
\text { einer } \\
\text { cartula }\end{array}$ & scriptura & scriptura & $\begin{array}{l}\text { tabulae chartae aut } \\
\text { ubicumque [donatio] } \\
\text { legatur }\end{array}$ & $\begin{array}{l}\text { per cartulam } \\
\text { firmare }\end{array}$ & $\begin{array}{l}\text { scriptura } \\
\text { munificentia etiam } \\
\text { testibus subscript. } \\
\text { roborata }\end{array}$ \\
\hline $\begin{array}{l}\text { Regelung der } \\
\text { Schreibun- } \\
\text { kundigkeit }\end{array}$ & & & $\begin{array}{l}\text { donator [litteras] } \\
\text { ignorat: Vertreter- } \\
\text { unterschrift pro ipso }\end{array}$ & $\begin{array}{l}\text { Litteras } \\
\text { nescire }\end{array}$ & \\
\hline $\begin{array}{l}\text { explizit Hand- } \\
\text { zeichen mögl. } \\
\text { für Schenker }\end{array}$ & $\begin{array}{l}\text { sua manu } \\
\text { signo }\end{array}$ & signo & & $\begin{array}{l}\text { signum manu } \\
\text { propria }\end{array}$ & \\
\hline $\begin{array}{l}\text { explizit Hand- } \\
\text { zeichen mögl. } \\
\text { für Zeugen }\end{array}$ & $?$ & signa & & $\begin{array}{l}\text { signum manu } \\
\text { propria }\end{array}$ & \\
\hline $\begin{array}{l}\text { Anzahl von } \\
\text { Zeugen }\end{array}$ & $\begin{array}{l}\text { duo aut } \\
\text { tres }\end{array}$ & $\begin{array}{l}\text { duo aut } \\
\text { tres }\end{array}$ & & $\begin{array}{l}\text { non minus quam } \\
\text { tres testes }\end{array}$ & überhaupt ja (s.o.) \\
\hline $\begin{array}{l}\text { Allegation bei } \\
\text { den gesta } \\
\text { municipalia }\end{array}$ & & & solennitas gestorum & $\begin{array}{l}\text { ante curiales } \\
\text { deferatur }\end{array}$ & scriptura allegetur \\
\hline $\begin{array}{l}\text { Anzahl der } \\
\text { Kurialen }\end{array}$ & & & & & 3 \\
\hline $\begin{array}{l}\text { Erreichbarkeit } \\
\text { von Kurialen }\end{array}$ & & & $\begin{array}{l}\text { apud iudicem aut } \\
\text { apud curiam (nicht } \\
\text { problematisiert) }\end{array}$ & $\begin{array}{l}\text { non possunt in- } \\
\text { veniri ad aliam } \\
\text { civitatem } \\
\text { deferatur }\end{array}$ & $\begin{array}{l}\text { si defuerint..., in alia } \\
\text { civitate aut apud } \\
\text { iudicem provinciae }\end{array}$ \\
\hline $\begin{array}{l}\text { Anzahl mitwir- } \\
\text { kender Gesta- } \\
\text { Beamter }\end{array}$ & & & & & $3+1$ \\
\hline
\end{tabular}

3. Kapitel 15 der FG erscheint damit als eine den Zeitumständen angepasste, pragmatische Lösung, die das Prinzip von Eintragungspflichten in öffentliche Bücher noch tradiert und die Relevanz von acta municipalia keineswegs negiert, die Erfüllbarkeit der formalen Voraussetzungen aber flexibel handhabt. Neu oder singulär ist nicht die Reaktion auf ein Fehlen von Kurialen vor Ort (das bedenkt auch das Edictum Theo- 
derici, das sich seinerseits hier stillschweigend auf CTh 8,12,8 stützt, ${ }^{58}$ so daß also auch unmittelbar hieraus in FG c. 15 die Lösung geschöpft worden sein könnte), aber variierend neu gegenüber dem EdTheod (und auch gegenüber CTh 8,12,8) ist die Regelung des Falles von Analphabetismus. Doch auch das ist nicht singulär, denn das findet sich ebenso in der LRomVis bzw. der Interpretatio, dabei allerdings auch nicht in ganz präziser Entsprechung.

Eine Verallgemeinerung für alle Schenkungen formuliert die Interpretatio und benennt dabei Mobilien wie Immobilien, c. 15 FG konzentiert sich dann aber auf die Immobiliarschenkung; die Berücksichtigung der Schreibunkundigkeit findet sich ebenfalls in der Interpretatio, dort aber mit anderer Lösung (Schenker muß jemand anderen für sich unterschreiben lassen), die nicht übernommen wird: c. 15 FG erlaubt das Handzeichen und zwar so wie es die LVis zulässt, nämlich sowohl als Möglichkeit für den Aussteller wie für die Zeugen. Die Erweiterung für Zeugen kennt ausdrücklich (wohl) nur die LVis und der CodEur (wohl noch) nicht, so daß die LVis dem c. 15 FG näher stehen dürfte. Anderseits hatte bereits CodEur und nicht erst die LVis die Wendung manu sua für das Handzeichen. Da die Erweiterung des Handzeichens auch auf die Zeugen eine größere materielle Bedeutsamkeit für den Normgehalt aufweist (nämlich Erlaubtsein des Handzeichens anstelle der eigenhändigen Unterschrift) als die erläuternde (und auch nicht fernliegende) manu-sua-Formulierung für das Handzeichen, scheint der Redaktor von c. 15 FG eher die Antiqua der LVis vor Augen gehabt zu haben als den Codex Euricianus (was dann als terminus post quem für FG c. 15 die Amtsdaten Leovigilds zu erschließen erlaubte, also 568-586 und die Spätdatierung Zeumers ${ }^{59}$ unterstützen würde). ${ }^{60}$ Deutet man erscheinungsmäßige Paral-

58 Vgl. Lafferty, Edictum Theoderici (Anm. 16), 241-243. Das Problem, daß sich vor Ort keine Beamten finden, die die Insinuierung vornehmen könnten, regelte schon eine Konstitution Honorius' im Jahr 415. Sie favorisierte dabei für die Zuständigkeit flexible Lösungen, aber beharrte unnachgiebig auf der grundsätzlichen Notwendigkeit der Insinuierung, vgl. CTH 8,12,8 hrsg. von Theodor Mommsen, Bd.1,2, Berlin 1905, 411: Gestorum quoque confectionem sive ante traditionem sive post traditionem fieri oportebit, ut instrumentum, quo continetur munificentia, aput acta publicetur, in hac quidem urbe aput magistratum census, in provinciis vero aput provinciarum rectores, vel si praesto non fuerint, aput magistratus municipales, vel si civitas ea vel oppidum, in quo donatio celebratur, non habeat magistratus, apud defensorem plebis, in qualibet civitate fuerit repertus: curatores enim civitatum ab huiuscemodi negotio temperare debebunt, ne tanta res eorum concidat vtilitate. Sed iam allegatas apud curatores donationes et gesta confecta valere necesse est, in posterum omnibus, quae statuta sunt, observandis, quoniam, si quid fuerit preaetermissum, nullius momenti videbitur esse donatio.

59 S.o. Anm. 39.

60 Bei alledem ist angesichts der Überlieferungslage der FG ein gehöriges Maß an Zurückhaltung geboten, da die spezielle Überlieferungslage erfordert, daß „bei der Interpretation der Frag. Gaud. jeweils auch die übrigen Teile der Sammlung einbezogen werden“ (Kaiser, Epitome Iuliani (Anm. 37), 824). Die ganze Handschrift stellt damit einen maßgeblichen Auslegungshorizont für die Fragmenta. So enthält die Hs in der secunda pars ein Kapitel „de donationibus“ aus den Ep. Aeg. C.Th.8,5 (Hänel, LRV (Anm. 19), 156), die aber c. 15 FG fernstehen, so daß man über die Formalia einer Immobiliarschenkung aus c. 15 FG weitaus mehr erfährt als aus den Ep. Aeg. C.Th. 8,5. Die Analyse Kaisers von c. 14 FG zur Mobiliarschenkung (a.a.O., 821ff.) wirft die Frage auf, ob die FG „,nur Exzerpte aus einem 
lelität als Einfluß, dann ergäbe sich damit für die Frage der Schreibunkundigkeit westgotischer Einfluß durch die LRV (oder die Interpretatio) auf c. 15 FG. Nach alledem drängt sich auf, nach einem Niederschlag dieser differierenden normativen Vorgaben im erhaltenen Urkundenmaterial zu fragen. Nach Stand der Dinge läßt sich aufgrund des Überlieferungsstandes bei Tjäder, Marini oder Spangenberg unter Einschluß der Formularpraxis auch nach den Forschungen Saupes ${ }^{61}$ aber nicht entscheiden, ob die Akzeptanz des Handzeichens auch für die Zeugen signifikant der ost- oder westgotischen Rechtspraxis zugewiesen werden kann. Entsprechend lässt sich hieraus auch nichts weiteres für c. 15 FG ableiten.

Doch in Hinblick auf die Frage, ob und wie viele Zeugen mitwirken müssen, steht c. 15 FG der Lex romana Visigothorum einschließlich der interpretatio fern, da sich weder LRV noch interpretatio damit befassen. Das Edictum Theoderici geht davon aus, daß Zeugen mit unterschreiben, nennt aber keine Zahl. ${ }^{62}$ Diesbezügliche Zahlenangabe weisen c. 15 FG und LVis wie CodEur auf, die beiden letztgenannten allerdings mit

größeren Werk“ sind (820). Es ist danach nicht einmal sicher, ob hier ein genuiner oder ein überarbeiteter Text vorliegt. In der Collectio Gaudenziana findet sich Schenkungsrecht nicht nur in der Aegidii Epitome am Ende, sondern in der secunda pars mit ihrem prägenden Anteil aus der LVis auch deren Schenkungsrecht (Kaiser, a.a.O., 800, 818, 675), dessen Kapitel V 2,7 sogar eine leicht abweichende Lesart bietet, die sich aber vielleicht auf Codex Euricianus c. CCCVII noch zurückführen lässt, wobei dessen Lücken hierüber kein abschließendes Urteil zulassen. Jedenfalls ergänzt die Collectio Gaudenziana dort nach suscriptores - accedant „praesentes fiant“ (Zeumer, LVis (Anm. 38), 216 Z 31): im Codex Euricianus könnte hierfür eine Vorlage gestanden haben, die sich näher mit den Zeugen und der Urkundenerstellung befasst hat und nach „firmitatem“ fortfährt (a.a.O. 17 Z. 18-23): „Et si ... [scriptu] ram non fuerint praesen[tes] ...s t[esti]um ... [Volunta]s autem si necessitas [est], [coram duobus a]ut tribus testibus ore [promulgari] p[ote $] \mathrm{s}[t]$. “ Im Detail doch merklich anders liest hier d'Ors, El Código de Eurico (Anm. 45), 33: „Testes vero si ad scripturam non fuerint praesentes ...us testium, voluntas non valeat. Voluntas autem si necessitas est, coram duobus aut tribus testibus ore tantum ordinari potest.“ Warum in der Collectio Gaudenziana neben der allgemeinen Immobiliarschenkung des c. 15 FG noch die spezielle Ehegattenschenkung überhaupt aufgenommen wurde, bleibt eigentlich offen. Kaiser hält es a.a.O. für möglich, daß der Redaktor der secunda pars rücksichtlich der einschlägigen Passagen aus den c. 14 und c. 15 FG den Text LVis 5,2,7 gestrichen habe, also in der secunda pars Redaktionsentscheidungen unter Berücksichtigung des bereits in der prima pars aufgenommenen Materials stattgefunden haben könnten. Die Probleme sind evident: Da die singuläre Überlieferung der FG in der Collectio Gaudenziana nichts über die eigene Genese der FG und Veränderungen seit ihrer Erstredaktion auszusagen erlaubt - und solche Veränderungen damit auch nicht auszuschließen sind. So ist es nicht nur möglich, daß die einzelnen Kapitel eine eigene Überlieferungsgeschichte haben, jedes Kapitel einen unterschiedlichen Entstehungszusammenhang haben und sämtliche damit keineswegs zwingend einem einheitlichen Zeithorizont zugewiesen werden können - so das zutreffende Monitum schon von Kaiser.

61 Wie Anm. 3. Zur Schreibunkundigkeit und Handzeichen vgl. a.a.O. 26, 39-40, 65-68.

62 Schon Gaudenzi, Sui rapporti tra l'Italia e l'impero d'oriente fra gli anni 476 e 554 D.C., Bologna 1889, 155 wies darauf hin, daß nach einer Konstitution Zenos eigentlich für die Insinuation bei den gesta keine Geschäftszeugen nötig, sondern überflüssig seien (vgl. C 8,53,31 [a.478] In donationibus, quae actis insinuantur, non esse necessarium indicamus vicinos vel alios testes adhibere: nam superfluum est privatum testimonium, cum pubblica monumenta sufficient), in c. 52 EdTheod ist allerdings von Zeugenunterschriften durchaus die Rede, eben aber ohne Nennung derer Anzahl. 
offenbar optionaler Flexibilität: zwei oder drei. C. 15 FG ist in dieser Frage ebenfalls flexibel, statuiert etwas anders jedoch ausdrücklich eine Mindestanzahl von drei. Dies wird aber nicht positiv formuliert (etwa: „drei oder mehr“ oder „mindestens drei“), sondern negativ: „nicht weniger als drei“. Das ist ein eigentlich antithetischer Ansatz, nämlich als eine sowohl klarstellende wie verneinend verschärfende Antwort auf eine Frage (,reichen zwei oder drei Zeugen?“) und so - hypothetisch - als teilweise eine Ablehnung der genannten westgotischen Lösung, denn zwei Zeigen reichen auf keinen Fall. Diese stilistische Beobachtung weist dann wiederum vielleicht ebenfalls darauf, daß dem Redaktor von c. 15 FG das westgotische Recht von LVis oder CodEur vor Augen gewesen sein mag (,zwei oder drei“) und er mit seiner vergleichsweise restriktiveren Lösung unmittelbar hierauf reagierte („,nicht weniger als drei“) ${ }^{63}$

Die ebenfalls westgotische LRV scheint im Spektrum der einzelnen Elemente von c. 15 FG dabei allerdings unmittelbar gar nicht auf. Die Verallgemeinerung auf Schenkungen und die Berücksichtigung der Schreibunkundigkeit hat zwar generell die interpretatio, aber implizit war letzteres schon in der LVis V 2,7 bzw. CodEur erfasst. So stark wie aber die Nichtberücksichtigung von LRV V,1 und selbst der interpretatio im übrigen für c.15 FG auffallen muß, so wäre doch hier an eine selbständige, wenngleich recht freie Heranziehung der interpretatio ${ }^{64} \mathrm{zu}$ denken, nämlich dergestalt, daß nicht nur kaum etwas übernommen, sondern das wenige sogar noch modifiziert worden

63 Es könnte allerdings auch eine viel näher liegende Antithetik vorliegen: in dem unmittelbar vorangehenden c. 14 FG geht es um Mobiliarschenkungen, bei denen zwei oder drei freigeborene Zeugen mitzuwirken haben (Zeumer, LVis (Anm. 38), 471): Si quis donaberit aliquid alio homini peculium suum, aut aurum sive argentum, aes aut ornamentum, mancipia aut de pecuio aliquid, non requirat postea quod donavit, neque vicissitudinem requirat; nisi quod et ille sua voluntate retribuere voluerit. Habeat tamen testes duo aut tres ingenuos, testantes, quod illum non inpromutuaverit, sed donaverit. [...]. Bezieht sich die Formulierung „nicht weniger als drei“ dann in c. 15 hierauf, würde das ein Licht auf die Redaktion der Vorschriften werfen, wenn das Moment der Zeugenanzahl bei c. 15 unter immanentem Bezug auf c. 14 klarstellend formuliert worden wäre. Im Zuge einer Redaktion beider Vorschriften mag das angehen, etwas plakativ die Mindestzeugenzahl hervorzuheben und so zwischen c. 14 (Mobiliarschenkung) und c. 15 (Immobiliarschenkung) zu kontrastieren. Nimmt man allerdings nicht so einen genetischen Zusammenhang der Redaktion an, treten die Unterschiede beider Regelungen doch markant hervor: bei c. 14 bezeugen die ingenui nur die schenkweise (und nicht nur leihweise) Überlassung, bei c. 15 sind sie offenbar notwendige Geschäftszeugen der Transaktion insgesamt. Die Alternativität von „zwei oder drei“ Zeugen bei der Mobiliarschenkung dient hier nur dem Schutz des Beschenkten vor Rückforderung und kann deshalb leichter in das Belieben der Beteiligten (habeat) gestellt werden. Zwar behandeln c. 14 und c. 15 gleichermaßen Schenkungen, die Qualität und Funktion der Zeugen ist aber ganz unterschiedlich. Andererseits stellt aber etwa c. 13 FG für eine prozessrechtliche Norm einen solchen inneren redaktionellen Zusammenhang thematisch einmal ausdrücklich her, wobei die FG die in Bezug genommene Stelle offenbar nicht aufweisen (Kaiser, Epitome Iuliani (Anm. 37), 820 Fn. 129): sicut superius scriptum est (Zeumer, LVis [Anm. 38], 471), so daß mit Reflexen auf dieser Metaebene der Textentstehung wiederum durchaus zu rechnen ist. Über eine hypothetische Klärung der Frage nach dem Bezugspunkt der Antithese kommt man also schwerlich hinaus.

64 Oder ihrer Epitomierungen, soweit sie den Fall der Schreibunkundigkeit überhaupt erwähnen, vgl. im einzelnen Hänel, LRV (Anm. 19), 156-157. 
wäre - doch im Grunde ist damit der Zusammenhang auch mit der interpretatio schon nur so lose, daß vermutlich sogar auch noch sie als relevante Vorlage ausscheidet. ${ }^{65}$

Die Allegierung der Urkunde in den gesta ist in der Interpretatio ebenfalls thematisiert, jedoch findet sich die zusätzliche Problematisierung der Nichterreichbarkeit von Kurialen nun im Edictum Theoderici (was auch Zeumer längst schon angenommen hatte) behandelt - dort fehlt aber jede Regelung zum Fall der Schreibunkundigkeit. Andererseits scheint die zweigleisige belegenheitsbezogene Kategorisierung der Liegenschaften als Schenkungsgegenstand in c. 15 FG (domus - villa) so deutlich nur im EdTheod (praedium urbanum - praedium rusticum) auf.

4. Insgesamt scheinen es also mindestens zwei, vielleicht drei, vielleicht sogar vier Vorlagen zu sein, aus denen FG 15 zusammengestellt oder auf die reagiert worden sein mag, nämlich

1. die Antiqua der LVis,

2. die Interpretatio zu CTh 8,12,1 bzw. LRV 8,5,1,

3. das Edictum Theoderici, und schließlich (aber doch recht fernliegend)

4. CTH $8,12,8$

Was besagt diese „Kollagierung“ nun für die Ausgangsfrage zum Umgang mit Rechtswissen und Komplexität? Die Frage nach den Wirksamkeitsvoraussetzungen für eine Immobiliarschenkung ist eine jedenfalls komplexe Frage, da offenbar eine ganze Reihe von Umständen zusammenkommen müssen, um sie beantworten zu können. FG c. 15 verkörpert durchaus einen Mehrwert in Rechtsklarheit und Regelungsbreite gegenüber den diskutierten evtl. Vorlagen, die kombiniert, aber auch auf das Brauchbare skelettiert werden. Dabei bezieht sich die Lösung nicht auf explizierte Referenzquellen. Ein solches Vorgehen ist gelegentlich im gleichen romanischen Akkulturationsraum für das gleiche Regelungsproblem (Formvoraussetzungen für Immobilienschenkung) andernorts durchaus anzutreffen, nämlich in der Lex romana Burgundionum:

22,3 Sciendum tamen, donationis, tam aviaticas quam nuptialis, gestorum sollenni allegatione firmandas, praeter illas nuptiales donationes, quae intra ducentorum solidorum summam taxata conlatione potuerit inveniri.

22,4 Gesta autem secundum locorum consuetudinem fieri placuit, nec interest, apud quem defensorem fuerint celebrata, secundum legem Theudosiani sub titulo: De donationibus. ${ }^{66}$

Einen freieren Umgang mit den Verfahrensmodalitäten bei den Gesta für die Allegation / Insinuierung der Schenkungsurkunde kennt also auch schon die LRomBurg in

65 Für Erwägungen sonstiger Zusammenhänge der FG mit der Interpretatio im Breviar: Vismara, Fragmenta Gaudenziana (Anm. 37), 35-36.

66 Ed. von Salis (Anm. 35), 145; gemeint ist hier sicherlich CTh 8,12,8 (vgl. oben Anm. 58). 
Tit. 22,4 - darüberhinaus eine Anerkennung abweichender örtlicher Praktiken bei den Gesta, und insgesamt auch noch einen ausdrücklichen Verweis auf den CTh.

Man wird FG c. 15 wohl nicht überinterpretieren, wenn man annimmt, daß es zwei regrediente Entwicklungen notiert und darauf reagiert, nämlich einerseits auf die Ausdünnung der Verwaltungsstrukturen, der Präsenz von Kurialen und der Leistungsfähigkeit der Gesta municipalia als Registerbehörde, andererseits auf die Abnahme von Schreibfertigkeit. Die Reaktion kann dabei eine Bewältigung tatsächlicher aktueller Verhältnisse darstellen oder einen Regelungsbedarf unterstellen, wenn und weil man ihn in vorhandenen anderen Rechtstexten vorfindet und deshalb einfach übernimmt. In letzterem Fall wäre die Aufnahme nicht durch praktische Erfahrung der lokalen Gegenwartszustände indiziert, sondern eher eine Intention zur vorsorglichen Normbevorratung. $\mathrm{Zu}$ derartigen Redaktionskontexten treffen solche Texte normalerweise keine Aussagen und diese angenommenen Prämissen ihrer Entstehungskontexte sind deshalb mit mehr oder weniger Wahrscheinlichkeit notwendig meistens spekulativ. Die Bewältigungsstrategie ist in FG c. 15 jedenfalls die der Vereinfachung. Vereinfachung kann Vergröberung bedeuten, kann aber auch das Ergebnis einer gewissen Abstraktion darstellen. Beide Elemente klingen selbst in so einer kurzen Regelung wie c. 15 an: die Vergröberung, indem das Prinzip der erforderlichen Allegation der Urkunde in den Gesta von der zwingenden örtlichen Zuständigkeit entknüpft wird, was die Leistungsfähigkeit des Registerwesens in seiner Präzision der dokumentierenden Erfassung der entsprechenden Verfügungen beeinträchtigt. Eine Abstraktion liegt in der Lockerung der Formalien hinsichtlich der Unterfertigung des Ausstellers.

Für den Umgang mit der Komplexität von (Rechts-)Wissen bedeutet c. 15 FG auch seine Verallgemeinerung, weil es generell um Immobiliarschenkungen geht, die aus den spezielleren Kontexten der Vorlagen, nämlich Kontexten von Ehegattenschenkung oder Schenkung von Todes wegen, herausgelöst erscheinen (dabei aber doch auch noch beispielhaft konkret bleibt, wenn als Gegenstand der Schenkung „domus“ oder „villa“ genannt werden, doch auch die Vorlagen sind beispielsorientiert). Verallgemeinerung erscheint damit als auch eine Vereinfachung.

Wieviel konzeptionelle Intentionalität c. 15 bei alledem zu entnehmen sein kann, bleibt fraglich. Freilich verrät der Redaktor nicht, wie er dazu kommt, seine Regelung zusammenzubauen, verrät noch nicht einmal seine Bausteine und verrät erst recht nicht, wie viel normativer Anspruch ihr zukommen soll. ${ }^{67}$ Dabei ist der in c. 15 faßbare Text schon selbst auch noch unsicherer als er scheint: denn die überlieferte Form könnte ihrerseits schon durch bewusste oder unbewußte Eingriffe oder Verluste geprägt sein, womit in der ganzen Collectio Gaudenziana zu rechnen ist: ${ }^{68}$ Das vorlie-

67 Liebs, Römische Jurisprudenz (Anm. 37), 181 lehnt gerade wegen der Neuerungen in den FG insgesamt eine Qualifizierung als Privatarbeit ab. In diesem Sinne auch schon Zeumer, Westgothische Gesetzgebung (Anm. 39), 467: „Sie gehören, wenn überhaupt der westgothischen Gesetzgebung und nicht nur der Rechtslitteratur, jedenfall nicht der Reichsgesetzgebung, sondern einer diese ergänzenden Provinzialgesetzgebung an“.

68 Vgl. oben Anm. 60. 
gende c. 15 würde dann nicht eine „Urform“ darstellen - aber trotz einer eventuellen Interpolation auch als kreierter und in einer Sammlung von Rechtstexten auf gleicher Augenhöhe (d.h. theoretisch gleichem Geltungsanspruch) wie alle anderen erscheinender Passus wenigstens theoretisch dennoch als „Wirktext“ in Betracht kommen.

\section{Transformationsperspektiven}

Ein Titel wie „Verformung, Verdrängung und Verlust von Rechtswissen in den Leges“ beschreibt Veränderungsmodi. Eine prima facie so pointiert negativ und damit notwendig provokant formulierte Sichtweise steht in der Antithetik der alten Frage nach Kontinuität und Diskontinuität, kann aber den Blick auf den Vorgang der Dynamik selbst lenken, in dem der Umgang mit Rechtswissen in den Leges auch gesehen werden kann. Als Ergebnis der „Mikrobetrachtungen“ zum c. 15 der Fragmenta Gaudenziana steht zwar (leider) keine neue Zuordnungsthese für diese Quelle insgesamt, zeigen ließ sich aber, wie selbst ein letztlich so marginales Detailproblem, in ganz differenzierten Zusammenhängen stehend, über eine bloß kompilierende Lösungsstruktur hinausgeht und als möglichst paßgenaue aktuelle Reaktion auf aktuelle Regelungsbedürfnisse erscheinen kann. Das korreliert mit den angestellten „Makrobeobachtungen“. Die zweifellos schwierigen Rahmenbedingungen in der Völkerwanderungszeit für die Erhaltung, Fertigung und Verfügbarkeit von Rechtstexten kontrastieren mit dem immer wieder sichtbaren und ganz unterschiedlichen Motiven zuzuschreibenden Impetus, solche Texte zu erstellen, $\mathrm{zu}$ formen und $\mathrm{zu}$ haben. Was konkret damit dann anzufangen war, entzieht sich häufig demgegenüber der Transparenz, ändert aber nichts daran, daß ingesamt ein virulentes und facettenreiches Bild entsteht, dessen Deutung bei weitem noch nicht abgeschlossen ist. Die Phase der Leges bedeutet also freilich nicht das Ende des Rechtswissens, sondern seinen Umbau, der zwar sicher keinem einzelnen großen Plan folgt, aber auch keineswegs nur Demontage, sondern vielfältige Umformung verkörpert, die spezifisch planvoll erscheinen kann. ${ }^{69}$ Sie dient oft genug sichtbar intentional der Bewältigung von Regelungsbedürfnissen mit - mehr oder weniger beschränkten - Mitteln des Rechts. Auch das Recht in den Leges erfordert so als Anlaß wie Ergebnis von Wissenstransformation seine epochenspezifisch bezogen selbständige Würdigung. ${ }^{70}$

69 Exemplarisch wegen der ausdrücklich erfragten Interdependenz zwischen Wirtschaftspraxis und steuernden normativen Reaktionen bzw. Prämissen vgl. etwa Dieter Hägermann, Die rechtlichen Grundlagen der Wirtschaftsentwicklung im Nordwesten des fränkischen Reiches, in: La Neustrie, hrsg. von Hartmut Atsma, Sigmaringen 1989 (Beihefte der Francia 16,1), 341 - 365.

70 Das betont zurecht seit längerem schon Harald Siems immer wieder, so ausdrücklich ders., Die Entwicklung von Rechtsquellen zwischen Spätantike und Mittelalter, in: Von der Spätantike zum Frühen Mittelalter: Kontinuitäten und Brüche, Konzeptionen und Befunde, hrsg. von Theo Kölzer und Rudolf Schieffer, Ostfildern 2009 (VuF 70), 245 - 285 (284, hier bes. These 2: „... Es ist das Recht seiner Zeit.“). 



\title{
The Resources of the Past: Paschasius Radbertus and his Epitaphium Arsenii*
}

\begin{abstract}
In a sophisticated dialogue between himself and two fellow monks, Radbert of Corbie lamented the loss of his beloved Abbot Wala, nicknamed 'Arsenius' (d. 836). This Epitaphium Arsenii was not just an epitaph, but above all a polemical defence of his one-time master, who was accused of having been unfaithful to his emperor, Louis the Pious. Radbert made the most of his expert knowledge of classical and late antique Christian literature. As Wala's constant companion, the author had been an actor in the turbulent political events he narrated two decades later. He did so for an audience of insiders that was still familiar with the revolts against Louis the Pious in 830-833, and appreciative of Radbert's many references to the biblical, classical and late antique imperial history. This contribution explores some of the ways in which these resources of the past were used to persuade Wala's critics, and to make sense of a problematic present.
\end{abstract}

Paschasius Radbertus (c.790 - c.860) used to refer to himself as "the lowliest scum of all monks" (Pascasius Radbertus monachorum omnium peripsema), yet in the monastery of Corbie he was a prominent figure, for he was a close associate of two renowned abbots, Adalhard (d. 826) and Wala (d. 836). These powerful half-brothers, cousins of Charlemagne, were known as Antonius and Arsenius. Both men suffered royal disfavour and exile in 814 when Louis the Pious became sole emperor; this happened to Wala/Arsenius once more in 830-834 when he got involved in the rebellions against Louis. Together with its abbot, Corbie got on the wrong side of the emperor, and so did Wala's protégé Radbert (as I shall call this author from now on). Only by 843 , three years after Louis' death, did Radbert become the abbot of this illustrious royal monastery, but already less than seven years later, sometime between 849 and 853, he had to step down because of internal conflicts in Corbie and trouble with King Charles the Bald. ${ }^{1}$ He was a prolific biblical commentator who nowadays is

\footnotetext{
* For Rosamond McKitterick, friend and colleague, on the occasion of her retirement as Professor of Medieval History at Cambrige University.

1 On Paschasius Radbertus' biography: Ludwig Traube, Prooemium, in: MGH Poetae 3, Berlin 1896, 39-40; Henri Peltier, Pascase Radbert, abbé de Corbie. Contribution à l'étude de la vie monastique et de la pensée chrétienne aux temps carolingiens, Amiens 1938; David Ganz, Corbie in the Carolingian Renaissance, Sigmaringen 1990 (Beihefte der Francia 20), 29-33; Henry Mayr-Harting, Two abbots in politics. Wala of Corbie and Bernard of Clairvaux, in: Transactions of the Royal Historical Society (5th series) 40 (1989), 217 - 237; Mayke de Jong, Familiarity lost. On the context of the second book of the Epitaphium Arsenii, to appear in: Politische Theologie und Geschichte unter Ludwig dem Frommen /Histoire et théologie politiques sous Louis le Pieux, hrsg. von Martin Gravel und Sören Kaschke
} 
mostly known for a treatise on the Eucharist. ${ }^{2}$ His magnum opus is his massive commentary on Matthew, however, on which he started as a young man and worked until the end of his life. ${ }^{3}$

Radbert also wrote two works commemorating Adalhard and Wala. To both, he referred as "epitaphs" or funeral orations. ${ }^{4}$ The Epitaphium Arsenii, his tribute to Wala, will be central in this paper. ${ }^{5}$ Like the Commentary on Matthew, it had a long genesis: whereas the first book was written soon after Wala's death in 836, the second was only added two decades later, when Radbert was an old man in retirement. The Epitaphium is the work of a brilliant scholar who, at the height of his formidable intellectual powers, harnessed the textual resources of the past to his cause - that is, defending and safeguarding Wala/Arsenius' reputation, and, by proxy, his own. With the Bible and patristic scholarship at the centre of his intellectual universe, this author operated in a wide-reaching temporal and spatial matrix that included classical literature and the history of late antique imperial Christianity. Drawing upon these resources, he created an eclectic yet authoritative past, as moral

(Relectio. Karolingische Perspektiven - Perspectives carolingiennes - Carolingian Perspectives, 2). For Adalhard's and Wala's biographies, see Brigitte Kasten, Adalhard von Corbie. Die Biographie eines karolingischen Politikers und Klostervorstehers, in: Studia humaniora 3 (1986), and Lorenz Weinrich, Wala. Graf, Mönch und Rebell. Die Biographie eines Karolingers, Lübeck 1963. Especially the latter relies heavily on the Epitaphium Arsenii.

2 Paschasius Radbertus, De corpore et sanguine domini, hrsg. von Beda Paulus (CCCM 16)

3 Radbert called himself a senex in his prologue to book 5 of Expositio in Matheo, hrsg. von Beda Paulus (CCCM 56 A) 469, line 213-215. On Radbert's biblical commentary, see Ganz, Corbie (Anm. 1), 31-33, $82-87$.

4 Paschasius Radbertus, Vita Adalhardi c. 1 PL 120, cols. 1507 -1582. Radbert (c. 1, col. 1507) invoked Ambrose's De obitu Valentiniani imperatoris as his main model, and announced he wanted to imitate the fathers who "wrote epitaphs for their dearest most eloquently" (qui suis epitaphia charis facundissime condiderunt; ibid. c. 2, col. 1509); cf. Chiara Verri, L'arte di ritratto. La descrizione del santo nel Vita Adalhardi di Pascasio Radberto, in: Amicorum Societas. Mélanges offerts à François Dolbeau pour son 65e anniversaire, hrsg. von Jacques Elfassi, Cécile Lanéry und Anne-Marie Turcan-Verkerk, Firenze 2013 (Millennio Medievale 96; Strumenti e Studi 34), 635 - 56. I would not classify this text as hagiography, however.

5 Paschasius Radbertus, Epitaphium Arsenii, hrsg. von Ernst Dümmler, in: Abhandlungen der königlichen Akademie der Wissenschaften zu Berlin, Philosophische und historische Klasse 2 (Berlin: Verlag der königlichen Akademie der Wissenschaften, 1900), cited fortwith as EA; also Migne, PL 120 (Paris, 1852), cols. $1557-1650$, which is Dom Jacques Mabillon's text. Cf. Walter Berschin, Biographie und Epochenstil im lateinischen Mittelalter, vol 3: Karolingische Biographie 770-920, Stuttgart 1991, 318 - 325; Chiara Verri, Il libro primo dell'Epitaphium Arsenii di Pascasio Radberto, in: Bulletino dell'Istituto Storico Italiano per il Medio Evo 103 (2001/2), 33-131 On this text and the rebellions against Louis the Pious, see David Ganz, The Epitaphium Arsenii and opposition to Louis the Pious, in: Charlemagne's Heir. New Perspectives on the Reign of Louis the Pious (814-840), ed. by Peter Godman and Roger Collins, Oxford 1990, 537-50; Mayke de Jong, The Penitential State. Authority and Atonement in the Age of Louis the Pious (814-840), Cambridge 2009, 102-111; Courtney M. Booker, Past Convictions. The Penance of Louis de Pious and the Decline of the Carolingians, Philadelphia 2009, $42-50$. 
vantage point from which he made sense of the turbulent events of his own dismal day and age.

Radbert lived and worked in Corbie, a royal abbey with one of the best-endowed libraries in the Carolingian empire. It harboured an outstanding collection of Cicero's works, as well as Terence's plays, Priscian's grammar, Ovid's letters, and historical work by Caesar, Livy and Sallust, to name but a few of the classical authors becoming available during Radbert's lifetime. ${ }^{6}$ These were exceptionally rich resources, and the Epitaphium is an exceptional text. Constructed as a dialogue among three monks of Corbie, with the author's alter ego Pascasius as the narrator, it manages to convey a liveliness that is exceptional in mainstream Carolingian learned prose. On the other hand, given the eclectic uses of a classical and late antique legacy, and the flexible way in which such older texts were integrated into a perspective that was both biblical and patristic, the Epitaphium is very much a product of Carolingian literary culture as it flourished in many ecclesiastical centres, monastic and otherwise.

The text is extant in only one manuscript from Corbie, written by several hands not long after the work was completed, and carefully corrected by a contemporary hand that possibly belongs to the author himself. ${ }^{7}$ Given the fundamental differences between the contents and style of the two books, it is unlikely that the first book was drastically altered when, some twenty years later, Radbert added his outspoken sequel. Instead, he seems to have used the reticent earlier book as a foil for its much more explicit and polemical successor. As we shall see, the two books constitute one literary work, held together by the towering figures of Ambrose and Jeremiah. This overarching structure of the work will be discussed first, followed by sections on Radbert's use of dialogue and his rhetorical strategies, his vision of the past as it transpires from nicknames and pseudonyms, and, finally, on his classicising vocabulary with regard to the political arena. In all these respects, Epitaphium shows how creatively the resources of the past could be used to create a new framework for interpreting the predicaments of the present. ${ }^{8}$

\section{Ambrose and Jeremiah}

Like the Vita Adalhardi he completed shortly after Adalhard's death in 826, Radbert's commemoration and defence of his beloved abbot and mentor Wala was presented

6 Ganz, Corbie (Anm. 1), 151-158. New sources cited in the Commentary on Matthew, from book V onwards, include Cicero's De Senectute, Laelius and De Officiis, as well as works by Bede, Augustine, Gaudentius, Irinaeus, Origen and Virgilius of Thapse; cf. Ganz, Corbie (Anm. 1), 83.

7 Paris, BnF lat. 13909; cf. Ganz, Corbie (Anm. 1), 145. The hypothesis about Radbert having corrected this manuscript himself needs to be tested; it may well be wishful thinking on my part.

8 Cf. Rosamond McKitterick, Sven Meeder and Clemens Gantner (eds.), The Resources of the Past in Early Medieval Europe (Cambridge, 2015); this is the result of the HERA-project 'Cultural Memory and the Resources of the Past, 400-1000' (2010-2013). 
as an epitaphium, a funeral oration. In both cases, this meant a conscious departure from the familiar structure of hagiography. Even though some features typical of a saint's vita remain, such as the holy man's dramatic rejection of the secular world, Wala's many virtutes were not of the traditional miracle-working kind. As has long been recognised, Radbert's main model was the funeral oration written by Ambrose of Milan (d. 397) for his brother Satyricus. ${ }^{9}$ Ambrose's poignant meditation on grief in the face of overwhelming loss, also a work in two books, must have resonated with Wala's recently bereaved pupils. Radbert voiced their feelings, in what seems at first glance to be a mixture of consolation and praise, but there is also an ongoing argument against those who took a different view: had not this abbot managed to provoke the anger of the emperor Louis the Pious during the rebellions of 830-833, with dire consequences for the entire community of Corbie? While Ambrose's funeral oration for his brother provided the Epitaphium's overall framework of consolation and commemoration, it also left room for a continuous debate about Wala's controversial deeds and intentions. To some extent, the genre of the epitaph served as a cloak and a pretext for a vicious attack on the great man's enemies.

The use of Ambrose's De excessu fratris Satyri as a literary model throughout the Epitaphium shows that its two books were meant to be one work. The same holds true for the pervasive presence of the Prophet Jeremiah in both books, to whom Wala was likened. This comparison is made right at the beginning of the first book, where the narrator, Pascasius, reminds his fellow monks that "our most unhappy times made another Jeremiah of him". ${ }^{10}$ No explanation was needed: like the prophet, Wala had warned his people of the dire consequences of its persistent disobedience to God, and like Jeremiah, he had been rewarded for his efforts by imprisonment and exile. The comparison was obvious, and it surfaces already in a letter Radbert sent in 831-832 to his pupil Warin, the future abbot of Corvey. Here, he referred to "our Arsenius, whom our times have now made into another Jeremiah". ${ }^{11}$ In other words, the similarity between Wala and Jeremiah was not just a figment of Radbert's literary imagination. At least since the first rebellion against Louis the Pious in the spring of 830 and his resulting exile from the court, Wala's inner circle had likened him to the prophet, and interpreted his actions in these terms. From then onwards, Radbert had Jeremiah on his mind; in the late 840 s he completed a brilliant

9 Ambrose, De excessu fratris Satyri, hrsg. von Otto Faller (CSEL 73, 207 - 325); Ganz, The Epitaphium Arsenii (Anm. 5), 543; Peter von Moos, Consolatio. Studien zur mittellateinischen Trostliteratur über den Tod und zum Problem der christlichen Trauer, 4 vols, Munich 1971-1972 (Münstersche Mittelalter-Schriften 3), vol 1, 140-142 and vol 2, 100-101.

10 EA I, prologue, 19: An ignoras, Severe, quod nostrae hunc infelicissimae vitae saecula Jeremiam alterum tulerunt ab illo?

11 Paschasius Radbertus, De corpore, prologus ad Warinum, hrsg. von Paulus, 3: ...quod Arsenius noster quem nostra nunc nobis saecula Hieremiam alterum tulerunt ab illo, in fidei te mihi commiserit ratione. 
Commentary on Lamentations. ${ }^{12}$ Over time, however, he emphasised different aspects of Jeremiah/Arsenius. In the Epitaphium's first book, he had been mostly the ill-fated and innocent victim of his relentless enemies, but in the second, he became above all the fearless speaker of truth to the mighty. As one of the monks put it to Pascasius, in a passage that set the tone for the second book:

I think you did not call him another Jeremiah without reason, because of the constancy of his fidelity (fides) and the harshness of his exterior - he who so audaciously inveighed (invexit) against the emperor, as we have seen, about so much concerning the sloth of luxury, and, moreover, the very bad habits of kings who have neglected the business of their office, because he [Louis] had been preoccupied with idle affairs. ${ }^{13}$

Although Ambrose and Jeremiah are two central figures connecting the two books, they do so in different ways. While Ambrose's funeral orations provided Radbert with the literary model of the funeral oration, it was Wala's actual conduct in the public arena that was interpreted within the framework of Jeremiah's history. The connection was phrased in exegetical terms: Wala's actions made him into the embodiment or manifestation (typus) of the biblical prophet. ${ }^{14}$ Unlike Jeremiah, Ambrose was never explicitly mentioned. All the same, his role in the Epitaphium far exceeded that of an exemplary author. His fearless facing up to Theodosius is constantly felt throughout the text, especially in the second book, where Wala is portrayed as speaking unpalatable truth to Louis and his court. As we shall see, Ambrose is at the very centre of Radbert's imagined world of ancient Christianity, constructed by means of aliases that only made sense to those who knew about Ambrose's confrontations with various members of the imperial family of his time. In the second book Ambrose and Jeremiah converge, reinforcing Wala's image as man who spoke out at his own risk, driven by a deep loyalty to God and the Carolingian imperial order.

12 Written not long after the Vikings plundered the Seine valley of 845, an event which Radbert described as both deeply shocking and quite recent: "not so long ago", he said, "no earthly king, nor any inhabitant of this earth, could have imagined that the enemy would invade our Paris (Parisius noster)"; Paschasius Radbertus, Expositio in lamentationes Hieremiae libri quinque, IV, c. 14, hrsg. von Beda Paulus (CCCM 85) 282, line 1218-1221. In opting for this date I follow Ganz, Corbie (Anm. 1), 31.

13 EA II, c. 2, 63: Ut sentio, non immerito tu altrum eum Hieremiam dicebas, ob constantiam fidei et frontis duritiam, qui tam audenter augusto invexit, tanta quae vidimus, ob luxus desidiam, necnon et pessimas regum consuetudines officii sui negotia, cum esset praeoccupatus vanis rebus, praetermisisse. 14 EA I, c. 2, 23 -24: An nescitis Jeremiam illum, cuius iste fert typum, licet in lacum satis coenosum a populo dimersus, quod demum levatus ad astra multum orat? [Or don't you know that Jeremiah, whose manifestation he [Wala] became, prayed much, having finally been elevated to the stars?]. 


\section{Dialogue}

For historians of the early Middle Ages familiar with the Dialogi of Gregory the Great, or with Alcuin's many educational disputations, it may come as something of a surprise to learn that the genre of dialogue became extinct in late antiquity. Supposedly, the rise of Christianity put an end to the public and open-ended exchange of views that had been the hallmark of classical dialogue. To cite Simon Goldhill, one of the proponents of this view: "The dialogue is only very rarely evidenced as a form for normative Christian writing, despite the strategic place of conversion and theological discussion in Christian communities. The catechism and other question-and-answer structures are not in any significant sense a dialogue: they are forms of exchange to aid controlled learning and to produce certain, fixed responses". ${ }^{15}$ For Richard Lim the new religion also spelled the end of dialogue, albeit for different reasons. In classical antiquity, Lim argues, the dialogue belonged to the elitist literary culture of paideia. It was highly influential, yet also a "boutique literary genre", and therefore very different from the inclusive Christian sermo humilis that aimed to reach as many people as possible, including those from lower social strata. Put briefly, the inherent elitism of the dialogue, as Lim called it, was ill-suited to a religious communication that aimed at the masses, so the demand for this particular literary form gradually disappeared. ${ }^{16}$

As Averil Cameron pointed out recently, however, the freedom, democracy and open-ended exchange with which Goldhill and others identify 'real', that is, Socratic, dialogue seems to be mostly a modern ideal. ${ }^{17} \mathrm{~A}$ related and equally vexed question is whether the dialogues transmitted through texts in any way reflect 'real' public debates and discussions. Since all dialogues available to historians are literary constructs, including the ones that are presented as spontaneous and open-ended, a sharp distinction between literary and viva voce dialogue is not helpful. What we are able to grasp are the cultural ideals of how a dialogue should proceed. ${ }^{18}$ This goes some way towards understanding how it may once have been conducted, but by no means all the way. If dialogues are to be the object of historical inquiry, the main question should concern the ways in which this literary genre and its more elusive underlying oral practice were understood by contemporaries. ${ }^{19}$

With this in mind, it would be fair to say that dialogues played a significant role in the exchange of ideas within the Carolingian scholarly elite, and could therefore

15 Simon Goldhill, Introduction: Why don't Christians do dialogue, in: The End of Dialogue in Antiquity, hrsg. von Simon Goldhill, Cambridge 2009, 5.

16 Richard Lim, Christians, dialogues and patterns of sociability in late antiquity, in: End of Dialogue, hrsg. von Simon Goldhill, Cambridge 2008, 171.

17 Averil Cameron, Dialoguing in Late Antiquity, Cambridge, Mass./London 2014, esp. 10 and 37. 18 As forcefully argued by Cameron, Dialoguing (Anm. 17), who concentrates on Byzantium.

19 As Cameron, Dialoguing (Anm. 17), 10 comments on Goldhill: "His kind of dialogue is an elite form of polite open-minded conversation between educated people”. 
be considered a "boutique literary genre" in Lim's sense of the word. This also holds true for Radbert's Epitaphium, which was definitely aimed at a restricted audience of insiders with a shared knowledge of the recent and more distant past, and the ability to appreciate its author's sophisticated rhetoric. The limited manuscript transmission seems to confirm this, but this is not to say that the text was meant for the monks of Corbie only, for it addressed contemporary moral issues that originated from the interconnected world of the cloister and the court. The integration of these two domains is visible, as are the resulting tensions. Given that Wala spent so much time at the palace, in the company of the ruler and his secular magnates, was he still a good abbot? This was a central concern in the first book, while the second revolved around the problem of Arsenius' alleged lack of fidelity to the emperor during the rebellion era of $830-833$. Had he broken the fides he owed Louis by resisting the legitimate ruler, and supporting his rebellious eldest son Lothar?

No other Carolingian dialogue has this kind of political relevance, to use a modern expression, and none drew so eclectically and effectively upon a whole host of biblical, classical and late antique models to get its points across. Moreover, the genre of dialogue meant that different views could be expressed, and then either refuted or endorsed by the narrator, who had the final say when opinions clashed. It enabled Radbert to first articulate certain criticism against Wala and then to contradict it, as eloquently as possible. Thus, in the second book a key objection could be raised against the deceased abbot: if he was indeed so humble and dead to the world, "why is it that he spoke up so deliberately and boldly in the assembly, in the presence of the emperor, amidst the most prominent leaders of the churches, namely counsellors of prelates as well as magnates?" 20 This is part of the second book's presentation of Wala as a consummate practitioner of frank speech, an aspect of the text that will be discussed below.

Although only two monks can be identified, all the interlocutors of the Epitaphium were most likely inspired by members of the community of Corbie, even though some may have been generalised into monastic types of the kind one might encounter in Carolingian religious life and literature. For example, the two figures that only make a brief appearance in the first book are opposites: while the illiterate Allabigus was a model of simplicity and sincerity, the world-wise Chremes (a name from Terence) had travelled widely with Wala, and could tell all about the great man's Italian exploits. ${ }^{21}$ Apart from this interlude, the entire dialogue is sustained by three discussants. Pascasius, Radbert's alias, is present in both books, and so is Adeodatus,

20 EA II, c. 5, 65: Nam cum esset tam humilis, quo nullus humilior, nullusque magis mortuus mundo videretur, quid est quod tam inter summos ecclesiarum, praesulum videlicet et senatorum, consules, in senatu coram augusto consulte constanterque loquebatur?. On Radbert's classicising vocabulary in this passage, see below.

$21 E A$ I, c. 8, 32-33. On monastic types: Mayke de Jong, Internal cloisters. The case of Ekkehard's Casus sancti Galli, in: Grenzen und Differenz im frühen Mittelalter. Forschungen zur Geschichte des Mittelalters 1, hrsg. von Walter Pohl und Helmut Reimitz, Wien 2000, 209-221. 
named after Augustine's son, but his role in the dialogue changes in the course of it: in the first book he is a youngster who asks innocent yet probing questions, but in the second he has become an older man who shared memories with Pascasius and helped to verify the latter's narrative. By then the gruff and outspoken Severus, a central figure in the first book, had "gone the happy way of all flesh". ${ }^{22}$ This was Radbert's older friend Odilman, to whom he had dedicated his Commentary on Lamentations in the late 840 s. $^{23}$ Severus' place was taken by Teofrastus, a younger monk whose frank comments helped to set a more polemical tone. Fiction and monastic life were intricately connected: twenty years later, Adeodatus and Pascasius had both aged and changed, Severus was dead, and Chremes had disappeared amidst "our troubles". ${ }^{24}$

Radbert was familiar with dialogues by Cicero and Augustine, as well as with Boethius's Consolation of Philosophy, ${ }^{25}$ yet his main source of inspiration for the Epitaphium seems to have been Sulpicius Severus's Gallus, a dialogue about the virtues of St. Martin written between 397 and $401 .^{26}$ The Gallus, like the Epitaphium, has three participants: apart from Sulpicius Severus himself there is Postumianus, a cultivated aristocrat who has just returned from a long voyage to monasteries in the eastern empire, and Gallus, a monk from Gaul who extols Martin's miracles in this region, claiming that they were much better than anything reported from the East. When he embarked on his second book, Radbert made it clear that three interlocutors were required, "in the way of the sacred fathers", and in order that three witnesses could testify to the truth. Apart from some clear biblical connotations, ${ }^{27}$ this may well be a reference to Sulpicius Severus and his dialogue on Martin's virtues. As the author of the Vita s. Martini, he would surely qualify as a 'sacred father'. Perhaps Odilman's monastic nickname, Severus, did not only derive from his typical severity, but also from the fact that Sulpicius Severus was something of a household name among the monks of Corbie.

22 EA II, prologue, 60.

23 Paschasius Radbertus, Expositio in lamentations Hieremiae I, p. 4, hrsg. von Paulus: Pascasii Radberti monachorum peripsema votorum liber primus fletibus explicandus seni Odilmanno Severo opera pretio consecratus. All five books were offered to Odilman/Severus.

24 EA II, prologue, 60: Sed quia interdum Severus ingressus est felix viam universe terre, et Cremes inter discrimina nostra iam discessit...

25 Ganz, Corbie (Anm. 1), 113; on Radbert and the classical and patristic sources of the Radbert's twp biographical works: Ganz, Corbie (Anm. 1), 101-120.

26 A conclusion also reached by Verri, Il libro primo dell'Epitaphium Arsenii di Pascasio Radberto (Anm. 5); Sulpicius Severus, Gallus - Sulpice Sévère, Gallus. Dialogues sur les "vertus” de saint Martin, hrsg. von Jacques Fontaine und Nicole Dupré, Paris 2006 (SC 510).

27 "For where two or three are gathered together in my name, there am I in the midst of them...." (Mt 18, 20); "In the mouth of two or three witnesses shall every word stand" (II Cor.13,1). I am grateful to Gerald Schwedler for these references. 


\section{What's in a name?}

In any discussion of Radbert's resources of the past, his remarkable pool of bynames or aliases should receive due attention. Monastic bynames had a long tradition. Alcuin famously bestowed them on his pupils, so the little 'raven' Hrabanus became Maurus, and Radbert called his own precocious disciple Warin 'Placidus'. Both Maurus and Placidus figure in Gregory's Dialogues, as St Benedict's two favourite pupils. ${ }^{28}$ Many of such bynames were nicknames that originated in the schoolroom or from another phase of monastic training and identity formation. It is not certain how Radbert came to be Paschasius. He remained a deacon all his life, possibly because he felt that a sinful period in his adolescence, when he briefly returned to the world, made him unsuitable for the priesthood. Did he therefore liken himself to the penitent deacon called Pascasius from Gregory's Dialogues, or did others see the similarity? ${ }^{29}$ Possibly, but this particular name, like many others, must have carried more than one association, not all of which can be fully retrieved. The outspoken monk Teofrastus, as he is called in the Epitaphium with a consciously 'Greek' spelling, ${ }^{30}$ must have been named after the Greek philosopher who was Aristotle's successor as leader of the Peripathetic School. As Theophrastus, he figures in two of Cicero's dialogues that Radbert was familiar with by the mid-840s, and probably well before: the Tusculan Disputations and the De finibus bonorum et malorum libri. ${ }^{31}$ However, there is another Theophrastus in Jerome's polemical treatise Adversus Iovinianum, presented as the author of a treatise against marriage incorporated in the church father's work..$^{32}$ Radbert admired both Cicero and Jerome greatly, so one possibility does not exclude the other.

Although the more specific meanings of some bynames elude us, they were clearly not intended to hide identities, but to reveal and emphasise the moral character of the person concerned. ${ }^{33}$ This not just held true for names that originated

28 Gregory the Great, Dialogi II, c. 4, hrsg. von Adalbert de Vogüé, Paris 1980, 6-7.

29 Gregory, Dialogi IV, c. 42, hrsg. von Adalbert de Vogüé, Paris 1980, 150; Conrad Leyser, Authority and Asceticism from Augustine to Gregory the Great, Oxford 1980, 108.

30 Paris, Bibliothèque nationale de France, lat. 13909, fol. 62v.

31 Cicero, Tusculanarum disputationes I. 45; III. 21, 68; V. 68, 85, 107, ed. by Frank E. Rockwood, Norman 1966; Cicero, De finibus bonorum et malorum, I.6, 13; IV.79; V.10-13, 54, 73, 85-86, hrsg. von H. Rackham, Cambridge Mass. 1971 (The Loeb Classical Library 17);. Theophrastus is invoked as an authority: Audi igitur, inquit, Luci; tecum enim mihi instituenda oratio est. Omnis auctoritas philosophiae, ut ait Theophrastus, consistit in beata vita comparanda; beate enim vivendi cupiditate incensi omnes sumus (Cicero, De finibus bonorum et malorum V.86). This could also have been Radbert's motto.

32 Hieronymus, Adversus Iovinianum I, c. 47, in: Migne PL 23, cols. 288-291.

33 Mary Garrison, The social world of Alcuin. Nicknames at York and at the Carolingian court, in: Alcuin of York, hrsg. von Luuk A. Houwen and Alasdair Andrew McDonald, Groningen 1998 (Germania Latina 3) 59-79; Mayke de Jong, Becoming Jeremiah. Radbert on Wala, himself and others, in: Ego Trouble. Authors and their Identities in the Early Middle Ages, Forschungen zur Geschichte des 
within a milieu of insiders, but also and especially for the negative aliases bestowed on the political protagonists of the Epitaphium's second book. Of course these would never be used to someone's face, let alone have contributed to the self-perception of the person in question, as was the case with monastic nicknames, but such meaningful labels alerted others to the true nature of the man or woman concerned. Most of the aliases of the second book came from a loosely constructed world of imperial Roman Christianity revolving around Ambrose, and around Wala's byname, Arsenius. Wala probably incurred this at an early stage, in the years 822-825 when he acted as an older second-in-command to the emperor's eldest son in the kingdom of Italy; this was reminiscent of the Arsenius (d. c. 450) who had tutored Honorius, the eldest son of Theodosius the Great. ${ }^{34}$ Obviously, this turned Lothar into Honorius, whose role in the Epitaphium is generally above reproach. By all accounts Louis should then have been Theodosius I, all the more so because of the current and favourable comparison of Louis's public atonement in Attigny (822) with Theodosius' penance in Milan (390). ${ }^{35}$ Yet this glorious name was consciously withheld, for Louis was called 'Justinian'. This carried associations not just with Justinian I (527-565), the lawgiver, but also with Justinian II (669-711) who had been killed by his own army, and perhaps most of all with Radbert's portrayal of Louis as being hopelessly under his second wife Judith's thumb. She was called 'Justina', after the second wife of Valentinian II (375-392); since Justina was known to have been Ambrose's worst persecutor, Judith's role as Wala's nemesis was made clear from the outset.

Radbert's choice of aliases was far from systematic, yet there was a logic to it that must have been obvious to a literate court. The other villain of the piece, the chamberlain Bernard of Septimania (d. 844), went by the name of Naso. Like the poet Ovid, Bernard had been accused of having committed adultery, in his case with the Empress Judith during the run-up to the rebellion of 830, and was exiled because of it. 'Phassur', for Ebbo of Reims, was the high priest who put Jeremiah in prison (Jer. 20:1), just as Ebbo, as the responsible archbishop, had been in charge of Wala's exile in $830-831 .^{36}$ Such names were not nicknames used in daily communication, but neither were they pseudonyms meant to hide identities. On the contrary, these were names that, situated in the context of a meaningful past, would give an

Mitttelalters 15, hrsg. von Richard Corradini, Rob Meens, Christina Pössel und Philip Shaw, Vienna 2010, $185-196$.

34 On Arsenius's past as a courtier at the palace of Theodosius, and his education in Greek and Roman philosophy, see Theodore the Studite, Life of Arsenius, chapters 3-6, 13 and 20. In chapter 20 of Theodore's Life, Arsenius is called 'the father of emperors'. This Greek text was not available in the ninth-century West, but most likely stories about the courtier Arsenius and his eventual monastic retreat into the desert were known. They would have fit Wala very well after his monastic exile in 814, and even better after 830 .

35 De Jong, Penitential State (Anm. 5), 122-131.

36 EA II, c. 16, 85; Jer. 20.2: et percussit Phassur Hieremiam prophetam et misit eum in nervum quod erat in porta Beniamin superiori in domo Domini. De Jong, Penitential State (Anm. 5), 109-110. 
immediate indication of the evil nature of those concerned. Although Radbert's choice of names was eclectic, many came from late antique Christian historiography, and especially from the Historia ecclesiastica tripartita, the fifth-century Greek church history translated a century later into Latin by Epiphanius, at Cassiodorus' behest. Corbie owned a copy, reputedly made for Adalhard when he was in exile in 814-821. Certainly Radbert knew this text, and he may even been the one who, as the late Klaus Zechiel-Eckes has argued, annotated the Corbie copy of the Historia tripartita and used the marked sections to create some of the papal letters in the Pseudo-Isidore's decretals. ${ }^{37}$ Although the precise implications of Zechiel-Eckes' discovery are still under discussion, the imaginative pool of names in the Epitaphium's second book comes from an imagined past that bears a strong resemblance to Pseudo-Isidore's forged papal letters. ${ }^{38}$ It is a past dominated by the kind of imperial Christianity in which Ambrose had one admonished the emperor, and Theodosius I had heeded the bishop's advice, in a way Louis the Pious had never managed. This ideal order was not one that clerics imposed on rulers, but a complementary collaboration between emperors and their churchmen, in which each partner remained within his own sphere of competence. The way in which this older imperial Christianity was evoked and held up to the present is reminiscent of the typology that connected Jeremiah and Wala. Whoever knew the biblical story of Jeremiah could readily understand Wala's actions and fate in these terms. Likewise, the assigning or withholding of certain names from Christian history created a typus, including an entire and meaningful literary context.

\section{Strategies of persuasion}

Already in his Life of Adalhard of 826, his earliest extant work, Radbert expressed his great admiration for Cicero's rhetorical work. He proudly showed that he had learned the great man's lessons by devoting ten special chapters to Adalhard's ethology, working down the entire list of natio, genus, fortuna, forma, sapientia, consuetudo domestica, and so on. ${ }^{39}$ Referring to Cicero's De inventione II, 1(c. 20) he recounted the story of Zeuxis who had allegedly used the five most beautiful maidens of Kroton

37 St Petersburg, Lat. F v I 11; Walter Jacob, Rudolf Hanslik, Die handschriftliche Überlieferung der sogenannten Historia Tripartita des Epiphanius-Cassiodor. Texte und Untersuchungen zur Geschichte der altchristlichen Literatur 54, Berlin 1954, 10 -11; Ganz, Corbie (Anm. 1), 143. The colophon on f. a verso reads: 'hic codex hero insula scriptus fuit iubente patre Adalhardo dum exularet ibi' (from 814 to 821). On the Historia tripartita in Corbie, see Klaus Zechiel-Eckes, Ein Blick in Pseudo-Isidors Werkstatt. Studien zum Entstehungsprozess der falschen Dekretalen. Mit einem exemplarischen editorischen Anhang, in: Francia 28/1 (2001), 37-90.

38 Zechiel-Eckes, Werkstatt (Anm. 37), 59 calls both "eine antikisierende Rückprojektion".

39 Paschasius Radbertus, Vita Adalhardi cc. 55 - 60, in: Migne PL 120, cols. 1536-1539; Alexandru Cizek, Der "Charakterismos" in der Vita Adalhardi des Radbert von Corbie, in: Rhetorica 7 (1989),185-204. 
as a model. He selected from each the very best, features, claiming that all the components of perfect beauty could never be combined in one person..$^{40}$ Radbert was so fond of this story that he even used it in his prologue to the first book of his Commentary on Matthew. ${ }^{41}$ At the very beginning of his Epitaphium as well, he likened himself to Zeuxis, to convey the difficulty of doing justice to his illustrious subject, but also to support his claim that he was aiming for the truth and nothing less. ${ }^{42}$ Writing a decade after he completed the Vita Adalhardi, his display of rhetorical expertise had become less self-conscious, although in the Epitaphium's first book it still remained important to impress his knowledge of the classics on his readers. Explicit references to classical sources range from the inevitable Virgil (Maro noster) to the less obvious Apocolocyntosis by Seneca, ${ }^{43}$ but it was Terence who took pride of place. In the second book, however, classical authors vanished from the scene, and only Jeremiah and Job were mentioned by name in the text. What had changed?

There are several possible answers to this question. To begin with, however much he grieved for his Arsenius, when he wrote the first book Radbert was a man in his forties, with hopes and ambitions for the future; by the time he added the second book, he was in his sixties and had been forced to retire from Corbie's abbacy as well as the political arena. Did he no longer have the need to impress the powers that were? This answer once satisfied me, ${ }^{44}$ but now I think the matter is more complicated. Radbert displayed as much rhetorical skill in the second book as in the first, yet his approach was a different one. In loud stage whispers, and constantly urging restraint, the first book darkly intimated that great injustice had been committed against Wala. Once a time would come when all could be told, but it had not yet arrived. The first book is full of "raging silences" (silentia furibunda), as Radbert expressed it, citing Statius, ${ }^{45}$ and thus could function as a foil for the much more outspoken second book. In the end, this contrast lent extra meaning to both parts of the diptych.

The regular presence of Terence in the first book, and his total absence in the second, is in fact a clue to the choices Radbert made. "The comic", as he was called, was explicitly called upon when the limits of what could be said were being stretched, and almost only in a context of seemingly ironical dispute. Such passages did not incorporate proper citations, but part-sentences and expressions from Terence's plays that were integrated into the direct speech of Radbert's interlocutors. In the

40 Paschasius Radbertus, Vita Adalhardi, c. 20, in: Migne PL 120, cols. 1518-1519.

41 Paschasius Radbertus, Expositio in Matheo I, hrsg. von Beda Paulus (CCCM 56).

42 EA I, prologue, $18-19$

43 EA I, prologue, 21; Ganz, Corbie (Anm. 1), 116-117.

44 Mayke de Jong, Heed that saying of Terence. On the use of Terence in Radbert's Epitaphium Arsenii, in: Carolingian scholarship and Martianus Capella: Ninth-century Commentary Traditions on Martianus's De nuptiis in Context. Cultural Encounters in Late Antiquity and the Middle Ages 12, hrsg. von Mariken Teeuwen und Sinéad O’Sullivan, Turnhout 2011, 277-305.

$45 E A$ I, c. 3, 25. 
process, the playwright's original meaning was usually lost. Here is just one example, in which the narrator, Pascasius, warns his outspoken fellow monk Severus to mind his words:

You attack sharply, brother Severus. I wish you would heed that saying of Terence: Nothing to excess, ${ }^{46}$ because all those in whom conscience is less steady, are more suspicious in I don't know which way and they take everything as an insult, and because of this they think they are always blamed ${ }^{47}$ for their acts. ${ }^{48}$

No doubt Radbert knew his Terence well, for the Corbie library had several copies; ${ }^{49}$ the witty altercations of these plays provided him with yet another model for dialogue. Yet Terence also entered the bloodstream of Carolingian learning in more indirect ways, through classical grammar and patristic writing. De doctrina christiana, Augustine's most well-known and available work in the Carolingian world, with the possible exception of his commentary on Genesis, was the prism through which many first encountered the classics, and were encouraged to explore these texts. Radbert was an avid readers of Augustine, who in De doctrina christiana relied on grammatical commentaries on Terence's Andria by Donatus and Quintilian, and also cited the comic in De civitate Dei. ${ }^{50}$ Not only Augustine used Terence, but Jerome did as well in his polemical treatises, and this, I suspect, had even more of an impact on the Epitaphium. In Adversus Iovinianum, the treatise featuring Theophrastus, Jerome cited Terence in a way Radbert would adopt as well, taking phrases and expressions that he then took out of context and integrated into his discourse, making it clear all along that these were Terence's words, loaded with authority as well as irony. ${ }^{51}$

46 Terence, Andrea, I.1, hrsg. von John Barsby (Loeb Classical Library 22-23) 54, lines 60-61: 'Non iniuria; nam id arbitror adprime in vita esse utile, ut nequid nimis'.

47 Terence, Adelphoe, IV, 3, hrsg. von John Barsby, 320, lines 605-606.

48 EA I, c. 2, 24: Acriter invehis, frater Severe. Velim caveas illud Terrentii: Ne quid nimis, quoniam omnes quibus minus est conscientia tuta, plus sunt nescio quo modo suspiciosi, atque ad contumeliam omnia accipiunt, et propter sua queque se semper cupari credunt.'

49 De Jong, Use of Terence (Anm. 44), 275-277. On Corbie as a centre for the transmission of Terence, see Michael D. Reeve, 'Terence', in: Texts and Transmission: A Survey of the Latin Classics, hrsg. von Leighton D. Reynolds, Oxford 1983, 412-420, at 418.

50 Augustine, De doctrina christiana, hrsg. von R. P. H. Green, Oxford 1995, III, c. 12, 136; cf. Danuta Schanzer, Augustine and the Latin classics, in: A Companion to Augustine, hrsg. von Mark Vessey und Shelley Reid, Oxford 2012, 171-174. On Augustine and grammar, see Anneli Luhtala, Grammar and Philosophy in Late Antiquity. A Study of Priscian's Sources, Amsterdam 2005, 138-144. For other use of Terence in Augustine, see Harald Hagendahl, Augustine and the Latin Classics, vol 2, Studia Graeca et Latina Gothenburgensia XX Göteborg 1967, 380-381. On Augustine's work in Corbie, cf. Ganz, Corbie (Anm. 1), 96-102.

51 For example, Hieronymus, Adversus Iovinianum I, c. 47, in: Migne PL 23, cols. 291-92; Hieronymus, Adversus Iovinianum II, c. 7, in: Migne PL 23, col. 310. 
In a similar way, Radbert referred to "that comic" (ille comicus), but he did so mostly in a quite specific context, namely in passages in which the limits of what could be said openly were challenged, albeit only implicitly and carefully. It is no coincidence that Terence figures most often in discussions that involve the frank and plain-spoken Severus. One particularly telling example is the intervention of the illiterate monk Allabigus, who took offence and delivered an ironical diatribe against all those disloyal to Arsenius, full of expressions from Terence. The narrator Pascasius then commented:

As I hear, this bald man who seemed illiterate has suddenly become a philosopher of lamentation, no doubt inspired by the spirit of him whom we bewail (...) For he is not one who assents to falsehood, as he makes himself out to be, but, in my view, a fearless speaker and prophet of truth. $^{52}$

Bringing in Terence meant not only invoking the idiom of past authority, both classical and patristic, but also extending the limits of propriety by irony and double entendre. This was for the happy few, but not everyone in the ninth century who appreciated Terence was necessarily a monk of Corbie. A lavishly illustrated manuscript of Terence's comedies was produced for the court of Louis the Pious around 825 by the scribe Hrotgarius and the painter Aldericus (Vat. Lat. 3838). This was the first in a long series of illustrated Terence manuscripts..$^{53}$

In the second book, however, Terence became superfluous, for by then Radbert had adopted his own version of frank speech (parrhesia or licentia) as his strategy of persuasion, presenting both Wala and himself as exiles and outsiders who openly and courageously spoke truth to power. Once Radbert had retired as abbot of Corbie, his position had become that of an outsider, but at the same time he had become more credible as someone who consciously adopted the stance of the parrhesiast. This was announced right at the beginning of the second book: Relictis omnibus (Lc. 5,11), the narrator Pascasius had regained his peace of mind, and should now complete his unfinished lament for Wala. ${ }^{54}$ As Irene van Renswoude has shown,

52 EA I, c. 8, 33: Ut audio, glaber iste qui videbatur idiota, factus est in subito querimoniarum philosophus, nec dubium quin spiritu ejus quem plangimus afflatus. Alioquin nisi eo esset attactus, quomodo talia praeoccupavisset, antequam filius eo veniret, quo circumfusi visceribus lamentandi erit tempus? Non enim assentator est falsi, ut se finxerat; sed invector, ut sentio, praecoque veritatis.

53 Florentine Mütherich, Book illumination at the court of Louis the Pious, in: Charlemagne's Heir, 593-604, at 597-598. See now David Wright, The Lost Late Antique Illustrated Terence, Vatican City (Biblioteca Apostolica Vaticana) 2006, with references to older literature; see esp. 183-187, and also the recent review of Wright's study by David Ganz in: Early Medieval Europe 18 (2010), 131-132. Bernhard Bischoff thought this manuscript was written in Corvey in the late 820s or early 830s. Cf. Bernhard Bischoff, Hadoard und die Klassikerhandschriften aus Corbie, in: Bernhard Bischoff, Mittelalterliche Studien. Ausgewählte Aufsätze zur Schriftkunde und Literaturgeschichte, 3 vols, Stuttgart 1966-1981, vol I, 49-63, at 60-61, n. 34.

54 EA II, prologue, 60: ...tandem divino dispensante iudicio, relictis omnibus, quia tibi, Pascasi, reddita est quies et libertas animi... 
frank speech as it had been practiced in antiquity did live on in the early Middle Ages, even though by this time the role of the philosopher had been taken over by bishops and abbots, preferably in the guise of prophets. Although the specific terminology connected with classical parrhesia disappeared, frank criticism of rulers by self-appointed outsiders did not. ${ }^{55}$ The older, sadder and wiser Radbert who added a second book to the Epitaphium was well aware of the basic principles of frank speech, and capable of putting both Wala and himself in the parrhesiast position: outside of the corridors of power, and therefore finally ready to speak out. This is signalled right at the beginning when he had Teofrastus, the newcomer to the dialogue who embodied frank speech, make the following pronouncements:

I am much astounded, given that we have been alerted by so many warnings on his [Arsenius'] part, that there is none of ours who dares to tell the full truth about that man to posterity, although he was daring enough to expose the sins of the people that had long accumulated: disasters, epidemics, famine, irregularities in the weather and also terrifying visions. ${ }^{56}$

This was the clarion call for a second book full of direct and vicious attacks on Bernard/Naso and Judith/Justina, yet these were presented as the inevitable result of truth-telling by someone who no longer had anything to lose. It is only at this point that Arsenius was transformed into the angry Jeremiah, prophet of doom. As such Radbert depicted his hero at Louis' court in the winter of $828-829$, on the eve of crisis, hurling dire warnings at the emperor and his inner circle. Now there was no more need for the subtlety or irony of Terence, or for his authority as one of the classical authors most cited by treatises on grammar as well as in patristic works. In the first book, Radbert had borrowed Terence's canonical language to get his points across, as his much cherished Jerome had done in his Adversus Iovinianum and other of his treatises and letters. But when he embarked upon the second book, he did so as Jeremiah, and when he did integrate authoritative language into his dialogue, as he had once done with Terence, it now came from Job. ${ }^{57}$ One reason may have been that, like Terence's plays, the Book of Job could be seen as a dialogue. More importantly, however, when it came to openly narrating Wala's

55 Irene van Renswoude, License to Speak. The Rhetoric of Free Speech in Late Antiquity and the Early Middle Ages, PhD thesis, Utrecht 2011; this thesis will appear as a book with Cambridge UP. The key words in the Epitaphium were constantia, or speaking constanter (as in EA II, c. 5, 65; see n. 447 above). As Van Renswoude (34) comments: "Constantia became an important notion in the Christian discourse of free speech. It was one of the terms with which occurrences of parrhesia in the Greek New Testament were translated into Latin”.

56 EA II, c. 1, 61: Obstupesco valde, cum eius tantis provocamur exemplis, quod nemo nostrum qui ad plenum veritatem de illo audeat posteris narrare, licet audeat detegere peccata populi longe diu accumulata, clades, pestilentias, fames, inaequalitates aerum, terroresque etiam visionum.

57 A theme explored in Mayke de Jong, Paschasius Radbertus, Jeremiah and Job. Political discourse and the biblical past in the mid-ninth century, in: Readers of the Bible in the Middle Ages, hrsg. von Jinty Nelson und Damien Kempf, London 2015, 57-76. 
fate and the perils of Louis's reign, the playfulness of Terence was singularly useless. So Radbert told the sad story of the emperor's penance of 833 in heavily laden prose taken mostly from Job 12. This was the authoritative language in which he which he could express the collective failure of the Carolingian leadership. The only truly almighty king was "He Himself who brought counsellors to a foolish end, and judges to insensibility; and he also loosens the belt of office of kings and girds their loins with a cord." ${ }^{58}$ This was a reflection on the public penance in 833 of Louis the Pious, who exchanged his royal cingulum or balteum for the cord of the penitent's garb..$^{9}$

Like others of his learned contemporaries, Radbert knew his classical rhetoric; he was even prepared to support his exegesis by identifying rhetorical patterns in Scripture. A case in point is his introduction to the fifth book of Lamentations, which in his view obeyed to the "law of the orators" (lex rhetorum) in that it provided an epilogue and summary of its four predecessors. ${ }^{60}$ No doubt a more thorough investigation of Radbert's copious exegetical oeuvre will yield more instances of this attitude; for now I find it most often in his earlier work, such as the Vita Adalhardi, or the first book of his Commentary on Matthew, where he praised Cicero as the 'King of Latin eloquence'. ${ }^{61}$ By the time he wrote the Epitaphium's second book, the power of Jeremiah as a truth-teller had probably become more important than impressing on his audience that he knew the tips and tricks of Cicero's De inventione. ${ }^{62}$

It has recently been suggested that in the Epitaphium, Radbert mostly used forensic or judicial rhetoric. Supposedly the narrator, Pascasius, operated as an advocate for the defence who called his witnesses, the interlocutors in the dialogue, and thus gradually constructed his plea, aimed at an audience that should be persuaded. ${ }^{63}$ There is a lot to be said for this view: in the background of the entire Epitaphium, one can hear the constant chorus of Arsenius' enemies. Something similar can be observed in the central part of Adalhard's Life, especially in passages about the great man's conversion to monastic life, and his later exile due to royal disfavour. On the other hand, conversion to monastic life was traditionally represented as the result of a conflict with secular world, and the saint's confrontation with his detractors was an integral part of hagiography. Sulpicius Severus' Gallus, Radbert's most likely model for his dialogue, is full of counter-attacks against Martin's ene-

58 EA II, c. 20, 91: Iob 12.17-18: adducit consiliarios in stultum finem et iudices in stuporem balteum regum dissolvit et praecingit fune renes eorum.

59 De Jong, Penitential State (Anm. 5), 277.

60 Paschasius Radbertus, Expositio in lamentations Hieremiae, hrsg. von Paulus, 310.

61 Paschasius Radbertus, Vita Adalhardi, c. 20, col. 1518C; Expositio in Matheo, I, prologue, hrsg. von Beda Paulus (CCCM 56,6) 1, 158.

62 Corbie also owned a mid-ninth-century manuscript of Ad Herrennium: Paris, Bibliothèque nationale de France, Lat. 7714, ff. 2-78; cf. Ganz, Corbie (Anm. 1), 151.

63 Matthew Kempshall, Rhetoric and the Writing of History, Oxford 2011, 196- 208. 
mies, which go hand in hand with fulsome praise of the saint. ${ }^{64}$ Another conspicuous feature of the Epitaphium's second book is its combination of demonstrative praise and vicious invective. Arsenius/Wala as the prophet who could have saved the realm was juxtaposed to his main adversary, the chamberlain Naso/Bernard. This, Radbert claimed, was a "debauchee" who abandoned everything honourable over which he was meant to govern; the idiot plunged himself into every pig's hole full of dirt. "Accordingly, when he came, like a wild boar, he turned the palace upside down, put an end to counsel and destroyed all the laws of reason...”. ${ }^{65}$ In late antique handbooks of rhetoric, praise (encomium or panegyric) and blame (invectio) formally belonged to the same rhetorical register, and it is not difficult to see why these two apparent opposites might complement and reinforce each other: maligning the hero's enemies went a long way towards praising him. ${ }^{66}$ Much of this needs more investigation, but no doubt Radbert knew what he was doing.

\section{Ciceronian terminology and Carolingian politics}

Only by the end of his life, when he wrote the Epitaphium's second book, Radbert began to use classical terminology to refer to political offices and institutions of his own day and age. He consistently used officium, rather than the more common term ministerium, for he knew Cicero's as well as Ambrose's De officiis. The four key words that return regularly in his second book - and never in the first - are respublica, senatores, consules, cives and patria. To translate these expressions simply as republic, senators, consuls, citizens and fatherland would be inviting anachronism, but the search for alternatives confronts us head-on with the difficulties of the transmission and transformation of knowledge over time. How to translate this terminology in a way that does justice to a Carolingian context? This is relatively straightforward when it comes to senatores and consules, for these are a ruler's inner circle, of the kind that was called to the palace at Aachen for the crisis meeting of the winter of 828-829; this placitum (the usual word) was called a senatus, and the senatores were the lay magnates, who deliberated along with their ecclesiastical counterparts, referred to as praesules. The consules present were the equivalent of the conciliarii, the most prominent royal counsellors. ${ }^{67}$ Wala belonged to this category,

64 Sulpicius Severus, Gallus, III, cc. $11-13$, hrsg. von Fontaine, 328-342, with bishops versus the saint.

65 EA II, c. 7, 67: ... amisarius ille, qui cuncta reliquit honesta, in quibus erat ordinatus; et immersit se fatuus ad omnia coeni volutabra. Siquidem ut advenit, ac si ferus aper evertit palatium, destruxit consilium, dissipavit omnia rationis iura; consules omnes, divinos, humanosque expulit, et attrivit; thorum occupavit, atque factiose, ita ut insidiae viderentur, manifestius omnia pervasit...

66 Richard Flower, Emperors and Bishops in Late Roman Invective, Cambridge 2013, 44-55.

67 EA II, c. 5, 65. For the Latin text, see above, n. 20. 
and so did Einhard. ${ }^{68}$ Patria is more difficult. In ninth-century parlance, this expression had more regional connotations, but were these retained in the many instances in which Radbert claimed that Wala fought for his patria, or did he use this word in a more generalised fashion? The latter is the case: patria is used in many cases where other authors might have said regnum, but the two expressions were also used alongside each other, as in this declaration of Wala's reasons for resistance, one of many in the Epitaphium's second book:

It is true, brother, that he saw the innumerable and tremendous evils which arose every day, but he was not able to foresee those that were in the future. These he wanted to counter and resist as much as he had it in him, out of fidelity to ruler and realm, out of love for the fatherland and the people, for the worship in religious communities and the salvation of their members, which were all more dear to him than his own life. ${ }^{69}$

At first glance, here the 'citizens' (cives) entered the discourse along with the patria, but on second consideration, these are the inhabitants of the Heavenly City: the monks, nuns and clerics who responsible for the worship of God in the 'churches' - that is, ecclesiastical institutions in charge of collective prayer for the salvation of the Christian people.

Are we then dealing with a classical terminology that was simply transferred from the Roman public domain to a religious and monastic context? As Radbert's use of the expression respublica shows, it was not as simple as that. The emphasis here was on the res, the landed resources. These were either public and therefore at the disposal of the king to hand out as benefices to his military men, or they belonged to "the churches", that is, monastic or canonical communities, as the gifts of the faithful. That such wealthy ecclesiastical institutions enjoyed royal protection (tuitio) meant that their surplus wealth might be used for the benefit of the kingdom. Despite occasional protest, this had been common practice under Charlemagne as well as Louis the Pious. In Radbert's vivid portrayal of the meeting at the palace in the winter of 828 , the secular magnates present complained that the respublica was so impoverished that they could not raise the necessary troops without recourse to ecclesiastical landed resources. Wala was willing to compromise, and to support the respublica on this one occasion, but he argued strenuously against turning this into an automatism: "Let nobody deceive you, most illustrious of emperors, that it is terribly dangerous to pillage at a later stage goods that have once been faithfully given to God, for the use of the poor and the servants of God, and to divert them

68 De Jong, Penitential State (Anm. 5), 170-176.

69 EA II, c. 8, 68: Verum, frater, quia videbat mala quae quotidie surgebant innumera et immensa: sed praenoscere non valuit quae futura erant: quibus, quantum ex se fuit, obviare voluit, et resistere pro fide regni et regis, pro amore patriae ac populi, pro religione ecclesiarum et salute civium: quae omnia cariora illi erant, quam sua vita. 
to secular uses, against divine authority". ${ }^{70}$ This argumentation reflects the debates of the synods of the 840s in the kingdom of Charles the Bald in which Radbert took part as abbot of Corbie, rather than those of the $820 \mathrm{~s}^{71}{ }^{71}$ The point I want to get across here, however, is that Radbert's articulated his views on the nature of the respublica in the context of conflict about royal control of about monastic property - for the "churches" in question were mostly monastic establishments. Significantly, the integrity of this monastic wealth was clarified by a comparison with a respublica that was the undisputed domain of the king:

So let what once has been legitimately consecrated to God, be freely conceded to His soldiers and poor, for the use of His army. Let the king have the public domain to dispense of freely for the benefit of his army, and let Christ thus have the estates of the churches, as if it were another public domain, entrusted to his faithful assistants for the use of the needy and his servants; and let it be the office of the king to that it is entrusted to men of the sort who manage it in a trustworthy way and act wisely, with foresight, so that all praise the Lord and rejoice in Christ, not just because of the promises of future things, but also because of the consolations of the present. ${ }^{72}$

Have res and publica been turned into one word too easily and automatically by the editor of the text? In the manuscript, they can also be read and understood as two separate words. Ecclesiastical wealth in general, and Corbie's in particular, was quasi alteram rem publicam, as if it was another public domain. This was worlds removed from Ciceronian understandings of the republic as a commonwealth, and even further from modern notions of the separation of church and state. The general underlying idea is the two orders, clerical and secular, could only work well together and in a complimentary fashion if they remained distinct. Within the Carolingian polity, often defined as ecclesia, the ruler functioned as the linchpin between the two domains, for it was his responsibility that both would function in a divinely ap-

70 EA I, c. 3, 64: Nemo te, inquit, augustorum clarissime, fallat, quia valde periculosissimum est, res semel Deo fideliter dicatas, ad usus pauperum et servorum Dei, violenter postmodum diripere, et ad saeculares usus contra auctoritatem divinam retorquere.

71 De Jong, Familiarity lost (Anm. 1) ; Mayke de Jong, Paschasius Radbertus and Pseudo-Isidore. The evidence of the Epitaphium Arsenii, in: Rome and Religion in the Medieval World. Studies in Honor of Thomas F.X. Noble, ed. Valerie L. Garver and Owen M. Phelan, Farnham 2014, 149-177; Patrick Breternitz, Ludwig der Fromme und die Entfremdung von Kirchengut: Beobachtungen zum Epitaphium Arsenii, in: Fälschungen als Mittel der Politik? Pseudoisidor im Licht der neuen Forschung. Gedenkschrift für Klaus Zechiel-Eckes, ed. Karl Ubl and Daniel Zieman, Wiesbaden 2015 (MGH Studien und Texte 57), 187-206.

72 EA II, c. 2, 62: Habeat igitur rex rempublicam libere in usibus militiae suae ad dispensandum: habeat et Christus res ecclesiarum, quasi alteram rempublicam, omnium indigentium et sibi servientium usibus, suis commissam ministris fidelibus: et hoc sit regis officium, ut talibus committatur, qui et fideliter dispensent, et sapienter provideant: quatenus omnes glorificent Deum et gaudeant in Christo, non minus ex futurorum promissis, quam et ex praesentiarum consolationibus. 
proved way. ${ }^{73}$ But neither did Radbert use the expression respublica to denote a domain that was merely 'public' because it was royal, with landed wealth that a king could dispose of as if it were his own property. This public domain transcended particular rulers and their specific needs; it was wealth for the common good of the kingdom. According to Wala/Radbert, if applied indiscriminately, this principle amounted to robbery, but there was a substantial counter-opinion that held that "churches" and their wealth were very much part of the public domain. As much as secular magnates, bishops and abbots were the ruler's faithful men (fideles), so they served the needs of the respublica. To say that ecclesiastical wealth was "as if” it was another public domain, even though it belonged to Christ, meant shifting the emphasis from res to publica. For all Radbert's protestations, the issue was not merely that secular men depredated the resources of 'The Church' writ large. It was about the question how the ruler was to use scarce resources for the common good, for the defence of the kingdom, the salvation of its people, and the care of its poor. The king protected the cultus divinus, but did this give him the right to use gifts to the altar? Only in special circumstances, if it was for the common good, said Wala/Radbert. It was in the course of such typically ninth-century discussions that the concept of a respublica as a commonwealth gradually assumed a more definite shape.

\section{Conclusion}

Admittedly, it is difficult to say whether Radbert had familiarised himself with the substance of Cicero's De officiis and De republica directly or indirectly. His Ciceronian vocabulary may also have come through Ambrose's De officiis, or through Augustine, who cited Cicero more than any other classical Latin author. ${ }^{74}$ A more precise analysis of Radbert's use of his sources is the topic of a different study, yet it worth remembering all the authors just mentioned were available to him, and a good many more. ${ }^{75}$ Northern Francia had all the authors just mentioned available. In Cicero as well as in his patristic reading he encountered an idiom that he could adopt for a new and original work about the political order of his own time. When he wrote

73 Mayke de Jong, Charlemagne's Church, in: Charlemagne. Empire and Society, hrsg. von Joanna Story, Manchester 2005, 103-135; Mayke de Jong, Ecclesia and the early medieval polity, in: Staat im frühen Mittelalter. Forschungen zur Geschichte des Mittelalters 11, hrsg. von Walter Pohl, Helmut Reimitz und Stuart Airlie, Wien 2006, 113 - 132.

74 Schanzer, Augustine and the Latin Classics (Anm. 50), 165-168. Much of Cicero's political thought came to the early medieval West via the channel of the Stoic tradition embraced by Ambrose and Augustine, a topic properly opened up by Marcia L. Colish, The Stoic Tradition from Antiquity to the Early Middle Ages, 2 vols, Leiden 1985.

75 On Corbie's rich library, see above all Ganz, Corbie (Anm. 1), with in-depth discussion on citations in Radbert's work on $81-91$. 
the Epitaphium's second book, he did so with consummate ease, and most often without any explicit references or citations. This work is only one instance in which classical vocabulary entered Carolingian political discourse, in ways that have not yet been sufficiently investigated. Radbert sharply contrasted a disorderly present with an authoritative past, but this tension also yielded new and fruitful perspectives on his own society. He implicitly assumed that his evocation of a biblical and late antique imperial Christianity would be shared by his discriminating audience, and the same held true of his explicit use of the classics. His use of concepts such as respublica cannot be perceived as the pedantic affectation of a small group of learned Carolingian churchmen, without any bearing on actual politics. ${ }^{76}$ Radbert was not just an author, but also an actor in the political events he related. His terminology brings us very close to the political debates as they flourished in the aftermath of the rebellions against Louis the Pious, and also to the topic of this volume: the transmission of a classical and late antique legacy in the (early) Middle Ages. Radbert's expert use of these resources of the past was highly selective, creative and exceptional, but at the same time, this gifted author offers a glimpse of the ninth-century corridors of power that is more vivid and informative than any other contemporary work.

76 Contra Jörg W. Busch, Vom Amtswalten zum Königsdienst. Beobachtungen zur 'Staatssprache' des Frühmittelalters am Beispiel des Wortes administratio, Hannover 2007 (MGH Studien und Texte 42), $98-113$. 



\title{
Untangling the strands: The spelling of the Épinal glossary
}

\begin{abstract}
This paper focuses on a group of some twenty-five Old English glosses from the Épinal glossary (c. 700). The Old English interpretations stand out due to one graphemic feature: they all use one of the runic characters wyn or thorn, which were adopted into the Old English alphabet to represent the phonemes $/ \mathrm{w} /$ and $/ \theta /$. A careful investigation of the sources of the lemmata reveals that, with three exceptions, these glosses stem from Isidore of Seville's Etymologiae or from Paulus Orosius' Historiae Adversum Paganos, but not from any of the other numerous sources of the glossary. This confirms the hypothesis that different orthographic systems were in use among the glossators contributing to the Épinal/Erfurt family of glossaries. The study thus uncovers one chapter in the earliest history of English spelling and contributes to a better understanding of the composition of Épinal/Erfurt.
\end{abstract}

\section{Introduction}

The Épinal glossary is part of a group of glossaries transmitting glossographic material that can be traced back to early Anglo-Saxon England or, more precisely, Canterbury in the late $7^{\text {th }}$ century. The importance of this very early manuscript cannot be underestimated: the family of glossaries to which the Épinal manuscript belongs represents almost the only evidence of what was read at the Canterbury school. Hence it is a key witness to an important period of scholarship in early Anglo-Saxon England. The glossaries document how - and which - Latin texts were studied and annotated, and they illustrate how glossed texts were transformed into alphabetical glossaries. At the same time, the use of Old English for many interpretations attests to the very early use of the vernacular as a written language. Thus, the glosses in the Épinal manuscript also constitute important evidence as to how Old English was put into writing.

In contrast to modern standardized orthographies, the spelling of early medieval attempts at vernacular writing tends to be highly idiosyncratic. Each scribe had to determine his or her own representation of the sounds of English. Some kept as closely as possible to Latin orthography, while others were more creative and came up either with spelling solutions of their own, or adopted characters from other scripts, most notably the runic alphabet, which was part of the Germanic cultural heritage of the Anglo-Saxons. Since glossaries are texts that are composite in nature, distinctive spellings may be used to identify glosses that were potentially written by the same scribe or group of scribes. In the Épinal glossary, there is evidence of a mixture of at least three different orthographies. In the present paper, 
some twenty-five glosses from this manuscript are investigated, which are singled out on the basis of their spelling: These glosses all display wyn $\langle\mathrm{p}\rangle$ or thorn $\langle\mathrm{p}\rangle$, two characters that were taken from the runic script to supplement letters for the specifically Old English sounds /w/ and $/ \theta /$. The two characters became the regular spelling solutions for the two sounds in "standard" Old English texts of the $9^{\text {th }}$ and $10^{\text {th }}$ century, but this was not yet the case in the late $7^{\text {th }}$ and $8^{\text {th }}$ century, hence their appearance in the Épinal glossary is conspicuous. ${ }^{1}$

\section{The Leiden family of glossaries}

The Épinal glossary, dating from c. AD 700, is the oldest extant representative of a large group of related glossaries including, among others, the Leiden, Erfurt and Corpus glossaries. ${ }^{2}$ The Leiden glossary (c. 800) represents an earlier stage in the arrangement of the glosses, despite the fact that the manuscript is about a hundred years younger than Épinal. Hence the group of related glossaries is often referred to as the Leiden family. The (first) Erfurt glossary (c. 820) is most closely related to Épinal; it was copied by a single Continental hand and derives from a common ancestor of Épinal and Erfurt. ${ }^{3}$ The (second) Corpus glossary (c. 825-50) transmits the Épinal/Erfurt material combined with glosses from other sources; since Corpus has correct forms where both Épinal and Erfurt display mistakes, it must be an independent copy of the original collection. ${ }^{4}$ The forms of Leiden, Erfurt and Corpus are therefore important witnesses to the same material and often shed light on forms in Épinal from a different angle. The glossaries of the Leiden family are interrelated in so far as they draw from a common stock of glossographic material, though they are by no means identical: they vary not only in length, but also in the arrangement of the glosses they preserve. Pheifer comes to the conclusion that "it is impossible to establish the precise relationship of all the glossaries containing Épinal-Erfurt material to

1 The glosses containing wyn or thorn are listed in the appendix (p. 169).

2 The manuscripts are: Épinal, Vosges, Bibliothèque Multimédia Intercommunale, MS. 72 (2), 94 107; Leiden, Universiteitsbibliotheek, VLQ 69, 20 - 36; Erfurt, Universitäts- und Forschungsbibliothek Erfurt/Gotha, Dep. Erf. CA $2^{\circ} 42,1-14^{\mathrm{v}}$; Cambridge, Corpus Christi College, MS 144, 4-64 ; the Erfurt and Corpus manuscripts contain more than one glossary. For details about these and other manuscripts belonging to the same group of glossaries, cf. Joseph Pheifer, Old English Glosses in the Épinal-Erfurt Glossary, Oxford 1974, xxi-xli; Bernhard Bischoff, Mildred Budny, Geoffrey Harlow, Malcolm B. Parkes und Joseph D. Pheifer (Hrsg.), The Épinal, Erfurt, Werden and Corpus Glossaries, Kopenhagen 1988, 13-25; Klaus Dietz, Die frühaltenglischen Glossen der Handschrift Staatsbibliothek zu Berlin - Preussischer Kulturbesitz - Grimm-Nachlass 132, $2+139$, 2, in: Mittelalterliche volkssprachige Glossen, hrsg. von Rolf Bergmann, Elvira Glaser und Claudine Moulin-Fankhänel, Heidelberg 2001, $147-70$.

3 Pheifer, Old English Glosses (Anm. 2), xxvi.

4 Bischoff, Budny, Harlow, Parkes und Pheifer, The Épinal (Anm. 2), 25; Pheifer, Old English Glosses (Anm. 2), xxix f. 
each other or to the archetype". ${ }^{5}$ The largest part of the material consists of all-Latin glosses, while a smaller proportion has Old English interpretations.

The presence of Old English reveals that the glosses originate from Anglo-Saxon England; references to two people named as Theodorus and Adrianus in various glosses even make it possible to identify the exact historical context of the creation of these glossaries. Michael Lapidge ${ }^{6}$ has demonstrated that the glossaries, in fact, reflect the activities of Theodore of Tarsus, who was appointed archbishop of Canterbury by Pope Vitalian in 668 and held this office from 669 until his death in 690, and Hadrian, who was abbot of St. Peter and Paul from 671 until he died in 709/10. ${ }^{7}$ The two famous teachers appear as sources of some of the interpretations, such as the following:

Cyneris nablis. idest citharis longiores quam psalterium. nam psalterium triangulum fit. theodorus. dixit (Leiden xii, 40) 'Cyneris [i.e. Grk. kivv' $\rho \alpha$ 'a stringed instrument']: nabla. That is, harps which are longer than a psaltery, for a psaltery is triangular. Theodore said so.'

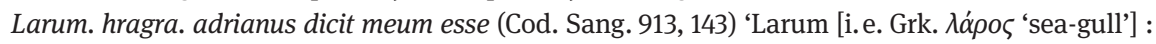
a heron. Hadrian says it is a sea-gull.'

Lapidge has interpreted such glosses as reflexes of viva voce teaching by the two notables; ${ }^{8}$ the wording of the interpretations makes it easy to imagine a classroom of Anglo-Saxon students listening to explanations of difficult vocabulary and taking notes.

5 Pheifer, Old English Glosses (Anm. 2), xl.

6 Michael Lapidge, The School of Theodore and Hadrian, in: ASE 15 (1986), 45-72, at 53-59.

7 The connection between the Leiden family of glossaries and Canterbury has recently been challenged by Rosamond McKitterick, Glossaries and Other Innovations in Carolingian Book Production, in: Turning Over a New Leaf: Change and Development in the Medieval Book, hrsg. von Erik Kwakkel, Rosamond McKitterick und Rodney Thomson, Leiden 2012, 60-68. Looking into the sources of the different batches of glosses in Leiden, she identifies St Gallen, where the Leiden manuscript was written, as the centre in which the glossary might also have been compiled. According to McKitterick, all but four of the forty-eight texts that provided lemmata for the Leiden glossary were available in St Gallen in the $9^{\text {th }}$ century (most of the manuscripts are still extant or they are listed in a $9^{\text {th }}$-century library catalogue). While Old English glosses may very well be due to the presence of Anglo-Saxons in St Gallen, the re-affirmed early dating of the Épinal glossary renders McKitterick's hypothesis problematic: the monastery of St Gallen was founded in $\mathrm{AD} 719$; the scriptorium was apparently working from about the $2^{\text {nd }}$ quarter of the $8^{\text {th }}$ century (the earliest surviving charter is dated to 731). Yet, the Épinal manuscript was written as early as the late $7^{\text {th }}$ century (Bischoff, Budny, Harlow, Parkes and Pheifer, The Épinal (Anm. 2), 14f.). Since Épinal includes a considerable amount of the Leiden material in a more elaborate arrangement (sorted alphabetically), there must have been an ancestor of Leiden which was used by the compiler of the Épinal manuscript that cannot have been produced in St Gallen - be it in the shape of interlinear glosses or already as glossae collectae as in Leiden. 8 Michael Lapidge, Old English Glossography. The Latin Context, in: Anglo-Latin Literature: 600899, hrsg. von Michael Lapidge, London 1996 [1992], 169-81, at 178; cf. also Bernhard Bischoff und Michael Lapidge (Hrsg.), Biblical Commentaries from the Canterbury School of Theodore and Hadrian, Cambridge 1994, at 173-9, 541. 
The activities of Theodore and Hadrian as teachers are described by Bede (Historia Ecclesiastica IV, 2) half a century later. He lists metrics, astronomy, arithmetic, ecclesiastical and biblical learning among the subjects studied. The teaching was apparently done in Latin as well as in Greek, the native language of both Theodore and Hadrian. Bede tells us that the students of the school who were still alive in his time spoke Latin and Greek as fluently as their own language. More specific details, however, cannot be deduced from Bede's account. ${ }^{9}$

Based on the different types of glossaries belonging to the Leiden group, it is possible to reconstruct the separate steps in the creation of the glossaries and, maybe, to gain further insights into the teaching methods of Theodore and Hadrian. The points of departure are the texts that were read and commented on at the school in Canterbury. The source texts include various books of the Bible, the Benedictine Rule, grammatical works by Donatus, Phocas, Sulpicius Severus, Rufinus, Isidore of Seville, Hieronymus, Cassian, Orosius, Gildas, Augustine, Gregory, etc. The work on these texts apparently resulted in interlinear glossing, both in Latin and in Old English, though no such glossed manuscripts survive. It remains unclear how exactly this venture was undertaken and what role Theodore's and Hadrian's teaching played. ${ }^{10}$

The gloss cited above, rendering Greek laros as both OE hragra 'heron' and mæw 'sea-mew, gull', suggests that the translator might have had access to different kinds of sources, which he combined. In this instance, it is possible that Hadrian corrected what someone else had said or what the scribe assumed a laros was. But we can also

9 Et quia litteris sacris simul et saecularibus, ut diximus, abundanter ambo erant instructi, congregata discipulorum caterua, scientiae salutaris cotidie flumina inrigandis eorum cordibus emanabant, ita ut etiam metricae artis, astronomiae et arithmeticae ecclesiasticae disciplinam inter sacrorum apicum uolumina suis auditoribus contraderent. Indicio est, quod usque hodie supersunt de eorum discipulis, qui Latinam Graecamque linguam aeque ut propriam, in qua nati sunt, norunt. (André Crépin, Michael Lapidge, Pierre Monat und Philippe Robin (Hrsg.), Histoire ecclésiastique du peuple Anglais / Historia ecclesiastica gentis Anglorum, Paris 2005).

10 On the sources of the Leiden family of glossaries cf. John Henry Hessels, A Late Eighth-Century Latin Anglo-Saxon Glossary. Preserved in the Library of the Leiden University (Ms. Voss. Q ${ }^{\circ}$ Lat. N$^{\circ}$. 69), Cambridge 1906; Karl W. Gruber, Die Hauptquellen des Corpus-, Épinaler und Erfurter Glossares, in: Romanische Forschungen 20 (1907), 393-494; Wallace Martin Lindsay, The Corpus, Épinal, Erfurt and Leyden Glossaries, Oxford 1921; David W. Porter, The Antwerp-London Glossaries and the First English School Text, in: Rethinking and Recontextualizing Glosses: New Perspectives in the Study of Late Anglo-Saxon Glossography, hrsg. von Patrizia Lendinara, Loredana Lazzari und Claudia Di Sciacca, Porto 2011, 153 - 178; David W. Porter, Isidore's Etymologiae at the School of Canterbury, in: ASE 43 (2014), 7-44; on the creation and function of glossaries in Anglo-Saxon England cf. Patrizia Lendinara, Was the Glossator a Teacher?, in: Quaestio 3 (2002), 1-27; Patrizia Lendinara, Glossaries, in: The Wiley Blackwell Encyclopedia of Anglo-Saxon England, hrsg. von Michael Lapidge et al., Chichester 2014; Hans Sauer, Language and Culture: How Anglo-Saxon Glossators Adapted Latin Words and their World, in: The Journal of Medieval Latin 18 (2008), 437 -68; Rolf H. Bremmer, Leiden, Universiteitsbibliotheek, Vossianus Latinus Q. 69 (Part 2): Schoolbook or Proto-Encyclopaedic Miscellany?, in: Practice in Learning. The Transfer of Encyclopaedic Knowledge in the Early Middle Ages, hrsg. von Rolf H. Bremmer und Kees Dekker, Leuven 2010, 19-54. 
imagine that the scribe came across hragra as a written translation (for example, as an interlinear gloss) and added Hadrian's correction. ${ }^{11}$ As David Porter has recently demonstrated, not only were Theodore and Hadrian consulted as authorities on difficult words, but also Isidore of Seville's Etymologies, which Porter identifies as "the reference book of first choice for practically any question" at the school of Canterbury. ${ }^{12}$ The Etymologies are, in fact, an ideal work for the purpose; they explain difficult vocabulary on the basis of similar-sounding words, which provide ideal mnemonic aids - though they are not etymologies in the modern understanding of the word. ${ }^{13}$ The words cyneris (i.e. cinyris from Ecclesiasticus 39:20) and laros, by the way, are absent from the Etymologiae; this might be the reason why Theodore and Hadrian were consulted.

In a second step, interlinear glosses were taken out of context and collected into text glossaries, so-called glossae collectae. In this type of glossary, the order of the head-words is the same as in the source text. Such glossaries might have been used when someone was studying a particular text. The Leiden glossary attests the glossae collectae stage, bringing together several groups of glosses, whose titles refer to the original sources (e.g. De Orosio, De Dialogorum) and in which the material still appears as it occurs in the texts. Porter ${ }^{14}$ has shown that not only do many interpretations in Leiden derive from Isidore's Etymologies, but also that the selection of lemmata sometimes depends on the Etymologies.

In a third step, rough alphabetical glossaries were created; different groups of glossae collectae were combined and put into alphabetical order based on the first letter of each lemma but ignoring the rest of the word (A-order). This stage is attested by the bulk of the material from Épinal and Erfurt. Lastly, the second letter was also taken into account in the sorting process (AB-order); this is what we find in the Corpus glossary as well as in some parts of Épinal and Erfurt. An overview of the different stages and the manuscripts in which they are attested is presented in Figure $1 .^{15}$

It is important to note that the typological stages of the glossaries (glossae collectae $\rightarrow$ A-order $\rightarrow$ AB-order) do not correspond to the chronology of the transmission of the manuscripts: the glosses in Épinal, dating from $\mathrm{AD} 700$, are mostly in A-order, whereas the much younger Leiden glossary, preserves the glossae collectae stage. The Corpus glossary, on the other hand, is only slightly younger than Leiden, but completely sorted

11 It is easy to understand how the confusion arose in the first place: obviously someone knew that laros was an aquatic bird, but didn't know - or failed to convey - exactly what kind of water bird.

12 Porter, Isidore's Etymologiae (Anm. 10), 13.

13 The Etymologies of Isidore of Seville, hrsg. von Stephan A. Barney, W. J. Lewis, J. A. Beach und Oliver Berghof, Cambridge 2006, $22-24$.

14 Porter, Isidore's Etymologiae (Anm. 10).

15 Lindsay, The Corpus, Épinal (Anm. 10), 1 -6 still provides the most detailed account of the process of creating glossae collectae and of the different steps in creating alphabetical glossaries. A different strand of glossographic activity is represented by class glossaries, which bring together items belonging to the same semantic field (e.g. plant names, animals, etc.). 


\begin{tabular}{llll}
\hline Interlinear glosses $\rightarrow$ & glossae collectae $\rightarrow$ & A-order glossary $\rightarrow$ & AB-order glossary \\
\hline (not attested) & Leiden (c. 800) & Épinal (c. 700) & Corpus (c. 825-850) \\
& & Erfurt (c. 820) & \\
\hline
\end{tabular}

Fig. 1 Stages in the creation of alphabetical glossaries

in $\mathrm{AB}$-order. Apart from that, the distinction between the different stages of dictionary making is not as clear-cut as my description might have made it appear. In fact, most of the extant glossaries represent a mixture of more than one stage. The Épinal and Erfurt glossaries, for example, combine words sorted after the first letter of the alphabet only with sets that take the first two letters into account. The scribe who compiled the glosses probably used various sources of glosses which were arranged in different ways. Normally, the AB-batches are much shorter and are added after the A-sections, but the pattern is not always exactly the same. ${ }^{16}$

\section{Wyn and thorn in the Épinal glossary}

The Épinal glossary consists of a total of about 3,280 entries, of which about 950 have Old English interpretations. Today, it is kept in Épinal in North-Eastern France, but the manuscript was probably written in England in the late $7^{\text {th }}$ or early $8^{\text {th }}$ century. ${ }^{17}$ The early history of the manuscript is unknown; it was in Moyenmoutier at least by the beginning of the $18^{\text {th }}$ century, but was probably there throughout the Middle Ages. The glossary was written by a single scribe $;^{18}$ it occupies the space of fourteen leaves of vellum, which are grouped into two quires. Both quires are incomplete: the middle leaf of the first quire, which once contained the end of the $\mathrm{C}$ batch, and the entire D and E sections, is missing as well as the last leaf of the second quire, which must have contained the remainder of the $U$ section until the end of the glossary. The parallel transmission of the glossary in the Erfurt manuscript makes it clear that some 600 glosses are missing. ${ }^{19}$ The pages of the Épinal glossary are divided into three neatly arranged pairs of columns (a-f), which provide the Latin (or Greek) lemmata on the left (columns a, c, e) and the Latin or Old English

16 On the arrangement of the different sections cf. Joseph D. Pheifer, Relationship of the Épinal, Erfurt, Corpus, and Werden Glossaries, in: Bischoff, Budny, Harlow, Parkes und Pheifer, The Épinal (Anm. 2), 54.

17 Bischoff, Budny, Harlow, Parkes und Pheifer, The Épinal (Anm. 2), $15 \mathrm{f}$.

18 Pheifer, Old English Glosses (Anm. 2), xxii.

19 Cf. Georg Götz, Corpus Glossariorum Latinorum, 5: Placidus Liber Glossarum, Glossaria Reliqua. Leipzig 1894, 353-59, 400f; Pheifer, Old English Glosses (Anm. 2), xxi. 
interpretations on the right (columns b, d, f). ${ }^{20}$ Each new alphabetical section is highlighted with a larger initial.

Pheifer puts the proportion of Old English interpretations at about one quarter to one third; their distribution across the manuscript, however, is quite unequal: on folio 4v, for example, there are 111 glosses, 32 of which (i.e. about one third) have Old English interpretations; on folio 3r, on the other hand, only 13 out of 114 glosses (i.e. one tenth) are in Old English. Furthermore, vernacular interpretations usually cluster together. This suggests that some of the glossaries which fed into the archetype of Épinal/Erfurt contained predominantly Old English interpretations and that others were purely Latin-Latin. According to Pheifer, the Orosius glosses probably fall into the first group: "[t]he proportion of bilingual glosses in these [i.e. Orosius] batches (about 65\%) is higher than elsewhere in Epinal-Erfurt [...] and the entries sometimes bunch together so as to approach continuous translation". ${ }^{21}$

A comparison of the spelling system of the Old English material in the Épinal glossary with other early Old English texts shows that the degree of graphemic variation displayed by the Épinal glossary is unusually high. On the one hand, the number of different graphs used to represent a single sound is considerable. For the representation of $/ \theta /$ and $/ \mathrm{w} /$, for example, there are six different spellings each: the dental fricative $/ \theta /$ is represented by the graphs $\langle\mathrm{th}\rangle,\langle\mathrm{d}\rangle,\langle\mathrm{p}\rangle,\langle\mathrm{\partial}\rangle,\langle\mathrm{t}\rangle$, and $\langle\mathrm{dh}\rangle$; the bilabial approximant /w/ by $\langle\mathrm{uu}\rangle,\langle\mathrm{u}\rangle,\langle\mathrm{p}\rangle,\langle\mathrm{uuu}\rangle,\langle\mathrm{uu}\rangle$, and $\langle\emptyset\rangle$. ${ }^{22}$ Other Old English texts display two to three variants at the most; furthermore, different variants are usually assigned to different sound positions (e. g. initial vs. medial/final, before certain sounds etc.). In Épinal, however, most of the graphs listed occur across different sound positions. Moreover, the most frequently used graphs for these sounds, $<$ th $>$ and $<\mathrm{uu}>$, cover a comparatively low percentage of the total of one sound position: $<$ th $>$ appears only in 68 percent of all instances of $/ \theta /$ in initial position and $<\mathrm{uu}>$ covers 85 percent of initial /w/. In other Old English spelling systems, the leading graphs are much more consistently used, which results in percentages that are significantly higher. ${ }^{23}$

20 An excellent electronic facsimile of the Épinal manuscript with facing pages of Schlutter's diplomatic edition is available on the Internet page of the Bibliothèque Multimedia Intercommunale d'Épinal (URL: www.bmi.agglo-epinal.fr); cf. Otto B. Schlutter, Das Épinaler und Erfurter Glossar, 1: Faksimile und Transliteration des Épinaler Glossars, Hamburg 1912a. For a detailed description of the Épinal manuscript see Pheifer, Old English Glosses (Anm. 2), xxi-xxv; Bischoff, Budny, Harlow, Parkes und Pheifer, The Épinal (Anm. 2).

21 Joseph D. Pheifer, Early Anglo-Saxon Glossaries and the School of Canterbury, ASE 16 (1987), 1744 , at 27

22 The last symbol $\langle\emptyset\rangle$ indicates a "zero" graph, i.e. a sound that is not represented in the spelling; this phenomenon occurs only once in Épinal (in 341 <asundun> for aswundun), but it is fairly common in early Old English if /w/ precedes the vowel / $\mathrm{u}$ / (cf. Annina Seiler, The Scripting of the Germanic Languages. A Comparative Study of "Spelling Difficulties" in Old English, Old High German and Old Saxon, Zürich 2014, 100f.)

23 For details see Seiler, The Scripting of the Germanic Languages (Anm. 22), 218-231. 
This high degree of variability coupled with a lack of consistency suggests that the variation displayed by the Épinal glossary does not represent the graphemic spectrum of a single scribe. Rather the evidence seems to point towards a mixture of different orthographies which were used by the writers of the sources of Épinal. At least one of these scribes seems to have applied a spelling system that regularly used the two runic symbols $\langle p\rangle$ wyn and $\langle p\rangle$ thorn. Since the characters adopted from the runic script stand out from the Latin alphabet, these glosses can be identified as belonging to a specific subset of glosses. Obviously, other items that do not contain the sounds $/ \mathrm{w} /$ or $/ \theta /$, as well as many of the Latin-Latin glosses, may also derive from the same original group, but there is no way of distinguishing them from the rest of the glossary on the basis of their orthography. ${ }^{24}$

Several facts show that, in general, the spelling variation in the Épinal manuscript goes back to an earlier stage of the glossary: first of all, the scribe who copied the extant Épinal manuscript was clearly not the one who introduced the runic characters since the two runes are often confused and their shapes are awkward. ${ }^{25}$ In Épinal $47^{26} p^{u}$ aar (with $u$ superscript over $p$ ), the very first instance of one of the runic characters in the glossary, the scribe obviously mistook initial wyn for the letter $p$, but afterwards realized that this didn't make any sense and corrected the reading with a superscript $u$ : the word is OE war 'sea-weed', a successful translation of the Latin lemma alga. Moreover, in Épinal 1037 pus suipae 'so much' on folio 14r, column $\mathrm{d}$, line 2, the two instances of thorn are shaped rather like wyn, i.e. with a triangular bow and without ascender:

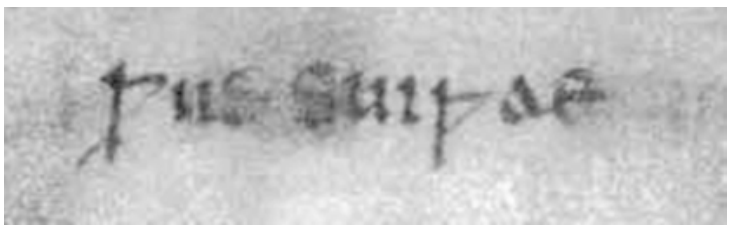

(Photograph: bmi)

The same applies to $444<$ poot $>$ and $564<$ uuop $>^{27}$ for OE wōp 'voice, song, speech', $601<$ pupistil> for OE pupistil 'sow-thistle', 613 <clipae> for OE clipe ${ }^{28}$ 'burdock' etc.

24 The fact that the two characters appear at all is unusual, since wyn and thorn were adopted into the Old English alphabet only later in the period: wyn is regularly used from the $9^{\text {th }}$ century onwards, thorn from the $10^{\text {th }}$ (cf. Seiler, The Scripting of the Germanic Languages (Anm. 22), 101 f., $133 \mathrm{f}$. 25 Cf. Otto B. Schlutter, Zum Epinalglossar, in: Anglia 35 (1912), $137-141$, at 138.

26 Glosses from Épinal/Erfurt are cited after Pheifer, Old English Glosses (Anm. 2), whose numbering corresponds to the edition in Henry Sweet, The Oldest English Texts, Early English Text Society, O.S. 83, London 1885.

27 The last letter of this word has a very strange shape: the bow is eye-shaped and consists of two strokes.

28 The form with $/ \theta$ / is poorly attested: the instance in Épinal is the only attestation in Old English. However, it appears to have survived into the $16^{\text {th }}$ c. (cf. Oxford English Dictionary, 2nd ed., Oxford 1989, www.oed.com, s.v. 'clithe, $n$.'). The word is attested in several variants in the Germanic languag- 
The confusion can be illustrated nicely by two consecutive glosses on folio 11r, column f, lines 17 and 18: 845 aengi pinga 'in any way' and 846 aec pan 'in addition to that' with a wyn-like, triangular bow in the first instance and a rounded, "proper" thorn in the second:

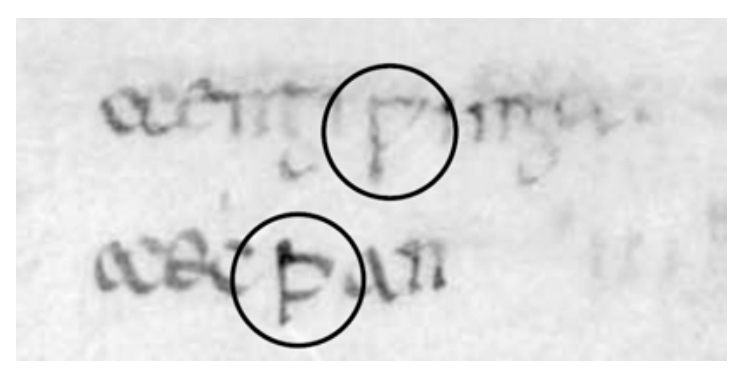

(Photograph: bmi)

This indicates that the scribe copied the shapes of wyn and thorn from an earlier exemplar, but was unfamiliar with the runic characters.

That wyn and thorn must have been present in the source of Épinal is also attested by the fact that some of the parallel glosses in the Erfurt manuscript are spelled with the letter $\langle\mathrm{p}\rangle$ rather than the wyn or thorn of Épinal. Both manuscripts were probably copied from a common ancestor, but the scribe who wrote the Erfurt glossary must have been a native speaker of Old High German since he introduced a number of German forms into the glossary. ${ }^{29}$ The Erfurt scribe also adjusted the spelling: in most cases, he or she substituted $<\mathrm{uu}, \mathrm{u}>$ for wyn and $<\mathrm{d}>$ for thorn, which are graphs commonly employed in early Old High German for the two sounds in question. In several instances, however, the scribe apparently did not recognize or understand the Old English word and used the letter $\langle\mathrm{p}\rangle$ instead of $\langle\mathrm{p}\rangle$ or $\langle\mathrm{p}\rangle$ (though a wyn-like shape is preserved in Erfurt 564 puod). In fact, this feature allows us to add one more instance to the group using runic characters: the Erfurt gloss 388 elleborus : poedibergæ (for OE wede-berge 'plant used against madness, hellebore') shows that the common ancestor of Épinal and Erfurt must have contained the letter $\langle p\rangle$, even though this gloss is not attested in the Épinal manuscript as the entire E section (as well as D and the end of $\mathrm{C}$ ) is missing. The corresponding item in the Corpus glossary 736 poedeberge also attests wyn for this entry; however, since Corpus often uses the more "modern" characters wyn and eth $<ð>$ against $<\mathrm{uu}>$ or $<\mathrm{d} / \mathrm{th}>$ in Épinal, the evidence from this manuscript carries less weight.

es (in $\mathrm{OHG}$ with <-d-, -dth-, -th-, -td-, -t- etc. $>$ ); the forms with $\mathrm{OE}<\mathrm{p}>, \mathrm{OHG}<\mathrm{th}, \mathrm{d}>$ may derive from Gmc. *klipōn- or ${ }^{\star} k l i ̄ p o ̄ n-($ cf. Rosemarie Lühr (Hrsg.), Etymologisches Wörterbuch des Althochdeutschen, 5: iba - luzzilo, Göttingen 2014, s.v. 'kledda, kletta'.)

29 On this topic cf. Heinrich Tiefenbach, Zu den althochdeutschen Glossen im altenglischen Erfurter Glossar, in: Language and Civilization. A Concerted Profusion of Essays and Studies in Honour of Otto Hietsch, hrsg. von Claudia Blank, Frankfurt a. M. 1989,114-123; Bischoff, Budny, Harlow, Parkes and Pheifer, The Épinal (Anm. 2), 17 -22; Pheifer, Old English Glosses (Anm. 2), xxv-xxviii. 
The evidence suggests further that the extant spelling variation in the Épinal glossary does not reflect a single orthographic system since, within individual interpretamenta, there is no mixture of the runic characters with any of the alternative spellings. In other words, those glosses of Épinal that use the runic characters do so consistently. The one exception, Épinal 564 uuop with <uu> (rather than wyn) as well as thorn in the same word, can be discounted since the parallel Erfurt gloss puod shows that the common exemplar must have had initial wyn, which, for once, was changed to <uu> by the Épinal scribe. ${ }^{30}$ On the other hand, those forms in which digraphs like $<\mathrm{uu}>$ or $<$ th $>$ occur seem to employ those spelling solutions throughout, as for example 232 uuaeterthruch (i.e. wæter-pruh 'water-pipe' as a translation of Latin ca[ta]ractis) with $<\mathrm{uu}\rangle,\langle\mathrm{th}\rangle$ as well as a third digraph $\left\langle\mathrm{ch}>{ }^{31}\right.$ In two cases, the same Old English word is attested in two orthographic systems: 452 uuestsuduuind vs. 118 pestsuppind and 1082 uuiduuuindae vs. 1059 piupindae. The following table provides an overview of all interpretations containing more than one instance of $/ \mathrm{w} /$ or $/ \theta /$ sorted according to the spelling system used. ${ }^{32}$

Table 1: Two spelling systems in the Épinal glossary for /w/ and / $\theta /$

\begin{tabular}{|c|c|}
\hline$\langle u u\rangle /\langle$ th $\rangle:$ & $\langle p\rangle /\langle p\rangle:$ \\
\hline 232 uuaeterthruch & 118 pestsuppind \\
\hline 248 unodaeuistlae (Er unodeuuislae) & 162 eastnorppind \\
\hline 452 uuestsuduuind (not in Erfurt) & 444 poot (Erfurt puoo ${ }^{d}$ ) \\
\hline 576 tha uuannan aetrinan & 564 uuop (Erfurt puod) \\
\hline 669 hsniuuith & 601 pupistil \\
\hline 699 bisiuuidi uuerci & 1037 pus suipae \\
\hline 780 thriuuuintri steor & 1059 piupindae \\
\hline \multicolumn{2}{|l|}{787 thothor } \\
\hline \multicolumn{2}{|l|}{877 cyniuuithan } \\
\hline \multicolumn{2}{|l|}{880 thebanthorn } \\
\hline \multicolumn{2}{|l|}{518 uualhuuyrt } \\
\hline \multicolumn{2}{|l|}{1045 uuandaeuuiorpae } \\
\hline 1082 uuiduuuindae & \\
\hline
\end{tabular}

Orthographic consistency also seems to extend to the letter eth $\langle\partial\rangle$, which is used

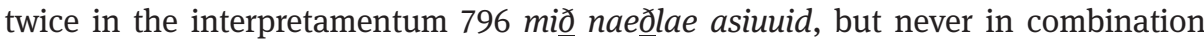
with any alternative spelling for $/ \theta /$. However, given the very limited number of

30 Initial wyn is also confirmed by the Corpus glossary entry 1196 pooð.

31 On the digraphs $\langle\mathrm{uu}\rangle,\langle\mathrm{th}\rangle$ and $\langle\mathrm{ch}\rangle$ in Old English spelling see Annina Seiler, Writing the Germanic Languages. The Early History of the Digraphs $\langle\mathrm{th}\rangle,\langle\mathrm{ch}\rangle$ and $\langle\mathrm{uu}\rangle$, in: Writing Europe, 5001450. Texts and Contexts, hrsg. von Aidan Conti, Orietta Da Rold und Philip Shaw, Cambridge 2015, $101-121$; <ch $>$ and $<\mathrm{gh}>$ occur in combination with $<$ th $>$ in thruch, slachthorn (672, Er slachdorn) and slaghthorn (957, Er salachthorn).

32 The table includes only instances of /w/ before vowels other than $/ \mathrm{u} /$ and outside consonant clusters since in more than 80 percent of all instances those cases are spelled with single $<\mathrm{u}>$. 
only eight instances of eth in the entire glossary, this piece of evidence is inconclusive.

\section{Sources of the wyn/thorn glosses}

In view of the textual history of the Épinal glossary, there is one interpretation that suggests itself as the most likely explanation for the peculiar distribution of spellings, namely that the different "orthographies" come from different sets of glossae collectae, or interlinear glosses, which were put together and reorganized into semi-alphabetical order. In total, there are 25 interpretamenta in the Épinal manuscript, plus one only attested in Erfurt, which transmit 31 instances of wyn or thorn (cf. Appendix). If the assumption is correct that they represent the spelling system of one set, or a small number of sets, of glossae collectae, it should be possible to identify the source texts.

In fact, with three exceptions, the lemmata of the glosses in question occur either in Isidore of Seville's Etymologiae (47, 118, 162, 388, 444, 601, 613, ?628, 763, 845, 846, 1014, 1068, 1071) or in Paulus Orosius' Historiae Adversum Paganos (532, ?542, 738, 741, 757, 760, 769, ?1037, 1093). The exceptions are glosses 173 (a Bible gloss), 564 (possibly from the Abavus glossary; cf. Pheifer Old English Glosses (Anm. 2), 96) and 1059 (lemma and interpretation probably from Jerome's Commentaria in Naum). While the Orosius batches have already been identified and collated by Lindsay, ${ }^{33}$ it has only recently been discovered to what extent the glossaries of the Leiden family are indebted to Isidore's Etymologies; ${ }^{34}$ this also extends to the glosses in Épinal/Erfurt. ${ }^{35}$

As Lindsay has pointed out, identifying sources of glossary items consists of more than finding a text in which the lemma in question appears. Single words often occur in various texts, and it is only when there are several words coming from the same chapter or passage that the origin of a group of lemmata can be identified with any certainty. ${ }^{36}$ Yet, some of the all-Latin items, with interpretations that extend to longer phrases, demonstrate their affiliation with the Etymologies beyond doubt, for example, the following two items from the A and C batches, respectively.

33 Lindsay, The Corpus, Épinal (Anm. 10), 23-31; cf. also Schlutter, Zum Epinalglossar (Anm. 25). 34 Isidore's Etymologies were identified as a source of the Leiden glossary by Hessels, A Late EighthCentury Latin Anglo-Saxon Glossary (Anm. 10); Porter, Isidore's Etymologiae (Anm. 10), 9, however, has pointed out that "the Etymologiae played a far greater role in 'Leiden' than Hessels suspected." 35 Pheifer lists 17 -18, 39, 167, 235, 388, 391, 430, 445, 449, 458, 786, 839, 873, 875 -6, 891, 905, 907, 1064 as "probable borrowings from Isidore's Etymologies" (Pheifer, Old English Glosses (Anm. 2), xlv, liv), some of them among the glosses which Lindsay identified as Hermeneumata items. In my estimation, many more glosses in Épinal/Erfurt probably derive from the Etymologies, but this needs a comprehensive reassessment of the sources of all lemmata, including Latin-Latin glosses. Porter (Porter, The Antwerp-London Glossaries (Anm. 10), 163-66) has looked into Lindsay's Hermeneumata batch in the A-section of Épinal/Erfurt and has come to the same conclusion. 36 Lindsay, The Corpus, Épinal (Anm. 10), v. 
Épinal, fol. $3^{\mathrm{r}} \mathrm{cd}, 1$. 27: Auiaria : secreta nemora quod haues frequentant Isidor, Etymologiae, XVII.vi.9: Aviaria secreta nemora, dicta quod ibi aves frequentant. 'An aviaria is a hidden grove so called because it is the haunt of birds (avis).'

Épinal, fol. $4^{\mathrm{r}}$ ab, 1. 2: Cetra : scutum loreum quo utuntur afri et hispani Isidor, Etymologiae, XVIII.xii.5: Scetra scutum loreum sine lingo, quo utuntur Afri et Mauri. 'A [s] cetra (i.e. caetra) is a shield of woven leather without wood, which the Africans and Moors use. ${ }^{37}$

In both cases, lemma as well as interpretation clearly derive from the Etymologies, or possibly from an Isidorian epitome, as suggested by Porter, ${ }^{38}$ which establishes that Isidore was used as a source for Épinal/Erfurt. Both items are located in the vicinity of wyn/thorn interpretations: Auiaria occurs two words down from 118 affricus : pestsuppind 'south-west wind' and cetra right after 173 cartellus : pindil 'basket'. This is significant despite the fact that in the glossary the lemmata were rearranged in alphabetical order: the sorting process described above, which mostly involved only the first letter of the alphabet, results in groups of connected glosses - even if the relationship is by no means straightforward.

The first example on folio $3^{r}$, columns cd, seems to belong to a veritable Isidorian batch, which occurs at the very end of the A section (1l. 23-28). ${ }^{39}$ It is interrupted only by a single gloss on line 26 on an insect from Leviticus (with the incongruous Old English translation dora 'bumblebee'):

23 arbusta

24 anser

25 affricus

26 atticus

27 auiaria

28 auena loca in quo arbores nascuntur goos 'goos'

pestsuppind 'south-west wind'

dora 'bumblebee'

secreta nemora quod haues frequentant

agrestis harundo 'wild reed'
Isidor, Etym. XVII.vi. $2^{40}$

Isidor, Etym. XII.vii.52 (or vii.1)

Isidor, Etym. XIII.xi.9

Bible, Leviticus 11: 22

Isidor, Etym. XVII.vi.9

Isidor, Etym. XVII.ix.106

37 Here and below, Isidore's Etymologies are quoted from Wallace Martin Lindsay (Hrsg.), Isidori Hispalensis Episcopi Etymologiarum siue Orginum libri XX, 2 vols, Oxford 1911; translations come from Barney, Lewis, Beach und Berghof, The Etymologies (Anm. 13). Words that correspond to the Épinal entry are highlighted by underline.

38 Porter, Isidore's Etymologiae (Anm. 10).

39 It is situated after four "leftovers" from a Phocas batch which Lindsay identified (Lindsay, The Corpus, Épinal (Anm. 10), 16) and one other gloss archioretys : libros duo from Hieron. De Vir. Illustr. 13. Based on the preceding Phocas batch, Pheifer suggests that anser : goos derives either from Phocas or from a Hermeneumata gloss. However, as Book XII of the Etymologies on animals appears to be strongly represented in Épinal/Erfurt, an Isidorian origin for this gloss is equally likely (Pheifer, Old English Glosses (Anm. 2), 66, n. 117).

40 Arbusta, arbor novella et tenera, in qua insertio fieri potest; et dicta arbusta quasi arboris hasta. Alii arbustum locum in quo arbores sunt volunt accipere [...]. 'A sapling (arbustum) is a new and pliant tree, in which a graft can be made, and it is called arbustum as if it were 'the spear of a tree' (arboris hasta). Others would take arbustum as the place where trees grow.' (Barney, Lewis, Beach und Berghof, The Etymologies (Anm. 13), 341). 
Pheifer has tentatively identified the Greek-Latin glossary Hermeneumata Pseudodositheana as the source of 118 affricus : pestsuppind and of the three other wind names occurring in Épinal/Erfurt, 162 boreus : eastnorppind, 311 circius : uuestnorduui[n]d (only Erfurt) and 452 fa[v]onius : uuestsuduuind (only Épinal). However, since all four wind names occur in close proximity in Isidore's Etymologies in chapter XIII.xi.9-13 on winds, the lemmata may very well derive from this passage. ${ }^{41}$ Even the ablative case of the all-Latin item $5^{\mathrm{r}} \mathrm{ef} / 5$ fauonio : zephyro finds its correspondence in another section of the Etymologies (IX.v.25).

In any case, there seem to be several original groups of wind names in Épinal. Evidence for this hypothesis is provided by $452 \mathrm{fa}[\mathrm{v}]$ onius : uuestsuduuind, which differs not only in terms of the spelling from the other Old English wind names, but also with respect to its position in the glossary. As has been mentioned, the alphabetical sections of Épinal/Erfurt combine different groups of lemmata that are sorted either according to the first letter only or according to the first two letters of a word. All glosses containing wyn or thorn appear in A-order sections; fa[v]onius : uuestsuduuind, on the other hand, is the first member of an AB-order batch, which is placed at the end of the F-section and which runs from FA through to FL. ${ }^{42}$ This implies that at least one of the wind names has reached Épinal/Erfurt by a different layer of glosses, whatever its ultimate source.

Another extended Isidore batch surrounds the gloss 613 lappa : clipae on fol. $7^{\mathrm{v} a b} / 12$. With the exception of laris : men (i.e. laros : mǣw 'gull', cf. above) on line 8 , all lemmata along with the Latin parts of interpretations, from at least line 7 as far as line 13, can be identified in the Etymologies. The batch is strikingly similar to the one surrounding affricus: The material from the Etymologies mostly derives from chapters XII on animals and XVII on plants and the straggler in both cases is a gloss on an animal from Leviticus 11:

41 Pheifer's argument in favour of the Hermeneumata as a source (Pheifer, Old English Glosses (Anm. 2), 89, n. 452) is based on the translation of favonius as uuestsuduuind (rather than west wind), which is paralleled by a rendering of lips 'south-west wind' as fauonius in the Hermeneumata (cf. Georg Götz, Corpus Glossariorum Latinorum, 3: Hermeneumata Pseudodositheana, Leipzig 1892, 172, lines 9-15). This would imply that the Old English interpretations are translations of the Greek, rather than the Latin wind names in the glossary, which doesn't seem very likely. Furthermore, there are other mistakes in the Hermeneumata which are not reflected in the Epinal wind names.

42 Cf. Pheifer, Relationship of the Épinal (Anm. 16), 54. 
7 lycisca

8 laris

9 limax

10 lumbricus

11 labrusca

12 lappa

13 lentum uimen canis ex lupo et cane natus

men 'sea-gull'

snel 'slug'

regenuuyrm 'earthworm'

uitis agrestis

clipae 'burdock'

toch gerd 'pliant branch'
Isidor, Etym. XII.ii. $28^{43}$

Bible, Leviticus 11: 16

Isidor, Etym. XII.v.7

Isidor, Etym. XII.v.13

Isidor, Etym. XVII.v. $3^{44}$

Isidor, Etym. XVII.ix.66

Isidor, Etym. XVII.vii.51

Another similarity with the Isidorian batch described above lies in the fact that it also appears right at the end of an A-order section; the gloss following lentum uimen on line 14 ligustrum : hunaegsugae, which Pheifer considers a possible Abstrusa item, represents the last word of the L-order section, followed by LA-order glosses.

Comparable batches of glosses from the same source can be found in connection with most of the wyn/thorn words. An Orosius batch which comprises some forty-five items on folio $6 \mathrm{v}$ contains 532 interuentu : pingungae and 542 inditas : pa gisettan. ${ }^{45}$ In addition also the following four glosses are embedded in an extensive Orosius cluster of almost sixty glosses: ${ }^{46} 738$ perduellium : porgifect, 741 per seudoterum : porh ludgaet, 757 per anticipationem ${ }^{47}$ : porch ob[u]st and 760 per uispellones : porçh byrgeras.

Incidentally, the three glosses that cannot be attributed to either of the two sources appear in close connection with Isidorian items. ${ }^{48}$ Several explanations are possible: we can imagine that, by coincidence, the three words got attached to the Isidore glosses in the transition from one glossary stage to the next and that the scribe who assembled those glosses is the one responsible for the $p / p$ spellings. On the other hand, it also seems possible that the stragglers are not random addi-

43 Lycisci autem dicuntur, [...] canes nati ex lupis et canibus, cum inter se forte miscuntur. 'Dogs born from the chance mating of wolves with dogs are called lycisci [...].' (Barney, Lewis, Beach und Berghof, The Etymologies (Anm. 13), 253)

44 Labrusca est vitis agrestis [...]. 'The labrusca is a wild vine [...].' (Barney, Lewis, Beach und Berghof, The Etymologies (Anm. 13), 339)

45 The batch starts with $6^{\mathrm{v} a b} / 33$ intractabilis : unlidouuac and goes as far as $6^{\mathrm{V}} \mathrm{ef} / 6$ increpitans : insonans. There are three stragglers in the batch that are not from Orosius: ab/38 inuitiandi : negandi, cd/9 iners : asolcaen, 16 incissibus quando quaedam inalbabeto littera transponitur (cf. Lindsay, The Corpus, Épinal (Anm. 10), 27; Pheifer, Old English Glosses (Anm. 2), 94f.).

46 This batch starts with $9^{\mathrm{r}} \mathrm{ef} / 27$ pestiferum : nigrum uel putridum and ends with $9^{\mathrm{v}} \mathrm{cd} / 8$ (= Pheifer $760)$ per uispellones : porçh byrgeras. The only gloss not from Orosius is $9^{\mathrm{v}} \mathrm{ab} / 32$ propalatum : manifestum, a Bible gloss (Hebr. 9:8); cf. Lindsay, The Corpus, Épinal (Anm. 10), $28 \mathrm{f}$.

47 The lemma per anticipationem does not appear in the standard editions of Orosius' Historiae, but it does occur in vi, 11/17 in some of the manuscripts as well as in the editio princeps from from 1471. Since there is only a single gloss that does not come from Orosius in the entire batch, this implies that the version of Orosius used for the glossary must have included this addition. Book vi, chapter 11 is also the source of 769 pice sebo : unamaelti sperpi, another one of the wyn/thorn glosses. 48173 cartallus is preceded by calculus (Isidore, Etym. XVI.iii.5) and followed by cetra (XVIII.xii.5); 564 lepor is followed by lagones (XX.xiv.6), luscus (X.163), luridus (X.162) etc; 1059 uoluola is placed between uestibulum (XV.vii.2) and uittas (XIX.xxxi.6). 
tions, but were triggered by the Etymologies themselves: in the case of the biblical gloss 173 cartellus : pindil 'basket', it might have been the explanation of the synonyms canistrum and cophinus (Isid. Etym. X.ix.8-9) which resulted in the inclusion of the word in the glossary. Porter ${ }^{49}$ has identified several instances in the Leiden glossary in which the glossator selected lemmata based on what could be explained with the help of the Etymologies; this could be a comparable case..$^{50}$ In a similar way, the gloss 564 lepor : subtilitas uel uuop might have been a topic of discussion in connection with lepus, leporis 'hare' and lupus, lupi 'wolf', which occur in Isidore's section on grammar and also make an appearance in the L-section of Épinal/Erfurt.

The last straggler, 1059 uoluola : piupindae [...] has a very close analogue in a passage from Jerome's Commentaria in Naum (see appendix). The gloss might have been grouped with material from Isidore's Etymologies in a class glossary on plant names. If this gloss is more closely connected to the Isidorian material, the plant name volvus 'a type of edible bulb' may have served as a trigger. Incidentally, this word appears twice in chapter XVII (ix.88, x.19), which is heavily represented in Épinal/Erfurt and provides the source for four more of the wyn/thorn glosses: 47 alga (ix.99), 388 elleborus (ix.24), 601 lactuca (x.11), 613 lappa (ix.66). Of course, such identifications remain speculative, but in view of the heavy contribution of the Etymologies to the glossary, they don't appear to be too far-fetched.

\section{Summary and conclusion}

Investigating the glosses that use the characters wyn or thorn in the Épinal (and Erfurt) glossary demonstrates that different orthographic systems were in use among the earliest writers of Old English. The distribution of spellings shows that $\langle\mathrm{p}\rangle$ and $\langle\mathrm{p}\rangle$ are not randomly employed: first of all, wyn and thorn are not mixed with any of the alternative spellings; secondly, they can be pinpointed principally to two sources, Isidore's Etymologies and Orosius' History. This indicates that not all sets of glossae collectae that were assembled to construct the Épinal/Erfurt glossary used these characters, but that the scribe of the Épinal manuscript retained (? most of) the spellings of his immediate sources.

It should be pointed out that not all Isidore and Orosius glosses use wyn and thorn; there are various words with alternative spellings $(<\mathrm{uu}\rangle,\langle\mathrm{u}\rangle$; $\langle$ th $\rangle,\langle\mathrm{d}\rangle$ etc.) that also come from these texts. Since the digraphs appear to have been the standard

49 Porter, Isidore's Etymologiae (Anm. 10), $14 \mathrm{f}$.

50 Cartallus is regularly glossed as canistrum or cophinus, also in combination with vernacular translations: cf. Abstrusa CA 118 cartallum : canistrum; cartallum : canistrum .i. cratto (in an $11^{\text {th }}$ c. manuscript from Prague); or Cartallum, est canistrum vel cophinus, ut dicit Hugutio [bishop of Ferrara, c. 1200; gloss listed in du Cange s.v.]; incidentally, Hugutio's Liber Derivationum may very well derive directly from Isidore's Etymologies (Barney, Lewis, Beach and Berghof, The Etymologies (Anm. 13), 25). 
system used in the Épinal manuscript (cf. above), it is possible that some of the spellings were replaced in the copying process. My impression, however, is that the wyn/ thorn glosses belong to specific sections of Epinal/Erfurt, even though this assumption has to remain tentative: clearly, none of the wyn/thorn glosses occurs in the sections of Épinal that are sorted in $\mathrm{AB}$ order (which normally follow the A-order batches). Furthermore, within the A-order sections, some of the wyn/thorn words appear close to the beginning or end of the respective section (e.g. affricus, boreus, lappa) and there are several clusters of wyn/thorn interpretations. This may indicate that the glosses derive from specific sets of glossae collectae from Isidore and Orosius. Another hypothesis is that various scribes using different orthographies added interlinear glosses to the two texts, since wyn/thorn glosses also appear close to each other in the source texts of the lemmata.

Searching for the sources of the wyn/thorn glosses has opened a Pandora's box since many of the previous attributions have to be reconsidered, especially with respect to the contribution of Isidore of Seville's Etymologies. The examples presented in this paper clearly show that Pheifer's comment on a lack of extended batches from Isidore needs to be revised:

The material from these two sources [i.e. Virgil scholia and Isidore's Etymologies] is sufficient to prove independent derivation, although the absence of extended batches suggests that the compiler used short lists of glossae collectae rather than the full text of a Virgil commentary or of the Etymologies. ${ }^{51}$

However, at this stage, the exact amount of Isidorian material in Épinal/Erfurt cannot be assessed. Porter has identified "abbreviation of the Etymologiae as a general academic strategy at Canterbury" (24). More research, encompassing the entire material of Latin-Latin (or Greek-Latin) glosses, will be necessary to clarify the extent of the indebtedness of Épinal/Erfurt to Isidore. In connection with the sources of the lemmata, the relationship of vernacular and Latin interpretation should also be taken into consideration.

51 Pheifer, Old English Glosses (Anm. 2), liv. 


\section{Appendix}

Each entry includes the following information:

- number in Pheifer's (or Sweet's) edition of the Old English elements of Épinal/ Erfurt, $^{52}$

- indication of folio, columns and line in the Épinal manuscript,

- lemma and interpretation in Épinal and parallel forms of interpretation in Er(furt), C(orpus), L(eiden), a translation of the interpretation based on Bosworth \& Toller, $^{53}$ and

- the source of the lemma (Latin text of Isidore's Etymologies from Lindsay, ${ }^{54}$ translation by Barney et al. ${ }^{55}$ Latin text of Orosius' History from Zangemeister, ${ }^{56}$ translation by Fear). ${ }^{57}$

47: $1^{\mathrm{v} a b} / 28$ alga $: p \backslash$ u/aar

Er uar, C - L xlvii, 23 alga : uuac (OE wār 'sea-weed, waur')

Isidore, Etym. XVII.ix.99: Alga nascitur in aquis, segetis similis. 'Seaweed (alga) grows in water, and is like a crop of grain.'

118: $3^{\mathrm{r}} \mathrm{cd} / 25$ affricus : pestsuppind

Er uestsuduuind, C 102 pestsuðpind, L - (OE westsūp-wind 'south-west wind')

Isidore, Etym. XIII.xi.9: Africus a propria regione vocatus; in Africa enim initium flandi sumit. 'Africus is named from its particular region, for it is in Africa that it starts to blow.'

162: $3^{\mathrm{v}} \mathrm{cd} / 34$ boreus : eastnorppind

Er eustnorduind, C 312 eastnorðpind, L - (C ab borea eastannorpan - Orosius) (OE eāstnorp-wind 'north-east wind')

Isid, Etym. XIII.xi.13: Idem et Boreas, quia ab Hyperboreis montibus flat. 'It [Aquilo] is also called Boreas, because it blows from the Hyperborean mountains.'

173: $4^{\mathrm{r}} \mathrm{ab} / 1$ cartellus : pindil

Er pindil, C 348 pindil, L - (OE windel 'basket')

?Vulgate (Deut. 26:2, 4; Jer. 6:9): in cartallo / cartallum / ad cartallum

52 Pheifer, Old English Glosses (Anm. 2); Sweet, The Oldest English Texts (Anm. 26)

53 Joseph Bosworth and Thomas Toller, An Anglo-Saxon Dictionary, Oxford 1882-1921.

54 Lindsay, Isidori (Anm. 37).

55 Barney, Lewis, Beach and Berghof, The Etymologies (Anm. 13).

56 Karl Zangemeister (Hrsg.), Pauli Orosii Historiarum adversum paganos libri VII: accredit ejusdem liber apologeticus, Wien 1882 (Corpus scriptorium ecclesiasticorum latinorum 5).

57 Andy T. Fear (Hrsg.), Orosius: Seven Books of History against the Pagans, Liverpool 2010. 
388: [not in Epinal, sections containing end of C, D and E are missing in Epinal] Er elleborus : poedibergæ, C 736 pung poedeberge, L - (OE wede-berge 'plant used against madness, hellebore')

Isidore, Etym. XVII.ix.24: Elleborum memorant in Graecia circa Elleborum quondam fluvium plurimum gigni, atque inde a Graecis appellari. 'They record that much hellebore (elleborum) grows in Greece near the river Elleborum, and thence it is so called by the Greeks.' (cf. Pheifer, Old English Glosses (Anm. 2), n. 388: “? Isidore, Ety. xvii. 9/24")

444: $5^{\mathrm{r}} \mathrm{ef} / 13$ facundia : eloquentia vel poot

Er puoo/d/, C - L - (OE wōp 'voice, song, speech')

Isidore, Etym. X.171 or, more probably, VIII.vii.8: Saturici autem dicti, sive quod pleni sint omni facundia, sive a saturitate et copia [...] 'Satirists (saturicus) are so called either because they are filled with all eloquence, or from fullness (saturitas) and abundance [...]'

532: $6^{\mathrm{V}} \mathrm{cd} / 10$ interuentu : pingungae

Er ingungae, C 1093 pingunge, L - (OE pingung 'intercession, intervention')

Orosius, Hist. 3.23.66: interventu solius fidei Christianae 'only through the coming of the One True Christian Faith’ (cf. Lindsay, The Corpus, Épinal (Anm. 10), 27)

542: $6^{\mathrm{V}} \mathrm{cd} / 24$ inditas : pagisettan

Er ða gisettai, ${ }^{58} \mathrm{C} 1103$ ða gesettan, L - (OE ða demonstrative?, OE gesettan 'set, put, place')

The lemma probably derives from one of the following passages of Orosius's History: 3.23.12 colonias in Indis conditas 'the colonies established in India' (Cf. Lindsay, The Corpus, Épinal (Anm. 10), 27).

5.16.6 homines laqueis collo inditis 'the men had nooses tied round their necks'

5.18.8 ciues Romanos indicta caede iugularunt 'condemned all the Roman citizens to death and slaughtered them' (cf. Pheifer, Old English Glosses (Anm. 2), n. 542: “did the glossator's text read indictos?")

564: $7^{\mathrm{r}} \mathrm{ab} / 19$ lepor : subtilitas vel uuop

Er puod, C 1196 wooð, L xlviii, 21 leporem : decorem (OE wōp 'eloquent, lofty speech') ?Abavus glossary LE 22 lepor sermo subtilis uel leuis (cf. Pheifer, Old English Glosses (Anm. 2), n. 564)

601: $7^{\mathrm{r}} \mathrm{ef} / 18$ lactuca : pupistil

Er popistil, 1179 puðistel, L - (OE pü-pistel 'sow-thistle')

58 Pheifer has pa gisettai, Sweet $\partial a$ gisettan; the form in the manuscript is clearly $\partial a$ gisettai (fol. $\left.7^{\mathrm{r}} \mathrm{ef} / 41\right)$. 
Isidore, Etym. XVII.x.11: Lactuca dicta est quod abundantia lactis exuberet 'Lettuce (lactuca) is so called because it flows with an abundance of mild (lac, gen. lactis)' (cf. Pheifer, Old English Glosses (Anm. 2), n. 601: "confused with lactuca agrestis 'wild lettuce' (Her. 558/23, etc.) because of its white, milky juice.” The Isidore passage explains nicely why the confusion arose.)

\section{3: $7^{\mathrm{v} a b} / 12$ lappa : clipae}

Er clifae, C 1184 clibe, L xv, 36 lappa : clitę; xviii, 2 lappa : clate (OE clipe, clife 'burdock')

Isidore, Etym. xvii, 9.66: Lappa dicta quod habeat caulem ingentem per terram dispositam. 'Burdock (lappa) is so called because it has a huge stalk extending across the ground.' (cf. Porter, Isidore’s Etymologiae (Anm. 10), 27)

\section{8: $7^{\mathrm{v}} \mathrm{ef} / 16$ morgit : milcip}

Er milcid, C 1323 milcit, L - (OE meolcian 'to milk')

?Isidore, Etym. I.xxxvii.30 (on a passage from Virg., Ecl. 3, 90): Qui hos ergo diligit, faciat quae contra naturam sunt, id est, iungat vulpes et mulgeat hircos. 'Therefore, whoever loves them would do things contrary to nature, that is, he would yoke foxes and milk billy-goats.'

Cf. Jan Hendrik Hessels, An Eighth Century Latin-Anglo-Saxon Glossary Cambdridge 1890, xxxiv: " $r$ for l: M 257 (morgit for mulget)"; Pheifer, Old English Glosses (Anm. 2), n. 628: “Cf. Philox. MU 8 mulget $\alpha^{\prime} \mu \varepsilon \dot{\lambda}(y) \varepsilon ı$ [...] : morgit is one of the "purely colloquial, half-Romance forms' noted by Sweet, OET 10.”

738: $9^{\mathrm{v}} \mathrm{ab} / 11$ perduellium : porgifect

Er dorhgifecilae, C 1537 porhgefeht, L (duellionis - belli) (OE purh gefeoht 'through battle')

Orosius, Hist. 5.22.9: in tali ergo uel defectu uel perduellione sociourum 'During such a defection, or act of treason, by our allies'

Cf. Lindsay, The Corpus, Épinal (Anm. 10), 29; Pheifer, Old English Glosses (Anm. 2), n. 738: "por(h)gifect 'war' (here only) may be a nonce-word coined from perduellum."

741: $9^{\mathrm{v}} \mathrm{ab} / 16$ perseudoterum : porh ludgaet

Er dorh ludgaed, C 1538 ðorh ludgæt, L - (OE purh 'through', lud-geat 'back door') Orosius, Hist. 7.6.17 per pseudothyrum [...] euaserit 'he escaped through a secret gate' or 7.29.3 tamquam per pseudothyrum inducitur 'so to speak, inveigled [...] through a secret passage’ (Cf. Lindsay, The Corpus, Épinal (Anm. 10), 29)

757: 9vab/33 per anticipationem : porch obst

Er dorh obust, C 1546 dorh obst, L - (OE porh 'through, OE ofost 'haste')

Orosius, Hist. 6.11.17: magnisque stragibus factis [per anticipationem] plurimas praedas agit. 'After indulging in much slaughter, he [in anticipation? hurriedly??] carried off an even greater amount of booty.' 
The lemma per anticipationem only appears in certain manuscripts of Orosius's History $\left(\mathrm{R}^{2}=\right.$ Rehdigeranus $108,9^{\text {th }} \mathrm{c}$., $\mathrm{T}=$ Monacensis $6380,10^{\text {th }} / 11^{\text {th }} \mathrm{c}$., $\mathrm{Z}=$ Leningradensis FV 1 n. 9, $1^{\text {st }}$ half $9^{\text {th }}$ c.; cf. Zangemeister 386) as well as in the editio princeps from 1471 , which is based on manuscript $X^{2}=$ Monacensis $22025,11^{\text {th }} / 12^{\text {th }}$ century (cf. Marie-Pierre Arnaud-Lindet (Hrsg.), Orose: Histoires (Contre les Païens), 3 Bde, Paris 1990, xcv). The lemma of gloss 769 pice sebo also derives from Orosius 6.11 (see below).

Lindsay, The Corpus, Épinal (Anm. 10), 29) lists this gloss among the Orosius words, but does not indicate a particular passage; Pheifer, Old English Glosses (Anm. 2), n. 757 tentatively identifies Augustine, Quaestiones in Heptateuchum, ii. 177.4 as a source.

760: $9^{\mathrm{v}} \mathrm{cd} / 8$ per uispellones : porçh by $\mid r /$ geras (c erased but still visible)

Er dorh buyrgenas, C 1547 ðorh byrge[ras], L - (OE byrgere 'burier')

Orosius, Hist. 7.10.7: cuius cadauer populari sandapila per uespillones exportatum 'His body was carried out in a pauper's coffin by the public pall-bearers' (Cf. Lindsay, The Corpus, Épinal (Anm. 10), 29)

763: $9^{\mathrm{v}} \mathrm{cd} / 14$ perpendiculum : colpred

Er coldraed, C 1548 colðred, L 36 perpendiculum ... : pundar (OE col-præd 'coal thread, plumb-line')

Isidore, Etym. XIX.xviii.1/2 Perpendiculum est quod semper adpenditur. 'The plumbline (perpendiculum) is so named because it is always set to hang down (apendere).'

769: $10^{\mathrm{r}} \mathrm{ab} / 32$ pice seuo : unamaelti sperpi

Er cinamelti spreui, C 1581 unamaelte smeoruue, L - (OE un-amelt 'unmelted', OE smeru 'tallow')

Orosius, Hist. 6.11.26: cupas pice sebo et scindulis repletas 'they filled barrels with pitch and tallow'

845: $11^{\mathrm{r}} \mathrm{ef} / 17$ quoquo modo : aengi pinga

Er aengi dinga, C 1701 aenge pinga, L - (OE ǣnig 'any', ping 'thing')

Isidore, Etym. V.xxvii.3: Supplicium proprie dictum non qui quoquo modo punitur, sed ita damnatur ut bona eius consecrentur in publico redigantur. 'The term penalty (supplicium), strictly speaking, is not used with regard to someone who is punished in any way at all, but with regard to one who is sentenced in such a way that his goods are "set apart as sacred" (consecrare) and are paid into the public treasury.' Or possibly Isidore, Etym. XVI.xv.11: In maleficiis quoquo modo inferatur discordias excitat. 'However it [sideritis] is introduced into magical practices, it arouses disagreement.'

846: $11^{\mathrm{r}} \mathrm{ef} / 18$ quin etiam : aec pan

Er aec don, C 1695 aec ठon, L - (OE eac pan 'in addition to that') 
Isidore, Etym. XVI.ii.6: Quin etiam pecudes, armenta et iumenta sale maxime provocantur ad pastum. 'And even livestock, flocks, and beasts of burden are called to pasture particularly with salt.'

1014: $14^{\mathrm{r}} \mathrm{ab} / 15 \mathrm{a}$ talpa : pand

Er uuond, C 1973 pond, L 227 talpa : uoond (OE wond 'a mole')

Isidore, Etym. XII.iii.5: Talpa dicta, quod sit damnata caecitate perpetua tenebris [...]. 'The mole (talpa) is so called because it is condemned to perpetual blindness in the dark (tenebrae).'

1037: $14^{\mathrm{r}} \mathrm{cd} / 2$ tantisper : pus suipae

Er dus suidae, C 1982 ðus suiðe, L - (OE pus swiðe 'so much')

?Orosius, Hist. 3.15.3: Pontius dux eorum in tantum abusus est uictoriae securitate 'their commander Pontius was so sure of his victory' (cf. Pheifer, Old English Glosses (Anm. 2), n. 1037: "? A gloss on Orosius iii. 15/3 in tantum abusus est: cf. Cyrillus 300/ 46 Év $\tau o \sigma o u ́ \tau \omega$... in tanto tantisper.”)

The exact lemma tantisper does not occur in Orosius, though it is listed in Lindsay's T-batch (Lindsay, The Corpus, Épinal (Anm. 10), 30) with the label “frequent”.

1059: $14^{\mathrm{v} a b} / 21$ uoluola : piupindae herba similis hederae quae u[i]tibus et frugibus cicumdari solet

Er uuidubindae, C 2158 uuduuuinde, L involuco : uudubindlae (OE wudu-winde 'woodbine')

Hieronymus, Commentaria in Naum, 1:10: Volvola [Al. Vulvula] autem herba est similis hederae, quae vitibus et virgultis circumdari solet, et in longum serpere. (Migne, PL 25, 1239)

In my view, both lemma and the Latin part of the interpretamentum are based on the above passage from Jerome's commentary in Naum and not, as suggested by Pheifer, on Pliny xxi.23: est flos non dissimilis (lilio) herba quam conuoluolum uocant, nascens per fructeta (quoted in Pheifer, Old English Glosses (Anm. 2), n. 1059).

1068: $14^{\mathrm{v} a b} / 33$ uertigo : edpalla

Er edualla, C 2096 eduuelle, L xlvii, 16 vertigo : edualle (OE ed-wille 'a whirlpool') Isidore, Etym. IV.vii.3: Vertigo autem est quotienscumque ventus consurgit, et terram in circuitum mittit. 'Vertigo ("spinning") occurs whenever the wind rises and sends the earth into a spin.'

1071: $14^{\mathrm{v} a b} / 37$ uespas : paeffsas

Er uuaeps, C 2098 uuaefsas, L - (OE wæps 'a wasp')

Isidore, Etym. XII.viii.4: Vespae ... 'Wasps (vespa) ...' (or viii.2)

1093: $14^{\mathrm{v}} \mathrm{cd} / 31$ uitiato oculo : unpyctgi egan

Er undyctis ægan C 2133 unðyhtge egan, L - (OE unpyhtig eāgan 'weak eyes') 
Orosius, Hist. 4.6.38: qui uitioso oculo haec uident 'For they perceive these present troubles with diseased eyes' (cf. Otto B. Schlutter, Weitere Beiträge zur altenglischen Wortforschung. Altenglische Entlehnungen aus dem Keltischen, in: Anglia 36 (1912), 59-78, at 69 n5; Pheifer, Old English Glosses (Anm. 2), n. 1093) 


\section{Tradieren}





\title{
Julian Führer
}

\section{Verbrannte Steuerliste oder zerstörte Verwaltung?}

\section{Zum Umgang mit Verwaltungswissen im merowingischen Frankenreich}

\begin{abstract}
This paper seeks to examine the extent to which, in the Merovingian period, the Roman administration system was still intact. The focus lies on tax administration and the knowledge connected with it. The author analyses relevant accounts in Gregory of Tours and Fredegar and reaches the conclusion that Merovingian kings adopted the late Roman system of taxation on a large scale.
\end{abstract}

Factum est autem, in diebus illis exiit edictum a Caesare Augusto, ut describeretur universus orbis. Haec descriptio prima facta est praeside Syriae Quirino. Et ibant omnes, ut profiterentur, singuli in suam civitatem. ${ }^{1}$ Das Lukasevangelium beginnt seinen wohl bekanntesten Abschnitt mit der Erwähnung einer Veranlagung der Bevölkerung. Diese descriptio fand regelmäßig statt und ist insofern ein Vorgang mit viel Routine. Gerade deshalb lassen sich an diesem Prozess Vorgänge der schrittweisen Anpassung an veränderte Rahmengegebenheiten untersuchen. Wie wurde ein solches Wissen über die Verhältnisse der Bevölkerung generiert? Wie wurde mit solchen Dokumenten, denn es handelt sich notwendig um eine schriftliche Fixierung zu Zwecken der Steuererhebung, in dieser Zeit umgegangen? Können wir im Untersuchungszeitraum, der Spätantike und Frühmittelalter umfasst, von Vernichtung oder gar Verdichtung von steuerlicher Administration sprechen?

Der Streit, inwieweit sich römische Verwaltungsstrukturen erhalten haben, ist alt und nicht entschieden; letztlich handelt es sich um einen Zweig der großen Debatte um Bruch oder Kontinuität zwischen Spätantike und Mittelalter. ${ }^{2}$ Auf der einen Seite

Ich danke Dr. Martin Heinzelmann (Paris) für wertvolle Hinweise.

1 Lk 2,1-3 („In jenen Tagen erließ Kaiser Augustus den Befehl, alle Bewohner des Reiches in Steuerlisten einzutragen. Dies geschah zum erstenmal; damals war Quirinius Statthalter von Syrien. Da ging jeder in seine Stadt, um sich eintragen zu lassen.“). Übersetzung: Neue Jerusalemer Bibel, Freiburg 2000, 1461.

2 Hierzu ist eine Fülle an Literatur erschienen, die aber aufgrund der schwankenden Kategorienbildung, was jeweils spezifisch antik und mittelalterlich sei, kaum zu befriedigenden Ergebnissen führen kann. Exemplarisch: Paul Egon Hübinger (Hrsg.), Zur Frage der Periodengrenze zwischen Altertum und Mittelalter, Darmstadt 1969 (Wege der Forschung 51). Auf neuer Basis: Alexander Demandt, Die Zeitenwende von der Antike zum Mittelalter, in: Von der Spätantike zum frühen Mittelalter: Kontinuitäten und Brüche, Konzeptionen und Befunde, hrsg. von Theo Kölzer und Rudolf Schieffer, Ost- 
stehen diejenigen, die den größtmöglichen Bruch postulieren, gerne unter Verweis auf die von den germanischen Horden angerichteten Verwüstungen; auf der anderen Seite wird angenommen, es habe eine sehr starke Kontinuität gegeben, die germanischen Verbände von Franken, Goten und anderen seien letztlich längst römisch sozialisierte Gruppen, die in römischen Diensten einem Akkulturationsprozeß unterworfen gewesen seien. ${ }^{3}$ Es gibt immer einen gewissen Grad an Kontinuität und immer einen gewissen Grad an Wandel, es kommt auf die Gewichtung und auf die Perspektive an. Für die Frage des Übergangs von spätantiker Verwaltung und Steuerwesen zum Frühmittelalter gerade in Gallien sind regionale Unterschiede zwischen Nord und Süd stark in bezug auf das Fortleben von Strukturen diskutiert worden, hier ging es immer wieder um die Gesta municipalia und die Frage, wie sich der Übergang von einer Art kommunal organisierten, aber auf einer höheren Ebene angeordneten Schriftlichkeit mit öffentlicher Archivierung zu einer Archivierung beim Empfänger gestaltete. ${ }^{4}$ Besonderes Augenmerk auf die Kontinuität der öffentlichen Finanzen hat vor bald hundert Jahren Alfons Dopsch gelegt. ${ }^{5}$ Für einen drastischen Bruch im Steuerwesen hat sich hingegen vor allem Ferdinand Lot ausgesprochen; ${ }^{6}$ mittlere Positionen, die Wandel und Kontinuität gewichten, nehmen am ehesten Reinhold Kaiser und Walter Goffart ein. ${ }^{7}$ Jean Durliat verlieh der Diskussion im Jahr 1990 mit der Annahme ganz

fildern 2009 (Vorträge und Forschungen 70), 17-34; neuerdings Mischa Meier, Ostrom - Byzanz, Spätantike - Mittelalter. Überlegungen zum „Ende“ der Antike im Osten des Römischen Reiches, in: Millennium 9 (2012), $187-254$.

3 Nach einem gewissen Überwiegen der Kontinuitätsthese mit als wohl sichtbarstem Ertrag einer vielbändigen Reihe „The Transformation of the Roman world“ (14 Bände, 1997 - 2004), die mit Mitteln der Europäischen Wissenschaftsstiftung gefördert wurde, wurde von John. B. Ward-Perkins, The fall of Rome and the end of civilization, Oxford 2005 und Peter Heather, The fall of the Roman Empire, London 2005, wieder das Vernichtungsparadigma in die Diskussion eingebracht, allerdings nicht ohne lebhaften Widerspruch hervorzurufen.

4 Kürzlich erschienen ist eine Studie von Josiane Barbier, die von einer erheblichen Kontinuität dieser Art Verwaltungsführung im merowingerzeitlichen Gallien ausgeht, vgl. Josiane Barbier, Archives oubliées du haut Moyen Âge. Les gesta municipalia en Gaule franque (VI ${ }^{\mathrm{e}}$ IX ${ }^{\mathrm{e}}$ siècle), Paris 2014 (Histoire et archives 12). $\mathrm{Zu}$ diesem Komplex jüngst auch der Band Documentary Culture and the Laity in the Early Middle Ages, hrsg. von Warren C. Brown, Marios Costambeys, Matthew Innes und Adam J. Kosto, Cambridge 2013, und dort vor allem die Beiträge von Nicholas Everett, Lay documents and archives in early medieval Spain and Italy, c. 400-700, 63-94, und Warren C. Brown, The gesta municipalia and the public validation of documents in Frankish Europe, 95-124.

5 Alfons Dopsch, Wirtschaftliche und soziale Grundlagen der europäischen Kulturentwicklung aus der Zeit von Caesar bis auf Karl den Großen, 2 Bde., 2. Auflage, Wien 1923-1924.

6 Ferdinand Lot, L'impôt foncier et la capitation personnelle sous le Bas-Empire et à l'époque franque, Paris 1928 (Bibliothèque de l'École des Hautes Études. Sciences historiques et philologiques 253). Lot hat seine Argumente infolge der Forschungskontroverse noch einmal aktualisiert, vgl. Ferdinand Lot, Nouvelles recherches sur l'impôt foncier et la capitation personnelle sous le Bas-Empire. Complément au fascicule CCLIII de la Bibliothèque de l'École des Hautes Études, Paris 1955 (Bibliothèque de l'École des Hautes Études. Sciences historiques et philologiques 304).

7 Reinhold Kaiser, Steuer und Zoll in der Merowingerzeit, in: Francia 7 (1979), 1-17; Walter Goffart, Old and New in Merovingian Taxation, in: Past and Present 96 (1982), 1-21. 
neuen Schub, es habe sehr viel weitreichendere Kontinuitäten gegeben, als bislang angenommen wurde. ${ }^{8}$ Nun ist 2012 eine Studie von Élisabeth Magnou-Nortier erschienen, die in großer Breite noch einmal das ganze Dossier aufarbeitet, ${ }^{9}$ so dass hier nicht die gesamte Frage von Kontinuität und Wandel, gegebenenfalls eingeschränkt auf das breite Feld der Administration, behandelt werden kann. ${ }^{10}$ Vielmehr soll die Fragestellung speziell das Verwaltungswissen ins Blickfeld nehmen: Wer verfügte über das nötige Wissen, wer generierte es, wer konnte es verändern, welche Aushandlungsprozesse treten uns aus den Quellen des Frühmittelalters entgegen?

Ein weströmisches Reich als Zentralinstanz hat es nach 476 in der hergebrachten Form nicht mehr gegeben. Was trat an seine Stelle? Wurden die Bewohner nicht mehr in Steuerlisten eingetragen? In der Spätantike wurde, zumindest vom Anspruch her, regelmäßig veranlagt, darüber sind wir recht gut informiert. ${ }^{11}$ Allerdings waren ganze Bevölkerungsgruppen von der Zahlung von Steuern ausgenommen, so dass es immer wieder Konflikte darum gab, ob nun eine Steuerpflicht bestand oder nicht. ${ }^{12}$ Die Bewohner Roms genossen Steuerbefreiung, ein Infragestellen dieses Privilegs wurde als ungeheuerlich dargestellt. ${ }^{13}$ Im Frankenreich stellten sich in diesem Zusammenhang

8 Jean Durliat, Les finances publiques de Dioclétien aux Carolingiens (284-889), Sigmaringen 1990 (Beihefte der Francia 21). Vgl. zur sich ergebenden Diskussion um Durliats These Wolf Liebeschütz, Cities, taxes, and the accomodation of the barbarians. The theories of Durliat and Goffart, in: Kingdoms of the Empire. The Integration of Barbarians in Late Antiquity, hrsg. von Walter Pohl, Leiden / New York / Köln 1997 (The Transformation of the Roman World 1), 135-151.

9 Élisabeth Magnou-Nortier, Le système fiscal et sa gestion dans le royaume des Francs à l'épreuve des sources ( $\mathrm{V}^{\mathrm{e}}-\mathrm{XI}$ siècles), Genève 2012.

10 Für das Gebiet Galliens vgl. die Beiträge von Jean Vezin (L'influence des actes des hauts fonc-

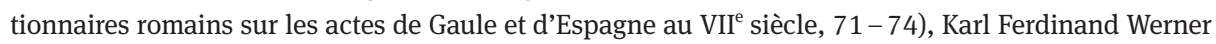
(Missus - marchio - comes. Entre l'administration centrale et l'administration locale de l'Empire carolingien, 191-239) und Reinhold Kaiser (Teloneum episcopi. Du tonlieu royal au tonlieu épiscopal dans les civitates de la Gaule (VI ${ }^{\mathrm{e}}$ - XII ${ }^{\mathrm{e}}$ siècle), 469-485), in: Histoire comparée de l'administration, hrsg. von Werner Paravicini und Karl Ferdinand Werner, München / Zürich 1980 (Beihefte der Francia 9).

11 Arnold H. M. Jones, The Later Roman Empire, 284-601: A Social, Economic and Administrative Survey, 3 Bde., Oxford 1964 ist immer noch der Ausgangspunkt für die Auseinandersetzung mit den wirtschaftlichen Gegebenheiten des spätrömischen Reiches; zum Spezialproblem vgl. Ernest Stein, Histoire du Bas-Empire, Bd. 1: De l'État romain à l’État byzantin, Paris 1959, 73 - 76, 115 - 117, 195 197, 220 - 224; Alexander Demandt, Die Spätantike. Römische Geschichte von Diocletian bis Justinian, $284-565$ n.Chr., 2. Auflage, München 2007 (Handbuch der Altertumswissenschaft III,6), 294296.

12 Der Codex Theodosianus (Theodosiani libri XVI cum constitutionibus Sirmondianis, hrsg. von Theodor Mommsen und Paul Krüger, Berlin 1904), XIII,10,2 von 313 z. B. legt fest, dass wie bereits in den östlichen Provinzen und wie schon unter Diocletian üblich die römische plebs von der capitatio ausgenommen sein sollte. Zum Problemfeld des Fiskalrechts und der Migration vgl. John H.W.G. Liebeschuetz, Cities, taxes, and the accomodation of the barbarians, in: From Roman provinces to Medieval Kingdoms, hrsg. von Thomas F.X. Noble, London 2006, 309-324.

13 Laktanz, De mortibus persecutorum. Die Todesarten der Verfolger, hrsg. von Alfons Städele, Turnhout 2003 (Fontes Christiani 43), 26,2, 160: Cum statuisset censibus institutis orbem terrae de- 
natürlich andere Probleme: Wer war steuerpflichtig, in welcher Höhe, welche Steuern und Abgaben wurden in welcher Form eingetrieben, und vor allem - wie wurde das erforderliche Verwaltungswissen generiert? Es wird wohl wie im römischen Reich bei der Besteuerung hauptsächlich in Naturalien geblieben sein, allerdings war dafür in der Spätantike der Prätorianerpräfekt gemäß den Weisungen des Kaisers zuständig, was sich in späterer Zeit natürlich änderte. ${ }^{14}$ Die Buchführung über Veranlagung, Forderungen und Zahlungen erforderten schriftliche Dokumentation bei der Verwaltung ebenso wie bei Steuerpflichtigen zur Abwehr allfälliger ungerechtfertigter Forderungen. ${ }^{15}$

Hauptertragssteuer war seit Diocletian, also seit etwa 300, die annona, Hauptbemessungsgrundsatz die capitatio-iugatio, eine kombinierte Kopf- und Besitzsteuer; seit 312 fand die Feststellung des Gesamtbedarfs an Steuern (Indiktion) alle 15 Jahre statt. ${ }^{16}$ Gerade diese Neuveranlagung durch Diocletian, wir würden es wohl eine große Steuerreform nennen, fand natürlich viele Gegner und wurde dem Kaiser, dessen Bild in späteren Jahrhunderten ohnehin das eines üblen Christenverfolgers war, als weitere Untat vorgeworfen. Die Ablieferung in Naturalien wich nach erfolgter Stabilisierung der Währung im 4. und 5. Jahrhundert zunehmend einer Zahlung über in Geld (adaeratio). ${ }^{17}$ Gleichzeitig wurde die Leistungspflicht auch über andere Abgabeformen erfüllt. $^{18}$

Was war hierbei im Frühmittelalter anders? Zunächst einmal ist nicht davon auszugehen, dass die römische Rechtstradition über Nacht verschwand, in Vergessenheit geriet oder vernichtet wurde. ${ }^{19}$ Es ist hinlänglich bekannt, dass die sogenannten Leges barbarorum wie die Lex Salica mehr oder weniger stark auf den

vorare, ad hanc usque prosiluit insaniam, ut ab hac captivitate ne populum quidem Romanum fieri vellet inmunem. Ordinabantur iam censitores, qui Romam missi describerent plebem.

14 Demandt, Spätantike (Anm. 11), 294, vgl. CodTh I,5,6, I,5,7.

15 Auf beiden Seiten haben sich punktuell Dokumente erhalten, vgl. z. B. CodTh XI,1,13 und dazu mit Belegen aus einer Region mit etwas günstigeren Überlieferungsbedingungen Jonathan Conant, Public administration, private individuals and the written word in Late Antique North Africa, c. 284 - 700, in: Documentary Culture (Anm. 4), 36-62, hier 47.

16 Demandt, Spätantike (Anm. 11), 294-295.

17 Diese Tendenz ist bereits in Italien zur Zeit Odoakers festzustellen, vgl. Ernest Stein, Histoire du BasEmpire, Bd. 2: De la disparition de l'empire d'Occident à la mort de Justinien (476-565), Paris / Bruxelles / Amsterdam 1949, 199, und wird nun allgemein für die Spätantike seit der Stabilisierung der Währung angenommen, vgl. Demandt, Spätantike (Anm. 11), 294 und Hartmut Galsterer, Art. Steuern IV. Rom, in: Der Neue Pauly 11 (2001), 982 - 986, hier 984. Die Quellen zur adaeratio bei Otto Seeck, Adaeratio, in: RE I,1 (1893), 340-341.

18 Stefan Esders, „Öffentliche“ Abgaben und Leistungen im Übergang von der Spätantike zum Frühmittelalter: Konzeptionen und Befunde, in: Von der Spätantike (Anm. 2), 189-244.

19 Stefan Esders, Römische Rechtstradition und merowingisches Königtum. Zum Rechtscharakter politischer Herrschaft in Burgund im 6. und 7. Jahrhundert, Göttingen 1997 (Veröffentlichungen des Max-Planck-Instituts für Geschichte 134). 
Grundlagen des römischen Vulgarrechts standen. ${ }^{20}$ Bei der Lex Romana Visigothorum und der Lex Romana Burgundionum erscheint die Verbindung zur römischen Rechtstradition bereits im Titel. Die Jurisprudenz stand, wie Detlef Liebs eindrucksvoll gezeigt hat, in den westlichen Nachfolgereichen des Imperium Romanum während langer Zeit auf der Basis der spätantiken Kodifikationen wie des Codex Theodosianus und des Codex Iustinianus und wurde weiterhin gepflegt, auch wenn unter den Theodosiani libri in unseren Quellen wahrscheinlich eher Breviarhandschriften als Volltexte zu verstehen sind. ${ }^{21}$ Es sei darauf verwiesen, dass die frühesten Handschriften zumindest des Codex Theodosianus aus Epochen und Regionen überliefert sind, in denen zum Schreibzeitpunkt wohl schon Franken, Goten, Langobarden oder andere Verbände die römische Herrschaft abgelöst hatten. ${ }^{22}$

Die Steuerlast wurde in der Spätantike in den uns erreichbaren erzählenden Quellen allgemein als drückend empfunden. Heißt das, dass dem so war? Wahrscheinlich wird es allgemein schwierig, Quellen $\mathrm{zu}$ finden, die eine bestehende Steuerlast als angemessen oder gar zu leicht bezeichnen, ganz gleich aus welcher Epoche. Für die Spätantike jedoch erscheint recht deutlich, dass die Rahmenbedingungen tatsächlich ungünstig waren. Die erforderlichen Summen für den Unterhalt

20 Zum Begriff des Vulgarrechts vgl. Ernst Levy, Weströmisches Vulgarrecht: Das Obligationenrecht, Weimar 1956 (Forschungen zum römischen Recht 7); Franz Wieacker, Recht und Gesellschaft in der Spätantike, Stuttgart 1964 (Urban-Bücher 74), 38. Zum Fortleben des römischen Rechts in den Leges vgl. etwa Harald Siems, Zum Weiterwirken römischen Rechts in der kulturellen Vielfalt des Frühmittelalters, in: Leges - Gentes - Regna. Zur Rolle von germanischen Rechtsgewohnheiten und lateinischer Schrifttradition bei der Ausbildung der frühmittelalterlichen Rechtskultur, hrsg. von Gerhard Dilcher und Eva-Marie Distler, Berlin 2006, 231-255.

21 Vgl. z. B. den Eintrag im Bibliothekskatalog von St. Gallen aus der Mitte des 9. Jahrhunderts (St. Gallen, Stiftsbibliothek, Cod. Sang. 728, 17), Mittelalterliche Bibliothekskataloge Deutschlands und der Schweiz, Bd. 1: Die Bistümer Konstanz und Chur, bearb. von Paul Lehmann, München 1918, 79 mit dem Abschnitt De legibus und dort als erstem Eintrag Lex Theodosiana, lex Ermogeniana, lex Papiani, lex Francorum, lex Alamannorum in volumine I.Vgl. auch Detlef Liebs, Römische Jurisprudenz in Gallien (2. bis 8. Jahrhundert), Berlin 2002 (Freiburger rechtsgeschichtliche Abhandlungen, neue Folge 38), 97 99 über die Greifbarkeit des Codex Theodosianus in Gallien.

22 Eine sehr nützliche Übersicht bietet hierzu die „Bibliotheca legum. Eine Handschriftendatenbank zum weltlichen Recht im Frankenreich“, die unter der Leitung von Karl Ubl entstanden ist (http://www. leges.uni-koeln.de/lex/codex-theodosianus/) [18.9.2013]. Hier die mutmaßliche Herkunft der vorkarolingischen Handschriften und Handschriftenfragmente des Codex Theodosianus: Berlin, Staatsbibliothek Preußischer Kulturbesitz, Phillips 1745 (7. Jh., Lyon oder Burgund), Exzerpte aus Codex Theodosianus und Constitutiones Sirmondianae; Halberstadt, ehem. Bibliothek des Domgymnasiums, Frg, 1 (5. Jh., Norditalien); Paris, Bibliothèque nationale de France, lat. 8907 (ausg. 5.-7. Jh, Norditalien?), Exzerpte aus Codex Theodosianus; Paris, Bibliothèque nationale de France, lat. 9643 (6. Jh., Lyon), Codex Theodosianus VI-VIII; Turin, Biblioteca Nazionale Universitaria, A.II.2 (5.-8. Jh., Frankreich und Italien?), Codex Theodosianus XIV-XVI (Palimpsest, 1904 verbrannt); Vatikan, Biblioteca Apostolica Vaticana, Reg. lat. 886 (6. Jh., Italien oder Lyon?), Codex Theodosianus IX-XVI; Vatikan, Biblioteca Apostolica Vaticana, lat. 5766 (7.-8. Jh.), Codex Theodosianus Fragmente, Palimpsest, zur Turiner Handschrift gehörend; Zürich, Staatsarchiv C VI 3 (5./6. Jh., Gallien oder Italien), Fragmente von Codex Theodosianus X. 
von Verwaltung und Heer waren enorm, gleichzeitig mussten die Kurialen in den Civitates für die Abführung der veranlagten Steuersummen an die Zentralverwaltung garantieren, ${ }^{23}$ so dass im Falle von Schwierigkeiten bei der Steuererhebung die Kurialen mit ihrem eigenen Vermögen einstehen mussten, nicht selten bis zu ihrem eigenen Ruin. ${ }^{24}$ Natürlich war es in einer solchen Gesellschaft nicht mehr wie zuvor erstrebenswert, zu den Kurialen, also den städtischen Honoratioren zu gehören, weshalb diese Position nun erblich wurde und der diesen Stand betreffende Abschnitt im Codex Theodosianus nicht weniger als 192 Abschnitte enthält; ${ }^{25}$ es wird deutlich, dass der administrative Rahmen den gegebenen Realitäten nicht mehr genügte. ${ }^{26}$ Entsprechend versuchten sich die Kurialen oder Decurionen, sich ihren Ämtern durch Flucht aufs Land zu entziehen. ${ }^{27}$ Kolonen ihrerseits desertierten förmlich von den ihnen zugewiesenen Ländereien, so heißt es. ${ }^{28}$ Einem Sinken der Ertragsangabe infolge der Aufgabe der Bewirtschaftung durch die Eigentümer begegnete man Ende des 4. Jahrhunderts mit einer Übertragung der darauf liegenden Forderungen auf das Gesamtvermögen der Steuerpflichtigen. ${ }^{29}$ Wenn das Steueraufkommen durch eine Änderung in der Veranlagung oder die Flucht von Decurionen gesunken war, gab es das Instrument der zusätzlichen Zwangssteuern. ${ }^{30}$ Entsprechend wurde das Verhalten der Decurionen als Willkür wahrgenommen, und man muss annehmen, dass es zwischen der letztlich abgeführten Summe und dem, was die Decurionen effektiv

23 CodTh XI,1,15 (366), vgl. Demandt, Spätantike (Anm. 11), 295.

24 Manfred Fuhrmann, Rom in der Spätantike, Reinbek bei Hamburg 1996, 29-30.

25 CodTh XII,1, De decurionibus. Vgl. zum Gesamtkomplex Hermann-Josef Horstkotte, Die „Steuerhaftung“ im spätrömischen „Zwangsstaat“, 2. Auflage, Frankfurt/Main 1988 (Beiträge zur klassischen Philologie 185), 98.

$26 \mathrm{Zu}$ den Transformationen und den Möglichkeiten, die sich für Amtsträger dennoch ergaben, vgl. Avshalom Laniado, Recherches sur les notables municipaux dans l'empire protobyzantin, Paris 2002 (Travaux et mémoires du Centre de recherche d'histoire et civilisation de Byzance. Monographies 13). 27 Vgl. z. B. Zosimos (um 500), Historia nea II,38, in: Zosime, Histoire nouvelle, hrsg. von François Paschoud, Bd. 1, Paris 1971, 111 - 112, der über Constantin berichtet, dieser habe das Vermögen der

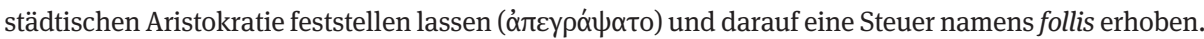
Da diese Steuer auch über Constantins Tod hinaus erhoben worden sei, hätten sich die Städte entvölkert. Gerade in bezug auf Kaiser Constantin ist bei Zosimos natürlich quellenkritische Distanz angebracht; terminologisch entspricht die Wortwahl des Zosimos dem lateinischen describere. Vgl. zum Phänomen als solchem Kaiser, Steuer und Zoll (Anm. 7), 3; Horstkotte, „Steuerhaftung“ (Anm. 25), 105 -110; nuancierend: Christian Witschel, Sterbende Städte? Betrachtungen zum römischen Städtewesen in der Spätantike, in: Schrumpfende Städte. Ein Phänomen zwischen Antike und Moderne, hrsg. von Angelika Lampen und Armin Owzar, Köln 2008, 17 - 78.

28 Laktanz, De mortibus persecutorum 7,3, S. 104: Adeo maior esse coeperat numerus accipientium quam dantium, ut enormitate indictionum consumptis uiribus colonorum desererentur agri et culturae uerterentur in siluam. Ebenso wie Zosimos gegenüber Constantin ins Negative übertreibt, so tut Laktanz dies hier wohl gegenüber Diocletian.

29 CodTh XIII,11,4 (393), vgl. Horstkotte, „Steuerhaftung“ (Anm. 25), 80.

30 Vgl. Ammianus Marcellinus XVII,3,2-4: [Über den Caesar Julian] Cumque Florentius praefectus praetorio cuncta permensus, ut contendebat, quidquid in capitatione deesset, ex conquisitis se supplere firmaret, talium gnarus animam prius amittere quam hoc sinere fieri memorabat. 
eingenommen haben, mitunter auch eine Differenz zugunsten der Steuereintreiber gegeben haben mag. ${ }^{31}$ Salvian von Marseille beschrieb dies für seine Region, wobei er die Erhebungspraxis als willkürlich geißelte und besonders darüber klagte, dass subalterne niedere Verwaltungsleute und Kuriale die Sätze festlegten und sich so letztlich in eine Position begaben, die ihnen nicht zustand. ${ }^{32}$ In der Praxis erwies sich, dass nicht alle Forderungen realisierbar waren, und so wurden offene Steuerforderungen während fünf bis sechs Jahren aufrechterhalten und dann amnestiert. ${ }^{33}$

An die praefecti praetorio war im Jahr 365 das ausdrückliche Verbot ergangen, eigenmächtige zusätzliche Steuerforderungen zu erheben. ${ }^{34}$ Die Veranlagung und die Steuereintreibung wurden offenbar bei Bedarf gewaltsam durchgeführt, wie mehrere Quellen berichten, und zwar sowohl heidnische als auch christliche Quellen, die über einen weiten Zeitraum der Spätantike hinweg in verschiedenen Regionen entstanden, so etwa der Christ Laktanz in De mortibus persecutorum von Beginn des 4. Jahrhunderts, der Heide Ammianus Marcellinus in den Res gestae von Ende des 4. Jahrhunderts und der Kirchenschriftsteller Theodoret (Mitte 5. Jahrhundert) in der Historia religiosa. ${ }^{35}$ Gemeinsam dürfte diesen Quellen und ihren Urhebern wohl der allgemeine Unwille zum Abführen von Steuern in einem „Zwangsstaat“36 gewesen sein, aber auch eine sich jeweils aus dem gesellschaftlichen und religiösen Umfeld der Urheber ergebende Distanz zum Herrscher. ${ }^{37}$ Eine Veranlagung der römischen Bevölkerung, wie

31 Stein, Bas-Empire, Bd. 1 (Anm. 11), 195. Abgesehen von der möglichen Topik der Klage über Steuereintreiber ist hier auf CodTh XII,1,117 zu verweisen, in dem Kaiser Theodosius 381 diese Art der Bereicherung mit einer schweren Strafandrohung belegt: Quilibet principalium vel decurionum vel decoctor pecuniae publicae vel fraudulentus in adscribtionibus inlicitis vel inmoderatus in exactione fuerit inventus, iuxta pristinam consuetudinem non solum a vobis, quibus propter loci dignitatem rerum summa commissa est, verum a iudicibus ordinariis plumbatarum ictibus subiciatur.

32 Salvian von Marseille, De gubernatione Dei, 17-18 (Salvien de Marseille, Euvres, Bd. 2: Du gouvernement de Dieu, hrsg. von Georges Lagarrigue, Paris 1975 (Sources chrétiennes 220): Illud est grauis quod plurimi proscribuntur a paucis, quibus exactio publica peculiaris est praeda, qui fiscalis debiti titulos faciunt quaestus esse priuatos; et hoc non summi tantum, sed paene infimi, non iudices solum, sed etiam iudicibus obsequentes. Quae enim sunt non modo urbes sed etiam municipia atque uici, ubi non quot curiales fuerint, tot tyranni sunt?

33 Conant, Public administration (Anm. 15), 58 mit mehreren Belegen des beginnenden 5. Jahrhunderts.

34 CodTh XI,16,11 (365): Nihil a provincialibus extraordinaria patimur indictione deposci (an den praefectus praetorio Secundus).

35 Laktanz, mort. pers. 23, 152 (zu Diocletian, mit den oben Anm. 28 genannten quellenkritischen Reserven); Amm. XXII,16,23 (über die Ägypter): erubescit apud eos, si qui non infitiando tributa plurimas in corpore uibices ostendat, Theodoret, Historia religiosa 17.

36 Horstkotte, „Steuerhaftung“ (Anm. 25), 20 analysiert die einer solchen Terminologie zugrundeliegenden, nicht immer zutreffenden Vorannahmen; vgl. ebd. 26: „Steuerforderungen waren und sind grundsätzlich unpopulär.“

37 Hartmut Galsterer, Art. Steuern IV. Rom, in: Der Neue Pauly 11 (2001), 982-986, hier 984 bezweifelt ebenfalls die Unmäßigkeit der Steuerforderungen: „Die vielen überlieferten Klagen hängen wohl einerseits mit der hochbürokratisierten Art der Eintreibung zusammen, andererseits mit der veränderten Quellenlage für diese Zeit, die nun auch die Sicht von unten spiegelt.“ Ob Laktanz und 
sie Laktanz als ungehemmte Gewaltorgie zügelloser Schergen des maßlosen Christenverfolgers Diocletian beschreibt, zog sich über mehrere Jahre hin, entsprang aber einem wohl kaum bestrittenen Rechtserfordernis. ${ }^{38}$ Wenn die angelegten Kataster ihre Gültigkeit nach einem bestimmten Zeitraum verloren hatten, waren sie gemäß einer Weisung des Codex Theodosianus öffentlich zu verbrennen. ${ }^{39}$

Veränderte sich das Prozedere nun wesentlich, als nicht mehr die römischen Kaiser und ihre Präfekten, sondern die fränkischen Könige und ihre Verwaltungsleute für die Steuererhebung zuständig waren? Der zeitliche Abstand zwischen den spätantiken Quellen des 4. und 5. Jahrhunderts und Gregor von Tours († 594) ist beträchtlich, die politischen Gegebenheiten hatten sich grundlegend geändert, aber der Grad des Umbruchs ist immer wieder unterschiedlich bewertet worden. ${ }^{40}$ Gregor entstammte dem gallischen Senatorenstand und verfügte sowohl über erhebliche Bildung als auch über ein Familienbewusstsein, das ihn lange Verbindungslinien bis in frühere Zeiten ziehen ließ. ${ }^{41}$ An mehreren Stellen seines Hauptwerkes, der „Zehn Bücher Geschichten“, werden Steuererhebungen thematisiert, so auch in einer berühmten Passage des fünften Buches: ${ }^{42}$

König Chilperich aber ließ neue und harte Steuern in seinem ganzen Reiche ausschreiben. Deshalb verließen viele dessen Städte und ihre Güter und zogen nach andern Reichen, indem sie es für besser hielten, anderswo in der Fremde zu leben, als sich so harten Bedrückungen auszusetzen. Es war nämlich festgesetzt, dass jeder Besitzer von seinem eigenen Grund und Boden eine Amphora

andere hochgebildete und wohlsituierte Autoren tatsächlich „von unten“ berichten, sei dahingestellt. Schon Goffart, Old and New (Anm. 7), 15 unterstreicht, dass ein Herrscher, der energisch Steuern einfordert, nie populär ist.

38 Demandt, Spätantike (Anm. 11), 295.

39 CodTh XI,28,2 (Arcadius und Honorius, 395): chartas superfluas discribtionis cremari censemus, XI,28,3 (Arcadius und Honorius, 401): Omnium titulorum, sive qui ad inlustres viros praefectos praetorio sive qui ad largitiones nostras pertinent, usque in consulatum primum clementiae nostrae, id est usque indictionem quintam decimam, quae proxima fuerit, reliqua universa concedimus. Atque ut ipsa memoria reliquorum intercidat, chartas omnes, sive quas tabularii civitatum sive officia iudicum sive officium palatinum sive discussores habent, quibus tamen eius temporis et debitorum nomina et debita continentur, undique in medium congregatas palam flammis iubemus aboleri. Vgl. Magnou-Nortier, Système fiscal (Anm. 9), 169.

40 Goffart, Old and New (Anm. 7), 3 - 4 betont, dass innerhalb der zweieinhalb Jahrhunderte zwischen Diokletian und Justinian selbst bei stabilen inneren Verhältnissen ohnehin ein merklicher Wandel eingetreten sein müsste.

41 Benedikt Konrad Vollmann, Art. Gregor von Tours, in: Reallexikon für Antike und Christentum 12 (1983), 895 - 930; Martin Heinzelmann, Gregor von Tours, „Zehn Bücher Geschichte“. Historiographie und Gesellschaftskonzept im 6. Jahrhundert, Darmstadt 1994. Zur Herkunft speziell Karl Friedrich Stroheker, Der senatorische Adel im spätantiken Gallien, Tübingen 1948, 112; Martin Heinzelmann, Bischofsherrschaft in Gallien. Zur Kontinuität römischer Führungsschichten von 4. bis 7. Jahrhundert. Soziale, prosopographische und bildungsgeschichtliche Aspekte, München 1976 (Beihefte der Francia 5), 112.

42 Eine vollständige Zusammenstellung der einschlägigen Passagen bietet Margarete Weidemann, Kulturgeschichte der Merowingerzeit nach den Werken Gregors von Tours, 2 Bde., Mainz 1982 (Römisch-Germanisches Zentralmuseum, Monographien 3), Bd. 1, 327-331. 
Wein auf jeden halben Morgen gebe. Aber es waren auch noch viele andre Steuern auferlegt, sowohl von dem übrigen Grund und Boden, als von den Sklaven; das alles war gar nicht aufzubringen. So scharte sich das Volk von Limoges, da es sich von solcher Last bedrückt sah, am 1. März zusammen und wollte den Referendar Marcus töten, der beauftragt war, die Steuern einzutreiben; und es würde das auch getan haben, wenn ihn nicht der Bischof Ferreolus von der drohenden Gefahr befreit hätte. Die Menge bemächtigte sich aber der Steuerbücher und verbrannte sie. Hierüber wurde der König höchlich erzürnt, sandte Männer von seinem Throne ab und ließ das Volk auf das härteste heimsuchen, machte es durch harte Strafen mürbe und tötete viele. Man sagt, dass damals selbst Äbte und Priester an Pfähle gespannt und allen möglichen Foltern ausgesetzt wurden, weil die königlichen Sendboten sie fälschlich anschuldigten, sie seien bei dem Aufstande beteiligt gewesen; auch wurden darauf dem Volke noch drückendere Steuern auferlegt. ${ }^{43}$

Ein eindeutigeres Beispiel für Vernichtung von Verwaltungswissen ist zunächst kaum denkbar; diese Stelle bietet aber noch weit mehr Erkenntnispotential. Es ist von Libri discriptionum die Rede; descriptio war bereits im Lukasevangelium der Terminus technicus für Steuerlisten, also Katasterverzeichnisse. ${ }^{44}$ Vielleicht hat Gregor ihn gerade deshalb hier eingeführt. Chilperich erhob Steuern; konnte er das? Offenbar hatte er in seinem fränkischen Teilkönigreich eine leitende Funktion übernommen, die es mit sich brachte, dass er wie ein spätantiker praefectus praetorio die Steuererhebung durchführte. Er erhob Steuern „in seinem Reiche“, also in einem fränkischen Teil-

43 Chilpericus vero rex discriptiones novas et gravis in omne regno suo fieri iussit. Qua de causa multi relinquentes civitates illas vel possessiones proprias, alia regna petierunt, satius ducentes alibi peregrinare quam tali periculo subiacere. Statutum enim fuerat, ut possessor de propria terra unam anforam vini per aripennam redderit. Sed et alii functionis infligebantur multi tam de reliquis terris quam de mancipiis; quod implere non poterat. Lemovicinus quoque populus, cum se cernerit tali fasci gravari, congregatus in Kalendas Martias Marcumque referendarium, qui haec agere iussus fuerat, interficere voluit; et fecisset utique, nisi eum episcopus Ferreolus ab inminente discrimine liberasset. Areptis quoque libris discriptionum, incendio multitudo coniuncta cremavit. Unde multum molestus rex, dirigens de latere suo personas, inmensis damnis populum adflixit suppliciisque conteruit, morte multavit. Ferunt etiam, tunc abbatis atque presbiteros ad stipitis extensis diversis subiacuisse tormentis, calumniantibus regalibus missis, quod in siditione populi ad incendendus libros satellitis adfuissent, acerbiora quoque deinceps infligentes tributa. Gregorii episcopi Turonensis Historiarum libri X, hrsg. von Bruno Krusch und Wilhelm Levison, 2. Auflage, Hannover 1951 (MGH SS rer. Merov. I,12), V,28, 233-234. Die Übersetzung nach der Ausgabe Gregor von Tours, Zehn Bücher Geschichten, hrsg. von Rudolf Buchner, Darmstadt 1956 (Ausgewählte Quellen zur deutschen Geschichte des Mittelalters 2), 335-337.

44 Umfassend hierzu Emil Vetter, Art. descriptio, in: Thesaurus linguae latinae 5,1 (1909-1934), 664-667, hier 665: strictiore sensu de tributariorum descriptione et de tabulis, quibus ea comprehenditur, vel etiam de tributi onere. Die von Vetter gelieferten Belege setzen allerdings erst in der Spätantike ein (Codex Theodosianus und Codex Iustinianus, jeweils mit Novellen, sowie Gregor von Tours). Hingegen hat describere, anscheinend ausgehend von der Stelle im Lukas-Evangelium, auch bei Iuvencus und Hieronymus (auf diesem beruhend dann auch bei Prosper) diese Bedeutung. Daneben scheint aber auch Cicero in Pro Flacco 32 diesen Sinn zu evozieren; die weiteren Belege sind durchgehend spätantik. Vgl. Emil Vetter, Art. describere, in: Thesaurus linguae latinae 5,1 (1909-1934), $656-664$, hier 658. 
königreich ${ }^{45}$ und nicht etwa im gesamten merowingischen Frankenreich oder nur in Limoges. Er tat dies aber, wie sich aus dem weiteren Kontext ergibt, anscheinend nicht in seinem eigentlichen Reichsteil, dem Reich von Soissons, sondern im annektierten Reichsteil seines verstorbenen Bruders Charibert. ${ }^{46}$ Vor allem aber erhob er neue Steuern; der Umstand, dass er Steuern an sich einzog, erschien Gregor von Tours in diesem Zusammenhang nicht weiter anstößig. ${ }^{47}$ Hiermit erhob sich Chilperich deutlich über die Kompetenzen eines praefectus praetorio und dokumentierte seinen Anspruch auf umfassende Herrschaft in seinem Reichsteil; letztlich erteilte Chilperich seinem referendarius Marcus den Auftrag zum Einziehen der Steuern und nahm damit die Position des römischen Kaisers in diesem Teilreich ein. Wir müssen hier also von einer Sondersteuer ausgehen, wie sie etwa Ammianus Marcellinus für die Spätantike geschildert hat. ${ }^{48}$ Es geht um Abgaben auf Landbesitz, aber auch auf das Eigentum an Menschen. Steuerpflichtig sind die Bewohner der civitas Limoges, auch dies ist nicht ungewöhnlich: die civitates bildeten Steuerbezirke innerhalb der regna. ${ }^{49}$ Der Steuerpflicht unterlagen generell die Gallorömer, während die Franken von der Zahlung von Steuern befreit waren. ${ }^{50}$ König Theudebert unternahm wohl den Versuch, auch die Franken einzubinden, jedoch führte dieses Unternehmen nicht zum Erfolg und fand so keine Fortsetzung. ${ }^{51}$

Das Repertoire der Klage über unmäßige Steuereintreibung hingegen ist komplett vorhanden: Willkür, gewalttätige Erhebung, unbezahlbar hohe Steuerforderungen, Steuerflucht aus Not - und sogar das Foltern durch Festbinden oder Aufhängen wird in diesem Kontext bereits bei Laktanz berichtet. ${ }^{52}$ Für die Schilderung von Steuererhebungen durch böse Herrscher gibt es wohl in der Tat einen abrufbaren, aktualisierbaren Wissenskanon. Gregor von Tours argumentiert hier einmal mehr in römischgallorömischer Tradition. In dieser Tradition steht übrigens auch der Zahltag am 1. März, und es existieren weitere Zeugnisse für die gezielte Vernichtung von Unterlagen der Finanzverwaltung im Kontext von Unruhen im 6. Jahrhundert auch aus dem

45 Weitere Belege hierfür: Greg. Tur. Hist. IV,1 und IX,30, vgl. Weidemann, Kulturgeschichte (Anm. 42), Bd. 1, 327.

46 Georg Scheibelreiter, Die barbarische Gesellschaft. Mentalitätsgeschichte der europäischen Achsenzeit 5. - 8. Jahrhundert, Darmstadt 1999, 26.

47 Scheibelreiter, Barbarische Gesellschaft (Anm. 46), 25.

48 Vgl. oben Anm. 30.

49 Weitere Belege: Greg. Tur. Hist. III,25 (Clermont), IV,2, V,26 (Vannes), VI,22, VII,23 (Tours), IX,30 (Poitiers, Tours), X,7 (Clermont), vgl. Weidemann, Kulturgeschichte (Anm. 42), Bd. 1, 327.

50 Heike Grahn-Hoek, Die fränkische Oberschicht im 6. Jahrhundert. Studien zu ihrer rechtlichen und politischen Stellung, Sigmaringen 1976 (Vorträge und Forschungen, Sonderband 21), 109-110; Scheibelreiter, Barbarische Gesellschaft (Anm. 46), 23.

51 Greg. Tur. Hist. VII,15: Die Franken sind unter Childebert I. ingenui und sollen nun zahlen, was deren Widerstand hervorruft, vgl. Lot, Impôt (Anm. 6), 91; Scheibelreiter, Barbarische Gesellschaft (Anm. 46), 24.

52 Zur möglichen Benutzung von Laktanz und Anlehnung an dessen Darstellungsweise durch Gregor von Tours vgl. künftig eine Studie von Julian Führer und Gerald Schwedler (in Vorbereitung). 
östlichen Teil des römischen Reiches. ${ }^{53}$ Auch die Lebensgefahr für den Steuereintreiber ist kein Sonderfall, da König Theudeberts Berater wegen der Belegung der Franken mit Steuern sogar im Trierer Kirchenasyl gesteinigt wurde ${ }^{54}$ und ein iudex König Chilperichs nach dem Tod seines Schutzherrn in die Pariser Bischofskirche fliehen musste und sein Besitz niedergebrannt wurde. ${ }^{55}$ Und noch ein Element des Steuerwesens zur Merowingerzeit kennen wir bereits aus früheren Zeiten: Amtsträger hatten auch jetzt die Einnahmen gegenüber dem König zu garantieren, und so liehen sich Graf Eunomius von Tours und sein Vizegraf Injuriosus 583 Geld, um die tributa publica vorfinanzieren zu können. ${ }^{56}$

Referendarii gab es in Ost und West, sie fertigten Schriftstücke für den Kaiser aus oder arbeiteten beim Patriarchen von Konstantinopel. ${ }^{57}$ Bei Gregor von Tours und in bezug auf das merowingische Königtum handelt es sich um königliche Amtsträger, die direkt vom König eingesetzt waren, also nicht als Bedienstete des comes oder des Bischofs in den civitates aktiv wurden. ${ }^{58}$ Zudem hatten nicht nur Könige einen referendarius, sondern zum Beispiel auch die Königin Ulthrogotha. ${ }^{59}$ Diese Beamten scheinen als kompetente Verwaltungsfachleute, die das Vertrauen des Königs genossen, für verschiedene hohe Posten geeignet, ob nun als Bischof oder in der bisherigen Tätigkeit über den Tod ihres Vorgesetzten hinaus. ${ }^{60}$ Für die Erhebung von Steuern wurden sie anscheinend vor allem dann eingesetzt, wenn es etwa nach einem Herrscherwechsel keinen lokal zuständigen comes gab. ${ }^{61}$ Sie waren die Garanten für die Kontinuität von Verwaltungswissen auch über die Dauer von Herrschaften und die Existenz von Teilreichen hinaus.

53 Peter Sarris, Lay archives in the Late Antique and Byzantine East: the implications of the documentary papyri, in: Documentary Culture (Anm. 4), 17-35, hier 19 mit weiteren Beispielen aus Konstantinopel, Alexandria und Antiochia.

54 Greg. Tur. Hist. III,36; vgl. Lot, Impôt (Anm. 6), 91; Scheibelreiter, Barbarische Gesellschaft (Anm. 46), 24.

55 Scheibelreiter, Barbarische Gesellschaft (Anm. 46), 25-26.

56 Vgl. Kaiser, Steuer und Zoll (Anm. 7), 7; Scheibelreiter, Barbarische Gesellschaft (Anm. 46), 28, vgl. Greg. Tur. Hist. VII,23 (Geldgeber ist ein Jude). Vorgestreckte bzw. garantierte Steuern auch bei Theodoret, Historia religiosa c. 17, vgl. o. Anm. 35. Weitere Belege für den comes civitatis und seine vicarii oder exactores als Steuereintreiber: Greg. Tur. Hist. VI,22, VII,23, IX,30, X,7, X,8, X,21, De virtutibus sancti Juliani 16, vgl. Weidemann, Kulturgeschichte (Anm. 42), Bd. 1, 327.

57 Otto Eger, Art. Referendarius, RE I A,1 (1914), 461-462; vgl. Codex Iustinianus I,50,2, Nov. Iust. 10, Cassiodor Variae VI,17.

58 Weidemann, Kulturgeschichte (Anm. 42), Bd.1, 90. Lt. Stroheker, Adel (Anm. 41), 123 war diese Position in der zweiten Hälfte des 6. Jahrhunderts vorwiegend Römern vorbehalten.

59 Greg. Tur. Hist.V,42 (über Bischof Maurilio von Cahors): Sed cum episcopatum eius multi expeterent, ipse Ursicinum, qui quondam referendarius Ulthrogotho reginae fuerat, elegit.

60 Vgl. Greg. Tur. Hist. V,3: Siggo quoque referendarius, qui anolum regis Sigyberthi tenuerat et ab Chilperico rege ita provocatus erat, ut servitium, quod tempore fratris sui habuerat, obteneret, ad Childeberthum regem, Sigyberthi filium, relicto Chilperico, transivit.

61 Weitere Belege: Greg. Tur. Hist. III,36, V,4, VII,15, glor. mart. 47, virt. Juliani 17, vgl. Weidemann, Kulturgeschichte (Anm. 42), Bd. 1, 327. 
Jedoch ist diese berühmte Stelle nicht die einzige Passage bei Gregor von Tours, in der es um Steuerlisten und deren Vernichtung geht. Nur wenige Kapitel später ist es die Königin Fredegunde, die ihrem Gemahl, dem bösen König Chilperich, einen Rat gibt, da das Reich von einer Seuche heimgesucht wird und ihre beiden Kinder schwer erkrankt sind:

\begin{abstract}
„Komm also jetzt, wenn du willst, und laß uns diese ungerechten Steuerrollen verbrennen. Unserm Kronschatze sei genug, was unserm Vater und König Chlothar genug war.“ So sprach die Königin und schlug mit den Fäusten an ihre Brust, befahl die Steuerbücher zu bringen, welche Marcus aus ihren Städten beigebracht hatte, und warf sie in das Feuer; dann wandte sie sich wiederum zum Könige und sprach: ,Was zögerst du noch! Tue, was du mich tun siehst, damit wir, wenn wir schon unsere süßen Kleinen verlieren, doch der ewigen Strafe entgehen.' Da ging’s dem König durchs Herz, und er warf alle Steuerbücher in die Flammen; und als sie verbrannt waren, schickte er Leute ab, die den Besteuerungen für die Zukunft Einhalt tun sollten. ${ }^{62}$
\end{abstract}

Wenn die Zuordnungen korrekt sind, verfügt Königin Fredegunde in diesem Abschnitt über eigene civitates und demzufolge über ein eigenes Steueraufkommen. Die dramatisch aufgeladene Handlung kumuliert in einer echten Vernichtung angeblich sämtlicher Steuerkataster, derer Chilperich habhaft werden konnte. Fredegunde läßt sich die Bücher vom referendarius Marcus (es ist derselbe wie in dem Abschnitt zu Limoges) bringen, Chilperich scheint sich entweder an der Verbrennung ihrer Bücher zu beteiligen oder aber, was im Kontext wahrscheinlicher ist, die an seinem Herrschaftssitz (Soissons) aufbewahrten Register zu vernichten. Das Verbot künftiger Besteuerungen kann im Grunde nur meinen, dass auf außerordentliche Besteuerungen oder auf Neuveranlagungen zuungunsten der Steuerpflichtigen künftig verzichtet werden sollte, denn die unter König Chlothar I. üblichen Sätze blieben offenbar unangetastet. ${ }^{63}$ Die gedruckte Übersetzung ist dahingehend zu präzisieren, dass mit den künftigen descriptiones keine Besteuerungen, sondern (Sonder-)Veranlagungen gemeint sind. ${ }^{64}$

Diesen Kontext kann eine dritte Passage bei Gregor von Tours vielleicht etwas erhellen helfen. Im 30. Kapitel des neunten Buches des Geschichtswerks berichtet Gregor, König Childebert (II.) habe den Hausmeier der Königin Florentianus und den comes palatinus Romulf auf Einladung des Bischofs Marowech als Steuerschätzer nach Poitiers geschickt, denn seit der letzten Veranlagung seien viele gestorben, so dass die

62 „Nunc, si placet, venite; incendamus omnes discriptionis iniquas, sufficiatque fisco nostro, quod sufficit patri regique Chlothario. "Haec effata regina, pugnis verberans pectus, iussit libros exhibere, qui de civitatibus suis per Marcum venerant, proiectosque in igno, iterum ad rege conversa: „Quid tu“, inquid, „moraris? Fac quod vidis a me fieri, ut, etsi dulces natos perdimus, vel poenam perpetuam evadamus“. Tunc rex, conpunctus corde, tradedit omnes libros discriptionum igne; conflagratusque, misit qui futuras prohiberent discriptionis. Greg. Tur. Hist. V,34, Übersetzung Buchner (Anm. 43), 345. Vgl. auch Weidemann, Kulturgeschichte (Anm. 42), Bd. 1, 328.

63 So Lot, Impôt (Anm. 6), 86; Durliat, Finances (Anm. 8), 101 sieht hier eher eine Streichung der infolge einer grassierenden Seuche aufgelaufenen Steuerschulden säumiger Zahler.

64 Eindeutig Lot, Impôt (Anm. 6), 99-100. 
Steuerlast für Witwen, Waise und „Altersschwache“ (bzw. Zahlungsunfähige) ${ }^{65} \mathrm{zu}$ schwer geworden war. Die Gesandten befreiten die Armen von den Steuern, veranlagten die anderen gemäß ihrer Stellung, und daraufhin wandten sich die beiden nach Tours. ${ }^{66}$

Die Steuerveranlagung ist in der Schilderung Gregors weder gewalttätig noch ungerecht, sondern sogar gewollt, vom Bischof gewissermaßen angefordert. ${ }^{67}$ Sie gehorcht im Gegenteil der Notwendigkeit einer Anpassung an in Form und Inhalt veränderte Rahmenbedingungen und erfüllt sämtliche Kriterien eines guten Rechtsaktes. ${ }^{68}$ Laktanz und Theodoret hatten das Vorgehen bei einer Steuerschätzung ganz genauso berichtet, nur aus einer sehr negativ gefärbten Perspektive. Gregor enthält sich einer Wertung. ${ }^{69}$ Dies ändert sich jedoch abrupt, als der Schauplatz nach Tours, in seine Bischofsstadt wechselt:

Als sie aber auch hier den Bewohnern die Zahlung der Steuer aufbürden wollten (sie sagten nämlich, sie hätten die Steuerrolle in Händen, wonach man zur Zeit der früheren Könige gesteuert hätte), antwortete ich ihnen und sprach: „Dass die Stadt Tours zur Zeit König Chlothars zur Steuer veranlagt worden ist, ist allgemein bekannt; auch wurden die Steuerrollen damals dem Könige überbracht, doch ließ er sie aus Ehrfurcht vor dem heiligen Bischof Martinus verbrennen. Nach dem Tode König Chlothars leisteten die Bewohner der Stadt König Charibert den Eid der Treue; dafür versprach er ihnen eidlich, dass er ihnen keine neuen Vorschriften und Gebräuche auferlegen, sondern sie in dem Stande belassen wolle, in dem sie vordem unter der Herrschaft seines Vaters gelebt hätten; auch gelobte er, ihnen keine neuen Anordnungen eine Schatzung betreffend aufzuerlegen. Gaiso aber, der zu jener Zeit hier Graf war, nahm die Steuerrollen, die, wie erwähnt,

65 Debilis ist in diesem Kontext auch terminus technicus für ,zahlungsunfähig‘, vgl. Weidemann, Kulturgeschichte (Anm. 42), Bd. 1, 328.

66 Greg. Tur. Hist. IX,30: Childeberthus vero rex discriptores in Pectavo, invitante Maroveo episcopo, iussit abire, id est Florentianum maiorem domus reginae et Romulfum palatii sui comitem, ut scilicet populus censum, quem tempore patris reddidirat, facta ratione, innovata re, reddere deberet. Multi enim ex his defuncti fuerant, et ob hoc viduis orfanisque ac debilibus tributi pondus insiderat. Quod hi discutientes per ordinem, relaxantes pauperes ac infirmos, illos quod iustitiae conditio tributarios dabat censo publico subdidirunt. Et sic Turonus sunt delati. Vgl. Émile Lesne, Histoire de la propriété ecclésiastique en France, Bd. 1: La propriété ecclésiastique en France aux époques romaine et mérovingienne, Lille / Paris 1910 (Mémoires et travaux des facultés catholiques de Lille 6), 257; Heinzelmann, Gregor von Tours (Anm. 41), 45.

67 Dies ergibt sich möglicherweise auch aus der Chronologie: Dieses Kapitel ist ins Jahr 589 zu datieren, die letzte Veranlagung hatte noch unter dem 575 ermordeten König Sigibert stattgefunden, so dass eventuell der 15-Jahres-Zyklus der diokletianischen Indiktion dahinterstehen mag - Lot, Impôt (Anm. 6), 88 ist hier allerdings sehr vorsichtig.

68 Vgl. für die Definition Isidor von Sevilla, Etymologien V,21: Qualis debet fieri lex. Erit autem lex honesta, iusta, possibilis, secundum naturam, secundum consuetudinem patriae, loco temporique conveniens, necessaria, utilis, manifesta quoque, ne aliquid per obscuritatem in captionem contineat, nullo privato commodo, sed pro communi civium utilitate conscripta.

69 Sandrine Linger, Puissance sociale des domini d'après l'œuvre de Grégoire de Tours, in: Aux sources de la gestion publique, Bd. 3: Hommes de pouvoir, ressources et lieux du pouvoir ( $V^{\mathrm{e}}-\mathrm{XIII}{ }^{\mathrm{e}}$ siècles), hrsg. von Elisabeth Magnou-Nortier, Lille 1997, 51-69, hier 60 betont, dass der Bischof hiermit schlicht einer ihm obliegenden Aufgabe nachkommt. 
die Beamten in früheren Zeiten angefertigt hatten, und fing an, die Steuer zu erheben. Da ihn jedoch der Bischof Eufronius daran hinderte, begab er sich mit dem wenigen Geld, das er erhoben hatte, zum König und zeigte ihm die Steuerrollen vor, in denen der Zins verzeichnet war. Da seufzte der König, denn er fürchtete die Macht des heiligen Martinus, und warf die Rollen in das Feuer; die eingetriebenen Goldstücke aber sandte er der Kirche des heiligen Martinus mit der Versicherung, keiner von den Einwohnern von Tours solle hinfort dem Staatsschatze steuern." ${ }^{\text {“70 }}$

Hier ist die Terminologie etwas anders, die Steuerforderung des Königs wird als capitularium bezeichnet. ${ }^{71}$ Nicht erst Chilperich, sondern bereits sein Vater Chlothar I. hatte bei Gregor von Tours die Neigung, Steuerlisten zu verbrennen, und Chilperichs Bruder Charibert ebenfalls, der bei Gregor aus Furcht vor dem Groll des heiligen Martin die entsprechenden Aufzeichnungen über die Einnahmen vernichtete. Bemerkenswert ist, dass der Graf Gaiso durchaus Einnahmen erzielen konnte, aber durch den Konflikt mit Gregors Amtsvorgänger wohl nicht weit damit kam. ${ }^{72}$ Anders als im Fall von Limoges führt Gregor dies leider nicht weiter aus, obwohl er für seine civitas bestens informiert war. Wenn wir diese Geschichte für bare Münze nehmen, heißt das, dass Chilperich mit seinem Handeln durchaus in einer Tradition stand. Der Erlaß von Steuern als besonderer Gunsterweis ist auch nicht singulär, sondern ebenfalls auch in weiteren Fällen belegt, so zum Beispiel, auch bei Gregor von Tours, durch König Theudebert I. für die civitas Clermont. ${ }^{73}$ Der Wortwechsel zwischen Bischof Gregor einerseits und Hausmeier und Pfalzgraf andererseits eskalierte dann noch. ${ }^{74}$ Die Be-

70 Sed cum populis tributariam functionem infligere vellent, dicentes, quia librum prae manibus haberent, qualiter sub anteriorum regum tempore dissolvissent, respondimus nos, dicentes: ,Discriptam urbem Toronicam Chlothari regis tempore, manifestum esse, librique illi ad regis praesentiam abierunt; sed, conpuncto per timorem sancti Martini antestitis rege, incensi sunt. Post mortem vero Chlothari regis Charibertho rege populus hic sacramentum dedit; similiter etiam et ille cum iuramento promisit, ut leges consuetudinesque novas populo non infligeret, sed in illo, quod quondam sub patris dominationem statu vixerant, in ipso hic eos deinceps reteneret; neque ullam novam ordinationem se inflicturum super eos, quod pertinerit ad spolium, spopondit. Gaiso vero comes eiusdem temporis, accepto capitulario, quem anteriores scriptores fecisse commemoravimus, tributa coepit exigere. Sed ab Eofronio episcopo prohibitus, cum exacta parvitate ad regis direxit praesentiam, ostendens capitularium, in quo tributa continebantur. Sed rex ingemiscens ac metuens virtutem sancti Martini, ipsum incendio tradidit; aureos exactos basilicae sancti Martini remisit, obtestans, ut nullus de populo Toronico ullum tributum publico redderit. Greg. Tur. Hist. IX,30, Übersetzung Buchner (Anm. 43), 281.

$71 \mathrm{Zu}$ dieser Terminologie vgl. Stefan Esders, „Öffentliche“ Abgaben (Anm. 18), 214.

72 Vgl. Weidemann, Kulturgeschichte (Anm. 42), Bd. 1, 328.

73 Greg. Tur. Hist. III,25: Omne tributo, quod in fisco suo ab eclesiis in Arvernum sitis reddebebatur, clementer indulsit. Angeblich galt ein solcher Steuererlass auch schon seit Leo I. (467 - 474) für Lyon, Greg. Tur. Gloria confessorum 62, vgl. Lesne, Propriété (Anm. 66), 257, und für Marseille, vgl. Cassiodor, Variae IV,26, vgl. Kaiser, Steuer und Zoll (Anm. 7), 6; ein römisches Vorbild liefert Theodosius II. in CodTh XI,1,33 mit einem Erlass der capitatio zugunsten von Thessaloniki.

74 Greg. Tur. Hist. IX,30: Haec me dicente, responderunt: ,Ecce librum prae manibus habimus, in quo census huic populo est inflictus'. Et ego aio: ,Liber hic a regis thesauro delatus non est nec umquam per tot convaluit annos. Non est mirum enim, si pro inimicitiis horum civium in cuiuscumque domo reservatus est. Iudicavit enim Deum super eos, qui pro spoliis civium nostrorum hunc post tanti temporis transacto spatio protulerunt: 
steuerung an sich, so Gregor im Ergebnis, wäre nicht unrechtmäßig, doch verfügte die Stadt Tours hier über Sonderrechte, die sich auf die besonderen Qualitäten des heiligen Martin zurückführen lassen. Höchst bemerkenswert ist Gregors Argumentation, der zunächst eine lückenlose Reihe von Eiden von Chlothar über Charibert bis zu Childebert II. konstruiert und damit die Forderung abzuwehren sucht, vor allem aber schlaglichtartig eine Art doppelter Buchführung erkennen lässt: Die Steuerrollen, auf deren Basis eine rechtmäßige Forderung erhoben werden könnte, müssen demnach beim König selbst deponiert sein und gehören dort zum thesaurus ${ }^{75}$ es gibt aber anscheinend auch solche Rollen, die außerhalb des Hortes greifbar sind. Das Verwaltungswissen wird demnach sowohl zentral als auch dezentral organisiert. Margarete Weidemann postuliert hier allgemein die Existenz eines primären Katasters, der hier also durch die Libri descriptionum bezeichnet würde, und eines sekundären Katasters, des capitularium. Sie nimmt an, dass Charibert den sekundären Kataster von Tours habe verbrennen lassen, der primäre, von Chlothar verbrannte, Kataster aber in der civitas selbst noch als Abschrift vorhanden gewesen sei, wodurch Beamte auf ihn zugreifen konnten. ${ }^{76}$ Es ist fraglich, ob von einer planvoll durchgeführten doppelten Buchführung beim König und in den civitates tatsächlich und in diesem Fall auch für sämtliche civitates der fränkischen Teilreiche (und darüber hinaus?) ausgegangen werden darf. Die Möglichkeit dieser Existenz weist allerdings auf Überlieferungs- und Beweissicherung in Finanzangelegenheiten hin, ebenso planvoll wie auf weiteres Tradieren und wohl auch regelmäßige Réécriture ausgelegt. ${ }^{77}$ Somit vernichteten Chlothar, Charibert und Chilperich, wenn wir Gregor glauben wollen, jeweils planvoll Teile ihres Königsschatzes, nämlich Rollen, die letztlich realisierbare Titel für jährliche Einkünfte darstellten. Der Umgang mit dem Verwaltungswissen scheint bei genauer Lektüre eher in regelmäßiger Aktualisierung statt in unbedachter Vernichtung zu bestehen und die effektive Vernichtung dokumentiert, zumindest in Gregors Darstellung, eher den Verzicht auf übermäßige Forderungen als eine Preisgabe von administrativer Kompetenz.

Das Zeugnis Gregors als unmittelbaren Zeitgenossen muss sicherlich hoch eingeschätzt werden, auch wenn die oftmals exemplarische Intention der Kapitel- und Buchstruktur inzwischen erkannt wurde, die in die Interpretation der Einzelstellen einfließen muss. Der Bischof von Tours komponierte sein Werk anscheinend sehr

75 Matthias Hardt, Gold und Herrschaft. Die Schätze europäischer Könige und Fürsten im ersten Jahrtausend, Berlin 2004 (Europa im Mittelalter 6), 131-132.

76 Weidemann, Kulturgeschichte (Anm. 42), Bd. 1, 328. Durliat, Finances (Anm. 8), 98 - 99 schließt hier wie auch an anderen Stellen seines Buches aus der Existenz solcher Kataster für einzelne Bezirke auf deren Existenz in anderen Regionen.

77 Methodisch: Arnold Esch, Überlieferungs-Chance und Überlieferungs-Zufall als methodisches Problem des Historikers, in: HZ 240 (1985), 529-570. Zum Terminus der Réécriture und seiner Anwendung in der Geschichte des Frühmittelalters vgl. Monique Goullet, Ecriture et réécriture hagiographiques. Essai sur les réécritures de Vies de saints dans l'Occident latin médiéval (VIII ${ }^{\mathrm{e}}-\mathrm{XIII}{ }^{\mathrm{e}}$ s.), Turnhout 2005 (Hagiologia 4). 
bewusst. Gregor verfasste eine Weltchronik und unterschied sehr klar zwischen Gut und Böse (und zwar schon in der Vorrede). ${ }^{78}$ Während das erste Buch den Gang der Weltgeschichte bis zum Tod des heiligen Martin zusammenfasst und das zweite Buch hauptsächlich die Taten Chlodwigs referiert, behandeln spätere Bücher den guten König Gunthramn und den bösen König Chilperich. ${ }^{79}$ Die signifikante Häufung von negativ gefärbten Berichten über Steuern im fünften Buch der Geschichten findet hier ihre Erklärung. Durch den parallelen Aufbau der Kapitel bei Laktanz und Gregor wird Chilperich als böser König möglicherweise in die Nähe des Christenverfolgers Diocletian gerückt.

Der Eintritt der fränkischen Könige in die römischen Strukturen, der mit der Übernahme von Militärkommandos durch Chlodio und Childerich I. im 5. Jahrhundert seinen Anfang genommen hatte, ${ }^{80}$ erfolgte im Zusammenspiel mit lokalen Verwaltungsfachleuten, die auch in der Umbruchsphase dafür sorgten, dass es eine öffentliche Finanzverwaltung gab. ${ }^{81}$ Dies setzt Wohlwollen auf beiden Seiten, natürlich auch Vertrauen und ein Interesse der Merowingerkönige am Fließen von Steuern voraus. Zumindest Letzteres darf man wohl voraussetzen, vor allem wenn die eigene Gefolgschaft, auf der die Macht des Königs zunächst basierte, hiervon erst einmal nicht tangiert war. ${ }^{82}$

Wie erfolgte nun die Neustrukturierung des Wissens infolge einer politischen Stabilisierung im 7. Jahrhundert? Günstig scheint zunächst, dass die bekannteste erzählende Quelle im Frankenreich aus dieser Zeit, der sogenannte Fredegar, im dritten Buch seiner Chronik das Geschichtswerk Gregors von Tours zusammenfasste. ${ }^{83}$ Wie geht dieser Autor mit den Steuerkapiteln bei Gregor um? Werden sie gewissermaßen neutral referiert, werden sie gekürzt, gestrichen, unterliegen sie einer Réécriture? An zwei Beispielen lässt sich diese Quelle auf die Frage hin untersuchen, ob hier von einer Réécriture im technischen Sinne gesprochen werden kann, wie ihn Gérard Genette in seinem Werk Palimpsestes. La littérature au second degré definiert hat ${ }^{84}$ und wie ihn vor allem Monique Goullet für die frühmittelalterliche Hagiographie fruchtbar gemacht

78 Greg. Tur. Hist. Prol.: cum nonnullae res gererentur vel rectae vel inprobae.

79 Heinzelmann, Gregor von Tours (Anm. 41), 44 bezeichnet Buch V von Gregors Geschichtswerk als dem „spirituellen Konflikt zwischen Bischof und König“ gewidmet.

80 Sebastian Scholz, Die Merowinger, Stuttgart 2015 (Urban Taschenbücher 748), 30 - 34.

81 Scheibelreiter, Barbarische Gesellschaft (Anm. 46), 28, allerdings mit der kaum nachprüfbaren und daher letztlich unhaltbaren Behauptung: „Das einlangende Geld war als Bereicherung des Schatzes hoch willkommen, es bestand eine naive Freude daran, aber es fehlte die königliche Einsicht in finanzpolitische Notwendigkeiten.“

82 Scheibelreiter, Barbarische Gesellschaft (Anm. 46), 25.

83 Vgl. zuletzt zur Fredegars Regestierungstechnik Roger Collins, Die Fredegar-Chroniken, Hannover 2007 (MGH Studien und Texte 44); Gerald Schwedler, Lethe and „delete“. Discarding the Past in the Early Middle Ages. The Case of Fredegar, in: Collector's Knowledge. Aufbewahren oder wegwerfen - wie Sammler entscheiden. What is kept, what is discarded, hrsg. von Anja-Silvia Göing, Anthony Grafton und Paul Michel, Leiden / Boston 2013 (Brill's Studies in Intellectual History 227), 71 - 96.

84 Gérard Genette, Palimpsestes. La littérature au second degré, Paris 1982. 
hat. ${ }^{85}$ In diesem Sinne wäre nach der Textgrundlage Fredegars, also Gregors von Tours Geschichten, als Hypotext und nach der Neubearbeitung als Hypertext zu fragen. Fredegars gestraffte Fassung der neuen Steuern Chilperichs in Limoges liest sich folgendermaßen:

Chilperich gab den Befehl, von allem Volke seines Reiches äußerst drückende Steuern einzutreiben. Der Referendarius Marcus, der diese Steuereinhebung durchführte, wurde von den Leuten aus Limoges an den Kalenden des März getötet, als er alle Steuertafeln bei sich hatte; alle Steuertafeln wurden verbrannt. ${ }^{86}$

Man könnte zunächst meinen, Fredegar habe Gregor nicht ganz verstanden, aber tatsächlich verstärkte er systematisch die Aussage: alles Volk ist betroffen (anders als bei Gregor), Marcus wird nicht nur bedroht, sondern tatsächlich erschlagen, und alles wird verbrannt. Aber Fredegar ändert auch die Terminologie etwas. Die descriptio ist nicht mehr eine Veranlagung, sondern eine Steuerforderung, die Libri discriptionum sind jetzt poleptici, Polyptycha. ${ }^{87}$ Die Fredegar-Chronik beruht in Buch III auf Gregor von Tours, in den ersten beiden Büchern auf dem Liber generationis des Hieronymus; dort ist an einer Stelle von chartis publice incensis die Rede, woraus bei Fredegar polepticis poblicis incensis werden. ${ }^{88}$ Der Wechsel der Terminologie ist bei Fredegar also keiner stilistischen Variante im Einzelfall geschuldet, sondern mehrfach eingetreten, auch im zweiten Buch, das sonst durchgehend den Wortlaut bei Hieronymus reproduziert.

Der Verlust an Details ist der Redaktionstechnik unseres Epitomators geschuldet, gleichzeitig aber verschärft er bestimmte Züge. Auch hier also ein subtiles Überbieten der Vorlage, in diesem Fall Gregors von Tours? Subtilität ist Fredegar vergleichsweise selten unterstellt worden, jedoch scheint mir, dass ein Unterbieten oder ein Nachlassen an Prägnanz kaum je von einem Epitomator bewusst betrieben wurde. Die terminologische Justierung bei Fredegar ist hier möglicherweise signifikant: Waren diese Libri Verwaltungsschriftgut aus der Zentrale der Macht, so sind Polyptycha üb-

85 Vgl. Goullet, Réécriture (Anm. 77), besonders die Abschnitte I,II,2 (Amplification et niveaux de styles, 70 - 84) und II,I,2 (Les techniques de réduction, 118 - 133), jeweils anhand vieler Beispiele aus der Hagiographie verdeutlicht, sowie die Beiträge in Monique Goullet und Martin Heinzelmann (Hrsg.), La réécriture hagiographique dans l'Occident médiéval. Transformations formelles et idéologiques, Ostfildern 2003 (Beihefte der Francia 58).

86 Chilpericus discripciones gravissemas in omni populo regni sui fieri iussit. Marcus refrendarius, qui hanc discriptionem faciebat, secum omnes polepticus ferens, Kalendis Marciis a Limodecinis interfectus est, et omnes poleptici incendium sunt concrematae. Fredegarii Chronica, hrsg. von Bruno Krusch, Hannover 1888 (MGH SS rer. Merov. 2), III,80, 115. Übersetzung nach: Quellen zur Geschichte des 7. und 8. Jahrhunderts, übers. von Andreas Kusternig, Darmstadt 1982, 145-147.

87 Everett, Spain and Italy (Anm. 4), 77. Brown, Gesta municipalia (Anm. 4), 100 mit weiteren Belegen für diesen Terminus.

88 Hieronymus, Chronicon zum Jahr 118: Hadrianus reliqua tributorum urbibus relaxauit chartis publice incensis, vgl. Fredegar II,37, 62: Atrianus [...] benigniter tributa urbium plurima relaxavit, polepticis poblicis incensis. 
licherweise lokal erstellte Besitzverzeichnisse, in der Terminologie Margarete Weidemanns also allenfalls sekundäre Kataster. ${ }^{89}$ Der Fokus scheint hier von der Zentrale weg zu den Besitzern gegangen zu sein. Möglicherweise überträgt der Redaktor der Fredegarchronik also seine Wahrnehmung des 7. Jahrhunderts auf die Verhältnisse des 6. Jahrhunderts, wobei er Gregors bewusst gesetzten Terminus nicht mehr korrekt deuten konnte. ${ }^{90}$ Im nicht mehr von Gregor von Tours abhängigen Teil der Fredegarchronik geht es durchaus ebenfalls um Steuern; diese einzuziehen, gilt dort buchstäblich als Himmelfahrtskommando. ${ }^{91}$ Gegen den in diesem Fall beauftragten Bertoald ergeht der aus den Klagen über Kuriale altbekannte Vorwurf, er habe sich an Steuereintreibungen selbst bereichert. ${ }^{92}$ Detaillierte Angaben über die Form der Veranlagung und über den aktualisierenden Umgang mit Verwaltungswissen sucht man hingegen im selbständigen Teil der Chronik vergebens. In der Epitome Gregors im dritten Buch der Fredegarchronik ist hingegen eine bei Gregor nicht zu findende Episode inseriert, die die Zahlung von drei solidi als Kopfsteuer als hart, aber hinnehmbar beschreibt. ${ }^{93}$

Schlaglichtartig erscheinen immer wieder Angaben über Steuerzahlungen und das Generieren von Verwaltungswissen darüber in den Quellen der späteren Merowingerzeit. Sie sind jedoch meist nicht ausführlich genug, um eine Verallgemeinerung wagen zu können. Das Edictum Chlotharii legt fest, dass in der Vergangenheit erhobene neue Forderungen zu überprüfen und abzumildern sind. ${ }^{94}$ Die Recensio A der Vita Balthildis bezeugt die Aufhebung der Kopfsteuer. ${ }^{95}$ Der Liber Historiae Francorum

89 Vgl. Weidemann, Kulturgeschichte (Anm. 42), 328 (wie o.). Hierzu eine bei Weidemann und in der sonstigen Literatur wenig diskutierte Stelle aus den Formulae Marculfi, hrsg. von Karl Zeumer, Hannover 1886, I,19 (MGH Formulae 55-56), die für Steuerregister den Begriff des Polyptychons wählt: Precipientes ergo iobemus, ut, se memoratus ille de caput suum bene ingenuus esse videtur et in poleptico publico censitus non est, licenciam habeat comam capitis sui tunsorari. Zur Datierung, mutmaßlich in zeitlicher Nähe zu Fredegar, vgl. Alice Rio, Legal Practice and the Written Word in the Early Middle Ages. Frankish Formulae, c. 500-1000, Cambridge 2009, 85 - 88.

90 Vor dem Irrtum, diesen Fehlschluss aus der Perspektive des 21. Jahrhunderts für das Frühmittelalter aufgrund der Terminologie zu wiederholen, warnt Étienne Renard, Administrer des biens, contrôler des hommes, gérer des revenus par l'écrit au cours du premier Moyen Âge, in: Décrire, inventorier, enregistrer entre Seine et Rhin au Moyen Âge. Formes, fonctions et usages des écrits de gestion, hrsg. von Xavier Hermand, Jean-François Nieus und Étienne Renard, Paris 2012 (Mémoires et documents de l'École des Chartes 92), 7-36, hier 10.

91 Fredegar IV,24-25, 130 - 131: Ut Bertoaldus pocius interiret, eum ripa Segona usque Ocianum mare per pagus et civitates fiscum inquerendum dirigunt.

92 Fredegar IV,26-27, 131-132.

93 Fredegar III,12, 95-96, zeitlich in die Regierung des Aegidius für den vertriebenen Childerich im dritten Viertel des 5. Jahrhunderts angesiedelt. Vgl. Lot, Impôt (Anm. 6), 90.

94 Edictum Chlotharii, hrsg. von Alfred Boretius, Hannover 1883 (MGH Capit. I), II, 8, 22, vgl. Kaiser, Steuer und Zoll (Anm. 7), 7.

95 Vita s. Balthildis recensio A, hrsg. von Bruno Krusch, Hannover 1888 (MGH SS rer. Merov. 2), c. 6, 488. Hierzu vgl. Robert Folz, Les saintes reines du moyen âge en Occident (VI $-\mathrm{XIII}^{\mathrm{e}}$ siècles), Bruxelles 1992 (Subsidia hagiographica 76), 32; Yitzhak Hen, Culture and Religion in Merovingian Gaul, A.D. 
von etwa 727 berichtet aus mythischer Vergangenheit, dass der römische Kaiser Valentinian II. den Franken Steuereintreiber schickte und dass die Franken auf die Forderungen mit Totschlag an den exactores reagierten. ${ }^{96}$ Die Vita sancti Eligii weiß von Steuerzahlungen in Gold. ${ }^{97}$ Im 7. Jahrhundert wird König Dagobert I. in der Vita des heiligen Bischofs Sulpicius von Bourges die Erhebung von Abgaben zugeschrieben; sein Nachfolger Chlodwig II. schaffte diese Abgaben wieder ab und ließ sich die darüber angefertigte discribtio ausliefern. ${ }^{98}$ Auf der anderen Seite, bei den Zahlern von Steuern und Abgaben, scheinen sich im Einzelfall Rechnungen oder zumindest Aufstellungen erhalten zu haben. ${ }^{99}$ Die Überlieferungschance solcher nur während kurzer Zeit relevanter Administrativschriftstücke ist allerdings denkbar gering, so dass das weitgehende Fehlen solcher Dokumente kaum verwundern kann.

Unsere Überlieferung ist höchst lückenhaft und mag von Anfang an recht schmal gewesen sein. Das gilt für die erzählenden Quellen, aber auch in bezug auf die Libri descriptionum, die uns nicht erhalten sind. Über regionale Besonderheiten, die über den geographischen Berichtshorizont Gregors von Tours hinausgehen, wissen wir noch weniger. Eher zufälligen Umständen verdanken wir die Erhaltung dreier Polyptycha aus Saint-Victor de Marseille, Saint-Remi de Reims und aus Saint-Germain-des-

481-751, Leiden 1995 (Cultures, beliefs, and traditions 1), 54; Martina Hartmann, Die Königin im frühen Mittelalter, Stuttgart 2009, 82.

96 Liber historiae Francorum, hrsg. von Bruno Krusch, Hannover 1888 (MGH SS rer. Merov. 2), c .3, 243.

97 Das Kloster Solignac zahlt Steuern für den Hof, ein monetarius bereitet das Gold vor, obwohl es sich eigentlich um eine Naturalabgabe handeln würde. Der Text stammt von etwa 620, vgl. Lot, Impôt (Anm. 6), 86-87 und die Vita Eligii, hrsg. von Bruno Krusch, Hannover/Leipzig 1902 (MGH SS rer. Merov. 4), I,15, 681. Die Steuern existieren also noch in ihrer jeweiligen Form, werden aber nicht mehr in der ursprünglichen Form (bar oder über Ablieferung von Naturalien), sondern über Verrechnung beglichen. Die Läuterung durch den Münzmeister ist bereits in CodTh XII,7,3 (Valentinian und Valens, 367) belegt, vgl. Dopsch, Grundlagen (Anm. 5), Bd. 2, 527. Zur Ablösung von Naturalzahlungen durch Geldzahlungen siehe oben Anm. 17; zu Eligius und den Steuerzahlungen in Gold jetzt Martin Heinzelmann, Eligius monetarius: Norm oder Sonderfall? in: Die merowingischen Monetarmünzen als Quelle zum Verständnis des 7. Jahrhunderts in Gallien, hrsg. von Jörg Jarnut und Jürgen Strothmann, Paderborn 2013 (MittelalterStudien 27), 243-291, hier 267, 275.

98 Vita s. Sulpicii Bituricensis, hrsg. von Bruno Krusch, Hannover/Leipzig 1902 (MGH SS rer. Merov. 4), c. 6, 375-376, vgl. Lesne, Propriété (Anm. 66), 257.

99 Schlaglichtartig zeigen als Einbandverstärkungen erhaltene Pergamentbögen des 7. Jahrhunderts (ChLA 18, Nr. 659), wie im Martinskloster von Tours die Zahlung von Abgaben verzeichnet wurde; Art und Menge der zu zahlenden Abgabe wurden verzeichnet und - wohl nach erfolgter Zahlung - anscheinend von anderer Hand ausgestrichen. Hierzu vgl. Pierre Gasnault, Documents comptables de Saint-Martin de Tours à l'époque mérovingienne, Paris 1975; Shoichi Sato, The Merovingian accounting documents of Tours. Form and function, in: Early Medieval Europe 9 (2000), 143-161; Renard, Administrer (Anm. 91), 30. Fundgeschichte und Abbildung: Charlotte Denoël, Buchhaltungsdokumente der Abtei Saint-Martin de Tours, in: Credo. Christianisierung Europas im Mittelalter, Bd. 2: Katalog, hrsg. von Christoph Stiegemann, Martin Kroker und Wolfgang Walter, Petersberg 2013, 159. 
Prés bei Paris, die alle erst im 9. Jahrhundert angelegt wurden. ${ }^{100}$ Dass die Libri descriptionum allgemein nicht erhalten sind, ist weniger Vernichtung von Verwaltungswissen als ganz normale Aussonderung nicht mehr benötigten bürokratischen Schriftgutes im Laufe der Zeit. Die Überlieferungswahrscheinlichkeit ist für diese Art Schriftlichkeit ohnehin sehr gering, zudem ist wohl auch der Rollencharakter und mithin der mutmaßliche Beschreibstoff Papyrus in Rechnung zu stellen, dessen Erhaltung noch einmal unwahrscheinlicher wäre. ${ }^{101}$ Wichtig ist festzuhalten, dass die Libri descriptionum bei Gregor von Tours ein Speicher von Verwaltungswissen von autoritativer Kraft sind, ein Wissensspeicher, der auch Wissen generiert und soziale Realitäten schafft. Ihre normative Kraft wird nicht angezweifelt, allenfalls ihre Anwendbarkeit im Einzelfall. Bei Gregor besteht eine deutliche Einsicht in die Notwendigkeit einer geregelten Finanzverwaltung, daraus ergab sich eine grundsätzliche Legitimität von Steuererhebungen und Veranlagungen, ebenso die Legitimität und Notwendigkeit von Anpassungen. Abgelehnt werden illegitime, gewaltsame oder exzessiv betriebene Steuereintreibungen. Die bei Fredegar erkennbaren Raffungen und die vereinzelten Hinweise in den Quellen könnten auf eine Restrukturierung im 7. Jahrhundert hinweisen und auf ein steigendes Bewusstsein dafür, dass hergebrachte Kategorien nicht mehr praktikabel waren. ${ }^{102}$

Es darf auch nicht vergessen werden, dass es um 500 noch deutliche Hinweise für administrativ determinierte Beziehungen der fränkischen Könige zum oströmischen Kaiserhof gab; die König Chlodwig vom Kaiser übersandten codecillos de consolato ${ }^{103}$ sind hierfür ebenso ein Indiz wie die zahlreichen im Grab des Königs Childerich gefundenen oströmischen Goldmünzen, die man als Föderatenlohn gedeutet hat. ${ }^{104}$ Der Übergang von römischer zu fränkischer oder sonstwie gentiler Herrschaft vollzog sich üblicherweise nicht in einem drastischen Bruch, der mit der Vernichtung ganzer Makrostrukturen einhergegangen wäre. Dennoch lassen die Nachrichten über Beziehungen der Frankenherrscher zum Kaiser in Konstantinopel mit der Zeit nach, auch

100 Robert Fossier, Polyptyques et censiers, Turnhout 1978 (Typologie des sources du moyen âge occidental 28), 17 -21, Jean-Pierre Devroey, Au-delà des polyptyques. Sédimentation, copie et renouvellement des documents de gestion seigneuriaux entre Seine et Rhin (IX ${ }^{\mathrm{e}}-\mathrm{XIII}{ }^{\mathrm{e}}$ siècle), in: Décrire, inventorier (Anm. 91), 53-86.

101 Sarris, Lay archives (Anm. 53); Matthew Innes, Archives, documents and landowners in Carolingian Francia, in: Documentary Culture (Anm. 4), 152-188.

102 Anscheinend ging die Steuerhebung zunehmend auf die Bischöfe über, so dass eine andere Instanz das Verwaltungswissen generierte und administrierte. Für die Bischöfe von Reims lässt Flodoard entsprechende Hinweise seit der Amtszeit des Bischofs Somnatius (ca. 610 - 630) einfließen, vgl. Walter Goffart, From Roman Taxation to Medieval Seigneurie. Flodoard and the Frankish Polyptychs, in: Speculum 47 (1972), 373-394, hier 375; Kaiser, Steuer und Zoll (Anm. 7), 13; Renard, Administrer (Anm. 91), 20.

103 Greg. Tur. Hist. II,38: Igitur ab Anastasio imperatore codecillos de consolato accepit.

104 Patrick Périn und Michel Kazanski, Das Grab Childerichs I., in: Die Franken. Wegbereiter Europas. Vor 1500 Jahren: König Chlodwig und seine Erben, Mainz 1996, Bd. 1, 173-182, hier 178-180 (abwägend). 
wenn man nicht unterschätzen sollte, wie stark die Chronik des sogenannten Fredegar ihre Aufmerksamkeit auf Ereignisse im Osten richtet und wie stark wir von vergleichsweise wenigen Quellen abhängig sind.

Steuerrollen wurden verbrannt, mitunter von aufgebrachten Bürgern einer civitas - in diesem Fall notierte Gregor von Tours dieses Ereignis als außergewöhnlich, und Fredegar übernahm es in seine Epitome, wo er einiges vergröberte. Mitunter sorgte aber auch der König als rechtmäßiger Eigentümer für die Verbrennung dieser Verzeichnisse, und dies gehorcht, dies sei noch einmal betont, dem normalen Ablauf des römischen Rechts. ${ }^{105}$ Sie gehörten zum Königsschatz, nicht mehr zu einer in römischer Tradition stehenden und subsidiär organisierten Finanzadministration mit Kurialen. ${ }^{106}$ Die Überreste dieser Struktur erkennen wir bei den comites und referendarii, die für die Sicherung der Einnahmen zuständig sind. Dennoch bleiben die Einnahmen dann beim König, verlassen also nicht mehr die jeweiligen fränkischen Teilreiche. Hierin wäre dann doch neben aller imaginären oder tatsächlichen Vernichtung die Verdichtung und die Neuausrichtung des Verwaltungswissens zu sehen.

105 Oben Anm. 39. Thomas Werner, Den Irrtum liquidieren. Bücherverbrennungen im Mittelalter, Göttingen 2007 (Veröffentlichungen des Max-Planck-Instituts für Geschichte 225) entwickelt eine Typologie, die wesentlich auf Urteilsspruch (Verurteilung einer Schrift oder einer Person) und Ausführung dieses Spruches beruht. Die Episode von Limoges aus Greg. Tur. Hist.V,28 wird auf 553 in einen Katalog der mittelalterlichen Bücherverbrennungen aufgenommen, aber in der Erörterung nicht weiter herangezogen.

106 Lot, Impôt (Anm. 6), 99 (in der Diktion der Zeit): „Le roi franc ... entasse, comme un sauvage, le produit de l'impôt [...] pour acheter la conscience des fidèles de ses parents. “Vgl. allgemein Hardt, Gold (Anm. 75), $131-132$ u. ö. 



\title{
Ian Wood
}

\section{The Problem of Late Merovingian Culture}

\begin{abstract}
The focus of this contribution is knowledge of the Fathers and the Classics in the Merovingian period. The cultural landscape of this period should not be regarded as one of deprivation when compared to that of classical antiquity, but rather as a transformation of the knowledge system. The Merovingian educational elite tended to direct its attention mainly towards the reception of Biblical texts and patristic writings, which meant that classical works lost part of their importance. Merovingian culture did not distinguish itself by literary novelties. Rather, it can be characterized by its restructuring of existing texts in the fields of hagiography, church history and historiography. This forms an important foundation for the blossoming of the Carolingian period.
\end{abstract}

Late Merovingian Culture tends to be defined in negative terms. It is not late-Antique, nor is it Carolingian: it is not Visigothic, Irish nor Anglo-Saxon. It is regarded as the poor survival of what was already the decadent culture of the Age of Gregory of Tours. All these points are, of course, true: in certain respects one can talk about the seventh and early eighth centuries as marking a decline from what came before and also as constituting a low point with regard to what came after. It is also true that the late seventh and early eighth centuries in Francia offer no individual writer to compare with Julian of Toledo, Adomnan, and indeed a number of Irish writers, as well as Aldhelm (educated in both Irish Iona and at the School of Theodore and Hadrian at Canterbury) and Bede. Cultural decline in this period of a century and a half seems to be a particularly Frankish problem.

Yet such negative comparisons do not help us greatly to define late Merovingian culture. One can talk in terms of a decline in educational standards: the Schools of Gaul certainly came to an end, and the parish and episcopal centres that replaced them scarcely imbued their scholars with the literary skills so apparent in the fourth century - that is a story that was told by Pierre Riché. ${ }^{1}$ Yet before becoming too maudlin about the decline in educational standards one should remember Henri-Irenée Marrou's attack on late classical civilisation. ${ }^{2}$ Few would take that particular aspect of Marrou's argument Saint Augustin et la fin de la culture antique at face value any longer, and indeed Marrou in his Retractatio of 1949 admitted the severity of his onslaught on the cultural standards of the fourth century. ${ }^{3}$ Even so, his stress on the limiting effect of the Quadrivium and Trivium has some value.

1 Pierre Riché, Education et culture dans l'Occident barbare, Paris 1962.

2 Henri-Irénée Marrou, Saint Augustin et la fin de la culture antique, Paris 1938.

3 Henri-Irénée Marrou, Saint Augustin et la fin de la culture antique. Retractatio, Paris 1949. 
Equally, one can accept with reservations one of the other onslaughts on early medieval culture, and talk in terms of a linguistic decline. Judged by classical standards, the Latin of the sixth and seventh centuries is poor - certainly outside Ireland and England, where the language had to be learnt entirely from grammars. But any such statement needs to take on board the fact that classical Latin was the Latin of a very restricted elite. In the seventh century we are faced with writing from a wider range of social classes and of regions, and with 'Latin as she is spoke'. Moreover, language changes: ${ }^{4}$ as a living language Merovingian Latin is interesting, ${ }^{5}$ and its best writers have their own literary strengths, as Erich Auerbach understood. ${ }^{6}$

Yet, while the Merovingians did not write classical Latin, they were not entirely ignorant of the classics, as we shall note. It is true that our knowledge of classical culture depends on Carolingian, and not Merovingian, manuscripts, yet it is worth remembering that the texts that the Carolingians copied had been preserved and transmitted by their predecessors, who were not entirely ignorant of what was in existence. It is also the case that the scripts that the Carolingians perfected had their origins in the Merovingian world. ${ }^{7}$ At the same time, transcription of texts into the reformed script and language of the Carolingian period no doubt led to the disposal of earlier copies.

In what follows, however, I do not want to look at the Merovingian period simply as an age of transmission between the Late Antique and Carolingian Worlds - nor do I want to look directly at the creativity of late Merovingian writers in expanding various genres, though they certainly were creative, not least with regard to hagiography ${ }^{8}$ and the liturgy. ${ }^{9}$ I will take those achievements for granted, as much as I will assume that the writers of historical texts contributed significantly to the

4 Yitzak Hen, Culture and Religion in Merovingian Gaul, AD 481-751, Leiden 1995, 183, with n. 78.

5 Michel Banniard, Viva voce. Communication écrite et communication orale du IVe au IXe siècle en occident latin, Paris 1992; Roger Wright, Late Latin and Early Romance in Spain and Carolingian France, Liverpool 1982.

6 Erich Auerbach, Mimesis: dargestellte Wirklichkeit in der abendländischen Literatur, Bern 1946, ch. 4.

7 David Ganz, The Merovingian Library of Corbie, in: Columbanus and Merovingian Monasticism, hrsg. von H.B. Clarke and Mary Brennan, Oxford 1981, 153-172; David Ganz, The preconditions for Carolingian Minuscule, in: Viator 18 (1987), 23-44: Rosamond McKitterick, 'The scriptoria of Merovingian Gaul: a survey of the evidence', in: Columbanus and Merovingian Monasticism, hrsg. von H.B. Clarke and Mary Brennan, Oxford 1981, 173 - 207; Jean Vezin, Une demi-siècle de recherches et de découvertes dans le domaine de l'écriture mérovingienne, in: Archiv für Diplomatik 50 (2004), 247-275.

8 E. g. Monique Goullet, Martin Heinzelmann und Christiane Veyrard-Cosme (Hrsg.), L'Hagiographie mérovingienne à travers ses réécritures, Sigmaringen 2010; Paul Fouracre, Merovingian history and Merovingian hagiography, in: Past and Present 127 (1990); Paul Fouracre and Richard Gerberding (Hrsg.), Late Merovingian France. History and Hagiography, 640-720, Manchester 1996.

9 Hen, Culture and Religion in Merovingian Gaul (Anm. 4), 184; Yitzak Hen, The Royal Patronage of Liturgy in Frankish Gaul, London 2001. 
genre in which they were working - and here I note that work on Gregory of Tours, Fredegar and the Liber Historiae Francorum currently in progress is forcing a re-evaluation of their writing. ${ }^{10}$ I will not try to argue a case for the theological ability of any late Merovingian, although they were certainly not as clueless over doctrine as is often assumed: there is even a Biblical commentary - the so-called Pseudo-Theophilus - which might well be a Frankish work, and is certainly preserved in a Merovingian context. ${ }^{11}$ Rather, I want to look at the knowledge of existing texts shown by Franks of the seventh and early eighth centuries. Carolingian culture would depend on these same resources, and would unquestionably do rather more with them: but it is worth looking at the Merovingians' own use of earlier writings.

I leave aside Merovingian legal culture, both secular and ecclesiastical, subjects that have attracted some attention. Yet, it is to the Merovingians that we must look for the transmission of late Roman law, in the form both of the Theodosian Code and of the Breviary of Alaric, since seven out of the surviving manuscripts of these two texts may have been written in pre-Carolingian Francia. ${ }^{12}$ Equally important is the role of the Frankish Church of the sixth and seventh centuries in the compilation of collections of canon law, as Hubert Mordek has demonstrated in his study of the Vetus Gallica. ${ }^{13}$ And there are other smaller collections of canons and letters of canonical significance from the Merovingian period, which are worthy of consideration as Ralph Mathisen has demonstrated. ${ }^{14}$ I leave these aside, along with the liturgical and hagiographical achievements of the Age.

All these studies have begun with manuscripts, and it is there, but in a rather more general way, that I want to begin. Manuscripts are a staple of Carolingian scholarship. By contrast they are practically absent from discussions of classical Antiquity and the Later Empire. This is a straightforward result of manuscript survival: hardly any date from the period before 500: thousands survive from the long ninth century.

10 Helmut Reimitz, History, Frankish Identity and the Framing of Western Ethnicity, 550 - 850, Cambridge 2015.

11 Yitzak Hen, A Merovingian Commentary on the Four Gospels (Pseudo-Theophilus, CPL 1001), in: Revue des Études Augustiniennes 49 (2003), 167 - 187.

12 Ian Wood, The Code in Merovingian Gaul, in: The Theodosian Code, hrsg. von Jill Harries und Ian Wood, London 1993, 161 -177; Ian Wood, Le Bréviaire chez les Burgondes, in: Le Bréviaire d'Alaric. Aux origines du Code civil, hrsg. von Michel Rouche und Bruno Dumézil, Paris 2009, 151 - 160; Stefan Esders, Römische Rechtstradition und merowingisches Königtum. Zum Rechtscharakter politischer Herrschaft in Burgund im 6. und 7. Jahrhundert, Göttingen 1997. For the manuscripts, see Elias Avery Lowe, Codices Latini Antiquiores, Oxford 1934-1971 [henceforth CLA], I, 110; I/IV, 446; V, 556, 591, 617, 625; VIII, 1064. See also the two supplementary articles by Bernhard Bischoff, Virginia Brown, Addenda to Codices Latini Antiquiores, in: Medieval Studies 47 (1985), 317 - 366, and Bernhard Bischoff, Virginia Brown und James J. John, Addenda to Codices Latini Antiquiores II, in: Medieval Studies 54 (1992), 286-307.

13 Hubert Mordek, Kirchenrecht und Reform im Frankenreich. Die Collectio vetus Gallica. Die älteste systematische Kanonessammlung des fränkischen Gallien, Berlin 1975.

14 Ralph Mathisen, Between Arles, Rome, and Toledo. Gallic collections of canon law in Late Antiquity, in: Cuadernos 'Ilu 2 (1999), 33-46. 
The Merovingian period sits uneasily in between. There are plenty of manuscripts from the period 500 to 750: perhaps 700 in all, of which around 200 come from Francia, and of those perhaps 175 come from the period after $600 .{ }^{15}$ Not surprisingly, given these relatively low numbers, far less attention has been paid to Merovingian manuscript production than to Carolingian, and the subject has been far less well integrated into broader discussions of the period. Moreover, to my knowledge, there is no list of late Merovingian manuscripts, and any attempt to create one is fraught with difficulty. Lowe's Codices Latini Antiquiores provides an obvious starting point, but few manuscripts are really closely dated. Paleography can only provide a rough chronological indication. Lowe very reasonably labelled his manuscripts by century, sometimes indicating the end of one and the start of another. For the Merovingianist 'eighth-century' is not a very useful descriptor, because fifty years of the hundred is outside his or her date range: the CLA places relatively few manuscripts firmly in the first half or middle of the eighth century. Lowe also used such descriptors as pre-Carolingian uncial, though that is a stylistic statement, rather than any clear indication that the manuscript in question was written before $751 .{ }^{16}$ In other words, any attempt to provide an overview of manuscript production from the mid seventh to the mid eighth century is necessarily speculative. Even so, the exercise is not unrevealing.

The figures that follow are at best estimates: not only is the dating necessarily speculative: descriptions of the contents of individual manuscripts are sometimes sketchy. Of course, collections of canons and other short documents are not easily described in a few lines: this, for instance, is the case with the four Merovingian canonical manuscripts, to which one might add a fifth, eighth-century manuscript, studied by Mathisen: ${ }^{17}$ not only do they include the canons of church councils, but also papal and theological letters. Equally, Brussels, Bibliothèque Royale 9850 -2, which is identified by Lowe as a collection of homilies and a commentary on the Gospels, turns out to be a rather interesting collection that does indeed include ten sermons of Caesarius of Arles and the so-called Gospel Commentary of Pseudo-Theophilus (which is derived largely from works of Jerome, Eucherius of Lyon and Arnobius), but also boasts pope Pelagius' Verba Seniorum, and the Decretum Gelasianum. ${ }^{18}$ Quite apart from the inclusion of Pseudo-Theophilus, the collection is interesting, and takes us beyond the standard works of Augustine, Jerome and Gregory the

15 See the statistics supplied in the Wikipedia entry on Codices Latini Antiquiores. I attach a provisional list drawn up from the CLA, in the light of the Leuven Database of Ancient Books (www.trismegistos.org). I am greatly indebted to Helmut Reimitz and, especially, to David Ganz for checking the list and providing additional information.

16 The Leuven Database of Ancient Books often provides reference to more recent judgments on the date and provenance of the manuscripts.

17 CLA VIII, 1162 (Cologne 212): V, 620 (Paris BN 12097): VI, 836 (Toulouse, 364): VIII, 1061 (Berlin, Phillipps 1745): I, 96 (Vatican Pal. Lat. 574).

18 CLA X, 1547: Hen, A Merovingian Commentary on the Four Gospels (Anm. 11), 170. 
Great, which we will meet regularly in what follows. The manuscript as a whole was commissioned by abbot Nomedius of Saint-Médard in Soissons, who lived around the year 700 , but who is otherwise more or less unknown ${ }^{19}$ - moreover Soissons is not usually singled out as a centre of Merovingian culture (unlike Corbie or Luxeuil), despite the fact that it was probably there that the Liber Historiae Francorum was composed. ${ }^{20}$

What follow are, thus, ballpark figures, rather than an exact quantification of the number of copies of individual works to have survived from the period 600 to 750 . Although there are some legal and liturgical manuscripts, the vast majority are theological. In particular a significant proportion of the works copied are by Jerome, Augustine, Gregory the Great, and Isidore. There are copies of six of Jerome's Biblical commentaries, together with his Contra Jovianum. ${ }^{21}$ There are also manuscripts which include letters of Jerome. ${ }^{22}$ Augustine's letters and sermons are yet more popular. ${ }^{23}$ Among his longer theological works, however, only the De Genesi ad litteram survives in several copies. ${ }^{24} \mathrm{~A}$ smaller range of Gregory the Great's works are preserved in Merovingian manuscripts, but there is one copy of the Cura pastoralis, ${ }^{25}$ as well as two each of the Commentary on Ezekiel and the Homilies on the Gospels, ${ }^{26}$ four of the Dialogues, ${ }^{27}$ and a remarkable nine copies of the Moralia. ${ }^{28}$ There are manuscripts with eleven works of Isidore, almost all of which are from the eighth century. ${ }^{29}$ No other theologian attracts the same attention as these four, though there are seven manuscripts with sermons of Caesarius. ${ }^{30}$ Origen, remarkably, is to be found in five manuscripts, one of which contains both his commentary on Genesis and on Leviticus. ${ }^{31}$ Ambrose is represented only by three manuscripts, ${ }^{32}$ Maximus of

19 Hen, A Merovingian Commentary on the Four Gospels (Anm. 11), 173.

20 Richard Gerberding, The Rise of the Carolingians and the Liber Historiae Francorum, Oxford 1987, $150-159$.

21 CLA V, 656, 657; VI, 776, 782b, 808; IX, 1379; X, 1454.

22 CLA VI, 762, 781, 782a; X, 1556; XI, 1616.

23 CLA VI, 173; VII, 614; VIII, 1141; IX, 1376, 1396; Supp, 1807.

24 CLA V, 547; VII, 855; Supp, 1745.

25 CLA III, 300.

26 CLA V, 634; XI, 1617: CLA XI, 1627; Supp, 1750.

27 CLA VII, 924; X, 1588; XI, 1626; Supp, 1808.

28 CLA II, 163 (Suppl), 174; IV, 497; V, 542, 692; VI, 745, 759; VII, 1015; IX, 1258. Of these CLA 692 would appear to be the earliest, but CLA 163 has been dated to 680-720: Babette Tewes, Die Handschriften der Schule von Luxeuil, Wiesbaden 2011, 147-149.

29 De Ecclesiastics Officiis, CLA IX, 1235: De Legibus, CLA V, 556; De natura rerum, CLA V, 564a, 567: Differentiae, CLA VII, 849: Etymologies, CLA VII, 604b: CLA Supp (1985), 1854 (seventh-century): Excerpta Patrum, CLA V, 664: Liber Proemiorum, CLA VI, 744, 766; VIII, 1141: Questions on the New Testament, CLA VIII, 1157; Sententiae, CLA V, 567: Soliloquies, CLA VII, 917: Synonyma, CLA VII, 929; VIII, 1197; IX, 1426.

30 CLA VII, 173, 917; VIII, 1105, 1142; IX, 1330; X, 1547a; XI, 1658.

31 CLA II, 128, 182; V, 532; VI, 774; XI, 1612

32 CLA VI, 802, 807; VII, 913. 
Turin, ${ }^{33}$ Cassian, ${ }^{34}$ and Basil ${ }^{35}$ by two apiece, and $\mathrm{Leo}^{36}$ and Julianus Pomerius ${ }^{37}$ by one.

The other most striking group of texts are the historical manuscripts. Most famously there is the earliest Fredegar codex, in which what has come to be known as the Fourth Book of Fredegar follows on from versions (edited in tune with the compiler's interests) of Hippolytus, Eusebius-Jerome, with continuations from Hydatius, the opening of Isidore's Chronicle, as well as an abridgement of the first six books of Gregory of Tours. ${ }^{38}$ This deserves recognition as a serious attempt at constructing past history. There are three other Merovingian copies of Eusebius-Jerome. ${ }^{39}$ Orosius, whose work was known to Fredegar, is also preserved in one or perhaps two Merovingian manuscripts. ${ }^{40}$ Most striking, however, is the transmission of Gregory of Tours: there are six or seven manuscripts that include versions of his Histories: ${ }^{41}$ seven or eight if one adds the Fredegar abridgement. As far as I know, only the Moralia survives in a greater number of Merovingian copies. The bishop of Tours inevitably dominates our reading of the sixth century, but he also casts a strong shadow over the seventh and eighth centuries, and beyond.

All in all, the manuscripts surviving from late Merovingian Gaul cannot be said to reveal a particularly lively intellectual world, but nor do they suggest a world in the doldrums. Of course a good number of the manuscripts in question come from a limited number of centres: notably Luxeuil, ${ }^{42}$ Corbie $^{43}$ and Lyon ${ }^{44}$ - and at the end of our period, Echternach. ${ }^{45}$ The manuscript evidence might, thus, indicate a few oases of scholarly activity in an otherwise barren world - although the existence of a good number of manuscripts that cannot be ascribed to any known centre, or

33 CLA VI, 778; VII, 913.

34 CLA VI, 724; XI, 1625.

35 CLA VI, 805; XI, 1598.

36 CLA VIII, 1197.

37 CLA IX, 1391.

38 CLA V, 608.

39 CLA V, 594; VI, 841; VII, 860.

40 CLA V, 171; VI, 765.

41 CLA I, 107; V, 670, 671; VI, 742a 742b (perhaps post 750); VIII, 1122; X, 1584. See Reimitz, Historiography of the Future (Anm. 10).

42 McKitterick, The scriptoria of Merovingian Gaul (Anm. 7); David Ganz, Texts and Scripts in Surviving Manuscripts in the script of Luxeuil, in: Ireland and Europe in the Early Middle Ages, Texts and Transmissions, ed. by Proinseas Ni Chathain and Michael Richter, Dublin 2001, 186-203; David Ganz, The Luxeuil Prophets and Merovingian Missionary Strategies, in: Beinecke Studies in Early Manuscripts, ed. by Robert G. Babcock, New Haven,1991, 105 - 117; Tewes, Die Handschriften der Schule von Luxeuil (Anm. 28).

43 David Ganz, Corbie in the Carolingian Renaissance, Sigmaringen 1990.

44 Elias Avery Lowe, Codices Lugdunenses Antiquiores, Lyon 1924; McKitterick, The scriptoria of Merovingian Gaul (Anm. 10), $177-184$.

45 Nancy Netzer, Cultural Interplay in the Eighth Century. The Trier Gospels and the makings of a scriptorium at Echternach, Cambridge 1994. 
which have been ascribed to otherwise little known communities, suggests that this is not the case. We have already noted the Nomedius codex from St Médard: ${ }^{46}$ equally striking is the copy of Origen's commentaries on Leviticus and Joshua, as well as Optatus of Milevis, that has been ascribed to St Jean de Reôme, ${ }^{47}$ an ascription that is all the more interesting in that the manuscript would seem to antedate Jonas of Bobbio's vita of the monastery's founder. A centre that has received little more attention, to which a number of Merovingian manuscripts have been ascribed, is Laon. ${ }^{48}$ Such examples suggest that culture was not just confined to a limited number of active monastic and episcopal centres. As we shall see, this impression is more than confirmed by the evidence of texts composed in Merovingian Francia.

I turn first to the most famous body of Merovingian literature, its hagiography- a body of material, one might note, that I have not mentioned in the context of Merovingian manuscripts. Famously there is only one Merovingian saint's life preserved in a manuscript that can be dated before 800: the Vita Wandregisili, which survives as what is effectively a small booklet. ${ }^{49}$ To this should be added the earliest copy of the Transitus Fursei. ${ }^{50}$ There is also a Merovingian copy of Eucherius' Passion of the Agaune Martyrs ${ }^{51}$ and another of the Gallo-Roman saint, Lupus of Troyes..$^{52}$ In addition there are eighth-century manuscripts of a Latin version the Life of Abraham the Hermit, ${ }^{53}$ and of a collection of passiones. ${ }^{54}$ Comparison between the Merovingian hagiographical works edited by Bruno Krusch and Wilhelm Levison and the manuscript survival of those works is a salutary reminder of how unrepresentative our surviving source material may be.

It is also worth remembering how misleading are the six volumes of saint's Lives published in the MGH. Most of the texts that were edited by Krusch and Levison were not written in the Merovingian period, or, if they were, they only survive in later versions. If we limit ourselves to works written between 600 and 750, alongside the works of Jonas of Bobbio, only the Lives of Audoin, Balthild, Bonitus, Fursey, Germanus of Granval, Gertrude, Leodegar (in its first recension), Praeiectus, and Sadalberga - as well as the Additamenta Nivialense de Fuillano and the Visio Baronti - are regarded as certainly Merovingian, ${ }^{55}$ although there are a number of others which

46 CLA X, 1547.

47 CLA XI, 1612.

48 CLA II, 128, 174; V, 630, 656; VI, 765, 766.

49 CLA V, 675.

50 CLA II, 202. See Oliver Rackham, Transitus Beati Fursei. A translation of the eighth-century manuscript Life of St Fursey, Norwich 2007.

51 CLA V, 589.

52 CLA XI, 1607.

53 CLA VI, 708.

54 CLA IX, 1238.

55 Monique Goullet, Introduction, in: L'hagiographie mérovingienne à travers ses réécritures (Anm. 8), 17. To Goullet's list I add the anonymous Vita Desiderii and the Vita Sadalbergae, on 
most scholars would now accept as pre-Carolingian. ${ }^{56}$ Among them there is the problematic text of the Vita Eligii: as with other texts there is much debate over the extent to which it was subject to réécriture, but that it is largely a work of the seventh century seems unquestionable. ${ }^{57}$ One might note, however, that this is certainly not the sum total of hagiographical works written in the late Merovingian period. Apart from anything else, it excludes Lives and Passions of non-Merovingian saints, for example the Passio of the Tergemini of Langres, written around 610 by Warnacharius. ${ }^{58}$

It is not my intention here to go through the achievement of the Merovingian hagiographers, although they undoubtedly did enrich the genres of both monastic and episcopal hagiography, as well as that of visionary literature. Rather, I wish to note the significance of the Merovingian saint's Lives as an indication of the resources available to the authors. The Bible, of course, is infinitely the greatest resource for our writers. Some hagiographers seem to refer to no other text. Krusch noted nothing but Biblical citations in the Passiones of Leodegar, and interestingly the one surviving letter of Leodegar himself is packed with Biblical references, but no other literary allusion has been noted. ${ }^{59}$

Leaving aside the Bible, we find an interesting, if limited list of citations. Much of it is to earlier hagiography. Among the classics of hagiographic literature there is Athanasius' Life of Antony, Paulinus' Life of Ambrose, Possidius's Life of Augustine, and Jerome's Lives of Hilarion and Paul. All of these are cited by Jonas of Bobbio in the preface to the first book of the Vita Columbani ${ }^{60}$ - and, while Jonas is exceptional in his listing of models, prologues and prefaces are the most likely section of a vita to include acknowledged citation of earlier hagiographical texts, which could amount to a setting out of one's models and credentials. Jerome's hagiography is also cited a number of times in the Vita Eligii. ${ }^{61}$

Among vitae from sixth-century Italy cited by Merovingian authors there is the Life of pope Silvester. ${ }^{62}$ It is a work that was already known by Gregory of Tours, ${ }^{63}$

which see Hans Hummer, Die merowingische Herkunft der Vita Sadalbergae, in: Deutsches Archiv 59 (2003), 459-493.

56 Goullet, Introduction (Anm. 55), 17 -18. In what follows I have largely ignored these 'potentiallyMerovingian' texts.

57 Martin Heinzelmann, L'hagiographie mérovingienne. Panorama des documents potentiels, in: L'hagiographie mérovingienne à travers ses réécritures (Anm. 8), 69-70.

58 Jean-Charles Picard, Langres, in: Topographie chrétienne des cités de la Gaule, IV, Province ecclésiastique de Lyon, hrsg. von Brigitte Beaujard, Paul Albert Fevrier, Jean-Charles Picard, Charles Pietri und Jean-François Reynaud, Paris 1986, 48.

59 Passiones Leodegarii, hrsg. von Bruno Krusch, Hannover 1910 (MGH, SRM V); Epistulae Aevi Merowingici Collectae, 17, hrsg. von Wilhelm Gundlach, Berlin 1892 (MGH, Epp III, Merowingici et Karolini Aevi I) (= Epistulae Aevi Merowingici, 6, CCSL CXVII (Turnhout, 1957)).

60 Jonas, Vita Columbani, I, 1, hrsg. von Bruno Krusch, Hannover 1905 (Ionae Vitae Sanctorum Columbani, Vedastis, Iohannis, MGH, SRG).

61 Vita Eligii, hrsg. von Bruno Krusch, Hannover 1902 (MGH, SRM IV).

62 Wilhelm Levison, Konstantinische Schenkung und Silvester-Legende, in: Aus Rheinische und Fränkische Frühzeit, hrsg. von Wilhelm Levison, Dusseldorf 1948, 396-417. 
and is cited by the authors of the Vita Germani Grandivallensis, the Passio Praeiecti, and the Vita Eligii. ${ }^{64}$ This interest in the Life of Silvester suggests a rather greater attention to the papacy than is usually associated with the Merovingian world - a point that is also illustrated by the copies of Gelasius' Decretum and pope Pelagius' Verba Seniorum in the Pseudo-Theophilus manuscript, ${ }^{65}$ and indeed of various papal letters which are to be found among the canon collections. ${ }^{66}$ I leave aside the works of Gregory the Great, though they too can be read as indicating an interest in Rome. Among the Gallo-Roman texts cited by hagiographers are the Dialogues and Vita Martini of Sulpicius Severus, ${ }^{67}$ the Lives of Hilary and Honoratus of Arles, ${ }^{68}$ as well as Constantius' Life of Germanus of Auxerre, ${ }^{69}$ and the Vita Caesarii. ${ }^{70}$ There are also references to works written in the Merovingian period itself: to the Lives of Hilary of Poitiers and Germanus of Paris, by Venantius Fortunatus, ${ }^{71}$ and from the seventh century, Jonas' Life of Columbanus, ${ }^{72}$ the Transitus Fursei, ${ }^{73}$ and the Passio Praeiecti. ${ }^{74}$ This awareness of very recent texts is particularly enlightening when we want to trace networks and communications.

There are some interesting, although perhaps not entirely surprising, groups of citations, which can plausibly be seen as reflecting particular networks or regional interests. The Lives of Hilary, Honoratus and Caesarius, are cited in the Life of an Arles saint, the nun Rusticula. References to the Life of Columbanus are to be found in texts from centres that had some connection with the Columbanian movement, including Saint-Wandrille, Laon (in the case of Sadalberga), and Grandval (where the author of the Passio Germani, Bobolenus, had the same name as an

63 Gregory of Tours, Decem Libri Historiarum, II, 31, hrsg. von Bruno Krusch und Wilhelm Levison, Hannover 1951 (MGH, SRM, I, I).

64 Vita Germani Grandivallensis, 1, 4, 6, hrsg. von Bruno Krusch (MGH, SRM V); Passio Praeiecti, 14 , hrsg. von Bruno Krusch (MGH, SRM V); Vita Eligii, 10.

65 CLA X, 1547.

66 Mathisen, Between Arles, Rome, and Toledo (Anm. 14).

67 Citation of Sulpicius Severus in Jonas, Vita Columbani, I, 1; Vita Rusticulae, 23, hrsg. von Bruno Krusch (MGH, SRM IV); Vita Eligii, 2, 21, 34, 38; Vita Germani Grandivallensis, passim; Vita Sadalbergae, passim, ed. by Bruno Krusch (MGH, SRM V); Vita Amandi, 6, 9, hrsg. von Bruno Krusch (MGH, SRM V).

68 Citations of the Lives of Hilary and Honoratus in Vita Rusticulae, 22, 24, 25; Vita Eligii, I, 1. 69 Citation of Constantius, Vita Germani, in Vita Wandregisili, 3, hrsg. von Bruno Krusch (MGH, SRM $\mathrm{V})$.

70 Citation of Vita Caesarii in Vita Rusticulae, 6, 11, 15, 16.

71 Citation of Vita Hilarii in Jonas, Vita Columbani, I, 1; Vita Germani in Jonas, Vita Iohannis, 19, hrsg. von Bruno Krusch (Ionae Vitae Sanctorum).

72 Citations of the Vita Columbani in Vita Wandregisili, 1; Vita Germani Grandivallensis, passim; Vita Sadalbergae, passim; Passio Praeiecti, passim.

73 Citations of the Transitus Fursei in Vita Wandregisili, 3.

74 Citation of Passio Praeiecti in Vita Sadalbergae, pref. 
early abbot of Luxeuil, suggesting a family link). ${ }^{75}$ The author of the Passio Praeiecti is harder to place, but Praeiectus and his hagiography would seem to have had Columbanian associations. ${ }^{76}$

The citations of earlier vitae by hagiographers give us some sense of the hagiographic tradition within Francia. Yet, neither this provable hagiographic tradition, nor indeed the collection in the Monumenta can really convey the liveliness of the Merovingian interest in the Lives of saints and their cults. For that one has to turn to the development of the so-called Hieronymian Martyrology - certainly nothing to do with Jerome, and equally certainly having its origins in the Merovingian world. Exactly how the collection developed is unclear, but one stage of development unquestionably occurred in late-seventh-century Luxeuil, ${ }^{77}$ and it is witnessed by eighth-century manuscripts from both Luxeuil and Echternach. ${ }^{78}$ Although the Anglo-Saxons (including Acca at Hexham and Bede at Jarrow) and the Irish would soon show an interest in the idea of a martyrology, its main early development appears to have been Frankish and seventh century.

Alongside the citations of earlier hagiographic texts to be found in the Merovingian vitae and passiones, there are allusions to some of the classics of ascetic literature. Jonas, for instance, cites the writings of John Cassian, ${ }^{79}$ while the author of the Vita Eligii refers relatively frequently to works by Rufinus, both the Historia Monachorum as well as the Historia Ecclesiastica ${ }^{80}$ - though here one does not know whether the citations belong to a phase of réécriture. Perhaps most striking is the interest shown in Gregory the Great's Dialogues, which are cited in the Transitus Fursei, a text that has plausibly been dated to $656-7,{ }^{81}$ and the Visio Baronti of $678-9,,^{82}$ as

75 This suggests diffusion of the text albeit within a very specific group: Ian Wood, The Vita Columbani and Merovingian hagiography, in: Peritia 1 (1982), 63-80, at 68-69. See also Albrecht Diem, Monks, Kings, and the Transformation of Sanctity. Jonas of Bobbio and the end of the Holy Man, in: Speculum 82 (2007), 521-559. Alexander O'Hara, The Vita Columbani in Merovingian Gaul, in: Early Medieval Europe 17 (2009), 126-153, argues for a wider readership, but essentially points at that identified by Wood and Diem, although he adds to Wood's list of vitae influenced by Jonas the Vita Sadalbergae, now thought to date from c.680 (see Heinzelmann, L'hagiographie mérovingienne (Anm. 57), 80-81, where there is also discussion of the Jonas-influenced Vita Segolenae, written between 642 and the composition of the Vita Wandregisili).

76 Fouracre and Gerberding, Late Merovingian France (Anm. 8), 258-260; Ian Wood, The Ecclesiastical Politics of Merovingian Clermont, in: Ideal and Reality in Frankish and Anglo-Saxon Society, hrsg. von Patrick Wormald, Oxford 1983, 34-57, at 35, n. 2.

77 See most recently, Felice Lifshitz, The Name of the Saint. The Martyrology of Jerome and Access to the Sacred in Francia (627-827), Notre Dame 2006.

78 CLA V, 605, 664.

79 Jonas, Vita Iohannis, 18.

80 Vita Eligii, I 33; II 1, 3, 6, 8, 10, 26, 31, 81.

81 Transitus Fursei, 1. For the date, Alain Dierkens, Abbayes et Chapitres entre Sambre et Meuse (VIIe-XIe siècles), Sigmaringen 1985, 304, n. 147.

82 Visio Baronti, 1, 17, and passim, hrsg. von Wilhelm Levison (MGH, SRM V); Isabel Moreira, Dreams, Visions and Spiritual Authority in Merovingian Gaul, Ithaca 2000, 158-167. 
well as the contemporary Passio Praeiecti and the slightly later Vita Boniti. ${ }^{83}$ Nor are the Dialogues the only work of Gregory's to be cited: the Visio Baronti alludes to the Homilies on the Gospels, ${ }^{84}$ while there are citations of the Moralia in the Passion of Praeiectus and the Life of Wandregisil. ${ }^{85}$ In this last instance we may be able to link the interest shown in the pope's works with the known visit of the saint's nephew Godo to Rome, where he was given relics and books by pope Vitalian. ${ }^{86}$ It is worth remembering the prominence of works by Gregory among manuscripts of the Merovingian period: as we have already seen, the Moralia, the Homilies on the Gospels and the Dialogues, all exist in Merovingian copies. Here there is a neat coincidence of manuscript and citation evidence.

The allusions and citations provided by Merovingian hagiographers thus allow us to see them working consciously within the broader tradition of western hagiography, and, to a lesser extent, with some theological awareness. The Vita Wandregisili also reveals a knowledge of Isidore's Sententiae, ${ }^{87}$ while Jonas would seem to have known the Etymologies ${ }^{88}$ - both of them texts preserved in eighth-century manuscripts. ${ }^{89}$

There is less evidence for knowledge of the pagan classics, though it is not entirely absent. Jonas appears to cite Livy and the Metamophoses of Ovid, ${ }^{90}$ while the Vita Eligii (again assuming that we are not dealing with a Carolingian interpolation) cites the Ars Amatoria. ${ }^{91}$ To these Jonas adds citations of Sallust and Vergil ${ }^{92}$ - which may, of course, reflect what he had learnt at Bobbio rather than what was available in Francia. Sallust, however, was known to Gregory of Tours, who twice cites his opinions. $^{93}$

Works of hagiography do not have to demonstrate a mastery of the subtler points of theology, and it is true that the Merovingian Age marked no theological high point - though we would be wrong to think that there was no interest in the material. As we have seen the Gospel Commentary of Pseudo-Theophilus was transcribed in Francia, and it may even be a Frankish composition. ${ }^{94}$ An awareness of the Tricapitoline and Monothelete crises can be traced in our sources. In particular, we have evidence

\footnotetext{
83 Passio Praeiecti, 36; Vita Boniti, 4, 30, hrsg. von Bruno Krusch, Hannover 1913 (MGH, SRM VI).

84 Visio Baronti, 6, 17.

85 Passio Praeiecti, pref.; Vita Wandregisili, 1.

86 Ian Wood, Between Rome and Jarrow: papal relations with Francia and England, from 597 to 716, in: Chiese Locali e Chiese Regionali nell'alto medioevo, Settimane di Studio LXI (Spoleto, 2014), 297-317, at 306.

87 Vita Wandregisili, 1.

88 Jonas, Vita Columbani, II, 25.

89 CLA VII, 604; VIII, 567.

90 Jonas, Vita Columbani, I, 2, 3.

91 Vita Eligii, II, 36.

92 Jonas, Vita Columbani, I, 1, versus; II, 2, 5, 9.

93 Gregory, Decem Libri Historiarum, IV, 13; VII, 1.

94 Hen, A Merovingian Commentary on the Four Gospels (Anm. 11).
} 
for pope Martin canvassing for support in the context of the Lateran Council of $649 .{ }^{95}$ There is no evidence that the Merovingian Church intervened significantly in the debates, but Frankish churchmen were certainly kept informed. ${ }^{96}$ Chrodobert of Paris reveals that in order to reply to a question about the adultery of nuns he had checked the canons of the œcumenical councils ${ }^{97}$ - a point, of course, that takes us back to the world of the Vetus Gallica. The citations that litter his letter are, however, entirely Biblical. Moreover we do have a sixth- or seventh-century manuscript of the Council of Antioch. ${ }^{98}$ It is true that the Merovingian world produced no Julian of Toledo, Aldhelm or Bede in the late seventh century, but we should not dismiss Merovingian learning too easily.

Chrodobert is probably to be identified with Frodebert of Tours, whose epistular exchange with Importunus of Paris gives us a totally different impression of his learning than does his other surviving letter. ${ }^{99}$ The exchange appears to include allusions to the grammarian Donatus, as well as such theologians as Augustine and, above all Jerome. ${ }^{100}$ We thus see that a bishop might limit his range of literary reference to the Bible or the canons in his correspondence - and this is echoed in the letter of Leodegar and the collection of Desiderius of Cahors ${ }^{101}$ - or he might show a much greater cultural range, depending on the addressee. That Desiderius' knowledge stretched beyond the Bible is made clear in his Carolingian vita, which talks of his education in the studia litterarum, his Gallicana eloquentia, and his skill in leges Romanae. ${ }^{102}$ Although the Life is probably to be dated to the ninth century, its author had access to authentic information, including the saint's correspondence.

Our best evidence for theological knowledge in Merovingian Francia comes from the Liber Scintillarum of Defensor of Ligugé. ${ }^{103}$ Four of the manuscripts that contain the Liber Scintillarum, together with a fifth fragment, might belong in the eighth cen-

95 Wood, Between Rome and Jarrow (Anm. 86), 310-311.

96 Wood, Between Rome and Jarrow (Anm. 86).

97 Epistulae Aevi Merowingici, 16 (MGH, Epp. III = ep. 4 CCSL).

98 CLA Supp (1992), 1870.

99 Gerardus J.J. Walstra, Les cinq épitres rimées dans l'appendice des Formules de Sens, Leiden 1962. On the letters see now Danuta Shanzer. The tale of Frodebert's tail, in: Colloquial and Literary Latin, hrsg. von Eleanor Dickey, Cambridge 2010, 376-405, and Yitzhak Hen, Changing places. Chrodobert, Boba, and the wife of Grimoald, in: Revue Belge de Philologie et d'Histoire 90 (2012), $225-244$.

100 Walstra, Les cinq épitres rimes (Anm. 99), 36; Shanzer. The tale of Frodebert's tail (Anm. 99), $388-391,393$.

101 Epistulae Aevi Merowingici, 17 (MGH, Epp. III = ep. 6 CCSL): Desiderius of Cahors, Epistulae, hrsg. von William Arndt (MGH, Epp. III).

102 Vita Desiderii Caturcensis, 1, hrsg. von Bruno Krusch (MGH, SRM IV).

103 I have discussed this further in The Irish in England and on the Continent in the seventh century, Oxford O’Donnell lectures 2012. See now Peritia 26 (2015), 171-198, and Peritia 27 (2016) (forthcoming). 
tury, but even the earliest would seem to have been written after $750 .{ }^{104}$ Of Defensor himself we know little, although the preface of the work allows us to conclude that he was a monk of Ligugé, and that he addressed his work to abbot Ursinus, who would appear to have been the same as the author of the second Passio Leodegarii, which was dedicated to bishop Ansoald of Poitiers. ${ }^{105}$ This small group in Poitiers is interesting because it lies outside the area with which we can associate most of the late Merovingian manuscripts and texts - it is far to the west of Luxeuil, Corbie and Lyon. Despite its foundation by St Martin, Ligugé is not a known centre of intellectual achievement. This makes Defensor's work all the more precious.

The Liber Scintillarum is not a particularly original work: it is a florilegium, although the organisation of the chosen passages, which revolves around a series of moral themes, is very much Defensor's own. What, however, is extraordinary about the text is the range of works cited. ${ }^{106}$ In addition to the Bible, Defensor cites most of the Church Fathers, but above all Jerome, Augustine, and Gregory the Great. He knows a number of Jerome's commentaries, but most often cites his letters. Of Augustine's works he turns most to the Enarrationes in Psalmos. Gregory he cites yet more often, and especially the Moralia, the Homilies on Ezekiel and on the Gospels, as well as the Regula Pastoralis, and the Dialogues. He also quotes with notable frequency from Isidore, citing the Synonyma, the De Ecclesiasticis Officiis, and above all the Sententiae. And he has access to a large number of much rarer authors, among them Ephraem the Syrian. Although the Liber Scintillarum contains few classical citations, they are present: there are quotations from Aristotle, Cicero, Hesiod and Terence. In other words Defensor had access to most of the texts that we have already discussed, and a good deal more. He allows us to be reasonably certain that the evidence of the manuscripts of Merovingian Gaul and of the citations to be found in Merovingian hagiography should not be understood as indicating the existence of a few pools of knowledge in an otherwise desolate intellectual landscape, but rather a much more general level of theological and even secular knowledge, spread over a geographically large proportion of the Merovingian kingdom.

This picture is enriched when we add the texts of historical works written in the Merovingian period. Although Fredegar's concerns are a good deal less ecclesiastical than are those of Gregory of Tours, he was clearly interested in some Church matters, as can be seen in his comments on bishop Desiderius of Vienne ${ }^{107}$ and more especially in his intimate knowledge of the Life of Columbanus, which certainly puts him

104 Würzburg, Universitätsbibl, M.p.th.f.13: see the list in Henri-M. Rochais (Hrsg.), Defensor de Ligugé, Livre d'étincelles, vol 1, Sources Chrétiennes 77 (1961), 45. Also CLA Supp (1985), 1815, for an additional eighth-century manuscript.

105 Rochais (ed.), Defensor de Ligugé (Anm. 104), vol 1, 16-21.

106 See the index in Henri-M. Rochais (Hrsg.), Defensor de Ligugé, Livre d'étincelles, vol 2, in: Sources Chrétiennes 86 (1962), 321 - 344.

107 Fredegar, IV, 32, hrsg. von Bruno Krusch, Hannover 1888 (MGH, SRM II). 
somewhere within a monastic circle, ${ }^{108}$ whether or not he was a monk, which he may well have been. It is not, however, in the text of what is usually called the Fourth Book of Fredegar's Chronicle, but rather in the earlier sections, that one best sees the resources available to the compiler of the work. We have already noted the use made in books I and II of Liber Generationis of Hippolytus, the Chronicles of Eusebius-Jerome, Hydatius and Isidore - a fair collection of historical writing. In addition, the author knew an account of the Trojan legend that does not seem to have come down to us. ${ }^{109}$ In Book III a version of the Gesta Theoderici (a legendary account of Theodoric the Great) has been integrated into the abbreviated version of Gregory of Tours' Histories. ${ }^{110}$ Fredegar is certainly not an unlearned chronicler lacking resources, but would appear to have been engaged in presenting an extremely sophisticated discussion of government - although his precise goals are unclear, owing to his failure to complete the work. ${ }^{111}$

The Liber Historiae Francorum is a less ambitious text, but again one would be wrong to underestimate the author's skill or resources. As in the case of most Merovingian writers, his or her chief resource was the Bible. The extent to which Biblical reference enriches the historian's argument is only just beginning to be appreciated. ${ }^{112}$ The Bible apart, the author's chief source was Gregory of Tours, but both Lex Salica ${ }^{113}$ and Isidore's Etymologies ${ }^{114}$ are cited. Once again, like Fredegar, the author of the Liber Historiae Francorum had access to a version of the Trojan legend. ${ }^{115}$

The Trojan legend provides an interesting insight into the limitations of our knowledge of Merovingian culture. It was clearly available, being referred to in both Fredegar's Chronicle and in the Liber Historiae Francorum. The version of the legend that was cited, however, was certainly not that of Homer, or indeed Vergil (although there is some evidence for knowledge of the Aeneid as well as the Eclogues and the Georgics in Merovingian Francia). ${ }^{116}$ It may have been the Ilias Latina, though it is more likely to have been the History of Dares of Phrygia - but clear manuscript

108 Fredegar, IV, 36. Ian Wood, Fredegar's Fables, in: Historiographie im frühen Mittelalter, hrsg. von Anton Scharer und Georg Scheibelreiter, Wien 1994, 359-366, at 360.

109 Fredegar, II, 3-5, 8, 18, 36; III, 2.

110 Fredegar, II, 57. On this see Ian Wood, Iocundus in fabulis: the value of friendly advice, in: Splendor Reginae. Passions, genre et famille, hrsg. von Laurent Jégou, Sylvie Joye, Thomas Lienhard und Jens Schneider, Turnhout 2015, 327-338.

111 Wood, Fredegar's Fables (Anm. 108), 359-366.

112 Philipp Dörler, The Liber Historiae Francorum - a model for a new Frankish self-confidence, in: Networks and Neighbours, 1, 1 (2013), at http://networksandneighbours.org/index.php/n/article/ view/34.

113 Liber Historiae Francorum, 4, hrsg. von Bruno Krusch (MGH, SRM II).

114 Liber Historiae Francorum, 5.

115 Liber Historiae Francorum, 1.

116 Vita Balthildis, B, 2, hrsg. von Bruno Krusch (MGH SRM II); Jonas, Vita Columbani, I, 1, 29; II 2, $5,7$. 
evidence for the presence of the text of Dares has to wait until the early Carolingian period. ${ }^{117}$ The references to Troy in our Merovingian sources, and the availability of Dares in the Carolingian world suggests that seventh-century Francia played an important role in the development and dissemination of the medieval Troy story - but that can only be an inference.

Dares, and indeed the Gesta Theodorici, take us beyond the Biblical and theological resources of late Merovingian Francia, and indeed beyond the classical. By the early eighth century a number of exotic works were circulating within Francia. For instance, the Latin translation of the strange apocalyptic text known as PseudoMethodius survives in a manuscript written apparently in 727 , while a second abridged translation may date from $732 .{ }^{118}$ This is particularly remarkable, given that the Syriac original seems to have been composed shortly after 690, and it may well have been translated into Greek before a Latin version was produced. ${ }^{119}$ Such transmission from the Greek East sorts ill with our standard picture of Merovingian culture, though it should be noted that Fredegar apparently had access to Byzantine sources, ${ }^{120}$ and a possible reference to Procopius' Vandalic War has been noted in the Transitus Fursei of $656-7 .^{121}$

The text of Pseudo-Methodius appears to have been known to the author of the fantastical geographical work known as Aethicus Ister. ${ }^{122}$ This must have been written in the mid eighth century, since the author appears to quote the Liber Historiae Francorum, as well as Pseudo-Methodius, ${ }^{123}$ and it was circulating within Bavaria well before $800 .{ }^{124}$ Access to the History of the Franks would seem to indicate that Aethicus Ister originated in Francia, and in many respects the author's sources overlap with works we have already mentioned: Orosius, Isidore's Etymologies and Sententiae, letters of Jerome, as well as Vergil. Among rarer works, he had access to Mac-

117 CLA Supp, 1744. For the Trojan legend in the early Middle Ages see now Kivilcim Yavuz, Transmission and Adaptation of the Trojan Narrative in Frankish History between the Sixth and Tenth Centuries, PhD thesis, University of Leeds 2015.

118 CLA VII, 604c; Richard Pollard, One Other on Another: Petrus Monachus' Revelationes and Islam, in: Francia and Medieval France, hrsg. von Meredith Cohen und Justine Firnhaber-Baker, Farnham 2010, $25-42$.

119 Gerrit J. Reininck, Pseudo-Methodius. A concept of history in response to the rise of Islam, in: The Byzantine and Early Islamic Near East I: The Literary Sources, hrsg. von Averil Cameron und Lawrence I. Conrad, Princeton 1992, 149-187.

120 Andreas Fischer, Rewriting history. Fredegar's perspective on the Mediterranean, in: Western Perspectives on the Mediterranean. Cultural Transfer in Late Antiquity and the Early Middle Ages, 400 - 800 AD, hrsg. von Andreas Fischer und Ian Wood, London 2014, 55 - 75.

121 Transitus Beati Fursei, 12, hrsg. von Oliver Rackham, 30, n. 48.

122 Michael W. Herren (Hrsg.), The Cosmography of Aethicus Ister. Edition, Translation, and Commentary, Turnhout 2011.

123 Herren, The Cosmography of Aethicus Ister (Anm. 122), xxxviii-xl.

124 Winfried Stelzer, Ein Alt-Salzburger Fragment der Kosmographie des Aethicus Ister aus dem 8. Jahrhundert, in: Mitteilungen des Instituts für Österreichische Geschichtsforschung 100 (1992), $132-149$. 
robius' Somnium Scipionis, the Liber Monstrorum, a version of the Alexander legend, and Cosmas Indicopleustes. ${ }^{125}$

It used to be thought that Aethicus Ister must have been written in Ireland, or at least by an Irishman. ${ }^{126}$ An Irish provenance, however, seems to be unlikely, and at least in terms of the sources used by the author, there is no reason to deny a Frankish author. Essentially, most of the resources available to the seventh-century Irish can be shown to have been known in Francia - though there are exceptions in the field of computistics, and among the works of Isidore. ${ }^{127}$ As regards Isidore's œuvre, however, different works seem to have been available in the various parts of western Europe: nowhere, not even Spain, can one demonstrate a knowledge of his complete output.

The picture I have presented is, deliberately, one in which no emphasis has been placed on either the Irish or the Anglo-Saxons - in certain intellectual traditions the saviours of western civilisation. ${ }^{128}$ The argument for this insular contribution to culture has not a little to do with the ideology of French catholics in the nineteenth century, who were working for a religious revival, and saw the achievements of Daniel O'Connell over the matter of catholic emancipation as an example to be followed. ${ }^{129}$ Columbanus was the prototype for O'Connell, who was idolised by, among others, Montalembert - and it is with him and his friend Frédéric Ozanam that the view of the Irish salvation of of western Europe begins.

What our early medieval sources suggest is a much more complex picture. Francia was not uncultured at the time of Columbanus' arrival: this was, after all, the age of Gregory of Tours, whose sophistication is becoming ever more apparent, and of Venantius Fortunatus. But Columbanus could be seen as the figurehead of a monastic reform movement. As in most such movements the reformers overemphasised the weakness of what came before - and indeed Jonas, who largely created the model of Columbanus the reformer, conceded as much in other of his writings: John of Reôme appears as a sixth-century forerunner of the Irish saint in Jonas's Vita Iohannis (and one might note that it is to his monastery that one of the manuscripts of Origen has been ascribed). ${ }^{130}$ This is not to deny Columbanus' own charisma, his intellectual and rhetorical ability (apparent in his letters and sermons), or his role in popularising monasticism in north-eastern Francia. He also played a role in introducing the type of text known as the penitential to the continent, although its original introduction was surely the work of Britons, and above all Gildas, who seems to have invented

125 Herren, The Cosmography of Aethicus Ister (Anm. 122), xxxiv-lv.

126 Herren, The Cosmography of Aethicus Ister (Anm. 122), xiv.

127 Wood, The Irish in England and on the Continent in the seventh century (Anm. 103).

128 E.g. Thomas Cahill, How the Irish saved Civilization, New York 1995.

129 Ian Wood, Modern Origins of the Early Middle Ages, Oxford 2013, 144-146.

130 Albrecht Diem, The Rule of an "Iro-Egyptian” monk in Gaul. Jonas'Vita Iohannis and the construction of a monastic identity, in: Revue Mabillon 19 (2008), 5-50: CLA 11, 1612. 
the genre. ${ }^{131}$ To admit a Columbanian movement or Columbanian influence is not to claim that Frankish culture was nothing before the Irishman's arrival. That is clearly nonsense.

The same can be said of the Anglo-Saxon impact on Frankish culture. There is no question that Anglo-Saxons, notably Willibrord and Boniface, had a major impact on the Rhineland, and at Echternach in particular one can see a combination of Frankish, Irish and Anglo-Saxon cultural traditions, ${ }^{132}$ but the Austrasians did not need the Anglo-Saxons to raise them from an uncultured mire. Indeed, in the mid-seventh century it was Francia that was supplying the resources on which the Anglo-Saxons of the eighth century depended. Many of the books that would ensure that Wearmouth-Jarrow had an outstanding library in the days of Bede were collected by Benedict Biscop in Lyon and Vienne. ${ }^{133}$ Bertila, abbess of Chelles in the second half of the seventh century, apparently sent teachers and books to Wessex and west Mercia. ${ }^{134}$ If, as has been claimed, the Transitus beati Fursei was written by an Englishman on the continent ${ }^{135}$ - a claim which is remarkable given the probable date of composition of the text, which is probably $656-7$, and thus far earlier than other surviving Anglo-Saxon religious works in Latin - one would have to guess that the author had been trained by one of the masters and teachers who Bede says were introduced to Kent and East Anglia by bishop Felix. ${ }^{136}$ Felix, however, was a Burgundian, so the author's education would have been a Frankish one, even if he were an AngloSaxon by birth. Bede, it might be remembered, did not belittle the religion and learning of mid-seventh-century Francia, seeing it rather as a magnet for Anglo-Saxon princesses looking to enter nunneries, ${ }^{137}$ as well as providing resources on which Wearmouth-Jarrow depended.

Late Merovingian Francia was not, then, a region lacking in culture: there had been no destruction of classical civilisation, although we can certainly talk about decline if we take as our criteria an ability to write in the style of Cicero and a knowledge of the Latin classics. These were not central to Merovingian culture, which looked first and foremost to the Bible and then to the Church Fathers. With regard to the latter, the distribution of their works was patchy: some works that we would regard as outstanding (Augustine's City of God, for instance) were apparently

131 Richard Sharpe, Gildas as a Father of the Church, in: Gildas, New Approaches, hrsg. von Michael Lapidge und David N. Dumville, Woodbridge 1984, 193-205.

132 Netzer, Cultural Interplay in the Eighth Century (Anm. 45).

133 Bede, Historia Abbatum, 4, hrsg. von Christopher Grocock und Ian Wood, Oxford 2013 (Abbots of Wearmouth and Jarrow).

134 Patrick Sims-Williams, Religion and Literature in Western England, 600 - 800, Cambridge 1990, 110, 204.

135 Rackham, Transitus beati Fursei (Anm. 50), vi.

136 Bede, Historia Ecclesiastica, III, 18, hrsg. von Charles Plummer, Oxford 1896 (Baedae Opera Historica).

137 Bede, Historia Ecclesiastica, III, 8. 
unknown or nearly so. But others were remarkably widespread, including Gregory's Dialogues and, more surprising given its intellectual toughness, the Moralia.

Of course we can talk about a dumbing down of culture - but then many an age would be hard pressed to compete with that of Augustine, Jerome and Ambrose. We do not find authors capable of the intellectual fireworks of the Church Fathers, nor even of Gregory the Great, Isidore or Bede, in seventh-century Francia. Yet the culture that there was seems to have been remarkably well spread: we see it in Lyon, Luxeuil, Corbie, Soissons Laon, and Ligugé, as well as other centres that produced works of hagiography and history. Arguably this culture had spread more widely and more deeply than the brilliant aristocratic culture of Sidonius Apollinaris and the late Roman aristocracy.

Rosamond McKitterick, in a phrase approved by Yitzhak Hen, has talked of 'a late Merovingian and early Carolingian preoccupation with authority, orthodoxy and correctness, that was to become the prevailing characteristic of Carolingian scholarship.'138 This certainly identifies some aspects of culture in the late seventh and early eighth centuries: notably the emphases on the Bible and on the Church Fathers. Those preoccupations depended on a remarkable dissemination of texts and of knowledge, which was not confined to elementary works of orthodoxy. And although the Merovingians produced no startlingly innovative theology or philosophy, they used that knowledge in original ways, in their history, their hagiography and their liturgy.

138 Hen, A Merovingian Commentary on the Four Gospels (Anm. 11), 185. 


\section{A provisional handlist of Merovingian manuscripts by date ${ }^{139}$}

c. 5 ? (otherwise dated c. 8)

5. 523: Paris, BN Lat 152, Hilary on Psalms (Lyon)

c. $5-6$

6. 772: Lyon, Bibl Ville. 425 (351) + Paris, BN Lat 1585, Psalter

C. 6 [12]

1. 110: Vat. Regin. Lat. 886, Cod. Theod (Lyon?)

5. 573: Paris, BN Lat $8913+8914$, Avitus (Burgundy)

5. 591: Paris, BN Lat 9643, Codex Theodosianus (Lyon)

5. 625: Paris, BN Lat 12161, Breviary of the Theodosian Code

5. 659: Paris, BN Lat 13367, Hilary on the Trinity

6. 724: Autun, Bibl Mun. $107+$ Paris, BN Lat nov acq 1629, Cassian, Institutiones

6. 771: Lyon, Bibl Ville 403 (329) + 1964 (1840), Heptateuch (Lyon)

6. 777: Lyon, Bibl Ville 478 (408), Augustine, de Consensu Evangeliorum

6. 807: Orleans, Bibl Mun 192 (169), Ambrose, Hexameron

8. 1064: Berlin, Staatsarchiv Phillipps 1761, LRV (Lyon)

9. 1324: Munich, CLM 22501, Breviary of Alaric

9. 1391: Wolfenbüttel, Herzog Bibl, Weissenburg 76, NT lections

c. $6-7$ [20]

1. 104a: Vat. Regin. Lat. 267, Fulgentius ad Monimum

1. 104b: Vat. Regin. Lat. 267, Fulgentius contra Arianos

5. 549: Paris, BN Lat 2739, fragment

5. 589: Paris, BN Lat 9550, Eucherius, Formulae Spirituales; Passio Acaunensium Martyrum (Lyon)

5. 619: Paris, BN Lat 12097: Canones Galliae; Catalogus Pontificum (Arles/Lyon)

5. 703a: Paris, BN Lat 12475: Breviary of Alaric

5. 703b: Paris, BN Lat 12475, Excerpta Moralia on OT (similar to Avitus codex)

6. 724: Autun, Bibl Mun. 107 + Paris, BN Lat nov acq 1629, Augustine, Enarrationes in Psalmos

(Spanish border zone)

6. 773a: Lyon, Bibl Ville 426 (352) + Paris, BN Lat 1629, Augustine, Enarrationes in Psalmos (Lyon)

6. 789: Metz, Bibl Mun. 732 + Montpellier, Bibl Univ 241, Cyril, de Ratione Paschae; Eucherius on the OT

6. 797: Orleans, Bibl Mun 19, Liber Regum

6. 805: Orleans, Bibl Mun. 192 (169), Rule of Basil (possibly French or Italian)

7. 864: Berne, Burgerbibl 380, Cledonius, Ars Grammatica

8. 1108: Karlsruhe, Aug CCLIII, Psalter

139 The list is based on the descriptions in E.A. Lowe, Codices Latini Antiquiores (Oxford, 1934-71) [CLA], with information from the two supplementary articles by Bernhard Bischoff, Virginia Brown, 'Addenda to Codices Latini Antiquiores', Medieval Studies 47 (1985), pp. 317 -66, and Bischoff, Brown und James J. John, Medieval Studies 54, 'Addenda to Codices Latini Antiquiores (II)', (1992), pp. 286-307. I have also consulted the Leuven Database of Ancient Books (www.trismegistos.org) for more recent opinions on dating. I am deeply indebted to David Ganz, for evaluation of the chronology, and to Helmut Reimitz. 
8. 1162: Köln, Dombibl 212, Collectio Canonum (580-604)

9. 1429: Würzburg Univ M P TH Q 1a, Kilian Gospels

10. 1481: Vienna Nature Lat 502, Gospels

10. 1556: Ghent, Univ 246, Jerome, Letters

11. 1612: St Petersburg, Publ Lib Q v 1.2, Origen, Homilies on Leviticus and Joshua; Optatus of

Milevis on Persecution (perhaps Moutiers St Jean)

Supp (1992). 1870: Colmar, Arch Dép, Frag 700, Acta Concilii Antiochensis

c. 7 [39]

1. 54: Vat. Lat. 7223 , Gospels

1. 107: Vat. Regin. Lat. 689 bis + Leiden, fr. 21 + Copenhagen, NY KGL SAML 1878 fol, Gregory of Tours, DLH Frag.

1. 111: Vat. Regin. Lat. 1204, Leges Visigothorum (Spain?)

2. 141: Cheltenham, Phillipps $1329+$ Yale, Gospels

2. 182: London, BL Burney + St Petersburg, F v 1.4, Origen, Homily on Balaam; Chrysostom

(Corbie)

4. 46: Turin, BN A II 2 + Vat Lat 5766 , Codex Theodosianus

4. 500: Verona, XL 38, Tractatus Philosophicus

5. 532: Paris, BN Lat 1625, Origen on Genesis

5. 607: Paris, BN Lat 10863, Lectionary

5. 671: Paris, BN Lat 17655, Gregory of Tours, DLH

5. 679: Paris, BN Lat nov acq 1063, NT (Copied at Corbie by scribes of 5. 671 (BN Lat 17655): Later at Beauvais)

6. 708: Amiens, Bibl Mun. 12 + Paris, BN Lat 10399 + Vat Regin Lat 329, Ephraem, Paraensis; Vita Abrahae Heremitae

6. 773b: Lyon, Bibl Ville 426 (352), Augustine, Enarrationes in Psalmos (Lyon)

6. 774a: Lyon, Bibl Ville 443 (372), Origen on Exodus (Lyon?)

6. 774b: Lyon, Bibl Ville 443 (372) + Paris, BN Lat nov acq 1591, Origen on Leviticus

6. 776: Lyon, Bibl Ville 468 (397) + Paris, BN Lat nov acq 602, Jerome on Jeremiah (Lyon?)

6. 778: Lyon, Bibl Ville 778, Maximus of Turin

6. 782a: Lyon, Bibl Ville 602 (519), Jerome, Letters

6. 782b: Lyon, Bibl Ville 602 (519), Jerome, Against lovinianum

6. 783: Lyon, Bibl Ville 604 (521) + Paris, BN Lat nov acq lat 1594, Augustine, Opuscula

6. 836: Toulouse, Bibl Mun 364 + Paris, BN Lat 8901, Canons (Albi, 666/7)

7. 860: Berne, Burgerbibl 219, Eusebius-Jerome (699-700)

7. 929: St Gall, Stift 226 + Zurich, Zentral RP $5+6$, Isidore, Synonyma; Hom ad Monachos

7. 954: St Gall, Stift 908, Council of Orange II; Leo to Flavian, etc

7. 993: St Gall, Stift 1396 V, Verba Seniorum

8. 1061: Berlin, Staatsbibl Phillipps 1745 + St Petersburg, Lat F.v.ll.3, Concilia Galliae; Notitia

Galliarum

8. 1102: Karlsruhe, Aug CCLIII, Missale Gallicanum

8. 1105: Karlsruhe, Aug CCLIII, Caesarius, Homilies

8. 1113: Karlsruhe, frag Aug 14, Gospels

9. 1235: Munster, Staatsarchiv MSC VII 2 a, Isidore, de Officiis Ecclesiasticis

10. 1547a: Brussels, Bibl Roy 9850-2, Sermons; Caesarius, Homilies; Pseudo-Theophilus,

Commentary on the Gospels (St Medard for Nomedius, s. 7 ex)

10. 1561: Naumur, Sem 42, Gospels

11. 1061: St Petersburg Publ Lib F v II 3, etc, Dionysus Exiguus; canons

11. 1659: NY, Pierpont Morgan M 334, Augustine on John to the Parthians (Luxeuil, 669: later at Beauvais) 
Supp. 1742: Paris, Archives Nat A XIX 1737, Fragmentum Mulomedicum

Supp. 1808: Trier, Stadtbibl Frag, Gregory I, Dialogues (Luxeuil influenced)

Supp (1985). 1836: Louvain, Kath Univ, Frag H Omont 2 A + Louvain-la-Neuve, Univ Cath, Frag H.

Omont 2B, LRV (Southern France or Spain)

Supp (1985). 1854: Paris, BN Lat 1719, Isidore, Etymologiae (Later at St Amand)

c. $7-8[28]$

3. 300: Ivrea, Bibl. Cap. 1, Gregory I, Pastoral Care

5. 519: Paris, BN Baluze 270, Medica

5. 522: Paris, BN Lat 152, Ezekiel

5. 564a: Paris, BN Lat $6400 \mathrm{G}$, Isidore, De Natura Rerum (Later at Fleury)

5. 578: Paris, BN Lat 9389, Echternach Gospels

5. 579: Paris, BN Lat 9427, Luxeuil Lectionary (Paris?)

5. 617: Paris, BN Lat 12021+12238, LRV (Later at Corbie)

5. 624: Paris, BN Lat 12161, Jerome-Gennadius, DVI

5. 692: Paris, BN Lat nov acq 2061, Gregory I, Moralia (Corbie?)

6. 742a: Cambrai, Bibl Mun 684, Gregory of Tours, DLH 1-6

6. 781: Lyon, Bibl Ville 600 (517) + Paris, BN Lat nov acq 446, Jerome, Letters

6. 808: Orleans, Bibl Mun 192 (169), Jerome on Isaiah (Fleury)

6. 812: Orleans, Bibl Mun 192 (169) + Paris, BN Lat 8305, Jerome on Zachariah (Fleury)

6. 841: Valenciennes, Bibl Mun 495 (455), Eusebius-Jerome (Luxeuil).

7. 614: Geneva, Bibl Publ MS lat 16 + St Petersburg, F 1.1 + Paris, Lat 11641, Augustine, Epistulae,

Sermons, Excerpta (Luxeuil: later at Lyon)

8. 808: Berlin, Staatsbibl Lat Qu 364 + Orleans, Bibl Mun 194 (169), Jerome on Isaiah

8. 1103: Karlsruhe, Aug CCLIII, Orationes

8. 1104: Karlsruhe, Aug CCLIII, Psalter

9. 1379: Wolfenbüttel, Herzog Bibl, Gud Lat 4.269, Jerome on the Psalms

9. 1391: Wolfenbüttel, Herzog Bibl, Weissenburg 76, Julianus Pomerius, de Vita Contemplativa

9. 1419: Würzburg, Univ M P TRH F 64 a, Augustine on Psalms (Luxeuil)

10. 1454: Lavanttal, St Paul, Stift 3, Jerome on Ecclesiastes (Luxeuil)

11. 1598: St Petersburg, Publ Lib F v 1.2, Rule of Basil (Corbie)

11. 1607: St Petersburg, Publ Lib F v I.11, Vita Lupi

11. 1616: St Petersburg, Publ Lib Q v 1.13, Gennadius, de Ecclesiasticis Dogmatibus; Jerome, Letters (Corbie)

11. 1617: St Petersburg, Publ Lib Q v I. 14, Gregory I, Homilies on Ezekiel (Luxeuil)

11. 1626: Barcelona, Bibl Cap, Gregory I, Dialogues

11. 1627: Barcelona, Bibl Cap, Gregory I, Homilies on the Gospels; Decretum

First half c. 8: 'Pre-Carolingian' [124]

1. 92: Vat. Pal. Lat. 493, Missale Gallicanum Vetus

1. 103: Vat. Regin. Lat. 257, Missale Francorum

1. 105: Vat. Regin. Lat. 316 + Paris, Lat. 7193, Gelasian Sacramentary (Corbie?)

1. 106: Vat. Regin. Lat. 317, Missale Gothicum (Burgundy/Autun)

2. 128: Cambridge, CCC 334, Origen, Homilies on Luke (Laon?)

2. 130: Cambridge, Gonville and Caius 820, Gelasian Sacramentary (Chelles)

2. 163: London, BL Add 11878 + Add 41567 + Cheltenham, Phillipps 36184 + Paris, NA 2388,

Gregory I, Moralia (Luxeuil?)

2. 171: Paris, BN Lat 10399 + London, BL Add 24144 + Brussels, Bibl Roy 19609, Orosius

(Stavelot?)

2. 174: London, BL Add 31031, Gregory I, Moralia (Laon?) 
2. 202b: London, BL Harley 5041, Vita Fursei (Peronne?)

2. 203: London, BL Harley 5792, Pseudo-Cyril; Glossary; Recepta medica

2. 219: London, BL Wilfred Merton 21, Gallican Sacramentary

2. 252: Oxford, Bod Laud Misc 126, Augustine, De Trinitate (Chelles)

4. 433: Rome, Vallicelliana B 62, Justus of Urguel on the Song of Songs (for Basinus of Trier)

4. 497: Verona, XL 38, Gregory I, Moralia (Luxeuil?)

5. 524: Paris, BN Lat 256, Gospels (For St Denis).

5. 541: Paris, BN Lat 2110, Eugippius; Augustine

5. 542: Paris, BN Lat 2206, Gregory I, Moralia

5. 547: Paris, BN Lat 2706, Augustine De Genesi ad Litteram

5. 548: Paris, BN Lat 2739, Excerpta Augustine, Jerome, Gregory I (Luxeuil?)

5. 556: Paris, BN Lat 4403 A, Isidore, de Legibus; LRV

5. 558: Paris, BN Lat 4808, Symphosius, Aenigmata (b minuscule).

5. 567: Karlsruhe, Landesbibl 339 + Paris, BN Lat 6413, Isidore, de Natura Rerum, Sententiae

5. 577: Paris, BN Lat 9382, OT Prophets (Echternach?)

5. 594: Paris, BN Lat 10399, Eusebius-Rufinus, HE

5. 604: Paris, BN Lat 10756 + Berne, Stadtbibl 611, Formulae; Cyclus Decennovennalis

5. 605: Paris, BN Lat 10837, Hieronymian Martyrology (Echternach)

5. 606a: Paris, BN Lat 10837, Calendar of Willibrord (Echternach)

5. 607: Paris, BN Lat 10863, Lectionary

5. 608: Paris, BN Lat 10910, Fredegar (Burgundy?) (715)

5. 620: Paris, BN Lat 12097, Canons (Lyon?)

5. 630: Paris, BN Lat 12168, Augustine, Questions on the Heptateuch (Laon)

5. 632: Paris, BN Lat 12190, Augustine, de Consensus Evangelium (Corbie)

5. 634: Paris, BN Lat 12207+12238+12243, Gregory I, Homelies on Ezekiel

5. 653: Paris, BN Lat 13246, Gelasian Sacramentary; Bobbio Missal; loca Monachiorum

5. 656: Paris, BN Lat 13348, Jerome, Questiions on Genesis (Corbie)

5. 657: Paris, BN Lat 13349, Jerome on Ecclesiastes (Corbie?)

5. 664: Paris, BN Lat 14086, Luxeuil Martyrology; Isidore, Excerpta Patrum (Corbie?)

5. 670: Paris, BN Lat 17654, Gregory of Tours, DLH (Later at Beauvais)

5. 673: Paris, BN Lat 18248, Antonine Itinerary (?)

5. 675: Paris, BN Lat 18315, Vita Wandregisili

5. 682: Paris, BN Lat nov acq 1575, Eugippius, Excerpta Augustini (Tours)

5. 683: Paris, BN Lat nov acq 2334, Pentateuch (Not clear if Gaul)

5. 688: Paris, BN Lat nov acq 1619 , Oribasius (?)

5. 691: Paris, BN Lat nov acq 1740, Octateuch

6. 740: Cambrai, Bibl Mun. 470, Philip, Expositio in lob (Anglo-Saxon centre)

6. 742b: Cambrai, Bibl Mun 684, Gregory of Tours, DLH 7-10

6. 744: Cambrai, Bibl Mun. 937, Isidore, Proemia

6. 745: Chartres, Bibl Mon. 40 (2), Gregory I, Moralia

6. 747: Chartres, Bibl Mon. 52 (78), Gospel

6. 752: Colmar, Bibl Mun. $45+$ Berne, Stadt-Uni 380, uncertain poet

6. 754: Colmar, Bibl Mun. $82+$ Gotha, Bibl MBR I. 75, Gospels

6. 759: Douai, Bibl Mun. 281+342, Gregory I, Moralia

6. 762: Epinal, Bibl Mun. 149 (68), Jerome, Letters (Tours, 744/5)

6. 765: Laon, Bibl Mun. 137, Orosius (Laon)

6. 766: Laon, Bibl Mun. 423, Isidore, Proemia

6. 173: Metz, Bibl Mun. Salis 140 (1) + London, BL Add MS 29972, Augustine, homilies (Luxeuil)

6. 802: Orleans, Bibl Mun. 154 (131) + Paris, BN Lat nov acq lat. 1598+1599, Cyprian; Augustine; Ambrose; Homilies 
7. 849: Basel, Univ F III 15 I, Isidore, Differentiae; Gennadius, de Ecclesiasticis Dogmatibus

7. 852: Basel, Univ N I 4 A + Freiburg, Univ 483, 12, Augustine, De Civ Dei

7. 855: Berne, Burgerbibl A 91 (8), Augustine, de Genesi ad Litteram

7. 859: Berne, Burgerbibl 199, Gospels

7. 862: Berne, Burgerbibl 358, Glossary

7. 604a: Berne, Burgerbibl 611, Glossary

7. 604b: Berne, Burgerbibl 611, Excerpts from Isidore, Etymologiae

7. 604: Berne, Burgerbibl 611 + Paris, BN Lat 10756, Asper, Ars Grammatica; Aenigmata; Hexasticha; Formulae

7. 604c: Berne, Burgerbibl 611, Computus; Pseudo-Methodius; Patristica Varia (727)

7. 604d: Berne, Burgerbibl 611, Physiologus; Excerpta Canonum

7. 604e: Berne, Burgerbibl 611, Receptarius

7. 868: Berne, Burgerbibl 645, Victorius, Cursus Paschalis; Notitia Provinciarum

7. 869: Berne, Burgerbibl 756, Commnentary on Leviticus (Anglo-Saxon centre)

7. 900 : St Gall, Stift $46+242+1398$ a, Book of Kings

7. 913: St Gall, Stift 188, Maximus of Turin, Homilies; Ambrose on the Sacraments (Luxeuil)

7. 917: St Gall, Stift 194, Caesarius of Arles, Homilies; Isidore of Seville, Soliloquies

7. 918: St Gall, Stift 194, Book of Solomon; Laterculus Notarum

7. 919: St Gall, Stift 194, Sacramentary (750)

7. 924: St Gall, Stift 214 + Zurich, Zentral C 184, Gregory I, Dialogues

7. 992: St Gall, Stift 1396 II, Commentrary on Donatus (Tours)

7. 1015: Zurich, Staatsarchiv C VI 3, Gregory I, Moralia

8. 1060: Berlin, Staatsbibl Phillipps 1743, Canones Conciliorum

8. 1073: Breslau, Stadbibl REHD 169, Gospels

8. 1101: Karlsruhe, Aug CCLIII, Oratio pro regibus Francorum

8. 1122: Karlsruhe, frag Augustine 104, Gregory of Tours, DLH; Textus Philosophicus

8. 1141: Kassel, Landesbibl Theol QU 10, Isidore, Proemia; Augustine, Homilies

8. 1142: Kassel, Landesbibl Theol Oct 5, Apocalyse; Caesarius, Homilies on Apocalypse

8. 1157: Köln, Dombibl 98, Isidore, Questions on NT (Tours)

8. 1159: Köln, Domblibl 165, Vitae Patrum

8. 1197: Fulda Landesbibl Boniface 2, Ep. Leo; Isidore, Synonyma (Luxeuil)

8. 1208: Gotha, Landesbibl MBR I 75, Victorius. Canon Paschalis; Canones Apostolorum

8. 1215: Harburg, Furstbibl 1. 2.4.2, Gospels (Echternach) (704-22)

9. 1238: Munich, CLM 3514, Passiones

9. 1258: Munich, CLM 6278, Gregory I, Moralia

9. 1274: Munich, CLM 6315+29022+29022e, Orosius; Jerome-Prosper

9. 1328: Munich, CLM 29033, Sedulius, Carmen Paschale (Luxeuil)

9. 1330: Munich, CLM $29047+14123$, Caesarius, Homilies; Expositio Symbolum

9. 1337: Munich CLM 29158a (etc), Prophets (Luxeuil)

9. 1341: Munich CLM 29168 a+21053, Canones Concilium

9. 1376: Wolfenbüttel, Herzog Bibl Aug 4.13.11, Augustine, Letters and Homilies (Luxeuil)

9. 1383: Wolfenbüttel, Herzog Bibl nov 404.2.13, Inventio s. Crucis (Luxeuil)

9. 1394: Wolfenbüttel, Herzog Bibl Weissenburg 86, Pompeius on Donatus; Cassiodorus, Institutions

9. 1396: Wolfenbüttel, Herzog Bibl Weissenburg 99, Augustine, Homilies

9. 1426: Würzburg, Univ M P TH F 79, Isidore, Synonyma

10. 1137: Admont, Stift 261, etc, Prophets

10. 1484: Vienna, Nat Lat 563, Various Patristics

10. 1518: Vienna, Nat Lat Ser 4213, Job (Luxeuil)

10. 1559: Maaseik, Canones Evangelium 
10. 1568: Copenhagen, Kon Bibl NY KGL SAML 58.8, Collectio Canonum; Pseudo-Gregory

10. 1571: The Hague, Museum 10 A 1, Philip, Expositio in lob (Tours)

10. 1584: Leiden, Univ Voss Lat Qu. 63, Gregory of Tours, DLH (Tours)

10. 1588: Utrecht, Univ 1003, Gregory I, Dialogues

11. 1623: St Petersburg, Publ Lib O v I 2, Gospel (Corbie)

11. 1624: St Petersburg, Publ Lib 0 v I 3, Gospel (Corbie)

11. 1625: St Petersburg, Publ Lib 0 v I 4, Cassian, Collationes (Corbie)

11. 1641: Toledo, Cathedral 13.3, Lectionary

11. 1658: NY, Pierpont Morgan M 17, Caesarius of Arles, Homilies (Luxeuil)

Supp. 1700: Hannover, Kestner Cul 1.48, Pseudo-Jerome, Breviary on the Psalms (Luxeuil area)

Supp. 1745: Paris, BN Lat 9377, Augustine, de Genesi ad Litteram (Luxeuil)

Supp. 1750: Paris, BN Lat nouv acqu lat 1177, Gregory I, Homilies on the Gospels

Supp. 1752: Paris, BN Lat nouv acqu 2389, Breviary of Alaric (Corbie)

Supp. 1807: Trier, Stadtbibl Frag, Augustine, Homilies (Luxeuil)

Supp. 1811: Weimar, Staatsarchiv, Hardenberg 1, Jeremiah

Supp (1985). 1827: Ghent, Univ 4051, Liber Regum (Corbie)

Supp (1985). 1851: Nurnberg, Germ Mus Kupferstich Kabinett, Kapsel 536/SD 286, Liber Esdrae

Bollandist Fragment (R. Gryson, 'Un fragment de parchemin en semi-onciale du Vle siècle (Lettres

saint Jérôme, Vie de Malchus', Analecta Bollandiana 130 (2012), pp. 241-54): Jerome, Letters, Life of Malchus 


\title{
Karl Ubl
}

\section{Eine Verdichtung der Lex Salica}

\author{
Die Septinas septem der Handschrift Paris, BN, lat. 4411
}

\begin{abstract}
The paper deals with the collection Septinas septem, a selective compilation of regulations of the Lex Salica. It can be dated between the Lex Salica version C and the elaborate treatment of the Lex Salica in the context of the Carolingian Reform. The composition and the consistent use of legal terminology demonstrate how, in Merovingian times, the Lex Salica was used and adapted in shortened versions. The second part of the paper consists of a first edition of the text of the Septinas septem from the recently rediscovered manuscript Paris, BN, lat. 4411.
\end{abstract}

Die Lex Salica ist im Vergleich zu anderen Rechtsbüchern des frühen Mittelalters kein Vorbild für gelungene Systematik. Die höchste Ebene der Gliederung zählt 65 Elemente, während im Codex Theodosianus und im davon abhängigen Breviar Alarichs II. die Einteilung in 16 Bücher die Orientierung erleichtert. Auch das Rechtsbuch des westgotischen Königs Eurich hatte in seiner vollständigen Fassung kaum mehr als 30 Titel. ${ }^{1}$ Was bei der Lex Salica jedoch das Problem der Orientierung handhabbar macht, ist der geringe Umfang im Vergleich zu den erwähnten Kodifikationen. Das fränkische Rechtsbuch nimmt in den Handschriften oft nur ein Zehntel des römischen Rechts in Anspruch. Dennoch versuchte man in der Karolingerzeit die Ordnung innerhalb der Lex Salica zu verbessern. In der D-Fassung, die Pippin der Jüngere wohl um das Jahr 764 veranlasste, ${ }^{2}$ wurde die Anzahl der Titel von 65 auf 100 erhöht, wobei inhaltlich verwandte Rechtsbereiche nebeneinandergestellt wurden. Im 9. Jahrhundert unterzog dann der Gelehrte Lupus von Ferrières die Lex Salica einer grundlegenden Revision, wobei er den Umfang von 70 Titel in der Version Karls des Großen als verbindlich akzeptierte, aber die einzelnen Titel neu anordnete und somit eine ausgefeilte Gliederung schuf. ${ }^{3}$ Eine andere Möglichkeit, den Zugang zum Inhalt des fränkischen

1 Vgl. die Rekonstruktion von Alvaro D’Ors, El Código de Eurico, Rom 1960 (Estudios visigóticos 2), $54-55$.

2 Hier folge ich Lex Salica. 100 Titel-Text, hrsg. von Karl August Eckhardt, Weimar 1953 (Germanenrechte N.F. 3), 42 - 55. Vgl. auch Karl Ubl, Die erste Leges-Reform Karls des Großen, in: Das Gesetz The Law - La Loi, hrsg. von Guy Guldentops und Andreas Speer, Berlin/New York 2014 (Miscellanea Mediaevalia 38), $75-92$.

3 Edition in: Lex Salica, hrsg. von Karl August Eckhardt, Hannover 1969 (MGH LL nat. German. 4/2), 197 - 230. Zur Methode vgl. Harald Siems, Textbearbeitung und Umgang mit Rechtstexten im Frühmittelalter. Zur Umgestaltung der Leges im Liber legum des Lupus, in: Recht im frühmittelalterlichen Gallien. Spätantike Tradition und germanische Wertvorstellungen, hrsg. von Harald Siems, Karin Nehlsen-von Stryk und Dieter Strauch, Köln 1995 (Rechtsgeschichtliche Schriften 7), 29-72; Oliver 
Rechts zu erleichtern, war die Anfertigung von exemplarischen Tabellen zu den Bußbeträgen. Von dieser Textsorte gibt es drei Zeugnisse: Die Septinas septem, die Septem causas und die Recapitulatio solidorum. Während die Recapitulatio ${ }^{4}$ erst zu Anfang des 9. Jahrhunderts entstanden ist und uns daher im Folgenden nicht beschäftigen soll, datieren die beiden ersten Texte aus der Zeit vor der Rechtsreform Karls des Großen. Besondere Beachtung verdienen die Septinas septem, da eine annähernd vollständige Fassung erst vor kurzem in der Pariser Handschrift lat. 4411 entdeckt werden konnte. ${ }^{5}$ Im Folgenden soll der Text zunächst vorgestellt und analysiert, dann mit den Septem causas verglichen und im Schlussteil des Aufsatzes kritisch ediert werden.

1. Der Forschungsstand zu den Septinas septem ist schnell zusammengefasst. Bisher war nur eine fragmentarische Version bekannt, die den ersten der sieben Teile des Textes umfasst und in vier miteinander verwandten Handschriften überliefert ist. ${ }^{6}$ Karl August Eckhardt notierte eine teilweise Übereinstimmung mit den Septem causas und nahm für beide Texte eine „merowingische Herkunft“ an. ${ }^{7}$ Der Titel der Septem septinas lautet in den vier Handschriften gleich: „Es beginnen die Sätze von den sieben Siebenern, das sind ähnliche Fälle. "8 Der Text ist in den vier bekannten Handschriften Teil einer Rechtssammlung in 18 Kapiteln aus der Zeit Karls des Großen. ${ }^{9}$ Die Sammlung umfasste neben den beiden fränkischen Rechtsbüchern (Lex Salica und Lex Ribuaria) auch die Lex Alamannorum und die sonst nicht überlieferte Lex Suavorum ${ }^{10}$ sowie eine Zusammenstellung von Kapitularien. Der letzte Herrschererlass ist das auf

Münsch, Der Liber legum des Lupus von Ferrières, Frankfurt am Main 2001 (Freiburger Beiträge zur mittelalterlichen Geschichte 14).

4 Die maßgebliche Edition ist: Pactus legis Salicae II 2: Kapitularien und 70 Titel-Text, hrsg. von Karl August Eckhardt, Göttingen 1956 (Germanenrechte N.F. 2), 529-534. Eine Neuedition erscheint unter dem Titel: Die Recapitulatio solidorum aus der Zeit Karls des Großen. Studie und Edition, in: Charlemagne. Les temps, les espaces, les hommes. Construction et déconstruction d'un règne, hrsg. von Rolf Große (im Druck).

5 Eine Handschriftenbeschreibung ist zugänglich auf www.leges.uni-koeln.de (zuletzt besucht am 13. 2. 2015).

6 Paris, Bibliothèque Nationale, lat. 4628 A (K35), 4631 (K36), 4760 (K34), 10758 (K33). Die Siglen richten sich nach der Edition von Eckhardt.

7 Pactus legis Salicae, 1. Einführung und 80 Titel-Text, hrsg. von Karl August Eckhardt, Göttingen 1954 (Germanenrechte N.F. 1), 163-164.

8 Für den lateinischen Text siehe unten die Edition.

$9 \mathrm{Zu}$ dieser Sammlung bislang: Leges Alamannorum, hrsg. von Karl August, Göttingen 1958 (Germanenrechte N.F. 4), 17 und Hubert Mordek, Bibliotheca capitularium regum Francorum manuscripta. Überlieferung und Traditionszusammenhang der fränkischen Herrschererlasse, München 1995 (MGH Hilfsmittel 15), 493 und 592. Bislang wurde nicht erkannt, dass das Titelverzeichnis der Sammlung ursprünglich in zwei Spalten angelegt war und dass in den überlieferten Handschriften eine Vermischung der Spalten stattfand.

10 Der Eintrag lautet richtig: Cap. XVII Lex suavorum. De eo qui hominem nobilem plagaverunt [!] id sunt cap. XVII. Paris, Bibliothèque Nationale, lat. 10758, S. 58. 
das Jahr 807 datierte Memoratorium de exercitu in Gallia occidentali praeparando. Die Septinas septem sind zwischen das Kapitular von Herstal (779) und die karolingische Recapitulatio solidorum gestellt. Eine Datierung lässt sich daraus nicht erschließen, weil die Sammlung nicht chronologisch geordnet ist. Vielmehr scheint der Redaktor der Sammlung besonders an Material über die Lex Salica interessiert gewesen zu sein. Vor die Lex Salica stellt er nämlich beide Prologe, eine Datierungsformel sowie zwei erklärende Texte, die Septinas septem und die Recapitulatio solidorum.

Mehr Aufschluss verspricht dagegen die zweite, bislang nicht beachtete, aber vollständigere Überlieferung in der Handschrift Paris lat. 4411. Bereits im Jahr 1849 hatte Gustav Hänel in seiner Ausgabe des Breviars Alarichs II. diesen Text erwähnt, ohne dass dieser Hinweis aber von der Forschung zur Lex Salica aufgegriffen worden wäre. ${ }^{11}$ Die Handschrift tradiert das Breviar (oder Lex Romana Visigothorum) ohne die Einleitungsworte König Alarichs II. Zwischen den Novellen der Kaiser des 5. Jahrhunderts und dem Beginn des Liber Gai sind auf zwei Blättern die Septinas septem eingebunden. Sie befinden sich auf den letzten beiden Blättern der 15. Lage, wobei auf dem zweiten Blatt (fol. 119) nur 8 Zeilen beschrieben sind und der Rest des Pergaments abgeschnitten wurde. Sowohl der Text der letzten Novelle des Kaisers Libius Severus ${ }^{12}$ (fol. 117 ${ }^{v}$ ) als auch der Text der Septinas septem (fol. 119') sind fragmentarisch, wobei aber nur wenige Sätze fehlen dürften. Da die beiden Blätter der Septinas septem (118119) mit den Blättern 113-114 verbunden sind, wurden die Septinas allerdings nicht zufällig oder fehlerhaft in die Lage eingebunden. ${ }^{13}$ Vielmehr wird man von einer bewussten Einfügung des Textes ausgehen müssen. Damit sind in dieser Handschrift mit der Lex Romana und der Lex Salica die beiden wichtigsten Rechtstraditionen des merowingischen Frankenreichs vereint, die trotz ihrer großen Diskrepanz seit dem späten 6. Jahrhundert vielfältigen Formen der Vermischung, Amalgamierung und Durchdringung ausgesetzt waren. Die Lex Ribuaria, die Formulae und die merowingischen Edikte sind für diesen Prozess die wichtigsten Zeugnisse. ${ }^{14}$

11 Lex Romana Visigothorum, hrsg. von Gustav Hänel, Leipzig 1849, LIX-LX.

12 Der Text endet: ... sivi ad alias nuptias vinerit nec // Paris, Bibliothèque Nationale, lat. 4411, fol. $117^{\mathrm{v}}$. Vgl. Lex Romana Visigothorum, Nov. Severi I, 312.

13 Die Lagenformel lautet: $2 \cdot(\mathrm{IV}+1)^{18}+8 \cdot \mathrm{IV}^{82}+\mathrm{III}^{88}[$ kein Textverlust $]+3 \cdot \mathrm{IV}^{112}+(\mathrm{IV}-1)^{119}+9 \cdot \mathrm{IV}^{191}$. Die Größe ist 240x170 mm (Schriftraum 205-230x130-150 mm) mit 23-26 Zeilen.

14 Vgl. u.a. Stefan Esders, Römische Rechtstradition und merowingisches Königtum. Zum Rechtscharakter politischer Herrschaft in Burgund im 6. und 7. Jahrhundert, Göttingen 1997 (Veröffentlichungen des Max-Planck-Instituts für Geschichte 134); Detlef Liebs, Römische Jurisprudenz in Gallien (2. bis 8. Jahrhundert), Berlin 2002 (Freiburger Rechtsgeschichtliche Abhandlungen N.F. 38); Alexander C. Murray, 'Pax et disciplina': Roman Public Law and the Merovingian State, in: Proceedings of the Tenth International Congress of Medieval Canon Law, hrsg. von Kenneth Pennington, Città del Vaticano 2001 (Monumenta iuris canonici. Series C. Subsidia 11), 269-286; Harald Siems, Zum Weiterwirken römischen Rechts in der kulturellen Vielfalt des Frühmittelalters, in: Leges - Gentes Regna. Zur Rolle von germanischen Rechtsgewohnheiten und lateinischer Schrifttradition bei der Ausbildung der frühmittelalterlichen Rechtskultur, hrsg. von Gerhard Dilcher und Eva-Marie Distler, Berlin 2006, 231 - 256; Harald Siems, Die Entwicklung von Rechtsquellen zwischen Spätantike und 
Können wir jedoch überhaupt einen merowingischen Ursprung des Textes annehmen, wie Eckhardt vermutete? Für einen solchen zeitlichen Ansatz sprechen einige Indizien. Zunächst ist die Schrift wohl deutlich früher einzuordnen, als man der bisherigen Literatur zum Teil entnehmen kann. Gustav Hänel schlug eine Datierung in das 9. Jahrhundert vor. In der rechtshistorischen Literatur, von Theodor Mommsen und Paul Meyer bis Detlef Liebs, folgte man diesem Vorschlag. ${ }^{15}$ Bernhard Bischoff widmete der Handschrift in seinem Zettelkasten nur kurze Notizen: Die erste lautete schlicht „IX“ und ist vielleicht nicht mehr als ein Exzerpt aus dem Katalog der Pariser Nationalbibliothek. ${ }^{16}$ Der zweite Eintrag beruht dagegen auf eigener Anschauung. Bischoff notiert einige paläographische Besonderheiten, legt sich auf die Datierung „IX in. in.“ fest und erwägt eine Entstehung in der Kanzlei. Begründet ist die zuletzt genannte Einschätzung wohl in der „feinen unregelmäßigen, bisweilen kursiven Minuskel“, in der die Datierungen der Kaisergesetze und auch die Septinas septem geschrieben sind. In einem Nachtrag zu den Codices latini antiquiores entschied sich Bischoff im Jahr 1992 schließlich für die Datierung in die zweite Hälfte des 8. Jahrhunderts, wobei er Ähnlichkeiten zum ab-Typ aus Corbie sowie zum Maurdramnus-Typ (ebenfalls aus Corbie) festhält. ${ }^{17}$ Dieses letzte Urteil Bischoffs ist überzeugend. Die Schrift hat nur wenige Gemeinsamkeiten mit der karolingischen Minuskel, sondern weist eher Verwandtschaft mit der Minuskel der Urkunden auf. Die spätmerowingische Herkunft wird durch Ähnlichkeiten zum a der Schrift des Laon-Typs nahegelegt. ${ }^{18}$ Auch die Haupthand kennt noch nicht das g der karolingischen Minuskel und verwendet viele Doppelformen (bei r, n, a und g) sowie Ligaturen. Diese Eigenheiten der Schrift schließen eine Entstehung im frühen 9. Jahrhundert, wie Bischoff sie zuerst vermutete, aus. Aufgrund dieser Befunde ist eine Entstehung in der Zeit von 750 - 780 im nordfranzösischen Raum anzunehmen. Damit ist Paris lat. 4411 gemeinsam mit der Handschrift aus Wolfenbüttel (Weißenb. 97) das älteste Zeugnis der Lex Salica.

Neben der Schrift bietet die Orthographie ein zweites Indiz für einen spätmerowingischen Ursprung. Der Titel im Akkusativ (Incipiunt sententias) ist ein untrügliches Zeichen für eine Zuordnung zum merowingischen Latein. ${ }^{19}$ Allein auf fol. $117^{\mathrm{r}}$ finden

Mittelalter, in:Von der Spätantike zum frühen Mittelalter: Kontinuitäten und Brüche, Konzeptionen und Befunde, hrsg. von Rudolf Schieffer und Theo Kölzer, Ostfildern 2009 (Vorträge und Forschungen 70), 245 - 286; Alice Rio, Legal Practice and the Written Word in the Early Middle Ages: Frankish Formulae, c. 500-1000, Cambridge 2009 (Cambridge studies in medieval life and thought 4. ser., 75).

15 Vgl. Liebs, Jurisprudenz (Anm. 14), 110 (mit älterer Literatur).

16 Handschriftenarchiv Bernhard Bischoff (Bibliothek der Monumenta Germaniae Historica, Hs. C 1, C 2). Microfiche-Edition. Mit einem Verzeichnis der beschriebenen Handschriften von Zdenka Stoklasková und Marcus Stumpf, hrsg. von Arno Mentzel-Reuters, München 1997 (MGH Hilfsmittel 16). 17 Bernhard Bischoff, Virginia Brown und James J. John, Addenda to Codices Latini Antiquiores (II), in: Medieval Studies 54 (1992), 286-307, hier 299-300 mit Tafel VI.

18 Fol. $118^{\mathrm{r}}$.

19 Vgl. Peter Stotz, Handbuch zur Lateinischen Sprache des Mittelalters, 3: Lautlehre, München 1996 (Handbuch der Altertumswissenschaften 2/5); Reinhard Kiesler, Einführung in die Problematik des Vulgärlateins, Tübingen 2006 (Romanistische Arbeitshefte 48). 
sich zahlreiche vulgärlateinische bzw. romanisierende Tendenzen: omnebus, ex ac, scelicet, usofructu, habit, vinerit, leceat, cum prolis nomerosa, in filiorum eletione, matrebus, necessetas. Dies trifft nicht nur für den Text des römischen Rechts zu, sondern auch für die Septinas septem. Verbformen wie incendedirit und dedirit, der Ausfall des Anfangs-H, die Vertauschung von e und i (ficerit), die Ersetzung von sc durch $\mathrm{x}$ (nexiente) usw. sind dafür mehr als deutliche Beispiele. Die Handschrift entstand sicher an einem Ort, der von der Reform der Orthographie in der Zeit Karls des Großen noch unberührt geblieben war.

Schrift und Orthographie der Handschrift legen somit als terminus ante quem eine Entstehung vor den Reformen Karls des Großen nahe. Der Wortlaut der Septinas septem enthält ebenfalls Indizien für einen merowingischen Ursprung. Zunächst ist festzuhalten, dass am Anfang des Textes die malbergischen Glossen in altfränkischer Sprache bewahrt sind, bevor der Schreiber gegen Ende das Interesse daran verloren zu haben scheint. Die Glossen wurden in den Fassungen aus der Zeit Karls des Großen konsequent aus dem Text der Lex Salica beseitigt, da sie kaum noch verständlich waren. Nur die D-Fassung Pippins bewahrte diese Reste der altfränkischen Rechtssprache. Das Interesse an den Glossen endete somit vor der Zeit Karls des Großen.

Ein weiteres Indiz ist die Vorlage der Septinas septem. Von den Redaktionen aus der Zeit vor Karl dem Großen scheiden die A und D-Fassung aus, weil die Septinas jeweils Kapitel enthalten, die in diesen Fassungen ausgefallen bzw. nicht vorhanden waren. ${ }^{20}$ Es bleibt also nur die C-Fassung über, die dem Autor über weite Strecken als Vorlage seiner Tabelle gedient hat. Darauf weist bereits der erste Titel über Brandstiftung in der Kirche hin, da diese Bestimmung erst in der C-Fassung hinzugekommen ist, in der DFassung aber durch die Klerikerwergelder ergänzt wurde, die in den Septinas noch unbekannt sind. Auffällig ist jedoch, dass der Text manchmal von $\mathrm{C}$ deutlich abweicht und malbergische Glossen enthält, die entweder gar nicht oder nur in D bzw. im frühen Druck von Herold nachgewiesen sind. ${ }^{21}$ Dies lässt darauf schließen, dass die Vorlage mit keiner der uns bekannten Handschriften der Lex Salica deutliche Gemeinsamkeiten hat. Angesichts der geringen Überlieferung des Rechtsbuchs vor dem Jahr 800 (allein zwei Handschriften) ist dieses Resultat aber nicht sonderlich überraschend.

Die Septinas septem sind somit zwischen der C-Fassung aus dem Ende des 6. Jahrhunderts ${ }^{22}$ und der karolingischen Bildungsreform entstanden. Eine nähere

20 Die Kapitel I 6 und V 1 sind nicht in der D-Fassung vorhanden. Die Lücken gegenüber der A-Fassung sind zahlreicher.

21 Die Glossen in I 1, I 5 und I 7 entsprechen der D-Fassung. Darüber hinaus ist der Wortlaut auch in II 3 und VI 1 näher an D als an C. Die Edition von Johannes Herold (1557) wirft besondere Probleme auf, da darin nicht nur eine Reihe noch heute bekannter Handschriften benutzt wurden, sondern auch heute verschollene Zeugnisse (nach Eckhardt auch von der C-Fassung). Zur Problematik der Editionsleistung von Herold vgl. Harald Siems, Studien zur Lex Frisionum, Ebelsbach 1980 (Abhandlungen zur rechtswissenschaftlichen Grundlagenforschung 42).

22 Zur Datierung der C-Fassung vgl. Karl Ubl, Inzestverbot und Gesetzgebung. Die Konstruktion eines Verbrechens (300 - 1100), Berlin 2008 (Millennium-Studien 20), 176-182. 
Eingrenzung ist nur annäherungsweise durch einen Vergleich mit den Septem causas möglich. Die Septem causas beruhen ebenfalls auf der C-Fassung und sind nach der Latinität zu schließen merowingischen Ursprungs. ${ }^{23}$ Daneben gibt es aber signifikante Unterschiede:

(a) Im Unterschied zu den Septinas enthalten die Septem causas keine malbergischen Glossen.

(b) Die Septem causas ordnen die Tatbestände und ihre Bußsummen aufsteigend von 15 solidi bis zu 1.800 solidi, während die Septinas absteigend von 200 solidi bis 15 solidi zählt.

(c) In den Septem causas wird größtenteils die Legalfolge im Aufbau der Lex Salica beachtet, d.h. der Kompilator nimmt zum Beispiel im fünften Kapitel Bestimmungen aus den Titeln 14, 24, 26, 29 und 41. Die Septem septinas springen dagegen hin und her im Text der Lex Salica. Die Anordnung richtet sich nicht nach der Legalfolge, sondern nach einem systematischen Interesse, da der Autor möglichst viele unterschiedliche Tatbestände in den einzelnen Kapiteln abbilden und jeweils in den folgenden Kapiteln aufgreifen wollte. So wird eine Abstufung der Delikte sichtbar: der Dorfüberfall (exspoliatio) wird mit 200 solidi gebüßt, die Ausraubung mit 100, die Ausraubung bei einem militärischen Überfall mit 621/2 und das Aufbrechen eines Schlosses mit 30. ${ }^{24}$ Oder: Die Ehe mit einer verheirateten Frau kostet 200 solidi, der Bruch eines Verlöbnisses 621/2, das Berühren der Brust einer Frau 45 und das Berühren des Armes 30. ${ }^{25}$ Solche Abstufungen begegnen auch bei Körperverletzung (debilitas), Tötung (homicidium), Diebstahl (furtum) und beim Sklavenrecht. ${ }^{26}$ Die Komposition der Septem septinas erforderte daher mehr Geschick und Verständnis für den Rechtsinhalt als die eher schematische Zusammenstellung in den Septem causas.

(d) Die Septinas beginnen programmatisch mit der Brandstiftung in der Kirche und mit der Tötung eines freien Franken. Der Kirchenschutz ist daher prominent an die erste Stelle gestellt, begegnet aber sonst nicht mehr. Die Septem causas sind dagegen freier in der Wortwahl und enthalten auch bislang nicht in der Lex Salica tradierte Bestimmungen. Zum Teil sind es Verallgemeinerungen von Tatbeständen, zum Teil Konstruktionen, um die Siebenzahl in jedem Kapitel zu gewährleisten. So taucht am Ende der Bischofsmord auf, der ein Wergeld für den Bischof von 900 solidi voraussetzt und erstmals in der Lex Ribuaria aus dem frühen 7. Jahrhundert nachweisbar ist. ${ }^{27}$ Singulär überliefert ist auch die Tötung eines Königsboten bzw. von Gefolgsleuten, die zwischen zwei Königen um Frieden

23 So bereits Heinrich Brunner, Deutsche Rechtsgeschichte 1, 2. Auflage, Berlin 1906, 442.

24 I 3, II 6, III5, VI 4.

25 I 5, II 1, IV 4, VI 6.

26 Debilitas: II 1, III 3, IV2 - 3 und IV 6,VI 3, VII 1. Furtum: II 6, IV 1, V 1 und V3 - 7; VI 2. Sklaven: I 7, II 2, V 2. Homicidium: I 2, II 3-5 und II 7.

27 Lex Ribuaria 40, 9, hrsg. von Franz Beyerle und Rudolf Buchner, Hannover 1954 (MGH LL nat. German. 3), 94. 
verhandeln. ${ }^{28}$ Beide Tatbestände legen eine Entstehung der Septem causas um die Mitte des 7. Jahrhunderts bzw. vor den Einheitskönigen ab 679 nahe, als das Bischofswergeld bereits in der Lex Ribuaria verankert war und noch mehrere merowingische Könige amtierten. Für die Septinas septem muss die Datierung zurückhaltender formuliert werden. Beide Texte haben zwar einige Überschneidungen, sind aber wohl nicht direkt voneinander abhängig. Aufgrund der vorhandenen malbergischen Glossen und des fehlenden Klerikerwergeldes scheinen die Septinas septem älter als die Septem causas zu sein. Sicherheit kann in dieser Frage allerdings nicht erreicht werden.

Die Septinas septem können somit als ein Zeugnis dafür gelten, dass die Lex Salica im 7. Jahrhundert kein vergessener Text war. Die gelegentlich geäußerte Meinung, das Rechtsbuch sei erst von den Karolingern wiederentdeckt worden, muss daher in Zweifel gezogen werden. ${ }^{29}$ Vielmehr war man bereits im merowingischen Frankenreich darum bemüht, die unorganisierte Zusammenstellung von Regelungen im fränkischen Rechtsbuch besser zugänglich zu machen. Die reflektierte Komposition der Septinas septem macht darüber hinaus deutlich, dass der rechtskundige Autor mit Tatbeständen wie furtum, exspoliatio, homicidium und debilitas operierte und in der Lage war, systematische Unterscheidungen konsequent anzuwenden. Ferner wird dadurch auch die Lebendigkeit und Funktionalität des Wergeld- und Bußensystems im Frankenreich unter Beweis gestellt. ${ }^{30}$ Es erlaubte, Tatbestände miteinander vergleichbar zu machen und unter systematischen Gesichtspunkten zu ordnen, und gab einen Rahmen vor, wie Konflikte mit Bezug auf abstrakte Wertgrößen gelöst werden konnten. Darüber hinaus belegen die Septinas septem, wie stark die fränkische Identität mit der Existenz einer eigenen Rechtsordnung verknüpft war. An mehreren Stellen ersetzt der Autor das ständische ingenuus durch das ethnisch konnotierte francus und grenzt somit die

28 Pactus legis Salicae, hrsg. von Karl August Eckhardt, Hannover 1962 (MGH LL nat. German. 4/1), 273: Si quis legadario regi in vi[a] adsallierit et occiserit et in mordrem miserit, sol. MDCCC culp. iud. Si quis andrustione qui inter duos reges pagaverit qui eum adsallierit et occiserit et in mordrem miserit, sol. MDCCC culp. iud. Eckhardt war der Meinung, dass es sich beim achten Kapitel um einen späteren Zusatz handeln müsse, weil der Titel nur sieben causae ankündigt. Die Siebenzahl kann sich jedoch auch auf die sieben Abschnitte eines Kapitels beziehen. Beide Bestimmungen sind jedenfalls in der Wortwahl (legatarius in der Lex Ribuaria 68, 3 und bei Marculf II 17) merowingisch.

29 Alexander C. Murray, Germanic Kinship Structure. Studies in Law and Society in Antiquity and the Early Middle Ages, Toronto 1983 (Studies and Texts 65), 131: „... Lex Salica was to a large extent a novelty in the Carolingian period ... “ Ähnlich das Urteil von Hermann Nehlsen, Zur Aktualität und Effektivität germanischer Rechtsaufzeichnungen, in: Recht und Schrift im Mittelalter, hrsg. von Peter Classen, Sigmaringen 1977 (Vorträge und Forschungen 23), 449-502, hier 464-466.

30 Vgl. Stefan Esders, „Eliten“ und „Strafrecht“ im frühen Mittelalter. Überlegungen zu den Bußenund Wergeldkatalogen der Leges barbarorum, in: Théories et pratiques des élites au haut Moyen Âge, hrsg. von François Bougard, Hans-Werner Goetz und Régine Le Jan, Turnhout 2011 (Collection Haut Moyen Âge 13), 261 - 282; ders., Wergeld und soziale Netzwerke im Frankenreich, in: Verwandtschaft, Name und soziale Ordnung (300 - 1000), hrsg. von Steffen Patzold und Karl Ubl, Berlin/New York 2014 (Reallexikon der germanischen Altertumskunde, Ergänzungsband 90), 141-159. 
fränkische Rechtstradition von der römischen Rechtsordnung ab. Der Text fügt sich in dieser Hinsicht in eine Entwicklung der „Frankisierung“ ein, die bereits seit dem späten 6. in der Überlieferung der Lex Salica sichtbar ist. ${ }^{31}$ Die Erforschung der Merowingerzeit wird daher durch diesen Neufund nicht unwesentlich bereichert.

31 Ruth Schmidt-Wiegand, Fränkische und frankolateinische Bezeichnungen für soziale Schichten und Gruppen in der Lex Salica, in: Stammesrecht und Volkssprache. Ausgewählte Aufsätze zu den Leges barbarorum. Festgabe für Ruth Schmidt-Wiegand, hrsg. von Clausdieter Schott, Weinheim 1991, 355-391, hier 382. Vgl. Helmut Reimitz, History, Frankish Identity and the Framing of Western Ethnicity, 550-850, Cambridge 2015, 112. 


\section{Edition}

In der Edition sind die Übereinstimmungen mit den Septem causas (fortan SC) in der Kapitelzählung kenntlich gemacht. Nach jeder Bestimmung werden die Parallelen in den verschiedenen Fassungen der Lex Salica aufgeführt, wobei sich die Zählung nach den von Eckhardt bestimmten Fassungen richtet ( $C, D$ und Herold). K33-K36 bezieht sich auf die von Eckhardt vergebenen Siglen für die Edition der Lex Salica. Eckige Klammern enthalten Zusätze des Editors.

K33 = Paris, BN lat. 10758, S. 75

K34 = Paris, BN lat. 4760, fol. $20^{r-v}$

K35 = Paris, BN lat. 4628 A, fol. $76^{\text {ra-rb }}$

K36 = Paris, BN, lat. 4631, fol. $118^{\text {va }}$

Paris $4411=$ Paris, BN, lat. 4411, fol. $118^{r}-119^{r}$

[Paris 4411] INCIPIUNT SEPTINAS SEPTI[M] DE LEGe salica. [K33-K36] INCIPIUNT ${ }^{a}$ SENTENTIAS DE SEPTEM SEPTINAS. HOC SUNT PARICULAS ${ }^{32}$ CAUSAS $^{\mathrm{a}}$. CAP. VII.

a-a Platz für Rubrik nicht ausgefüllt K35, Alia capitula ... K36

\section{[I 1=SC VI 5]}

[Paris 4411] Si quis ba[si]lica incendedirit, malb. alactrude teuoctidia ${ }^{a}$, sol.us CC culpabilis iudicetur.

[K33-K36] Si quis basilicam incenderit, sold. ${ }^{\mathrm{b}}$ CC culpabilis iudicetur.

${ }^{\text {a }}$ Der vierte Buchstabe ist nicht sicher zu identifizieren. ${ }^{\mathrm{b}} \mathrm{CC}$ sol. $\mathrm{K} 34$.

$[\mathrm{C} 55,7]$ Si quis basilica ubi reliquie sunt insertas aut ipsa basilica est sanctificata incenderit, malb. chenechruda ...

[D76] Si quis basilica incenderit, mallobergo alatrudua ...

[Herold 71, 1] Si quis voluntario ordine aut fortasse per negligentiam basilicam incenderit, mallobergo alutrude theotidio ...

Die Verbindung zweier malbergischer Glossen für den Tatbestand der Brandstiftung in einer Kirche ist singulär. Sie ist bislang nur aus der Edition von Herold bekannt, die aber häufig einen aus mehreren Versionen kompilierten Text bietet. So kann auch in diesem Fall nicht mit Sicherheit gesagt werden, ob die Vorlage der Septem Septinas auf eine von Herold benutzte Handschrift zurückgeht, zumal der weitere Wortlaut nicht übereinstimmt. Das Wort *alatrudea, erstmals in der D-Fassung nachweisbar, bedeutet nach allgemeiner Auffassung Heiligtumzerstörung ${ }^{33}$. Die zweite Glosse stellt Eckhardt zu ${ }^{*}$ theuischada (Mädchenscheren ${ }^{34}$ ) und ist somit hier am falschen Platz. Die Vorlage ist am nächsten zu D. In A nicht vorhanden.

32 Nach Du Cange wie im Französischen „pareil“.

33 Nach Eckhardt in Lex Salica 1962, 277 (jeweils mit Bezug auf ältere Literatur zu den Glossen). 34 Nach Eckhardt in Lex Salica 1962, 289. 


\section{[1 2]}

[K33-K36] Si quis francus francum occiderit, sold. CC culp. iudicetur.

$[\mathrm{C} 41,1] \mathrm{Si}$ quis ingenuus franco aut barbaro occiderit, qui lege salica vivit ... $[D 69,1]$ Si quis ingenuos Francum aut barbarum, qui Salica lege vivit, occiserit ...

Hier fehlt vermutlich ein Kapitel in Paris 4411, da sich ansonsten nicht die geforderte Siebenzahl ergibt. In der verkürzten Überlieferung steht hier der Tatbestand der Tötung eines freien Franken durch einen Franken, und zwar mit besonderer Betonung der fränkischen Identität.

\section{[1 3]}

[Paris 4411] Si quis villa aliena adsalierit et ibidem iusticia frierit, canis occiserit, hominis placaverit vel exinde aliquid exinde in carra duxerit, malb. turpofalteo, sol. CC culpabilis iudicetur.

[K33-K36] Si quis villa ${ }^{a}$ aliena ${ }^{a}$ adsallierit et ibidem hostia fregerit et canes occiderit et homines ${ }^{\mathrm{b}}$ plagaverit ${ }^{\mathrm{c}}$ vel aliquid exinde ${ }^{\mathrm{d}}$ in carro duxerit, sold. CC culpabilis iudicetur.

a-a villam alienam $K 35 \mathrm{~K} 36 .{ }^{\mathrm{b}}$ omnes $\mathrm{K} 34{ }^{\mathrm{c}}{ }^{\mathrm{c}}$ verbessert von späterer Hand in plagaverit K33; plagaverunt K34. ${ }^{\mathrm{d}}$ fehlt K35K36

$[C$ 14, 7] Si quis villam alienam adsallierit et ibidem ostia fregerit, canes occiderit vel homines plagaverit aut in carro aliquid exinde duxerit, malloberto turpefalthio ...

[D 17, 2] Si quis villam alienam adsallierit et ibidem hustia fregerit et canes occiserit aut homines placaverit aut exinde in carro aliquid duxerit, mallobergo turriphatio ...

Die malbergische Glosse bewahrt wie $C$ den besseren Wortlaut ( ${ }^{*}$ turpefalthio: Dorfüberfall $\left.{ }^{35}\right)$. Die Verlesung von ostia zu iusticia ist singulär. In A nicht vorhanden.

\section{[I 4=SC VI 2]}

[Paris 4411] Si quis alii erbas dedirit bibere, ut moriatur, malb. alfacto leodi, sol. CC culpabilis iudicetur.

[K33-K36] Si quis alicui herbas dederit bibere, unde moriatur, sol. CC culpabilis iudicetur. 
$[\mathrm{C} 19,1]$ Si quis alteri herbas dederit bibere, ut moriatur, malb. trouuerpo ...

[Herold 22, 1] Si quis alteri herbas dederit bibere ut moriatur malb. affectu leudi ...

$[D 25,1]$ Si quis alteri erbas dederit ut moriatur mal. co virgo ...

Die malbergische Glosse ist nur in Verballhornung auch bei Herold bewahrt. Sie verweist auf ${ }^{*}$ affalchio $=$ Beraubung, in alfalchio A1 für Lebensberaubung ${ }^{36}$. Die weitere Glosse leodi bedeutet Manngeld, was sich in der Buße von 200 sol. ausdrückt. Das Wort bibere fehlt in D (aber nicht D8).

\section{[1 5]}

[Paris 4411] Si quis uxore aliena vivo marito tullerit, malb. aptica et in alia mente apbat tedio salam tammo, sol. CC culpabilis iudicetur.

[K33-K36] Si quis uxorem alienam tulerit vivo marito, sold. CC culpabilis iudicetur.

$[\mathrm{C} 15,1]$ Si quis uxorem alienam tullerit vivo marito, malb. abtiga, ...

[Herold 16, 1] Si quis uxorem alienam vivo marito tulerit, malb. abtica: et in alia mente arba theus en lanthamo,...

$[\mathrm{D} 15,1]$ Si quis uxorem alienam tullerit vivo marito, malb. abteca, in alia mente abhacto velentemo, ...

Abtiga ist Entstellung von ${ }^{*}$ affalchech ${ }^{37}$. Nach $D$ wird eine alternative Glosse $\left({ }^{*}\right.$ ab hachteo levanthamo $=$ von lebendem Ehemann ${ }^{38}$ ) angeführt, wobei durch unterschiedliche Worttrennung eine ganz neue Fügung entsteht.

\section{[I 6=SC VII 6]}

[Paris 4411] Si quis hominem mortuum exfodierit et expoliaverit, malb. turnicale, sol. CC culabilis iudicetur.

[K33-K36] Si quis hominem mortuum exfodierit ${ }^{\mathrm{a}}$ et expoliaverit, sol. CC culpabilis iudicetur.

${ }^{a}$ verbessert von späterer Hand in efodierit $K 33$.

36 Lex Salica 1962, 277. Vgl. Elmar Seebold, Der germanische Rechtsterminus texaca und die Entführung von Sklaven in der 'Lex Salica'. (Untersuchungen zu den malbergischen Glossen II), in: Beiträge zur Geschichte der deutschen Sprache und Literatur 130 (2008), 438-458, hier 446-447. 37 Lex Salica 1962, 277. Vgl. Elmar Seebold, Frauenraub, Unzucht und Heirat mit Unfreien in der „Lex Burgundionum“ und der „Lex Salica“, in: Beiträge zur Geschichte der deutschen Sprache und Literatur 132 (2010), 366 -377, hier 375.

38 Lex Salica 1962, 276. 
$[\mathrm{C14}, 9] \mathrm{Si}$ quis hominem mortuum exfodierit vel expoliaverit malb. tornechallis sive odocarina, ...

$[\mathrm{C} 55,4] \mathrm{Si}$ quis corpus iam sepultum effoderit et expoliaverit, malb. tornechale, vvargo sit ...

[D18] Si quis corpus sepultum exfodierit et expoliaverit, vargus sit, .... malb. turnichal ...

Die Vorlage stammt hier eindeutig aus der C-Fassung. Bei Herold wie C, aber mit 100 Solidi Buße und daher nicht als Vorlage geeignet. Die Glosse gut überliefert aus ${ }^{*}$ turnechale $=$ Grabschänden ${ }^{39}$.

\section{[I 7=SC VI 3]}

[Paris 4411] Si quis francus francum vindederit et non redierit, malb. friofalcono acfarno, sol. CC culpabilis iudicetur.

[K33-K36] Si quis francus francum vendiderit, sol. CC culpabilis iudicetur.

$[\mathrm{C} 39,4] \mathrm{Si}$ quis hominem ingenuum vendiderit et postea in patria reversus non fuerit, malb. franchamo ...

[D67] Si quis hominem ingenuum plagaverit vel vindederit, malb. frio falcino, ...

Im Text wird die C-Fassung modifiziert und insbesondere die fränkische Identität hervorgestrichen. Die erste Glosse stimmt dagegen eindeutig mit D überein (Freien-Raub ${ }^{40}$ ), die zweite ist dagegen bislang unbekannt. Erneut scheint der Autor Glossen kompiliert zu haben. Nicht vorhanden in A.

[Hier bricht der Text in K33-K36ab]

\section{[II] DE SEPTINAS.}

\section{[II 1=SC V 5]}

Si quis linguam alterius capolaverit, malb. alalteo, sol. C culpabilis iudicetur.

$[\mathrm{C} 29,15]$ Si linguam alteri capulaverit, ut loqui non possit, malb. achaltea, ...

$[D 48,12]$ Si quis alterius linguam capulaverit, unde loquere non possit, malb.

alchacio (alcheio, halachacio) ...

Der Tatbestand nach C oder D formuliert, die Glosse entspricht jedoch eher C, wobei sie der postulierten Form ${ }^{*}$ alchaltea ${ }^{41}$ noch nähersteht. Nicht vorhanden in A. 


\section{[II 2=SC V 4]}

Si quis letum alienum, qui apud domino suo in oste fuerit, extra consilium domini sui ante rege per dinarium ingenuum demiserit, malb. maltho chiato friolito, sol. C culpabilis iudicetur.

$[\mathrm{C} 26,1]$ Si quis litum alienum qui apud domino suo in hoste fuerit extra consilium domini sui ante rege per dinario ingenuum dimiserit, malb. maltho chiado freoledo, ...

[D37, 1] Si quis litum alienum, qui aput domino suo in oste fuerit, extra consilium domini sui ante rege per dinario ingenuum demiserit, malb. maltholitho frioblito (malcho itto freio blito, maltho hithofrio blito), ...

Glosse sehr eng an $C$, weit weg von der angenommenen Urform der Glosse ( ${ }^{*}$ maltho thi atomeo leto $\left.{ }^{42}\right)$. Der Zusatz in hoste ist nicht in A vorhanden, daher scheidet A als Vorlage aus.

\section{[II 3=SC V 6]}

Si quis hominem in puteo $^{\mathrm{a}}$ ingenuum sine manus et pedis, quem inimici sui in via relinquerunt, occiserit, malb. uuas bugo, sol. C culpabilis iudicetur.

a auf Rasur

$[\mathrm{C} 41,9] \mathrm{Si}$ quis hominem invenerit in quadruvium sine manibus et sine pedibus quod inimici sui dimittunt et eum perocciderit, malb. frethfalto uuas bugo, ... [D74] Si quis hominem ingenuum sine manus et sine pedis, quem inimici sui in via truncatum relinquent occiserit, malb. uuas bucho, ...

Glosse stammt nicht aus A (friofalto), sondern aus $C$ oder D (uuasbucho = Verstümmelter auf dem Wasen $\left.^{43}\right)$. Der Satz zeigt Nähe zu $D$ wegen relinquere, aber quadruvium zu puteus aus $C$ verändert.

\section{[II 4]}

Si quis hominem in poteo iactaverit et vivus exinde evaserit et ad casa sua possit accedere, malb. calep sob dubio, sol. C culpabilis iudicetur.

42 Lex Salica 1962, 284. Vgl. Elmar Seebold, Texaca (Anm. 36), 448.

43 Lex Salica 1962, 291. 
$[C 41,10]$ Si quis hominem in puteum iactaverit et vox exinde exeat, malb. callis solio, ...

[Herold 44, 3] Si quis hominem in puteum aut in vipida iactaverit et vivus exinde evaserit, ut ad casam suam possit accedere, malb. chalip sub dupio, ... [D98] Si quis hominem in pucium aut in pelago inpinxerit vel in periculo mortis, et ipse exinde vivus evaserit et ipse causam suam possit mallare, malb. challis obduplio, ...

Der Text steht deutlich Herold am nächsten, die malbergische Glosse setzt eine falsche Worttrennung $\left({ }^{*}\right.$ chalifs obduplio $=$ Wassertauche eines Lebenden $\left.{ }^{44}\right)$.

\section{[II 5=SC V 7]}

Simili modo, qui alium in pelago inpinxerit, malb. pio marina, sol. C culpabilis iudicetur.

[C41, 11] Si quis hominem ingenuum in pellago inpinxerit, malb. phimarina ...

[A2 48,3] Simili modo qui alium in pellago inpinxerit, ...

[Herold 44,13] Simili modo qui in pelagus hominem inpinxerit, et exinde evaserit, malb. piomarina, ...

Die Aufteilung auf zwei Paragraphen wie in C, das simili modo wie bei A2 und Herold. Die Glosse so bei Herold, aber auch in C ähnlich, aus ${ }^{*}$ siomarina $=$ Seestoßen ${ }^{45}$. In den übrigen A-Handschriften und in $D$ nicht vorhanden.

\section{[II 6]}

Si quis hominem in furto expoliaverit, malb. treo mosido, sol. C culpabilis iudicetur.

[C14,9] Si quis hominem dormientem in furtum expoliaverit, malb. freomundo, ... sol. C culp. iud.

[Herold 18,10] Si quis hominem dormientem expoliaverit malb. chreo mosdo ... sol. C culpabilis iudicetur.

$[D 16,5]$ Si quis hominem ingenuum dormientem expoliaverit, mallobergo frio mosido, ... sol. C culp. iud.

Der Bezug des Textes ist durch den Wegfall von dormientem nicht mehr klar, die Glosse verweist auf ${ }^{*}$ chreomusido $=$ Leichenberaubung und nicht auf ${ }^{*}$ frio musido $=$ Freienberaubung ${ }^{46}$. Die Leichenberaubung wird jedoch in IV 5 behandelt. 


\section{[II 7=SC V 3]}

Si quis infantem in ventrem matris sue occiderit, sol. C culpabilis iudicetur.

$[\mathrm{C} 24,5] \mathrm{Si}$ quis infantem in ventrem matris suae occiderit aut antequam nomen habuerit infra novem noctibus, ...

$[\mathrm{D} 24,6] \mathrm{Si}$ vero infantem in utero matris occiserit, ...

Eindeutig C als Vorlage wegen ventrem, Herold fällt wegen anderer Bußsumme als Vorlage aus.

\section{[III] DE LXIIs.}

[III 1]

Si quis sponsam alienam tullerit et sibi in coniugium copolaverit, malb. sol. LXIIs.

$[\mathrm{C} 13,12]$ Si quis vero sponsa aliena tulerit et sibi in coniugium copulaverit, ...

[D 14, 8] Si quis spunsa aliena tullerit et sibi in coniugium sociaverit, mallobergo andratheo, ...

Eindeutig aus $C$ wegen copolaverit. Die malbergischen Glossen fehlen ab hier weitgehend.

\section{[III 2]}

Si quis oculum alterius tullerit, malb. sol. LXIIs culpabilis iudicetur.

[C29, 12] Si quis alteri oculum evellerit, mallobergo lichauina, ...

[Herold 32, 12] Si quis alteri oculum tulerit, malb. liclamina ...

$[D 48,10]$ Si quis alterum oculum eiecerit, mallobergo lichauina, ... solidus C

culpabilis iudicetur.

Das Verb tullerit nur in Herold vorhanden, nach der Bußsumme nicht aus der D-Fassung. In A nicht vorhanden.

\section{[III 3]}

Si quis hominem innocentem [fol. $118^{\mathrm{v}}$ ] absentem ad regem acusaverit, malb. sol. LXIIs culpabilis iudicetur.

[C18] Si quis hominem innocentem absentem illum ad regem accusaverit, ...

[D24] De cuique ad regem hominem innocentem absentem accusat, ... 


\section{[III 4]}

Si quis aliy [!] maleficium ficerit et evaserit, malb. sol. LXIIs culpabilis iudicetur.

$[\mathrm{C} 19,2]$ Si quis alteri maleficium fecerit et qui eum praesit exinde evaserit, ...

$[D 25,2]$ Si quis maleficium fecerit et qui eum priserit euaserit, ...

Nach C, weil in D fehlt alteri.

[III 5]

Si quis hominem in superventum expoliaverit, malb. mus do, sol. LXIIs culpabilis iudicetur.

[C14,1] Si quis hominem ingenuum in superventum expoliaverit, malb. musido, ...

[D16,1] Si quis hominem ingenuum in superventi expoliaverit, malb. mosido, ...

Glosse musido ( $=$ Beraubung $\left.{ }^{47}\right)$ in unterschiedlichen Formen und Fassungen belegt. Hier ist ein militärischer Überfall, nicht privater Raub gemeint.

[III 6]

Si quis homo per malo ingenio in corte in corte [!] alterum aut in casa vel ubilibet loco aliquid de furtum miserit, hoc est nexiente domino, ubi inventum fuerit, malb. sol. LXIIs culpabilis iudicetur.

[C34, 5] Si quis per malum ingenium in curte alterius aut in casa vel ubi et ubi [aus A: ubilibet] miserit aliquid de furtum hoc est nesciente domino cui curtis est et ibidem inventum fuerit, ...

[D56] Si quis in curte vel in casa vel in qualibet in furtum aut per malo ingenio aliquid miserit nesciente domino cuius domus est, ...

Sicher nicht nach D, weil andere Wortstellung und andere Wortwahl; auch C ist stark abgewandelt.

\section{[IV] DE XLV.}

[IV 1]

Si vero ingenuus aliquid de intus casa furaverit, malb. sol. XLV culpabilis iudicetur.

47 Lex Salica 1962, 285. 
[C11,5] Si vero clavem effregerit aut adulteraverit et sic in domum ingressus fuerit et exinde furtum aliquid tulerit, ...

[Herold 11,3] Si vero ingenuus de intus casa furaverit aut fregerit quod valent duo den., ...

$[D 12,3]$ Si vero ingenuus aliquid deintus casa furaverit aut clavem infrigerit aut adultaeraverit aut exinde aliquid in furtum portaverit, ...

Beides sehr verkürzt, Vorlage näher an Herold und D.

\section{[IV 2=SC III 5]}

Si quis polici de mano alterum excusserit, sol. XLV culpabilis iudicetur.

$[\mathrm{C} 29,4]$ Si quis policem de manu vel pede excusserit, ....

$[D 48,3]$ Si police de manu capulaverit, ...

Aus C-Fassung genommen wegen Verb (excusserit).

\section{[IV 3=SC III 6]}

Si quis naso alterum excusserit, sol. XLV culpabilis iudicetur.

[C29,13] Si nasum excusserit, ...

[Herold 32, 13] Si quis nasum alteri excusserit, ...

$[D 48,11]$ Si quis alterius nasum aut auriculam excusserit, ... sol. XV ...

Aus der C-Fassung übernommen, weil die Bußsumme übereinstimmt und D-Version mit Ohrverletzung kombiniert. Nicht in A vorhanden.

\section{[IV 4]}

Si quis mamella mulieris capolaverit, malb. sol. XLV culpabilis iudicetur.

[C20, 4] Si quis mamillam mulierem strinxerit/capulaverit, ...

$[\mathrm{D} 26,5]$ Si quis muliere mamella extrinxerit, ...

Das Verb capolare nur in C5 und Herold. In A nicht vorhanden.

\section{[IV 5=SC IV 3]}

Si quis hominem mortuum, antequam in terra mittatur, in furtum expoliaverit, malb. sol. XLV culpabilis iudicetur. 
$[\mathrm{C} 14,9] \mathrm{Si}$ quis hominem mortuum, antequam in terra mittatur, expoliaverit, ... sol. C culp. iud.

[Herold 18, 5] Si quis hominem mortuum, antequam in terram mittatur, in furtum expoliaverit, ... sol. XLV et in alia sententia ... sol. LXII cum dimidio culp. iud.

$[\mathrm{C} 55,1=\mathrm{D} 19,1] \mathrm{Si}$ quis corpus occisi hominis, antequam in terra mittatur, in furtum expoliaverit, ... sol. LXII semis culp. iud.

Nur Herold hat in furtum und die Bußsumme von 45 sol.

\section{[IV 6]}

Si viro pedis capolatus fuerit et ibidem mancus tenuerit, malb. sol. XLV culpabilis iudicetur.

[C29,10] Si vero pedes capulatus fuerit et ibidem mancatus tenuerit, ...

$[D 48,8]$ Si vero pedis capulatus fuerit et ibidem mancus teniat, ...

[IV 7]

Si quis secusium magistrum fur[averit] ${ }^{\mathrm{a}}$, malb. sol. XLV culpabilis iudicetur.

${ }^{\text {a }}$ nicht lesbar

$[\mathrm{A} 6,1] \mathrm{Si}$ quis seguisum magistrum furaverit, ...

$[\mathrm{C} 6,1]$ Si quis canem segusium magistrum furaverit ...

[Herold 6,2] Si quis segusium magistrum canem furaverit, ...

$[D 6,1]$ Si quis seusum magistrum furaverit, ...

Die Bußsumme ist nur bei Herold zu finden, da die anderen Fassungen 15 sol. nennen.

[V] DE XXXV.

[V 1]

Si quis caballum furav[erit $]^{\mathrm{a}}$, malb. anchisto, sol. XXXV culpabilis iudicetur.

${ }^{\text {a }}$ nicht lesbar

$[\mathrm{C} 38,3] \mathrm{Si}$ quis caballum spadum furaverit, mallobergo chanzisto, ...

[Herold. 41, 2] Si quis caballum spathum furaverit, malb. chengisto, ... $[D 63,1]$ Si quis caballum qui carruca trait, furaverit, malb. chana zascho, XLV sol. ... 
Nur in C (und bei Herold enthalten), nicht in A vorhanden und in D mit anderer Bußsumme. Die Glosse ist abzuleiten von ${ }^{*}$ changisto (=Hengst) ${ }^{48}$.

\section{[V 2]}

Si quis servum alieno ante ${ }^{a}$ rege per dinario ingenuum demiserit, malb. sol. XXXV culpabilis iudicetur.

${ }^{a}$ nicht gut lesbar

[C26, 2] Si quis vero servum alienum per denarium ante regem ingenuum dimiserit ...

[D37, 2] Si quis servum alienum per dinarium ante rege ingenuum demiserit, ...

\section{[V 3]}

Si quis servo alieno furaverit vel vindedirit, malb. sol. XXXV culpabilis iudicetur.

[C10] Si quis servum aut ancillam alienam furaverit, ... sol. XXXV culp. iud.

[Herold 11,1] Si quis servus aut ancilla caballum aut iumentum alterius furaverit ... sol. XXXV culp. iud.

[D11] Si quis servum aut ancillam furaverit et ei fuerit adprobatum, ... sol. XXX culp. iud.

Vorlage muss aus der C-Version genommen sein, da die Bußsumme übereinstimmt.

\section{[V 4]}

Si quis bimo tauro furaverit, malb. traslo, sol. XXXV culpabilis iudicetur.

$[\mathrm{C} 3,9] \mathrm{Si}$ bimum taurum furaverit, malb. trasile ...

[Herold 3, 8] Si quis bimum taurum furaverit, malb. traslo, ...

Nicht in A und D vorhanden. Die Glosse stimmt mit Herold überein, abgeleitet von *trasilo (=Kämpfer) ${ }^{49}$.

\section{[V $5=S C$ II 7]}

Si quis cervo domestico furaverit vel cellaverit, malb. sol. XXXV culpabilis iudicetur.

48 Lex Salica 1962, 280.

49 Lex Salica 1962, 289. 
$[\mathrm{C} 33,3] \mathrm{Si}$ vero alium cervum qui in venatione adhuc non fuerit domesticum occiserit aut involaverit, ... sol. XXXV culp. iud.

[D 51, 2] Si vero cervo domestico qui in venacione adhuc non fuisset, furaverit aut occiserit, ... sol. XV culp. iud.

Die Bußsumme stimmt nur mit C (und Herold) überein.

\section{[V 6=SC II 5]}

Si quis bovem furaverit, malb. hocno, sol. XXXV culpabilis iudicetur.

$[\mathrm{C} 3,7] \mathrm{Si}$ quis bovem furaverit, mallob. obsino/ocxino, ...

[Herold 3, 11] Si quis bovem furaverit, malb. ohseno ...

$[D 3,3]$ Si quis bovem aut vacam furaverit, mallob. podor ...

Glosse ist verdorben aus ${ }^{*}$ ochsino $(=O c h s e)^{50} . C$ (oder Herold) als Vorlage für die Glosse und den Text.

[V 7]

Si quis vacca cum vitulo furaverit, malb. sol. XXXV culpabilis iudicetur.

$[\mathrm{C} 3,4] \mathrm{Si}$ quis vaccam cum vitulo furaverit, ...

Nicht in D vorhanden, daher aus C (oder Herold) übernommen.

\section{[VI] DE XXX.}

[VI 1]

Si quis alteri aliquid de mano per virtute tullerit, raupaverit vel expoliaverit, malb. sol. XXX culpabilis iudicetur. [fol. 119r]

$[\mathrm{C} 61,1] \mathrm{Si}$ quis alteri de manum desuper illum aliquid per virtutem tullerit vel rapuerit, rem in capitale restituat et insuper sol. XXX conponat.

[Herold 64, 1] Si quis alter de manu aliquid per vim tulerit et raubaverit aut exspoliaverit, ... sol. XXX culp. iud.

[D95,1] Si quis de manu ad ira aliqud per virtutem tullerit aut rapuerit vel expoliaverit ... sol. XXX culp. iud.

Am nächsten an D (expoliaverit) oder an Herold.

50 Lex Salica 1962, 286. 


\section{[VI 2]}

Si quis iumenta aliena trebattit, malb. stalaca, sol. XXX culpabilis iudicetur.

[C38, 9] Si quis iumenta aliena trebatterit, malb. stalachaia ... sol. XXX culp. iud.

[D63, 6] Si quis iumenta aliena trabatterit et evaserit, mallobergo sitabahim, ... sol. XV culp. iud.

Die Glosse $(=\text { Stallvieh })^{51}$ nach $C$ oder Herold, nicht nach D, wo auch eine andere Bußsumme begegnet.

\section{[VI 3]}

Si quis hominem in capo placaverit et exinde ossa exierent, malb. sol. XXX culpabilis iudicetur.

$[\mathrm{C17}, 4] \mathrm{Si}$ quis hominem in caput ita placaverit et exinde trea ossa exierint, ...

[Herold 17,4] Si quis hominem in capite plagaverit et exinde ossa exierint, ...

$[D 22,3]$ Si quis hominem in capite placaverit et exinde ossa exierint, ... Im Wortlaut näher an D bzw. an Herold.

\section{[VI 4]}

Si quis clavem frierit et nihil tullerit et fugiens evadat, malb. sol. XXX culpabilis iudicetur.

$[\mathrm{C} 11,6]$ Si vero nihil tulerit et fugiens evadat, propter effracturam tantum ...

[Herold 11, 6] Si vero effregerit et nihil tulerit et fugiens evadit, propter effracturam tantum ...

[D12, 4] Si quis clavem effrigerit et nihil exinde portaverit, ...

Deutlichere Nähe zu C und Herold (fugiens evadat).

\section{[VI 5]}

Si quis cum rege ancella mihatus fuerit, malb. sol. XXX culpabilis iudicetur.

[C25, 2] Si quis vero cum regis ancilla mechatus fuerit, ...

[D36, 2] Si quis cum ancilla regi michatus fuerit, ...

51 Lex Salica 1962, 288. 


\section{[VI 6]}

Si quis brachium mulieris strinxerit, malb. sol. XXX culpabilis iudicetur.

[C20, 2] Si brachium strinxerit, ...

[D26, 2] Si brachium extrinxerit, ...

[VI 7]

Si quis campo alieno araverit et siminaverit, malb. sol. XXX culpabilis iudicetur.

[C27, 15] Si quis campo alieno araverit vel seminaverit, sol. XLV culp. iud.

[Herold 27, 19] Si quis campo alieno araverit et seminaverit, ... sol. XXX culp. iud.

[D46, 1] Si quis campo alieno araverit, ... sol. XV culp. iud.

D ist sicher als Vorlage auszuscheiden, Herold hat die deutlichsten Übereinstimmungen (Bußsumme und Wortlaut).

\section{[VII] DE XV.}

\section{[VII 1]}

Si quis dentem alterius excusserit [Abbruch]

[C29, 16] Si quis dentem alienam excusserit, ...

[Herold 29, 16] Si quis dentem excusserit, ...

$[D 48,13]$ Si quis alterius dentem excusserit, ... 
Peter Stotz

\title{
Hohe Weltgeschichte für langobardische Krieger
}

\author{
Verdichtung und Vereinfachung von Texten in der Handschrift \\ Bamberg Hist. 3
}

\begin{abstract}
This paper sheds light on a specific compilation of historical texts in an eleventh-century manuscript (MS Bamberg Hist. 3). The collection contains adapted versions of Paul the Deacon's Historia Romana, as well as works by Eutropius, Gregory of Tours and others. They were obviously designed to attract the attention of a broader and less educated audience. For this reason, they were revised linguistically and modified semantically in order to be more intelligible for the lay nobility of the period.
\end{abstract}

Mein Tagungsbeitrag entsprach weitgehend einem am 22. März 2013 in Florenz in italienischer Sprache gehaltenen Vortrag im Rahmen einer Tagung der Società internazionale per lo studio del medioevo latino (SISMEL) über „La letteratura di intrattenimento nel Medioevo latino“. ${ }^{1}$

Für die Entwicklung, welche die lateinische Sprache im Übergang zum Frühmittelalter genommen hat, ist kennzeichnend, dass neue Ausdrucksformen möglich geworden sind, welche den Aussagezielen und der Auffassungsgabe der jeweiligen Adressaten besser entsprochen haben. Da und dort lässt sich beobachten, wie älteres Textgut im Hinblick auf ein neues, wenig gebildetes Publikum zurechtgemacht worden ist. Ein schönes Beispiel dafür liefert eine Sammlung historischer Texte, die wohl etwa im dritten Viertel des 10. Jahrhunderts in Italien aufbereitet worden ist: ein Makrotext, ein theatrum historicum gewissermaßen, mit dem Ziel, ein vornehmes Laienpublikum zu belehren, zu unterhalten, aber auch zu bessern. Erhalten hat sich die Sammlung in der Handschrift Bamberg, Staatsbibliothek, Hist. 3, zwischen 996 und 1023 in Halberstadt niedergeschrieben nach einer nunmehr verlorenen Vorlage aus Mittel- oder Süditalien. Ihre wichtigsten Bestandteile sind: das Excidium Troiae, die Historia Romana von Eutrop / Paulus Diaconus, die römische und die Gotengeschichte des Jordanes, der spätmerowingische Liber historiae Francorum, die Historia Langobardorum des Paulus Diaconus, fünf Texte über Alexander den Großen und die Historia ecclesiastica gentis Anglorum von Beda Venerabilis. $\mathrm{Zu}$ den Alexandertexten gehören: 1] Nativitas et victoria Alexandri Magni regis, die lateinische Bearbeitung des griechischen Alexanderromans durch den Erzpriester (archipresbyter) Leo von Neapel

1 Die schriftliche Fassung erschien, unter dem Titel: Alexander der Große - nebst allen andern: die Bühne der Weltgeschichte in einer Bamberger Handschrift, in: Filologia mediolatina 21 (2014), 85111. Hiervon an dieser Stelle eine knappe Zusammenfassung. 
(ca. 951/969), 2] das Commonitorium Palladii, dem Verfasser der Historia Lausiaca zugeschrieben, 3] der Bericht des Dindimus über die Brahmanen, 4] der Briefwechsel (Collatio) von Alexander und Dindimus ${ }^{2}$ und 5] der angebliche Brief Alexanders an Aristoteles über die Wunder Indiens, eine Bearbeitung der wohl aus dem 7. Jahrhundert stammenden Vulgatfassung dieses Textes. Überhaupt stellen die meisten Bestandteile der Sammlung Bearbeitungen der Ausgangstexte dar, dies augenscheinlich zwecks besserer Verständlichkeit für vornehme langobardische Laien. Davon ausgenommen sind die beiden Werke des Jordanes sowie dasjenige Bedas. Demgegenüber war Leos Alexandergeschichte wohl von Anfang an in einer hierfür passenden Form gehalten. Manche Sprachzüge gehen in die Richtung eines frühen Volgare. Von älteren Forschungen abgesehen - genannt sei Friedrich Pfister -, hat sich vor allem Marek Thue Kretschmer ${ }^{3}$ mit der Darbietungsform dieser Texte auseinandergesetzt, mit Schwerpunkt auf der sprachlichen und inhaltlichen Umformung der Historia Romana, die er nach dieser Handschrift ediert hat. Den sich hieraus ergebenden Tendenzen wird in meiner Skizze noch etwas weiter nachgegangen.

Zahlreich sind die sprachlichen Anpassungen der Texte in Richtung auf eine volksnahe, zur mündlichen Umsetzung geeignete Sprache. Dies lässt sich recht schön an einer Probe aus dem Aristotelesbrief [Alexandertext 5] zeigen, bei dem Eva Hanetseder bereits 1994 zahlreiche sprachliche Besonderheiten herausgearbeitet hatte. ${ }^{4}$ Ins Auge fallen vor allem lexikalische Vulgarismen oder Regionalismen, von denen sich manche zum Italienischen in Bezug setzen lassen, etwa alipergus/-um für castra, bucca für os oder $a(u)$ scultare für audire. Vielfach wird dem hochlateinischen Wort ein volkstümlicheres in Form einer Glosse nachgestellt, etwa prunas id est carbones oder privignus id est filiaster. Weiterhin fällt auf - was Kretschmer bei der Historia Romana herausgearbeitet hat -, dass der differenzierte Wortschatz des Ausgangstextes vielfach eingeebnet wird zugunsten allgemeinerer, vielseitig anwendbarer Wörter. So nimmt mori allein schon in diesem Text die Stelle von vierzehn unterschiedlichen Ausdrücken ein. Die Bearbeitung der Texte erstreckt sich jedoch auch auf die erzählerischen Belange. Hierfür kann die Umformung einer bekannten Begebenheit aus der Langobardengeschichte des Paulus Diaconus (Buch 1, Kap.15) als Beispiel dienen. Aber auch pragmatisch-inhaltliche Aspekte lassen sich in großer Zahl namhaft machen. Lohnend ist es in dieser Hinsicht, die Umarbeitung der Collatio zwischen Alexander und Dindimus [Alexandertext 4] in Augenschein zu nehmen. Hier geht es nicht um die Er-

2 Hiervon ist nunmehr eine kommentierte Neuedition mit Übersetzung greifbar: Alexander der Große und die „nackten Weisen“ Indiens. Der fiktive Briefwechsel zwischen Alexander und dem Brahmanenkönig Dindimus. Einleitung, lateinischer Text, Übersetzung und Kommentar von Marc Steinmann, Berlin, 2012 (Klassische Philologie 4).

3 Marek Thue Kretschmer, Rewriting Roman History in the Middle Ages. The 'Historia Romana' and the Manuscript Bamberg, Hist. 3, Leiden, 2007 (Mittellateinische Studien und Texte 36).

4 Eva Hanetseder, Der angebliche Brief Alexanders an Aristoteles über die Wunder Indiens. Eine sprachliche Untersuchung der Fassung in der Bamberger Handschrift, in: Archivum Latinitatis medii aevi 52 (1994), $167-200$. 
zählung von Ereignissen, sondern um die Darstellung einer (außerchristlichen) Weltanschauung und Lebenspraxis. Manch antiker Zug, etwa die Erwähnung von Triumphen oder der Pyramiden, bleibt weg. Für Äußerungen geistiger Urbanität ist die Empfänglichkeit herabgesetzt; manches wird in elementar-christlichem Sinne vergröbert. ${ }^{5}$ Vielfach kommt es zu Änderungen oder Einschüben moralisch-erbaulicher Art. Keine Gelegenheit wird versäumt, Aussagen der Vorlage im Sinne von Bezugnahmen auf Höllenstrafen umzumünzen. Die eine oder andere Umdeutung mag unwillkürlich erfolgt sein. Selten nur kommt es zu Erweiterungen; ein Beispiel ist die Erwähnung der zwölf Taten des Herkules.

Das in der Bamberger Handschrift überlieferte Geschichtskompendium zeigt Ansätze zu einem mit bestimmten Zielen konzipierten Ganzen. Manche - nicht alle Bestandteile haben im Hinblick auf diese Ziele eine gewisse, zum Teil sogar eine recht starke Umarbeitung erfahren: sprachlich vor allem, aber auch inhaltlich, meist im Sinne von Vereinfachung und Verdichtung, manchmal bis hin zu einer gewissen Entstellung. Ein übergeordnetes Ziel ist zwar erkennbar, aber die Formung der Texte zeigt denn doch ein recht uneinheitliches Bild. Eine Frage, die hier nur gestellt, nicht beantwortet werden kann, ist die, ob derartiges Kompilieren und Adaptieren verbreiteter Praxis entsprach oder eher ein vereinzeltes, allenfalls nicht so recht geglücktes Experiment darstellt.

5 Zwei Beispiele: Didimus eröffnet sein Zeugnis mit der Aussage, dass die Brahmanen ein reines und einfaches Leben führten. Hier wird dies sofort ausgemünzt durch die Verdeutlichung: nulla peccata facimus. Und wenn er später sagt, sie wollten von Gottes Güte keinen schlechten Gebrauch machen, wird daraus: sed non facimus ea, quae contra Deum sunt. 



\section{Aus Altem ein Neues - Versuch eines Schlusswortes}

Die Auseinandersetzung mit historischen Umbrüchen, mit Krisen, Revolutionen und anderen Formen von sozialen, politischen und wirtschaftlichen Transformationen gehört spätestens seit der beginnenden Moderne zu den zentralen Themen der Geistesund Sozialwissenschaften. ${ }^{1}$ Besonderes Interesse gewonnen hat in jüngster Zeit die Analyse von Diskursen des Umbruchs im Zeichen von Bedrohungswahrnehmungen bestehender Ordnungen ${ }^{2}$ und die Frage nach den Voraussetzungen von Wissenstransfer im nicht nur europäischen historischen Kontext. ${ }^{3}$ Solche Fragestellungen markieren besonders deutlich, wie gross die Distanz geworden ist, die gegenüber den überkommenen Verfallsnarrativen besteht, mit denen die Zeit von Spätantike und Frühmittelalter so lange belegt wurde. ${ }^{4}$

Die Beiträge in diesem Band bewegen sich auf ähnlichen, aber doch etwas anderen Wegen. Sie untersuchen unterschiedliche Techniken und Formen des Umgangs mit Wissensbeständen aus der Antike in der Zeit des frühen Mittelalters. Dabei zeigt sich ein breites Spektrum von Annäherungen an überkommenes Wissen, das vom schlichten Verdrängen - man könnte auch sagen: Vergessen - bis hin zur gezielten Erweiterung oder Umarbeitung reicht. Schaut man näher hin, dann rückt mit der Kanonisierung von Wissensbeständen eine Technik immer wieder in den Vordergrund,

1 S. etwa Harold Berman, Law and Revolution, Bd. 1: The Formation of the Western Legal Tradition, Cambridge (Mass.), London, 1983; Bd. 2: The Impact of the Protestant Reformations on the Western Legal Tradition, Cambridge (Mass.), London 2003; Peter Brown, The world of late Antiquity. From Marcus Aurelius to Muhammad, erstmals London 1971; Neithard Bulst, Jörg Fisch, Reinhart Koselleck, Christian Meier, Revolution, Rebellion, Aufruhr, Bürgerkrieg, in: Geschichtliche Grundbegriffe, Bd. 5, hrsg. von Otto Brunner, Werner Conze und Reinhart Koselleck, Stuttgart 1984 (ND 2004), 653 788; Reinhart Koselleck, Kritik und Krise - Eine Studie zur Pathogenese der bürgerlichen Welt, erstmals Frankfurt a. M. 1973; aus neuester Zeit: Mike Rapport, Revolution, in: Aufruhr - Katastrophe - Konkurrenz - Zerfall, hrsg. von Ewald Frie und Mischa Meier, Tübingen 2014, 279-301 m. w. N.; s. a. allgemein Epochenschwelle und Epochenbewusstsein, hrsg. von Reinhart Herzog und Reinhart Koselleck, München 1987.

2 Ewald Frie / Mischa Meier, Bedrohte Ordnungen. Gesellschaften unter Stress im Vergleich, in: Aufruhr - Katastrophe - Konkurrenz - Zerfall, hrsg. von Ewald Frie und Mischa Meier, Tübingen 2014, 1-27, hier 4-7 und passim.

3 Dazu die Beiträge in: Wissen in Bewegung. Institution - Iteration - Transfer, hrsg. von Eva CancikKirschbaum und Anita Traninger, Wiesbaden 2015 (online verfügbar, URL: <http://www.harrassowitzverlag.de/dzo/artikel/201/001/1330_201.pdf?t=1455784681>, Zugriff: 26. Juli 2016), insbesondere der Beitrags ders., Institution - Iteration - Transfer. Eine Einführung, ebd., 1-13.

4 Dazu aus jüngster Zeit Ian Wood, The modern Origins of the Early Middle Ages, Oxford 2013, 5-13 und passim. S. im übrigen Stephan Dusil, Gerald Schwedler, Raphael Schwitter, Transformationen des Wissens zwischen Spätantike und Frühmittelalter. Zur Einführung (in diesem Band, 1-22). 
die auch in anderen wissensgeschichtlichen Zugängen betont worden ist ${ }^{5}$. Immer wieder nämlich werden in frühmittelalterlichen Textzeugnissen Tendenzen sichtbar, bestimmte Wissensbestände als, so könnte man vielleicht sagen, Referenzwissen festzuschreiben, wie etwa bei Isidor von Sevilla oder im Zusammenhang von Glossierungen, in denen - wie dann später durch die Glossa ordinaria - ein bestimmter Kanon von Inhalten als allgemein anerkannter Wissensbestand festgeschrieben wird. Medial umgesetzt werden solche Kanonisierungsprozesse im Frühmittelmittelalter in einem, wie die Beiträge dieses Bandes deutlich machen, überraschend breiten Spektrum von Textsorten, das von Kompilationen (so insbesondere im Zusammenhang von Rechtstexten), der gezielten Verarbeitung von älteren Texten (wie etwa in der Umschreibung der Weltgeschichte im Ms. Bamberg Hist. 3 oder in der Auseinandersetzung mit Livius) über Epitomierungen bis hin zu schlichten Textexzerpten reicht.

Allerdings - und in diesem Punkt reichen die Befunde des Bandes sogar über den ursprünglich gewählten perspektivischen Rahmen hinaus - bleibt es nicht beim Exzerpieren, Kompilieren und Tradieren. Es entsteht auch Neues. Das geschieht insbesondere dort, wo es darum geht, unter dem Vorzeichen insbesondere anderer religiöser Orientierungen die eigene Stellung in der Welt und insofern die eigene Identität zu bestimmen. Dabei ist die Geschichte offenbar ein zentrales Medium der Orientierung, wie sich in der Bedeutung der Hagiographie, in Neudeutungen von Weltgeschichte oder auch in der Auseinandersetzung mit Herrschaftspraktiken zeigt, die - wie im Fall der Steuer - auf ältere Zeiten zurückverweisen. Neues aus Altem entsteht allerdings vielleicht am häufigsten im Zusammenhang weltlicher rechtlicher Normativität. Hier nämlich werden zwar häufig langestreckte Textkontinuitäten insbesondere zum römischen Recht sichtbar, doch zeigt sich bei näherer Betrachtung, dass und wie in einer Art pragmatischer Fortschreibung situationsgebundene Anpassungen stattfinden. Bisweilen aber, das zeigt das Beispiel der lex salica sehr eindrucksvoll, finden sich sogar gezielte Neuansätze, durch die eine vom römischen Recht unterschiedene - im Fall der lex salica also fränkische - Rechtskultur herausgehoben werden soll. An dieser Stelle wird rechtliche Normativität besonders intensiv zur Beschreibung kollektiver Identitäten eingesetzt, die gezielt dem Überkommenen entgegen gestellt werden. Dabei scheinen es vor allem Herrschaftsinteressen sozialer Eliten oder auch des Königtums zu sein, die im Interesse der Ordnungsstabilisierung solche Formen der Erinnerungspolitik betreiben. Dem entspricht es, dass die Erinnerungsgestaltung durch die Unterdrückung von Wissen - wie etwa im Fall der Verbrennung von Steuerlisten ebenfalls im Zusammenhang von Herrschaftskonflikten geschieht.

Allerdings, so hat sich gezeigt, nicht alles Wissen ist in dieser Weise Gegenstand von Erinnerungsgestaltung: An der Gestaltung von Rechtswissen besteht offenbar ein grösseres politisch-pragmatisches Interesse als an der Gestaltung von meteorologischem Wissen, auch wenn in beiden Fällen durchaus die gleichen kulturellen Praktiken des Exzerpierens und Tradierens zur Anwendung kommen. Nicht zuletzt an

5 Vgl. Cancik-Kirschbaum / Traninger, Institution - Iteration - Transfer (Anm. 3), 9-10. 
diesem Punkt zeigt sich, dass und wie sehr die Entstehung von neuen Wissensordnungen, der Umgang mit Wissensbeständen und damit der Wissenswandel insgesamt von den sozialen Anforderungen an je unterschiedliche Wissensinhalte abhängt. Hier könnte ein Ansatzpunkt für weitere Forschungen liegen. 



\section{Register}

\section{Handschriften}

(Vgl. die chronologische Aufstellung der heute erhaltenen merowingischen Handschriften im Beitrag von Ian Wood, S. 217-222)

Admont, Stiftsbibliothek, 261

Amiens, Bibliothèque Municipale, 12

Autun, Bibliothèque Municipale, 107

Bamberg, Staatsbibliothek, Hist. 3

Basel, Universitätsbibliothek,

F III 15 I

N I 4 A

Berlin, Staatsbibliothek Preussischer

Kulturbesitz,

Lat. Qu. 364

Phillipps 1329

Phillipps 1761

Phillipps 1743

Phillipps 1745

Phillipps 36184

Bern, Burgerbibliothek,

199

219

358

380

611

645

756

A 91 (8)

Bern, Stadt-/ Universitätsbibliothek, 380

Breslau/Wroctaw, Universitätsbibliothek, REHD 169

Bruxelles, Bibliothèque Royale, 9850-2

19609

Cambrai, Bibliothèque Municipale, 470

684

937

Cambridge, Corpus Christi College,

144

334

Cambridge, Gonville and Caius College, 820219
202, 218

219

245,250

221

221

219

218

217

221

181, 202, 218

219

221

218

221

217

220-221

221

221

221

220

221

220

219-220

220

154

219
Cheltenham Phillipps $\rightarrow$ Berlin, Staatsbibliothek Preuss. Kult., Phillipps

Chartres, Bibliothèque Municipale, 40 (2)

220

52 (78)

220

Codex Legionensis $\rightarrow$ León, Bibliotéca Catedral, 15

Colmar, Archives Départementales, Frag 700218

Colmar, Bibliothèque Municipale, 45

82

220

Copenhagen, Kongelige Bibliotek, NY KGL SAML 58.8

NY KGL SAML 1878 fol

Den Haag, Museum Meermanno-

Westreenianum, 10 A 1

Douai, Bibliothèque Municipale, 281

342

Épinal, Bibliothèque multimédia intercommunale [Bibliothèque Municipale],

$72(2)$

154, 159

149 (68)

220

Erfurt, Universitäts- und Forschungsbibliothek Erfurt/Gotha, Dep. Erf.

CA $2^{\circ} 42$

Freiburg, Universitätsbibliothek, 483, $12 \quad 221$

Fulda, Landesbibliothek, Boniface 2

221

Genf, Bibliothèque Publique, Lat. 16

Ghent, Universiteitsbibliotheek,

246

4051

222

Gotha, Forschungsbibliothek, MBR I 75

$220-221$ 
Halberstadt, Bibliothek Domgymnasium,

Frg. 1

Hannover, Kestner, Cul 1.48

Harburg, Fürstbibliothek, 1.2.4.2

Ivrea, Biblioteca Capitolare, 1

Karlsruhe, Landesbibliothek,

Aug. CCLIII

Frag. Augustine 14

Frag. Augustine 104

Lat. 339

Kassel, Landesbibliothek,

Theol. Oct. 5

Theol. QU 10

Köln, Dom-/ Diözesanbibliothek,

98

165

212

Laon, Bibliothèque Municipale

137

423

Leiden, Universiteitsbibliotheek,

Fr. 21

Voss Lat. Qu. 63

Voss Lat. Qu. 69

León, Bibliotéca Catedral, 15

London, British Library,

Add 11878

Add 24144

Add 29972

Add 31031

Add 41567

Add 46676

Harley 5041

Harley 5792

Wilfred Merton 21

Louvain-la-Neuve, Bibliothèque de l'Université, Frag H Omont $2 \mathrm{~A}$

Lyon, Bibliothèque de la Ville

[Bibliothèque Municipale],

403 (329)

425 (351)

$426(352)$

$443(372)$

$468(397)$

$478(408$

$600(517)$

$602(519)$
181

222

221

219

732

220

Modena, Biblioteca Capitolare, O I 2

217-221 Montpellier, Bibliothèque Universitaire, 241217

218 München, Bayerische Staatsbibliothek,

$221 \quad \mathrm{Clm} 3514$

$220 \quad \mathrm{Clm} 6278 \quad 221$

Clm 6315

$221 \quad \mathrm{Clm} 14123$

$221 \quad \operatorname{lm} 21053 \quad 221$

Clm 22501

$221 \quad \mathrm{Clm} 29022$

$221 \quad \mathrm{Clm} 29033 \quad 221$

218, $202 \quad$ Clm 29047

Clm 29158a 221

Münster, Staatsarchiv, MSC VII 2 a 218

220

220

Naumur, Bibliothèque du Grand

Séminaire, 42

218 Nürnberg, Germanisches Museum, Kupfer-

222 stichkabinett, Kapsel 536/SD $286 \quad 222$

154 New York, Pierpont Morgan,

113 M $17 \quad 222$

M 334

219

219 Orleans, Bibliothèque Municipale,

$220 \quad 19 \quad 217$

$219154(131) \quad 220$

$219192(169) \quad 217,219$

117-118 Oxford, Bodleian Libraries,

220

220

Paris, Archives Nationales, A XIX $1737 \quad 219$

219 Paris, Bibliothèque Nationale de France, Baluze 270

Lat. 152

217, 219

217

Lat. 256

220

217

Lat. 1585

217

217, 218

Lat. 1625

218

218

Lat. 1629

217

218

Lat. 1719

219

217

Lat. 2110

220

219

Lat. 2206

220

218

Lat. 2706

220 
Lat. 2739

Lat. 2739, fragment

Lat. $4403 \mathrm{~A}$

Lat. 4411

Lat. $4628 \mathrm{~A}$

Lat. 4631

Lat. 4760

Lat. 4808

Lat. $6400 \mathrm{G}$

Lat. 6413

Lat. 7193

Lat. 7714

Lat. 8305

Lat. 8901

Lat. 8907

Lat. 8913

Lat. 9377

Lat. 9382

Lat. 9389

Lat. 9427

Lat. 9550

Lat. 9643

Lat. 10399

Lat. 10756

Lat. 10758

Lat. 10837

Lat. 10863

Lat. 10910

Lat. 11641

Lat. 12021

Lat. 12097

Lat. 12161

Lat. 12168

Lat. 12190

Lat. 12207

Lat. 12238

Lat. 12243

Lat. 12475

Lat. 13246

Lat. 13348

Lat. 13349

Lat. 13367

Lat. 13909

Lat. 14086

Lat. 17654

Lat. 17655

Lat. 18248

Lat. 18315

Lat. nov. acqu. 446

Lat. nov. acqu. 602

\begin{tabular}{|c|c|c|}
\hline 220 & Lat. nov. acqu. 1177 & 222 \\
\hline 217 & Lat. nov. acqu. 1063 & 218 \\
\hline 220 & Lat. nov. acqu. 1575 & 220 \\
\hline 223,244 & Lat. nov. acqu. 1591 & 218 \\
\hline $224,231-234$ & Lat. nov. acqu. 1594 & 218 \\
\hline $224,231-234$ & Lat. nov. acqu. 1598 & 220 \\
\hline $224,231-234$ & Lat. nov. acqu. 1599 & 220 \\
\hline 220 & Lat. nov. acqu. 1619 & 220 \\
\hline 219 & Lat. nov. acqu. 1629 & 217 \\
\hline 220 & Lat. nov. acqu. 1740 & 220 \\
\hline 219 & Lat. nov. acqu. 2061 & 219 \\
\hline 146 & Lat. nov. acqu. 2334 & 220 \\
\hline 219 & Lat. nov. acqu. 2388 & 219 \\
\hline 218 & Lat. nov. acqu. 2389 & 222 \\
\hline 181 & & \\
\hline 217 & Roma, Biblioteca Vallicelliana, B 62 & 220 \\
\hline 222 & & \\
\hline 220 & Sankt Paul im Lavanttal, Stiftsbibliothe & \\
\hline 219 & Cod. 3 & 219 \\
\hline 219 & Cod. 4/1 & $106-107$ \\
\hline 217 & Sankt Gallen, Stiftsbibliothek, & \\
\hline 181, 217 & 46 & 221 \\
\hline $218,219,220$ & 188 & 221 \\
\hline 220,221 & 194 & 221 \\
\hline $224,231-234$ & 214 & 221 \\
\hline 220 & 226 & 218 \\
\hline 218,220 & 242 & 221 \\
\hline 220 & 728 & 181 \\
\hline 219 & 908 & 218 \\
\hline 219 & 1396 II & 221 \\
\hline 217, 220 & $1396 \mathrm{~V}$ & 218 \\
\hline 202, 217, 219 & $1398 a$ & 221 \\
\hline 220 & St. Petersburg, Public Library, & \\
\hline 220 & F v I.1 & 219 \\
\hline 220 & F v I.2 & 219,222 \\
\hline 219,220 & F v I.4 & 218 \\
\hline 220 & F v I.11 & 141, 219 \\
\hline 217 & F v II.3 & 218 \\
\hline 220 & 0 v 1.3 & 222 \\
\hline 220 & 0 v I. 4 & 222 \\
\hline 220 & Q v I.2 & 218 \\
\hline 217 & Q v I.13 & 219 \\
\hline 139 & Q v I.14 & 219 \\
\hline \multicolumn{3}{|l|}{220} \\
\hline 220 & Toledo, Biblioteca Cathedral, 13.3 & 222 \\
\hline 218 & Toulouse, Bibliothèque & \\
\hline 220 & Municipale, 364 & 202,218 \\
\hline \multicolumn{3}{|l|}{220} \\
\hline \multicolumn{3}{|l|}{219} \\
\hline 218 & & \\
\hline
\end{tabular}

218

220

218

218

220

220

220

217

220

219

220

219

222

220

219

221

221

221

221

218

221

181

218

221

218

221

219

218

219

218

222

218

219

219

222

218 
Trier, Stadtbibliothek, Frag.

219, 222

Turin, Bibliteca Nazionale Universitaria,

A.II.2

181, 218

Utrecht, Universiteitsbibliotheek, 1003

Valenciennes, Bibliothèque Municipale, 495 (455)

Vatikan, Biblioteca Apostolica Vaticana,

Lat. 5766

Lat. 7223

Pal. Lat. 493

Pal. Lat. 574

Reg. Lat. 257

Reg. Lat. 267

Reg. Lat. 316

Reg. Lat. 317

Reg. Lat. 329

Reg. Lat. 689bis

Reg. Lat. 886

Reg. Lat. 1204

Verona, Biblioteca Capitolare, XL 38
222

181, 218

218

219

202

219

217

219

219

218

218

181, 217

218

218, 220

Wien, Österreichische Nationalbibliothek,

Lat. 502

Lat. 563

Lat. 4213

Weimar, Staatsarchiv, Hardenberg 1

Wolfenbüttel, Herzog August Bibliothek, Aug. 4.13.11

Gud. Lat. 4.269

Nov. 404.2.13 221

Weißenburg $76 \quad 217,219$

Weißenburg $86 \quad 221$

Weißenburg $97 \quad 226$

Weißenburg $99 \quad 221$

Würzburg, Universitätsbibliothek,

M P TH Q 1a

218

M P TH Q 13

M P TH F 79

M P TRH F 64 a $\quad 219$

Zürich, Staatsarchiv, C VI 3

181,221

Zürich, Zentralbibliothek,

C 184

221

RP $5 \quad 218$

RP $6 \quad 218$

\section{Werk- und Stellenverzeichnis}

Additamenta Nivialense de Fuillano

Albertus Magnus

De animalibus

Meteora

$$
\begin{aligned}
& 2,1,24-28 \\
& 3,3,4 \\
& 3,3,19-23
\end{aligned}
$$

Ambrosius

Hexameron

2,4,16

De excessu fratris Satyri

De officiis

Ammianus Marcellinus

Res gestae

$17,3,2-4$

$22,16,23$

Argumenta Vergiliana

Aristoteles, Meteora

Athanasius, Vita Antonii

Augustinus

De doctrina christiana

$2,28,42$

De civitate Dei
De Genesi ad litteram

203

Enarrationes in Psalmos

Bartholomaeus Anglicus

De proprietatibus rerum

63

Beda Venerabilis

Historia ecclesiastica gentis Anglorum 215, 245

De natura rerum

65,67

$$
1-24
$$

$25-36$

60

28

34

61

$37-51$

$61,62,65$

60

Breviarium Alarici

121, 201, 225

Caesarius von Arles, Sermones

203

Cassiodor

Historia ecclesiastica tripartita

141

Institutiones

95

Variae

$$
4,26
$$

190

6,17

187 
Cicero

De inventione 2,1

De officiis

De republica

Codex Euricianus

c. 307

Codex Gregorianus

Codex Hermogenianus

Codex lustinianus

Codex Theodosianus

$$
\begin{aligned}
& 1,5,6 \\
& 1,5,7 \\
& 8,12,1 \\
& 8,12,8 \\
& 11,1,13 \\
& 11,1,15 \\
& 11,1,33 \\
& 11,16,11 \\
& 11,28,2 \\
& 11,28,3 \\
& 12,1 \\
& 12,1,117 \\
& 12,7,3 \\
& 13,10,2 \\
& 13,11,4 \\
& 15,1,1 \\
& 16,1,1
\end{aligned}
$$

Collectio Herovalliana

Collectio Vetus Gallica

Constitutiones Sirmondianae

Cornelius Nepos, Cato

$$
\text { 3,3-4 }
$$

Corpus iuris civilis

Defensor von Ligugé

Liber scintillarum

Digesta lustiniani

Edictum Chlotharii

Edictum Rothari

$$
\text { c. } 386
$$

Edictum Theoderici

$$
\text { c. } 51
$$$$
\text { c. } 52
$$

Einhard, Vita Caroli

$$
\text { Epitome Aegidii }
$$

Eucherius, Passio Acaunensium Martyrum

Eusebius von Caesarea/Rufinus Historia ecclesiastica

Eutropius

Historia Romana

Breviarium $a b$ urbe condita 1 praef.

Excidium Troiae

Formulae Marculfi

Fragmenta Gaudenziana

c. 7

c. 10

c. 11

c. 12

c. 14

c. 15

180

127

124,127

180

182

190

183

184

184

182

183

195

179

182

72

72

106

201, 210

181

39

$8,20,72$

210, 211

20

194

114

$109,121,123$

122

122, 125

17

$106-107,124$

205

15, 204
Fredegar, Chronik

$1,2,2$

$2,1,2$

$2,37,62$

$3,12,95$

$3,80,115$

4,24

4,24

4,26

Fronto

Epistulae ad Antoninum

$$
\text { 105,13-17 }
$$

Gellius

Noctes Atticae

Praef. 11-12

Gesta Theodorici

Glossa ordinaria

Gregor I.

Cura pastoralis

Registrum epistolarum

9,34

Dialogi

2,4

4,42

Homiliae in Ezechielem

Moralia in Iob

Regula pastoralis

Gregor von Tours

Decem libri historiarum

Prologus

2,38

3,25

3,36

4,2

5,3

5,4

5,26
245, 246

32

32

245

194, 229

117

121

121

121

121

$124-126$

117-129

17, 204, 212

193

193

193

194

193

194

194

194

26

26, 31, 35

32

212, 213

250

203

15

136, 203, 208, 211, 216

139

139

203, 211

203, 211, 216

211

204, 212

192

196

186, 190

187

186

187

187

186 
5,28

5,34

5,42

6,22

7,15

7,23

9,30

10,7

10,8

10,21

De virtutibus sancti Iuliani

16

17

Hieronymus

Adversus lovinianum

Historia ecclesiastica

Commentaria in Naum

Vita Sancti Pauli Eremitae

Epistolae

Hinkmar von Reims

De ordine palatii

c. 21

Hippolytus, Liber generationis

Historia Lausiaca

Historia Dareti Phrygii

Homer, Ilias (latina)

Honorius von Autun

De imagine Mundi

1,57

1,60

Hydatius, Chronica

Hyginus, De viris illustribus

Interpretatio Pauli sententiarum

Isidor von Sevilla

Chronica

De ecclesiasticis officiis

De fide adversus ludaeos

De natura rerum

$$
\begin{aligned}
& 1-8 \\
& 9-28 \\
& 29 \\
& 29-38 \\
& 35 \\
& 39-48
\end{aligned}
$$

Epistolae

$$
3
$$$$
5
$$$$
6
$$

185, 197

188

187

186-187

186-187

$186-187$

$186-187,189-190$

186-187

187

187

187

187

143, 203

246

163,167

206

213

106

212

15, 246

212

212

63

63

63

212

33

19

87, 204, 212

211

87

$58-60,65$

67, 99-101

58

58

59

58

59, 62

58

87

88

88

89
Etymologiae

$51,55,85,86,87$, $89,90,91,100,153$, 156, 163, 166-174, 209, 212, 213

$$
1-2
$$

1,29

2,1

2,10

3

3,70

4,13

5,21

6,19

8,6

8,11

9,1

13

$13,1-6$

13,7-11

$13,12-22$

$13,8,1-2$

$13,10,5-11$

16

Historia Gothorum

c. 35

c. 51

Sententiae

Synonyma

lustinianus

Institutiones

Novellae

1

10

Iustinus

Epitoma Historiarum Philippicarum Pompeii Trogi

26

Jonas von Bobbio

Vita Columbani

Vita Iohannis

205, 206, 211

Juan Gil de Zamora

Historia naturalis

63

Kapitular von Herstal (779)

225

Konrad von Megenberg

Buch der Natur

51,65

$$
\text { 2,20 }
$$

2,25

66

Laktanz

De mortibus persecutorum

$$
7,3
$$


23,152

Leo von Neapel

Nativitas et victoria Alexandri Magni regis

Lex Alamannorum

245

106, 181, 224

Lex Baiuvariorum

Lex Burgundionum

18,1

22,4

Lex Francorum

Lex Hermogeniana

Lex Papiani

106, 108

106

$116-117$

$127-128$

181

181

181

106, $224-225$

Lex Ribuaria

40,9

228

68,3

229

Lex Romana Burgundionum

20, 106, 181

Lex Romana Curiensis

20

Lex Romana Visigothorum 19-20, 111, 123, 181, 225

5,1

126

$8,5,1$

$121-122,127$

Lex Salica 22, $105-107,180,212$, $224-225,227-228,231-244,250$

Lex Suavorum

224

Lex Theodosiana

181

Lex Visigothorum

$$
5,2,7
$$

$$
\text { 9,1,21 }
$$

118,123

$120,125-126$

Liber Gai

122

Liber historiae Francorum

225

Liber iudiciorum

$$
\text { 2,1,10 }
$$

Liber monstrorum

113

Liutprand, Novellae

77

118

Livius

$$
\begin{gathered}
\text { Ab urbe condita } \\
21 \\
21,5-14 \\
21,46,7-9 \\
21,58-59 \\
22,3,4-14 \\
22,4,1-6,7 \\
22,10-12 \\
22,19-22 \\
22,25-29 \\
\text { Periochae }
\end{gathered}
$$

$1 \mathrm{~B}, 40$

195, 212, 213, 245

214

115

116

(0)

Martianus Capella

De nuptiis Philologiae et Mercurii

Medicina Plinii

Memoratorium de exercitu in Gallia

$$
\text { occidentali praeparando }
$$

38

$\begin{array}{ll}2,24 & 38\end{array}$

$4,4 \quad 38$

$4,14 \quad 38$

$5,2 \quad 38$

$7,3 \quad 38$

$7,11 \quad 40$

$8,10 \quad 38$

$8,13 \quad 38$

$13 \quad 40$

$21 \quad 46$

$21,1 \quad 40,42$

21,4

21,6

$21,7-8$

42

41

41, 43

$42-43$

43,47

43

$43-44$

43

43

45

45

45

$45-46$

44

46

46

47

38

38

38

38

38

39

39

40

214

33

95

50

225

Origo gentis Romanorum $\quad 27,37$

Orosius

Historiae adversum paganos $\quad 153,163,167$,

$44 \quad 169-174$

12, 21, 29-48 Ovid

Metamorphosen

209 
Ars amatoria

Pactus legis Salicae

Pauli Sententiae

4,5,3

Paschasius Radbertus

Epitaphium Arsenii

1 prologus

1,2

1,3

1,8

2 prologus

2,1

2,2

2,3

2,5

2,7

2,8

2,16

Vita Adalhardi

De corpore, prologus

Expositio in lamentationes Hieremiae 138, 146

Expositio in Matheo 1

Passio Leodegarii

Passio Praeiecti

Paulinus, Vita Sancti Ambrosii

Paulus Diaconus

Historia Langobardorum

Pelagius I.

Verba seniorum

Decretum Gelasianum

Plinius der Ältere

Naturalis historia
2
$2,1-101$
$2,102-150$
$2,102-153$
2,107
$2,112-113$
2,141
2,151
$2,151-153$
2,152
2,153
$2,154-179$
$2,178-179$
$2,180-248$
$3-6$
7
$8-11$
$12-13$

133, 141, 142, 146

134

142,146

206, 211

208

206

116, 245

202

202

49-58

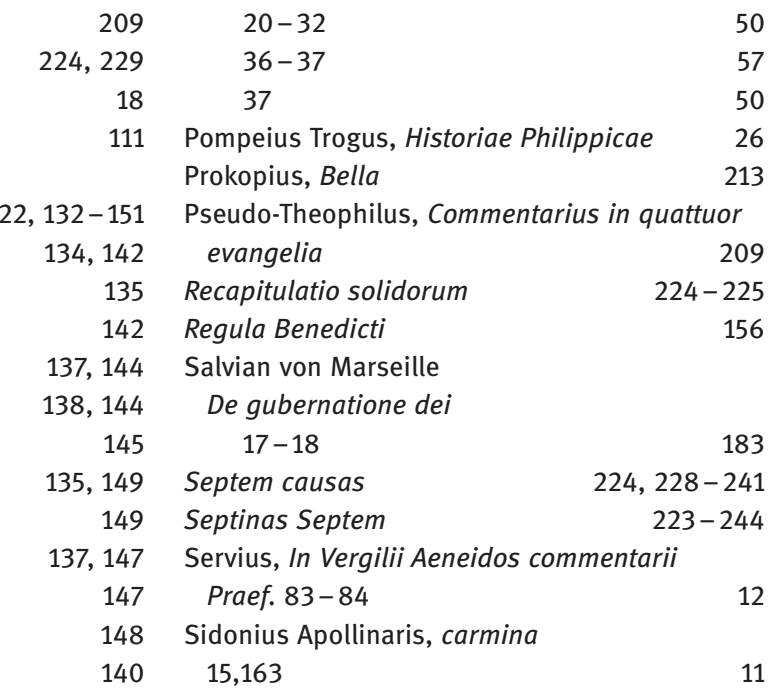

Sisebut, Vita Desiderii

88,100

Carmen de Luna

88,100

Solinus

Collectanea rerum memorabilium $\quad 49,51,55$ 5,8

55

32,37

55

Statius, Silvae

4,7,53-56

c. 5

15

Sulpicius Severus

Gallus

$138,146,147$

Vita s. Martini

138

Theodoret, Historia religiosa 17

183, 187

57, 58 Thomas von Cantimpré

De natura rerum

$63-65$

prologus

63

16,1

64

64

65,66

16,4

Terenz

Andria

143

Adelphoe

54, $62 \quad 4,3$

143

Transitus Fursei

Vergil

Aeneis

Eklogen

4,55

Georgica

12

50 Vinzenz von Beauvais

50 Speculum naturale 26

\section{0} 57

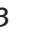


Visio Baronti

Vita Balthildis

Vita Abrahae Heremitae

Vita Audoini

Vita Balthildis

Vita Boniti

Vita Eligii

Vita Fursei Abbatis Latiniacensis

Vita Germani Grandivallensis
205, 208

205 Vita Praejecti 205

205

205

205, 208

195, 206, 208

205

205
Vita Sulpicii Bituricensis

Vita Wandregisili

Warnacharius, Passio Tergeminorum

Speusippi

Zosimus, Historia nea 2,38
205

205

195

205, 209

206

182

\section{Orts- und Personenverzeichnis}

Aachen 147

Adalhard 131-133, 141-142, 146

Adomnan von lona 199,210

Ägypten 27, 33

Aethicus Ister 213-214

Alarich II. 19, 112, 223, 225

Albertus Magnus 63, 65-66

Aldhelm von Sherborne 199, 210

Alexander der Grosse 245, 246

Alkuin 136, 139

Ambrosius von Mailand $58-59,63,66,133-$

135, 140 -141, 150, 203, 216-217, 220-221

Ammianus Marcellinus 11, 182-183, 186

Ansoald von Poitiers 211

Aristoteles $\quad 63-67,139,211,246$

Arnobius 202

Augustinus, Aurelius $\quad 49,91,93,133,138-$ $139,143,150,156,172,202-203,210-211$, 215-216, 217-222

Aulus Gellius $\rightarrow$ Gellius

Aurelius Victor 9, 13, 28

Ausonius, Decimus Magnus 12

Avitus von Vienne 29,217

Bartholomaeus Anglicus 63

Basilius von Caesarea 63, 204

Beda Venerabilis $\quad 60-67,199,208,210,215-$ 216, 245-246

Bernhard von Septimanien 140

Bertila von Chelles 215

Beseler, Gerhard von 75

Bonifatius, Heiliger 215

Bourdieu, Pierre 81-82

Braulio von Saragossa 55, 86-91

Burckhardt, Jacob 3
Caesar, Gaius Iulius 133

Caesarius von Arles $\quad 202-203,207,218,221-$ 222

Cannae 44-46

Canterbury 153, 155-157, 199

Cassianus, Johannes 156, 204, 208, 217, 222

Cassiodor 91, 95, 141, 221

Cassius Dio 13

Cato der Ältere 39

Charibert 186, 189-191

Childebert I. 186

Childebert II. 188, 191

Childerich I. 192, 196

Chilperich 184-193

Chindaswinth 102

Chlodwig II. 195

Chlothar I. 188, 190-191

Chrodobert von Paris 210

Cicero, Marcus Tullius $11,13,26-27,30,35$, 133, 138-139, 141, 146-150, 211, 215

Claudius Claudianus 11,100

Clermont 186, 190

Columbanus, Heiliger 214-215

Corbie $131,133,137-144,146,149-150$, 203-204, 211, 216, 218-220, 222, 226

Crassus, Publius Licinius 38

D’Alembert, Jean le Rond 74

Dagobert I. 195

Defensor von Ligugé $\quad 210-211$

Desiderius von Cahors 210

Desiderius von Vienne 15, 211

Dindimus 246-247

Diokletian 18, 180-184

Donatus $143,156,210,221$ 
Ebbo von Reims 140

Echternach 204, 208, 215, 219-221

Einhard 15, 17, 148

Ennius 12, 26

Épinal 153-174, 220

Erfurt 153, 157

Etrurien 44

Eucherius von Lyon 202, 217

Eufronius 190

Eunomius von Tours 187

Eurich 112, 223

Euripides 27

Eusebius von Caesarea 15

Eutropius 9, 32, 245

Fabius Maximus, Quintus 44-45

Felix, Bf. 215

Festus 9, 28

Flaminius, Gaius $\quad 43-44$

Florus 36

Fredegar 1, 17, 192-197, 204, 211-213, 220

Fredegunde 188

Fronto, Marcus Cornelius 26

Gaiso 189-190

Galen 63

Gallien $\quad 9,17,19,42,122,178,179,181$

Gellius, Aulus 26, 31,35

Gibbon, Edward 3, 74

Gildas 156, 214

Gregor I., Papst 15, 156, $202-203,208,211$, 216, 219-222

Gregor von Tours $14-15,17,29,184-197$, 199, 206, 209, 211-214, 218, 220-222

Gunthramn 192

Hadrian, röm. Kaiser 18

Hadrian von Canterbury 155-157, 199

Halberstadt 245

Hänel, Gustav 225

Hannibal 40-47

Hesiod 211

Hieronymus, Eusebius $\quad 30,139,156,173,185$, 193, 202, 203, 210, 220

Hinkmar von Reims 106-108

Homer 12, 27, 212

Honorius, Kaiser 124, 140, 184

Honorius von Autun 63,67

Hrabanus Maurus 139

Hyginus 33
Importunus von Paris 210

Indien 246

Injuriosus, Vizegraf 187

Iona 199

Isidor von Sevilla $55-67,85-103,112,153$, $156-157,163-168,203-204,211-214,218-$ 221, 250

Italien $\quad 21,38,40-44,119,180,245$

Jakob von Vitry 63

Johannes Scottus Eriugena 63

Johannes von Réôme 205, 214

Jordanes 9, 245-246

Juan Gil de Zamora 63

Judith, Königin 140

Julian, Heiliger 16

Julian von Toledo 199, 210

Julianus Pomerius 204, 219

Julius Obsequens 34,37

Justinus 26

Justinian I. $\quad 20,72,140$

Justinian II. 140

Kantorowicz, Hermann Ulrich 79

Karl der Grosse 107, 131, 148, 223-224, 227

Karl der Kahle 131, 149

Karthago 40

Konrad von Megenberg 51, 63-67

Laktanz 99, 183-186, 189, 192

Laon 205, 107, 216, 219-220, 226

Leiden 153, 157, 218, 222

Leowigild $\quad 87,101-102,112,118,124$

Libius Severus 225

Ligugé 211, 216

Limoges 186, 190, 193

Livius $12-13,25-48,133,209,250$

Lot, Ferdinand $\quad 3,178$

Lothar, Kg. 137, 140

Ludwig der Fromme 131, 134, 137, 140-141, $144-146,148,150-151$

Lukrez 26, 59, 100

Lupus von Ferrière 223-224

Luxeuil 203-204, 208, 211, 216, 218-222

Lyon 204, 211, 216-220

Mago 40-43

Marcus, referendarius $\quad 185-186,188,193$

Mark Aurel 26, 32

Marrou, Henri-Irénée $\quad 6,199$ 


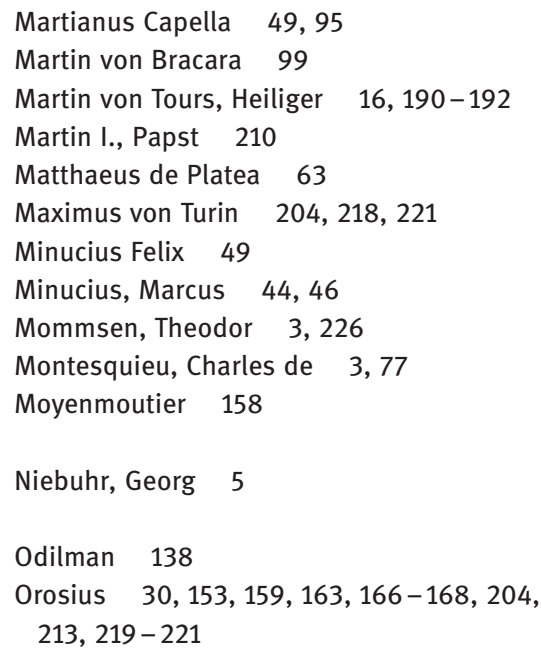

Salvian von Marseille 183

Satyricus 134

Savigny, Friedrich Carl von $\quad 74,76$

Scipio, Gnaeus Cornelius 40-42

Scipio, Publius Cornelius $\quad 40-47$

Seeck, Otto 3, 75

Servius Tullius, röm. Kg. 38

Sevilla 89

Sidonius Apollinaris 11,29

Sisebut 58, 85-89, 91, 99-101

Sisenand 89

Sizilien 40, 44

Soissons 186, 188, 203, 216

Solinus $\quad 49,50,51$

Somnatius 196

Sozomenos 15

Spanien 41, 42-45, 99, 102, 122

Spengler, Oswald 4

Suetonius 35

Sulla 38

Sulpicius Severus 138, 146, 156, 207

Sulpicius von Bourges 195

Suinthila 102

Teophrastus 138-139, 145

Terenz 27, 133, 137, 142-146, 211

Theodor von Canterbury $155-156,199$

Theodoret 15, 189

Theodosius I., 140-141

Theodosius II. $18,71-72,74-75,80,190$

Theudebert 186-187, 190

Thomas von Cantimpré $\quad 63-67$

Tiberius, röm. Kaiser 30

Toledo 89, 99, 222

Toynbee, Arnold 4

Troja 212-213

Ulthrogotha 187

Valens 32, 195

Valentinian II. 140,195

Valentinian III. 18,71

Valerius Maximus $\quad 35,47$

Varro, M. Terentius, Gelehrter 13, 92-93

Varro, M. Terentius, Feldherr 44, 46-47

Venantius Fortunatus 11, 207, 214

Vercondaridubnus, Gaius Iulius 39

Vergil 11-12, 27, 37, 57, 100, 209, 212- 213

Victor Vitoriensis (von Vita) 106

Vinzenz von Beauvais 63-64 
Vitalian, Papst 155, 209

Vogt, Joseph 3

Wala 131-150

Wamba 102
Warin von Corvey 134

Wearmouth-Jarrow 60, 215

Willibrod, Heiliger $\quad 215,220$ 